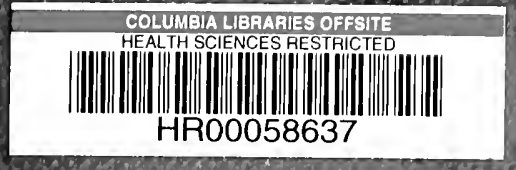

\title{
RECAP
}

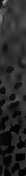

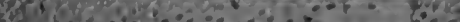

d

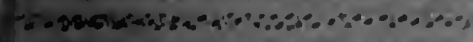

190.5 


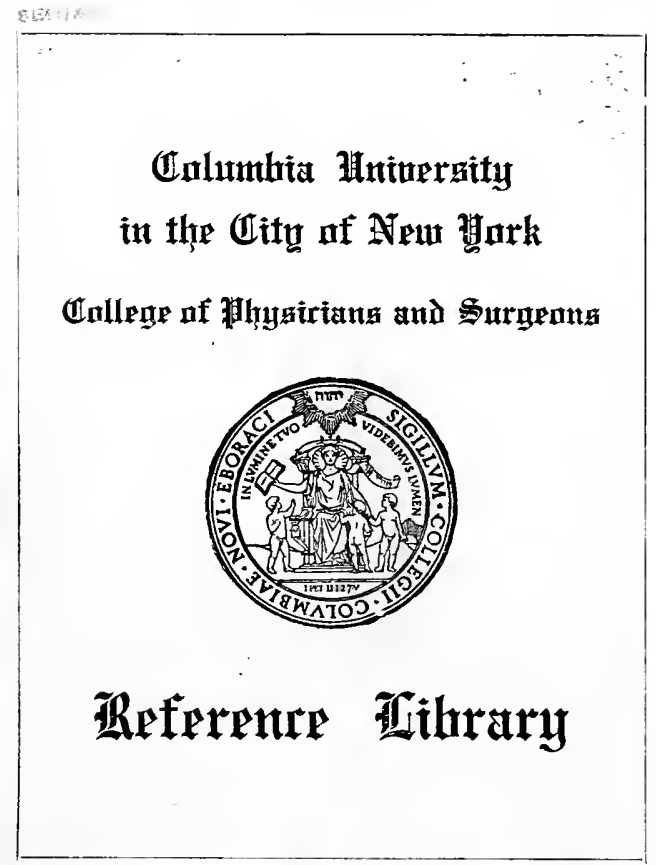


$\stackrel{\mathscr{G}}{\vec{a}}$ 


Digitized by the Internet Archive in 2010 with funding from Open Knowledge Commons 


\section{ANNUAL REPORT OF THE}

\section{SURGEON GENERAL OF THE PUBLIC HEALTH SERVICE OF THE UNITED STATES}

FOR THE FISCAL YEAR

\section{2}

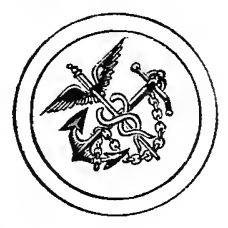




\section{LETTER OF TRANSMITTAL.}

Treasury Department,

OfFice of The Secretary,

Washington, December 10, 1912.

SIR: In accordance with section 9 of the act of Congress approved July 1, 1902, "An act to increase the efficiency and change the name of the Marine-Hospital Service," I have the honor to transmit herewith the report of the Surgeon General of the Public Health Service for the fiscal year 1912 .

Respectfully,

Franklin MacVeagh, Secretary.

The Speaker of the House of Representatives. 


\section{CONTENTS.}

Administrative organization................................... 9

Scientific research............................................... 10

Typhoid fever, investigations-

Lincoln, Nebr..................................... 12

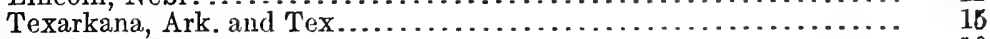

Oskaloosa, Iowa......................................... 16

Selma, Ala............................................. 17

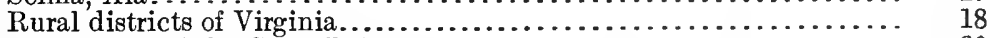

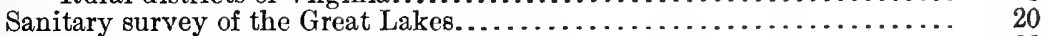

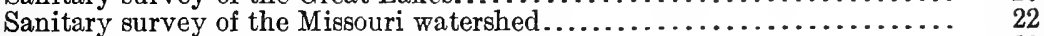

Measles, investigations of.................................. 23

Typhus fever, investigations of.................................... 23

Trachoma, investigations-

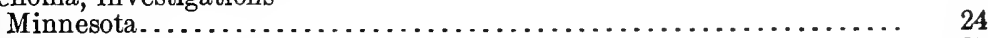

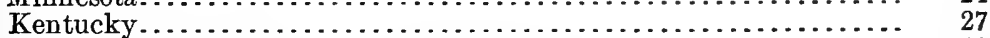

Rocky Mountain spotted fever, investigations of................... 28

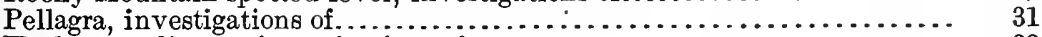

Hookworm disease, investigations of ..................................... 33

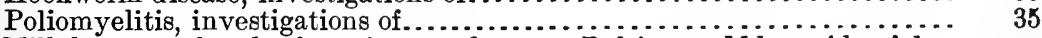

Milk-borne outbreak of septic sore throat at Baltimore, Md., epidemiological study of.

Effects of pasteurization on the nutritive value of milk, investigation of..

Studies of cholera in cooperation with the International Office of Public Hygiene.

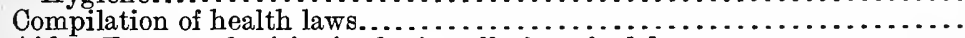

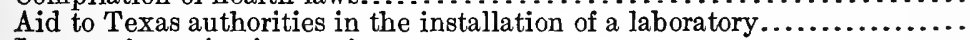

Leprosy investigation station-

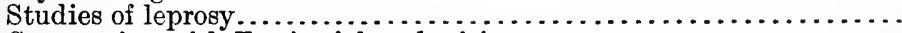

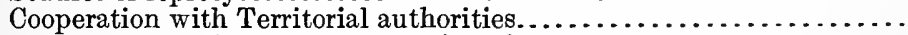

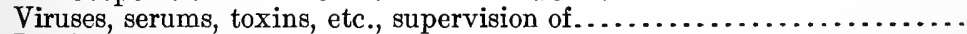

Hygienic Laboratory . . . . . . . . . . . . . . . . . . . . . . . . . .

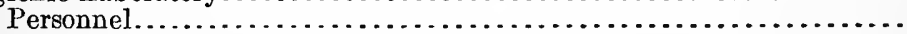

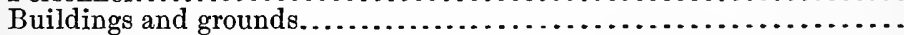

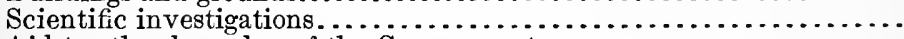

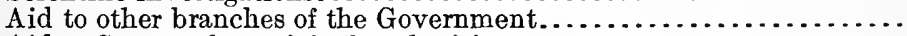

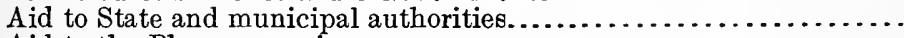

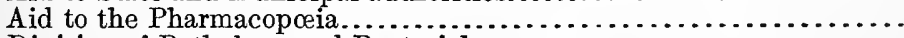

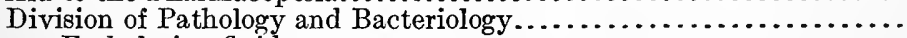

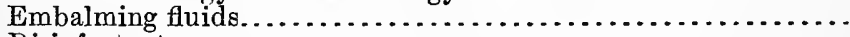

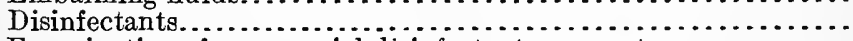

Examination of commercial disinfectants....................

Antirabic virus, preparation and distribution of...............

Need of branch laboratory at New York.......................

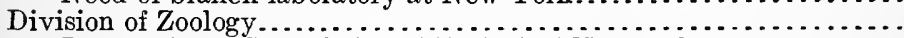

International Commission of Zoological Nomenclature..............

Index catalogue of medical and veterinary zoology...............

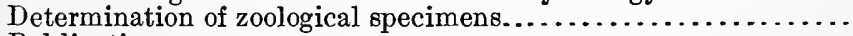

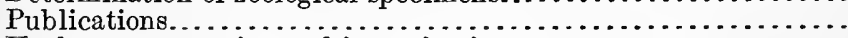

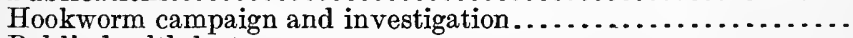

Public health lectures................................

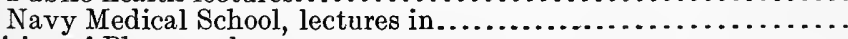

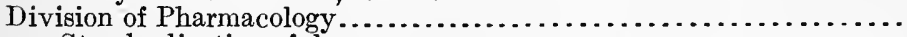

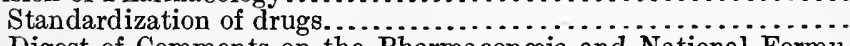

Digest of Comments on the Pharmacopœia and National Formu-

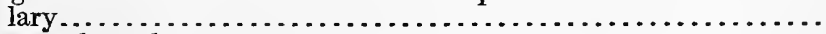

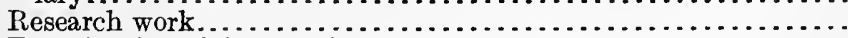

Examination of drugs; miscellaneous analyses.................

Cooperation with the Pharmacopœia, other departments, etc..... 
Scientific research - Continued

Hygienic Laboratory-Continued.

Page.

Division of Chemistry............................... 53

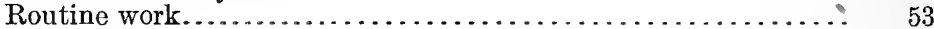

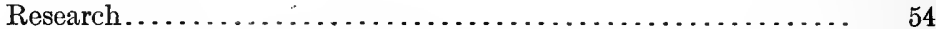

Public health exhibits.

Tenth Annual Conference of State and Territorial Health Authorities with the service.

Sixth International Sanitary Conference of the American Republics......

Representation at meetings of scientific and sanitary associations and congresses.

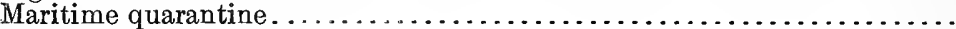

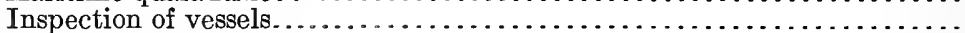

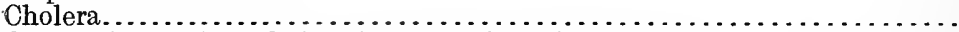

Quarantine against cholera from Russia and Italy ..................

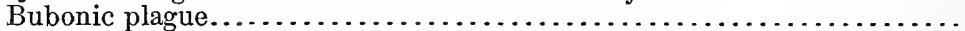

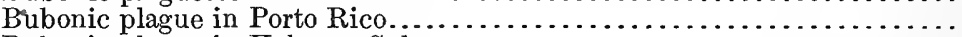

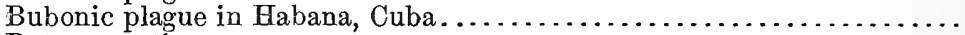

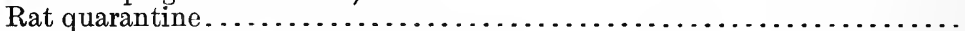

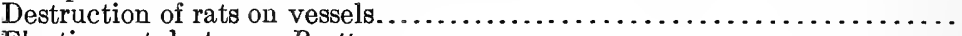

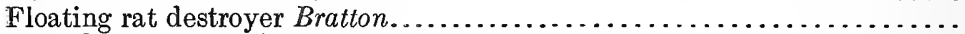

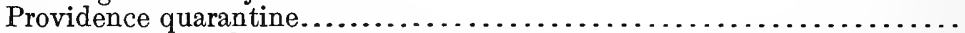

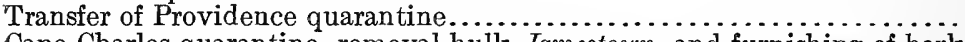

Cape Charles quarantine, removal hulk Jamestown, and furnishing of bark Chase

Key West quarantine, transfer floating hospital Wisteria from Mobile quarantine.

Galveston quarantine station, establishment of. . . . . . . . . . . . . . . . . .

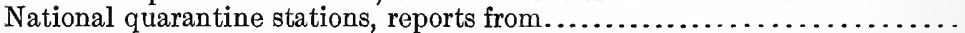

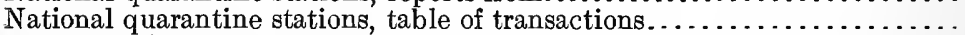

Foreign and insular quarantine stations . . . . . . . . . . . . . . . . . . .

Foreign and insular quarantine stations, table of transactions..........

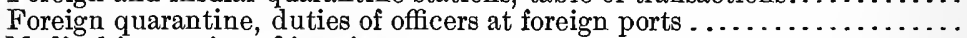

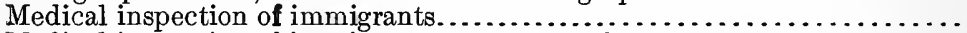

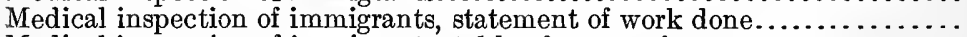

Medical inspection of immigrants, table of transactions..................

Medical inspection of immigrants, reports from stations. . . . . . . . . . .

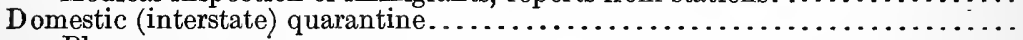

Plague-suppressive measures..........................

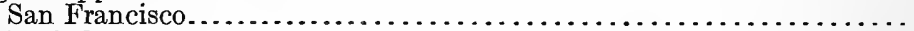

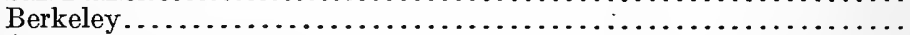

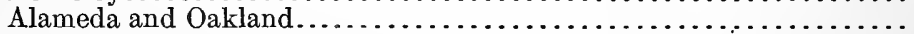

Character of work performed. . . . . . . . . .

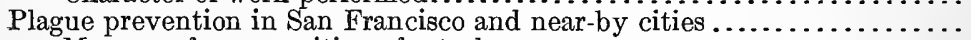

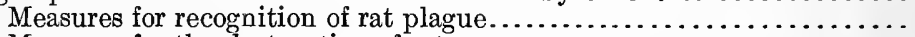

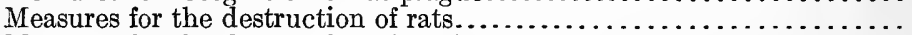

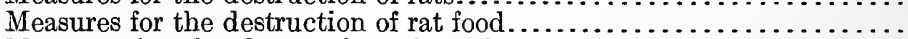

Measures for the destruction of rat harbors, and for permanent rat proofing of buildings, etc.

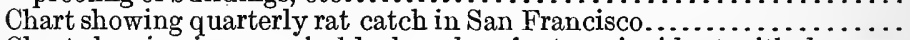

Chart showing increase in black and roof rats, coincident with decrease in brown and Norway rats.

Rats trapped in other cities.

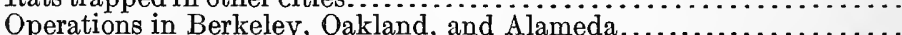

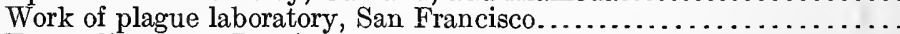

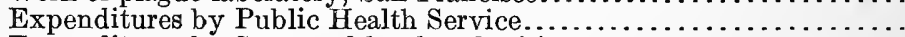

Expenditures by State and local authorities....................

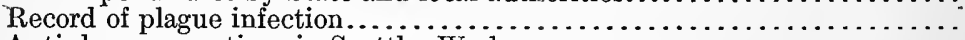

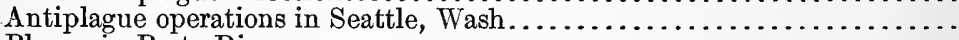

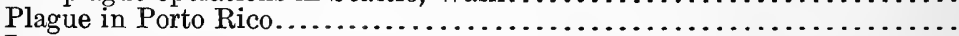

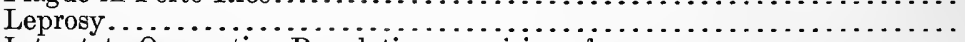

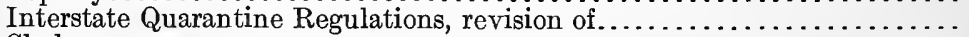

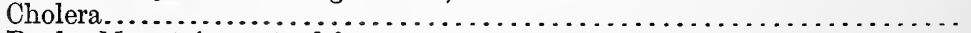

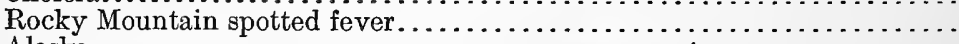

Alaska.

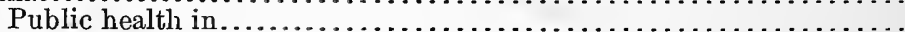

Sanitary inspection of Government buildings.

\section{6}

57

60

62

62

62

62

62

62

65

69

69

71

72

72

73

73

74

74

82

82

82

110

131

131

132

134

145

145

145

154

154

159

145

145

146

147

148

151

152

154

154

155

160

160

159

162

162

163

163

164

164

167

167

169 
Page.

Public Health Reports...................................... 170

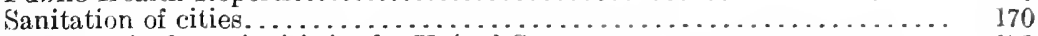

Cerebrospinal meningitis in the United States................... 171

Texas, cerebrospinal meningitis, cases and deaths reporterl to Jan-

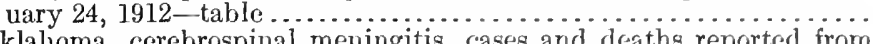

Oklahoma, cerebrospinal meningitis, cases and deaths reported from December 1, 1911, to $\mathrm{March} 27,1912$-1able . . . . . . . . . . . . . .

Malta or Mediterranean fever in the United States....................

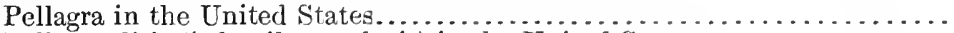

Poliomyelitis (infantile paralysis) in the United States..............

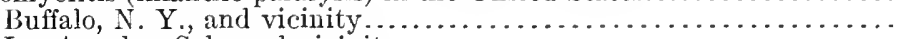

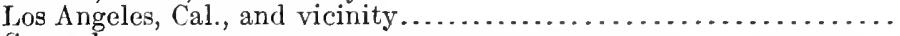

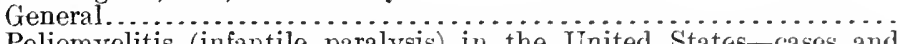

Poliomyelitis (infantile paralysis) in the United States-cases and deaths reported during the years 1910 and 1911 -table..........

Poliomyelitis (infantile paralysis) reported from January 1 to June

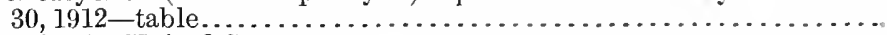

Leprosy in the United States.

Leprosy, cases reported during the calendar year 1911 and cases

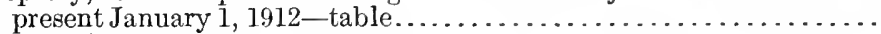

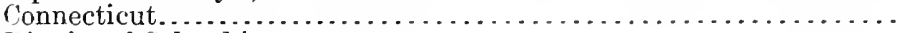

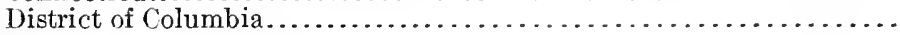

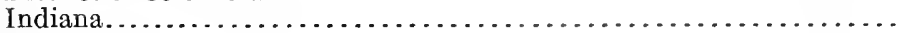

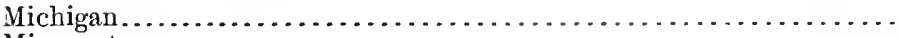

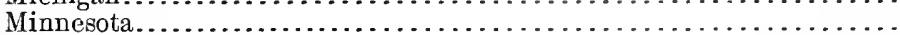

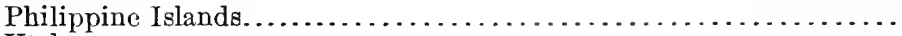

Utah.

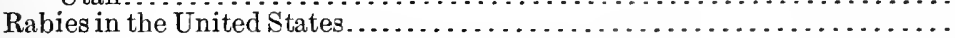

Rabies in the United States 1908 and 1911 -table...............

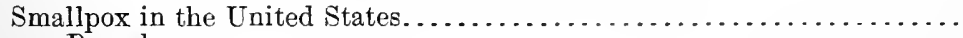

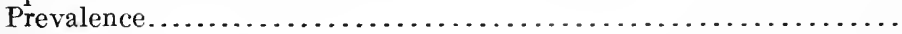

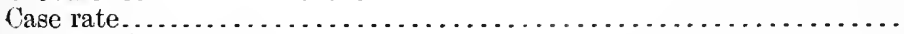

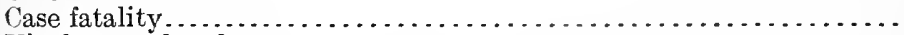

Virulent outbreaks.

Table No. 1.-Showing by months the number of cases of smallpox reported in certain States during the calendar year $1911 . . . . . .$.

Table No. 2.-Showing the number of cases of and deaths due to smallpox reported in certain States during the calendar years 1909, 1910,

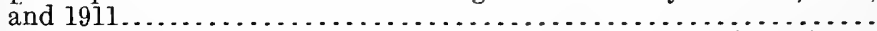

Table No. 3.- Showing the smallpox case rate per 1,000 inhabitants and fatality rate per 100 cases in certain States during the calendar

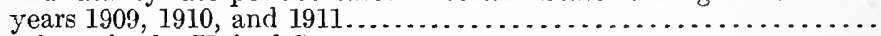

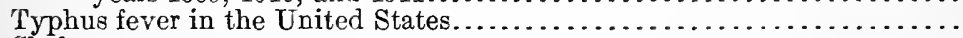
Cholera.

Italy.

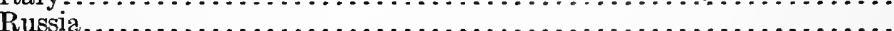

Cases of cholera reported on vessels from July 1 , 1911 , to October 1 ,

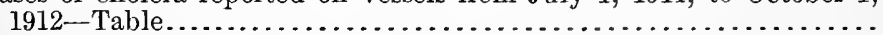

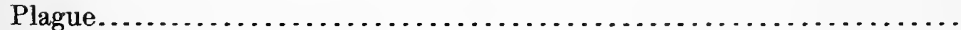

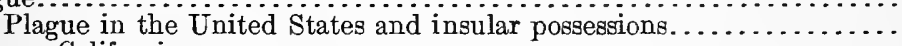

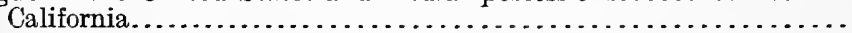

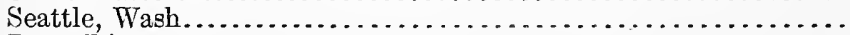

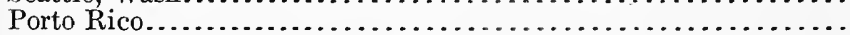

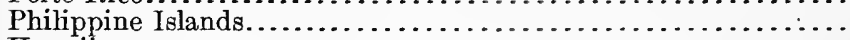

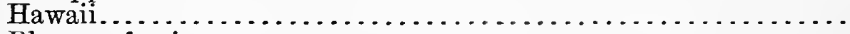

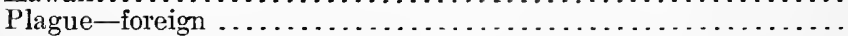

Caces of plague reported on vessels from July 1 , 1911 , to OctoYellow fever:

ber 1,1912 -table..............................

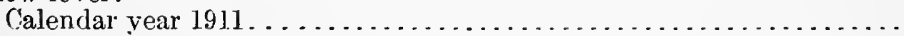
Yellow fever-cases and leaths rejorted during 1911 -table .....

Calendar year 1912. . . . . . . . . . . . . . . . . . . . . . . . . . .

Ycllow fever-cases and deaths reported from January 1 to June 30,1912

Cases of yellow fever reported on vessels from July 1,191$]$, to October

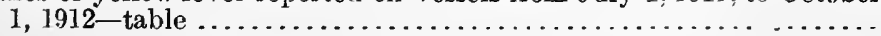

\section{2}

173

173

173

173

174

175

175

178

178

179

180

180

180

181

181

182

182

183

183

184

185

185.

185

186

187

188

188.

189

189

190

190.

190.

191

192

192

192

192

192

192

192

193

193.

194

195

196 
Marine hospitals and reliet: Page.

Relief stations...................................... 199

Relief to seamen .................................... 199

Relief to natives of Alaska............................... 199

Aid to different branches of the Govemment service: Revenue-Cutter Service; Steamboat-Inspection Service; Life-Saving Service; Immigration Service; Civil Service Commission; Isthmian Canal Commission....

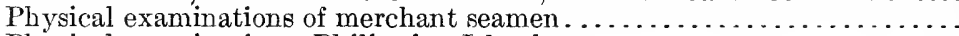

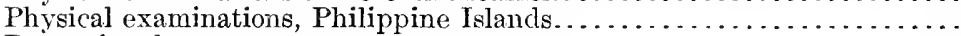

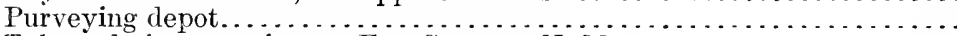

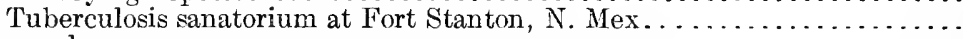

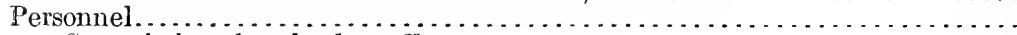

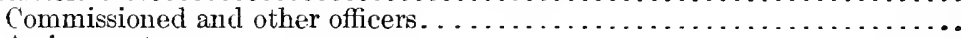

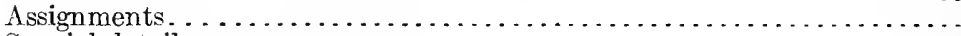

Special details . . . . . . . . . . . . . . . . . . . . . . . . . .

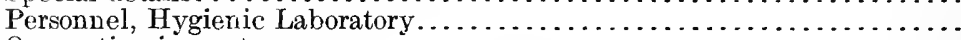

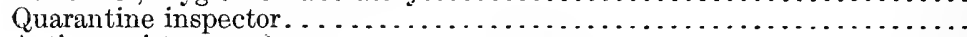

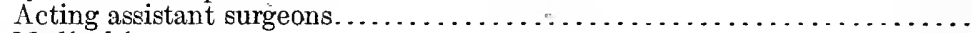

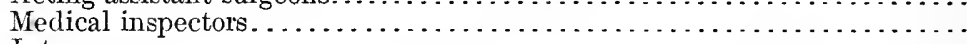

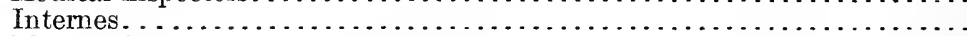

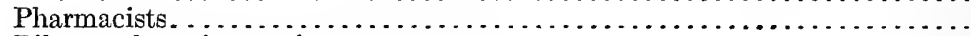

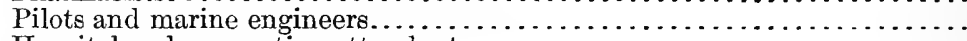

Hospital and quarantine attendants. . . . . . . . . . . . . . . . . .

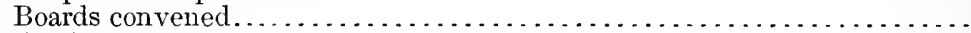

Publications:

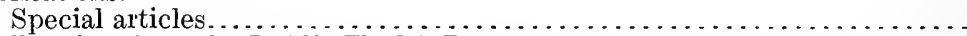

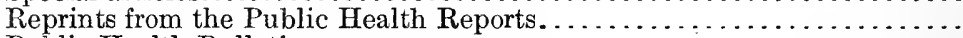

Public Health Bulletins. . . . . . . . . . . . . . . . . . . . . . . .

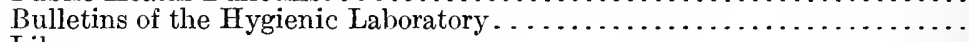

Library

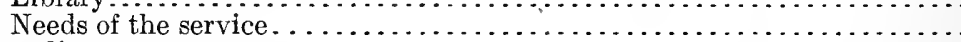

Appendix:

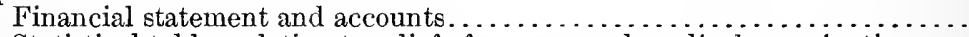

Statistical tables relating to relief of seamen and medical examinations.... Index.

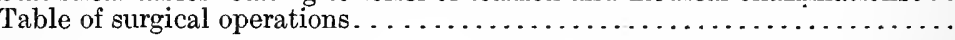




\section{OPERATIONS OF THE UNITED STATES PUBLIC HEALTH SERVICE}

1912 



\title{
ANNUAL REPORT OF THE SURGEON GENERAL OF THE PUBLIC HEALTH SERVICE.
}

\author{
Treasury Departaent, \\ Bureau of the Public Healtil Service, \\ Washington, D. C., November 1, 1912.
}

SIR: I have the honor to transmit to Congress, in accordance with the act of July 1, 1902, the following report of the transactions of the Public Health Service for the fiscal year ending June 30, 1912, together with subsequent transactions of special importance up to the present date.

This is the forty-first annual report of the service in the one hundred and fourteenth year of its existence, and the first under its present name, as changed by the act approved August 14, 1912.

\section{New Legislation.}

The act of Congress approved August 14, 1912, changes the name of the service, provides for additional functions in the direction of public health work, and increases the pay of commissioned medical officers. The passage of this law marks a new epoch in the history of the health activities of the Federal Government, and it is believed clearly recognizes the Public Health Service as the central health agency of the Nation. The law follows:

AN ACT To change the name of the Publie Health and Mariue-Hospital Service to the Publie Ilealth Service, to increase the pay of officers of said service, and for other purposes.

Be it enacted by the Senate and House of Representatives of the United States of America in Congress assembled, That the Public Health and Marine-Hospital Service of the United States shall hereafter be known and designated as the Public Health Service, and all laws pertaining to the Public Health and Marine-Hospital Service of the United States shall hereafter apply to the Public Health Service, and all regulations now in force, made in accordance with law for the Public Health and Marine-Hospital Service of the United States shall apply to and remain in force as regulations of and for the Public Health Service until changed or rescinded. The Priblic Health Service may study and investigate the diseases of man and conditions influencing the propagation and spread thereof, including sauitation and sewage and the pollution either directly or indirectly of the navigable streams and lakes of the United States, and it may from time to time issue information in the form of publications for the use of the public.

SEc. 2. That beginning with the first day of October next after the passage of this act the salaries of the commissioned medical officers of the Public Health Service shall be at the following rates per annum: Surgeon General, six thousand dollars; Assistant Surgeon General, four thousand dollars; senior stugeon, of which there shall be ten in number, on active duty, three thousand five hundred dollars; surgeon, three thousand dollars; passed assistant surgeon, two thousand four hundred dollars; assistant surgeon, two thousand dollars; and the said officers, excepting the Surgeon General, shall receive an additional compensation of ten per centum of the annual salary as above set forth for each five years' service, but not to exceed in all forty per centum: Provided, That. the total salary, including the longevity increase, shall not exceed the following rates: Assistant Surgeon General, five thousaud dollars; senior surgeon, foul thousand five hundred dollars; surgeon, four thousand dollars: Provided further, That there may be employed in the Public Health Service such help as may be provided for from time to time by Congress.

Approved, August 14, 1912. 


\section{SCIENTIFIC RESEARCH AND SANITATION.}

The conduct of scientific investigations of matters pertaining to the public health is one of the great functions of the Federal Government, and perhaps one of the most important in view of our form of government. By this means not only is Federal administration of public health matters simplified, but local authorities are aided and knowledge of hygiene extended. In view of the great interest taken in public health matters, and their bearing on economic conditions, a great many problems have been presented to the Service for solution during the past fiscal year. The activities in this respect have accordingly been greater than those of previous years, notwithstanding the fact that there has been no material increase in facilities with which to carry them on. The providing of such facilities has not kept pace with the volume of scientific work to be performed, and adequate advancement of public health work by the Federal Government depends on such provision.

By the act of March 3, 1901, providing for a new building for the Hygienic Laboratory, investigations of contagious and infectious diseases and matters pertaining to the public health were given definite status in law. Provision was thus made for laboratory investigations which would be systematically carried on. Prior to June 30,1912 , all investigations undertaken were in accordance with this authority and the authority contained in the act of February 15, 1893 , to cooperate with and aid State and municipal health authorities in their measures for the prevention of the spread of contagious and infectious diseases.

It had long been recognized, however, that there was need of additional authority to undertake field investigations of scientific and practical public health problems, and by the act of Congress approved August 14, 1912, broader powers have been conferred on the Public Health Service to-

study and investigate the diseases of man and conditions influencing the propagation and spread thereof, including sanitation and sewage and the pollution either directly or indirectly of the navigable streams and lakes of the United States.

There is thus abundant authority for both laboratory and field investigations which, with provision of adequate facilities, will insure the performance of a greater amount of necessary sanitary work.

Many highly important problems now await solution. Among them may be mentioned the determination of the conditions causing pellagra and a number of other diseases of unknown etiology, the influence of those diseases on interstate traffic, the standardization of biologic and other therapeutic products, the determination of the relation of housing and other conditions to labor efficiency, and the prescribing of reasonable standards to control stream pollution.

Requests are received daily from all parts of the country for scientific information regarding sanitary problems. In most instances these requests relate to problems affecting more than one State, and they are an excellent indication of the present status of public 
health administration and the needs in relation thereto. In one section of the country the question of the pollution of streams is pressing for solution; in another, it may be industrial accidents and poisoning; in another, the relation of milk supply to infant morbidity; and in still another, the bearing of traffic and transportation on the continued prevalence of communicable diseases. In response to demands, investigations of some of these problems have been undertaken.

Administrative supervision of the scientific investigations has been maintained through the bureau Division of Scientific Research. These investigations have been conducted through the several laboratories. Mention will subsequently be made of these laboratories, and the stations utilized for research purposes. A now center created during the year under authority of law for research work is at the marine hospital at Mobile, Ala., systematic studies of malaria having been undertaken at that station. In order that these several stations may be properly utilized, and the provisions of the act of August 14, 1912, complied with, some additional appropriations should be made.

Among the subjects that have received attention through the division and laboratories during the past year is typhoid fever. In the last annual report, page 27 et seq., mention is made of investigations conducted by officers of the service at North Yakima, Wash:, Little Rock and Fort Smith, Ark., and Charlestown, W. Va. The investigations at Little Rock, Ark., were made by Passed Asst. Surg. W. H. Frost, and extended from July 13 to September 5 . The same officer was at Fort Smith from September 6 to September 30, and the results of his studies appeared in the Public Health Reports of October 27, 1911. The studies at Charlestown, W. Va., which extended from August 19 to September 13, were made by Asst. Surg. J. R. Ridlon, and the results published in Public Health Reports of November 17, 1911. The studies in Yakima County, Wash., were made by Passed Asst. Surg. L. L. Lumsden, and the results published in Public Health Bulletin No. 51.

The influence of the studies in Yakima County and the subsequent important administrative work carried on by the local health officer have attracted attention throughout the country, and they may be taken as an excellent example of the value of scientific field investigations and cooperation on the part of the service with State and local authorities.

As an additional evidence of the value of such work in the interest of the public health, mention may be made of a recent letter from the mayor of Little Rock who, in describing a number of sanitary improvements which had been made in that city, such as the reorganization of the health department, the better care of indigent patients, changes in the water supply, etc., concluded by stating that the good results obtained could chiefly be attributed to the investigations made and the recommendations based thereon.

Investigations into the origin and prevalence of typhoid fever were conducted in a number of other localities during the year, and recommendations made for its control in those localities. There is probably no single disease whose study is of as great importance at the present time. It prevails in practically every part of the United States and is spread by many agencies, and any light thrown on its 
transmission and prevention will have a bearing on the improvement of insanitary conditions generally.

The investigations mentioned were made at Texarkana, Ark.-Tex., Lincoln, Nebr., Oskaloosa, Iowa, and Washington, D. C., and in rural districts of Virginia.

\section{Investigation of an Outbreak of Typhoid Fever at Lincoln, NeBr.}

At the request of the governor of Nebraska, made on October 16, 1911, on behalf of the city council of Lincoln, Nebr., Passed Asst. Surg. L. L. Lumsden was detailed to make an investigation of an outbreak of typhoid fever in that city, especially with a view to determining the sources of the infection and the measures necessary for the control of the disease.

The investigation was begun on November 4 and terminated on November 17,1911 . It comprised an epidemiological study of cases reported from July 1 to November 1 , a sanitary survey of the city and its immediate environs, bacteriological examinations of the water supply, and inspections of dairies and other places where foods were sold or prepared for sale.

In the four months, July, August, September, and October, 1911, 161 cases were reported in the city. Of these, 141 were investigated. No definite information was obtainable in about 20 of the reported cases, but during the course of the investigation of the reported cases 9 others were learned of and investigated, making a total of 150 cases investigated. 'Of these 150 cases 6 were in persons who had become infected while away from Lincoln, leaving 144 for detailed consideration.

Upon investigating the cases it was determined that the disease had been much more prevalent in the section of the city north of $J$ Street and east of Fourteenth Street than in other sections of the city. That section contains about one-fourth of the city's population and furnished about 84 per cent of all the cases reported and investigated which occurred in July, August, September, and October, 1911. Of the 23 cases occurring in persons who lived outside the especially affected section, 11 ware in persons who, during the 30 days prior to illness, had gone into the affected section from time to time and drank water from the taps while there. In the especially affected section the general sanitary conditions were better than those for some of the other sections of the city and somewhat better than those for the average section of the city.

The disease appeared to be distributed generally throughout the population in the affected section without any strikingly disproportionate number of cases in either one of the sexos or in any particular age groups. The age distribution was not suggestive of a milk outbreak.

The season of occurrence of the outbreak suggested the possibility of flies, personal contact, milk, ice cream, green vegetables, fruits, and other foods having been important factors in the spread of the infection. The epidemiological evidence collected strongly suggested that some of these were operative to some extent, but pointed beyond reasonable doubt to the conclusion that some factor other than these had been predominant in the distribution of the infection. 
'The epidemiological data pointed definitely to the city water' supply as the principal source of the infection responsible for the outbreak.

The public water supply was obtained from three artesian wells, known as the $\Lambda$ Street woll, tho F Street well, and the Rice well. These wells furnished about 3,274,000 gallons of water per day. 'The largest source of supply was the $\Lambda$ Streot woll, which furnished about 100,000 gallons por hour. 'The F Street well furnished about 33,000 gallons per hour, and the Rice well about 30,000 gallons per hour.

The examinations of the water from the Rice woll and the F' Street well gave no evidence whatever of contamination of these two sources. The examinations of the water from the A Street woll and from the taps and hydrants, however, gavo evidence of contamination.

During the spring and summer of 1911 the pump at the Rice well was run on an averago of about 20 hours per lay, that at the F Street well about 6 or 8 hours per day, and that at the A' Street well 24 hour's per day. When the F Street and the Rice well pumjs were not running, the mains in the sections receiving water from these two wells would be supplied entirely with water from the A Street well. 'Thus the water from the A Street woll was distributed over the entire city, but the distribution of water from the Rice well was largely confined to the section of the city north of J Street and east of Fourteenth Street, and the distribution from the F Street well was largely confined to the section north of J Street and west of Fourteenth Street. The distribution of the typhoid outbreak corresponded very strikingly with the distribution of water from the Rice well. This fact, along with the evidence obtained by the epidemiological investigation of cases, pointed strongly to the Rice well as the source of infection, but the findings in the investigation did not justify a dogmatic conclusion that this well had been the source of the infection. It was conceivable that during the period of causation of the outbreak the soil about the well lacked its usual filtering, or some other qualities, to prevent contaminating matter in the surroundings of the well from entering the well. The relation of the period of causation of the outbreak to rainfall was noted.

Upon terminating the investigation on November 17, a verbal report was made to the city council. The meeting of the council for the purpose of receiving the report was public and was attended by a number of interested citizens. The findings of the investigation were discussed and the following conclusions and recommendations submitted:

\section{CONCLUSIONS.}

1. That a distinct outbreak of typhoid fever had occurred during August, 1911, in that section of the city bounded on the south by J Street and on the west by Fourteenth Street.

2. That insanitary conditions in respect to faulty privies and water-closets, personal contact, flies, and foods probably had operated to some extent in the spread of the infection, but that the chief source of the infection immediately responsible for the outbreak was the public water supply.

3. That the infection responsible for the outbreak reached the water supply either at the Rice well or at some place or places in the water mains distributing water especially to the section north of J Street and east of Fourteenth Street.

4. That it was highly advisable to engage the services of an expert sanitary engineer with a view to having determined as exactly as possible all dangerous relations of sewers to water mains and wells.

5 . That the water of the Rice well and the F Street well during the period of investigation was free from contamination, but that this finding did not prove that the Rice 
well had not been dangerously polluted during the period of causation of the outbreak and offered no assurance whatever that this well might not become dangerously con. taminated at any time in the future.

6. That the water of the A Street well was found during the investigation to show evidence of pollution of such character as to suggest sewage as its source and that the water from that well should be regarded as potentially dangerous.

7. That all three of the public wells were of a grossly faulty type from a sanitary standpoint and should be reconstructed as soon as practicable, so as to have tubular water-tight casings extend from the deep water-bearing stratum to the surface.

\section{RECOMMENDATIONS.}

1. Have bacteriological examinations of the water from each of the three wells and physical examinations of the wells continued practically daily until corrections of faulty conditions in and about the wells have been made, so that if any pronounced pollution should occur it could be discovered promptly and precautions taken accordingly.

2. Engage an expert sanitary engineer to make a complete survey of the water and sewage systems.

3. Have cement basins constructed in Rice and A Street wells to receive the water coming up through the pipes from the deep water-bearing stratum and to exclude absolutely from the water supply all water which might find its way through the walls of the wells.

4. Have doors over manholes leading to the reservoir at the A Street well made tight so as to prevent contamination of the water by dust and surface washings.

5. Have all insanitary conditions, particularly in respect to faulty privies, in the vicinity of the wells corrected.

6. Have done away with, as soon as practicable, the obviously needless superstructures over and around the wells, and have any additional wells in contemplation constructed in accordance with well-recognized modern sanitary principles for artesian wells.

The complete report of Passed Asst. Surg. Lumsden on this investigation was published in the Public Health Reports of May 24, 1912.

\section{Investigation of an Outbreak of Typhoid Fever in Two Schools in Washington, D. C.}

A number of cases of typhoid fever occurred in two girls' boarding schools of the District of Columbia during the month of October, 1911. In one of the schools two cases developed on October 9, and one on October 20; in the other, four diagnosed cases and one suspected case occurred, with definite onsets of illness, as follows: One on October 14, two on the 16th, one on the $17 \mathrm{th}$, and one on the 19 th.

The request for an investigation by the service came from the principal of one of the schools, with the explanation that she understood the health department of the District had no authority in the case. After a conference with the District health officer, Passed Asst. Surg. L. L. Lumsden was detailed to conduct an investigation of the outbreak, particularly with a view to ascertaining whether the infection had been contracted outside of the District of Columbia.

The investigation was begun on Octoker 25. The synchronous occurrence of the cases suggested a common source of infection. A restaurant at Mount Vernon, Va., was first suspected, as most of the girls of one school and quite a number of the girls in the other school had taken lunch there on the same day, September 30. The menu had been the same for both parties, and included ice cream and tomato salad.

Mount Vernon was visited on October 27, and it was then ascertained that the ice cream had come from a Washington establishment and the tomatoes for the salad had been purchased at the Alexandria, 
Va., market. No history of sickness was found among the workers or the associates of the workers at the restaurant. No evidener was therefore obtained to further implicate Mount Vernon ats a possible source of infection.

At that time, October 28 , the only case so far definitely diagrnosed in one of the schools was that of one of the girls who had been to Mount Vernon. The four suspected cases were all among those pupils who had not taken the trip. On Octoler 29 it was finalls determined by blood (Widal) tests that three of these cases were typhoid. This eliminated Mount Vernon as a source of infection for the whole group of cases occurring in the two schools.

The case rate for the schools as compared with that for the whole city appeared to exclude the water supply as a source of infection.

Besides the trip to Mount Vernon and the city water supply. there appeared to be nothing common to both schools except the milk supply, which was obtained from one of the local dealers. An examination of the records at the District health office showerl that out of 116 cases of typhoid fever reported in October, 13, or about 11 per cent, had occurred among persons using milk furnished by this dealer. Besides the reported cases the investigator knew personally of five other cases of typhoid fever which had developed during October among users of milk frôm this dairy. It is estimated that this dealer supplies 4 per cent of the local population. Therefore it appeared that in October typhoid fever was three or four times as prevalent among those using. his milk as among the general population of the District.

Passed Asst. Surg. Lumsden, after considering all the evidence collected, concluded that the cases under investigation had been caused beyond reasonable doubt by the milk supply of the schools. The matter was found to properly come under the jurisdiction of the District health officer, and the facts were communicated to him for such action as he might deem advisable.

\section{Investigation of Trphom Fever in Texarkana, Ark.-Tex.}

At the request of the representative in Congress of the first district of Texas, and with the assent of the State boards of health of Arkansas and Texas, Asst. Surg. J. R. Ridlon wos detailed on November 18,1911 , to investigate the causes responsible for an outbreak of typhoid fever at Texarkana.

From September 1 to November 15, 1911, there occurred in the two cities 36 cases of typhoid fever, which, estimating the population at 15,000 , would give a morbidity rate of 240 per 100,000 . The mortality was very low, only 1 death being reported, being a case fatality of 2.8 per 100 . No records were available to make possible a comparison with previous years; but it seemed that the disease had been unusually prevalent during the above-mentioned period.

The investigation comprised a careful study of the cases, a sanitary survey of the city, inspection of the public water system, bacteriological examinations of water and milk, making of Widal tests as an aid in diagnosis, and examinations of blood and stools from the attendants of one dairy.

It was found that 33 out of 34 cases gave a history of using milk as a beverage, or on cereals, or in both ways, within 30 days prior to 
onset of sickness. Of the 33 cases using milk 25 , or 75 per cent, obtained the whole or a part of the milk from one dairy farm, 3 of the other 8 cases took part of their meals at various restaurants' and may possibly have used some of the same milk. In 1 other case the infection was probably acquired by contact. The general features usually attributed to milk-borne typhoid epidemics, namely, special incidence of disease among users of suspected milk, in milk drinkers, in the better class of houses, and among women and children, sudden onset with short incubation period, low mortality rate, lessening of contact cases, etc., were observed in the series of cases.

Evidence was lacking that the public water supply had played any appreciable part in the causation of the epidemic, although in a few cases not otherwise accounted for the use of water from shallow wells could be considered a possible source of infection.

The conclusions were that, 25 of the 34 cases arising in the city, or 73.5 per cent, could be attributed to the use of milk from one dairy, 1 case to contact, leaving 8 cases unaccounted for, the most probable source of infection in these cases being milk, ice cream, or well water.

On the completion of the investigation, definite recommendations were made by Dr. Ridlon to the local authorities for the protection of the milk and food supplies, the extension of the sewerage system, the disposal of refuse, and the adequate control of typhoid cases by means of reports, proper instructions, etc.

The report rendered by Asst. Surg. Ridlon was published in the Public Health Reports of February 16, 1912.

\section{Investigation of Typhoid Fever at Osiraloosa, Iowa.}

At the request of the State board of health of Iowa, Passed Asst. Surg. W. H. Frost was on April 10, 1912, detailed to conduct an investigation into the causes of an unusual prevalence of typhoid fever in Oskaloosa, Iowa, during the months of March and April, 1912.

From September, 1911, to the latter part of March, 1912, no cases of typhoid fever were reported, whereas from the latter part of March to April 23, there were reported 72 cases in the city and immediate vicinity. It was apparent that the epidemic had its beginning about March 19, the date of the earliest reported case, reached its maximum during the first week of April, and commenced to decline by the second week of April.

In attempting to find the origin of the epidemic, the following facts were considered: Its being limited to Oskaloosa and University Park; its general distribution among persons of various ages and occupations, living in all parts of the town, under most diverse conditions; the suddenness of the outbreak, affecting at almost the same time a large number of people who had little in common; the transmission of the disease, usually by taking typhoid germs into the mouth, most commonly in food or drink; and the presence of the germs in the fecal discharges or urine of infected people.

The most probable cause of the epidemic was, therefore, some article of food or drink quite uniformly distributed among the residents of Oskaloosa and University Park, distributed less commonly, if at all, among the residents of the neighboring country, and also likely to become contaminated with human sewage, and consumed without cooking. 
Milk, raw fruits and veretables, ice, and contact with provions cases were quite definitely excluded by a calcelul investigation as important factor's in causing the epirlenic. This left the water sup)ply as the most probalnle source of infection.

The evidence that the city water was responsible for the epidemic was summarized as follows:

1. This water was the only article of food or drink found to have been common to the great majority of the patients within the 30 days previous to their illness. All but 2 of the 65 cases investigated gave a definite account of having used this water.

2 . The epidemic was pretty definitely limited to the area of distribution of this water supply, namely to Oskaloosa and University Park.

3. Other probable causes for the epidemic can be excluded by a careful analysis of the data obtained from investigation of cases.

4. The epidemic presented the general characteristics of water-borue epidenics of typhoid fever, namely, sudden explosive onset, even distribution among the consumers of the water regardless of occupation, sanitary conditions of their homes, and relation to previous known cases of the disease. The proportion between children and adults affected was about what has been found usual in water-borne epidemics of typhoid fever.

5. A part of the water supplied to the city during the 30 days preceding the outbreak came from a source subject to pollution, namely, the Skunk River. While it is not possible to definitely locate the exact source of pollution of the river in this instance, it is at least highly suggestive that about the middle of February a case of typhoid fever occurred in a person living about 8 miles above Oskaloosa; and that, according to information obtained from the family, up to the 1st of March, that is, until the diagnosis of typhoid fever had been made, the discharges from this case were emptied, without draining directly, into a small s ream which flows into a creek tributary to the Skunk River. An associate of this patient was taken sick at about the same time, with what may have been a mild case of typhoid fever, though no definite statement can be made as to the diagnosis, as this case was seen by a physician only once. The stools and urine of this patient were likewise emptied upon the ground where they would probably have been washed eventually into the river.

6. The time of the beginning of the epidemic, about March 19, would indicate that the infection of the water which caused the outbreak probably took place about March 1 , about the date of a considerable thaw, which might be expected to wash a considerable accumulation of sewage into the river.

7. The pumping of water from the river to the city was discontinued March 14, and from the reservoir March 23, since which time very little water has been pumped from either source. At the present time, about four weeks after the discontinuance of this water, the epidemic has apparently ceased.

Definite recommendations were submitted by Dr. Frost at the conclusion of his investigation, not only for the securing of a safe water supply, but also for the elimination of such other conditions as have been found instrumental in causing outbreaks of typhoid fever, specific advice being given for the disposal of sewage, fly destruction, supervision of dairies and ice cream depots, screening of foodstuffs, and adequate care of typhoid-fever patients.

Dr. Frost had during his investigation the active aid of Dr. M. F. Boyd, first assistant bacterio ogist of the State board of health, the report that embodied their conclusions being published in pamphlet form by the city authorities.

Investigation of Sanitary Conditions in Selma, Ala., in Relation to the Prevention of Typhom Fever.

At the request of the city authorities of Selma, Ala., seconded by the State health officers and the United States Senators from the State, Passed Asst. Surg. L. L. Lumsden was detailed on April 10, 1912 , to investigate the sanitary conditions of Selma, with special reference to the propagation and spread of typhoid fever.

69450-H. Doc. 971, 62-3-2 
The investigation included a sanitary survey of the city and its environs, inspections of alleys, back yards, cellars and basements, dairies, groceries, bakeries, restaurants, fruit stores, markets, and other places where food was sold or prepared for sale, a study of the water supply, and a particular search for breeding places of flies and mosquitoes.

According to information furnished by the city physician, there were at least 10 deaths from typhoid fever in the city during the year 1911, this apparently very conservative estimate giving the city, with its population of 13,649 , a typhoid death rate of 73.2 per 100,000 in 1911. Judging from hearsay evidence, as no records were available, it was deemed highly probably that the average annual typhoid death rate for the last 10 years had exceeded 73 per 100,000 .

The conclusions reached by Dr. Lumsden upon completion of the investigation were as follows:

1. Typhoid fever is highly prevalent in Selma cluring the summer and fall seasons year after year.

2. The prevalence of typhoid fever in Selma results from the dissemination of human excreta from the bedside of the sick, from the numerous insanitary surface privies, from occasional faulty water-closets, and from promiscuous deposits of stools and urine; fingers, flies, food, and shallow well water operating as the principal factors in the conveyance of the infection.

3 . The prevention of typhoid fever and of other diseases caused by excreta-borne infections in Selma is thoroughly feasible; the measures most urgently needed being sanitation of the privies, proper collection and disposal of stable manure, garbage, and other refuse, screening and cleanly methods to insure the carrying out of proper precautions at the bedside of the sick.

4. The creation and maintenance of an efficient local department to direct the work of sanitation would be the best investmeut that the citizens of Selma can make.

Definite recommendations were submitted by Dr. Lumsden to the city authorities for the remedying of the defects pointed out in the foregoing conclusions. A complete report of the investigation, the conclusions reached, and the recommendations made was subsequently rendered by him. Copies of this report were forwarded to the State health officer of Alabama, the president of the county board of health, and the mayor of Selma.

On acknowledging receipt of Dr. Lumsden's report, the mayor of Selma expressed his concurrence in the views expressed therein, mentioned the adoption of many of the minor suggestions, and the willingness of the local administration to carry out the other recommendations as rapidly as possible.

\section{Investigation of Typhoid Fever in the RuRaL Districts of Virginia.}

Mention was made in last year's report (p. 34), of the investigation of typhoid fever eonducted in the rural districts of Virginia by Passed Asst. Surg. L. L. Lumsden in cooperation with Dr. A. W. Freeman, assistant commissioner of health of the State.

Neighborhood outbreaks were investigated in 6 different counties, viz, Henrico, Northampton, Wythe, Grayson, Culpeper, and Fauquier. Altogether about 200 cases were investigated epidemiologically, the homes of the persons affected being visited and inspected, and histories of the cases in respect to food, drink, contact with previous cases, etc., obtained. 
In serne of the outbreaks personal contact with clinically recogni able cases appeared to be a major factor in the causation of the disease, while in ofluers this factor clid not appear in be very highly operative. In some of the outbreaks the evidence was clear that water supplies played a very minor role, if any, in the spread of the infection. In view of the insanitary conditions in respect to the disposal of human excreta which obtained in all of the neighborhoods visited and the frequency with which cases developed among persons who had not been associated previously with known cases, and who lived in hones some distance from homes at which persons were ill with the discase, the investigators regard it as highly probable that human carriers-persons who become infected without having the disease in a clinically recognizable form--and flies play an important part in the spread of the infection from home to home in the rural districts gencrally.

It was observed that the carrying out of proper bedside precautions to prevent the spread of infection from patients was quite exceptional, and the occurrence of secondary cases in the homes was frequent. A handbag laboratory outfit was employed and Widal tests were made in a number of cases to verify the clinical diagnosis. In several instances persons living in infected homes, but who had had only minor inclispositions not more than slightly suggestive of typhoid, clinically gave positive Widal reactions.

The conclusions reached by the investigators as a result of the first summer's work were as follows:

1. Typhoid fever in the rural districts of Virginia is largely a matter of the summer months, appearing quite regularly at the beginning of June and ending usually about the middle of September.

2 . In the winter months localized water-borne outbreaks of the disease sometimes occur.

3 . In the summer months water appears to be for the rural districts a relatively minor factor iu the transmission of the infection.

4. Direct personal contact with the sick, particularly in those nursing the patients, is an important means of spread of the disease.

5. Milk and foods of various kinds coming trom infected houses frequently carry the infection.

6. General dissemination of human feces, particularly by the fly and on the feet of fowls and domestic animals, is an important means of spread.

7. Mild cases of typhoid infection, clinically unrecognizable, serve frequently as distributors of the infection. Such cases probably occur in considerable numbers wherever typhoid is prevailing.

Drs. Lumsrlen and Freeman have resumed their studies of typhoid in the rural districts of Virginia, and this summer they are conducting in certain selected districts intensive epidemiological investigations, using a well-equipped field laboratory as an aid in endearoring to trace out the lines of travel of the infection.

In recent years extensive studies of typhoid fever have been made in a number of American cities, but there have been made heretofore in the United States no very extensive studies of the great problem of rural typhoid. This investigation by Drs. Lumsden and Freeman appears therefore to be particularly opportune.

Upon the completion of their studies the findings in detail and the conclusions drawn are to be published. 


\section{Sanitary Survey of the Great Lakes.}

The investigations into the sewage pollution of the Great Lakes by Passed Asst. Surg. A. J. McLaughlin, referred to on page 35 of last year's report, were completed during the year, the results being published in Hygienic Laboratory Bulletin No. 83. This bulletin contains the data relative to Lake Superior and St. Marys River, Lake Michigan and the Straits of Mackinac, Lake Huron, St. Clair River, Lake St. Clair, and the Detroit River, and Lake Ontario and St. Lawrence River, similar information for Lake Erie and Niagara River having been published in Hygienic Laboratory Bulletin No. 77.

Passed Asst. Surg. McLaughlin's general conclusions on the completion of the investigations were as follows:

There is an undue prevalence of typhoid fever in many cities and towns in the drainage basin of the Great Lakes.

This excessive prevalence of typhoid fever, especially in the winter and spring months, is due in greatest measure to sewage pollution of interstate and international waters used as a source of public water supplies.

Given the sewage pollution of the source of supply, the excessive prevalence is made possible by the use of such water mnfiltered ancl untreated or by the faulty operation or poor efficiency of filter plants. Most of the cities with excessive prevalence of typhoid fever 11se unfiltered surface water as a public supply, although disasters have occurred where inefficient filtration was being depended upon to make a polluted water safe. Some of these unfiltered lake supplies are alleged to be safe, but proper bacteriologic examination is not made daily. In one large lake city a sample is sent occasionally to a State laboratory; in another. a bacterial count is made daily, but no $B$. coli estimation is made. the only test employed to detect pollution being the obsolete and very indefinite method of animal inoculation.

Some filter plants have serious structural defects. Others are structurally satisfactory, but improperly or carelessly operated. Some well-constructed modem plants are struggling with a bad raw water in which the bacterial content is so higl that even with fair efficiency of the plant the filtered water cannot be classed as safe. In some instances there is no adequate bacteriologic control, and samples of the water are examined only once or twice a month.

In many of these cities excessive rates prevail for the group of diseases classified as enteritis or diarrhea. In most of these places a distinct winter.and spring prevalence is demonstrable. coupled with a coincidently high typhoid fever rate. This enteritis to some extent seems to be water borne, and the disease sometimes called "winter cholera" is presumably entirely water borne. Some of the so-called enteritis and winter cholera may be typhoid fever or bacillary dysentery. An exhanstive investigation of the diarrhea and enteritis of children is necessary to determine accurately the real incidence of the various entities which are grouped under this heading.

The undue prevalence of typhoid fever is an interstate menace and is responsible for the spread of the disease from one State to another, when such undue prevalence is manifest in (1) cities of commercial or industrial importance; (2) tourist resorts which attract visitors by their natural or artificial advantages; (3) summer resorts.

The drainage basin of the Great Lakes contains many cities and communities in each ot the three classes. Not only is typhoid infection distributed by these polluted water supplies to the thousands of visitors from other States, but railroad trains and vessels take their food and drink supplies from these infected centers and distribute such supplies en route to their interstate passengers.

\section{REMEDIES.}

The prime requisite is safe water supplies. Filtered or treated supplies must be substituted for the present polluted or dangerous public supplies where adequate protection of sucl supplies against pollution is not feasible. No single method of water purification or sterilization can be expected to be applicable in all instances. The degree of purification necessary, the character of the raw water. and the financial condition of the community must be considered, and the remedy should be selected which will result in a safe water.supply at the least cost.

In regard to raw lake water alleged to be safe, bacteriologic examinations, including bacterial counts and quantitative estimation of $B$. col $i$. should be made daily. No accurate deductions as to the quality of a raw water can be drawn from a few scattered examinations. To have value, bacteriologic examinations must lie made rlaily for 


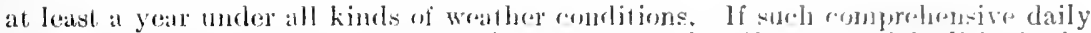

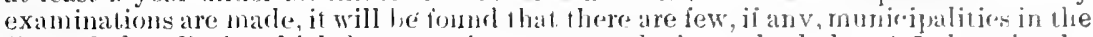

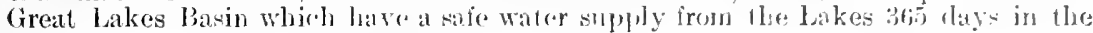
year without filtration or tratminal

In those cities which possess fiher plants "Xjort sujpervision is noecestry. will daily bacteriologic examination of lhe raw and filtered or trouterl water. In sone cases

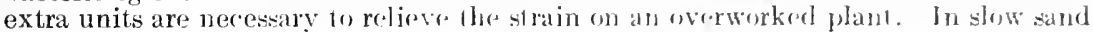

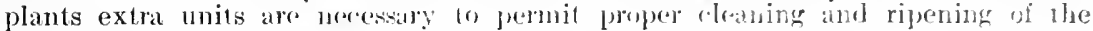
"schnnutzdecke."

They are also necessary when mrehaniral filder plants are in use, to provirle for necessary repairs or the renewal of parts of the working units. There should he the closest supervision of municipal filter plauts exercised hy he blate and rity loards of health to maintain efliciency and insure poper proteretion of the pullic health.

In the prevention of the sprearl of water-bone conlagions rliscase in the basin of the Great Lakes as the problem now stands sewage treathent is secondary in impronce to filtration or treatment of the pullic water supplies. It will always be an ajd and will sometimes be a necessity in furnishing a raw water which (an l.e rendered safe without undue expense. In general it is cheaper to purify water than lo purify sewage, but sewage purifiration thould le carried far enough to insure a good raw water for the filters.

It would be unreasonable to expect a large cily to expend millions for sewage purification for the protection of the water supply of some near-loy village or small city, provided the water supply of the smaller communily could be rendered safe or another supply substituted at a much smaller cost.

No general rules can be tormulated for the disposal of sewage in the Lake coities. Each city must he studied separately, the remedy depending upon local conditions. In general the nethods necessary will be simple because of the enormous volume of water available for dilution, which eliminates the factor of nuisance. From the standpoint of menace to health. the degree of purifiration required will depend upon the amount of the sewage and the proximity of waterworks intakes.

Dilution as a means of sewage disposal should l.e permitted for economic reasons wherever possible without detriment to the public health up to the point where the sewage contributed does not put an undue strain or an unreasonable responsibility upon filter plants by making the lacterial count and the colon content of the raw water too high for saiety.

Actual pollution of waterworks intakes by sewage from ships is difficult to demonstrate, but its possibility is apparent at once. In most instances the elimination of such pollution from the problem would not result in a safe water, as there is usually other more consistent pollution near by. Marking out of zones about the intakes such zones not to be crossed by vessels, or cluring the crossing that all toilets be closed has been suggested. This has serious objections, viz, failure to close the toilets for some reason and the impossiljility of maintaining a zone where the channel is narrow, as, for instance, at the Lime Kiln crossing above Detroit. The most satisfactory solution of the problem seems to be the installation of retention tanks on vessels for human excreta.

Sewage pollution of intakes ly the deposition of dredgings containing sewage sludge has probably taken place, and its results in one instance at least seem to have been disastrous. However, in all instances where complaint has been made against dump. ing such dredgings there was an obvious necessity for filtration or treatment of the public water supply as a protection of the public health, for reasons independent of the dredging, and further, if such necessary water purification had been effected, it would have afforded ample protection against the alleged ill effect of the dredgings.

Aside from these facts, it must he apparent to everyone that the dumping of $d$ redgings from a sewage-polluted river into the current of a stream used as a source of public water supply is a very dangerous and unwise procediure. Such dredgings should be dimped in still water, either behind breakwaters or retaining walls or in mid-lake many miles from shore and from the nearest waterworks intakes.

In order to secure efficient and uniform results from the application of these remedies it is necessary to have two distinct official standards: (1) Standards of raw water; (2) standards of filtered or treated water.

In the opinion of the writer the best way to fix the boundaries of permissible pollıtion of interstate or international waterways is to fix standards of raw water at the intakes. A second standard for the filtered or treated water is necessary in order to insure safe water for interstate travelers. These standards should be based upon the bacterial count and the quantitative estimation of $B$. coli and should be the minimum requirements to prevent the spread of disease, such as typhoid fever or Asiatic cliolera in inlerstate traffic, the various States retaining the right to impose additional requirements, consistent. with State laws where such laws exist. 
Dr. McLaughlin's studies are probably the most extensive of this character yet undertaken in this country, and both of the bulletins presenting them have aroused considerable interest and discussion. There is no doubt that these investigations will bring home to many communities the necessity for improvement in their water supply, and will also serve as a basis on which to enact needed legislation relative to the subject.

\section{Sanitary Survey of the Missouri Watershed.}

In a letter of November 24, 1911, Dr. S. J. Crumbine, secretary of the State board of health of Kansas, stated that the governor of that State had appointed a commission to cooperate with like commissions from the States of Miissouri, Nebraska, Iowa, and North Dakota in an investigation of the sanitary conditions of the Missouri River. In view of the fact that the Missouri River is an interstate stream, he requested the detail of a competent officer of the service to join in the investigations. Passed Asst. Surg. A. J. Melaughlin, who had just completed a sanitary survey of the Great Lakes, was accordingly detailed April 9, 1912, to undertake studies of the pollution of the Missouri, and to secure in so far as possible the cooperation of the States and municipalities interested.

In the correspondence with the State board of health of Kansas, it was stated that it would be impracticable for the service to carry on all of the intensive studies necessary to make the investigations complete, and that the studies would be in the nature of a preliminary survey with a view to determining the points at which intensive studies should subsequently be conducted.

On request, Dr. McLaughlin received the cooperation of the State boards of health of Kansas, Nebraska, Missouri, and Iowa. On account of limitations of State board appropriations, it was suggested that the large eities which were most vitally interested should assist in the investigations, and the health authorities of Kansas City and St. Joseph, Mo., and Omaha, Nebr., were asked to cooperate. As a result, samples were taken regularly at 20 points on the river, and laboratory work was done at 7 points, as follows:

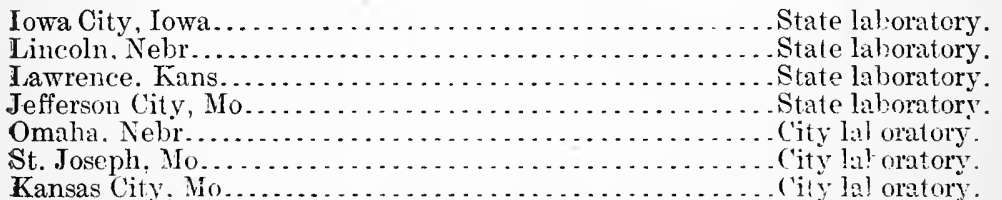

The vast area to be covered and the necessity for uniformity in the observations made at the various sampling stations soon made evident that Dr. McLaughlin alone could not properly supervise the work. Accordingly, at his request, Passed Asst. Surg. J. S. Boggess was detailed May 15, 1912, to assist him in the work and in the collection of data bearing on the investigation.

The data secured are being compiled and a report is now in course of preparation. The facility with which the work was conducted is gratifying, demonstrating as it does that effective cooperation between Federal, State, and municipal health officials is foasible and advantageous. 
INVESTIGATIONS OF MEASLES.

The study of measles, borun in the Irgienic Laboratory during the previous fiscal year, by the director, .j. F. Anderson, and Passed Asst. Surg. J. Goldlucrger, was continued during the early part of the last year, and a considerable atdition to the knowledge of the disease was obtained. That portion of the work refered to in the last report of the laboratory showed that the disease could be reproduced in monkeys by inoculation of blood draw during at loast the early eruptive stage.

The latest studies during the past fiscal year have shown that the virus of measles resides in the nasal and buceal secretions and that, with such secretions collected within at least the first 48 hours of the appearance of the cruption, the discase rould be produced in monkeys.

Inoculations made with secretions collected not later than 48 hours for the purpose of determining the duration of infection gave uniformly negative results. From this it would appear that the nasal and buccal secretions of cases of measles are inl'ective during the early preeruptive and early eruptive period of the disease and that they are not usually infective 48 hours after the eruption has appeared.

The question of the infectivity of the s(ales was also investigated. Many physicians have believel that the scales in cases of measles were infectious; but the studies made in the laboratory showed that in no instance was it possible to produce measles in monkeys by the inoculation of the clesquamated epithelium from cases of the disease. The conclusion seems justified that the desquamated epithelium of measles does not, in itself, carry the virus of the disease.

On account of the cessation of the epiclemic of measles in the city of Washington the studies on this disease have been temporarily discontinued, but it is hoped that the opportunity may recur for a resumption of the studies.

\section{Investigations of Typhus Fever.}

In the annual report for 1910 , page 27 , mention was made of investigations of typhus fever undertaken by Passed Asst. Surgs. J. F. Anderson and Joseph Goldberger in the City of Mexico. These officers, while engaged in investigations at that time, showed that "tabardillo," or Míexican typhus, and Rocky Mountain spotted fever are distinct diseases. They also succeeded in transmitting the former disease to monkeys, and from observations macle expressed the opinion that it is transmitted by the body louse. Their studies in 1910 were unfortunately interrupted by the severe illness of Dr. Goldberger, who contracted typhus fever, rendering necessary their return to Washington.

At the time it was thought that typhus ferer did not prevail anywhere in the Uniter States, and that, therefore, there was no opportunity of continuing the studies undertaken in Viexico.

Dr. Nathan E. Brill, of New York, had, however, reported in medical journals from time to time upon a type of fever observed by him in Mount Sinai Hospital, New York, clinically closely resembling typhus fever as observed in the City of Mexico. Impressed by this close resemblance, Drs. Anderson and Goldberger endeavored to obtai 
materials from cases of the disease described by Brill for purposes of study in order to determine its relationship to typhus fever.

Such efforts were not successful until September, 1911, when four cases of the disease were seen at different times in New York and Brooklyn. Blood obtained from one of these cases was used for the inoculation of monkeys. The animals, after an incubation period of about 10 days, developed typical reactions similar in all respects to those induced in monkeys by the inoculation of blood from cases of typhus fever.

Having established the susceptibility of the Rhesus monkey to infection by the inoculation with blood from cases of typhus fever in Mexico and cases of the disease described by Brill in New York, it became necessary to determine their relationship by cross immunity tests. For this purpose, monkeys which had recovered from Brill's disease were taken to Nexico City, along with a number of controls, and necessary inoculations made. As a result of the studies in the Hygienic Laboratory at Washington, and in Mexico City, the conclusion was reached that the Rhesus monkey is susceptible to infection by inoculation with the blood from a case of "Brill's disease"; that one attack of the disease in the monkey induces a definite immunity to a subsequent infection with virulent blood of the same strain; that monkeys recovered from an infection with "Brill's disease" are immune to subsequent infection with virulent blood from a case of Mexican typhus fever; and that monkeys recovered from an infection of Mexican typhus fever are immune from a subsequent infection with "Brill's disease." By these cross immunity experiments, therefore, it was definitely proven that the disease described by Brill is identical with the typhus fever that prevails in Mexico. It thus became evident that typhus fever of a mild form had prevailed in New York for years, and there is every reason to believe that it has also prevailed in other large cities along the Atlantic seaboard.

The studies of typhus fever have been continued at the Hygienia Laboratory, and a number of papers, giving the results of these investigations, have been published in the Public Health Reports, and many new facts have been brought out. Among the most important of these have been further facts in regard to the nature of the virus of typhus fever, the possible relation of the head louse to the spread of the disease, the part played by the body louse in transmission, the nonfilterability of the virus, immunity reactions, etc. All of the abovementioned papers and the additional facts brought forth have been collected together, and are being published as Hygienic Laboratory Bulletin 86.

The studies on typhus fever are being continued at the Hygienic Laboratory with the particular object in view of determining the duration of infectivity of the louse, and also, if possible, isolating the specific agent.

\section{Investigation of Trachoma in Minnesota.}

Hearings before the Committee of the House of Representatives on Expenditures in the Interior Department called attention to the great prevalence of trachoma among the Indians on various reservations in Minnesota. It was also reported that the disease was present among the miners of the Mesaba and Vermilion ranges of that State. 
At a meeting of the executive commitee of the stato boarel of hoalth of Minnesota, held on April 10, 1912, a resolution was passed requesting the bureau to send to Minnesota an expert in trachoma for a st udy of the situation, especially as related to the spread of tho disease in interstate traffic. The request was subsequently seconded by Representatives in Congress from the States of Minnesota, Wisconsin, and North Dakota.

Surg. Taliaferro Clark, who has had large experience with trachoma, was detailed for this duty, the Commissioner of Indian Affairs having previously stated the acquiescence of his office in the proposed investigation, in so far as the Indian reservations were affected by it, and his willingness to render all practicable assistance.

After consulting with the State health authorities, it was recognized that it would be impossible to make within the limited time available a detailed study of the prevalence of trachoma in Minnesota. It was therefore decided to limit the investigation to a preliminary survey, with a view to determining the existence of trachoma in certain communities, the presence or absence of foci of infection, the spread of the disease among the white population, the danger of further spread, and the recommendation of remedial measures.

The investigation was begun at the Indian reservations of White Earth and Leech Lake, special attention being devoted to the Indian boarding and day schools on the reservations and the public schools contiguous to them in Mahnomen, Becker, Hubbard, and Cass Counties. '

The total number of Indians examined was 545, 253 of whom, or a percentage of 46.1 , were found infected with trachoma. Of 413 Indian school children, 127, or a percentage of 30.7 , were also so infected. Suspicious cases were not taken into account in compiling these figures.

Out of 1,428 pupils in the public schools examined, only 3 cases were positively diagnosed as trachoma, 6 others being considered as suspicious.

Conclusions were derived as follows: Trachoma has not spread from the Indian to the resident white population, this being due to the lack of association between the two races; the public schools may contribute to the spread of the disease, chiefly through the attendance of mixed-blood pupils. The only cases found in the public schools were in pupils with mixed blood. As "mixed bloods" attend public schools in considerable numbers, and trachoma is quite prevalent among them, the danger from this source becomes apparent.

The remedy advocated by Surg. Clark would then consist in the organization of a systematic medical inspection of the public schools, all cases of trachoma to be excluded from school until they can be readmitted without danger to others. In addition the child must be followed to its home, the source of infection located, the family instructed as to the danger of the disease and the precautions to be observed, and proper treatment made available by a system of school or district nursing.

Coping with the disease among the adult Indian population may prove more difficult, in view of the natural aversion of the Indian to a prolonged course of treatment. Employment of persons with trachoma in the lumber camps in the reservations or on excursion boats should be forbidden, these measures to be enforced by declaring the 
disease conditionally quarantinable. Treatment of the disease should be made compulsory, if necessary, by the gathering of the Indians into villages provided with adequate medical supervision and a small hospital for the treatment of severe cases.

The origin of the disease among the Indians is not known. Trachoma is not indigenous to America, and was not recognized as being prevalent until a comparatively recent time. Cases of long standing were, however, observed among the Indians, proving that the disease has existed in that section of the country for many years, perhaps 40 or more, a probable hypothesis attributing its introduction to the lumbermen. Once introduced, the habits of the Indians have contributed to its perpetuation and spread.

A similar investigation among the mining and school population of the Mesaba and Vermilion ranges in Itasca and St. Louis Counties was next conducted. The majority of these miners are of foreign birth, and the only way to obtain their consent to an examination was by telling them that no names would be taken, that the information obtained would not be used to deport anybody, and that the objects of the examination were the determination of the existence of trachoma and the devising of means for its cure. In the Mesaba range 1,319 miners were examined, 34 of whom, or a percentage of 2.7 , had trachoma, while 11 others were considered suspicious; 6,829 school children were also examined, 7 of whom were found to have trachoma, and 11 others were considered suspicious. The percentage of trachoma sufferers among school children in the Mesaba region was thus found to be one-tenth of 1 per cent. In the Vermilion range 392 miners were examined and an Indian school with 83 pupils were examined without finding a single case of trachoma.

The data collected shows that trachoma prevails to a greater or less degree among the miners of every district examined in the Mesaba range, and that it is also present in the public schools. Furthermore, every case found among the miners was active, and certainly contagious.

The origin of the disease can probably be traced to the existence of foci of infection prior to the year 1897, when trachoma was declared a dangerous contagious disease, thus making persons with the disease subject to deportation. Insanitary boarding houses in which miners of foreign birth congregate without regard to hygienic conditions are probably the most potent agent in the spread of the disease.

In order to control the further spread of trachoma, Surg. Clark opines, some system of cooperation should be worked out between the State authorities and the mining companies. In addition, the disease should be made reportable and conditionally quarantinable, so that cases which can not adequately be treated at home could be removed to a hospital; the State should assume the responsibility for the diagnosis of cases; no families, having children in the public schools, should be allowed to take as boarders persons suffering with trachoma; mining companies should cause every new applicant to be examined for the detection of trachoma, and cause to be made or assist in making an examination of persons already in their employ; the companies should also supervise the sanitary conditions under which their men live and institute a campaign of education against the disease among them. 
In regard to the public schools, Dr. Clark states that the samo measures advocated for the Indian schools will be found eflective, namoly, modical inspection of pupils, cxchusion of trachoma pationts, employment of school or district nurses, and sanitary supervision of pupils sent home on account of infection.

The above investigations and recommendations by Sures. Clark can only be considered as preliminary in character. It has already been decided that, if no unforeseen cilcumstances prevent, the same officer will, at the request ol the State board of health, be cletailed again to Minnesota for a thorough survey ol the trachoma situation, especiully as relates to the prevalence of the discase.

A resolution passed by the American Medical Association at its meeting in Atlantic City, June 3-7, 1912, having requested the service to conduct a nation-wicle investigation of the prevalence of trachoma, it is intended to extend the scope of the investigation, so as to make it cover those States from which the disease lias been reported.

\section{InVESTIGATIONS OF 'Tracioma IN KentéckY.}

At the request of the State health authorities of Kentucky, Passed Asst. Surg. J. MeMullen was detailed on July 1, 1912, to conduct an investigation into the prevalence of trachoma in the rural districts of that State, where the discase had been reported as of unusual frequency.

The counties investigated wore Knott, Perry, Leslie, Breathitt, Owsley, all lying in the mountainous part of eastern Kentucky, and Clark, which is in the blue-grass region bordering the mountains. A total of 3,974 persons were examined, 500 of whom were found suffering from trachoma, or over $12 \frac{1}{2}$ per cent. These figures represent only cases in which a positive diagnosis was made, as all suspicious cases were carefully excluded. While, as a rule, only the rural schools were in session, it is thought that a sufficient number were visited to give a fair idea of the amount of the disease present in each county, the percentage of infection among the pupils being taken as an index of the general situation. The majority of the persons examined were therefore school children, but opportunity was also taken to examine the teachers, persons in the vicinity of the schools, and, whenever found advisable, homes of suspects were visited, and people on the roadside examined. Different portions of the same county vary as to the percentage of trachoma present. In one, for instance, it is estimated that 40 families, or about 300 persons, reside on one creek. From 60 to 75 per cent of these families were infected with trachoma, the proportion in each family varying from a few cases to all its members. The disease was less prevalent in the towns, but in at least one instance trachoma was found by Dr. McMullen in more than 50 persons residing in and about the town where he was stopping.

The disease was found in all possible aspects, from the acute onset of a few wecks' duration to the terminal stage of cicatrization and total blindness. Many of the cases had existed for a long time, and not a few for 40 and 50 years. The source of the original infection is obscure, but the disease has undoubtedly been present beyond the recollection of the oldest inhabitants. Insanitary habits among the poorer class of people have been instrumental in the spreal of 
the disease. Large families are the rule among the mountain folks, the average of children being 8 or 10 . The whole family often sleep, live, and cook in the one room of the home, and in addition use the same towel for days without changing, and wash in the same basin, which is often a stone partially buried beside the well and having a depression on the top, the thorough cleansing or even emptying of this rudimentary basin being practically impossible. Some of the houses have no windows or they are so small as to lack the necessary air space and ventilation, while in winter they are closed as tight as their construction will permit. If a disease as contagious as trachoma is introduced, all the facilities for its rapid transmission will be found present.

The measures deemed advisable by Dr. McMullen for the prevention and gradual eradication of the disease in Kentucky coincide generally with those suggested by Dr. Clark for Minnesota. The curative and prophylactic problem in localities so heavily infected with trachoma as the mountainous regions of Kentucky have been shown to be is a serious one. Both from health and economic standpoints it is of the greatest importance that the situation should be met in an efficacious manner. It is in the interest of all the inhabitants of the State that State and municipal health authorities should undertake and carry out systematic measures of eradication, and sufficient means should be provided for this purpose.

\section{Investigations of Rocky Mountain Spotted Fever.}

A description was given in last year's report (see p. 40), of the investigations of Rocky Mountain spotted fever conducted by the service in the Bitter Root Valley, Mont., from May 12 to August 7, 1911, at the request and with the cooperation of the State health authorities. A paper relative to these investigations was subsequently published in the Public Health Reports of May 17, 1912.

These studies were begun again by Passed Asst. Surg. T. B. McClintick, on April 1, 1912. As in the previous year, the work assumed two aspects: (1) Tick extermination by (a) dipping of domestic stock and $(b)$ killing of small wild animals, and (2) Laboratory investigations.

From April 1 to July 1, 1912, the following stock was dipped or redipped: Horses, 402 ; cattle, 851 ; sheep, 157.

Three arsenical dipping fluids were used, of which three different varieties were given a trial. The dipping fluid kills the male and the unengorged female tick very satisfactorily. If the females have reached a stage of partial engorgement before the animal is dipped, the dipping fluid will not kill all of them, nor will it prevent a portion of them from reaching the state of complete engorgement. It has further been demonstrated that some of these engorged females will oviposit and that some of their eggs will hatch. The experiments have not yet been carried far enough to determine what percentage will hatch. In addition to the experiments with ticks on domestic stock that are being carried on along this line, similar experiments are being conducted with guinea pigs.

One important point brought out by the dipping work is that the tick is very loath to attach to and seldom reaches the replete 
stage on an animal that has been clipped. As to how long after dipping an animal this holds true has not been exactly determined, but probably for at least a few weeks and moro or lesi throughout the tick season. It has been aimed to dip the stock erery 10 days or two weeks, but some of it was not dipped oftener than once a month, and a small portion of it but once or twice during the season. Nevertheless, on scarcely any of this stock has it been possible to find many ticks after the ticks that were on the stock at the time of the first dipping were eliminated, and practically no fully engorged ones have been found. Some experiments along this lino aro being done with guinea pigs, and so far the results seem to coincide with those obtained with domestic stock. So far it has been impossible to develop larvæ (seed ticks) on pigs that one month previously had been dipped, although they readily develop on pigs that have not been dipped. If these results as they appear now are finally confirmed it will greatly reduce the work of dipping the domestic stock, as the period between dippings can be very materially increased. The object then will be to dip the stock early, oven before the tick appears, after which it can be dipped about once a month.

Columbian ground squirrels are found in the Bitter Root Valley in large numbers, and it is against this rodent that the campaign of extermination is principally waged. Other small mammals are common but not near so numerous as the ground squirrel. Practically all the small wild mammals, and particularly the ground. squirrel, are hosts for feeding and developing the larval and nymphal forms of the tick.

The work of extermination was again taken up the latter part of Mareh, 1912. The methods of destruction of rodents used the previous year were again used, but principally poison and carbon bisulphide. The poison was used early, before the vegetation came out, and with it a great many rodents were destroyed. Later the territory was gone over with carbon bisulphide and, in addition to the original 8 square miles, about 2 more square miles were covered. From April 1 to July 1 the following mammals were killed by shooting and trapping:

Ground squirrels (C. columbianus) . . . . . . . . . . . . . . . . . 2,245

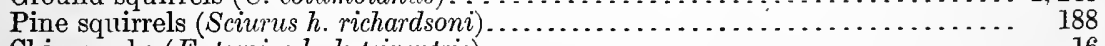

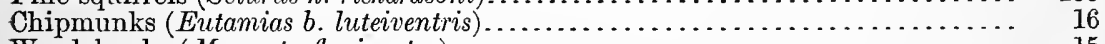

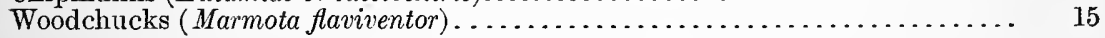

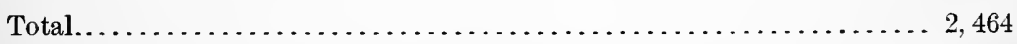

The wild mammals, particularly the ground squirrels, were almost completely exterminated on the territory covered. Poisoning and fumigating with carbon bisulphide proved very efficient in the work of extermination, but the former must necessarily be used early in the season, before the new vegetation appears. About 200 gallons of carbon bisulphide were used.

The ticks were very plentiful at the beginning of the past season. They were found most abundant as soon as the weather warmed up and then began to decrease in numbers until about the 1st of July, when there were very few to be seen. 
Laboratory investigations were taken up in conjunction with the tick-eradication work, for the purpose of investigating the status and prevalence of the infection among ticks and lower animals in nature. Most of the small wild mammals inhabiting the Bitter Root Valley are susceptible to experimental infection with spotted fever, but it does not produce in. any of them pathological lesions sufficient for diagnostic purposes. The diagnosis can only be established by making blood inoculations from the suspected animal into a highly susceptible animal, such as the guinea pig.

A study of the susceptibility and immunity of some of the wild mammals to spotted-fever infection was made by inoculating them with the virus of the disease and then about five days later making inoculations of their blood into guinea pigs. The animals were as a rule caught in territories badly infested with ticks

During this season (1912) the approximate number of animals examined and experimented with is as follows: 175 ground squirrels, 20 woodchucks, 1 coyote. 12 rock squirrels, 1 mountain goat, and 1 wood rat.

The experiments with these animals have not yet reached the stage where the results can be reported. The ground squirrels examined were caught in the vicinity of the following places: Lo Lo Valley, Darby, Hamilton, Victor, Stevensville, and Florence.

Ticks have been collected and placed on a total of 61 guinea pigs. The number of ticks placed on each pig varied from about 5 or 10 to 50 or 60 . The ticks were collected from the Lo Lo Valley, and in the vicinity of Darby, Hamilton, Stevensville, Florence, from the area on which the dipping, etc., is being done near Victor, and from 6 mountain goats. Of the 61 guinea pigs on which the ticks were placed, 7 of them developed spotted fever as a result of being bitten by the ticks. These 7 pigs were bitten by ticks from the following localities: Three from the selected area near Victor, 1 from Florence, and 3 from one of the mountain goats.

About 150 ticks were also collected in the State of Idaho where spotted fever is very prevalent in mild form and placed on guinea pigs, but none of the pigs developed spotted fever.

A number of ticks were infected and allowed to engorge on guinea pigs, with the young of which it was hoped to continue experiments in Washington to determine the possibility of infecting nonimmune ground squirrels with the larval and nymphal form of infected ticks.

So far this season there has been a total of 7 human cases of Rocky Mountain spotted fever in the Bitter Root Valley as follows: Three at Hamilton, 1 at Florence, and 2 from the Lo Lo Valley. Four of the cases were fatal. There have been no cases in the territory in which Dr. McClintick's work was being done, although as stated above, infected ticks have been found there this season. This is the first season in years that at least one human case of spotted fever has not originated there. Just at the close of the season and after the eradicative measures had been suspended, Dr. McClintick unfortunately became himself infected, presumably in his laboratory, and died of the disease after an illness of six days. While the work will be continued by another officer of the service already selected, his death is a great loss to the country, highly qualified as he was to carry on public-health and research work. 
Investigations of Pellagira.

As stated on page 40 of last year's report, the marine hospital at Savannah, Ga., has been made the chief base for the study of pellagra by the service, Passed Asst. Surg. C. H. Lavinder and Asst. Surg. R. M. Grimm being placed in charge of the work there.

A fairly complete laboratory is now in working order, and investigations have been made along the following lines: Clinical and laboratory studies on pellagrins received in the wards; the collection of statistics on the geographical distribution and prevalence of pellagra in the United States; and epidemiologic sturlies of the disease in the field.

Numerous delays have occurred in the work on account of lack of adequate facilities, the laboratory having been in working order for less than half of the year, and still lacking some necessary equipment.

Efforts have been made to secure pellagrins for the hospital by means of newspaper and medical magazine notices, besides bringing the matter to the attention of the medical profession. As a result, a total of 14 pellagrins have been secured for observation in the wards. Unfortunately, most of these cases have not been entirely suitable for the purpose, but there are not as ret sufficient applications to allow selection of cases. An encouraging leature is the steady increase in applications.

Studies made on these patients have included, besides the ordinary clinical observations, some experimental therapy and some experimental laboratory work. Some new drugs have been tried, and some effort was made to treat one or two cases with a leucocytic extract prepared in the laboratory from rabbits. Several monkeys have been inoculated with material derived from pellagrins and are now under experimentation. In addition to this, some feeding experiments have been carried on both in chickens and in monkeys, the results of which are not, however, yet ready for publication.

For the collection of statistics a return mailing card was prepared and a supply of 20,000 cards furnished for the use of the officers in charge of the work The mailing and tabulation of these cards has been going on for some time. The States of Virginia, Kentucky, North and South Carolina, Georgia, Alabama, Mississippi, and Louisiana have been circularized and the replies tabulated with the exception of one State. In addition, letters have been written to all of the State health officers and to all of the superintendents of insane asylums in the United States. It is hoped that the results of this work will soon be ready for publication.

Asst. Surg. Grimm spent last season and all of this season up to date in the States of Kentucky, South Carolina, and Georgia making field studies of pellagra. The results of the work done in Kentucky and South Carolina have already been published in the Public Fiealth Reports of September 22, 1911, and February 23, 1912. The results of the other investigations and a complete review of the work done will be publisher subsequently. In these field studies an attempt was made by Dr. Grimm to see as many cases of pellagra as possible and to collect data which might possibly throw any light on the etiology of the disease; 140 cases were studied by him in Kentucky and 380 in South Carolina. It would have been desirable to report upon the total number of pellagrins in the regions visited, but this was found 
impracticable, as the reports of cases were obtained through local physicians, and it was known that in a number of cases no medical advice had been secured by the patients. While the data collected is of considerable interest, it can not be deemed of a conclusive character, and further investigations will be needed to determine their relative value.

Inspection of Reform School for Girls of the District of Columbia.One of the inmates of the Reform School for Girls of the District of Columbia having died at the Freedmen's Hospital of a disease diagnosed as pellagra, the board of trustees of the school, through the president, Mr. J. N. McGill, requested the detail of an officer of the service to examine the institution, not only as to sanitation, but also as to the food supplies, with a view to determining the influence of existing conditions on the possible causation of the case of pellagra.

The Reform School for Girls being a Federal institution, Passed Asst. Surg. B. S. Warren was instructed to visit the school. The sanitary conditions of the institution were found to be excellent, with the exception of the diet furnished to the inmates, which did not contain enough meat or other proteid element. The lighting of the buildings, both natural and artificial, was sufficient. The ventilation, dependent on natural methods, was in all cases adequate. Plumbing, toilets, sinks, etc., were all in apparently safe condition and kept clean. There was no evidence of overcrowding.

No physical examinations were made, but a general inspection of the inmates showed that they were in apparently normal condition as to weight and proportional height, no evidence of illness being noted. An isolation hospital in a suitable location was maintained, and proper precautions taken on the admission of inmates to keep them under observation in hospital to prevent the introduction of communicable diseases.

Dr. Warren recommended that a better-balanced diet be furnished and records kept of the quantity given each inmate, together with records of the weight and height of the inmates on admission and monthly afterwards, while the advisability was suggested of keeping records of the hemoglobin percentage of the blood of the inmates.

Further comprehensive studies of pellagra necessary. - The whole subject of pellagra should be thoroughly studied from different angles. When first reported in Alabama, the disease was unknown to most of the medical profession of the United States. Now it is a common and daily event in the professional life of hundreds of practitioners. It has spread with almost amazing rapidity, and has been reported from at least 40 States and the District of Columbia. Complete and accurate statistics for the entire United States are wanting, but from an extensive inquiry begun by the service some months ago, and soon to be completed, it is conservatively estimated that since 1907 there have occurred not less than 30,000 cases, with an average case mortality of about 38 per cent computed on exact figures for eight States studied. In many sections of the country the disease now prevails in epidemic form and is menacing the life and health of the entire. population. All governments with experience unite in regarding it as a national calamity, both from financial and public-health standpoints.

When consideration is given to the nature of the disease, its chronicity and termination often in invalidism, insanity, or death, 
the lack of definite knowledge as to its causation and transmission, the unsatisfactory results of treatment, its rapid and continuous spread, the class of people affected, and the uncasy state of the pulslic mind in many places, then the thorough investigation of this mysterious disease assumes immediate importance.

The deep interest and carnest appreciation of the gravity of the situation are evidenced by the activity of the local hoalth oflicials of the many States affected.

While studies have been carried on as activaly as possible, the lack of sufficient money and the necessary facilities have provented investigation on a scale commensurate with the problems involrol. 'Tlese problems can not be arlequately met by the hacteriologist or clinician or pathologist alone. To hope for satisfactory results, complete und extensive studies must be made from all sides, and in order to do so larger appropriations will be recuired.

\section{Investigations of Hookworm Disease.}

During this last fiscal year the Hygienic Laboratory has continued its investigations of hookworm disease, and cooperated with the State health authorities and with the Rockefeller Sanitary Commission in the movement for the eradication of the disease, the activities of the service officers engaged in this work being deroted to research and technical matters.

In addition to the States mentioned in the last annual report of the service (Virginia, North Carolina, South Carolina, Georgia, Alabama, Mississippi, Louisiana, Arkansas, and Tennessee, with Florida working independently), Kentucky and Texas hare now instituted an active campaign against the disease in question. Further, the disease has been found in California, Maryland, Nerada, Oklahoma, and West Virginia.

Hookworm infection has been demonstrated in 93 of the 100 counties in Virginia; in 99 of the 100 counties in North Carolina; in 140 of the 146 counties in Georgia; in every county in. South Carolina; in 66 of the 67 counties in Alabama; in 77 of the 79 counties in Mississippi; in 27 of the 59 parishes in Louisiana ; in 57 of the 75 counties in Arkansas; in 95 of the 96 counties in Tennessee; in 22 of the 119 counties in Kentucky. The foregoing statistics include the reports up to December 31,1911 , as reported by the State boards of health in question. Of the 884 counties in these 10 States, infection has been demonstrated by the State boards of health in 719 ; the remaining 156 counties had not been surveyed when these statistics were summarized.

The survey as thus far conducted clearly brings out the original claim made by the Hygienic Laboratory in 1902 that the disease was especially severe in the sandy coastal plain.

By means of conferences between representatives of the State boards of health, the Public Health Service, and the Rockefeller Sanitary Commission both the standards and the plans of work in the various States have been standardized, so that all of the State boards that are associated in the informal organization are keeping their permanent records in the same manner, and are following practically the same methods.

$69450--H$. Doc. $971,62-3-3$ 
As very important elements in these records may be mentioned, in particular the survey to determine the degree of infection in different localities, and the survey to determine the sanitary conditions as to soil pollution in the different counties.

In reference to the degree of infection, the survey had been completed on December 31, 1911, for 78 counties in 9 States; Dr. Stiles states that the result shows, an infection among the rural children from 6 to 18 years of age in these counties ranging in degree from 2.5 per cent to 90.2 per cent.

During the calendar year 1910 medicine was dispensed by the above-mentioned agencies to 14,423 persons, and during the calendar year 1911 to 140,378 persons. By June 30,1912, the total number of persons to whom medicine has been dispensed had reached nearly a quarter of a million.

The sanitary survey had been conducted in 125 counties in 9 States up to December 31, 1911. Dr. Stiles states that a total of 43,448 rural homes had been inspected, and of this number 21,308 had been marked zero in sanitation (in respect to soil pollution) because they had no privy at all.

The basis of marking on soil pollution is uniform in the different States, the system being adopted that was originally proposed by Dr. Lumsden and Dr. Stiles. This system is as follows:

All privy and sewer types in use are classified under the heads "A," "B," "C," "D," "E," and "F" and to each type is assigned its rating of efficiency on the scale of 100 . The survey is made by countics, and is based upon an inspection of at least 100 rural homes per county, taken at random in different localities. Usually from 200 to 700 homes per county are examined, and permanent record is made of their condition.

At the request of the State board of health of Texas, Dr. Stiles made a special preliminary survey in that State to determine the approximate distribution of the infection. His report was submitted to the State board of health, and was published in its official bulletin.

At the request of the State board of health of Mississippi, Dr. Stiles was detailed to aid the board in a special public health campaign, which lasted about three weeks.

The policy followed by the Hygienic Laboratory in reference to hookworm work is based upon the fundamental fact that the best results can be obtained by supporting in every way possible and by emphasizing the importance of the State and local boards of health. While this service does not by any means take the position that there are not Federal problems connected with the hookworm question, it does take the unqualified stand that it is the duty of any locality in which soil pollution exists to put a stop to the soil pollution in that particular locality. Specifically, it is primarily the duty of the States and counties to pass and to enforce sanitary privy laws, and it is the duty of the Federal Government to aid in every legitimate way in impressing upon the priblic the importance of supporting their own State and local public health agencies. This is a fundamental principle underlying all of the field work in hookworm disease conducted by officers of the service.

Hospital work. - In accordance with the act of Congress which authorized the service to admit into the marine hospitals a limited number of patients suffering from diseases affecting the public health, 
for purposes of study, the United States Marine Hospital at Wilmington was designated as one for special study of the parasitic diseases, and beginning with July 1, 1911, part of the work of the Division of Zoology of the Hygienic Laboratory was carried on at the hospital in question. Patients suffering from various parasitic diseases were admitted to the wards, and their casc's were studied in detail. Several special articles giving some of the results of these studies will appear in the near future.

A considerable portion of the work at Wilmington was based upon hookworm disease, and will be reporter upon later as soon as the results of 1911 can be correlated with certain results of 1912 . By taking up special problems at this and other hospitals, it is hoped that the service may render valuable aid to the.States in their fight against hookworm disease.

Full time county health officers needed.-Theoretically the most important, and practically at the present moment the weakest point in the entire public health organization of the country is the position of the county health officer or county superintendent of health. Public health work in general involves, in addition to the purely technical work, certain elements in particular, namely, education of the public (which may be compared in a general way to publicschool education) and enforcement of public health laws (which may be compared in general to the system of sheriffs and police organizations). Some of our counties liave excellent county health officers, but in the vast majority of cases the men are underpaid for the work, and they therefore are unable to perform fully the necessary public health duties.

While this service is authorized to aid the State and local boards of health, more particularly on the technical sides of the questions involved and in the educational campaign, the extent of such cooperation depends upon available appropriations. Moreover, the point can not be emphasized too strongly that the political application of the police powers leading to a prevention of soil pollution, and thus the eradication of certain diseases, is a function that devolves more especially upon the State and local authorities. The most feasible method of preventing soil pollution and extending public health work seems to lie in the development of efficient, full time county health officers.

\section{Investigations of Poliomyelitis.}

In response to a request from the board of health of Cincinnati, Ohio, Passed Asst. Surg. W. H. Frost carried on investigations of anterior poliomyelitis in that city and vicinity during the months of October and November, 1911. In this work he had the hearty cooperation of the health department and physicians of the city, and for a time Dr. Paul G. Woolley was associated with him in the work, and made the pathological studies in connection with the epidemic.

During the investigation attention was given to the prevalence of anterior poliomyelitis, its clinical features and clinical classification, epidemiology, pathological and experimental studies. Data were collected bearing on the incidence of poliomyelitis in Cincinnati and vicinity, there being 163 cases, or 27.4 cases per 100,000 population. 
For purposes of making epidemiologic studies case cards were used and risits made in so far as possible to the family of each case reported in Cincimnati. Epidemiologic records were thus collected personally in 78 cases, and more or less complete records obtained from the attending physicians in 16 other cases. All the data thus collected have been analyzed and included in a manuscript which it is expected will be issued in bulletin form.

In summarizing the results of his work, Dr. Frost stated, in effect, that the epidemic, though not large, was unprecedented in the area involved; that the cases observed presented some unusual clinical characteristics, an unusual high percentage of then showing indications of involvement of the bulbar centers, and that in a series of cases studied there was a fairly constant moderate mucous leucocytosis.

In Cincinnati, the first case was reported in the week ending August 26, and the epidemic reached its maximum during the first three weeks in October. Cases continued to occur with decreasing frequency through December and January.

As stated by Dr. Frost the ratio of incidence was greatest in children under five years of age. The carliest cases reported were widely separated, and most of the cases throughout the epidemic showed no traceable connection with previous recognized cases.

\section{Epidemiological Study of a Milk-borne Outbreak of Septic Sore Throat in Baltimore, MiD.}

Early in March, 1912, many physicians in Baltimore noticed the unusual occurrence of cases of sore throat, differing in some striking particulars from cases ordinarily observed.

The matter was brought to the attention of the bureau, and Passed Asst. Surg. W. H. Frost was instructed on March 23, 1912, to proeeed to Baltimore and cooperate with the State and city health authorities in an investigation of the extent and source of the epidemic. The data already collected seemed to indicate that the epidemic had originated with the use of milk from one of the largest dairies of the city and had subsided as soon as proper methods of pasteurization were introduced in that dairy.

An investigation was therefore outlined in cooperation with the city department of health which would embrace the collection of reports of cases, epidemiological and bacteriological studies, and an inspection of the suspected dairy. This program was carried out only partially, as various difficulties were found. The disease is not reportable, and as the investigation was undertaken several weeks after the acme of the epidemic, the voluntary reports obtained from a small percentage of the physicians were fragmentary in character. It was impossible to ascertain the accuracy of the diagnosis in many of the cases reported, and the material for the bacteriological studies was very unsatisfactory, as only a few cultures obtained from local bacteriologists could be utilized.

In all, 602 reports of cases were received, but it may be estimated that certainly not less than 1,000 , and perhaps as many as 3,000 , cases occurred, causing 30 or more deaths.

While the data collected was incomplete, their analysis seems to warrant the following conclusions: The outbreak of "septic sore throat," which occurred in Baltimore, chiefly during February and 
March, 1912, was apparently a streptococous infection; it is clear that the infection was disseminated chiefly by the milk marketer by one of the largest dairies of the city, the cpidemic having probably been augmented and prolonged by contact infection; it may bo conjecturer that the milk became inlected prior to its recoipt at the plant, the inadequate "flash" process of pastrurization employed at the dairy being responsible for the survival of the infertive agent; as to the original souree of the infection, it nuy be sumiscel that either the pathogenic germs were introduced into the milk by some infected person or that they proceeded from the udrler of soine of the cows, the latter being the most probable hypothesis, although no evirlence to this effect is available, in spite of a velerinary cxamination of all the herds from March to $\Lambda$ pril.

Special interest attaches to this epiclemic, as severul similar epidemics, apparently due to the same infoctive agent, a re reporter in the literature. Two of these epidemics, the one in Boston in Nay, 1911 , and the one in Chicago in the winter of 1911-12, welc also quite severe and traceable to infection through milk.

These epidemics illustrate the need of further regulations for the protection of the milk supply and, especially in cases where pasteurization is used, the importance of having the milk pasteurized either under official supervision or by methods found efficient by the health authorities.

It is expected to have the report of the investigation published by the bureau in bulletin form.

Investigation of Efecots of Pasteurization on tile Nutritive VALUE OF MILK.

A joint letter dated April 4, 1912, was received from a committee representing the Washington Section, Woman's Welfare Department of the National Civic Federation, and the Association for the Prevention of Tuberculosis in the District of Columbia, urging that a study be made by the service in cooperation with the Bureau of Animal Industry of the Department of Agriculture as to the effects of pasteurization on the nutritive value of milk and also of the relative value of raw and pasteurized milk as food for infants and invalids.

The proposed investigation was in line with previous work done at the Hygienic Laboratory, the results of which have been published in bulletins of that institution, and after conferring with the officers of the Bureau of Animal Industry it was decided to take up the studies suggested in the above-mentioned communication as soon as the Bureau of Animal Industry would be in a position to furnish the milk needed for the purpose, as the milk used must necessarily be under the control of those making the investigation. Dr. A. D. Melvin, Chief Bureau of Animal Industry, stated subsequently that his bureau would be ready to supply 10 gallons of milk each day, beginning July 5 .

A feeding station with the necessary equipment has been established at the Hygienic Laboratory for these studies, Passed Asst. Surg. A. M. Stimson being put in charge of them, and one nurse employed to assist him. It is planned to continue this investigation for at least one year, and preferably longer, in order to make the 
results of real value. The amount of milk which will be furnished by the Bureau of Animal Indutry is considered to be sufficient for approximately 25 to 30 babies daily.

The results of this investigation will be published in a bulletin, the two bureaus interested to receive full credit for their respective part. The Bureau of Animal Industry will handle the part relative to the methods of production and delivery of milk and the Hygienic Laboratory the part relative to methods of feeding and results obtained thereby. These investigations may be taken as an excellent example of the numerous instances of cooperation of other bureaus with the Public Health Service in public health problems.

\section{Studies of Cholera in Cooperation with the International Office of Public Hygiene.}

At a meeting of October 9,1911, the permanent committee of the International Office of Public Hygiene adopted the following resolution:

\section{The committee considering-}

1. That the present condition of our scientific knowledge as to the etiology of cholera and the biology of vibrios, both choleraic and choleriform, is still very incomplete.

2. That for example we are ignorant how in countries where the disease is either endemic or epidemic in an intermittent fashion, the persistence of the cholera virus is brought about during the periods which separate the acute increases of infection, and in the course of which no cases of cholera are observed, it is therefore logical to conclude that if this point was elucidated, and knowing where to direct the prophylactic measures, of which the field of action during these periods of calm or limitation, it might often be possible to foresee epidemic recrudescences, and perhaps to hope to extinguish the foci whence proceed invariably the cholera pandemics, and this at a cost of less sacrifice than that imposed on humanity by a single one of these pandemics.

3. That every progress made in this direction would have the effect of rendering prophylactic measures more efficacious.

It is agreed to pursue the studies of the questions hereto annexed, and in the first place to consider the probem of the persistence of the choleraic virus, during the interepidemic periods.

The execution of the project was intrusted to an international commission, of which Surg. H. D. Geddings was one of the members. The commission decided to begin these studies both in the localities where cholera had prevailed during the year 1911 and in aggregations of persons coming from these localities. The investigations would be aimed in a general way to finding out whether the cholera vibrio persists-

I. In man.

(a) By cases of cholera occurring in small number and at long intervals.

(b) By chronic gastrointestinal affections either in children or in adults.

(c) Among persons having had cholera, especially those with a tardy convalescence, with protracted persistence of the vibrio.

(d) Among healthy persons who have not had cholera (bacillus carriers).

II. In surroundings external to man, as: Watercourses, sewers, garbage collections, privy vaults, etc.

In order that the work undertaken might be more easily comparable, it was suggested that the technique followed should be in accordance with the conclusions of the bacteriological commission of the International Office of Public Hygiene. ${ }^{1}$ 
It was also decided to combine the results of the bacteriological examinations and consider them in strict relation with (1) the epidemiological facts collected on the progress and evohution of cholera; (2) observations of all the conditions which may appeas to be of at nature favoring the persistence of the choleraic virus.

The commission authorized a number of the members to communicate with the sanitary authorities of the countries in which the work could be undertaken. One of these members was Surg. Geddings, who brought the matter to the attention of the bureau, suggesting that the views of the director of health of the Philippine Islands be ascertained on this subject.

Passed Asst. Surg. V. G. Heiser, who is director of health and chief quarantine officer for the Philippines, was communicated with, and he stated in reply that studies very much like those outlined by the committee of the International Office of Public Hygiene were already under way in the islands at the time the letter was received.

\section{C'OMpilation of Health IaAws.}

Mention has been made on pages $43-45$ of the annual report for 1910 and page 15 of the annual report for 1911 of the compilation of health laws undertaken by this bureau at the request of the conference of State and provincial boards of health. The work has been progressing steadily, if somewhat slowly, on account of the limitations imposed by the inadequate office force and the exigencies of routine work.

So far, the following oulletins have been issued, containing laws relative to various subjects bearing on the public health:

Public Health Bulletin No. 45, A Digest of the Laws and Regulations of the Various States Relating to the Reporting of Cases of Sickness.

Public Health Bulletin No. 49, Ophthalmia Neonatorum, an Analysis of the Laws and Regulations Relating Thereto in Force in the United States.

Public Health Bulletin No. 52, Vaccination, an Analysis of the Laws and Regulations Relating Thereto in Force in the United States.

Public Health Bulletin No. 54, Organization, Powers, and Duties of Health Authorities, an Analysis of the Laws Relating Thereto in Force in the United States.

Public Health Bulletin No. 56, Digest of Laws and Regulations Relating to HabitForming Drugs.

Public Health Bulletin No. 57, Common Drinking Cups and Roller Towels, an Analysis of the Laws and Regulations Relating Thereto in Force in the United States.

In preparing these compilations special care has been taken not only to publish the text of the laws, but also to briefly analyze their. provisions, and supplement them by abstracts of court decisions bearing on the interpretation of the legislation compiled.

An effort will be made to publish in the near future compilations of laws relative to other public health subjects, as it is believed that these bulletins serve a real need by showing in concrete form the status of health legislation in this country and promoting uniformity of action by the various States. With a view to keep in touch with new legislation and make it promptly available for study by other authorities, it is intended to publish in the Public Health Reports all new legislation as soon as possible after it is enacter. 
Aid to Texas Authorities in the Installation of a Laboratory.

During the month of February requests were received from the State health officer of Texas, Dr. Steiner, and from one of the members of the delegation of that State in Congress, urging that an officer of the service be detailed to advise the State health authorities in the installation of laboratory facilities for the production of antimeningococcic, antidiphtheritic, and other serums.

The epidemic of cerebrospinal meningitis under which the State was then suffering made the production of antimeningococcic serum of great importance, as its prompt administration would tend not only to check the mortality from this disease, but it would also be influential in preventing the formation of new foci of infection which might spread the disease in interstate traffic. In view of these facts, Passed Asst. Surg. A. M. Stimson, of the Hygienic Laboratory, was ordered on February 23 to proceed to Texas for the purpose indicated.

After a careful consideration of local conditions, the conclusions reached by Dr. Stimson were that it would be inadvisable to carry out the project on the scale originally planned by the Texas authorities, as the available funds and accommodations would make its successful realization improbable. The location, lighting, and especially the stable facilities and the water supply were found to be inadequate for the work contemplated.

It was therefore suggested by Dr. Stimson to the State health officer to limit the installation to a laboratory for diagnostic purposes and for the production of typhoid vaccine. In the case of antimeningococcic serum it would have been impossible even under the most favorable circumstances to have the product ready for distribution before a period of five or six months, and it seemed probable that by that time the epidemic of meningitis would have subsided to such an extent as to not justify the manufacture of the serum by the State. In the case of this serum, and also of antidiphtheritic serum and vaccine virus, it was recommended that action be postponed until a more liberal appropriation would be available, and a plan was presented to obtain in the meanwhile these products from the manufacturers at a more reduced cost.

The above recommendations were concurred in by the State health authorities. Preparations were made for the installation of a laboratory in accordance with Dr. Stimson's detailed plans, and the manufacture of other biological products was deferred until legislative action is obtained.

\section{Laprosy Investigation Station.}

On October 23, 1911, Passed Asst. Surg. G. W. McCoy took command of the leprosy-investigation station, superseding as director Passed Asst. Surg. D. H. Currie, who had been transferred to San Francisco.

The work done during the year may be considered under two different headings: (1) Investigations of leprosy proper; (2) duties of the director as sanitary adviser to the governor of Hawaii.

The studies of leprosy have continued along lines previously laid. As in the previous year, the major portion of these studies have been conducted at the Kalihi receiving station in preference to Molokai. 
The experimental work in the treatment of leprosy has (omprised mainly vaccine therapy and serum therapy. Abrut 20 pationts havo been given subcutaneously varying amounts of tha acid-fast bacillus grown from cases of the disease. The cultures wore in some cases killed by heat; in others by trikresol; while in still others liviner organisms were used. No visible inprovement has taken place in tho patients during the period of treatment, which call hardly cause surprise in view of the extremely slow evolution of leprosy. In several cases a serum secured from an immunized horse was triect. The results have not been encouraging, but efforts are being made to obtain a more potent serum, particularly one with bacteriolytic properties. None of the so-called specifics-chaulmoogra oil, iodide of potassium, etc.-have been used; but, whenever required, symptomatic remedies have been administered in adrition to the purcly experimental treatment.

Following experiments previously made with flies and mosquitoes, work has been begun with lice, bedbugs, and fleas for the purpose of determining their rôle as possible agents in the transmission of leprosy. So fal the positive results have been limited to two head lice taken from a case of nodular leprosy, both of which showed large numbers of acid-fast bacilli. Much more work will have to be done with these insects before issuing any definite statement relative to this subject.

Certain epidemiological studies are in progress, having for their object the determination of the success of segregation and the nature of the association that apparently is necessary for the spread of leprosy. The field is not especially good for these studies, as leprosy is so prevalent in Hawaii that results in attempting to trace the disease to any given source or focus are likely to be misleading.

Acting Asst. Surg. H. T. Hollmann has succeeded in growing an acid-fast bacillus from cases of rat leprosy. The organism differs from the human leprosy bacillus and from other acid-fast organisms so far studied at the station.

A number of bulletins covering the work done have been published during the year, reference to them being made elsewhere.

The cooperation with the Territorial authorities has been maintained throughout the year in these investigations, and also in the diagnosis of cases, etc.

\section{COOPERATION WITH TERRITORIAL AUTHORITIES.}

During the year Passed Asst. Surg. D. H. Currie, Surg. R. Blue, and Passed Asst. Surg. G. W. McCoy served in succession as sanitary adviser to the Governor of Hawaii, the last officer being still discharging that duty at the end of the year. This work furnished opportunity for the study of quite a number of health matters and required in a number of cases the taking of trips through the islands.

The focus of plague infection in the Hamakua district of Hawaii, where the disease has been present since 1910 , was studied on two trips to that region, the data collected being very interesting, although rather puzzling. Cases of the disease have occurred at irregular intervals, the remarkable feature being that in 10 out of the 11 cases reported the bubo was in the neck, and in the other 1 in the axilla. 
As only a small percentage of buboes occur usually in the neck, this fact deserves notice, there being a possibility, if deductions can be made from experimental work, that the disease was not transmitted in these cases in the usual way (through fleas), and that ingestion may have played a part in it.

As plague-infected rats have been found at irregular intervals, the Territorial board of health inaugurated an extensive campaign of rat catching and rat poisoning. The extermination of the rodents in the cane fields is a problem somewhat similar to the ground squirrel situation in California, and probably, in view of the limited funds available, all that can be expected is to keep the camps and villages free from infection by continuing aggressive measures against rodents in those places.

One case of plague in the mongoose, a rodent found in large numbers in the islands, has been observed, but the significance of this finding has not yet been determined.

Two laboratories are maintained by the Territorial board for the examination of rodents, Passed Asst. Surg. McCoy having inaugurated at these laboratories the system of detecting plague infection by the study of the gross lesions rather than by depending exclusively upon microscopical examinations.

The majority of the laborers employed by the great sugar plantations live in camps, and a large number of these have been visited by Dr. McCoy in company with the Territorial authorities with a view to suggesting improvements in the sanitary conditions.

F Following the occurrence of a case of yellow fever at Honolulu, a general campaign of mosquito eradication was undertaken through the city, Passed Asst. Surg. Currie, Surg. Blue. and Passed Asst. Surg. McCoy having been in succession in immediate charge of the work. The work of finding and destroying breeding places for mosquitoes was carried on for a period of about three months with the aid of men secured from the military establishment, after which a change was gradually made to civilian inspectors. The city was divided into six districts, each district being under the supervision of an inspector. Each district was subdivided into eight sections, each section being under the subdivision of a foreman.

$T$ he work has developed nothing new in respect to the places where mosquitoes breed and the method of dealing with them. The three species of mosquitoes found in Honolulu are, Stegomyia scutellaris, Stegomyia calopus, and Culex fatigans. The reduction of Stegomyiæ has been comparatively easy, as they usually develop in smaller collections of water, such as in tin cans, broken bottles, house gutters, etc., which are easily dealt with. The Culex, which often breeds in such places as rice plantations, swamps, etc., have been more difficult to deal with, as often considerable expense is involved in the remedying of conditions.

The measures employed have been collection of cans, bottles, etc., removal of house gutters or correction of structual defects, and the oiling of places that could not be corrected otherwise. When breeding occurred in water standing on the ground, in ponds, swamps, etc., draining and filling and the introduction of larvæ-destroying fish were employed when practicable. Larvæ-destroying fish were found to be exceedingly useful. A discussion of these measures will be found on page 1029 of the Public Health Reports of June 28, 1912. 
The following compilation from the daily reports of the inspectorbetween November 9, 1911, and .July 1, 1912, shows the general scope of the work:

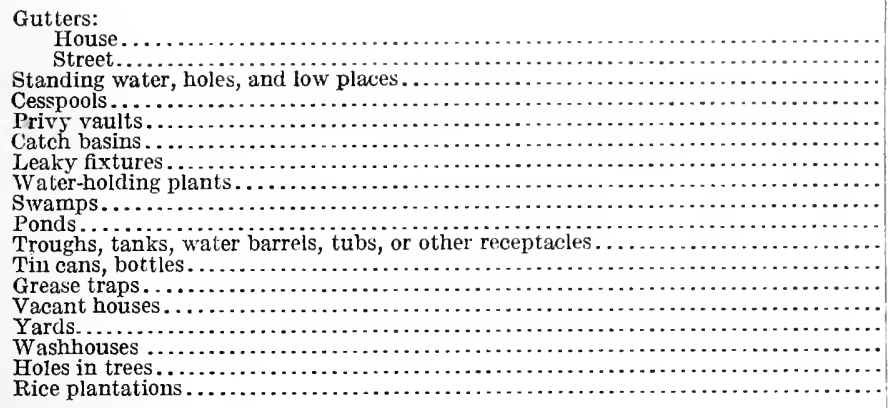

$\begin{array}{rr}35,918 & 1,139 \\ 6,164 & 545 \\ 22,089 & 1,15.5 \\ 22.172 & 1,051 \\ 27,445 & 621 \\ 13,381 & 1,199 \\ 4,015 & 4,015 \\ 33,174 & 1,65.5 \\ 2,433 & 375 \\ 1,130 & 1415 \\ 45,175 & 4,395 \\ 271,252 & 3,573 \\ 5,901 & 45 \\ 2,000 & 990 \\ 2,800 & 50 \\ 2,100 & 131 \\ 10.850 & 175 \\ 278 & 163 \\ & \end{array}$

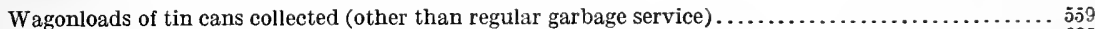

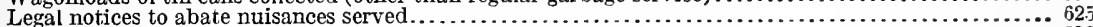
Nuisances abated .

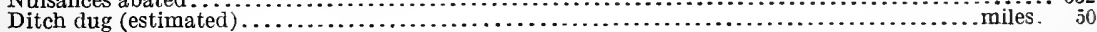

During the seven months that the work has been carried on a sum of about $\$ 100,000$, provided locally, has been expended. At present the work is costing about $\$ 2,000$ per month, a sum sufficient to employ 18 inspectors and 10 laborers, which is considered adequate.

The work of mosquito eradication, while directly under the Territorial board of health, received material assistance from the county authorities, chiefly in the collection of garbage. A committee composed of eight, one of whom was an officer of the service, who served as executive officer of the committee, had, however, immediate supervision of the work.

The director of the leprosy investigation station has also served as one of the members of the sanitary commission of Honolulu, a commission consisting of five members created by the legislature to examine into and report on sanitary conditions in Honolulu, making appropriate recommendations. It is understood that the report of this commission will be published in due time by the Territorial authorities.

\section{Supervision of Viruses, Serums, Toxins, and Analogous Products.}

In the administration of the act of July 1, 1902, regulating the sale of viruses, serums, toxins, etc., in interstate traffic, 29 establishments were inspected; 20 of these were relicensed, and 5 new licenses were issued. The reissue of 4 licenses was still under consideration at the end of the fiscal year. One establishment has gone out of business, and one license was revoked.

A list of the establishments holding licenses on July 1, 1912, was published in the Public Health Reports of July 5, 1912, and in the Treasury Decisions of July 11, 1912. 
In response to a request received from the president of the Georgia State board of health, the laboratory of the board was inspected. The report of this inspection and of the laboratory examination of samples of antirabic virus and diphtheria antitoxin was made to the State board of health September 11, 1911. Since it was ascertained that it was not intended to sell the products in interstate traffic, no action was taken in respect to the issue of a license.

In October the bureau learned of eight cases of tetanus in Baltimore, which had recently occurred after vaccination. The assistant director of the Hygienic Laboratory investigated the cases and procured samples of vaccine virus taken from the same lots which had been used on the persons suffering from tetanus. All of the virus had been prepared by one manufacturer. The samples were examined in the Hygienic Laboratory, but no tetanus spores were found. However, the occurrence of eight cases of tetanus in persons who had been vaccinated with the virus of one manufacturer was so extraordinary that it was thought necessary to make a special examination of his methods. Accordingly, his laboratory was visited by the assistant director of the Hygienic Laboratory, who found no fault with either the methods or equipment used.

In the course of the same month the bureau received from Dr. Eugene H. Porter, State commissioner of health, Albany, N. Y., detailed reports of 3 cases of postvaccinal tetanus that had occurred in New York State, 2 at Saratoga Springs, and 1 at Canisteo. The virus used in these cases was all supplied by one manufacturer, not the manufacturer whose virus had been used in the Baltimore cases. Samples of virus furnished by Dr. Porter were examined in the Hyglenic Laboratory, but no evidence of their being contaminated with tetanus was found.

The simultaneous occurrence of several cases of tetanus in persons raccinated with the virus of the same manufacturer is a circumstance to arouse suspicion; but many other persons were vaccinated about the same time without bad result with virus taken from the same lot. This is true with regard to the cases in Baltimore and those in New York. It can not be doubted that if one portion of the lot contained tetanus spores all the rest would contain them, since the virus is so thoroughly triturated that they would be distributed through it generally.

Inasmuch as cases of tetanus, if of frequent occurrence following raccination, could not fail to excite suspicion, Passed Asst. Surg. Edward Francis has been assigned to conduct in the Hygienic Laboratory a careful investigation of the entire subject, using such opportunities as might be offered from time to time.

The investigation has been along several lines, including an elaboration of the most satisfactory manner of determining, by cultural and other means, the presence of tetanus spores in vaccine virus. For this purpose vaccine virus has purposely been contaminated with tetanus spores and studies have been made for the best method to detect their presence therein.

In addition, a large number of samples of vaccine virus have been examined in the laboratory for the specific organism of tetanus without, however, having been able to demonstrate their presence.

Examinations have been made of the same laboratory number of vaccine virus as was used for the vaccination of persons who after- 
wards developed tetanus; but tetanus spores were not found in the vaccine examined in the laboratory.

The problem is one of such great importance to the whole question of vaccine and the consequent protective meusures against sinallpox that it is believed the best interests will be conserved by a thorough and painstaking investigation of the entire subject.

\section{The Hygienis: Laboratory.}

The activities of the Hygienic Laboratory have boen continued as in previous years. The results of some of the investigations made have already been roferred to under appropriate special headings in this report.

The work of the laboratory has increased to such an extent, due to taking up new lines of work, as to necessitate an increase in the number of the staff.

Personnel.-The personnel of the laboratory at the end of the fiscal year consisted of the director and assistant director, 3 professors in charge of divisions, 10 commissioned medical officers, 9 technical assistants, 1 artist, 2 pharmacists, and 29 attendants, or a total of 56 , this being the same number connected with the laboratory at the beginning of the year. The number of scientific workers should be increased.

It is the settled policy of the bureau to send officers of the commissioned medical corps to the laboratory shortly after appointment. for purposes of instruction, but on account. of the limited force and the great amount of work required of it, this has been found impossible until the numbers in the corps shall have been sufficiently increased to permit of such details. On account of the character of work required at the several stations and in the field, it is necessary now for every officer who has to engage in public-health work to have a sufficient knowledge of laboratory methods to properly perform his duty. There is need also of additional attendants. The laboratory buildings have been enlarged and the amount of work has increased, but the number of attendants remains practically the same.

Two additional attendants should be provided for, and they should receive compensation commensurate with the duties performed. The laboratory has had difficulty in retaining the services of employees at present inadequate rates of pay. During the past fiscal year there were a larger number of resignations of laboratory attendants, many of whom acquired a high degree of efficiency in certain lines of work at the expense of a considerable amount of the time of the research workers. These resignations have practically all been due to the fact that the compensation of none of them was in excess of $\$ 50$ a month.

It is becoming increasingly difficult to obtain competent employees for such services as are required in the laboratory at a compensation of $\$ 50$. The minimum salary for employees engaged in such work should be $\$ 60$ a month. Such employees are required to have a fair degree of education and to be dependable. They are constantly having to do with laboratory animals under experiment, infected with dangerous diseases, and it has happened moro than once that they have been directly exposed to infection from animals under experiment. 
Buildings and grounds.--Recommendation has been made in previous reports for additional buildings at the Hygienic Laboratory. Separate appropriations should be made for an addition to the present Hygienic Laboratory building, and for a special small building for disinfection experiments and housing of animals.

There is urgent need of additional space at the Hygienic Laboratory to prevent overcrowding and to provide for the increased amount of research work going on there. In the annual estimates of appropriations for the fiscal year 1911 there was included an item of $\$ 175,000$ for the construction of a fireproof addition to the present building.

In accordance with the act of August 14, 1912, authorizing more extensive investigations, a considerable amount of new work should be undertaken in the laboratory. In order that this may be done, it is necessary that additional laboratory facilities and space should be provided, including means for the observation of patients suffering from the particular diseases under investigation.

In the last annual report recommendation was made for an appropriation of $\$ 25,000$ for a building in which to conduct disinfecting experiments and house laboratory animals. The necessity for this building has become increasingly urgent. The present frame buildings are rapidly deteriorating, and unless some provision is made for their replacement, it will soon become necessary to entirely discontinue the breeding of laboratory animals on the premises. Previous recommendations with respect to the above-mentioned buildings are respectfully renewed. Until the building for housing animals is authorized it will be impracticable to complete the grading of the grounds, provision for which has already been made.

Scientific investigations.-Reference has previously been made under special headings to investigations in which the Hygienic Laboratory was largely concerned. In addition, a large amount of work was performed in the laboratory. A considerable number of exhibit materials were collected, many specimens were examined for public-health purposes, and aid rendered to other branches of the Government, to State and municipal authorities, and to other organizations.

\section{AID TO OTHER BRANCHES OF THE GOVERNMENT.}

Health officer of the District of Columbia.-During the fiscal year 113 specimens of water were examined at the request of the health officer of the District of Columbia, and reports made to him thereon. These specimens of water consisted chiefly of samples taken from the public wells in and around the District, particularly those from wells used as a supply of drinking water at public schools.

At the request of the health officer of the District, the director of the Hygienic Laboratory appeared in police court and gave expert testimony in connection with the prosecution of milk dealers for the sale of impure milk.

Isthmian Canal Commission.-During the year 11 treatments of antirabic virus were furnished the Isthmian Canal Commission for use in the Canal Zone.

Civil Service Commission.-At the request of the Civil Service Commission representatives of the laboratory gave assistance to the 
commission in rating papes's of applicants lon various scientific positions coming under the avil service. 'The rating of over 20() paper's was given.

Bureau of Mines.-At the request of tho Bureau of Mines, Asst. Surg. S. C. Hotchkiss was engaged during the greater portion of the fiscal year in investigations of health conditions among metal and coal miners in Colorado, particularly with reference to the prevalence of lung diseases among them. In addition, he prepared and presented papers at various meetings on the health of mincrs. On account of the death of Dr. Hotchkiss this work has been temporarily interrupted.

Bureau of Animal Industry. - At the request of the Bureau of Animal Industry a considerable number of proprietary disinfectants were examined in the laboratory in regard to their toxic and poisonous properties. 'The results of these examinations will probably be used in the prosecution of manufacturers of these preparations. Mfany manufacturers have a practice of labeling their disinfectants "nonpoisonous" or "nontoxic," whercas the investigations made in the laboratory have shown all disinfectants made from the coal-tar derivatives to be toxic.

Antityphoid vaccinations of Government employees.-At the request of the administrative officer's of a number of branches of the United States Government antityphoid vaccine was administered to their field men who desired the same.

Lectures.--During the year officers of the laboratory delivered lectures before members of the Naral Medical School.

Examination of Government employees for tuberculosis.-During the last fiscal year 19 persons, as against 14 in 1911, were examined at the request of their administrative superiors to determine whether they were suffering from tuberculosis. Four presented positive evidence of tuberculosis, 13 were negative, and 2 were not determined.

In addition, Government employees have been examined at the laboratory at the request of their superior officers in regard to disa. bilities from other causes.

\section{AID TO STATE AND MUNICIPAL AUTHORITIES.}

During the year, at the request of State or municipal health authorities, 17 lots of cholera antiglutinating serum were sent out to be used in making diagnoses of cholera. A number of specimens of various kinds were received from State and municipal health officers for examination in the laboratory.

Representatives of the State boards of health of Virginia and Arkansas were extended the facilities of the laboratory for purposes of instruction. There is a tendency on the part of State and municipal health authorities to have their laboratory men avail themselves of these opportunities. This is highly desirable, since it encourages uniformity in laboratory work and stimulates cooperation between such authorities and the Federal Public Health Service. The utilization of the facilities of the Hygienic Laboratory is encouraged by the bureau, and it would be an important aid in the advancement of public health work if a permanent school of instruction were established. At small cost, regular courses of instruction could be inaugurated which would be productive of the greatest benefit. 
AID TO THE REVISION COMMITTEE OF THE PHARMACOPCEA.

The cooperation of members of the laboraotry staff with the revision committee of the pharmacopœia was continued during the fiscal year. The director, by virtue of his position on the revision committee, and as chaiman of subcommittee No. 3 on biologic products, has had supervision over the preparation of that part of the revision of manuscript having to do with this class of therapeutic agents. In addition, standard methods for the determination of boiling points, melting points, and solubilities have been prepared by representatives of the laboratory. Further reference to this subject will be found in the report of the division of pharmacology.

\section{DIVISION OF PATHOLOGY AND BACTERIOLOGY.}

Studies on a number of the subjects mentioned in the last annual report have been continued in the division of pathology and bacteriology. Among these may be mentioned examinations of viruses, serums, and toxins, studies of embalning fluids and disinfectants, and preparation and distribution of antirabic virus.

Embalming fluids.--Passed Asst. Surg. Francis has continued his studies upon embalming fluids and as a result has, in cooperation with the Division of Chomistry, prepared a formula for a cheap and efficient embalming fluid. By using this fluid and by means of multiple injections in human cadavers, he has been able to preserve such cardavers, even when kept at body heat for almost indefinite periods.

His work has been presented in the form of papers before the National Funeral Directors and Embalmers Association.

Disinfectants. - The work of Passed Asst. Surg. McClintic and the director of the laboratory on the elaboration of a standard method for the examination of disinfectants has been continued and the method arrived at published in laboratory Bulletin 82. This method was formally recommended at the recent meeting of the State boards of health with the Public Health Service for adoption by the State boards. It is now quite generally used by manufacturers of disinfectants for the standardization of their products and by health organizations in the awarding of contracts for the purchase of disinfectants.

Examination of commercial disinfectants.-Passed Asst. Surg. McClintic, using the standard method elaborated, during the year examined 54 commercial disinfectants to determine their phenol coefficient. The results of this work have been published in Bulletin 82 of the laboratory.

There is perhaps no subject of much greater practical importance than the question of the standardization of disinfectants. The bulletin by Passed Asst. Surg. McClintic has received a great deal of attention by all those interested, and it is believed that this work has been of the greatest good in improving the manufacture and sale of these products.

It is hoped that the services of another officer will be available in order that this work may be continued.

Antirabic virus.-The preparation and distribution of antirabic virus from the Hygienic Laboratory has shown a steady and pronounced increase during the fiscal year just closed. During that time 
84 patients wore given the troatment at the laboratory and 1, 104; treatments were sent to State boards of health and other's. The distribution of these latter is shown in the following table:

Sent to-

Arkansas.

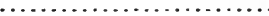

California.

Colorado.

Delaware.

Iowa.....

Illinois.

Indiana.....

Kansas....

Maryland

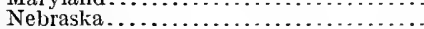

North Carolina.

\begin{tabular}{|c|c|c|}
\hline $\begin{array}{l}\text { Number } \\
\text { of treat- } \\
\text { ments. }\end{array}$ & Sent to- & $\begin{array}{l}\text { Number } \\
\text { of treal. } \\
\text { ments. }\end{array}$ \\
\hline 4 & North Dakota... & 11 \\
\hline 264 & South Garolina.. & is \\
\hline 132 & Tennessee........ & 9 \\
\hline 4 & Virginia.............. & 72 \\
\hline 12 & Washington (state) $\ldots \ldots \ldots \ldots \ldots \ldots \ldots \ldots$ & 2 \\
\hline 41 & Wiseonsin $\ldots \ldots \ldots \ldots \ldots \ldots \ldots \ldots \ldots \ldots \ldots$ & 5 \\
\hline 140 & Isthmian Canal Zone................ & 11 \\
\hline 61 & U. S. Navy Department..... & 3 \\
\hline 43 & Ellis Island............... & 1 \\
\hline 38 & New Jersey............... & $\mathrm{i}$ \\
\hline 2 & Total.... & 1,106 \\
\hline
\end{tabular}

Since the treatment was inaugurated at the laboratory there have been 2,847 treatments sent out from the laboratory and $4: 29$ persons have received treatment at the laboratory up to June 30,1912 .

During the year the heads of 94 animals were received at the laboratory to determine whether the animals were suffering from rabies. Of this number; 49 gare a positive result and 16 were in such a state of decomposition that it was not possible to make an examination.

Studies have been begun by Passed Asst. Surg. Stimson to determine by experiments upon monkeys the value of the different methods of treatment used in other laboratories as compared with the method used here. The results of these studies will not be known for at least six months.

Branch laboratory at New York.-On account of the lack of hospital and clinical facilities at the Hygienic Laboratory, certain investigations of contagious and infectious diseases have been greatly handicapped. This lack of facilities has rendered necessary from time to time the detail of officers by the bureau to Ellis Island in order to obtain materials for purposes of study. In order to obviate this necessity and to provide laboratory facilities in connection with the stations of the service at the port of New York, there should be established there a small research laboratory. At the immigration and marine hospitals, which are within a short distance of each other, there are cared for daily approximately 500 patients. These patients come from all parts of the world, and many of them are suffering with obscure exotic diseases. Their early and correct diagnosis is necessary to protect the public health.

At the immigration hospital it is necessary to detect dangerous contagious diseases, such as cerebrospinal meningitis, trachoma, and tuberculosis, and loathsome diseases, such as leprosy, favus, and syphilis. These diseases are all mandatory; that is, those suffering from them are required to be deported. Correct diagnosis is of the utmost importance, and the securing and preserving of laboratory evidence is essential.

It is now known that certain diseases, such as typhoid fever, cholera, and hookworm disease, are transmitted by healthy carriers.

69450--H. Doc. 971, (;2-3-3-4 
Their detection rests solely upon laboratory evidence. Other diseases, such as scarlet fever and measles, require careful studies to determine their causes, methods of transmission, and measures of control, and at the above mentioned hospitals the clinical material available for such studies is abundant.

Under the law of July 1, 1902, governing the manufacture and sale of viruses, serums, and toxins, all importations of such products are required to be examined before release from the customhouse. Samples of the products in question arriving at New York should be examined in a laboratory at that place properly equipped for the purpose.

All of the above-mentioned laboratory work and research could be conveniently carried on in a single laboratory adequately equipped. Its installation in one of the hospitals mentioned would obviate the necessity of any special appropriation for quarters, fuel, lights, and water.

DIVISION OF ZOOLOGY.

International Commission of Zoological Nomenclature.-Cooperation with the International Commission on Zoological Nomenclature has been continued through the Hygienic Laboratory, Prof. Stiles serving as secretary of the commission. This commission is composed of 15 professional zoologists elected from the world at large and serving as an international court of appeals for nomenclatorial questions upon which differences of opinion arise. The Smithsonian Institution has furnished the secretary with a private secretary for this work. Fifty-one opinions have thus far been rendered. They are published by the Smithsonian Institution and distributed free to the zoological profession.

Many zoologists who apparently have not grasped the real problems of nomenclature, and their relation to the scientific work of future generations, have become dissatisfied with the law of priority, which forms the basis of the present International Code of Zoological Nomenclature, and there is a determined effort being made to modify this law. The present situation indicates that in the near future there may be two distinct zoological codes in operation, thus bringing into zoology the same confusion that exists to-day in botany. The situation, which is viewed by some men as exceedingly acute, will come up for discussion at the next International Congress of Zoology in March, 1913, at Monaco. It is believed by this division that even admitting the acute stage of the situation at the present moment, the solution of the difficulties at hand is not impossible, but is dependent very largely upon conducting the discussions in a more judicial and diplomatic manner than has characterized many of the papers thus far published on the subject. This division sees no insurmountable obstacle in arriving at a solution of the problem which ought to be acceptable to both sides to the controversy.

Index catalogue of medical and veterinary zoology. - The division of Zoology of the Hygienic Laboratory and the Division of Zoology of the Bureau of Animal Industry have continued to cooperate in the preparation of an index catalogue of medical and veterinary zoology. The author's catalogue has now been published in full. Of the subject catalogue, the trematode portion was published several years ago, and the proof reading for the cestode portion has now been 
completed. Work is now being done on tho nomatode portions, and on the host catalogue.

Determination of zoological specimens.-The Division of \%oology has continued to mako zoological determinations of animal parasites for physicians, boards of health, etc., and a large number of such determinations as aids in diagnosis have, been made.

Upon several occasions emergencies have ajisen in varions stato boards of health, when their laboratories were swanped with unforeseen work in connection with microscopic detrruination of specimens sent to the State laboratories by physicians and other's in the States in question, and in these emergencies the zoological division. has been appealed to by the State boards for aid. It is always a pleasure for the service to help any State board of health in work of this kind.

Publications.-A number of articles have been written for the Public Health Reports and for various merlical and educational journals dealing with practical problems of sanitation and the terhnical side of hookworm disease and amebiasis.

Hookworm campaign and investigation.-The chicf attention of the Division of Zoology this year has been occupied with the technical side of hookworm disease in connection with the eradication campaign carried on by the State boards of health as described in another portion of this report.

Public health lectures.- In addition to the regular work of the Division of Zoology discussed in the foregoing, there has been a very heavy demand for addresses before medical and scientific socicties and for more popular lectures for teachers' institutes and popular audiences on various public health subjects.

During the fiscal year 1911-12, Dr. Stiles has given 77 addresses and lectures on various public health subjects, reaching a total audience of 12,955 persons.

Navy Medical School.-At the request of the president of the Navy Medical School, a series of lectures was given before the medical school on the subject of medical zoology.

\section{DIVISION OF PHARMACOLOGY.}

Standardization of drugs.-Work on methods for the physiolugical standardization of a number of important drugs was continued. A laboratory bulletin (No. 76) on the Physiological Standardization of Ergot was published, in which the various methods which have been proposed were critically examined and compared. A number of the more widely employed proprietary and other preparations of this drug were examined and compared with preparations of known origin; this work showed the practical worthlessness of some of the commercial preparations. Since the publication of this bulletin a number of manufacturers have adopted the suggestions contained in it as to dating their products and as to standardizing them physiologically. The division has cooperated with the committee of revision of the United States Pharmacopœia and with a special committee of the American Pharmaceutical Association in work on ergot and a number of other drugs.

Work on the standardization of digitalis has been continued. Among the subjects investigated were the influence of the season upon 
the resistance of the frog (the animal best suited for such work) to digitalis and the action of a number of pure principles belonging to the digitalis series.

A colorimetric method for estimating the activity of desiccated suprarenal glands and the solutions of the active principle of the glands was devised and the results obtained compared with determinations made by the usual physiological methods. Satisfactory agreements were found and the calorimetric method has been adapted to the neods of the Pharmacopœia for suitably testing this product and making it conform to a definite standard of activity. Moisture and ash determinations were made in a large number of samples of desiccated suprarenals for the purpose of recommending pharmacopœial standards for these tests. An investigation has also been made of the relative activity of the glands of different animals. The importance of work of this character is shown by the discovery that some of the commercial preparations of this gland are 13 times as strong as others. In this work the division has had the cooperation of the committee of revision of the United States Pharmacopœia and of some of the large manufacturing firms.

The suggestion that the desiccated thyroid gland used in medicine should be standardized so as to contain a definite percentage of organically combined iodine has been accepted by a number of manufacturers and preparations of a much more uniform character are now on the market than was formerly the case. In connection with this work an investigation of the seasonal variations of the iodine content of the thyroid gland and of the differences between the glands of various animals has been made.

Digest of comments on the United States Pharmacopoia and National Formulary. - The preparation of the digests of comments has been continued. The literature on these two national legal standards for drugs as well as the literature relating to the pharmacopœias of foreign countries has been reviewed almost to date. During the year two laboratory bulletins (Nos. 79 and 84) with a total of 1,519 pages were issued on the subject. These compilations are proving of much value to the revisers not only of the United States Pharmacopoia, but to those of other pharmacopoias; in fact they seem to be considered the standard works of reference on this subject throughout the world. Thus the Pharmaceutisch Weekblad (Amsterdam), in commenting upon the "admirable completeness with which the authors refer to the comments on official articles occurring in upward of 250 publications," states that the " "Digests' have come to be indispensable to all who desire a complete review of the matter published on the subjects discussed." Various health officers and others connected with the enforcement of pure drug laws, teachers, and others have testified as to the value these digests have been to them in their work.

There has also been published as public health bulletin No. 56 a manuscript entitled "Digest of the Laws and Regulations in Force in the United States Relating to the Possession, Use, Sale, and Manufacture of Poisons and Habit-Forming Drugs." This is the first complete analytical compilation of the laws on this subject which has been made.

Research work.-In addition to the research work in connection with the standardization of drugs, similar work has been carried on 
along a number of other lines. Among these wore further 'xperiments on the physiological processes involved in anajhylaxis and the action of antitoxic sera and other proteins (part of this work haring been published as laboratory bulletin $\mathrm{No}$. So); the toxicity of many of the more common disinfectants as compared with carbolic aciol; the solubility, method of determining and the pharmacological and toxic action of thymol with especial reference to the "xtensive use of this drug in the treatment of hookworm discase; the comparative efficiency and safety of a number of other remedies recommended for hookworm disease; funther work on the thrroid with especial reference to the detection of small amounts of its secrestion in disease of the thyroid gland and the influence of rarious dicts upon its activity; the specific action of various dicts upon other organs of internal secretion and the development and growth of cascinomata in mice; the synthesis of a large number of new compounds of the choline type and a study of some of their pharmacological actions; the comparative safety of the chloroform manufactured by various processes; the action of certain drugs on the uterus.

Examination of drugs; miscellaneous analyses.-One hundrod and fifteen samples of drugs were received from the purvering depot and examined to determine if they complied with the requirements of the United States Pharmacopœia; 11 were rejected for noncompliancea somewhat larger percentage than during the preceding year.

A number of samples of an alleged remedy for pellagra (" $\mathrm{Ez}-\mathrm{X}-\mathrm{Ba}$ " and "Pellagracide") were analyzed; they were found to consist principally of iron, aluminum, magnesium and calcium sulphates. The. analytical results indicated that such a preparation could have been made by digesting a low-grade iron ore or a weathered iron-bearing mineral in sulphuric acid and diluting with water.

A number of miscellaneous cxaminations have been made in connection with the work of other divisions of the laboratory, such as the chemical examination of certain alleged antitoxins, the examination of disinfectant solutions, of water, etc.

Cooperation with the United States Pharmacopoia, other departments, etc.-The division has continued to cooperate with the Committee of Revision of the United States Pharmacopœia, two members of the division being members of the committee of revision; also with. the Committee on the National Formulary; the Council on Pharmacy and Chemistry of the American Medical Association, of which two members of the division are members. The division is represented on the Committee on Pliysiological Assay of the American Pharmaceutical Association and other committees of this association as well as of the American Medical Association. A number of experiments have been carried on at the request of officials of the Department of Agriculture charged with the enforcement of the insecticide law. Members of the division have several times been requested to act as examiners for the Civil Service Commission in special cases.

\section{DIVISION OF CHEMISTRY.}

The routine analytical work for the year included the chemical analysis of 20 samples of water, the examination of 59 drugs and chemicals submitted on competitive bids for use at the several stations, and the examination and preparation of chemicals and other products 
for use in the several divisions of the laboratory. In addition, a number of miscellaneous specimens, such as urine, renal calculi, disinfectants, blood stains, etc., were examined and reported upon.

Considerable time of one officer was devoted to the installation and investigation of the Harker fumigating and disinfecting apparatus on the United States quarantine steamer Bratton. This system of fumigation was favorably recommended by that officer, principally on the ground of its applicability to deratization of vessels containing cargoes liable to serious injury by sulphur dioxide. Such cargoes are particularly liable to harbor rats, inasmuch as they include many foodstuffs imported from the Orient. The system is based on the fact that the gases from the funnels of steam vessels are quickly fatal to all animals by reason of a small percentage of carbon monoxide, the lethal effect of which is much increased by the replacement of approximately half of the oxygen of the original air by carbon dioxide. While quickly fatal to all animals in the hold, the gas has little effect on the men on deck, because its lethal properties rapidly diminish with progressive dilution with air. The gas may also be made to destroy insects which may be present on addition of carbon disulphide, carbon tetrachloride, etc.

Research.- In cooperation with the division of bacteriology the division has studied the methods of preparation and the stability of various types of embalming fluids. The net results of these studies has been the establishment of a formula for a highly satisfactory embalming fluid.

At the request of a representative of the Supervising Architect's Office, Passed Asst. Surg. Norman Roberts studied and made certain improvements in a sanitary air tester for carbon monoxide which, in its original form, had been devised in the above-mentioned office. The improvements consisted in: (1) A modification of the connections of the apparatus, whereby the alkaline absorbent solution was more conveniently and more accurately measured without exposure to air; (2) the utilization of the Pettenkofer method of absorption of carbon dioxide by excess of alkali and back titration with acid, and (3) a convenient combination container and burette for the acid solution was devised, which was found applicable for a number of volumetric analyses. The apparatus in its original form was unsatisfactory even for approximate analyses, but as improved, it gives very competent results.

During the year a very considerable portion of the time of the chief of the division was devoted to attempts to establish on a firm experimental basis his theory of an ammonia system of acids, bases, and salts. The import of this work in brief is to show that just as water is the typical substance from which the large and familiar class of oxygen acids, bases, and salts are derived, so ammonia is similarly the typical compound upon which a new system of acids, bases, and salts is being developed. The details of the year's accomplishments in this respect are given in papers enumerated in another paragraph of this report.

In order to fulfill its functions as a chemical laboratory maintained as a part of an establishment for the promotion of the public health provision should be made to provide equipment for researches in physical chemistry, and the personnel of the division should be increased in number. 
PUBLIC IIEALIII EXIIIBJTS.

One of the results of the increased interest in public houlth matters now taken by the people of the country has been the demand for exhibits which may serve as object lessoms in modern sanitation and also show the progress alrealy accomplished in various branches of medicine and allied sciences. Loans of such rexhibits have been requested during the year by civic associations, medical societies, ete., and unfortunately most of these requests had to be refused compliance, as the material on hand was inadrequate to fuliill the demands.

The service presented exhibits, however, on a number of occalsions, illustrating the work performer.

At the request of the medical and chirurgical faculty of Maryland, one such exhibit was sent to Baltimore during the "lhealth week," subsequently extended to last from February 19 to March 9, 1912. Valuable exhibits were also installed in the same building by the health authorities of the State and the city. "The "health week" proved a great success, the public taking great interest not only in the exhibition, but also in the lectures delivered in connection therewith, and the State legislature showing their appreciation of the work by visiting the exhibit building on February 26 . The service exhibit comprised a number of models, as rat-infested house and kitchen, rat-proof dwelling, house screened against mosquitoes, sanitary and insanitary privies, ete., and quite an assortment of maps, charts, colored drawings, miscellaneous photographs, prepared specimens, and printed literature, all bearing relation to the activities of the service, especially in connection with the investigation and prevention of such diseases as leprosy, plague, rabies, tuberculosis, uncinariasis, typhoid fever, typhus fever, etc. By special arrangement, one evening's session (February 20) was devoted to lectures by officers of the service, setting forth work recently done for the protection of the public health.

At the baby-saving show held at Philadelphia, Pa., May 18-26, 1912 , the service was also, at the urgent request of the committee in charge, represented by a limited exhibit, consisting chiefly of charts relative to infant mortality and its prevention.

The most elaborate exhibit presented during the year was at the meeting of the American Medical Association, at Atlantic City, June $3-7,1912$.

As illustrating the changed attitude of the people in general toward graphic presentation of public health questions, mention may be made of the set of charts on hookworm disease and soil pollution, prepared by the service, the whole edition of which was entirely exhausted almost immediately after publication, and a new edition of 5,000 sets authorized by Congress for distribution by Senators and Representatives.

The education of the public in sanitary matters is a vital question, and the Federal Government should by all means encourage its promotion. In no better way can this be accomplished than by the assembling of suitable exhibits which could be loaned to local organizations interested in furthering this end. There is no doubt that the establishment of a museum of hygiene, under the administration of this service, would fulfill a real public need, as this institution could thus be made a center for the preparation and distribution of exhibits not only for local and State events, but also national and international. 
Tenth Annual Conference of State and Insular Health AUthorities.

In accordance with the provisions of existing law, the tenth annual conference of State and Territorial health authorities with the Public Health and Marine-Hospital Service was held in Washington June 1, 1912. Sixteen States and the District of Columbia and Porto Rico were represented at the conference. Hawaii designated as representative one of the officers of the service, but the notice of the appointment reached the bureau too late for use at the conference.

The provisional program comprised the following subjects: Report of committee on morbidity statisties; adoption of a uniform standard for disinfectants; control of cerebrospinal meningitis; control of typhoid fever; control of Rocky Mountain spotted fever; and control of typhus fever.

After a thorough discussion of the various subjects by the health officers present, the following resolutions were adopted:

\section{'MORBIDITY REPORTS.}

In order to make available to the health authorities of the States, Territories, and insular possessions of the United States, for their use and guidance in the protection of their respective communities, information regarding the prevalence and geographic distribution of certain diseases, and the occurrence of outbreaks and epidemics, be it resolved:

1. That the health authorities of the States, Territories, and insular possessions of the United States, including the District of Columbia, shall notify the Surgeon General of the Public Health and Marine-Hospital Service immediately by telegraph (collect) and letter upon the occurrence of a case or cases of cholera, yellow fever, typhus fever, plague, or Rocky Mountain spotted or tick fever, giving the number and location of cases, and that said authorities shall render monthly reports of the number of cases notified of smallpox, leprosy, scarlet fever, measles, diphtheria, typhoid fever, poliomyelitis, cerebrospinal meningitis, dysentery, Rocky Mountain spotted or tick fever, and other diseases notifiable in their respective jurisdictions; said monthly reports to be made on or before the 20th day of each month for the preceding calendar month, and to give the distribution of cases of smallpox, leprosy, poliomyelitis, cerebrospinal meningitis, Rocky Mountain spotted or tick fever, and typhoid fever, by counties, or by counties and cities, or by towns (townships), or by towns (townships) and cities; and that when in a State one or more cities are excepted by statute, charter, or otherwise from reporting the occurrence of the notifiable diseases to the State department of health, and the State report therefore is exclusive of cases occurring in such cities, the cities thus excluded shall be enumerated.

2. That upon the occurrence of an unusual outbreak, or in the event of a sudden increase in the number of cases of smallpox, scarlet fever, diphtheria, typhoid fever, poliomyelitis, cerebrospinal meningitis, or Rocky Mountain spotted or tick fever in any locality, the Surgeon General of the Public Health and Marine-Hospital Service shall be immediately notified by telegraph (collect) and letter of such unusual outbreak or sudden increase.

3 . That in the primary notification of smallpox to local health authorities the date when the patient was last vaccinated and whether the disease is of the benign or virulent type shall be stated; that in all outbreaks of smallpox in which one or more deaths occur a report of such data as can be obtained regarding the origin of the first case or cases and the history of the outbreak shall be made to the Surgeon General after the subsidence of said outbreak; that all reports of cases of smallpox made by the State or other health authorities to the Surgeon General shall be divided into four classes:

(a) Those vaccinated within a period of seven years preceding the attack.

(b) Those whose last vaccination occurred more than seven years antedating the attack.

(c) Those who have never been successfully vaccinated.

(d) Those in which no definite history is to be obtained.

4. That in reporting the occurrence of cases of leprosy such data as it is possible to obtain regarding the patient's history shall be given. 
5. That the Surgeon General shall, under the direction of the Secretary of this Treasury, pursuant to section 4 of an act approved February 15, 1893, entitled "An act granting additional quarantine powers and imposing additional duties upon the Marine-Hospital Service," compile and publish the reports forwarded in compliance with the foregoing in the Public Health Reports for the information of the health authorities of the several States, Territories, and insular possessions, including the District of Columbia.

PHENOL COEFFICIENT OF DISINHECTANTS.

Resolved, That the United States I'ublic Ilealth and Marine-Hospital Service IIy: gienic Laboratory Standard Method for the determination of the phenol coefficient of disinfectants be recommended to the several State boards of health as the standard method; that all regulations regarding disinfectants be based upon this standard; and that the phenol coefficient be required to be stated on the label oi each package cone taining such disinfectant.

CONTROL OF TYPHOHD FEVER.

Resolved, That a committee be appointed to recommend a working plan for the con. trol of typhoid fever and practical neasures which can be generally enforced for the prevention of this disease.

Resolved, That all cases of typhoid fever should be placed in properly constructed and conducted hospitals, unless it be possible to isolate the patient at home with a trained nurse in charge.

Cerebrospinal MeNingitis.

Resolved, That the Surgeon General appoint a committee to report iurther on the subject of cerebrospinal meningitis at the next meeting.

The presence of Hon. Franklin MacVeagh, Secretary of the Treasury, at one of the sessions, and his active participation in the discussion of public health work in general, lent additional interest to the conference this year, as showing the realization by high Government officials of their responsibilities in this matter.

The transactions of the conference will, as heretofore, be published in full in a Public Health bulletin.

\section{Sixth International Sanitary Conference of the American REPUBLICS.}

Mention was made in the annual report for last year (p. 94 et seq.) of the meeting of the Fifth International Sanitary Conference at Santiago, Chile, November 5-12, 1911.

Eighteen American Republics were represented at the conference, a greater number than at any previous one. The inaugural session. was held at the University of Chile, the president of the Republic, the cabinet, and the diplomatic corps being present. The address of welcome was delivered by the minister of foreign affairs, other speeches being made by Dr. Alejandro del Rio, the provisional president of the conference, and the delegates of the various countries represented.

The business sessions began on November 6 , and were presided over by Dr. Del Rio, who was confirmed as permanent president. Reports were presented by the various delegations on the following topics mentioned in the program:

1. Sanitary laws, regulations, and measures adopted in each country since the fourth conference.

2. Fulfilment of the resolutions adopted in the first four sanitary conferences.

3. Report relating to the adoption of the convention of Washington of 1905 and of the modifications of its ninth article by the Fourth International Sanitary Conference and the Fourth International American Conference (of Buenos Aires).

4. Constitution and work of the reporting international sanitary commissions. 
5. Sanitation of cities and specially of ports indicating the participation which the National Government has had in the execution of these works.

6. Prophylactic measures taken against plague, cholera, and yellow fever, with special mention of the methods employed for the destruction of rats, flies, and mosquitoes.

7. Criterium by which the health authorities must be guided to determine when a person shall be considered immune from yellow fever.

8. National and international protective measures relating to tuberculosis, venereal diseases, smallpox, malaria, trachoma, leprosy, and scleroma, legislation adopted against these diseases and the results obtained.

9. Monthly and yearly statistics of morbidity and mortality in the principal ports and cities; information in regard to the adoption of Bertillon's nomenclature.

10. Sanitary inspection of international maritime and terrestrial traffic in case of communicable or quarantinable diseases, their specification. Regulations relating to the retention or devolution of patients in such circumstances.

11. Sanitary laws on immigration.

12. Data on the adoption of maritime sanitary documents approved by the fourth conference.

The resolutions adopted by the conference were as follows:

(1) Resolved, (a) That the appreciation of the conference be manifested to the Governments that have been represented.

(b) That in so far as possible delegates accredited to future conferences be hygienists and particularly that they be citizens of the country. they represent.

(c) To recommend that at least one of the delegates from each country be a sanitary officer of high rank, or one who has attended one or more previous conferences.

(2) Resolved, That the countries that have not been prompt in forwarding at regular intervals sanitary information to the International Sanitary Bureau of Washington and the International Information Bureau of Montevideo, respectively, be requested to do so with regularity. Such reports to include $(a)$ the demography of the chief cities and ports, $(b)$ the status of contagious diseases.

(3) Resolved, That the International Sanitary Bureau of Washington make a study of all the resolutions presented to or adopted by this conference with the purpose of including in the program of the Sixth Conference the modifications of or amendments to the Washington convention of 1905 which, in its opinion, should be made.

(4) Resolved, That the different Governments be requested to organize complete and practical courses for the education of hygienists and that in future they insist on special requirements (diplomas, etc.), for those to be employed in sanitary work.

(5) Resolved, That all the Republics that are signatories to the Convention of Washington comply with the provisions of the said convention.

(6) Resolved, To recommend that death certificates be executed by physicians only, especially in cities and ports, with the object of improving the reports of vital statistics.

(7) Resolved, To recommend to the different Governments the installation of State or Government laboratories for the inspection of food products and beverages, entering through their respective customhouses.

(8) Resolved, To recommend that those countries where leprosy exists make an exact and detailed study of the number of lepers existing within their confines; that they establish colonies for their isolation and enact restrictive laws or ordinances with reference to this disease.

(9) Resolved, To recommend to the Governments of the American Republics that they promote or facilitate investigations on the existence, frequency, and contagiousness of scleroma (rhino-scleroma).

(10) Resolved, That the regulation of prostitution in cities and especially in seaports, is recommended; said regulation to be in the hands of physicians especially prepared for this kind of work, the necessary examinations to be carried out in fully equipped dispensaries, and where possible, sufficient power conferred to confine in hospital those liable to transmit venereal diseases.

(11) Resolved, To recommend to the various Governments the creation in their respective countries of a permanent tuberculosis commission. The International Sanitary Bureau of Washington will urge the establishment of such commissions through the ministers of the various Republics resident in Washington. The several Republics should also communicate with one another for the purpose of giving information as to the methods employed and the results obtained.

(12) Resolved, To recommend that when a vessel enters a port a bulletin be posted aboard to inform the passengers as to the quarantine requirements and the laws and regulations upon which the same are based. 
(13) Resolved, To recommend to the signatories of the fonvention of Washington that they so adjust their quarantine regulations as to make them erontorm with the requirements of said convention.

(14) Resolved, To recommend that those countries having quarantine rotriction. against vessels from another country, maintain aboard such vo-sels sunitary phyician? with the necessary technical knowledge.

(15) Resolied, 'To recommend that all vessels carrying passengers or immigrants be provided with the necessary equipment for disinfection.

(16) Resolved, To recommend that in the disinfection of vessels controls be employed in order to determine the efficacy of the operation.

(17) Resolved, To recommend that all vessels carrying passengers be provided with sufficient hospital space for the sick, and accommodations for the isolation of those suspected of, or those suffering from transmissible diseases.

(18) Resolved, That the international information committees of the American Pepublics, in addition to the duties imposed by previous conferences, shall inform their Governments of the obligations contracted in each international sanitary conference in which they have been represented, or of obligations specially ratified.

(19) Resolved, That in order to consider an individual immune to yellow fever he must have had an attack of that disease, which fact must be certified to by the sanitary. authority of the port of departure.

(20) Resolved, (a) To recommend that the construction of waterworks and sewerage systems, as well as the management of the same, be under the control of the State or municipality and under no circumstances be the subject of private gain; and (b) that the selection of potable water supplies for urban districts be made by hygienists and engineers in accord, giving due attention to a study of the watershed and the possibility of pollution.

(21) Resolved, That the Governments here represented should always give preierence when undertaking sanitary works to those cities or ports where there exist exotic diseases or infectious-contagious diseases of grave character.

(22) Resolved, To reiterate the recommendation of the Third International Sanitary Conference, held in the City of Mexico in 1907, to promote the enactment of laws relative to obligatory vaccination and revaccination against smallpox.

(23) Resolved, That all passengers from cholera-infected districts, or who may have been in contact with those infected with cholera, shall be subject to a bacteriological examination of their stools, and to sanitary observation so long as the cholera bacillus is present therein. That convalescents from an attack of cholera shall be kept under observation until the cholera bacillus has disappeared from the stools.

(24) Resolved, That the sanitary report to be presented by each delegation at future conferences be handed to the secretary in printed form and in sufficient number to be distributed among the delegates at the preliminary session.

(25) Resolved, To recommend that the Sixth International Sanitary Conference include in its program the study of epidemic cerebrospinal meningitis and acute poliomyelitis.

(26) Resolved, To reiterate the recommendations made by previous sanitary conferences upon the methods of prophylaxis against plague, insisting specially on the destruction of rats, on land as well as on board vessels.

The International Sanitary Bureau of Washington was constituted as follows: President, Surg. Gen. Walter Wyman, United States of America. Members: Dr. Alejandro del Río, Chile; Dr. Hugo Roberts, Cuba; Dr. Oscar Dowling, United States of America; Dr. Salvador Ortega, Guatemala; Dr. Eduardo Licéaga, Mexico; Dr. Luis Razetti, Venezuela.

The International Sanitary Committee of Montevideo is as follows: President, Dr. Ernesto Fernández Espiro. Members: Dr. Joaquin de Salterain, and Dr. Julio Etchepare, secretary.

Montevideo, Uruguay, was selected as the place to hold the next meeting.

A more detailed report of the conference by Surg. G. M. Guiteras, who, with Surg. J. C. Perry, formed the delegation of the United States, will be found in the Public Health Reports of March 8, 1912.

The transactions of the conference have been forwarded by this Bureau to the Pan American Union for publication, and it is understood that they will be soon available for distribution. 
Representation at Meetings of Scientific and Sanitary Associations and Congresses.

During the year officers were detailed to the following meetings of scientific and sanitary associations and congresses in the United States and abroad:

Association of Surgeons Atlantic Coast Line Railroad, Norfolk, Va., July 25-26, 1911.

American Pharmaceutical Association, Boston, Mass., August 14-19, 1911.

American Hospital Association, New York City, September 19-22, 1911.

National Association of Funeral Directors, Atlantic City, N. J., September 20, 1911.

Association of Military Surgeons, Milwaukee, Wis., September 26-29, 1911.

Michigan State Medical Society, Detroit, Mich., September 27-28, 1911.

Association for Prevention of Lake Pollution, Chicago, Ill., September 20, 1911.

Chicago Medical Society, Chicago, Ill., October 4, 1911.

National Committee on Milk Standards, New York City, October 4-6, 1911.

Medical Association of the Southwest, Oklahoma City, Okla., October 10-12, 1911.

Mississippi Valley Medical Association, Nashville, Tenn., October 17-19, 1911.

National Conference on Pellagra, Columbia, S. C., November 2, 1911.

Fifth International Sanitary Conference of American Republics, Santiago, Chile, November 5-12, 1911.

Clinical Congress of Surgeons of North America, Philadelphia, Pa., November 7-16, 1911.

Southern Medical Association, Hattiesburg, Miss., November 14-16, 1911.

American Association for the Study aud Prevention of Infant Mortality, Chicago, Ill., November 16-18, 1911.

American Public Health Association, Havana, Cuba, December 4-9, 1911.

Seaboard Medical Association, Newport News, Va., December 5-7, 1911.

National Association for the Prevention of Pollution of Rivers and Waterways, Baltimore, Md., December 13, 1911.

New York Academy of Medicine, New York City, January 25, 1912.

New York Milk Committee, New York City, January 25-27, 1912.

1912.

"Health week," Medical and Chirurgical Society, Baltimore, Md., February 19,

Farmers' Conference, Savannah, Ga., February 22, 1912.

Council on Medical Education, American Medical Association, Chicago, Ill., Feb- . ruary $26-27,1912$.

Council on Health and Public Instruction, American Medical Association, Chicago,

Ill., February 26-27, 1912.

Association of American Medical Colleges, Chicago, Ill., February 28, 1912.

National Confederation of State Medical Examining and Licensing Boards, Chicago,

Ill., February 29, 1912.

First District Medical Society of Georgia, Millen, Ga., February 29, 1912.

Illinois Water Supply Association, Urbana, Ill., March 5-6, 1912.

New York Academy of Medicine, New York City, March 19, 1912.

Medical Society of the Missouri Valley, Colfax, Iowa, March 21-22, 1912.

Tennessee Health Officers' Conference, Nashville, Tenn., April 2-4, 1912.

American Association of Pathologists and Bacteriologists, Philadelphia, Pa., April 4-6, 1912.

Conference of State, County, and City Boards of Health, Seattle, Wash., April 8-9,

1912.

Seventh International Congress on Tuberculosis, Rome, Italy, April 14-20, 1912.

Alabama State Medical Association, Birmingham, Ala., A pril 16-19, 1912.

State Medical Society and Conference of the State Board of Health, Del Monte, Cal., April 16-18, 1912.

Association of American Medical Commissions, Louisville, Ky., May 1-3, 1912.

Texas State Medical Association, Waco, Tex., May 7-9, 1912.

Southern Sociological Congress, Nashville, Tenn., May 7-10, 1912.

Civic League, Manassas, Va., May 14, 1912.

Indiana Health Officers' School, Indianapolis, Ind., May 15-16, 1912.

Infant Hygiene Conference, Philadelphia, Pa., May 22, 1912.

Health Conference, Chesterton, Md., May 22, 1912.

Wisconsin Medical Society, Milwaukee, Wis., May 24, 1912.

National Association for the Prevention and Study of Tuberculosis, Washington,

D. C., May 30-31, 1912. 
American Academy of Medicine, Atlantic City, N. J., Na! 31-June 1, 1912.

American Society of Tropical Medicine, Atlantic City, X. J., June 3, 1912.

American Medical Association, Atlantic City, N. J., June 3-7, 1912.

New Jersey State Pediatric Society, Spring Lake, N. J., June 10, 1912.

Kansas Health Officers' Conference, Lawrence, Kans., June 10-15, 1912.

Alabama Coal Operators' Association, Birmingham, Ala., June 11, 1912.

Association of Surgeons of the Southern Pailway, Washington, D. C., June 11-13, 1912.

Association of Surgeons of the Norfolk \& Western Riailroad, Columbus, Ohio, June 18-19, 1912.

North Carolina Medical Society, Hendersonville, N. C., June 18-20, 1912.

Committee on Standards of Water of the National Association for the Prevention of Pollution of Rivers and Waterways, New York City, June 27, 1912.

In addition, the bureau was regularly represented by the Lnited States delegate, Surg. H. D. Geddings, at the meetings of the permanent committee of the International Office of Public Hrgiene at Paris, and at the meetings of various committees of the "Fifteenth International Congress on Hygiene and Demography by the Surgeon General, Asst. Surg. Gen. J. W. Kerr, and the director of the exhibition, Passed Asst. Surg. J. W. Schereschewsḳ̣. 


\section{MARITIME QUARANTINE.}

Total Inspections.

During the fiscal year ended June 30, 1912, the United States Public Hiealth Service inspected a total of 12,911 vessels at the domestic and insular quarantine stations and at foreign ports. Of this number 1,418 were fumigated or disinfected, either on account of actual infection or for the destruction of disease carriers, such as rats and mosquitoes. Passengers and crews to the number of 1,564,071 were also inspected to determine whether they were infected with any of the diseases quarantinable under the Treasury regulations.

\section{Quarantine Against Cholera from Russia and Itaiy.}

This disease has not been a factor in quarantine operations during the current summer on account of the fact that its appearance in the two countries above mentioned was limited to only one or two localities, and the infection was circumscribed in extent. However, the following circular directed against the introduction of cholera into the United States is now in force:

MODIFICATION OF DEPARTMENT CIRCULAR NO. 47.

1911.

Department Circular No. 66.

Public $\overline{\text { Health }}$ and

Marine-Hospital Service.
TREASURY DepartMent, Office of THE Secretary, Washington, November 16, 1911.

To national, State, and local quarantine officers, collectors of customs, ship owners and agents, and others concerned:

Until further notice, department circular No. 47 of July 19, 1911, "Addition to Quarantine Regulations-Cholera Bacillus Carriers," is to apply only to infected vessels.

Franklin MacVeagh, Secretary.

\section{Bubontc Plague in Porto Rico and in Habana, Cuba.}

The presence of this disease was officially confirmed in San Juan, P. R., on June 19, 1912, and in Habana, Cuba, on July 6, 1912. It is believed that the existence of plague infection in rodents so antedated the appearance of the disease in human beings as to warrant the incorporation into this annual report of the histories of the plague infection in the localities above mentioned.

\section{BUBONIC PLAGUE IN PORTO RICO.}

The diagnosis of plague in San Juan, P. R., was officially made on June 19, 1912, three days after the first suspicious case was reported, so that little time was allowed for preparations for outgoing precautions which would protect the rest of the island, the United States, 
and other countries, and yet not toogreatly hinder commerce. Xrvertheless on the day following the declaration of the existence of plagrue the outgoing quarantine regulations were put in full forec, and the shipping interests were working in complete harmony with the quarantine authorities. 'Ihis was accomplished by calling together the agents of transportation lines and prominent merchants, explaining to them the ends to be accomplished and discussing the best methods for carrying them out.

The measures taken come under the following heads:

(1) Fumigation of vessels.

(2) Prevention of rats going aboard ressels, (a) directly, (b) in freight.

(3) Deratization and rat proofing of piers and water front.

(4) Inspection of passenger's' baggage.

The above measures are applied to (1) coastwise vessels for other Porto Rican ports, (2) vessels for the United States proper, (3) ressels for foreign ports.

Two large piers have been repaired and altered in accordance with recommendations of the service, so that they are practically rat, proof. Another large wharf is being divided into rat-proof come pounds and the old rat-infested wharfs have been condemned and are being rebuilt.

At present and since the beginning of the outbreak the following routine is carried out: Vessels bound for other Porto Rican ports are allowed to load, after fumigation, at approved wharfs and in the daytime only. A clear space, 20 feet wide, free of all freight or litter, is. maintained along the water front where loading is allowed. All vessels and lighters must anchor in the stream from $6 \mathrm{p}$. m. to $6 \mathrm{a}$. m. All cargo is inspected by a qualified inspector of the service, and any" packages, such as crates or baskets, that might harbor rats are either repacked under the eyes of the inspector, or fumigated in the holds. of the vessels with 4 per cent sulphur dioxide, six hours exposure. All vessels are fumigated empty at least once a month and are given special permits to leave port.

Vessels bound for theUnited States discharge in daylight, at approved wharfs, with all precautions against rats, anchoring at least 1,000 feet out during the night. After discharge they are fumigated in the manner to be described and are loaded from open lighters in the bay. All freight outbound is inspected, the attempt being made to have all packages rat tight, or if not so, such as fruit boxes, to prevent, the storage in any but approved rat-free localities. The inspection of passengers and baggage is made just before sailing.

The precautions taken with vessels bound for foreign ports cone sist of holding said vessels in quarantine in the bay, together with the inspection of passengers, baggage, and freight going aboard. As all of these vessels have passengers and freight in transit, fumigation is not attempted.

The fumigation of vessels is done as follows:

1: A primary inspection of the entire vessel is made to ascertain the structural peculiarities of the vessel and its general condition. The blue prints are then exam: ined for the purpose of getting the cubic capacities of the holds, engine room, fire. room, bunkers, and the other compartments. Where these capacities are not shown on the charts they are obtained by taking actual measurements.

2. In the holds the dunnage is piled or slung up, so as to be entirely free from the floor and not in any way afford a hiding place for rats. The limbers (planking boards) 
over the bilges are removed so that the fumes may circulate under and between the sheathing. The sounding and bilge-pipe casings are removed in part so that the fumes may penetrate these parts. In the forepeaks and lazarets where the mates' and boatswains' stores are kept, it is necessary to have the greater number of the ropes, canvas, etc., carefully removed. In having the stores removed from these places prior to fumigation, the greatest of care is taken that no rats come out with the stores which are inspected, both when they are taken out and when placed back.

3. In the provision storeroom all open stores and articles likely to be injured by the sulphur are inspected and ordered removed to the decks. The same is true of the living quarters, dining rooms, social hall, etc.

4. Prior to lighting the pots, the officer in charge of fumigations makes a personal examination of all parts of the vessel to see what everything is ready for efficient and safe fumigation.

5. Engine rooms, bunkers, and shaft alley are given 7 hours' exposure, so all fires are orlered drawn or banked for a period of at least 10 hours.

6 . The living quarters on the main deck, galleys, etc., forecastle, and second cabins are given 7 hours' exposure of $4 \frac{1}{2}$ per cent gas. The staterooms, etc., on the promenade and hurricane decks are not fumigated unless some special reason exists for varying from this rule. All of these rooms are ininutely inspected to make certain that they harbor no rats and that there are no rat holes. They are then ordered to be kept closed during the time the vessel is undergoing fumigation, nmless they are actually occupied. The holds are given an exposure of at least 3 per cent gas for 12 hours or more.

7. All of the deck paraphernalia. including rope lockers, life-preserver lockers, frebucket racks, telegraph, pipe, and steering-gear casings, fresh vegetable and potato bins, lifeboats and rafts are inspected for the purpose of finding and destroying rodents. In quite a number of cases rats have been found in such places.

9. After the fumigation, a minute inspection is made of all parts and a search for tats made. In the living quarters, galleys, storerooms, etc., and in the holds, the dunnage, which had been previously piled up, is torn apart and examined.

10. As a final precantion. the clecks are ordered to be washed down if they are littered up and seem to warrant this treatment.

Between June 19 and August 31, 1912, 41 steamships and 133 sailing vessels were fumigated; approximately 62,000 pounds of sulphur has been burned in doing this work.

With certain exceptions, it is intended to keep up the abovedescribed measures indefinitely, in accordance with the number of plague cases occurring both in human and rodents. The modifications for the relief of shipping proposed are: First, allowing loading at rat-proof piers that are to be cleared of all freight once weekly, and, second, fumigation at longer periods than every voyage of about three weeks, as soon as the fumigations fail to yield rats, which will, of course, not be until provisions to prevent rats boarding the ressels at New York and other United States ports are strictly enforced.

In the inauguration of the foregoing quarantine operations at San Juan, most valuable and timely assistance was received from the United States Revenue Cutter Service. The captain commandant placed at the disposal of the service at San Juan the revenue cutter Algonquin which, with its complement of 7 officers and 63 men, performed valuable duty in connection with the many quarantine activities. It is desired in this connection to acknowledge the valuable service rendered by the commander of the Algonquin, Capt. James $\mathrm{H}$. Brown, who was unfailing in his efforts to aid the bureau in the emergency which presented.

The insular authorities and the shipping and business interests of San Juan have cooperated with the service in every way and have promptly made all changes in their wharves when requested to do so. On the other hand, the chief quarantine officer has required nothing not considered absolutely necessary. Much of the rat proofing of 
wharves is of a more or less temporary nature and will be changed to that of a permanent character as new construction is made. It is believed that vessels leaving San Juan are as safe, from a plague standpoint, as it is possible to make then without imposing prohibitive restrictions.

\section{Bubonic Plague in Habaxa, C'uba.}

The existence of bubonic plague in Habana was first confirmed on July 6, in the case of a Spaniard who was taken sick on June 30 . Since that date two more cases developed, one confirmed July 9 ; and the other on July 22. These last cases resulted in death. 'There were therefore three cases with two deaths from plague known to have occurred between July 6 and September 1, 1912. An investigation made by the Cuban sanitary authorities showed that there had occurred one, if not two, very suspicious cases, also rosulting in death, prior to the first case officially confirmed. All the cases were in persons of one neighborhood, the first, however, three blocks distant from the last cases.

The Cuban health authorities had suspected the possible existence of plague prior to the occurrence of human cases. 'The official report of the presence of plague in Porto Rico was received by them on June 20 , and on the same day, an anonymous communication was received from a resident to the effect that an unusual mortality among rats had occurred in an area covering three blocks which were within a square of the Caballeria wharves. An investigation of this report elicited the information that the mortality among rats had been noticed during the preceding two weeks, and that the unusual mortality had ceased by the time the information reached the sanitary department. Several dead rats were found, but on necropsy were negative as to plague.

The presence of infection can therefore be reasonably dated as early as the first week in June. Between June 24 to July 8, 291 rats were caught within this infected district, and none was found to show plague infection. From July 8 to September 1, 1912, 8,166 rats were autopsied, of which none proved to have plague. Since July 8 there has been maintained a systematic campaign for extermination of rats in a zone including the old city of Habana, which allowed a broad margin over the true infected squares. The campaign was extended to include the wharves, also Casa Blanca and Regla, which are towns across the bay. The quarantine service also took measures for eradicating rats from lighters and coastwise vessels laying alongside of wharves.

The campaign, briefly stated, includes inspection of houses, and the cleaning up of houses, trash and rubbish, disinfection of infected houses, rat proofing of buildings, regulations for the proper storage of foodstuffs, proper disposal of garbage in tight metal containers, as well as the trapping and placing of poisons for rats.

The rapid control of the infection may be attributed to the early discovery and report of the presence of infection, and the active measures taken by the sanitary department in dealing with the known infected area, as already outlined. Other factors contributing to the favorable campaign are that the buildings in Habana are to a great extent rat proof in structure, also that old sewers where rats usually

69450-H. Doc. 971, 62-3-5 
find refuge did not extend beyond the squares where infection was found. It is noteworthy that an old sewer line, which is very short, extends along the actually known infected blocks, thus limiting the possible refuge or exodus of rats beyond these blocks.

\section{OUTGOING QUARANTINE.}

Passed Asst. Surg. R. H. von Ezdorf arrived in Habana July 9, 1912 , with instructions to organize the outgoing quarantine service for the United States and enforce the foreign quarantine regulations, - 1910, paragraphs 35-40. In order to carry out these instructions the personnel of the office was increased. The following is a list of employees on duty: Passed Asst. Surg. R. H. von Ezdorf, Acting Asst. Surgs. P. Villoldo and Richard Wilson, 1 clerk, 1 chief disinfector, 1 assistant disinfector, 3 sanitary guards, and 1 laborer.

Every facility was given to the representative of the United States Public Health Service to familiarize himself with the sanitary conditions regarding the prevalence of plague in all its details by the officials of the Cuban sanitary department.

Accordingly the infected zone was soon defined, and on July 14 was determined as including the confines of the old city of Habana. For the purpose of permitting passenger travel, the bureau authorized that first-class passengers could embark for United States ports without detention provided they were nonresidents in this zone for seven days preceding their application for a certificate of health issued the day before the intended sailing. All other classes of persons, originating in Habana, were required to enter the Triscornia detention camp for a sufficient period of time to cover seven days to the date of arrival at the United States port.

Passengers originating from outside of Habana and suburbs, arriving the same day or day before their intended sailing, were permitted to embark. All such persons leaving Habana for the United States were individually certified by this office as having presented satisfactory evidence of residence outside of the infected zone during seven days preceding embarkation.

An official request was made, through the American minister, Mr. Beaupre, of the Cuban Government for the use of Triscornia detention camp for detaining passengers intending to sail for United States ports, which was promptly granted. Accordingly, detention of passengers began July 15, 1912.

On August 10, owing to the evidence of control of plague infection, the infected zone was narrowed to extend from Cuba Street to the bay, and on August 26, the bureau issued an order removing all restrictions on passenger traffic except inspection; the individual certification of passengers was discontinued, and all passengers in apparent good health allowed to embark.

VESSELS AND CARGO.

Steamship agents were advised with regard to the measures necessary before bills of health would be issued to vessels sailing for a United States port direct. Circulars setting forth the requirements were issued as follows:

July 22, 1912: "The following regulations on account of plague in the port of Habana, for vessels sailing for ports in the United States, must be observed so far as practicable:

"Every precaution must be taken to prevent rats, fleas, or other vermin from getting aboard.

"Vessels should remain in open bay. Where vessels have lain at a dock, such vessel, when empty, must anchor in open bay, and be subjected to fumigation before sailing.

"If cargo is to be taken on, after such fumigation, it must be reported in order that a sanitary guard may be detailed to inspect the cargo, and see that the lines from lighters are properly guarded, by use of rat guards and tarring, in order to prevent the possible passing of rats from lighters to the ship.

"Vessels will be required to take on cargo only by daylight; after sunset all lighters or any other craft must be away from the vessel, by anchoring or otherwise, and no lines permitted to extend between the vessel and lighter or any other craft.

"No freight shall be shipped unless from plague-free districts, and all freight will be subject to inspection by the sanitary guard to observe that it is rat free.

"All general freight is required to be taken from a rat-proof wharf, unless it can be shown that the character of the freight is not liable to harbor rats. 
"Vessels sailing for ports in the United States, via Cuban ports, are subject to fumigation by the Cuban quarantine service. This fumigation will only be certified on the United States bill of health provided that it is done under supervision of a representative from the quarantine office and in accordance with the reriuirements of the United States Quarantine Regulations."

On July 24, 1912, the following additional instructions in connection with the above circular letter of the $22 \mathrm{~d}$ instant were issued:

"All vessels for ports in the United States must be fumigated at this port. Such fumigation will be done only when the vessel is in open bay, and should be done when the vessel is empty.

"A request from agent, captain, or owner to have such vessel fumigated must be made in ample time, preferably a day or two before the intended sailing.

"A list giving the amount of sulphur, pots, and pans required will then be given. This material must be furnished by the vessel.

"It will be required that crews, or any laborers the vessel desires to employ, shall assist in filling and placing of the pots as may be directed.

"Empty vessels are fumigated with 3 pounds of sulphur per 1,000 cubic feet for 6 hours. Vessels with cargo are fumigated with 4 pounds per 1,000 cubic feet for 12 hours.

"The time for beginning fumigation, which is counted from the moment all parts of the vessel are closed, should be not later than $11 \mathrm{a}$. m., in order that the vessel may be inspected and opened up before sunset, otherwise the fumigation will be continued throughout the night.

"All vessels fumigated must remain closed until ordered to be opened up in the presence of the inspecting officer, otherwise ressels will be required to undergo a second fumigation.

"You are respectfully requested to instruct captains and officers on vessels to assist in the enforcement of these requirements."

Instructions were also issued to the service sanitary inspectors at Habana as follows:

"You are directed to enforce the following regulations regarding cargoes, vessels, and passengers:

"Vessels must remain in open bay.

"No crew will be allowed to go ashore.

" Lighters while alongside of vessels must have their lines freshly tarred for a distance of 4 feet, or have rat guards attached.

"Lighters may remain alongside of vessels only by daylight, to anchor away or leave the vessels at sunset.

"Cargo: Make note regarding the class of cargo, packing, name of wharf from which it was taken.

"No freight whatsoever, loaded at Caballeria Wharf, shall be accepted, unless a special permit is issued by this office.

"General freight will be accepted from such rat-proof wharves as the three Paula Wharves, Havana Electric Wharf, or Scovel Wharf.

"Sugar and burned fertilizer, in sacks, may be taken from San Jose and Regla Wharves.

"Ore, asphalt, tobacco in bales, and such other freight as is known not to harbor rats, may be taken from any approved wharves.

"Hides are shipped wet, salted down, and after disinfection, for which a certificate must be shown.

"Boxes, barrels, bags must be whole and in first-class condition and show no evidence of openings by which rats might have entered, or that they have been harbored therein. Bags of sugar will usually show holes where a sample has been taken, but must otherwise be in good condition.

"No fruit or vegetables packed in crates, or barrels, with holes for ventilation, may be shipped unless covered with close wire netting, not more than one-half inch mesh, so as to be secure against the entrance of rats.

"Crated merchandise without any class of packing may be shipped provided inspection can be made to assure its freedom from rats, or any hiding place for rats therein.

"Careful examination of all packages, or bales, in which excelsior, hay, straw, grass, or like packing has been used, must be made, and if satisfactory proof of recent packing, within 24 hours of shipment, and all precautions taken in direct handling from shipping point to a rat-proof wharf, is not obtainable, shall not be shipped, but ordered to be repacked or subjected to sulphur fumigation, supervised by this office.

"Any article or merchandise so packed as to be liable to harbor rats will not be allowed shipment, unless repacked, or fumigated under the supervision of this office, if practicable.

"No passengers are to be allowed to embark until the medical officer of the service is on board. 
"You are directed to examine all lifeboats for rats or evidences of rats, and report on same in your daily report.

"You will report on all articles or freight which you have rejected for shipment.

"Any irregularities in connection with these instructions, which may be observed by you, should be immediately reported to this office.

"You will show this letter of instructions to the captain of the vessel as your authority to enforce the foregoing regulations."

On August 26, 1912, the following supplement to above orders' was issued:

"Fruit and vegetables in crates, taken on lighters from Paula or Havana Central Wharves may be shipped in crates without wire screening, but careful inspection is enjoined."

For the guidance of officers clearing vessels a set of instructions with reference to the form of certification to be made on bills of health were formulated. With few changes these were approved by the bureau, in the following form:

\section{SPECIAL REGULATIONS.}

1. (a) Ward Line vessels, New York to Habana and return, are allowed to proceed from Habana without fumigation, with the understanding that they are fumigated on arrival at New York. A note is made on bills of health, recommending that they be fumigated at New York.-Bureau Order July 16, 1912.

(b) These vessels may go to the Scovel Dock to unload, and are to be fumigated in open bay before taking on cargo.

(c) Ward Line vessels, New York, Habana, and Mexican ports, and return to be fumigated while empty at Vera Cruz. These vessels to remain in open bay while in the harbor, to take on and discharge cargo by daylight only, are to be certified as having complied with paragraph 35, United States Quarantine regulations. The officer will satisfy himself that the fumigation done at the Mexican port has been efficient, otherwise the recommendation will be the same as made under 1. $a$., or, if practicable, fumigation will be done here.

2. (a) P. \& O. vessels, mail boats, Key West and Habana, steamships Mascotte and Miami, remain in open bay, discharge cargo by daylight, and may take on tobacco cargo. Fumigation of these vessels will be done once each month, and will be repeated on successive trips if any rats are found until freed from rats, when fumigation will be resumed once a month. These vessels have been deratized by seven successive fumigations, between July 9 and 25, 1912 .

(b) The steamship Olivette must bring a certificate of recent fumigation, enter in the morning, leave in the evening before sunset of the same day. Vessel will comply in all respects with paragraph 35, United States Quarantine Regulations, while in Habana, recommendation to be made on bill of health that the vessel be fumigated on discharge of cargo.

\section{GENERAL REGULATIONS FOR ALL OTHER VESSELS.}

3. All fumigations of vessels will be done in open bay, when the vessel is empty, if possible.

4. Vessels which have lain at a dock in Habana at any time, or which have discharged or taken on cargo at night in open bay, must be fumigated before sailing for a port in the United States, even though precautions have been taken against the ingress of rats. Vessels so fumigated may take on cargo by daylight only, no lighter or any other craft to remain alongside at night.

5. Vessels which have been fumigated two or more times at a United States port, or at this port, during one month, complying in all respects with paragraph 35, United States Quarantine Regulations, while in this port, namely:

"Remain in open bay, discharge and take on cargo by daylight only. No lighters to remain alongside at night."

will be so certified, provided fumigation is done thereafter when the vessel is empty, at least once every month.

6. Vessels arriving in Mabana from the United States or other clean foreign ports, remaining in open bay, discharging cargo by daylight, taking all precautions against ingress of rats from empty lighters and then proceeding to a port in the United States, direct, or via Cuban ports, will be treated as follows:

(a) If empty, fumigation in open bay to kill rats, if the vessel is sailing direct for a port in the United States. If sailing via Cuban ports, fumigation as often as may be necessary to insure extermination of rats. Regular line vessels to fumigate once a month. 
(b) If with (argo in transit: Cortified as having compliod with paragraph 35 , lniture States Quarantine Regulations, while in this port.

(c) If taking (argos at this port, with part, carero in transit, such oprerations to be done by daylight; recommenelation on bill of hratth that the veswel bes funigated at the United States port.

7. No vessels to lor cortifferl as complying with paragraph 35, Cnitrol States (2narantine Regulations, muless a sanitary guard or other officer from this office has supervised the operations.

J'ASSENGERS.

"No passengers are to be allowed to embark until the medical officer of the service is on board."

\section{Fumigatons.}

As a general rule, empty vessels were fumigated with sulphur dioxide, by burning of 3 pounds of sulphur per 1,000 cubic feet and, when with cargo, 4 pounds per 1,000 cubic feet. All materials for fumigation were supplied by the vessels. The amount of sulphur to be used was rapidly calculated, from the gross tonnage, using 3 pounds or 4 pounds, as the case might be, for each 10 tons gross. Not more than 10 pounds of sulphur would be placed in a pot to be burned. Frequently the fumigation would continue throughout the night, so that the time often exceeded the time required under the regulations.

Summary of the transactions from July 6, 1912, when quarantine against the port went into effect, until Sept. 1, 1912.

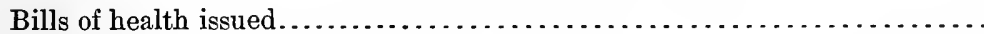

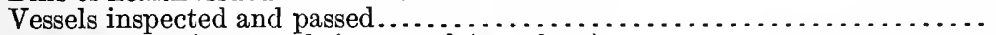

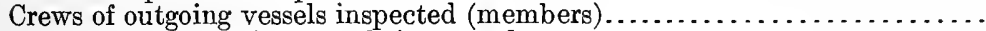

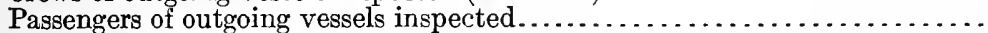

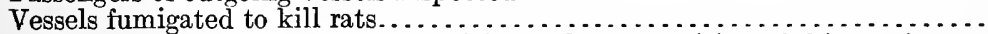

Vessels fumigated by Cuban authorities under supervision of this service....

Number of vessels certified as complying with par. 35, United States Quaran-

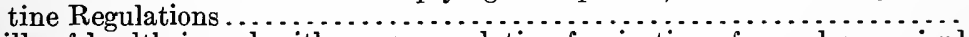

Bills of health issued with recommendation fumigation of vessel on arrival

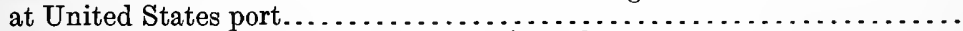

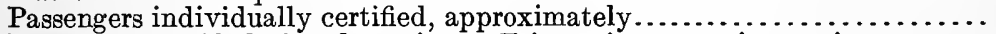

Passengers certified after detention at Triscornia quarantine station:

For New York . . . . . . . . . . . . . . . . . . . . . . . . . . . . . . .

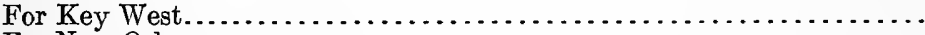

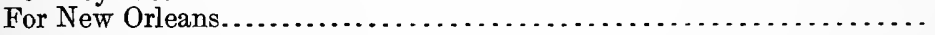

205

\section{RAT QUARANTINE-DESTRUCTION OF RATS ON VESSELS.}

This important work, which has been discussed in the annual reports of the service for the past four years, has been still further developed as to its scope by the promulgation of department circular No. 37, of July 10, 1912, and also by bureau general order of August 9, 1912, which appear below:

[1912-Department Circular No. 37. Public Health and Marine-Hospital Service.]

Addition to Quarantine Regulations-Precautions Against Rats Leaving Vessels.

Treasury Department,

OFFICE OF THE SECRETARY,

Washington, July 10, 1912.

To National, State, and local quarantine officers, collectors of customs, shipowners and agents, and others concerned:

In accordance with the act of Congress approved February 15, 1893, and to further prevent the entrance of plague into the United States, the following regulation, in 
addition to those contained in Quarantine Regulations of the Treasury Department issued October 20,1910, is hereby promulgated and shall remain in force until otherwise ordered:

"Vessels from ports in South America and the West Indies, Africa, Russia, China, India, and the Pacific islands, while lying in United States ports, shall have all lines or hawsers leading to wharves or shore protected by rat guards (for description see p. 907, Public Health Reports, June 7, 1912), and all gangplanks shall be raised at night unless men be placed near by to destroy escaping rats."

\section{Franklin MacVeagh, Secretary.}

\section{August 9, 1912.}

\section{Medical offcers in command, and acting assistant surgeons in charge, national quaran-} tine stations:

SrR: This letter of instructions is intended to replace bureau letter of July 15, 1912. and its contained instructions are to be carried out in conjunction with the directions contained in department circular No. 37, of July 10, the provisions of which are to be made operative in the case of all of the ports hereinafter referred to.

Vessels from the following named ports are to be fumigated throughout for the destruction of rats upon their arrival at United States ports, and the masters of said vessels are to be directed in writing by you to have all lines or hawsers leading to shore protected by rat guards, when such vessels are lying at United States ports, all gangplanks to be raised at night unless men be placed near by to destroy escaping rats.

\section{List of ports from which vessels must be treated as outlined above.}

(1) Liverpool, England, and other English ports in which plague appears subsequent to the issuance of this order.

(2) All ports in South America (including the river ports thereof.)

(3) All ports in the West Indies.

4) All ports in Africa (including the Azores, Canary Islands, Cape Verde Islands, and Madeira.)

(5) All ports in Asia (including those of the Straits Settlements, Japan, the Philippine Islands, and the Malay Archipelago.)

(6) All ports of Australia.

In the event any vessel from any port included in the above list arrives with a certificate from an accredited officer of the service, showing that the vessel has been fumigated for the destruction of rats at the foreign port of departure just prior to the sailing of the vessel, the quarantine officer may waive fumigation in his discretion if, as a result of a careful examination to this end, he is convinced that the fumigation has been effective.

Vessels carrying perishable cargoes, unless contraindicated by their general sanitary status, may be given provisional pratique and allowed to proceed to the wharf, there to remove sair perishable cargo, prior to the process of fumigation, the vessel, however, to be protected during the removal of such perishable cargo by being breasted off from the wharf, and by the use of rat guards and other precautions, such as the raising of gangplanks to prevent the escape of rats from the vessel.

Medical officers are directed, where practicable, to make regular inspections to determine whether the masters of vessels are properly carrying out the rat funnel and other precautions to prevent the escape of rats from vessels. An effective compliance with these precautions should be enforced.

Certain cases are likely to arise in which vessels will arrive with cargoes such as iron ore, coal, or nitrates, from isolated ports where perhaps the vessel has taken her cargo in midstream. Such ports, although geographically considered as falling within the scope of this order, may not be individually considered dangerous from the standpoint of furnishing plague-infected rats. On this account, upon the receipt of this letter, you will consult the statistics of the ports from which vessels have departed before arriving at your station and make recommendations as to any ports which might in your opinion be considered exceptions to this general order.

You are directed to acknowledge this letter immediately upon its receipt. Respectfully, 
Portable Rat Destroyer.

THE REFITTING OF THE STEAMER BRATTON WITH A MOULER PATDESTROYING DEVICE.

The Harker fumigating apparatus was installed on the steamer Bratton, and this vessel was placed in commission at Philadelphia, $\mathrm{Pa}$., to be used in the work of eradicating rats from vessels at that port. The apparatus utilizes the flue gas from furnaces or boilers, which gases are ordinarily wasted. This in itself constitutes a saving of expense as compared with the use of sulphur, which costs from 2 cents to 4 cents a pound, and in addition there is the advantage that the funnel gas used by the Harker apparatus is neither corrosive to metals nor destructive to fabrics as is the case with sulphur, although the funnel gas has no disinfecting properties, nor is it recommended as an insecticide.

In using the Harker apparatus the funnel gases are collected through the tapping of the side of the furnace smokestack or funnel (the top of the funnel being temporarily closed during this process) and after the aspiration of the gas into the Harker apparatus, a washing and cooling process is gone through with before the gas is propelled into the holds or other compartments of vessels intended to be fumigated. It appears that when even 1 ton of coal is burned up, the volume of gas produced is enormous, being over 400,000 cubic feet, and this gas is said to contain not more than 8 per cent to 10 per cent of oxygen, and may contain considerably less if a good draft is maintained and a proper depth of the fuel is kept.

The Harker apparatus consists of five principal parts-a blower, engine, cooler, distributor, and disinfectant tank. All of these parts are brought together on one bedplate and compactly arranged so as to take up little space. When the gas is conveyed from the smokestack or funnel it is led into the cooler, which is one of the compartments of the apparatus. Into this cooler a supply of sea water is pumped. The hot gas while being passed through this chamber is cleaned and cooled by the action of the water, and the soot and other impurities are washed out, The cool and clean gas is then forced into another compartment from which it is distributed into pipes which convey the gas into the holds or other compartments of the vessel.

It is usual when this machine is installed on vessels to not only connect it with the funnel, in the case of a large steamer, but also to connect it with the funnel of the donkey boiler. The machine is said to be capable of forcing 1,500 cubic feet of gas per minute into the hold of a vessel.

In order to test this apparatus the quarantine steamer Bratton was thoroughly overhauled and repaired by order of the Secretary, who became personally interested in developing the Bratton for the purpose under consideration, that is, for the purpose of adapting her as a modern floating fumigating plant. It was thought that the Government might at any time require the use of a vessel which could be propelled under its own steam and be used in a large harbor to go from one vessel to another for the purpose of destroying rats.

After the overhauling of the vessel the Harker apparatus was installed and Passed Asst. Surg. Norman Roberts was detailed from 
the Hygienic Laboratory to conduct the experiments with the funnel gas. In the report of this officer the statement is made that the apparatus kills rats on vessels quickly and surely, and that neither the surfaces of the vessel, food, clothing or any article of ordinary cargo is damaged if the process is conducted with reasonable skill and care. Furthermore, it is stated that the fire-extinguishing properties of the gas cause it to be safe. It has few if any of the disadvantages which are present in the fumigation of vessels by sulphur, which is the method commonly used.

A chemical analysis of the Harker gas, delivered by the apparatus, showed that it was composed of carbon monoxide up to 3 per cent, carbon dioxide 10 per cent, oxygen as low as 8 per cent, nitrogen and other gases to total 100 per cent.

It may be said in a few words that the tests to which the apparatus has been so far subjected show that the latter has now a wide field of usefulness, especially in such ports as Philadelphia, where the task is imposed upon the service of fumigating vessels from plague-infected localities.

\section{The Transfer to National Control of the Quarantine Func- tion at Providence, R. I.}

As a result of preliminary negotiations between the honorable the Secretary of the Treasury and the mayor of the city of Providence, relative to the transfer to national control of the quarantine function at Providence, the following letter dated April 30, 1912, was addressed by the mayor of Providence to the honorable the Secretary of the Treasury, said letter inclosing resolutions adopted by the city council of Providence and a permissive act passed by the Rhode Island General Assembly:

City of Providence, Executive Department,

Henry Fletcher, Mayor, City Hall, April 30, 1912.

Hon. Franklin MacVeagh,

Secretary of the Treasury, Washington, D. C.

Sir: By virtue of authority in me vested, I have the honor to transmit to you herewith a copy of a resolution adopted by the city council of Providence, R. I. (together with a copy of a permissive act passed by the Rhode Island General Assembly and approved by his excellency the governor on April 18, 1912), requesting the Secretary of the Treasury of the United States to establish a complete system of national quarantine for the port of Providence, and providing, in the event of such establishment, for a suspension of the duties of the quarantine health officer and sentinel of this port for so long a period as such Federal quarantine inspection shall be maintained. Most respectfully, yours,

Henry Fletcher, Mayor.

[Joint resolution of the city council, No. 97, approved Mar. 5, 1912.]

The City of Providence.

Resolved, That the city solicitor is hereby directed to apply to the general assembly for such legislation as will provide that, upon the establishment by the United States of a system of quarantine inspection for the port of Providence, the duties of the quarantine health officer and sentinel thereof shall be suspended for so long a period as such quarantine inspection shall be maintained, and that, upon the establishment of a complete system of national quarantine for said port, the city of Providence shall be relieved of fụther maintaining its system of quarantine for said port. substantially in conformity with the accompanying draft act, and that upon the passage of such legis- 
lation the city of Providence hereby requests the Sectreary of the 'Treasury of the United States to establish a complete system oi national glarantine for the port of Providence and authorize the mayor to transmit to said Secretary a copy of this resolution certified by the city clerk.

A true copy:

Witness:

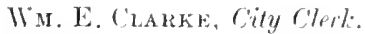

[In general assembly, January session, A. D. 1912.]

STATE OF RHOHE ISIANI, FTC.

IN ACT In amendment of and in addition to chapter 114 of the general laws, entitled "Ot quarantine."

It is enacted by the general assembly as follows:

Section 1. Chapter 114 of the general laws, entitled "Of quarantine," is hereby amended by adding thereto the following section:

"SEc. 17. Whenever the United States of America shall put in force a system of national quarantine inspection for the port of Providence the duties of the quarantine health officer and sentinel or said city shall be suspended for so long a period as such quarantine inspection shall be maintained, and whenever said United States shall establish a quarantine station, ground, or anchorage on or in the Providence River or Narragansett Bay north of Conimicut Point, and put in force a completesystem of national quarantine for the port of Providence, the provisions of sections 1 to 12 , both inclusive, of this chapter shall not apply to the city of Providence or the port thereof."

SEc. 2. This act shall take effect upon its passage.

State of Rhode Island,

OfFice of the Secretary of State,

Providence, A pril 26, 1912.

I hereby certify the foregoing to be a true copy of the original act approved by his excellency the governor on the 18th day of April, A. D. 1912.

In testimony whereof, I have hereunto set my hand and affixed the seal of the State aforesaid the date first above written.

[SEAL.]

J. Fred Parker, Secretary of State.

A medical officer of the service, Passed Asst. Surg. Richard H. Creel, was detailed on May 23, 1912, to assume the duties of quarantine officer at the port of Providence, which station is now regularly incorporated into the list of national quarantine stations.

\section{The Fitting Out of the Old Revenue Bark "Chase" for Service at Fort Monroe, Va.}

For a number of years the officers and men at the Cape Charles quarantine station (boarding division) have resided on the old hulk Jamestown, which was loaned by the Navy Department for the purpose above mentioned, but on account of the worn-out condition of the Jamestown it was necessary to replace her with the Chase, which latter vessel has been entirely renovated and fitted up for this purpose.

\section{Transfer of the Hospital Ship "Wistaria" to Key West, Fla.}

This vessel, formerly stationed at Mobile, has been transferred to Key West, Fla., to replace the detention ship McAdam, which was destroyed in August, 1910, by a hurricane. The Wistaria is being refitted as a floating quarantine hospital. 
New Quarantine Station at Galdeston, Tex.

This station is nearing completion, and it is predicted will be ready for occupancy by December 1, 1912. The station is located on Pelican Spit, upon newly made land, which is surrounded by a bulkhead The area of the station comprises about 3 acres, and so far 9 buildings have been constructed. The hospital capacity at this station is 30 beds, and there are detention facilities for about 100 persons. The station is about 2 miles distant from the city of Galveston, and is equipped with a wharf 300 feet long, in front of which there is at present a depth of 20 feet of water. It is the intention to increase this depth in the near future.

\section{Reports from the National Quarantine Stations.}

During the fiscal year ended June 30,1912 , at the various stations in the United States a total of 7,908 vessels were inspected, including 275 disinfected either for the destruction of mosquitoes as a precaution against the introduction of yellow fever or for the destruction of rats and other vermin as a precaution against plague.

In addition 957 ressels were spoken and passed, making a grand total of 8,865 vessels and 530,452 passengers and crews passing under the observation of the service at ports in continental United States.

Following are the summaries of the operations at the various quarantine stations:

Alexandria (Va.) quarantine.-Acting Asst. Surg.- Arthur Snowden in charge. Three vessels, carrying 31 members of crew, were inspected and passed.

At Alexandria, Va., the quarantine inspection is also made of vessels destined to Washington, D. C.

Eastport (Me.) quarantine.-Acting Asst. Surg. E. M. Small in charge.

Eight hundred and thirty-three steamers and 59 sailing vessels were inspected. These vessels carried a total of 55,841 passengers and crew.

Portland (Me.) quarantine.--Surg. J. M. Eager in command.

One hundred and eighty-seven steamers and 55 sailing vessels were inspected and passed. These vessels carried 25,838 passengers and crew.

Perth Amboy (N. J.) quarantine.-Acting Asst. Surg. Charles W. Naulty, jr., in charge.

During the past year the transactions have been the greatest since the opening of the station in 1904, and the prospects are bright for a further increase in the volume of the business for the ensuing year.

There have been no cases of quarantinable disease. The steamship Kirby Bank arrived July 25, 1911, from Tampico with suspicious case of gastroenteritis. Bacteriological examination for cholera was negative and vessel granted free practique after 24 hours' detention.

Two vessels arrived without United States bill of health and were reported to the department for further action.

The past winter was the most severe for years, and for several days at a time the harbor was completely frozen over. Boarding was extremely difficult and dangerous, and on several occasions without the assistance of a New York towboat would have been impossible 
Delaware Breakwater quarantine.-Post-office and telegraphir: address, Lewes, Del. Acting Asst. Surg. George G. Hart in charge.

Twenty-two steamers and 8 sailing vessels were inspected and passed. One steamer was fumigated.

Cape Charles quarantine.-Passed Asst. Surg. Hugh S. Cumming in command.

\begin{tabular}{|c|c|c|c|}
\hline$\cdot$ & Steam. & Sailing. & Total. \\
\hline 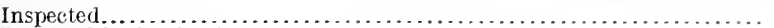 & stin & 4 & 572 \\
\hline Detained for fumigation. & ti & (1) & $f^{2}$ \\
\hline From infected ports not detainer because of previous fumigation at ports & & & \\
\hline of departure or call, certified by competent authority ................ & 55 & 0) & \\
\hline 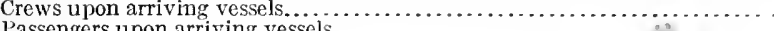 & ......... & $\ldots \ldots . .$. & 40,035 \\
\hline 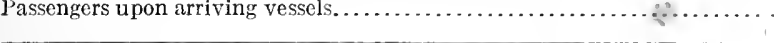 & $\cdots \ldots$. & $\cdots \cdots \cdots$ & 1,164 \\
\hline
\end{tabular}

Reedy Island quarantine.-Post office address, Port Penn, Del.; telegraphic address, Reedy Island, Del. Passed Asst. Surg. C'harles W. Vogel in command.

During the year 13 vessels were spoken and passed; 1,187 ressels were inspected and passed, of which 1,111 were steamers and 76 sailing vessels; 98,885 persons were inspected, of whom 43,892 were crews of steamers, 862 crews of sailing vessels, and 54,131 passengers on steamers. Glandular examinations were made of the crews of 11 vessels from plague ports, and temperatures taken of the crew of 1 vessel from a yellow-fever port. Ten vessels were disinfected, of which 8 were steamers and 2 sailing vessels.

On December 18, 1911, the steamship Chemnitz arrived at this station from Bremen. One case with suspicious eruption and 19 contacts were removed for observation. Two sleeping compartments and the hospital of the vessel were fumigated. The diagnosis in this case remains doubtful after recovery and discharge of the case. The doubt still remains whether it was a case of chickenpox or one of mild atypical smallpox.

On March 9, 1912, the steamship Rhein arrived from Bremen. One case with suspicious eruption and 47 contacts were removed for observation. All steerage passengers and crew of the vessel were vaccinated and the hospital fumigated. On the fourth day after removal of the case from the vessel the diagnosis of chickenpox was made and all contacts were released.

Antityphoid inoculations:

In addition to the routine quarantine transactions of the station, the antityphoid inoculation was administered during the year to the crew of the U. S. dredge Delaware. Fifty-one men received this inoculation. The inoculation was done at request of Maj. Deakyne, Corps of Engineers, United States Army, in charge of operations on the Delaware River and Bay. There had been a number of cases of typhoid fever among the crew of the vessel prior to the inoculation, and it was thought that the infection was conveyed from some source of infection aboard the vessel. For this reason the antityphoid inoculation was administered to every member of the crew. This was done in January of this year. Since that time there have been no further cases of typhoid fever aboard the vessel.

Washington ( $N . C$. ) quarantine.-Acting Asst. Surg. J. C. Rodman in charge. There were no transactions during the year. 
Cape Fear quarantine.-Post-office and telegraphic address, South port, N. C.; Asst. Surg. William M. Bryan in command.

Sixty-nine vessels arrived at quarantine during the year, from the following places. Domestic, 3; West Indies, 7; Cuba, 4; Porto Rico, 2; South America, 15; Europe, 36, and Canada, 2.

Seven vessels were fumigated, of which 5 were for the destruction of rats, mosquitoes 1 , and vermin 1 .

In addition to the routine work of quarantine the medical officer at this station has, at request of the local authorities, rendered assistance in a smallpox epidemic which occurred in this vicinity, and has also given sanitary advice to the city officials concerning privies and water supply.

Georgetown (S. C.) quarantine.-Acting Asst. Surg. M. P. Moorer in charge. One steamer was inspected. This vessel carried 27 crew.

Charleston (S. C.) quarantine.-Passed Asst. Surg. R. L. Wilson in command. One hundred and sixty-nine steamers and 6 sailing vessels were inspected and passed. The vessels inspected carried a total of 124 passengers and 4,764 crew.

Beaufort (S. C.) quarantine.-Acting Asst. Surg. Christopher G. Hay in charge. Two steamers and 1 sailing vessel were inspected and passed.

Port Royal (S. C.) quarantine-Acting Asst. Surg. William P. Gibbes in charge. No vessels were inspected during the year.

Savannah (Ga.) quarantine.-Asst. Surg. C. M. Fauntleroy in command. One hundred and sixty-seven steamers and 6 sailing vessels were inspected and passed, and 1 steamer was inspected and detained. Thirty-four vessels were spoken and passed. The vessels inspected carried 5,531 crew and 11 passengers.

South Atlantic quarantine.- The station now in the custody of two quarantine attendants, all public property being stored and kept in readiness for immediate use in the event the station is required for refuge purposes during a quarantine emergency.

Brunswick (Ga.) quarantine.-Acting Asst. Surg. J. A. Moncure in charge. Forty-one vessels were spoken and passed; 28 steamers and 24 sailing vessels inspected and passed. One vessel was fumigated.

No quarantinable diseases were encountered during the year.

Tampa Bay (Fla.) quarantine.-Post-office address, Fort De Soto, Fla. Telegraphic address, via Palmetto, Fla. Asst. Surg. Richard $\mathrm{H}$. Lyon in command.

One vessel was spoken and passed, 139 steamers and 93 sailing vessels were inspected and passed, and 26 steamers and 2 sailing vessels were disinfected. These vessels carried a total of 62 passengers and 6,077 crew.

Cumberland Sound quarantine.-Post-office and telegraphic address, Fernandina, Fla. Acting Asst. Surg. J. Louis Horsey in charge. Eighty-eight vessels were spoken and passed, 110 steamers were inspected and passed, and 25 sailing vessels were inspected and passed. On these vessels there were 4,079 passengers and crew.

St. Johns River quarantine.-Post-office and telegraphic address, Mayport, Fla. Acting Asst. Surg. Neil Alford in charge.

One hundred and three vessels, carrying 1,588 passengers and crew, were inspected, and 240 vessels were spoken and passed. 
Biscayne Bay quarantine.-Post-oflice and telecraphic ardross, Miani, Fla. Acting Asst. Surg. Jannes M. Jackson, jr., in charere.

Two hundred and nincty-live vessels were spokent and passed; 33 steamers and 100 sailing vessels were inspected and passed. These vessels carried a total of 1,463 passengers and crew.

Key West (Fla.) guarantine.-Acting Asst. Surg. S. 1). W. Light in charge.

During the year 60 sailing ressels, carrying crews aggregating 517 and 290 passengers, and 392 steam vessels with crews numbering 21,521 and 20,311 passengers, were inspected and passed.

One steam vessel, fron Progreso, Mexico, was held in quarantine to complete 6 days from date of fumigation and no quarantinable diseases were encountered during the year.

In the past this has been an inspection station only, with no facilities for the isolating or treating of such quarantinable diseases as might be met with, but a montl ago the steamer Wistaria was sent to this port, and after certain much needed repairs have been completed a limited number of persons can be isolated and treated aboard this barge. The station is equipped with a steam disinfecting chamber and a 36-foot boarding launch, and the personnel of the station consists of one acting assistant surgeon and three attendants.

Boca Grande quarantine.-Post-office and telegraphic address, South Boca Grande, Fla. Acting Asst. Surg. G. E. Atwood in charge.

Transactions at the Boca Grande Quarantine Station for the fiscal year ending June 80 , 1912.

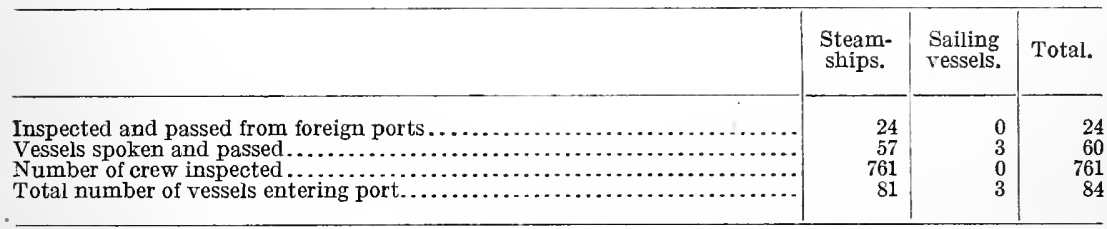

No quarantinable disease was encountered, only 1 vessel having been fumigated or detained.

Pensacola (Fla.) quarantine.-Acting Asst. Surg. W. Barnes in charge.

During the year 212 vessels were boarded and passed, 1 vessel was spoken and passed, 84 steamers were inspected and passed, and 23 vessels were disinfected; 128 sailing vessels were inspected and passed. On these vessels there were $5,400 \mathrm{crew}$ and 22 passengers. No cases of quarantinable disease occurred.

St. George Sound quarantine.-Post-office and telegraphic address, Carrabelle, Fla. Acting Asst. Surg. B. B. Blount in charge.

Twenty-two vessels, carrying crew aggregating 282 persons, were inspected and passed.

Port Inglis (Fla.) quarantine.-Acting Asst. Surg. B. W. Burland in charge.

During the year 18 steamers and 6 sailing vessels were spoken and passed; 18 steamers were inspected and passed. The 18 steamers inspected carried 544 crew. 
Mobile (Ala.) quarantine.-Passed Asst. Surg. L. D. Fricks in command.

The following is a summary of the vessels entering Mobile quarantine during the year, with the persons on board and their disposal:

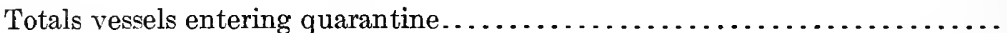

Sailing vessels.

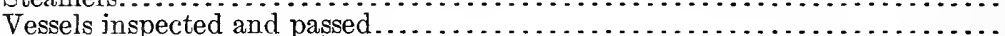

Vessels fumigated.

Vesels deta

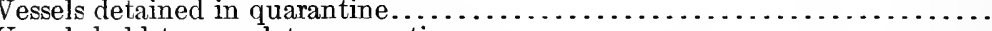

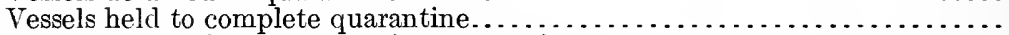

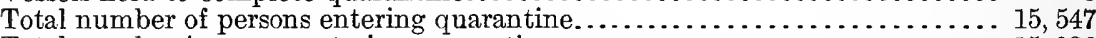

Total number in crews entering quarantine ..................... 15, 026

Total number of passengers entering quarantine................... ${ }_{521}$

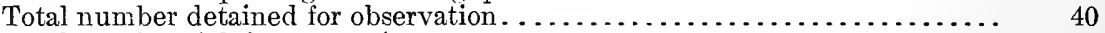

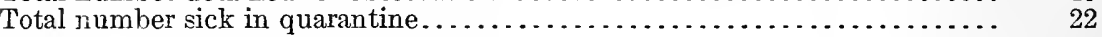

Pascagoula (Miss.) quarantine.-Acting Asst. Surg. B. F. Duke in charge.

One steamer and 91 sailing vessels were inspected and passed. These ressels carried 957 passengers and crew.

Gulf quarantine station.-Post-office and telegraphic address, Biloxi, Miss. Passed Asst. Surg. E. A. Sweet in command.

\section{Summary of transactions.}

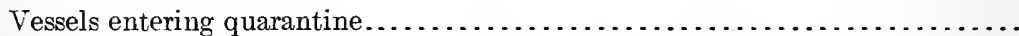

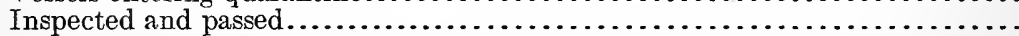

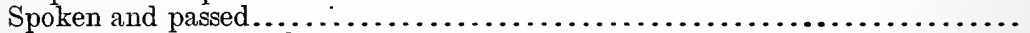

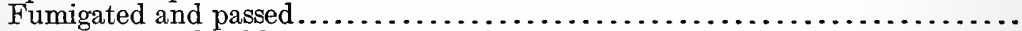

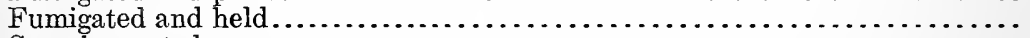

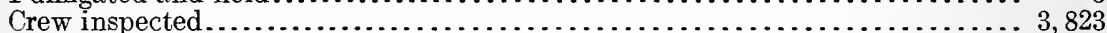

Passengers inspected............................................ 54

New Orleans quarantine.-Post-office address, Quarantine, La.; telegraphic address, via New Orleans, La. Passed Asst. Surg. G. M. Corput in command.

\section{General summary of transactions.}

Total number of ships...................................... 1, 387

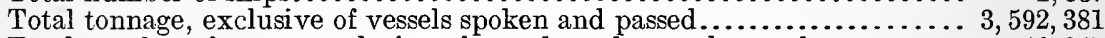

Total number of crews, exclusive of vessels spoken and passed............ 46,047

Total number of passengers, exclusive of vessels spoken and passed........ $\quad 11,456$

Total vessels fumigated....................................... 100

Total number of vessels on which temperatures were taken............ 692

Total number persons temperature taken....................... 30,293

Sick treated in hospital................................... 3

San Diego (Cal.) quarantine.-Acting Asst. Surg. W. W. McKay in charge.

Three hundred and thirty-five steamers and two sailing vessels were inspected and passed. Three vessels were fumigated. These vessels carried crews aggregating 7,197, and 4,240 passengers.

Port Harford, Cal.-Acting Asst. Surg. C. J. McGovern reports as follows: Forty-one steamers, carrying 1,584 crew, were inspected during the fiscal year. No quarantinable diseases were observed.

San Francisco (Cal.) quarantine.-Passed Asst. Surg. M. W. Glover in command. 


\begin{tabular}{|c|c|c|c|c|c|c|c|c|c|c|c|c|c|}
\hline \multirow{3}{*}{ Month. } & \multicolumn{6}{|c|}{ Vessels. } & \multicolumn{2}{|c|}{ From- } & \multicolumn{5}{|c|}{ I'rsennirt. } \\
\hline & \multicolumn{2}{|c|}{ 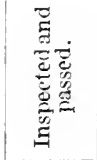 } & \multicolumn{2}{|c|}{ 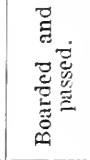 } & 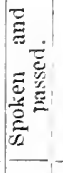 & \multirow{2}{*}{ 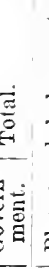 } & \multirow{2}{*}{ 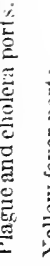 } & \multirow{2}{*}{ | } & \multicolumn{2}{|c|}{ Crew. } & \multicolumn{2}{|c|}{ Passengers. } & \\
\hline & 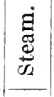 & $\dot{\overrightarrow{7}}$ & & 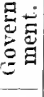 & 离 & & & & $\frac{\stackrel{\Xi}{\Xi}}{\frac{\Phi}{U S}}$ & $\overline{\widetilde{Z}}$ & $\underset{\mathscr{S}}{\stackrel{\Xi}{\tilde{E}}}$ & $\overline{\overline{\bar{J}}}$ & \\
\hline 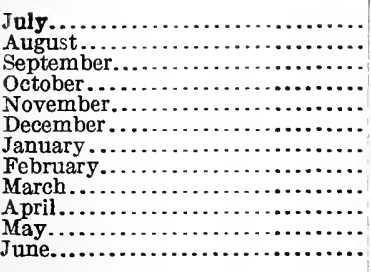 & $\begin{array}{l}40 \\
34 \\
50 \\
38 \\
36 \\
32 \\
37 \\
34 \\
33 \\
30 \\
36 \\
30\end{array}$ & $\begin{array}{r}7 \\
11 \\
41 \\
16 \\
11 \\
12 \\
8 \\
4 \\
9 \\
6 \\
8 \\
11\end{array}$ & $\begin{array}{l}6 \\
4 \\
4 \\
5 \\
4 \\
5 \\
4 \\
3 \\
5 \\
4 \\
4 \\
1\end{array}$ & $\begin{array}{c}2 \\
1 \\
1 \\
1 \\
1 \\
\cdots \\
\cdots\end{array}$ & \begin{tabular}{|c|c|}
$\cdots$ & \\
1 \\
$\cdots$ \\
$\cdots$ \\
$\cdots$ \\
$\cdots$ \\
$\cdots$ \\
$\cdots$ \\
$\cdots$ \\
$\cdots$
\end{tabular} & $\begin{array}{l}55 \\
50 \\
97 \\
61 \\
52 \\
49 \\
49 \\
41 \\
49 \\
42 \\
50 \\
44\end{array}$ & $\begin{array}{l}27 \\
26 \\
33 \\
23 \\
28 \\
26 \\
24 \\
25 \\
28 \\
25 \\
38 \\
28\end{array}$ & \begin{tabular}{r|r}
13 & \\
7 & \\
11 & \\
9 & 10 \\
9 & \\
13 & \\
8 & \\
11 & 7 \\
6 & \\
8 &
\end{tabular} & $\begin{array}{l}3,648 \\
2,753 \\
3,931 \\
3,378 \\
2,, 840 \\
2,667 \\
2,973 \\
3,381 \\
3,3827 \\
2,957 \\
4,007 \\
2,661\end{array}$ & $\begin{array}{r}101 \\
232 \\
2,628 \\
540 \\
352 \\
202 \\
117 \\
64 \\
148 \\
82 \\
146 \\
153 \\
\end{array}$ & $\begin{array}{l}3,907 \\
3,191 \\
3,565 \\
3,606 \\
3,151 \\
1,969 \\
3,137 \\
2,260 \\
2,815 \\
4,074 \\
2,898 \\
3,504\end{array}$ & $\begin{array}{r}2,594 \\
56 \\
5 \\
5 \\
3 \\
1 \\
3 \\
\cdots \\
\cdots \cdots \\
6\end{array}$ & $\begin{array}{l}\cdots . . \\
\cdots \cdots \\
\cdots \cdots \\
\cdots \cdots \\
\cdots \cdot \\
\cdots \cdot \\
\cdots \cdot \\
\cdots \\
4 \\
\end{array}$ \\
\hline 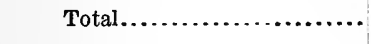 & 430 & 144 & 49 & 14 & 20 & 639 & 3311 & 112 & 38,223 & 4,765 & 38,077 & 2,673 & \\
\hline
\end{tabular}

VESSELS WITH QUARANTINABLE DISEASES ABOARD.

The American steamship Hanalei, plying regularly between San Francisco and San Pedro, Cal., arrived at the latter port January 6 ; 1912. After the passengers had been landed it was discovered that one of them had varioloid. The quarantine officer at San Pedro disinfected the stateroom occupied by this passenger and the vessel was directed to report to the San Francisco quarantine station.

On arrival at San Francisco the personnel was examined, 7 vaccinated, and the quarters disinfected. The vessel was then given pratique.

The United States Army transport Sherman arrived at this port April 14, 1912, with 4 Filipino messboys ill with smallpox. Three were cases of varioloid, while the fourth was a well-marked case of variola in pustular stage.

The Sherman left Manila March 15, and, arriving at Nagasaki March 20, sailed from there March 22. She reached Honolulu April 5 and sailed the same day for San Francisco. These cases were discovered April 11, six days out from Honolulu. From the history the first case to develop felt ill April 9. The disease seemed to have been contracted in Nagasaki.

As soon as discovered these cases were isolated in the ship's hospital and the contacts isolated in their quarters.

Upon inspection every precaution of isolation and vaccination. was found to have been taken, and, no further cases having developed, it was deemed safe to allow the vessel to disembark her passengers after removing the sick and contacts to the quarantinestation. The quarters occupied by these were sealed up and disinfected with formaldehyde, the seals to be undisturbed until the vessel be fumigated with $\mathrm{SO}_{2}$. This latter was done April 20.

The contacts were taken to the Angel Island station and bathed and their clothing and baggage disinfected. All were found to have- 
vaccination marks, old or recent. They were returned to the ship. The sick were held at the station until recovered.

Alaskan vaccination.-During the year, between March 15 and June 13, 1912, 45 vessels departing for Alaska were boarded, 6,485 crew examined, and 106 vaccinations performed.

Eureka, Cal.-Acting Asst. Surg. Charles C. Falk reports that during the year 13 steamers and sailing vessels were inspected and passed.

Los Angeles (Cal.) quarantine station and subports.-Surg. S. D. Brooks in command. This station includes three ports for quarantine inspection of vessels - San Pedro, Redondo, and Santa Barbara (including Gaviota).

Transactions.

\begin{tabular}{|c|c|c|c|c|c|}
\hline$\cdot$ & $\begin{array}{l}\text { Steamers } \\
\text { inspected. }\end{array}$ & $\begin{array}{c}\text { Sailing } \\
\text { vessels } \\
\text { inspected. }\end{array}$ & $\begin{array}{c}\text { Total } \\
\text { vessels } \\
\text { inspected. }\end{array}$ & $\begin{array}{c}\text { Vessels } \\
\text { fumigated. }\end{array}$ & $\begin{array}{l}\text { Total } \\
\text { passengers } \\
\text { and crews } \\
\text { inspected. }\end{array}$ \\
\hline 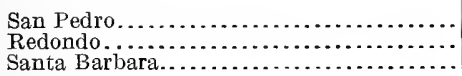 & $\begin{array}{r}80 \\
7 \\
1\end{array}$ & $\begin{array}{l}5 \\
3 \\
9\end{array}$ & $\begin{array}{l}85 \\
10 \\
10\end{array}$ & & $\begin{array}{r}4,065 \\
305 \\
190\end{array}$ \\
\hline
\end{tabular}

No quarantinable disease was found during the year.

Port Townsend (Wash.) quarantine and subports.-Passed Asst. Surg. Baylis H. Earle in command.

One steamer was spoken and passed, 165 steamers were inspected and passed and 5 detained, and 99 sailing vessels were inspected and passed and 3 detained. The steamers carried a total of 14,768 members of crews and 11,767 passengers, and the sailing vessels a total of 1,279 members of crews and 57 passengers. Of the vessels detained 4 steamers and 2 barks were fumigated for the destruction of rats and other vermin.

Coos Bay (Wash.) subport, North Bend.-Acting Asst. Surg. I. B. Bartle reports 1 sailing vessel inspected and passed.

South Bend (Wash.) subport.-Acting Asst. Surg. Wilson Gruwell reports 2 sailing vessels inspected and passed.

Port Angeles (Wash.) subport.-Acting Asst. Surg. F. S. Lewis. Columbia River (Oreg.) quarantine and subports.--Post-office and telegraphic address, Astoria, Oreg. Passed Asst. Surg. J. M. Holt in command.

During the year 37 steamers and 61 sailing vessels were inspected and passed. These vessels carried 4,400 passengers and crew.

Two vessels were in quarantine during the year on account of smallpox.

During the Astoria centennial celebration of August, 1911, the U. S. S. Hopkins was disinfected on account of diphtheria at the request of the naval officer commanding.

Preparations for the opening of the Panama Canal are being made. After that time the shipping at the Columbia River will unquestionably show a marked increase, and adequate equipment of its only quarantine station should be accomplished before that event.

Ketchikan, Alaska.-Acting Asst. Surg. Henry C. Story reports as follows: 24 vessels were inspected and passed together with 11,469 passengers and crew. 
TEXAS-MEXICAN BORDER INSPECTION.

El Paso, Tex.-Acting $\Lambda$ sst. J. W. Tappan reports that during the year 12,000 passengers arriving on trains were inspected, and in addition 36,000 aliens were examined at the immigration station; 2,383 vaccinations were performed.

Brownsville, Tex.-Acting Asst. Surg. G. D). Fairbanks reprorts no transactions during the fiscal year.

Approximately 50 vaccinations against smallpox have been made during the last few montlis.

Eagle Pass, Tex.-Acting Asst. Surg. Lea Hune reports that during the year 10,743 passengers were inspected.

Laredo, Tex.-Acting Asst. Surg. H. J. IIamilton reports that during the year 735 passenger trains entering from Mexico, carrying 44,344 passengers, wore inspected; 21,523 aliens entering from Mexico via railroad, ferry, and footbridge were inspected; 809 persons entering from Mexico were vaccinated upon cntry. T'le death and embalming certificates, together with the containers for 10 cadavers, were inspected; 1 corpse for reason of condition of cadaver and container and distance to be traveled in the United States was ordered re-treated and placed in hermetically-sealed container.

Vaccine sent by the bureau was distributed to county health officers of Presidio and Starr Counties, Tex., and to county judges of Starr and Zapata Counties, Tex., for emergency, to prevent spread of smallpox. One leper was refused entry; disease was typical, and had existed about eight years; he was a Mexican from the State of Guanajuato, Mexico. The stools of 12 persons were examined for ova uncinariæ with negative results.

An inspection of the lower Rio Grande River, including Mexican and United States territory, was made during the month of September for reason of an epidemic of smallpox which prevailed during the winter and spring months; last case was discharged in Starr County, Tex., on August 1, 1911; Starr County had 150 recorded cases; district of Camargo, Mexico, over 400 cases; Starr County appears to have received infection from Mexico and from Hidalgo County, Tex.; district of Camargo, Mexico, claims to have been infected by persons from Texas, returning from the cotton fields in the fall of 1911; Reynosa, Mexico, had 10 recorded cases; County of Hidlalgo, Tex., 65 recorded cases; Cameron County, Tex., over 400 recorded cases from 2 foci, 1 from Gonzales County, Tex., and 1 from San Fernando, Mexico, a place about 40 miles south of Cameron County, in Mexico; Matamoras, Mexico, had no record of cases, but unofficially had a few cases.

No doubt many cases were not recorded, but epidemic was very mild; practically no deaths.

69450-H. Doc. 971, 62-3-3-6 
Table giving transactions at national quarantine stations for the fiscal year ending June $30,1912.1$

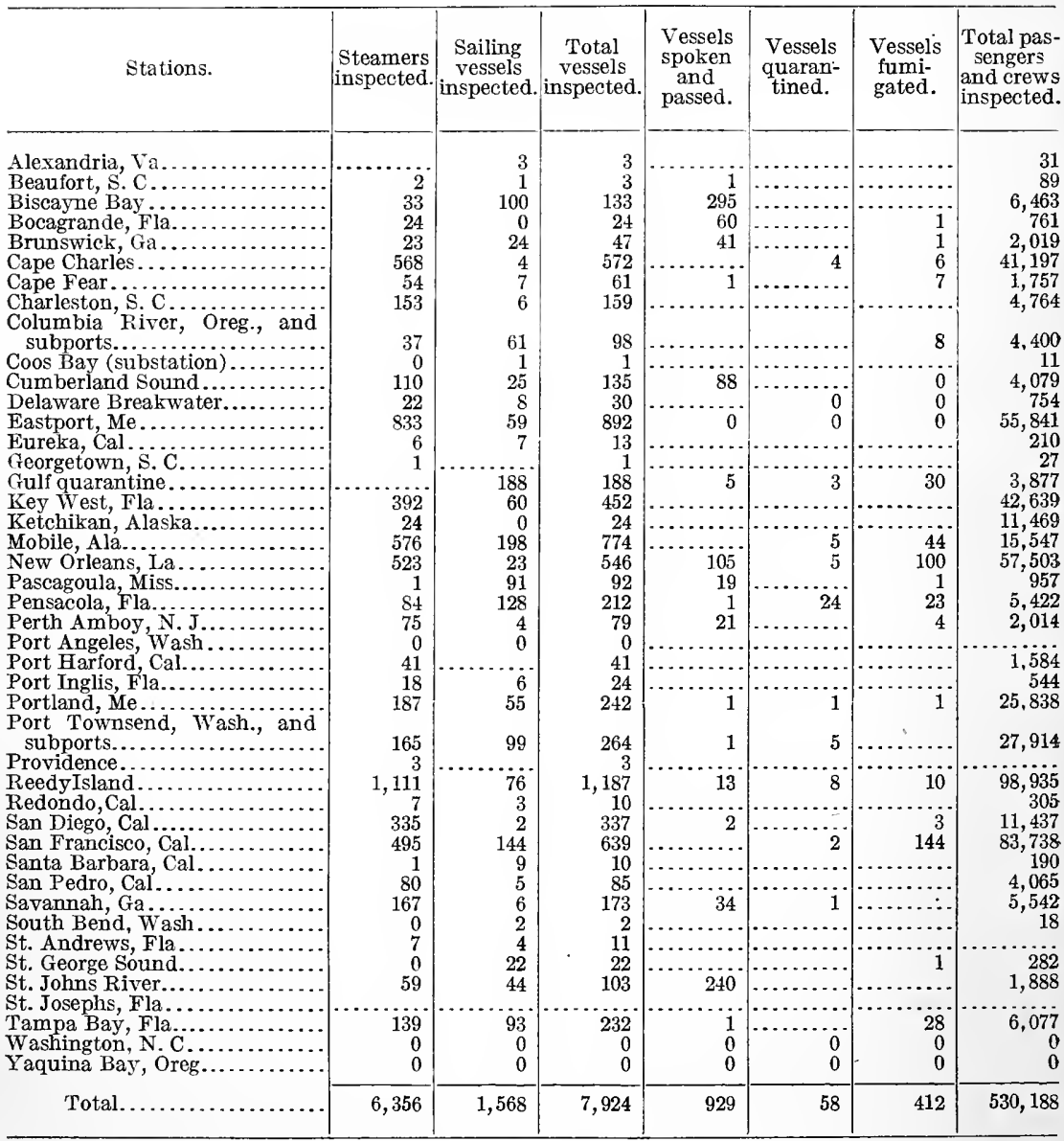

1 A number of the smaller stations at which there were no transactions are omitted from this table.

Table giving foreign, oriental, and insular stations and transactions for fiscal year ended June 30, 1912.

\begin{tabular}{|c|c|c|c|}
\hline Stations. & $\begin{array}{c}\text { Total } \\
\text { number } \\
\text { of vessels } \\
\text { inspected. }\end{array}$ & $\begin{array}{c}\text { Number } \\
\text { of vessels } \\
\text { fumi- } \\
\text { gated. }\end{array}$ & $\begin{array}{l}\text { Total num- } \\
\text { ber of pas- } \\
\text { sengers and } \\
\text { crews in- } \\
\text { spected. }\end{array}$ \\
\hline 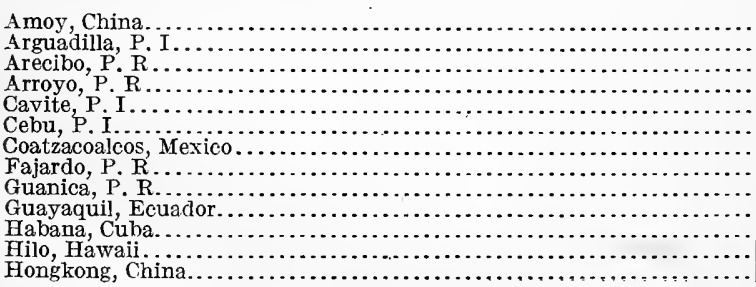 & $\begin{array}{r}45 \\
8 \\
10 \\
7 \\
7 \\
55 \\
154 \\
30 \\
5 \\
69 \\
986 \\
32 \\
443\end{array}$ & $\begin{array}{r}0 \\
0 \\
0 \\
2 \\
0 \\
59 \\
15 \\
0 \\
0 \\
57 \\
0 \\
43 \\
103\end{array}$ & $\begin{array}{r}4,612 \\
209 \\
713 \\
31 \\
1,506 \\
3,248 \\
8,163 \\
244 \\
119 \\
7,733 \\
94,347 \\
1,254 \\
73,798\end{array}$ \\
\hline
\end{tabular}




\begin{tabular}{|c|c|c|}
\hline $\begin{array}{c}\text { Total } \\
\text { number } \\
\text { of vessel } \\
\text { ins pecter. }\end{array}$ & $\begin{array}{l}\text { Number } \\
\text { of vessels } \\
\text { fimi- } \\
\text { gaterl. }\end{array}$ & $\begin{array}{l}\text { Total nim- } \\
\text { ber of pas- } \\
\text { sengers and } \\
\text { erews in- } \\
\text { specterl. }\end{array}$ \\
\hline 373 & 11.5 & 127,854 \\
\hline 11 & 2 & \\
\hline 103 & 120 & 9,513 \\
\hline 16 & 0 & 1,721 \\
\hline 16 & 0 & 402 \\
\hline 276 & 41 & 69,164 \\
\hline 0 & 0 & \\
\hline 162 & & 7,603 \\
\hline 3 & 0 & \\
\hline $\begin{array}{r}27 \\
3\end{array}$ & 2 & 82,185 \\
\hline $\begin{array}{r}3 \\
13\end{array}$ & 0 & $\begin{array}{r}52 \\
143\end{array}$ \\
\hline 943 & 391 & 166,025 \\
\hline 88 & 4 & 8,710 \\
\hline 275 & $\cdots$ & 181,956 \\
\hline 168 & 11 & 18,717 \\
\hline 79 & 41 & 4,219 \\
\hline 255 & 32 & 34,913 \\
\hline 153 & 25 & 37,092 \\
\hline 29 & 12 & 3,390 \\
\hline 318 & 68 & 80,799 \\
\hline 35 & 0 & 3,985 \\
\hline 5.203 & 1,143 & $1,033,619$ \\
\hline
\end{tabular}

IIonolulu, II awaii.

Humacao, P. R.....

Jloilo, P. I

Kahului, Hawai

Kobe, Japan

Koloa, Kauai, Hawaii.

La Guaira, Venezuela.

Lahaina, Maui, Hawaii

Llbau, Russia.

Mahukona, Hawaii

Manila, P.I.

Mayaguez, P.

Naples, Italy.

Ponce, P. R.

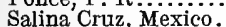

San Juan, P. R..

Vera Cruz.

Yokohama, Japan

Zamboanga, P. I.

Total

\section{Insular Quarantixe.}

OPERATIONS OF THE SERVICE IN THE PHILIPPINE ISLANDS.

GENERAL.

The year has been characterized by two most important developments concerning the detection of plague and cholera at quarantine. The experience in connection with cholera confirms the bacilli-carrier work done and the deductions made in the Manila outbreak in 1908 with regard to the importance of the cholera carrier in spreading the disease. It will be remembered that the Philippine observations were further confirmed in the experience of service officers stationed in Italy during 1910 , and last year by the quarantine practice which was adopted at New York, Boston, and other ports in order to prevent the introduction of cholera into the United States. These two subjects will be discussed more in detail under the heads of "Cholera" and "Plague."

\section{CHOLERA.}

It has long been surmised that cholera was perhaps frequently brought into the Philippine Islands and that many outbreaks of this disease were due to fresh importations. In view of the very careful quarantine inspection which was made of all persons entering the isiands from cholera-infected districts, it was believed to be reasonable to infer that cholera was not brought here by persons in the active stage of the disease. It has, however, repeatedly been pointed out that outbreaks of cholera in Manila often started among Japanese and that no satisfactory reason for this could be advanced. After the experience had with cholera carriers in Manila in 1908 and the 
cases that were found at the New York quarantine last year, it was believed to be advisable to make examination of the stools of at least the steerage passengers that came into the islands from places that are cholera infected or suspected of being infected. On account of the fact that such passengers since April 9, 1912, have been required to undergo a seven-days' quarantine on account of plague before entering the islands, there has been an excellent opportunity to make stool examinations in order to ascertain whether any cholera vibrios could be found. On account of the infrequency with which cholera. occurs among Chinese, it was assumed that these examinations among them would probably prove negative in so far as the cholera vibrio was concerned. In view of the foregoing, it is interesting to note that the five hundred and firty-seventh person examined showed active cholera vibrios and that the person from whom they were recovered was apparently in excellent health. The diagnosis was thoroughly confirmed by experienced laboratory workers in the Bureau of Science. The organisms agglutinated in dilutions of 1:5200 with cholera serum. The case occurred in a Chinese steerage passenger, who had a history of having left Canton five days previously.

On account of the fact that, so far as known, the Philippine Islands are entirely free of cholera, it was of the greatest importance that these cases were prevented from entering the islands.

In view of the Philippines experience, and on account of its confirmation in both Europe and America, it is proposed in the future to make the examination of stools, at least of steerage passengers, a routine procedure whenever there are cases of cholera in the countries from which such passengers come.

\section{PLAGUE.}

Service officers were fortunate enough to detect insidious cases of pneumonic plague which occurred upon vessels arriving from Hongkong and Shanghai. The first case occurred on November 4, 1911, on the British steamer Montrose at Cebu. The second case was detected on April 2, 1912. The British steamer Loongsang arrived in port from Hongkong after a voyage of 72 hours. The master of the vessel reported that 36 hours before reaching Manila a Chinese quartermaster dropped over dead. Twelve hours prior to his death he was reported to have complained of a pain in the lower part of his chest at the site of an injury which he had received some years before, but no special significance was attached to his illness. On account of pneumonic plague being suspected the body was immediately sent to the San Lazaro contagious morgue for autopsy. The gross anatomical findings were practically negative, with the exception of a congestion of the lower lobes of the lungs and inflammation of the bronchii. Smear preparations taken from the bronchii, however, showed bacilli suspicious of plague. A thorough laboratory examination was then begun, with the result that plague organisms were positively identified and the diagnosis of pneumonic plague confirmed.

On April 4 the steamer Zafiro arrived from Hongkong and, owing to the experience had with the steamer Loongsang, a very careful examination was made of all persons on board, but no signs of quarantinable disease could be detected. The history of the vessel showed that immediately prior to its departure from Hongkong it was 
fumigated throughout with sulphur under the direction of Surg. B. W Brown. On the morning of $\Lambda$ pril 6 a death in the person of a C'hinaman, who was the cook for the ('hinese crew, was reporterl. On investigation, it was ascertained that this cook had prepared the evening meal on April 5 and was seen about the deck between 9 and 10 o'clock that evening. On account of there being delay in serving the usual 5.30 a. m. breakfast for the crew on April 6 a search was made for the cook and he was discovered in lis bunk dead. Before 6 a. m. his body was already cold, and well-marked rigor mortis had set in. Careful examination failed to reveal any enlargenent in any of the palpable lymphatic glands. 'The body was immediately sent to the morgue for autopsy. The only gross pathological changes encountered were moderate edema of the lower lobes of the lungs. Smear preparations made from the spleen showed a bipolar staining organism. On the evening of April o the laboratory madc a positive diagnosis of pneumonic plague.

The British steamer Trisang arrived at the Mariveles quarantine station at 6.30 a. m. on 1 pril 30, 1912. The entire personnel was carefully examined, and, with one cxception, no case of sickness of a suspicious nature was encountered. Seventy-three passengers were detained. Of these, one, Co Sing: aged 51, Chinese, had a temperature of 38.9 and a pulse of 100 and a few indefinite symptoms which might be associated with the symptoms of pneumonia. He was isolated from the beginning, but strenuously objected to this, because he stoutly maintained that he was not sick. Up until May 6 he ran an irregular temperature, which oscillated between 38.6 and 39.8 . A careful physical examination was made of his lungs night and morriing, but no physical signs of disease were detected. On May 5 he expectorated a small quantity of blood. Smears of this were made, but no suspicious organisms were found. On the morning of May 6 his temperature suddenly dropped, and a slight enlargement of the glands in the right axilla was noted. By $5 \mathrm{p} . \mathrm{m}$. the axillary glands had increased considerably in size, the right side of the neck was swollen and tender, there was pain upon pressure in the right groin. Patient then stated that he felt very ill. Before midnight the palpable glands throughout the body were considerably increased in size. The physical signs of broncho-pneumonia were well marked. At 7 o'clock on the morning of May 7 the patient died. The autopsy and the subsequent laboratory examinations made by the bureau of science fully established the diagnosis of pneumonic plague.

From the foregoing it is evident that the cases on the steamers Loongsang and Zafiro must have been similar to the case at the Mariveles quarantine station. It is also apparent that we are dealing with a heretofore unreported manifestation of plague and that only the very greatest vigilance affords any reasonable hope that the introduction of plague into the Philippines by such cases can be avoided.

PLAGUE IN MANILA.

After an absence of six years in human beings and five years among rats plague was again found in the Philippine Islands on June 19 . A Filipino employed as a watchman at No. 235 Calle San Jacinto, in the Chinese district, who resided at No. 920 Calle Antonio Rivera, was found dead at his home on the date mentioned above after an 
illness of about three days. On post-mortem examination typical plague buboes were found in the right groin and axilla. Smears made from the spleen showed gram negative bipolar staining organisms, and inoculations made into guinea pigs resulted in typical attacks of plague. The organism which was recovered from the guinea pigs agglutinated plague serum in high dilutions. The source of infection is unknown. The nearest known focus of plague is at Hongkong, and there is no evidence to show that this man had been out of the country during the past few years. Test examinations of rats caught in the different districts of Manila, particularly those from importers' warehouses, have been made at weekly intervals throughout each year since 1907 and have always proved negative. Houses in the vicinity of which the man resided and where he worked showed evidences of rat infestation, but an examination made of many hundreds of rats that were caught there failed to reveal any plague infection, nor was there any history of unusual rat mortality having occurred anywhere in Manila.

The second death occurred on June 26 in the person of a Filipino woman, aged 44 years, of No. 1615 Calle Azcarraga, near the Arranque Market. She was found alive in her house and had been ill for three days. At the time she was transferred to the San Lazaro plague hospital she had a temperature of $41^{\circ} \mathrm{C}$., and was in a dying condition. The autopsy showed slightly enlarged glands of the left groin, but the other usual autopsy findings of plague were conspicuous by their absence. Smear preparations made from the glands of the groin and from sections of the spleen showed gram negative bipolar staining bacilli. Inoculations made into guinea pigs . produced typical attacks of plague, and the recovered organisms agglutinated with plague serum. This woman, from reliable evidence, had also not been out of the Philippine Islands during the past few years. At a near-by food store, where the woman is known to have purchased her food supply, four dead rats were found. These were taken to the bureau of science for diagnosis, but the post-mortem and inoculation experiments have proven negative.

The mortality rate for the city is rather below the normal, from which fact it may be inferred that no unrecognized cases are occurring.

Three rat-catching gangs have been put to work with the object of catching as many rats as possible in the vicinities in which the patients died and from other sections which are considered suspicious. So far all of the rats found have proven negative. From the foregoing it is evident that there are no reliable data with regard to the origin of the disease. From our present knowledge it would seem most likely that the disease must have been introduced by infected fleas, although, in view of the recent cases reported by McCoy in Hawaii and by observers in India, food infection should not be completely disregarded. If the disease was introduced by infected fleas it would seem most likely that they reached here on sick rats which came in cargo, like crates of onions or potatoes, baskets of eggs, garlic, fruit, or similar foodstuffs, which arrive almost daily in large quantities from China, Japan, and other plague-infected countries. Rats have actually been observed in such cargo, and it would not be at all impossible for an infected rat to have been introduced in this way.

The officers of the Public Health and Marine-Hóspital Service located in Hongkong and in Manila have long since recognized the 
danger of introducing plague in this way, but up to the present time it has been impossible to devise a practical method for cntirely eliminating the danger from the introduction of rats in this manner without placing prohibitory restrictions upon commerce. The theory of the introduction of the plague by means of food is slightly supported by the fact that at the autopsy of the first case ulcerated tonsils were found, but as no cultures were taken it is impossible to submit anything definite under this head.

\section{MEASLES.}

During the year a most severe epidemic of measles occurred in the Philippine Islands, which was more or less directly traceable to importations from the United States. In Manila and vicinity 534 cases and 23 deaths were reported. In view of the fact that the outbreaks of measles which occurred during the past 10 years in the Philippines have been very mild in character, with no mortality, the severe type of the disease which was imported naturally gave rise to considerable concern to the insular health officials. Upon a request of the bureau of health the quarantine service is now handling vessels with measles on board in the same manner as the regular quarantinable diseases.

SMALLPOX.

From a quarantine standpoint the constant presence of smallpox in more or less epidemic form in many of the near-by foreign ports with which the Philippines are in frequent and direct communication is a constant source of anxiety. The responsibility for the importation of fresh smallpox infection increases as the islands become more and more free from smallpox. During the severe epidemic in Hongkong in February and March, 1912, all persons arriving from that port were vaccinated before being allowed to land in the Philippines.

Smallpox was present on 13 vessels on arrival. The usual treatment was given each vessel and its personnel, and no further cases occurred.

LEPROSY.

Twelve vessels were disinfected, either wholly or in part, during the year on account of having had lepers on board. Only 3 lepers arrived on vessels from foreign ports; 1 was a passenger in transit for a foreign port, and was permitted to depart with the vessel, properly isolated; the other 2 were transferred to the San Lazaro Hospital.

\section{INSPECTION OF ARRIVING VESSELS.}

On account of the fact that the ports of the Philippine Islands are a great crossing place for vessels passing north, and south, east and west, and vice versa, and as these vessels practically always touch at the world's greatest infected centers, the importance of the Philippines from a quarantine standpoint will be readily apparent. Not only is the quarantine service there an important factor in guarding against the introduction of quarantinable diseases into the Philippines, but it is an important factor in aiding to prevent the introduction of quarantinable diseases on the Atlantic and Pacific seaboards of the United States. 
The United States Quarantine Laws and Regulations, with which all these vessels comply, can scarcely help but be of the greatest influence for improving the world's sanitation.

At Manila, 958 vessels arrived during the year that were inspected. At Iloilo, 84 were inspected, and at Cebu, 47. Vessels from foreign ports which made more than one Philippine port a port of call were inspected only at the first port of call.

VESSELS DISINFECTED.

During the year, 62 vessels were disinfected at the several stations of the service for the following causes:

Plague-infected vessels. . . . . . . . . . . . . . . . . . . . . . . . . . . . . . 4

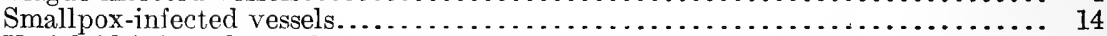

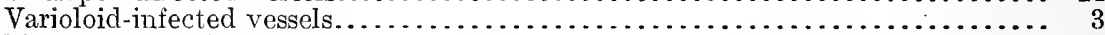

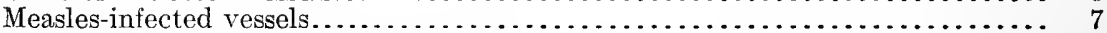

Vessels engaged in transporting lepers. . . . . . . . . . . .

Vessels having lepers as passengers................................... 8

Vessels disinfected for other causes. . . . . . . . . . . . .

That the disinfections and methods of treatment of infected vessels were effective is evidenced by no secondary case of quarantinable disease occurring among the persons on a vessel after the disinfection.

On the other hand, in cases when prompt quarantine treatment is not available, the difference is very clearly shown, as on the transport Warren, which, on arrival, had 3 cases of smallpox in isolation, 2 cases were found on inspection, and 10 cases developed shortly thereafter; a total of 15 cases of smallpox and varioloid on one vessel.

FUMIGATION OF VESSELS.

On account of the continuance of plague in foreign countries it is most necessary that the local shipping be kept free from vermin. The six months' rule was applied very rigidly, not only to the vessels in the interisland shipping, but also the launches engaged in bay and harbor work. In all, a total of 538 vessels were fumigated, for which 60,000 pounds of sulphur were used.

At Manila there were 345 vessels fumigated, as follows:

Large steamers............................................. 81

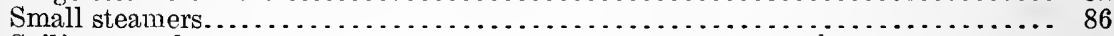

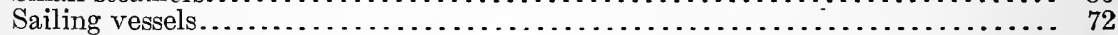

Seagoing lighters................................................... 9

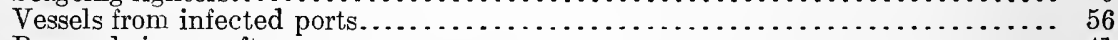

Bay and river craft ............................................. 41

At Iloilo there were 120 vessels fumigated; at Mariveles, 14; and at Cebu, 59.

The fumigations of vessels on account of actually having disease on board are not included in the above, but are classified among the disinfections.

It is believed that the fumigation work has been an aid to the general sanitation work being conducted in the Philippine Islands, and, in addition, it has promoted comfort aboard interisland vessels by destroying the vermin. It has also resulted in a vast saving to the owners of vessels and also to shippers, because great numbers of rats on a vessel are most destructive, and require a large amount of 
food for their maintenance, and considerable work and expense to repair the damage done. Rats are driven out of the ship's lifeluats by sprinkling them inside liberally with formalin before the fumigation of holds and compartments is started. The formalin is so irritating to the animals that they seldom fail to come out. The largest number of rats killed on any one vessel during the year was 176 .

MEDICAL 1NSPECTION OF IMMIGIANTS

All arriving aliens are subjected to the prescribed medical examination, in accordance with the immigration laws. On account of the fact that nearly all arriving Chinese are domiciled aliens and are not subject to the immigration restrictions, only such cases among them are examined as are brought to the attention of the qual'an tine officers by the immigration officials.

At the ports in the Philippines, the examination is made on board the vessel immediately after the quarantine inspection is concluded. Reexaminations are made as occasion requires at the immigrant detention stations. There were 3,132 arriving aliens examined, and 90 of these were certified as having defects which would affect their ability to earn a living, or as being afflicted with dangerous contagious diseases, principally trachoma.

This function occasions much arduous and annoying work, especially as protests and appeals are of constant occurrence. One special board was convened during the year to decide a contested case.

The countries represented in the certifications were Mexico 1, Russia 1, Turkey 4, Spain 2, China 5, Japan 52, and India 25.

VACCINATION.

The vaccination work was more extensive this year than any previous year. The work was carried on, first, for the prevention of smallpox among the crews of interisland vessels, and, secondly, for the prevention of the introduction of the infection of smallpox from the China coast.

Two methods are used - the use of scarifiers, and the use of a piece of gauze on the finger. This latter method is very satisfactory for women and children, who are thus vaccinated while they think you are just getting ready. Both methods show about equal results. The latter is less troublesome, because the constant sterilization of the scarifiers is eliminated, and there is no opportunity to charge that the scarification was done with hot instruments.

The city of Hongkong was visited by a most severe epidemic of smallpox during January, February, and March, 1912. For the protection of the Philippines, the following order was promulgated and was still in force at the close of the fiscal year:

All passengers arriving from Hongkong must be vaccinated before being permitted to land at ports in the Philippines. Cabin passengers, when inconvenient to be vaccinated on hoard the incoming vessel, can be vaccinated at the offices of the bureau of health or quarantine service. Each passenger, before being permitted to leave the vessel, shall register his or her name and bona fide residence address.

The vaccination of crews was continued during the year. Owing to some evasions of the rule to have every member of the crew vaccinated, a new order was issued April 9, 1912, calling attention, espe- 
cially of new masters and recently organized shipping firms, to the vaccination requirements, as follows:

In view of the fact that smallpox is again occurring among the crews of interisland vessels, attention is invited to the fact that this is caused by the officers of vessels disregarding the advice of this bureau by taking aboard new members of the crews who do not possess vaccination cards from the quarantine service. It has been the constant endeavor of this service to have every crew frequently vaccinated, and thus prevent the loss of time and expense of quarantine and disinfection. It is therefore urged that no new crews be employed every member of which does not possess a vaccination card. If a person, applying for a position on an interisland vessel, does not have a vaccination card, he should be sent to the quarantine office at once to be vaccinated before being allowed to go aboard. Your assistance and cooperation in this matter are necessary. The expense of disinfections of vessels due to failure to have crews vaccinated will hereafter be made a charge against the vessel.

During the year there were 4,737 members of crews vaccinated at Manila, 1,050 at Cebu, and 640 at Iloilo, or a total of 12,605 persons vaccinated by the service, of which number 5,500 were passengers, 6,427 were crew, and 678 local residents.

PLAGUE QUARANTINE AT MARIVELES.

At the opening of the fiscal year there were in quarantine at the Mariveles quarantine station 138 steerage passengers. The quarantine period at that time was sufficient time to aggregate seven days from the time of disinfection in Hongkong or Amoy, making practically four days at Mariveles. This quarantine continued until September 22,1911 , when it was discontinued.

Plague having again become epidemic in Hongkong and on the China coast quarantine was instituted against steerage passengers from Hongkong on April 6, and Amoy April 15, 1912. The quarantine imposed demanded a full seven days' stay at Mariveles. This was rendered necessary on account of the virulence of the epidemic and the nature of the plague encountered as demonstrated in the cases found on the Zafiro and Loongsang already mentioned.

Later in the season when the plague became pneumonic in character all persons who had lived in oriental quarters seven days prior to sailing from a plague-infected port were deemed liable to convey infection, and all such, irrespective of the class of ticket purchased, were held in quarantine for seven days after arrival at Mariveles.

Plague occurred among the passengers of the steamer Taisang while serving their seven days' quarantine.

During the quarantine in July, August, and September, 1911, there were 915 persons in quarantine; 138 were left over from the prior fiscal year, 777 entered quarantine, and 915 were released.

From April 6 to June 30, 1912, there were 1,670 persons who entered quarantine, 2 of these died, 1,601 were released, and 67 remain in quarantine at the end of the fiscal year. The latter number includes 1 cholera carrier.

\section{INTERISLAND QUARANTINE.}

Quarantine of vessels and their personnel between interisland ports, which in former years made up so large a part of the work of the quarantine officers, has been relegated to the past as a part of the insanitary period which, may it be hoped, will never return to the Philippines. With the exception of a few cases of smallpox, no occasion has arisen for the quarantine of vessels engaged in the 
interisland trade. Each vessel on arrival sends a certificate to the quarantine office stating the time of arrival, the ports of call, the number of persons on board, and whether any cases of suspicious illness has occurred on board during the preceding five days, and that the vessel is in a good sanitary condition. 'This latter statement is verified by inspection at some convenient time while the vessel is in port.

INSPECTIONS OF VESSELS IN PORT.

When the inspection of arriving interisland ressels was discontinued on account of the satisfactory conditions existing in the Philippines as regards quarantinable diseases, it was stated that inspection of such vessels while in port would be made at regular or irregular intervals, and that such vessels at all times were to be available for inspection with their crews. For the past three years this inspection has been conducted. Each ressel and its crew is inspected once while in port. The sanitary condition of the ressel is noted in a book kept for the purpose with columns for the condition of forecastles, latimes, galleys, bilges, etc., and at the same time inspection of the vaccination cards of the crew is made to ascertain if the vaccination rules are observed. This latter is made necessary for the reason that new crews for interisland vessels since the shipping strike are obtained almost entirely from the smaller provincial ports of call of the vessels and not at ports of entry.

RAT QUARANTINE.

The efforts of the quarantine officers have nerer been better employed than during the past year in the endearor to keep both interisland and foreign vessels making calls in the Philippines free from disease-carrying vermin. A total of 6,524 rats and mice were destroyed. It is believed that the number of rodents on ressels, due to the persistent periodical fumigation, is diminishing considerably every year. A blank form, printed in tour languages, is furnished every vessel fumigated, and the master is furnished an addressed envelope and urged to fill out the blank carefully after all animals killed are found, and then mail or send it to the quarantine office. In most instances the report is received, but many vessels leaving almost immediately after fumigation before the gas is out of the holds sufficiently to obtain a reliable count, frequently fail to forward the report, and the data are lost. The following were reported on the blanks, and since this represents only about 75 per cent of the vessels fumigated it is safe to infer that those vessels whose reports were not received had animals killed in the same proportion as those on which reports were made. The actual results would therefore be 33 per cent greater than that shown below:

\begin{tabular}{|c|c|c|c|}
\hline Animals destroyed. & Manila. & Iloilo. & Cebu. \\
\hline 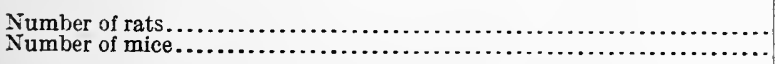 & $\begin{array}{l}3,411 \\
1,057\end{array}$ & $\begin{array}{l}692 \\
266\end{array}$ & $\begin{array}{r}1,056 \\
42\end{array}$ \\
\hline
\end{tabular}

This work during the year was accomplished without any antagonism on the part of shipowners or agents. Sulphur almost exclu- 
sively was used, by the pot method and by use of a sectional burner - designed by the Manila office.

In carrying on the rat quarantine in accordance with paragraph 112 of the regulations the same difficulty was encountered this year as heretofore with regard to many of the large vessels not being empty at Philippine or other oriental ports and only empty at ports in the United States. During the year not one of such vessels was noticed which had been fumigated at the United States port where the vessel had been entirely empty. It was understood that paragraph 112 applied particularly to such vessels at American ports.

The records show that 80 vessels coming under this class were fumigated at the several ports of the Philippines, and that the six-months rule was rigidly enforced; in fact, that vessels coming from infected ports were fumigated every time they were empty if loading cargo for the United States. Arrangements were also made for many fumigations abroad, particularly in England, at the ports of which country a number of vessels are empty that are never empty at Philippine ports, but are empty at ports of Puget Sound, and that always call at a number of infected ports on their voyage.

BILLS OF HEALTH.

The subject of bills of health as required by the United States Quarantine Laws and Regulations continues to be as little understood by the general issuing offices as heretofore. Consular officers and those charged with the issuance of bills of health very frequently issue a supplemental when there is no original in existence to supplement. The recommendation made in 1910 that only one blank form, embodying the features of both original and supplemental, be prescribed is still believed to be the best solution of the vexing problem. During the year 989 bills of health were inspected on arriving vessels and 1,261 bills of health were issued to departing vessels.

STANDARD RAT GUARD.

Owing to the various kinds of rat guards in use and the uselessness of some and the prohibitive cost of others, a number of experiments were made with the result that a rat guard was adopted designed on simple lines and yet a most efficient and economical guard. Nearly all vessels calling at Philippine ports are now provided with the new guard, and the results have been far more satisfactory both to the ship's officers and the sanitarian than with any other guard so far observed.

The special features of the guard are a single disk in two parts with a cylinder, or hollow axle, projecting on each side of the disk. The two parts are hinged by bolting at the periphery of the disk. There is a guide permitting a perfect apposition of the two parts of the disk when closed. It is adjustable to many different sizes of rope and when placed on the line fits closely by tying on both sides

PHYSICAL EXAMINATIONS.

The year just closed has been an interesting one from the point of physical examinations. Under the provisions of act 780 all applicants for licenses to serve as officers on vessels flying the American flag are required to be physically sound. The physical examinations 
are conducted by the quarantine officers at odd times between the arrival and departure of vessels. The cxaminations are made in the several quarantine oflices.

There were 522 applicants for marine licenses examined and six candidates for civil-service positions.

DOCK INSPECTION AND REPORTS.

A daily dock inspection was instituted as soon as the new piers were completed. 'This has continued unabated during the rear. A ctaily report is submitted by the inspecting officer of the vessels at the piers and the conditions found at each with regard to the carrying out of the antirat regulations, both by the vessels and by the pier employees.

The attempt to maintain a rat-free zone around the piers has not met with much success. Before the piers were built the sea walls were badly infested with rats that perhaps lived upon the garbage which floated ashore after being thrown overboard by ships in the harbor. This has now been prohibited, but it is believed that the rats live upon snails, small bugs, and other small animals that abound among the rocks. Traps are set daily on the riprap and in the warehouses near the wharfs.

Upon the request of this office, the insular collector of customs issued the following:

When a foreign or coastwise vessel berths at a Philippine Government pier, the master of the vessel shall, immediately after the lines have been secured to the pier, cause rat guards of sufficient size and proper construction to be placed on all lines leading to the pier, so as to prevent any rats from going ashore.

The master of a vessel alongside a pier shall also be required to have suitable rat guards placed on all lines leading from lighters or cascos to the vessel.

No cargo shall be discharged from or received on board a vessel at a pier before suitable rat guards have been placed on all the lines leading from the carriers to the vessel, and from the vessel to the pier.

When a vessel berthed at a pier has not a supply of suitable rat guards on board, a sufficient number shall be loaned to the vessel by the wharfinger in charge of the pier, receipt to be taken in each case for the rat guards so loaned.

All foreign and coastwise vessels docking at the Philippine Government piers shall be fended off from the piers a distance of a least 6 feet.

All cargo chutes and gangways connecting the vessel with the pier shall be removed at night, as soon as the vessel has stopped work of discharging or receiving cargo, and not put in place again until the following morning. This does not apply to the gangways of passenger vessels, which need not be removed until the pier is actually closed and work has been stopped.

The gates at the side entrances to the piers shall be kept closed, and the guard gates at the main entrance to the piers shall be lowered each night as soon as work on the pier ceases.

The wharfinger in charge of the pier shall be held strictly and personally accountable while on duty for the carrying out of these regulations, with the exception of those contained in paragraphs II and III, for the strict observance of which the customs inspector in charge of the vessel shall be held responsible. When the pier is closed and the wharfinger not on duty, the inspector in charge of the vessel during the daytime and at nighttime when the vessel works shall be held accountable for the observance of all the regulations contained in this general order. The night watchman on duty at the piers shall also be required to prevent, if possible, any violation of these regulations and report all violations of same taking place during his tour of duty.

For the violation of any of the provisions contained in paragraphs I, II, and III, of this general order, the master of the vessel shall be liable to a fine of not less than $P_{5}$, Philippines currency, and not more than $\mathbf{P}^{500}$, Philippines currency, in the discretion of the court.

A copy of this general order, which goes into effect immediately, shall be furnished the master of each vessel berthing at a pier, by the wharfinger in charge of the pier. 
CONSULAR QUARANTINE WORK.

The dual nature of the work at the ports of the Philippines increases the work to such an extent that it is often forgotten that the service there conducts not only the national quarantine, but also the work of consular officers. So far as the continental United States and the administration of the quarantine regulations are concerned, the Philippines are practically foreign ports. The issuing of bills of health and all the various measures carried out at foreign consulates with regard to certifying cargo, disinfecting hides, baggage, and effects, investigating the source of shipments of cargo, and of departing steerage passengers, disinfection and treatment of new crew and steerage passengers, fumigation and inspection of departing vessels, falls upon the service in its rôle of seeing that the quarantine regulations of the Treasury Department are complied with before issuing the bill of health. In accomplishing this work, the following statistics partly disclose the scope of the year's operations:

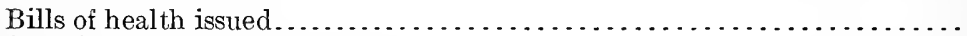

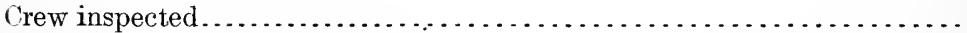

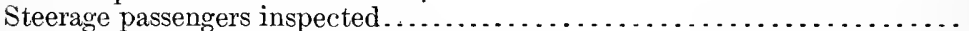

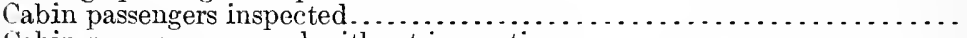

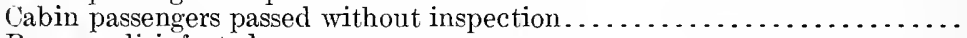

Baggage disinfected . . . . . . . . . . . . . . . . . . . . . . . . . . . . . .

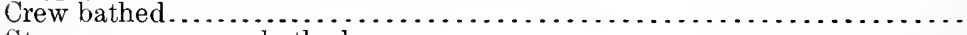

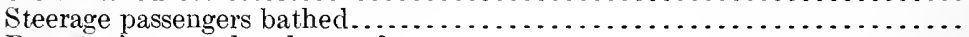

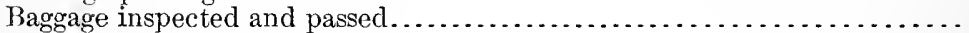

Cargo passed and certified......................................... $1,590,504$

Vessels inspected.

232

20,982

14,615

3,166

3,104

27,735

1,622

5,564

20,726

Vese

144

ressels disinfected and fumigated.

PATIENTS TREATED IN STATION HOSPITALS.

A number of patients were treated in the station hospitals. Among the most interesting were the cases of pneumonic plague, which arrived on the British steamer Montrose at Cebu November 4, 1911, and the case of pneumonic plague which developed in a person from Canton while in detention at Mariveles April 30, 1912. Both of these cases proved fatal.

There were 5 cases of smallpox and 1 case of varioloid treated at the Cebu station, all of which recovered.

At Mariveles, 1 case of smallpox remained in the hospital from the preceding year, and 4 cases from vessels were admitted during the year, and all recovered. One case of smallpox occurred in an employee of the quarantine station, who had had a previous attack of a disease that left pockmarks like those of smallpox.

One cholera carrier, detected at the Mariveles quarantine station during the last week in June, was admitted to the hospital and remains under observation at the close of the year.

On account of the insidious nature of the plague cases found at quarantine,' it has been the practice to remove from the detention groups all persons suffering with fever, however mild, suspicious rashes, or other noticeable symptoms, and place them in the hospital for observation and treatment.

AID TO OTHER SERVICES.

Board on marine examinations. - The physical examinations of all applicants for license as masters, engineers, mates, etc., were 
made during the year by the service at Manila, Iloilo, and Cebu. There were 522 applicants examined. The examination made is in scope similar to the examination of eadets for the Revenue Cutter or other similar rigid requirement services.

Board on food and drug inspection. - Since the Philippine Islands produce but few cattle or other meat-producing animals, nearly all the meat used is imported. Late in 1910, at the request of the board on food and drug inspection and the director of health, the quarantine officers took over the work of the inspection of meat and meat-products certificates accompanying the shipments of meat and meat products into the Philippines. 'This r ork has assumed very large proportions, requiring almost the entire time of a reliable clerk, as well as much attention on the part of the inspecting quarantine officers.

Lighthouse establishment.--The service maintains a lighthouse on the Mariveles reservation as an aid to navigation. The oil and materials are supplied by the lighthouse establishment, and the service takes care of the plant and furnishes the labor necessary to keep the light burning every night. The vessels of the lighthouse service are regularly fumigated and disinfected when necessary.

Bureau of Navigation. - The work of supervising the health of the personnel of the coast-guard fleet, the sanitation of the vessels and property of the bureau, which heretofore was conducted by the service, is now in the hands of a medical officer of the United States Army detailed for the purpose. He devotes his entire time to the work.

Bureau of health.-The service works hand in hand with the efforts of the bureau of health to improve the sanitary condition of the islands. At Iloilo the quarantine officer also acts as district health officer. Several officers have assisted in the collection of lepers, accompanying the collecting vessels on trips of from two to five weeks. During the first six months of this fiscal year, as well as eight months of the previous year, Pharmacist N. C. Comfort acted as superintendent of the magnificent new Philippine General Hospital at Manila. The quarantine officer at Mariveles acts as municipal physician of the town of Mariveles; all the inhabitants were treated over a period of two months for malaria in an attempt to rid the town of that disease. About 30,000 doses of quinine were administered, and the entire populace was again vaccinated. Vessels in the river and canals have been disinfected for the bureau of health when communicable disease occurred thereon.

Philippine civil-service board. - Physical examinations of applicants for positions under the Philippine civil service have been made, and examinations papers examined and rated when requested. At Iloilo six physical examinations were made.

Bureau of customs. - The customs and quarantine officers in their inspection work come in close contact, and the most cordial relations exist. Quarters and subsistence were furnished the customs inspectors and guards on duty at Mariveles during the long plague quarantine. Customs launches and cutters have been kept free from vermin and their sanitary condition supervised. Many employees have been given first aid and medical treatment, and such employees as applied at the office were vaccinated. Mutual use of each others' launches by employees is of daily occurrence. Services of customs 
employees in transmitting messages from the piers and to our launches when in the bay is appreciated and gratefully acknowledged.

Panama Canal Zone.-Baggage and shipments of personal effects destined for the Canal Zone were inspected, disinfected when necessary, and certificates furnished.

Foreign consular services. - Bills of health have been issued to vessels sailing from Philippine ports for foreign ports which are used by foreign consular officers as their bills of health from Philippine ports by merely viséing same. Certificates of origin of orchids, and much miscellaneous merchandise signed by our quarantine officers and then conntersigned by foreign consuls, are used to gain entrance for such shipments at European ports. The latter is done primarily as a benefit to the industrial interests of the Philippines and secondarily as a courtesy to the foreign consuls and shippers.

Immigration service.-D During the year 3,132 aliens who arrived were submitted to the usual immigration medical inspection at the several ports of entry of the islands.

Bureau of agriculture.-Owing to the ravages of rinderpest and other animal diseases among the cattle of the Orient, vessels that bring cattle to the Philippines are frequently infected with animal diseases. In such cases, when requested by the director of agriculture, the vessels were thoroughly disinfected by this service at all of its stations. Shipments of hides, horns, etc., between interisland ports, the manifests for which formerly had to be accompanied by a permit from a quarantine officer for landing, are now controlled entirely by the burean of agriculture.

Weather bureau.-The service continued to maintain a typhoon signal station on Mariveles Bay for the weather bureau. The past two years have been unusual in the small number of typhoons, and consequently a warning of their sudden approach has lately been of greater benefit in comparison than heretofore because their long absence tends to make seamen less on the lookout.

United States Army.-Army vessels having communicable diseases on board were disinfected Crews were vaccinated and launches and lighters disinfected and fumigated. The clothing and bedding of 105 soldiers from the island of Corregidor were disinfected at Mariveles. Sulphur and disinfecting apparatus on two occasions were loaned to the garrison at Fort Mills to disinfect hospital and barracks which had become infected. At Iloilo considerable bedding was disinfected.

Charitable institutions.-Every practicable aid is at all times given to the public charities. Disinfection of infected bedding for charity hospitals has been done. Medical services have been rendered to the poor at the stations of the service. Aid has been rendered in the search for persons in the provinces afflicted with diseases-and deformities easily relieved by operation and sending them to the hospitals.

Bureau of posts. - Additional regulations covering the discharge of the mail from vessels have been agreed upon. The postal authorities are now allowed to take mail from arriving liners by chute at any time of arrival at night, or while proceeding up the bay prior to quarantine inspection. Quarters have been provided at quarantine stations for field parties of the telegraph division. The cable ship was disinfected twice during the year. 
The quarantine inspection stations at Cavite and (Olongapo are maintained for the benefit of the vessels arriving at and dejarting from the United States Naval Station.

The senior medical offieer of the fleet details a Navy surgeon for appointment at each station as quarantine officer. This is done by the service at the request of the admiral commanding the Philippine Naval Station.

ILOSLO.

The object which, above all others, has engaged the strenuous efforts of the quarantine officer at Iloilo during the past year has been to prevent the reintroduction of plague, smallpox, and cholera from the near-by epidemic centers. Never in the history of American occupation have the Philippines been so free from dangerous communicable diseases, and at no time have such diseases knocked harder on the quarantine door for admittance. At Amoy, Saigon, Hongkong, and other ports within a lew days' sailing of Iloilo, plague, smallpox, and cholera have been epidemic throughout the entire year.

The new quays having been completed, foreign vessels now come up the river and berth alongside of them. This increases the chances of infected rodents gaining access to shore, consequently the most rigid antirat regulations and daily inspections were enforced.

JOLO.

At Jolo, the principal port of the Sulu group, arriving vessels come mainly from ports in Borneo and the Straits Settlements. While the tonnage arriving at this port is not large, yet it is a most important station from a quarantine standpoint.

MARIVELES QUARANTINE STATION.

Marivoles quarantine station was a busy place during the year. With the exception of a few months, active quarantine of steerage passengers was constantly in effect.

During the year 130 vessels called at the station -25 for pratique, 28 for fumigation, 57 to land passengers in quarantine, 20 for disinfection-and in addition 14 cattle boats were granted pratique at Mariveles prior to proceeding to the Matadero (slaughter station) at Sisiman, on Manila Bay, opposite the entrance and 30 miles from Manila.

During the year 29 partial or complete fumigations of vessels were performed. There were 27 vessels disinfected on account of having disease aboard or arriving from infected ports. Three vessels were disinfected on account of plague, four on account of having been used in transporting lepers to the colony at Culion, five on account of severe outbreaks of measles on board, and five on account of smallpox.

The quarantine officer at Mariveles acts as municipal physician for the town of Mariveles, and a free clinic is maintained daily which is of much real benefit to the inhabitants of the village.

An additional barracks was constructed during the year. It is built of reenforced concrete with tile roof and is fitted with steel 
bunk frames with canvas bottoms. A kitchen and bath building in two sections, which is to serve for two barracks, is nearing completion. The kitchen and bath building for the attendants was reconstructed during the year and is now in use.

\section{ZAMBOANGA.}

At Zamboanga the quarantine work was in charge of Acting Asst. Surg. J. W. Hanner. During the year 35 vessels arrived at Zamboanga directly from foreign ports. Vessels arrived at that port from the Celebes, Borneo and other Oceania ports from which vessels do not call at any other Philippine ports. Many of these are at times badly infected and the vigilance of the quarantine officer is put to a severe test in order that no introductions of quarantinable diseases may occur.

CEBU.

Plague was encountered at quarantine on the British steamship Montrose which arrived at Cebu November 4, 1911, with a case of suspicious illness on board which developed into pneumonic plague. The case was treated in the hospital at the Cebu station and resulted fatally. Autopsy and subsequent laboratory findings confirmed the clinical diagnosis. The crew of the vessel was held for seven days after disinfection but no further cases developed.

Smallpox occurred on five vessels and varioloid on one. All these cases were cared for during their illness at the station hospital and all recovered.

There were disinfected at Cebu seven vessels on account of having diseases on board, one tor plague and six for smallpox.

\section{STATISTICS.}

The work performed in the Philippines was of large proportions. When compared with other stations, and with the number of officers on duty, the figures are amazing. The following are culled from the great mass of statistics covering the quarantine work there, both for the protection of the 8,000,000 inhabitants of the Philippines, and for the protection of the coast cities of the United States:

Cavite and Olongapo:

Number of vessels inspected.

Number of crew inspected.

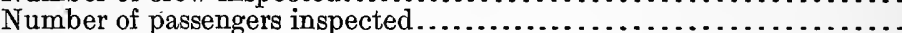

Number of pieces of baggage treated............................... Cebu:

Tumber of bills of health issued.

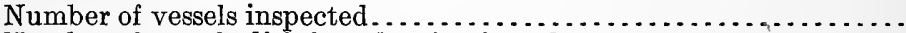

Number of vessels disinfected or fumigated . . . . . . . . . . . . . . . . . . . .

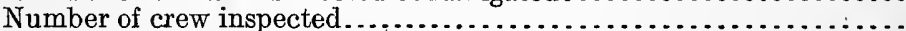

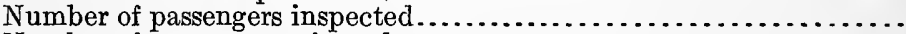

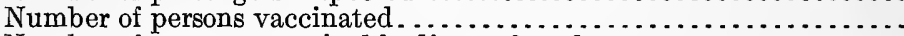

Number of cases quarantinable disease found.$\ldots \ldots \ldots \ldots \ldots \ldots \ldots$.

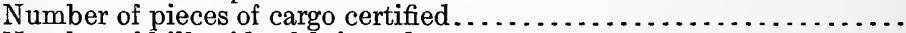
Iloilo:

Number of bills of health issued.

Number of vessels inspected............................. 103

Number of vessels disinfected or fumigated.................... 121

Number of crew inspected................................ 5,676

Number of passengers inspected......................... 2,837

Number of persons vaccinated ........................... 640

Number of pieces of cargo certified.................................... 145, 046

Number of bills of health issued........................... 195 
Jolo:

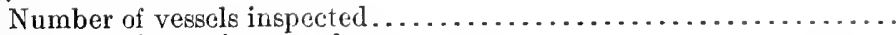

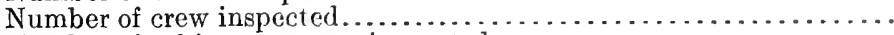

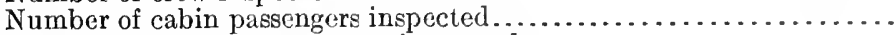

Number of steerage passengers inspected........................

Manila:

Number of bills of health issued...................................

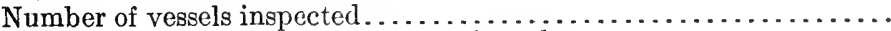

Number of vessels disinfected or fumigated . . . . . . . . . . . . . . . .

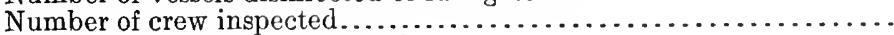

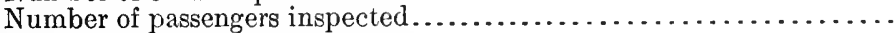

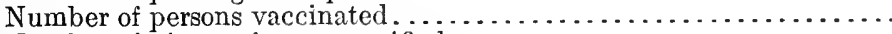

Number of pieces of cargo certified. . .......................... 321,434

Number of bills of health issued........................ 844

Mariveles:

Number of vessels at station . . . . . . . . . . . . . . . . . . . . . . .

Number of vessels disinfected or fumigated.................. 48

Number of crew bathed and effects disinfected.................. 1,692

Number of passengers bathed, effects disinfected................ 8,184

Number of pieces of baggage disinfected . . . . . . . . . . . . . . . .

Number of persons vaccinated............................. 2,563

Number of persons held in quarantine......................... 2,585

Zamboanga:

16,144

Number of vessels inspected........................... 35

Number of crew inspected.............................. 1,097

Number of cabin passengers inspected........................ 477

Number of steerage passengers inspected...................... 720

Number of bills of health issued.......................... 35

PERSONNEI.

The chief quarantine officer continued to act also as director of health for the Philippine Islands. During the first five months of the fiscal year he was absent from the islands, and Passed Asst. Surg. Carroll Fox was in charge of the quarantine service and also the bureau of health.

At the close of the fiscal year the official personnel of the service on duty in the Philippines and their assignments were as follows:

Passed Asst. Surg. Victor G. Heiser, chief quarantine officer for the Philippine Islands and director of health, in charge of the bureau of quarantine service.

Manila: Passed Asst. Surg. Victor G. Heiser, in command; Passed Asst. Surg. Carroll Fox, assistant director of health; Asst. Surg. D. C. Turnipseed; Pharmacist N. C. Comfort, chief clerk.

Mariveles: Asst. Surg. Robert Olesen, in charge. Acting Asst. Surg. William J. Linley, absent, sick.

Iloilo: Passed Asst. Surg. J. R. Hurley.

Cebu: Asst. Surg. Louis Schwartz.

Olongapo: Acting Asst. Surg. U. R. Webb.

Cavite: Acting Asst. Surg. Allen E. Peck.

Jolo: Acting Asst. Surg. George A. Skinner.

Zamboanga: Acting Asst. Surg. J. W. Hanner.

\section{APPROPRIATIONS.}

The appropriation for the expenses of the quarantine service in the Philippines for the fiscal year 1912 was provided for by the allotment made by his excellency the Governor General of the Philippine Islands. The Philippine Legislature failed to pass the appropriation bill for the general expenses of the Philippine government for the fiscal year 1912 , and by virtue of the provisions of the organic law the Governor 
General allotted the necessary funds. The quarantine allotment was worded the same as the appropriation act for the preceding year and carried an allotment of $\$ 62,500$, with authority to expend for current expenses the collections for the year.

The amount collected was $\$ 2,498.50$. Three funds for public works were available at the beginning of the year: One for the reconstruction of the Mariveles Wharf, in amount $\$ 24,328.79$; a balance for a concrete barracks at Mariveles; and a fund for a disinfecting building at Iloilo. To the balance of $\$ 563.41$ in the fund for a barracks at Mariveles the sum of $\$ 1,500$ was added in November, 1911. The work on the wharf project is still an office transaction. The fund of $\$ 1,750$ for the erection of a disinfecting building at Iloilo was increased during the year to $\$ 4,750$ by the transfer of $\$ 3,000$ from the current funds of the fiscal year 1912. That fund is still on hand, and actual construction work awaits the settlement of the land question.

\section{EXPENDITURES}

The administration of the Philippine quarantine service was conducted along the most economical lines. A general increase of expense is noted, occasioned by the gradual deterioration of the wooden buildings as well as the general equipment, much of which has now been in use 12 years, and has reached that stage where renewal and extensive repairs are to be expected.

The only extraordinary expenditure during the year was the sum spent to finish the barracks building and its kitchen and bathhouse at the Mariveles station. For that purpose $\$ 1,881.17$ was paid out of a fund of $\$ 2,063.41$, leaving $\$ 182.24$ remaining on hand for finishing the kitchen, which is as yet uncompleted.

For the regular expenses of the service, including the purchase of equipment, the maintenance of stations, salaries and wages, and contingent expenses, there was expended the sum of $\$ 56,090.01$ from the allotment for the service for the fiscal year, and $\$ 2,453.78$ was disbursed for outstanding obligations of the preceding fiscal year. The year closed with outstanding accounts payable estimated at $\$ 5,095$, funds for the payment of which are on hand. The unexpended balance when all the obligations of the year are paid will be insignificant. The financial statement shows in detail the money transactions. While these statements are expressed in United States currency, the actual transactions were all in Philippines currency.

Financial statement, Philippine quarantine service.

GENERAL APPROPRIATION, BUREAU OF QUARANTINE SERVICE.

Allotment, fiscal year 1912

$\$ 62,500.00$

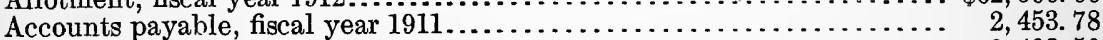

Refunds and collections................................................ $2,498.50$

Total .............................

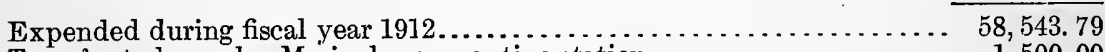

Transfer to barracks, Mariveles quarantine station...............

Transfer to disinfecting building, Iloilo............................... $3,000.00$

Unexpended balance................................................. $4,408.49$

Total.........................

Estimated accounts payable.......................... $5,095.00$

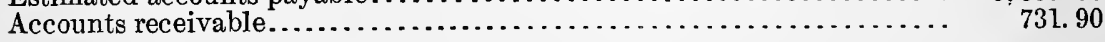




\section{QUARANTINE IN PORTO RICO.}

The chief quarantine officer for Porto Rico, Passed Asst. Surg. S. B. Grubbs, stationed at San Juan, reports for the fiscal year ended June 30, 1912, in substance as follows:

The organization of the service in Porto Rico is divided into the quarantine service, marine-hospital relief, immigrant inspection, and miscellaneous, and the work is carrierl out at the ports of San Juan, Ponce, Mayaguez, Fajardo, Humacao, Arecibo, Aguadilla, Arroyo, and Guanica.

The quarantine division is the most important, and the organization consists of a chief quarantine officer for Porto Rico and a quarantine officer for each port. The quarantine transactions for the year ender June 30,1912 , at the various ports were as follows:

San Juan:

Vessels inspected.

Vessels held in quarantime.

Vessels disinfected.

Passengers inspected

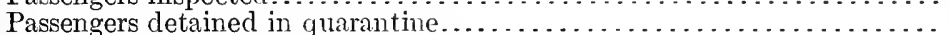

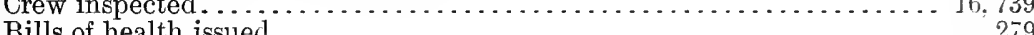

Ponce:

Vessels inspected $\ldots \ldots \ldots \ldots \ldots \ldots \ldots \ldots \ldots \ldots \ldots \ldots \ldots \ldots \ldots \ldots \ldots \ldots$

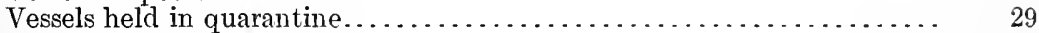

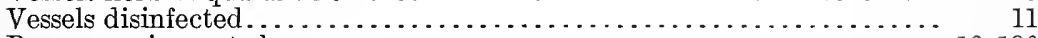

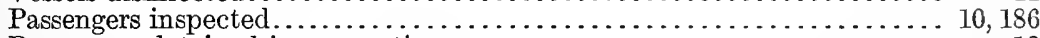

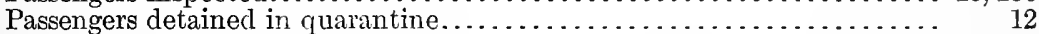

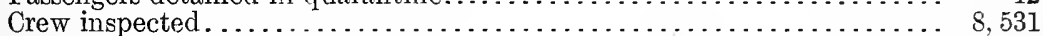

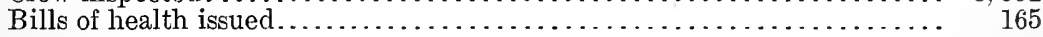

Mayaguez:

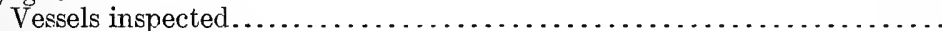

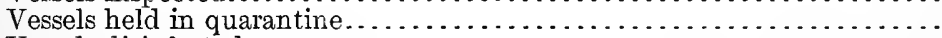

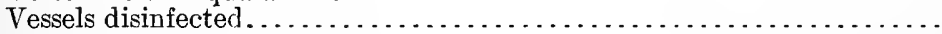

Passengers inspected.

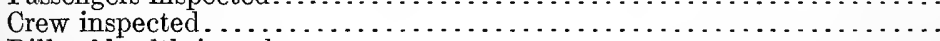

Fajardo:

Vessels inspected.

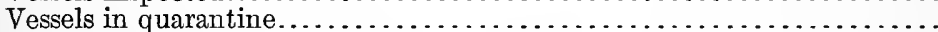

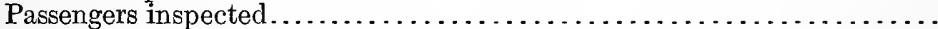

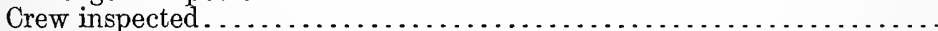

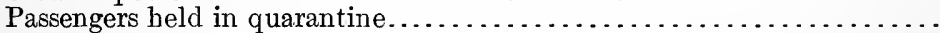

Bills of health issued.

Vessels in

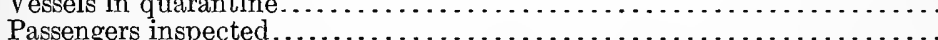

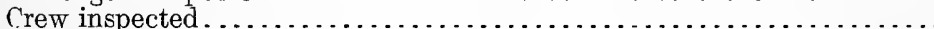

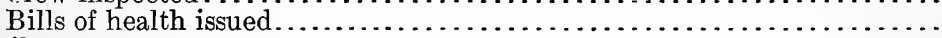
Arecibo:

Vessels inspected.

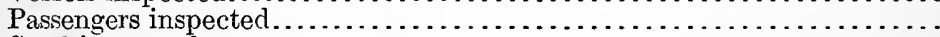

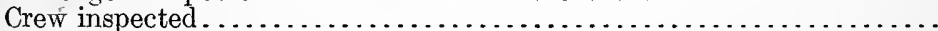
Arroyo:

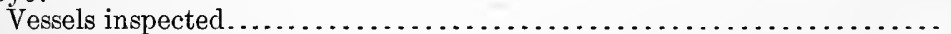

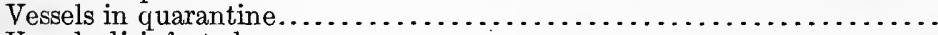

Vessels disinfected.

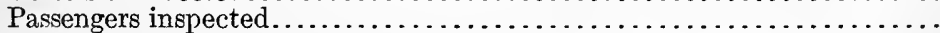

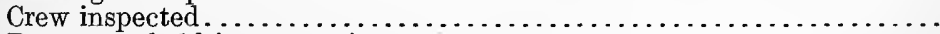

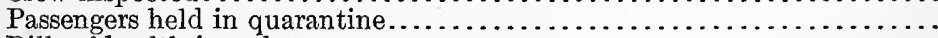

Bills of health issued. 
Humacao:

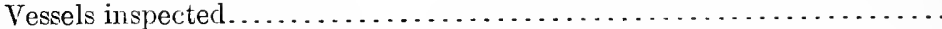

Vessels held in quarantine. . . . . . . . . . . . . . . . . . . . . .

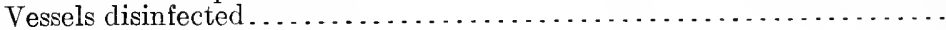

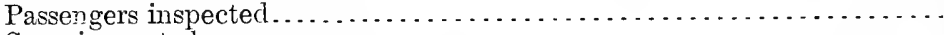

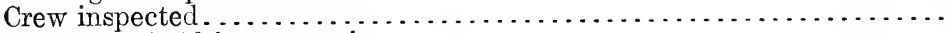

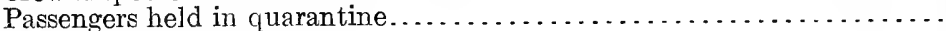

Guanica:

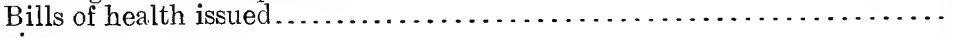

Vessels inspected.

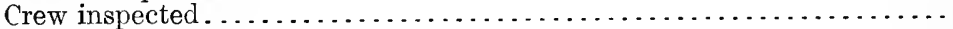

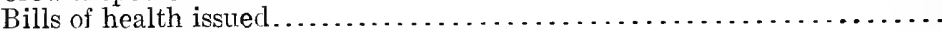

OPERATIONS OF THE SERVICE IN HAWAII.

ANNUAL REPORT OF SERVICE TRANSACTIONS IN THE HAWAIIAN ISLANDS FOR THE FISCAL YEAR ENDED JUNE 30, 1912.

The service operations in the islands are under the supervision of the chief quarantine officer with headquarters at Honolulu, and are divided under four heads:

1. Quarantine.

2. Plague laboratory.

3. Marine hospital.

4. Immigration.

The United States Quarantine Laws and Regulations were enforced by officers of this service at Honolulu and six subports of entry in the other islands.

At Honolulu the service has a first-class quarantine and disinfecting station located on a modern wharf at which vessels of 35 feet draft can berth. The disinfecting apparatus on the wharf consists of four double-jacketed steam chambers, three boilers for generating a sufficient amount of steam for operating the chambers, and two doubleended sulphur furnaces. Facilities for bathing persons detained in quarantine are amply sufficient to handle 200 persons per hour. At the quarantine station proper there are accommodations for 75 cabin and 600 steerage passengers. In addition there are wooden tent platforms which can be made available at short notice for 1,500 troops.

At Hilo, on the island of Hawaii, the service maintains a secondclass quarantine and disinfecting station, with facilities for fumigating vessels by the sulphur-pot method. There is as yet no provision for handling persons detained in quarantine except on shipboard or by arrangement with the board of health for use of its quarters temporarily.

\section{Quarantine transactions at Honolulu, Hawaii.}

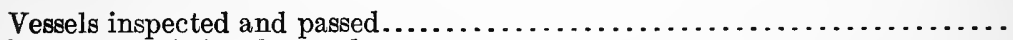

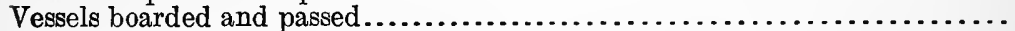

Vessels detained and disinfected for quarantinable diseases.................

Vessels detained and fumigated for mosquitoes.............................

Vessels detained and disinfected upon request for contagious diseases........

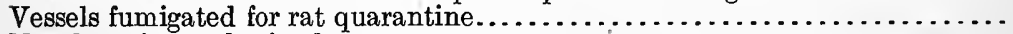

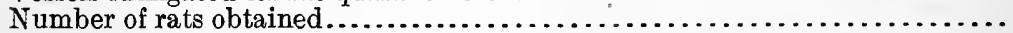

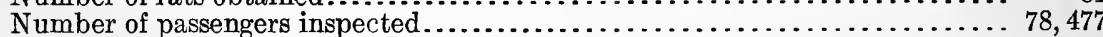

Number of crew inspected........................................ 49, 407

Number of passengers detained........................................ 2, 175

Number of crew detained........................................... 300

Number of persons detained upon request by board of health............. 1,340

Number of persons treated in quarantine hospital by board of health........ 296

Number of persons treated for quarantinable diseases.................. $\quad 38$ 
Number of persons treated for other than quarantinable diseases......... If

Number of persons detained and examined for cholera carriers............... 121

Number of persons bathed.................................. 3,230

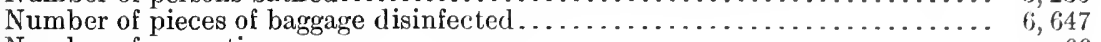

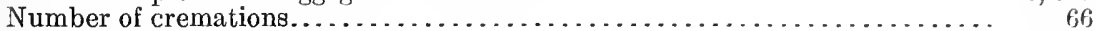

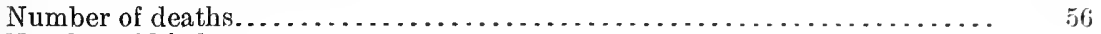

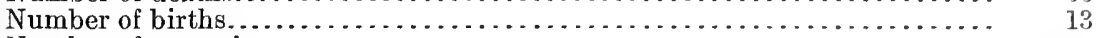

Number of autopsies...................................... 4

Number of persons vaccinated ............................... 1,915

QUARANTINE TRANSACTION AT SUBPORTS IN HAWAII.

(At the subports of Mahukona, Kahului, Lahaina, Port Allen, and Koloa, acting assistant surgeons of the service board and inspect incoming vessels.)

\begin{tabular}{|c|c|c|c|c|c|c|}
\hline & Hilo. & $\begin{array}{l}\text { Mahu- } \\
\text { kona. }\end{array}$ & Kahului. & Lahaina. & Koloa. & $\begin{array}{l}\text { Maka- } \\
\text { weli. }\end{array}$ \\
\hline $\begin{array}{l}\text { Vessels inspected and passed.................... } \\
\text { Vessels fumigated for rat quarantinc........ }\end{array}$ & $\begin{array}{l}32 \\
43\end{array}$ & 13 & 16 & 3 & & 3 \\
\hline 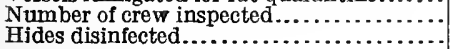 & $\begin{array}{l}1,254 \\
1,772\end{array}$ & 143 & 402 & 87 & & 52 \\
\hline
\end{tabular}

OCCURRENCE OF QUARANTINABLE DISEASES.

Plague.-No cases of plague either human or animal have occurred on any island, except that of Hawaii, during the year. On the island of Hawaii, plague-infected rats were obtained from various sections in the town of Hilo during the spring. The Hamakua coast extending in a northwest direction from Hilo was pretty extensively plague infected during the entire year. Four cases of human plague occurred among individuals, all being of the axillary or cervical type. The number of plague-infected rats found has been large. In February, 1912, out of a total of 1,021 rats taken, 14 were infected. March showed 63 infected out of 8,514 trapped, while during April only 2 infected rats out of 6,376 examined.

The Territorial board of health instituted a very thorough campaign to eradicate this plague infection; laboratories were established at Hilo and Honokaa. The force in the field for poisoning and trapping rats was greatly increased and the monthly catch of rodents from this section is now between 5,000 and 6,000. The country that is infected has been found to be extremely difficult to work in, the land being overgrown with a dense amount of foliage and shrubbery, while the contour of the land is very uneven, many gullies being found with very steep sides, which often require a long detour in order to reach the bottom. No plague-infected rats have been found along the Hamakua coast since the last week in April, and it is hoped that the measures taken and the work now on hand will result in ridding this coast of infection.

Yellow fever.-On October 21, 1911, the Japanese steamship Hongkong Maru arrived from ports of South and Central America, Salina Cruz, and Manzanillo, with a case of convalescing yellow fever on board. As a note of interest, this same vessel brought the first case of yellow fever, in the history of Hawaii, when she arrived from South America and Mexican coast ports October 30, 1910.

The vessel was held outside of the harbor for fumigation, after which she was permitted to receive coal and water. The tugboat 
and barge taking out the supplies being fumigated before leaving the harbor on each trip. On October 25, 1911, the vesesl departed for Yokahama, where she arrived without any additional cases occurring. A second case of yellow fever occurred in the case of a service attendant who had acted as night guard on the vessel during the four days that she remained outside at anchor. This case ended in recovery and was considered by all the medical men that saw it to be a typical case of yellow fever.

Cholera.- One vessel arrived during the year with a history of having landed a case of cholera at Kobe, Japan, with undoubted origin at Shanghai. The steerage passengers from those ports were removed and detained at the quarantime station and examined for possible cholera carriers, in accordance with department circular No. 47, of July, 1911.

Smallpox.- No cases of smallpox occurred in the Territory during the year, but five vessels arrived with histories of having liad the disease on board during the voyage.

Leprosy.-One vessel arrived from the Orient with a case of leprosy, which was turned over to the Territorial board of health.

Vessels inspected, etc.-Three hundred and seventy-nine vessels were inspected and passed; 40 were boarded and passed; 21 were disinfected for quarantinable diseases or upon request of the Territorial board of health, while 81 were fumigated for rat quarantine.

Vessels infected.-During the year seven vessels arrived at Honolulu which were actually infected or had been recently infected with quarantinable diseases, as follows: American steamship Manchuria arrived September 28, 1911, from Chinese and Japanese ports with a history of having landed a steerage pasisenger at Kobe with cholera. The passenger, a Hindu, had embarked at Shanghai, where cholera. was then prevailing, and was taken sick just as the vessel arrived at Kobe. Upon arrival here the steerage passengers from Shanghai and Kobe were removed to the quarantine station, bathed, detained, and examined for possible cholera carriers.' None being found, the detained persons were released.

Japanese steamship Chiyo Maru arrived October 5, 1911, with onc case of leprosy, which was removed from the vessel and turned over to the Territorial board of health.

Sixty-nine steerage passengers arrived on this vessel from Kobe and were detained at the quarantine station for possible cholera carriers.

Japanese steamship Hong Kong Maru from South and Centra] American ports, Salina Cruz, and Manzanillo arrived October 21, 1911, with a convalescing case of yellow fever aboard. The Hong Kong Maru had been fumigated at several ports, and the bills of health showed no cases of yellow fever at any of the ports touched at. The vessel was fumigated outside of the harbor and remained long enough to coal and receive water before departing for Yokohama.

British steamship Willesden arrived December 3, 1911, from Europe via Punta Arenas with 1,900 immigrants on board. Smallpox had broken out during the voyage, and upon arrival here there was found 24 typical cases, and in addition there were over 40 cases of measles and 2 of typhoid. During the voyage there had been 27 deaths from measles, marasmus, and other causes. All of the personnel of this vessel were removed, bathed, effects disinfected, and 
placed in isolation at the quarantine station. Doring the andese of the next two days vacoination was dono and many sureessful takes obtained. Between Decomber S, 1911, and J)ocomber 1S, 1911, thros new cases of smallpox occurred, with two deaths, one of the latter

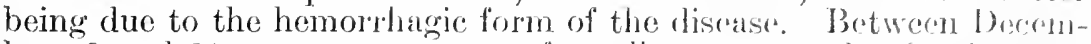
ber 18 and 26 seven more rases of smallpox ocerred. (m tambary 18, 1912, five new cases of smallpox oceurrerl among the immiorants outside of the hospital compound, and as 15 days frad clapsed since removal from the steamer it was comsidered that reinfertion had taken place, and it was therefore necessary to revaremate, bathe, and disinfect the clothing of tho rontacts, and to begin to count the period of incubation from this date. Finally the infection was gotten under control and the last of the immigrants wele discluarged from quarantine island on .January 31, 1912, making the detention of the personnel from this vessel 1 montl and 27 days. Smallpox. was not the only disease occurring among these immigrants, for there was, in addition, 1 case of diphtheria, 5.3 of measles, and 13 of typhoid. 'Thirty-six deaths occurred from all causes among' the immigrants while on quarantine island. Recapitulation of thir cases of contagious diseases, with the total number of deaths which occurred among these immigrants from December 3, 1911, to January 31, 1912, tho period they were under detention at the quarantinc station, was as follows:

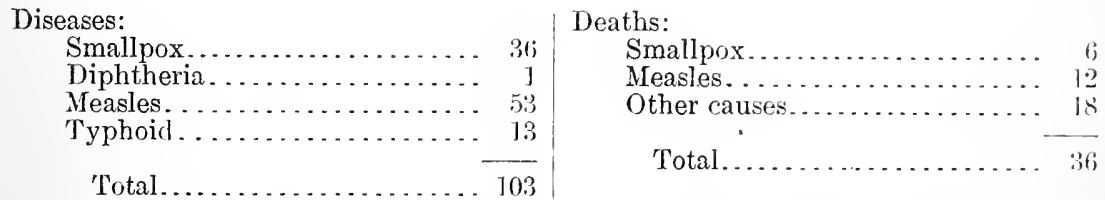

American steamship Navajo arrived December 23, 1911, from Ancon, Canal 7one. As the vessel had laid at the dock there for 14 days and had not been fumigated prior to departure, she was held outside and fumigated to destroy any possible mosquitoes with malarial infection.

Norwegian steamship Titania arrived from Manzanillo, Mexico, January 27, 1912, with a history of having had a member of the crew die at sea under rather suspicious circumstances. She was held outside the harbor and fumigated. Two members of the crew were found to be ill, one with gastric trouble and the other from malaria.

American steamship Siberia arrived February 16, 1912, from Yokohama with a case of smallpox in a Chinese steerage passenger. The vessel was taken to the quarantine wharf, the patient removed, 232 contacts bathed, effects disinfected, and placed in detention. The vessel after disinfection of the hospital and steerage quarters was released.

Japanese steamship Buyo Maru arrived February 16, 1912, from Mexican ports. She was detained outside the harbor and fumigated on account of mosquitoes.

Japanese steamship Tenyo Maru arrived March 4, 1912, with a history of having landed a case of smallpox at Yokohama. Surg. Irwin, the service representative at that port, had certified that all precautions had been taken, and as no secondary cases had occurred the vessel was granted pratique. 
British steamship Persia arrived April 16, 1912, with a diagnosis by the ship's surgeon of seven cases of smallpox. The vessel did not reach port until after sunset, but was allowed to come in to the harbor and dock at quarantine wharf, where she was boarded and the cases examined by artificial light. It was decided that the cases were probably chicken pox, but a definite diagnosis was postponed until the following morning, when an examination by natural light could be made. This was done and the seven cases, together with one which had occurred during the night, were found to be unmistakable chicken pox. The vessel was accordingly released and the board of health notified.

British steamer Harpalion arrived April 17,1912, with 1,476 Spanish and Portuguese immigrants direct from European ports. No quarantinable diseases were found on board, but many cases of measles, some of diphtheria, mumps, scarlet fever, and the various diseases of infants, due to poor ventilation and improper food were present. Upon the request of the Territorial board of health, the immigrants were removed from the vessel, bathed, effects disinfected, and placed in detention at the quarantine station. All of the expenses in carrying out the above were borne by either the United States Immigration Service, or the Territorial board of immigration. These immigrants were detained from April 17, 1912, to May 18, 1912, and during that time the following cases of illness, births, and deaths occurred among them:

Number of births, 3. Number of cases of illness, 293. Number of deaths, 26. Of the latter measles caused 22; diphtheria, 2; and other causes, 2 .

United States Army transport Thomas arrived May 4, 1912, with a case of varioloid in the person of a Filipino coal passer. This man, who was taken sick April 26, 1912, had been promptly discovered and isolated, and all contacts vaccinated, and the forecastle disinfected. The patient was practically well upon arrival at this port and was, therefore, given a bath, his clothing and the hospital disinfected, and the vessel granterl pratique.

American steamship China arrived May 14, 1912, with a history of having had a death occur on board just prior to arrival at Shanghai, the body being taken ashore for post mortem and bacteriological examination. Acting Asst. Surg. Ransom noted upon the bill of health that if the case proved to be one of plague he would cable; as no answer had been received when the vessel arrived at this port she was, after inspection, granted pratique.

United States Army transport Sherman arrived April 18, 1912, with a reported case of smallpox in the person of a Filipino fireman. Isolation had been carried out, contacts vaccinated, and crew's quarters disinfected. Upon examination of the case it was found to be one of chicken pox and, on the request of the transport quartermaster, was removed to the quarantine station and the hospital disinfected.

American steamship Manchuria, arrived May 21, 1912, from Chinese and Japanese ports, with a history of having landed a case of suspected plague at Shanghai, and a case of smallpox at Kobe. Note was made upon the Shanghai bill of health that if the case of suspected pest was proven so by bacteriological examination this office would be notified. No notice was received, so it was inferred that the case had proven negative. In regard to the case of smallpox, all precautions had been taken, and as 14 days had elapsed since the 
removal of the case, and there having been $n 0$ further sickness, the vessel was granted pratique.

American schooner Blakeley arrived May 22, 1912, from Valparaiso, and Iquique; she was held outside the harbor, and fumigated to destroy any possible mosquitoes on board.

Rat quarantine. - The vessels fumigated for the purpose of rat erarlication can be classified as follows:

(1) Vessels from foreign ports.

(2) Vessels bound for United States ports.

(3) Vessels engaged in interisland trade.

1. Only one vessel from a foreign port was fumigated during the year. The great majority of these vessels only make Honolulu a port of call, and as they are usually never empty of cargo, except at the mainland ports of the United States, fumigation here is therefore not practicable. With the careful and repeated fumigation at Hongkong and San Francisco, the trans-Pacific liners, are considered to have been more rat free than ever before. Experience has shown that fumigation twice a year of the trans-Pacific liners is not sufficient to maintain them in a fairly rat-free condition. It is beliered that the large majority of rats are brought aboard of a ressel in the cargo, and that only by fumigation of vessels at regular intervals of about three months can they be kept free of rats. It is further considered absolutely essential that in the fumigation of a vessel erery part of her should be included, with the possible exception of the dining saloon, ladies' lounging rooms, and similar places. In the past too little attention has been paid to the storerooms and the cabins.

If rats are anywhere in a ship, they will surely be found in the storerooms, and as passengers usually have fruit and other edibles in their cabins, it is common experience for rats to come out at night and partake of any food that may be handy, even eating the soap, of which they are very fond.

In the ordinary fumigation of the holds, crew, and steerage passengers' quarters of a trans-Pacific liner, the rats escape the sulphur fumes by the openings around pipes, etc., which gives them access to the cabin passenger accommodations.

Rats on all the liners as well as tramp steamers and other vessels are pretty constantly found on the boat deck, and it is always necessary to have the covers removed from the boats and other accessible places searched during the fumigation of a vessel.

2. There is a large trade in lumber, etc., between the mainland and Hawaiian Island ports, which is almost entirely carried by sailing vessels. These vessels, because it is impracticable, are allowed to lie alongside the dock without rat guards on the lines, while discharging cargo and are fumigated when empty, just prior to sailing.

Eighty-four vessels were fumigated for rat quarantine during the year, and as many of these vessels ply regularly between the mainland and the islands, they were consequently fumigated several times, for instance: Five were fumigated twice; two, three times; four, four times, and two, five times. The results clearly showed that vessels engaged solely in the carrying of lumber were not favorable to rats, for only 10 rats were obtained.

Vessels carrying miscellaneous cargo, particularly grain and foodstuffs, always showed rats or mice after fumigation.

The pot-and-pan method has been used altogether, the fumigation being started in the late afternoon and the vessel kept closed \&ll 
night and opened up and searched the folloning morning. The practice of having the vessel searched after completion of the fumigation by a trained quarantine employee, which practice was found to yield such good results in the work at the San Francisco quarantine station, has recently been staited here, and more rodents have been obtained as a result than eve $i^{2}$ previously, when the searching of a vessel and reporting of rats killed was left to the master of the vessel.

3. Vessels engaged in the interisland trade plying to the island of Hawaii were required to be fumigated every two months, on account of the presence of plague there, while those plying to the other islands were required to be fumigated every six months.

The vessels of the interisland fleet weie fumigated 18 times during the year. As the interisland steamers, particularly those fiom the island of Hawaii, make a practice of going alongside of vessels bound for United States ports for the purpose of transferring their cargo, usually sugar, it is considered that the fumigation every two months is a most important protective measure in that it reduces to a minimum the danger of rats passing from one vessel to another.

BOARD OF HEALTH.

All rats and mongoose caught in Honolulu are examined at the plague laboratory of the service, and during the year 27,235 rats and mongoose were trapped and examined for plague infection without any evidence of plag'ue being found.

In compliance with a request of the board of health made during the previous year, all vessels ar iving from Mexican and Central and South American ports were detained outside the harbor on arrival and fumigated for the purpose of destroying any possible anopholes mosquitoes that might be aboard.

The steamship Harpation arrived April 17, 1912, with Spanish and Portuguese immigrants, and upon the request of the president of the Territorial board of health the vessel was detained and remanded to the quarantine wharf on account of the presence of contagious diseases on board. During the voyage from Europe there had occuired among the immigrants 9 births, 17 deaths, and 107 cases of sickness; of the latter there were 58 cases of measles, 5 diphtheria, 1 scarlet fever, 1 varicella, 33 mumps, and 9 miscellaneous. The deaths were due to measles, bioncho-pneumonia, malnutrition, and other causes.

About 1,376 immigrants were detained at the quarantine station under observation from April 17, 1912, to May 18, 1912, during which time there occurred 3 births, 293 cases of illness, and 26 deaths. Measles was largely responsible tor the large proportion of the cases of sickness, there being 219 cases of this disease, while of the'deaths, measles was responsible for 22 , diphtheria caused 2, and for other causes there were 2.

Thirty-four cremations were performed at the quarantine station during the year upon request of the Territorial board of health.

Personnel.-At the close of the fiscal year the following officers were on duty in the Hawaiian Islands:

Honolulu: Passed Asst. Surg. F. E. Trotter, chief quarantine officer of the Territory of Hawaii. Edward R. Marshall, passed assistant surgeon. J. M. Gillespie, assistant surgeon. A. N. Sincloir, acting assistant surgeon. William F. James, acting assistant surgeon. Frank A. Stump, pharmacist. . Emma F. Smith, medical inspectress. 
Irik: [. L. Sexton, acting assistant surgeon.

Mahukona: B. D. Bond, acting assistant surgeon.

Lahaina: Franklin Burt, acting assistant surgeon.

Kahului: William F. Osmers, acting assistant surgeon.

Makaweli: Thomas J. West, acting assistant surgeon.

Koloa: $\Lambda$. H. Waterhouse, acting assistant surgeon.

The regular force of the entire station includes 27 men. Eleven are on duty at the quarantine station, 2 on the boarding launch, 1 in the quarantine office, 1 in the marine-hospital office, 3 in the plague laboratory, and there are in addition 9 laborers on the quarantine station.

Plague laboratory.-During the year there was a decrease in the number of rats examined, due partly to a temporary decrease in the force of rat catchers as well as to a possible diminution and wariness of the rats themselves. No plague-infected rats were found or reported during the year on any of the islands except that of Hawaii.

At Honokaa and along the adjacent coast of Hawaii plague prevailed during the year. Four human cases of plague occurred between February 10 and March 15, 1912, while the number of plague-infected rats found during the month of February and March amounted to 77. Immediately following this outbreak the Territorial board of health concentrated its force with the object of destroying the foci of the disease, and immediately the number of rats and mongoose trapped and poisoned began to increase.

No plague-infected rats have been found since April, and it is therefore hoped that the infection has been gotten rid of.

Too much praise can not be accorded the Territorial board of health, and in particular the president, Dr. J. S. B. Pratt, for the excellent and thorough manner in which this plague campaign on the island of Hawaii has been conducted.

Statistical data on the rat work at the service plague laboratory at Honolulu during the year.

Total rats and mongoose taken...................................... 235

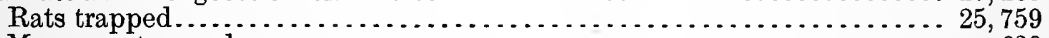

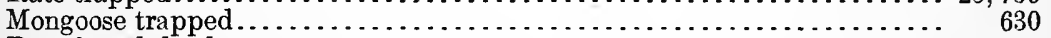

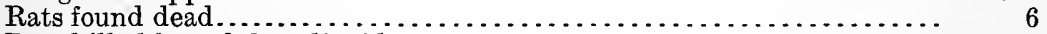

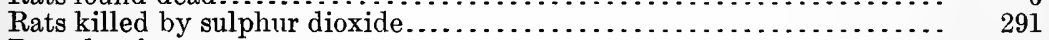

Rats shot from trees.................................... 549

Examined bacteriologically.................................. 23, 403

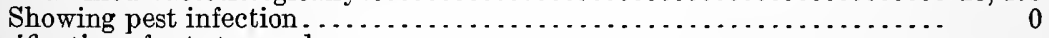

Classification of rats trapped:

Mus alexandrinus................................... 2,968

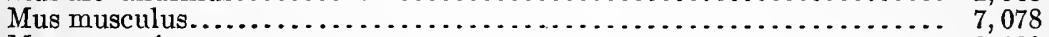

Mus norvegicus....................................... 2, 199

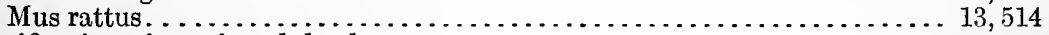

Classification of rats found dead:

Mus alexandrinus...................................... 1

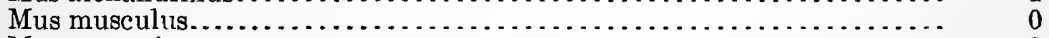

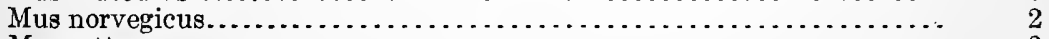

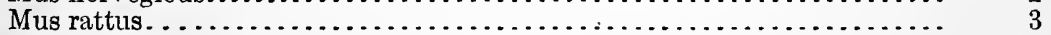

Classification of rats shot from trees:
$\quad$ Mus alexandrinus $\ldots \ldots \ldots \ldots \ldots \ldots \ldots \ldots \ldots \ldots \ldots \ldots \ldots \ldots \ldots \ldots$

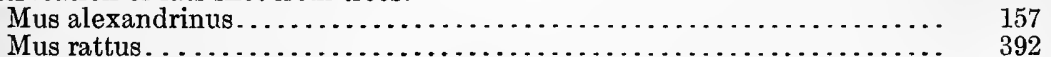

Classification of rats killed by sulphur dioxide:

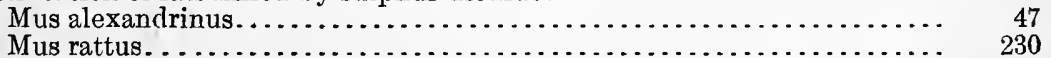

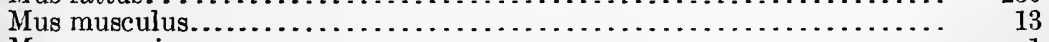

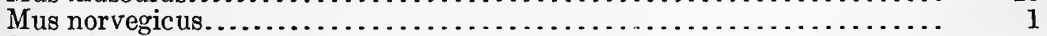

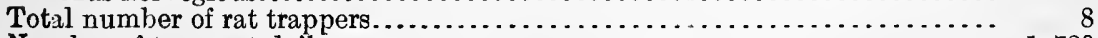

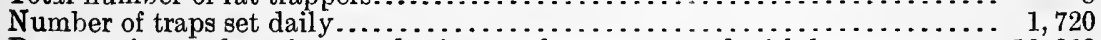

Decrease in number of rats and mice caught as compared with last year...... 10,868 
Hilo.

Number of Hilo rats referred to this laboratory for bacteriological diagnosis.

Number of Hilo human cases rejerred to this laboratory for bacteriological

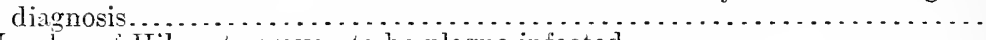

Number of Hilo rats proven to be plague infected . . . . . . . . . . . . . .

Number of Hilo human cases proven to be plague infected................

Number of Hilo rats not proven to be plague inferted....................

Number of Hilo hrman cases not proven to be plagne infected . . . . . . . . .

\section{Foreign Quarantine.}

The duties of officers of the Public Health and Marine-Hospital Service detailed at foreign ports are as follows:

First. The investigation into the previous whereabouts and the past and present sanitary history of all vessels destined for ports in the United States, its possessions, and dependencies.

Second. The inspection of vessels, crews, and passengers, and the certification of freight.

Third. The fumigation of ships to kill rats and mosquitoes, or the disinfection of ships when necessary.

Fourth. The observation, if necessary, under detention, of intending passengers for ports in the United States and its dependencies.

Fifth. Weekly reports of transactions.

Sixth. Weekly reports as to the health and sanitary conditions of the foreign port, and when possible of the country contiguous thereto.

Seventll. The certification; in conjunction with the United States consular officers, of the bills of health issued, said certificates to be made just prior to the departure of the ship and to cover all requirements provided for by the United States quarantine regulations.

\section{FRUIT PORT INSPECTION SERVICE.}

The fruit port inspection service was not maintained during this fiscal rear in accordance with the previous custom of maintaining acting assistant surgeons during the close quarantine season (Apr. 1 to Nor. 1) in the offices of the American consuls in the various Central American and West Indian fruit ports. The fruit ports were subjected to regular inspections by Acting Asst. Surg. R. P. Ames, who acted under the general supervision of Surg. J. H. White, who also made a survey of sanitary conditions in the "fruit ports which comprise Bocas del Toro, Panama; Bluefields, Nicaragua; Ceiba, Honduras; Livingston and Puerto Barrios, Guatemala; Port Limon, Costa Rica; and Puerto Cortez and Tela, Honduras.

\section{. INSPECTION AT OTHER FOREIGN PORTS.}

HABANA, CUBA.

The following is an extract from the report of Acting Asst. Surg. P. Villoldo for the fiscal year ending June 30, 1912:

Quarantine transactions.

Bills of health issued ....................................... 1,186

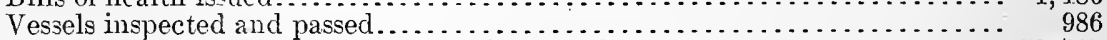

Member's of crews of outgoing vessels inspected........................... 53,617

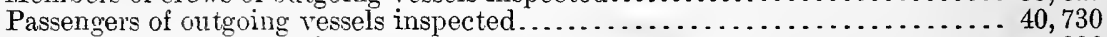

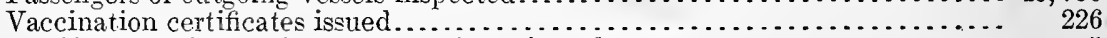

Certificates of immunity to yellow fever issued............................. 5 
Members of erews and passengers in boats sailing los the Linited States have been carefully inspected prior to depatrture, and whenever they were found to have abnormal temperature or any other sign of disease, note of the fact was made in the bill of houlti.

GENERAL TRANSACTIONS.

During the year medical attendance or minor surcical treatnent bas been given to 18 seamen from American bouts and to "2 men from party working on wreck of the U. S. S. Mains in Mabana Harbor.

Maj. Ferguson, in charge of the work on the Maine wreck. requested the officer at this station to reconstruct the skeletons that were found inside the wreck. 'This work was arconnplished with difficulty, as many of the bones were fractured or burned. Fifteen romplete skeletons and two incomplete ones were reconstructed.

Seven corpses of Americans who died in Cuba liave been embalmed and packed under the supervision of this offico prior to shipment to the United States.

GENERAL IHEALTH CONDITHS IV :THA.

The health conditions in Cuba during the year have becr good.

There have been no cases of quarantinable diseases, excepting a case of variola in a man who arrived in Cuba from Mexico in the stage of incubation, the invasion taking place two or three days after landing.

Toward the end of November, 1911, yellow fever was declared in Banes, Oriente Province, but the case wis soon reconsidered and declared negative.

Table showing, by months, the number of cases of transmissible diseases occurring in C"uiva.

\begin{tabular}{|c|c|c|c|c|c|c|c|c|c|c|c|c|}
\hline & 宫 & 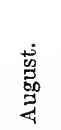 & 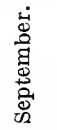 & $\begin{array}{l}\dot{0} \\
\stackrel{0}{0} \\
\stackrel{0}{0} \\
0\end{array}$ & 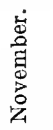 & 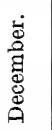 & 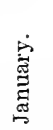 & 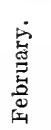 & $\begin{array}{l}\text { 总 } \\
\text { 恶 }\end{array}$ & 芯 & $\underset{\mathrm{z}}{\overrightarrow{\mathrm{z}}}$ & $\underset{\Xi}{\Xi}$ \\
\hline Taberculosis. & 163 & 157 & 137 & 136 & 134 & 122 & 131 & 133 & 146 & 143 & $13 i$ & 127 \\
\hline 1,eprosy........ & 6 & 5 & 11 & 5 & 5 & 6 & 5 & 6 & 1 & 2 & & 4 \\
\hline Malaria.......... & 144 & 120 & 135 & 152 & 198 & 196 & 142 & 129 & 152 & 122 & 104 & 114 \\
\hline 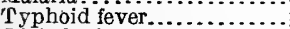 & 143 & 104 & 79 & 109 & 112 & 53 & 66 & 51 & 53 & 94 & 85 & 58 \\
\hline Diphtheria..... & 65 & 57 & 73 & 77 & 71 & 88 & 85 & 68 & 55 & 69 & 46 & 44 \\
\hline Scarlet fever..... & 19 & 14 & 9 & 10 & 3 & 59 & 18 & 27 & 31 & 26 & 43 & 10 \\
\hline Measles......... & 254 & 107 & 64 & 55 & 68 & 6 & so & 81 & 120 & 146 & 108 & 56 \\
\hline Varicella............. & 15 & 10 & 6 & 9 & 5 & 11 & 13 & 32 & 60 & 52 & 9 & 2 \\
\hline Fpidemic dysentery... & & & & 14 & & 1 & & & & & & \\
\hline Kabies..................... & & 2 & & & 1 & & & & & 8 & & \\
\hline Tetanus in newborn........ & 24 & 26 & 26 & 25 & 21 & 19 & 10 & 14 & 18 & & 16 & 27 \\
\hline Filariasis............................... & $\cdots$ & …... & & ....... & & & 2 & & & & & \\
\hline $\begin{array}{l}\text { Jengue........... } \\
\text { I terus gravis... }\end{array}$ & & & $\cdots \cdot$ & & 1 & & 1 & 1 & 2 & 3 & 4 & $\cdots$ \\
\hline Ifterus gravis.. & & & & & & & & & & & & \\
\hline
\end{tabular}

1 This table, as compared with the one of the previous year. shows a slight diminution in the number of cases of malaria, but on the other hand there has been an increase in the number of cases of typhoid fever, hetween th:e months of July and December.

HEALTH CONDITIONS IN HABANA.

The work of putting in the new sewer system in Habana has been continued, and during the first part of the year a large number of the streets were torn up, affording opportunity for rain water and sewage to collect in pools at many places in town. The work is now well advanced, and new pavement has been placed in all the principal 
streets and in a good many of the less important. 'The pavement consists of either Boston blocks, composition blocks, or asphalt; which kind is used depends on the traffic to which the street is subjected.

The water supply of the city has been somewhat scarce during the year. In explanation of this it was stated that many of the springs which supply the collecting cup had changed their course and now flow into the Almendares River. In order to remedy this, a dam was built to raise the level of the river in the neighborhood of the collecting cup. Several engineers claimed that this contrivance would result in the river water being driven into the collecting cup and the contamination of the water in the cup. After making a study of the conditions the writer believes that the collecting cup reccives about one-half of 1 per cent or less of river water. This contamination does not scem to have any injurious effects on the health of the inhabitants.

The oiling of water deposits has been carried out in an irregular manner, there having been lapses of several weeks when no work has been done in this direction.

The following table shows the number of deaths, by months, in the city of Habana during the fiscal year ending June 30, 1912:

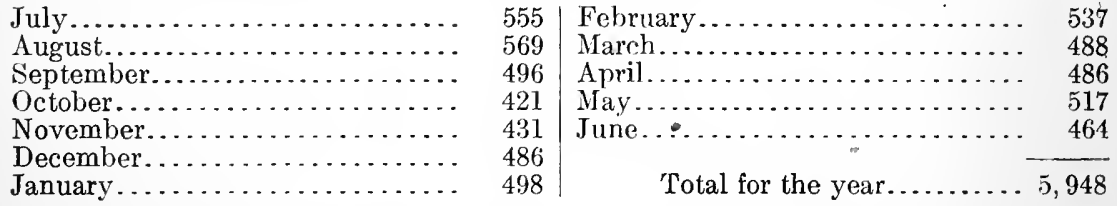

Taking the estimated population of Habana to be 330,000 , the annual mortality has been 18 per 1,000 .

CUBAN QUARANTINE TRANSACTIONS.

During the month of July, 1911, on account of a case of cholera which took place in New York City on July 22 in a man recently arrived in that city there was much alarm in town, and newspapers spoke of declaring quarantine against New York.

The local quarantine officers were concerned for some time, but soon it was understood that there was nothing to be feared from Now York, and nothing was done.

In August quarantine was declared by Cuban authorities against the State of Yucatan on account of cases of yellow fever being reported in Merida. At the same time Dr. Lebredo was sent to Merida to investigate the situation. His report stated that a good many cases were taking place, but that, although he had demonstrated a good many of these cases to the local health authorities, said cases were not officially reported.

On September 7 the Cuban quarantine service started to make bacteriological examination of feces of passengers coming from Mediterranean ports. This practice was continued for about four months, being discontinued when the cholera situation improved in Europe.

On June 20 the newspapers had news of an outbreak of plague at San Juan, P. R. This news was soon confirmed by cables sent to Cuban sanitary department from the bureau and from Porto Rico. On June 21 quarantine was declared by Cuban authorities against 
San Juan, P. R., and it was announced that Habana and Santiago, would be the only two ports in Cuba through which passengers from San Juan would be allowed to come into Cuba. At the same time the sanitary department started to distribute printed information about bubonic plague and its proplyylaxis and urging the destruction of rats. On June 29 it was announced that 5 cents would be pairl for every rat turned over to the sanitary department.

$$
\text { SALINA CRUZ, MEXICO. }
$$

Acting Asst. Surg. Alfredo E. Gochicoa reports as follows:

For the fiscal year ended June $30,1912,79$ ressels, 78 steamers and 1, sailing vessel, bound for ports in the United States and its insular possessions were iuspected, of which number 41 were fumigated. These vessels carried a total of 790 passengers and 3,429 crew. The fumigation of ressels learing Salina Cruz for ports in Hawaii is regularly performed for the destruction of mosquitoes.

The contagious diseases registered at Salina Cruz during the fiscal year reported have been as follows:

Asiatic cholera................. None.

Cholera nostras. .............. None.

Yellow fever....................

Smallpox................... Eight.

Typhus or ship fever........... None.

Typhoid fever..................

Scarlet fever................... None.

Diphtheria . ................... None.

Measles.....................

Whooping cough.............. Few cases.

Plague....................... None.

Relapsing fever................ None.

Tuberculosis.................. Not very frequent.

Malarial disease.................. Prevailing in the rainy season.

Total deaths from all causes during the fiscal year, 240 .

pUERTo Mexico (COATZaCoalcos), mexico.

Acting Asst. Surg. W. R. P. Thompson reports as follows: During the fiscal year ending June 30, 1912 (from Nov. 2, 1911, to Dec. 27, 1911, not included), 154 vessels were inspected, together with 7,415 persons in their crews and 748 passengers; 15 vessels were fumigated.

On February 28, 1912, a death from yellow fever was reported. This case was not confirmed; it originated at Acayucan.

On May 25, 1912, a death from yellow fever was reported. This case originated at San Juan Bautista, Tabasco, and was confirmed by autopsy.

The general health of the port during this time was good, the prevailing diseases being malaria and intestinal.

VERA CRUZ, MEXICO.

Acting Asst. Surg. I. A. Campbell reports (period May 1, 1912, to June 30, 1912):

Number of vessels inspected for United States ports. . . . . . . . . . . . . . 29

Number of vessels fumigated for United States ports..................... 12

Numbers of crew inspected....................................... 168

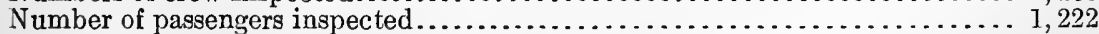

Steam vessels................................................. 38

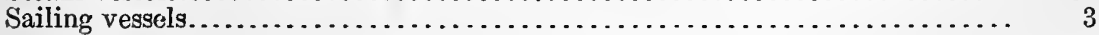

69450-H. Doc. 971, 62-3-8 
LA GUAIRA, VENEZUELA.

Acting Asst. Surg. W. J. S. Stewart reports as follows:

Mortality and morbidity from quarantinable diseases and the prevalence of such diseases.-Many persons regard all Venezuelan ports and inland cities as infected with yellow fever. This is not absolutely the case. The port of Maracaibo is infected-yellow fever is endemic there, and while there are not a great number of cases, still the disease is always present. The same has been true of the capitalCaracas-but if the present work of the health authorities be carried out this city will probably cease to be an endemic center of yellow fever. There has not been during the year 1912 any case of yellow fever in Puerto Cabello, and there have been but two cases in La Guaira. La Guaira is in the Department of Vargas, and consists for governmental purposes of three pueblos-La Guaira, Maiquitia, and Macuto. The latter place is about 5 miles from the port, and Maiquitia about $2 \frac{1}{2}$, although La Guaira and Maiquitia, being on the railroad to Caracas, are virtually continuous. Maiquitia and La Guaira, besides being on the railroad to Caracas, are connected by a narrow-gauge road, which continues on through La Guaira as far as Macuto. Yellow-fever cases have occurred during the year at Macuto and also in Maiquitia-more in both places than in La Guaira proper, as will be seen from the tables accompanying this report.

Plague--bubonic plague--has not been reported from any locality except Caracas during the year, and the cases and deaths from this cause will also be seen in the tables.

Other localities where yellow fever has been reported during the year, but no statistics have been available, are as follows: La Victoria, a city on the railroad between Caracas and Valencia; in Valencia, the terminus of the Grand Railroad of Venezuela; in El Valle (near Caracas), in Pitare, Guarenas, Guatire, Vela de Coro (in this locality there were a very considerable number of cases and deaths), and in Cua. These localities have all been reported to the bureau in the regular weekly reports from La Guaira.

Epidemic dysentery is present in almost all the larger cities-the amebic form - according to a very excellent report on the subject by Dr. Juan Iturbe. There is, however, one notable exception to the prevalence of this disease, and that is that the city of Ciudad Bolivar, on the Orinoco River, is virtually free from it, although the drinkingwater supply is taken almost entirely from the river in front of the city. This is explained (how efficiently is unknown) by the rapidity of the river current at the locality of the city.

The general mortality of Caracas for the seven months ending June 30, 1912 (before that date the records are not very reliable), was 1,610 in a population estimated at about 70,000 . The total mortality in La Guaira during the fiscal year was 435 in a population estimated at about 10,000. The figures include Maiquitia and Macuto.

Yellow fever occurred in La Guaira as follows during the fiscal year: November, 1911, 2 cases, and March, 1912, 1 case. In Macuto: March 17, 1912, 1 case; May 14, 1912, 2 cases, 1 death; May 28, 1912, 1 case, 1 death; and June 5, 1912, 1 case. In Maiquitia: July, 1911, 1 case, 1 death; February 25, 1912, 1 case; March 8, 1912, 2 cases; April 24, 1912, 1 case, 1 death; and June 17, 1912, 1 case and 1 death. 


\begin{tabular}{|c|c|c|c|c|}
\hline & \multicolumn{2}{|c|}{1911} & \multicolumn{2}{|c|}{1912} \\
\hline & Cases. & Jeaths. & Cases. & Deaths. \\
\hline $\begin{array}{l}\text { January............. } \\
\text { February ............. } \\
\text { March }\end{array}$ & $\begin{array}{l}25 \\
24 \\
15\end{array}$ & $\begin{array}{c}16 \\
9 \\
5\end{array}$ & $\begin{array}{r}12 \\
9\end{array}$ & 4 \\
\hline April......... & 10 & 12 & & \\
\hline May... & 6 & 6 & $\because 7$ & $\ddot{4}$ \\
\hline June.. & 7 & $\bar{j}$ & 1 & \\
\hline July & 9 & 8 & 8 & \\
\hline 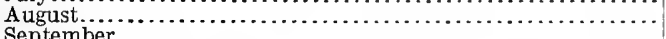 & 17 & 4 & 4 & 2 \\
\hline 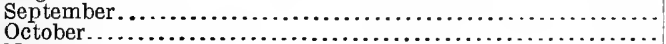 & 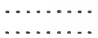 & $\begin{array}{r}6 \\
11\end{array}$ & & …........ \\
\hline November, & …......... & 8 & .... & \\
\hline 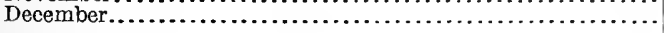 & .............. & 19 & & \\
\hline 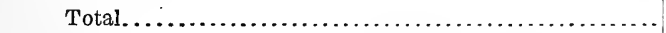 & 113 & 109 & 41 & 21 \\
\hline
\end{tabular}

There has not been a case of plague reported in the country during the fiscal year except in Caracas. Puerto Cabello and La Guaira are both absolutely free from this infection, also the suburbs of La Guaira, Maiquitia, and Míacuto.

Plague occurred in Caracas as follows during the years 1910, 1911, and 1912, to date. The figures in 1910 and 1911 are cases, not deaths, and the figures in the column 1912 include both cases and deaths. All cases occurring this year are fatalities.

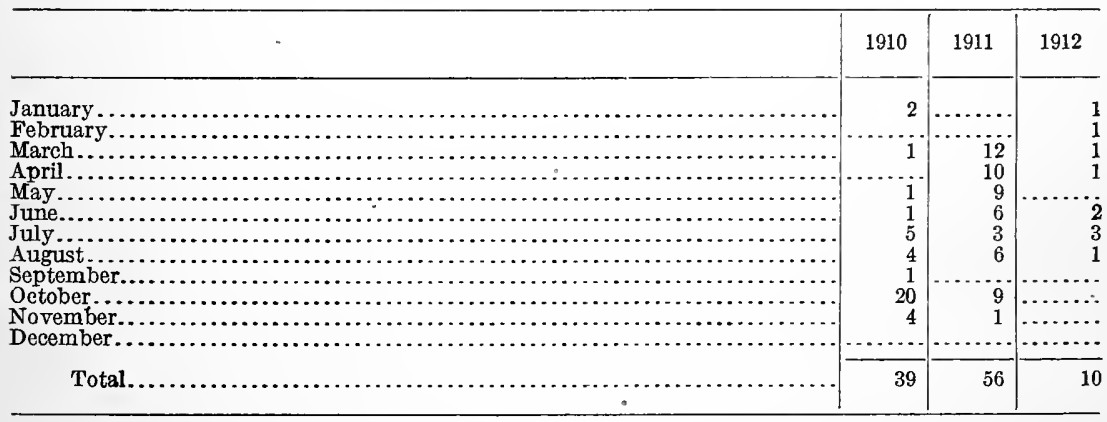

In regard to epidemic dysentery, a very serious epidemic occurred in Rio Chico and vicinity during May and June and July, 1912. This locality is about 60 to 70 miles to the eastward of La Guaira and near the coast, and is reached either by steamer or by railroad from Caracas for 30 miles and mule journey the remainder of the distance. It seems to have been occasioned by the repairs being made to an old Spanish aqueduct, which supplied the towns with drinking water. At all events, as soon as the aqueduct was opened the outbreak began. The aqueduct had not been cleaned for many years, perhaps never since the days when it was built by the early conquerors.

At all events, out of a total population of the four towns affectedvirtually one locality, however-not exceeding 11,000 persons, there were up to the middle of July, 1912, 1,298 cases of dysentery, and at the same time the health authorities sent to report also found no less than 1,206 cases of malarial fever. The fatalities were very heavy, those from dysentery amounting to 7.10 per cent and those from 
malarial fever to 2.78 per cent. The epidemic is still continuing, but in a m:lder form. The Government recognized the seriousness of the situation and sent the chief sanitary officer, a corps of assistants, and money and supplies to the stricken pueblos.

Tuberculosis, of course, is a very potent factor in the morbidity and mortality rates in Venezuela, but until such time as some means are taken to isolate cases and to prevent contamination of :ther well persons it will continue to be widespread.

\section{Summary of transactions for the year.}

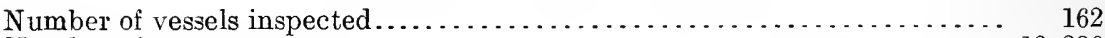

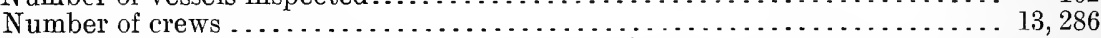

Number of passengers inspected (San Juan and Colon) ................ ${ }_{507}$

Number of pieces of luggage inspected (San Juan and Colon) . . . . . . . . . . 784

Number of passengers in transit. . . . . . . . . . . . . . . . . . . . .

Number of passenger excursionists.......................... 2, 471

Number of vessels fumigated at Puerto Cabello ....................... 28

GUAYAQUIL, ECUADOR.

Passed Asst. Surg. Herman B. Parker reports as follows:

Maritime quarantine. -During the fiscal year 69 bills of health were issued to vessels bound for United States territory; of these 58 were bound for the Canal Zone, 5 for San Francisco, and 6 for New York. Those vessels destined for the Canal Zone and San Francisco were subjected to a partial fumigation for the eradication of rats, except in instances where complete fumigation was done, owing to the presence of sickness on board or violation of the local quarantine regulations regarding anchorage. Those vessels bound for New York were inspected and passed only, according to custom, owing to the necessity of fumigation at a port south on the Pacific coast and our own quarantine station treatment on the Atlantic coast. In one instance it was impossible to inspect a vessel, the steamship Condor, leaving Guayaquil January, 1912, on account of the existence of a local revolution, and it is believed that that ressel was the means of conveying yellow fever to the Chilean coast, which resulted in many deaths.

During the fiscal year there were inspected 4,963 members of crews, 1,438 cabin passengers; and 1,332 steerage passengers.

Owing to the new regulations all passengers have been uniformly inspected and certificates issued prior to embarkation as well as the regular inspection on board ship.

The following is a summary of quarantine transactions for the year:

Bills of health issued .......................................... $\quad 69$

Vessels inspected and passed ............................................

Vessels passed without inspection.......................................... ${ }_{2}$

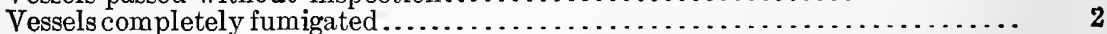

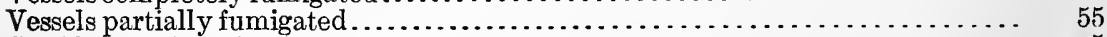

Certificates of fumigation ............................................

Number of crew inspected .......................................... 4,963

Number of eabin passengers inspected $\ldots \ldots \ldots \ldots \ldots \ldots \ldots \ldots \ldots \ldots \ldots \ldots \ldots \ldots \ldots, 1,438$

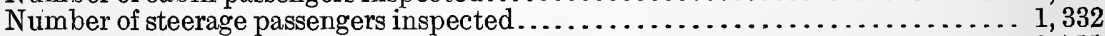

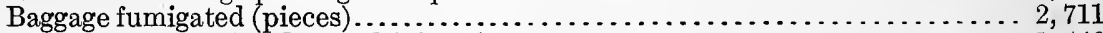

Baggage inspected and passed (pieces) ............................ 1, 440

Anchorage.-Ships bound for the Canal Zone use the anchorage below a point known as the "Matadero." This anchorage was 
adopted last year, and while it has been the cause of considerable complaint, it has also been the principal argument for the permanent sanitation of the city. Dr. Parker has always made it known to the authorities or those interested that as soon as the city was free from yellow fever that all vessels may anchor in front of the city, to the great relief of commerce and comfort of the traveling public. It is believed that this practical suggestion was the means of arousing and keeping before the public a general interest in sanitation.

Fumigation of vessels. - Owing to the above anchorage vessels are fumigated for the destruction of rats and vermin as possible conveyers of plague. As vessels are not permitted to dock and all cargo is carried to and fro in open lighters, the possibility of rat infection is reduced to a minimum, so much so that during the prevalence of plague infection at this port no suggestion has been made of ship infection. This danger can still further be reduced to a minimum if vessels from plague-infected ports be restricted to open bays or rivers at home ports and denied absolutely the privilege of docking. It is not believed that infection is fostered through commercial intercourse, except through the medium of rats gaining access to vessels while in dock at plague-infected ports. Likewise ships from plague-infected ports should not be permitted to dock at home ports in order that the ship may be kept as free as possible from these rodents, thus reducing the danger of accidental infection and propagation to a minimum.

Sulphur gas is the fumigating agent used. As a rule, it is generated in a Clayton apparatus, and from there pumped to the various parts of the vessel as required.

Certificates for cargo. - Cargo certificates at Guayaquil are restricted to hides, cotton, and kapoc, a vegetable wool. The former are required to be poisoned with arsenic and then fumigated on board the vessel, while the latter two are required to be freed from seeds. Cereals and rat foods generally are refused shipment. 'During the fiscal year 126 certificates were issued.

Yellow fever on board vessels.-During the month of January this disease appeared simultaneously on three vessels anchored in front of the city. One of these vessels was the U.S. S. Yorktown, on which 8 cases appeared with 2 deaths, 1 of which was Commander Bertolette, who died on the night following the surrender of the city to the Government forces. Seven of these cases were treated in a hastilyconstructed hospital in the service office with 1 death. In this aid to the Navy Department an American missionary, Mr. Reed, rendered valuable service, and to his untiring efforts only was it possible to obtain such good results. Every effort was made to detect the presence of the Stegomyia mosquito on board this vessel, but though hundreds of mosquitoes were taken the presence of this mosquito was not determined.

Plague on board vessels.-Only one case as far as known developed plague after leaving Guayaquil during the period covered by this report. This passenger recently arrived from the Orient, presented such a paludic aspect that he was advised to remain in Guayaquil until his condition improved. He remained 10 days and was then permitted to sail. During this period he contracted plague, which developed en route to Panama, where he subsequently died. 
Yellow fever in Guayaquil.-During the fiscal year there were reported 351 new cases of yellow fever with 208 recoveries and 155 deaths. This is an increase of 50 as compared with the previous year. It must be remembered, however, that during the last 16 days of December and during the entire month of January no reports were received from the director of health on account of the existing revolution. During this period it is impossible to accurately estimate the number of cases and deaths of this disease. A moderate estimate would probably be about 300 cases with a mortality of about 50 per cent. These cases occurred principally among the troops of the constitutional army, though many foreigners were also attacked.

Appended is a tabular statement showing the disease in 15-day periods for the year.

Yellow fever outside of Guayaquil.-This disease assumed epidemic proportions along the line of the railroad from Duran to Bucay, especially so when the number of nonimmune population is taken into consideration. In Duran there were re ported 22 cases with 8 deaths; in Yaguachi, 3 cases with 1 death; Milagro, 48 cases with 30 deaths; Naranjito, 22 cases with 13 deaths; Bucay, 14 cases with 6 deaths; Huigra, 1 case with no death; Catarama, 1 case with 1 death; Babahoyo, 2 cases with 2 deaths; Changui, 1 case with 1 death; Chobo, 5 cases with 1 death; and in Naranjal, 1 case with no death. No reports were received during the latter half of the month of December and the entire month of January. It is believed that many cases occurred that did not come under the observation of the sanitary authorities.

Appended is a table showing the disease in 15-day periods.

Plague in Guayaquil. - The total number of plague cases reported for the fiscal year was 361 , of which 224 recovercd and 136 died, a mortality of 60.71 per cent. This is a decrease of 241 as compared with the previous year. October, November, and December were the months of greatest prevalence. This year the disease was almost exclusively confined to the outskirts of the city, and with one or two exceptions to the native population.

Appended is a table showing the progress of the disease in 15-day periods for the year.

Plague outside of Guayaquil.- - Owing to the heavy rains and the fact that the entire country for 60 miles was practically under water this disease had little opportunity to spread. Communication was also cut off from many of the small river towns on account of the revolution, so that it may be said that the disease was confined to Guayaquil.

Malarial fevers in Ecuador. - This year was noted for the extent of the malarial infection not only in the coast cities but well up in the interior. The most of these cases were of the quotidian type, though as reported last year those cases from the altitudes frequently showed the tertian type. The only anopheles mosquito taken was the Anopheles argyrotarses subspecies Albipes.

Hookworm infection in Ecuador.-A report of the prevalence of this infection in Ecuador was submitted last year. During the present year it has been found that the infection prevails to an extent greater than was supposed. There are localities where it is thought no one is exempt from the disease, and the general use of the hemoglobinometer would not show an average greater than 40 per cent. A few of the people interested have been shown how easy it is to cure the condition and are giving routine treatment to their employees. 
Typhoid fever in Guayaquil.-This fiscal year has been characterized, among other things, by an epidemic of typhoid fever of considerable proportions. This disease commenced apparently in Posorja, a watering place near the Gulf, and was then brought to the city, where, in the absence of sewers and the disinfection of the excreta, several hundred cases have developed. No atteinpt is made to induce immunity by inoculation.

Poliomyelitis in G'uayaquil.-During the last three months several cases of this disease have come under observation.

Tuberculosis in Guayaquil.-This disease as reported last year is extremely widespread and probably causes more deaths than all the other contagious or infectious diseases combined. The habits of the people are largely responsible for the extent of the infection.

Leprosy in Ecuador.-There was considerable criticism on account of the report last year that this disease prevails to any extent in icuador. During the year a number of new cases have been seen, and it is believed that the disease is more common than was supposcd last year.

Permanent sanitary improvements during the fiscal year.-During the fiscal year no permanent sanitary improvements were reported, but with the failure of the existing contract it is believed that negotiations will soon be opened leading to the sanitation of the entire infected area of the Republic.

Following are two tables received from the director of health, Dr. Cornejo Gomez, showing the origin of all cases of plague and yellow fever reported in the city of Guayaquil during the last three years. It will be noted in these tables that yellow fever is reported most frequently in the center of the city, while plague is reported mostly in the outskirts.

Yellow fever in Guayaquil, Ecuador, during the fiscal year 1912.

\begin{tabular}{|c|c|c|c|c|c|}
\hline . & $\begin{array}{l}\text { Previ- } \\
\text { ously ex- } \\
\text { isting. }\end{array}$ & $\begin{array}{l}\text { New } \\
\text { cases. }\end{array}$ & $\begin{array}{l}\text { Recov- } \\
\text { ered. }\end{array}$ & Died. & $\begin{array}{l}\text { Remain- } \\
\text { ing. }\end{array}$ \\
\hline 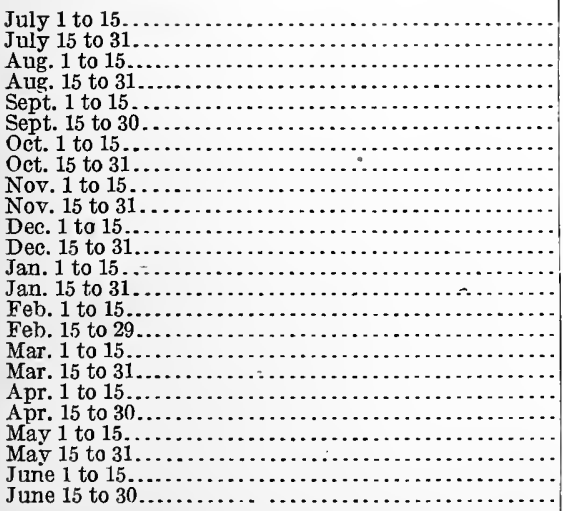 & 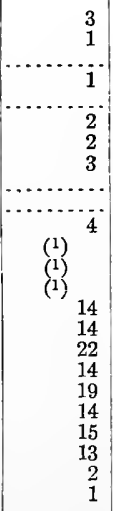 & $\begin{array}{r}1 \\
4 \\
4 \\
3 \\
3 \\
2 \\
5 \\
8 \\
7 \\
8 \\
8 \\
12 \\
(1) \\
(1) \\
\\
\\
(1) \\
45 \\
53 \\
50 \\
46 \\
29 \\
26 \\
27 \\
10 \\
4 \\
4\end{array}$ & 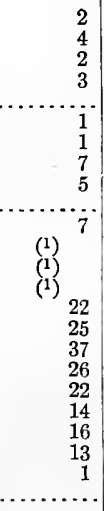 & $\begin{array}{rr} & 1 \\
1 \\
1 \\
1 \\
1 \\
1 \\
1 \\
1 \\
3 \\
4 \\
2 \\
\\
\\
4 \\
(1) & 7 \\
(1) & \\
(1) & \\
& \\
& \\
& 20 \\
21 \\
15 \\
12 \\
12 \\
11 \\
13 \\
8 \\
4 \\
2 \\
2\end{array}$ & ....... \\
\hline Total.......... & & 351 & 208 & 155 & 3 \\
\hline
\end{tabular}

1 During this period no report was received from the director of health on account of the existing revolu. tion. This disease prevailed very cxtensively during this period. 
Yellow fever outside of Guayaquil, Ecuador, during the fiscal year 1912.

\begin{tabular}{|c|c|c|c|c|c|c|c|c|c|c|c|c|c|}
\hline & $\frac{\dot{b}}{\vec{B}}$ & 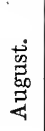 & 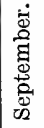 & $\begin{array}{l}\frac{8}{8} \\
\frac{0}{0} \\
\stackrel{0}{0}\end{array}$ & 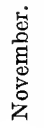 & 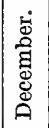 & 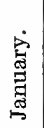 & 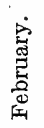 & 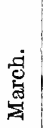 & 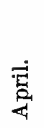 & 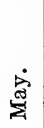 & 弯 & 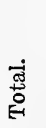 \\
\hline $\begin{array}{l}\text { Duran: } \\
\text { Cases...... }\end{array}$ & & & 1 & 3 & & 3 & (1) & 10 & 2 & 1 & 1 & 1 & 22 \\
\hline Deaths... & $\cdots$ & $\cdots \cdot$ & .... & 1 & $\cdots$. & $\stackrel{\overrightarrow{0}}{2}$ & (1) & 4 & & & 1 & $\ldots$ & 8 \\
\hline $\begin{array}{l}\text { Yaguachi: } \\
\text { Cases... }\end{array}$ & & & & & & & (1) & 1 & & 2 & & & 3 \\
\hline Deaths.. & 1 & .... & .... & . & & ... & (1) & & .. & & $\cdots$ & $\cdots$ & 1 \\
\hline Milagro: & & & & & & & & & & & & & \\
\hline Cases $\ldots \ldots \ldots \ldots \ldots \ldots \ldots \ldots$ & 8 & 1 & .... & 3 & 2 & 7 & (1) & 8 & 2 & 7 & 5 & 5 & 48 \\
\hline $\begin{array}{l}\text { Deaths } \\
\text { Naranjito: }\end{array}$ & 8 & .... & .... & $\cdots$ & 1 & 1 & (1) & 6 & 2 & 6 & 2 & 4 & 30 \\
\hline $\begin{array}{l}\text { Naranjıto: } \\
\text { Cases } . \ldots \ldots \ldots \ldots \ldots \ldots \ldots \ldots \ldots \ldots \ldots \ldots \ldots \ldots \ldots\end{array}$ & 2 & & $\mathbf{3}$ & & 1 & & (1) & 2 & 1 & 7 & 4 & 2 & 22 \\
\hline 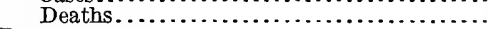 & & $\cdots$ & 1 & & 1 & ... & (1) & 2 & 1 & 4 & $\begin{array}{l}4 \\
2\end{array}$ & 2 & 13 \\
\hline Bucay: & & & & & & & & & & & & & \\
\hline Cases.... & $\ldots$ & . . & ... & 3 & 5 & & (1) & 5 & & & & 1 & 14 \\
\hline 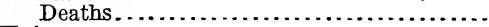 & .... & .. & ... & 1 & 3 & $i$ & (1) & 2 & ... & & .... & .... & 7 \\
\hline Huigra: & & & & & & & & & & & & & \\
\hline Cases... & & & .... & & & ... & (1) & $\ldots$. & 1 & & ... & & 1 \\
\hline Deaths. & $\ldots$. & $\cdots$ & $\cdots$ & & & $\cdots$ & (1) & $\ldots$ & & & $\cdots$ & .... & .... \\
\hline Catarama: & & & & & & & & & & & & & . \\
\hline Cases................... & 1 & & & & & & (1) & & & & & & 1 \\
\hline $\begin{array}{l}\text { Deaths } \\
\text { Ban }\end{array}$ & 1 & ... & ... & ... & .... & $\cdots$ & (1) & ... & & & $\cdots$ & $\cdots$ & 1 \\
\hline $\begin{array}{l}\text { Babahoyo: } \\
\text { Cases...................... }\end{array}$ & 1 & 1 & & & & & (1) & & & & & & \\
\hline Deaths........................... & 1 & 1 & & & & $\cdots$ & (1) & .... & $\ldots$ & &. & $\cdots$ & 2 \\
\hline Changue: & & & & & & & & & & & & & \\
\hline Cases $\ldots \ldots \ldots \ldots \ldots \ldots$ & & & 1 & $\ldots$ & & .... & (1) & & & & & ... & \\
\hline 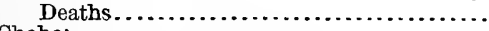 & ... & $\ldots$ & 1 & & & $\cdots$ & (1) & .... & . & & $\cdots$ & $\ldots$ & 1 \\
\hline Chobo: & & & & & & & & & & & & & \\
\hline Cases... & & & & & 2 & 1 & (1) & .... & & & & 2 & 5 \\
\hline $\begin{array}{l}\text { Deaths. } \\
\text { Naranjal: }\end{array}$ & $\cdots$ & & & & & ... & & .... & & & & & \\
\hline Cases.. & & & & & & & (1) & & 1 & & & & \\
\hline & & & & & & & & & & & & & \\
\hline
\end{tabular}

1 Reports were not received from Dec. 15, 1911, to Feb. 1, 1912, owing to the existing revolution.

Plague in Guayaquil, Ecuador, during the fiscal year 1912.

\begin{tabular}{|c|c|c|c|c|c|}
\hline & $\begin{array}{l}\text { Previ- } \\
\text { ously ex- } \\
\text { isting. }\end{array}$ & $\begin{array}{l}\text { New } \\
\text { cases. }\end{array}$ & Cured. & Died. & $\begin{array}{l}\text { Remain. } \\
\text { ing. }\end{array}$ \\
\hline 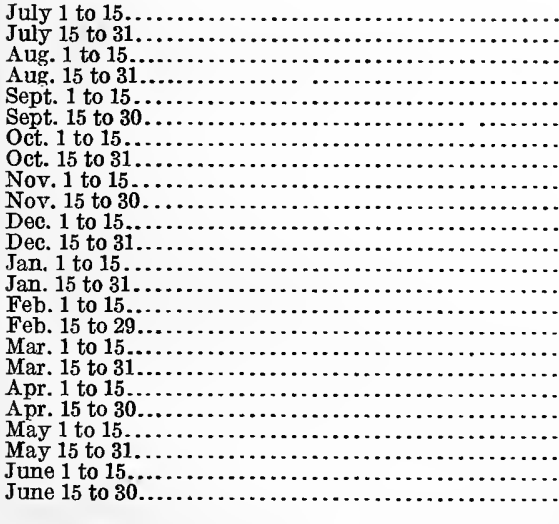 & 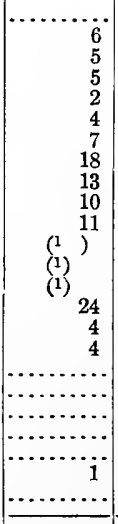 & $\begin{array}{rr} & 7 \\
10 \\
9 \\
9 \\
9 \\
15 \\
22 \\
41 \\
41 \\
51 \\
57 \\
& 46 \\
& 56 \\
(1) & \\
(1) & \\
(1) & \\
& 13 \\
& 9 \\
& 8 \\
& 4 \\
\ldots \ldots . .\end{array}$ & 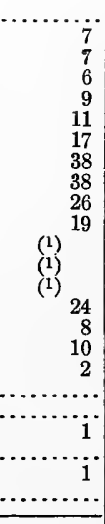 & $\begin{array}{rr} & 1 \\
4 \\
2 \\
6 \\
4 \\
4 \\
8 \\
13 \\
18 \\
22 \\
19 \\
\\
\text { (1) } \\
23 \\
(1) \\
(1) \\
\\
\\
& \\
& 1 \\
& 2 \\
& 2\end{array}$ & 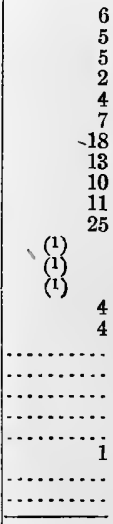 \\
\hline Total.................. & & 361 & 224 & 136 & \\
\hline
\end{tabular}

${ }^{3}$ During this period no report was received from the director of health on account of the existing revolution. 
HONGKONG, CHINA.

Surg. B. W. Brown reports as follows:

Bills of health were issued to 443 vessels, anrying 1:2,5th abin passengers, 19,725 steerage, and 41,495 in (crews; 16,60:3 steerage and 31,398 members of crew were bathed, and 48,58: pieces of baggage were disinfected; 103 vessels were fumigated with sulphur and 1,146 rats killed. The crews' quarters on 340 vessels were disinfected with either formaldehyde or bichloride of mercury. 'The following list of cargo was either stored or disinfected:

Human hair (cases)

Bristles (cases).

Hides (pieces)

Old rubber (bales)

Feathers (bales)..

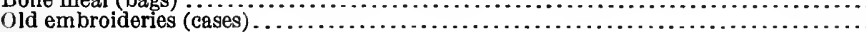

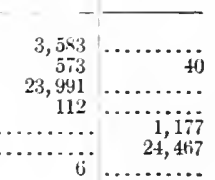

The rat reports from the colonial Government give a total of 93,474 rats caught during the fiscal year, and of this number 398 were infected. The following communicable diseases were reported during the fiscal year:

Cases. Deathe.
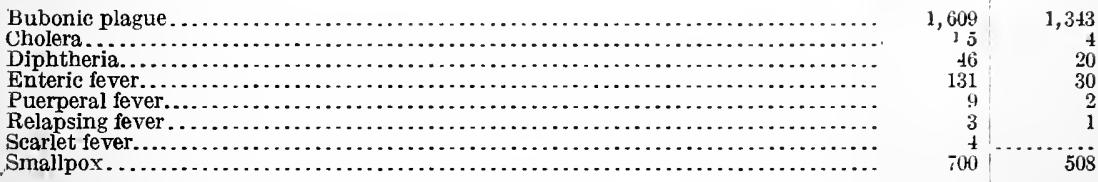

1 Imported.

The epidemic of plague which began in April, 1911, gradually diminished, only 56 cases and 25 deaths occurring in July, and 20 cases with 2 deaths in August. The last case was reported on August 18, 1911. During the autumn and early winter an occasional case occurred. The present epidemic began in January, 1912, and to date there have been reported 1,520 cases with 1,270 deaths. This has been the most serious epidemic for the past 10 years. A small proportion of the cases were pneumonic plague and no case occurred among the Europeans. Along with the epidemic of plague Hongkong has experienced quite a severe epidemic of smallpox. A small number of cases occurred during the summer and autumn of 1911, but the real epidemic did not begin until November, 1911; since this time 741 cases with 537 deaths were reported; the epidemic ceased about June 1, and at present the port is free from smallpox. Nothing new in sanitary procedure or treatment was dereloped during this epidemic. Crews, steerage, and second-class passengers were required to be vaccinated, and first-class passengers advised to be vaccinated and a glandular examination made and temperature taken. From March 12 to June 30, 1912, 28 cabin passengers, 105 steerage, and 44 of the crews were removed from various vessels 
at the regular inspections, suffering with fever. No definite diagnosis could be made. Two of these removals, the only ones that could be traced after leaving the ships, died five days later with plague. In spite of our careful examinations 1 of the crew died en route to Manila and another case died in Manila two or three days after passing the Manila quarantine, and 1 case occurred on a vessel bound for the United States before reaching Japan. At present the plague is rapidly diminishing.

AMOY, CHINA.

Acting Asst. Surg. A. Bonthius reports as follows:

Forty-five original bills of health were granted, 1 to U. S. S. Monterey and 44 to 3 British steamers going direct to Philippine Islands. These steamers run between Amoy and Philippine Islands only.

Three supplemental bills of health were granted.

On the British steamers, 4,612 passengers sailed to the Philippine Islands. This number includes cabin and steerage passengers, and is composed of almost entirely Chinese, occasionally a European.

All passengers are carefully examined just before the hour of sailing, especially with reference to temperature, and in plague season for swollen painful glands also. All doubtful passengers are refused passage. All steerage passengers and the ship's Chinese crew are bathed and their clothes disinfecter just before the hour of sailing. Any cabin passengers considered needing to be bathed and their clothes disinfected are likewise bathed and their clothes disinfected.

The ships running regularly between Amoy and the Philippines are fumigated twice yearly with sulphur.

All domiciled Chinese of the Philippine Islands returning to China on leave of absence requiring recommendation for "overtime certificates" on account of health reasons are examined at the consulate and accepted or rejected.

SHANGHAI, CHINA.

Acting Asst. Surg. S. A. Ransom reports as follows:

Transactions.

Vessels spoken and passed..................................... $\quad 16$

Steamers inspected and passed $\ldots \ldots \ldots \ldots \ldots \ldots \ldots \ldots \ldots \ldots \ldots \ldots \ldots \ldots, 152$

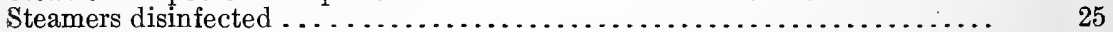

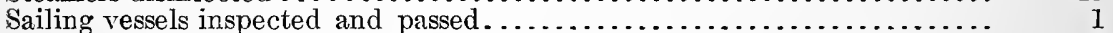

Sailing vessels disinfected.................................. 1

Number of crew on steamers.............................. 21, 817

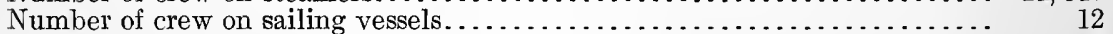

Number of passergers on steamers.................................. 15, 275

Number of bills of health issued.............................. 169

Number of persons bathed......................................... 1,442

Number of pieces of baggage disinfected $\ldots \ldots \ldots \ldots \ldots \ldots \ldots \ldots \ldots \ldots \ldots, 1,731$

Number of pieces of freight viséed $\ldots \ldots \ldots \ldots \ldots \ldots \ldots \ldots \ldots \ldots \ldots \ldots \ldots . \ldots \ldots 7,169$

Number of pieces of freight disinfected $\ldots \ldots \ldots \ldots \ldots \ldots \ldots \ldots \ldots \ldots \ldots \ldots, 4,184$

The duties of the officer in charge of this station include the issue of all bills of health granted to vessels bound from Shanghai to the United States, the Philippine Islands, Honolulu, the Canal Zone, etc. The disinfection of vessels infected with disease or for the destruction of disease-carrying vermin, bathing of personnel where necessary and the disinfection of their effects, the supervision of all cargo shipped, the inspection and disinfection of such goods as require it, and the 
issue of all certificates covering the sanitary condition of ships, personnel, and cargo. In addition lighters conveying cargo to the vessels mentioned above are fumigated periodically, to keep them as free as possible from rats, etc.

All of this work is done under the immediate personal supervision of the medical officer in charge here. Inspections are invariably held before issuing bills of health, except in the case of United States naval vessels, and with regard to these a certificate as to their sanitary condition is accepted from their medical officers. The freight which passed under the eye of this office during the year just closed aggregated over 80,000 tons.

Quarantinable disease.-- Of these diseases, smallpox, leprosy, and plague are found in Shanghai the year around, the latter disease for the most part in rats. But there were quite a number of human cases also last year. Cholera appears each year, but there was no epidemic of this disease last year. Yellow fever is at present unknown here, but with the opening of the Panama Canal and the fact that Stegomyia calopus is found here in considerable numbers, and the additional fact that their breeding places can not possibly be destroyed because of the conditions necessary for rice cultivation, the date of the appearance of this disease is probably not far distant.

One case of plague, diagnosed post mortem by culture and inoculation, was removed here in May from the Panama Maru, en route Hongkong to Tacoma. The vessel was held up and disinfected in Kobe upon information from this office, the steamer having sailed before diagnosis was made.

Vessels from Shanghai to ports under the jurisdiction of the United States are, as heretofore, required to lie in the stream and use lighters for loading and unloading. Loading is restricted to daylight as far as possible-in the majority of cases it is carried on exclusively by daylight-and rat guards are required to be used on all lines day and night. In addition, the lighter companies are required to have their boats fumigated with sulphur periodically under the supervision of this office, the work being done by the Shanghai Disinfecting Co. This concern, however, has become quite independent lately, owing to a very large increase in the work.

YOKOHAMA, JAPAN-QUARANTINE AND SANITATION IN JAPAN.

Surg. Fairfax Irwin reports, in part, as follows for the fiscal year ended June 30, 1912:

\section{Summary of transactions.}

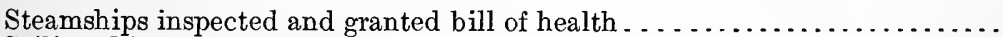

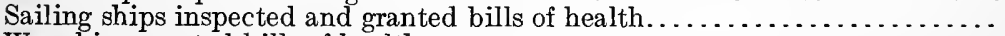

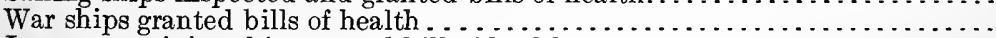

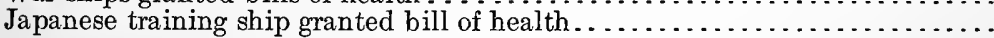

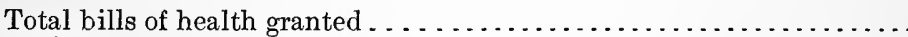

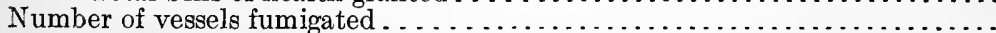

Saloon passengers upon the above vessels $\ldots \ldots \ldots \ldots \ldots \ldots \ldots \ldots \ldots \ldots \ldots, 8,115$

Second-class passengers upon the above vessels $\ldots \ldots \ldots \ldots \ldots \ldots \ldots \ldots \ldots \ldots, 2,913$

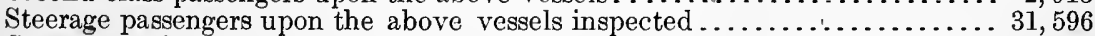

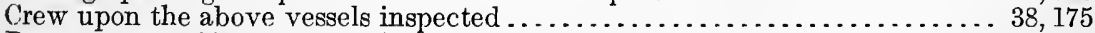

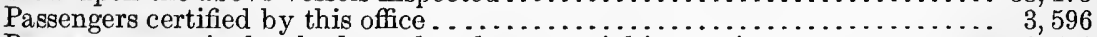

Passengers required to bathe and undergo special inspection . . . . . . . . . . 3,560

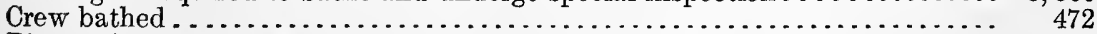

Pieces of steelage baggage disinfected under supervision of this service...... 8, 108 
On incoming vessels to this port the following cases of quarantinable disease were noted: A case of smallpox on steamship China, from Honolulu. The medical officer at Hongkong was notified, the vessel being due there November 17 . The proper precautions were there taken. A telegram received from the consul general at Hongkong June 19 stated that two Filipinos landed there from steamship Persia had died of plague. The ship was due to arrive at this port the same evening. The Japanese harbor authorities were notified and the ship was remanded to the quarantine station at Nagahama. A case of smallpox was brought on steamship Tenyo Maru on 23d of March and landed at Nagahama. The usual precautions were taken.

In Yokohama, during the year ending December 31, 1911, the following cases of contagious diseases were reported, namely:

\begin{tabular}{|c|c|c|}
\hline & Cases. & Deaths. \\
\hline 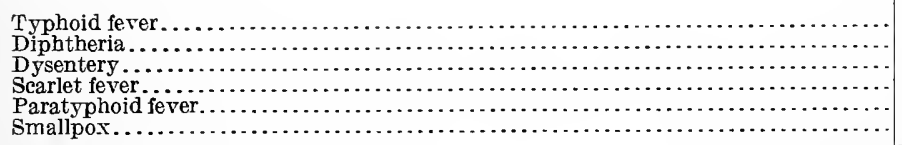 & $\begin{array}{r}266 \\
155 \\
61 \\
79 \\
21 \\
2\end{array}$ & $\begin{array}{r}56 \\
49 \\
19 \\
22 \\
2\end{array}$ \\
\hline Total.. & 584 & 139 \\
\hline
\end{tabular}

Two cases of smallpox were reported-on June 19 an East Indian, just returned from Vladivostok, and on November 16 a resident returned from Honolulu per steamship China.

During this year, ending May 31, from January 1, there were the following cases of contagious disease reported at this port, viz:

\begin{tabular}{|c|c|c|}
\hline & Cases. & Deaths. \\
\hline $\begin{array}{l}\text { Typhoid fever } \ldots \ldots \ldots \ldots \ldots \ldots \\
\text { Diphtheria }\end{array}$ & $\begin{array}{l}30 \\
74\end{array}$ & $\begin{array}{l}10 \\
17\end{array}$ \\
\hline $\begin{array}{l}\text { Diphthera } \\
\text { Dysentery }\end{array}$ & $\begin{array}{r}74 \\
8\end{array}$ & \\
\hline 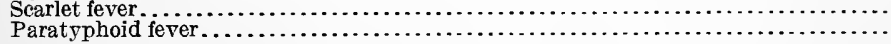 & $\begin{array}{l}6 \\
1\end{array}$ & \\
\hline Total... & 119 & 27 \\
\hline
\end{tabular}

During the year 1911, ending December 31: The number of rats bought by the city health office was 302,562 . No infected rat was found. The last infected rat was found on July 25, 1909. The last case of human plague was on July 12, 1909.

Vaccination.-There were 18,661 cases during the year 1911. Of the above 9,258 were successful and 9,403 unsuccessful, including 4,375 of second vaccinations.

All vessels for the Philippine Islands when empty, or carrying cargo not likely to be injured by the process, are required to be fumigated, as also all vessels bound for American ports. All steerage passengers are bathed and their effects steamed. The same precautions are taken for second-class passengers, unless their personal history is proved to be favorable. Consular invoices and boat notes are viséed and certificates of origin for foodstuffs are required with the invoices. Certificates of fumigation for plants and bulbs destined for California are required. Disinfection is required for human hair, 
skins, feathers, and porsonal eflects of undetermined origin. Attontion is invited to the uncertainty of fumigation of passenger ressels in transit. At the quarantine station at Nagahama it is fone with carbon monoxide gas. As is known, this gas although fatal to rats does not kill fleas, and yet sulphur can not be used for fear of injury to the cargo. The difliculty of disinfecting old passenger slips was illustrated in the case of the stramship Persia, fumigated at Nagrihama with carbon monoxide gas. A number of rats were killerl, although the vessel had been disinfected a few days before with sulphur at Hongkong. Captains of ressels of ten objact strenuously to the disinfection of storerooms, principally it is believed on account of the difficulty of removing stores. Naturally storerooms are more likely to harbor rats than any other part of a ship. A certificate of disinfection is never granted unless all storerooms and forecastle are are thoroughly fumigated as well as holds.

\section{Sanitury conditions-Empire of Japan.}

Cholera.-There were only 9 cases and 4 deaths reported during the year ended December 31, 1911.

Dysentery.-According to the annexed official statistical table there were 27,466 cases and 6,009 deaths. This shows a slight decrease compared to that of the previous year.

Typhoid fever.- This disease also shows a slight decrease in total cases, 34,138 , and 6,830 deaths.

Smallpox.-There were 202 cases and 34 deatlis. Most of these were in Nagasaki-ken, having been reported there 142 cases and 23 deaths.

Typhus fever.-There were only 3 cases, all fatal.

Scarlet fever.-This disease shows an apparent decrease. There were reported 1,339 cases and 200 deaths. Comparing this to the previous year, the number reported for same time was 2,359 cases and 464 deaths.

Diphtheria.-This disease shows an increase over the previous year. There were 20,094 cases and 5,228 deaths.

Plague.-No human plague was reported in Japan, except in TaiWan (Formosa), during the year ended December 31, 1911.

Leprosy.-The number of cases of this disease now under treatment in hospitals is 1,254 .

The attached table explains the sanitary conditions of different districts of Japan.

The following report of infectious and contagious diseases for the four months ending April 30 in Japan has just been received.

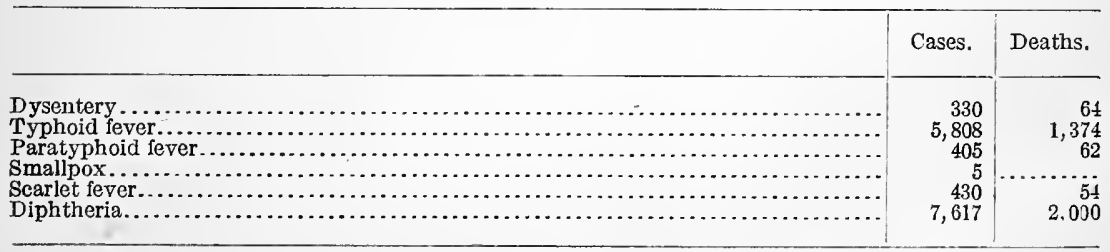

Sanitary conditions of Yokohama. - The population of Yokoliama, according to the last census of December 31, 1911, is given as 444,039 . The registered births were: Male, 4,700, and female, 4,278, making a 
total, 8,978. The deaths were 6,754 . The anmual death rate was 15.22, as compared with 13.8 last year. The official report of contagious diseases has been given in a previous paragraph. There have been no cases of human plague or cholera and but two cases of smallpox during the year 1911 .

Formosa.-Epidemic disease in Formosa presented the following number of cases: Plague, 380 cases with 334 deaths; dysentery, 207 cases and 80 deaths; smallpox, 3 cases; typhoid fever, 760 cases and 163 deaths; diphtheria, 69 cases and 37 deaths; scarlet fever, 8 cases and 1 death.

KOBE, JAPAN.

Acting Asst. Surg. Garland P: Moore reports in part as follows on the transactions at this station during the fiscal year ending June 30, 1912:

Steam vessels inspected and granterl bills of health 274

Sailing vessels inspected and granter bills of health. . .

Total bills of health granted.............................. 276

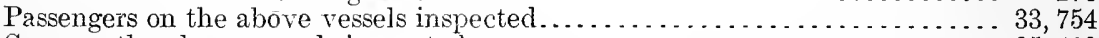

Crew on the above vessels inspected . . . . . . . . . . . . . . . . . . . . . . . 35,410

Pieces of baggage disinfected ............................... 7,530

Number of persons bathed, disinfected, and their effects disinfected........ 4, 860

Vessels fumigated....

Pieces of freight inspected and disinfected......................... 611

Manifests visée 1 for 250,618 tons of cargo.

Consular bills of health were issued to 276 vessels, of which 47 were original and 229 were supplemental.

The crews and passengers of all these ships were inspected at the time of their departure. Fourteen cases of infectious diseases were discovered on ships in this harbor, to wit: Smallpox 4 cases, leprosy 2 cases, measles 7 cases, chicken pox 1 case.

Forty-one ships for Manila and the United States were fumigated with sulphur dioxide gas.

Every effort has been made to prevent the access of rats to ships destined to American ports. Rat guards are used on all ropes between ships and cargo lighters, and all lighters carrying freight to ships are required to undergo disinfection periodically with sulphur to kill rats, which usually infest them in great numbers. These cargo lighters are also engaged frequently in unloading cotton and rice from India, and their frequent disinfection is an important safeguard. Fumigation of all ships bound for United States ports and the Philippine Islands was required when they were empty.

Disinfection of hides, skins, human hair, and personal effects with a doubtful sanitary history was done.

Grain and cereals were required to be stowed in rat-proof warehouses before shipment.

A check on cargo is maintained by having all boat notes and consular invoices submitted for approval and counter signature.

During the past year this port has been unusually free from quarantinable diseases as compared with recent former years; only two cases of cholera having been reported in Kobe and four cases in Osaka, a few miles distant. The origin of these cases has not been positively determined, though cholera is undoubtedly endemic in Osaka.

No. cases of plague occurred, and plague-infected rats have not been found for several months. 
The steamship) Tacoma Maru, en route from Jlongkong to 'lacoma, disembarked a case of bubonic plague at Nagusaki in May of this year. The ship proceeded to Kobe, where she was detained in quarantine, fumigated with sulphur', and the jussenger's' and 'rews' cflects were disinfected with steam. Notwithstanding the fact that this ship had been treated with sulphur before her departure liom IIongkong, 16 rats were killed aboard of her here. I ('hinese steerage passenges from Hongkong was removed from the Panamu. Marm, at Shanghai, suspected of having plague. The first examination of the contents of the suspect's bubo showed a negative result and the ship proceeded as far as Kobe, bound for Tacoma, when a telegram was sent by the service oflicer at Shanghai to the medical officer in charge of the United States Public Jealth Service at Lobe informing him that cultural methods had proven conclusively the case to be one of bubonic plague. The ship was guarantined and thoroughly disinlected with sulphur, the personnel kept under observation for seren days, and their effects steamed.

The steamships Suveric, Shinyo Maru, Chiyo Maru, and Manchuria arrived at Kobe during the past winter from Hongkong, each having a case of smallpox on board. 'The cases were removed, direct contacts isolated, the ships disinfected, crews and passengers raccinated, bathed, and their bedding and effects disinfected. Yo other cases developed on any of the above-mentioner ships.

Dysentery seems to be increasing throughout the entire Empire of Japan. In Kobe there were 309 cases, with 68 deaths, as against 14] cases last year.

Leprosy, tuberculosis, and typhoid fever still exist to an alarming extent.

When cholera appeared here in September, 1911, the special regulation with reference to this disease was enforced. Steerage passengers were detained under observation six days before being allowed to embark for the United States or its possessions, and every precaution was taken to exclude infection from ships.

The following is a list of contagious diseases which appeared during the past fiscal year:

KOBE.

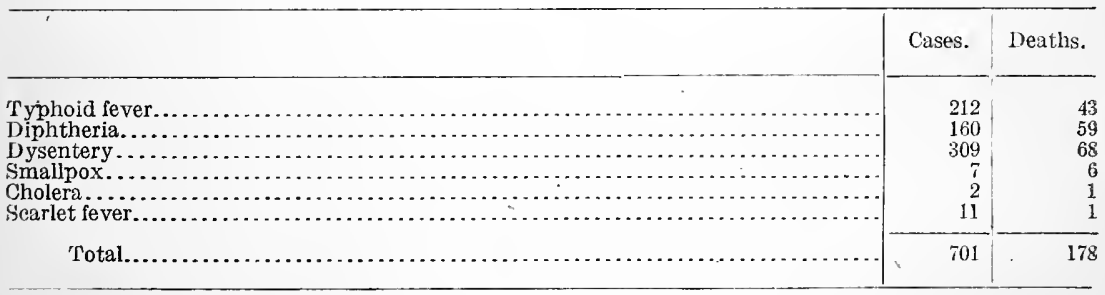

OSAKA.

\begin{tabular}{|c|c|c|}
\hline & Cases. & Leaths. \\
\hline Typhoid fever.... & 993 & 106 \\
\hline Diphtheria. & 425 & 125 \\
\hline 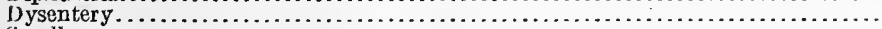 & 430 & 99 \\
\hline 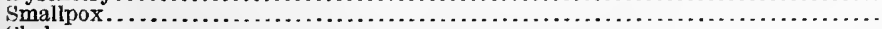 & 1 & .......... \\
\hline 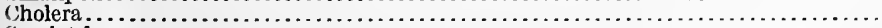 & 4 & 2 \\
\hline 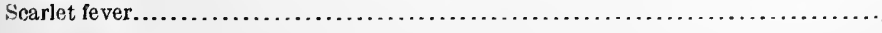 & 23 & 1 \\
\hline 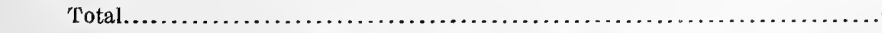 & 1,876 & 333 \\
\hline
\end{tabular}


LIBAU, RUSSIA.

Owing to the prevalence and spread of Asiatic cholera in Russia and the danger of the importation of this disease through immigrants arriving in the United States, a medical officer of the service, Acting Asst. Surg. C. M. De Forest, was assigned to duty in the office of the American consul at Liban, Russia, on September 26, 1908.

Transactions.- The transactions for the fiscal year ended June 30, 1912, are as follows:

Bills of health issued. . . . . . . . . . . . . . . . . . . . . . . . . . .

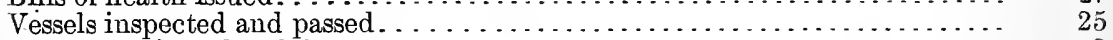

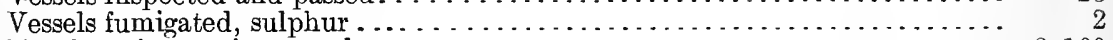

Number of crews inspected . . . . . . . . . . . . . . . . . . . . . . 3,166

Number of passengers examined:

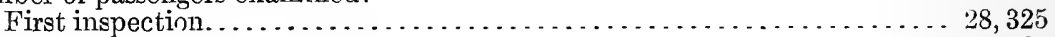

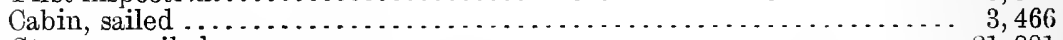

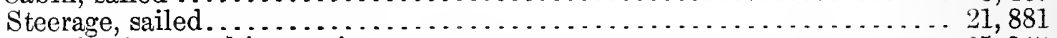

Baggage:

Examined, second inspection . . . . . . . . . . . . . . . . . . 25,347

Inspected for foodstuffs. . . . . . . . . . . . . . . . . . . . . . . . 23, 309

Disinfected........................................ 5,132

Plague has been reported during the year in the Government of Astrachan, Ural District, Odessa, Turkestan, along the Eastern Siberian Railway and along the Transbaikal Railway.

Cholera was reported in 23 different Governments and districts and in Mongolia and Manchuria. No cases, however, have during the year occurred west of Moscow or north of Kief. All in the eastern and southern Provinces. No cases were reported from November 19, 1911, until June 17, 1912, when one case was reported in the city of Astrachan.

Typhus fever is present in almost every large city in Russia.

Leprosy.- - It was stated on August 20, 1911, that in Russia there were over 10,000 cases of leprosy, and of this number only 1,000 were in leprosoriums. The remainder mix with the people and are said to form a constant source of infection.

\section{NAPLES, ITALY.}

Surg. H. D. Geddings reports as follows for the fiscal year ending June 30, 1912:

Statistics of the service at Naples, Messina, and Palermo, Italy.

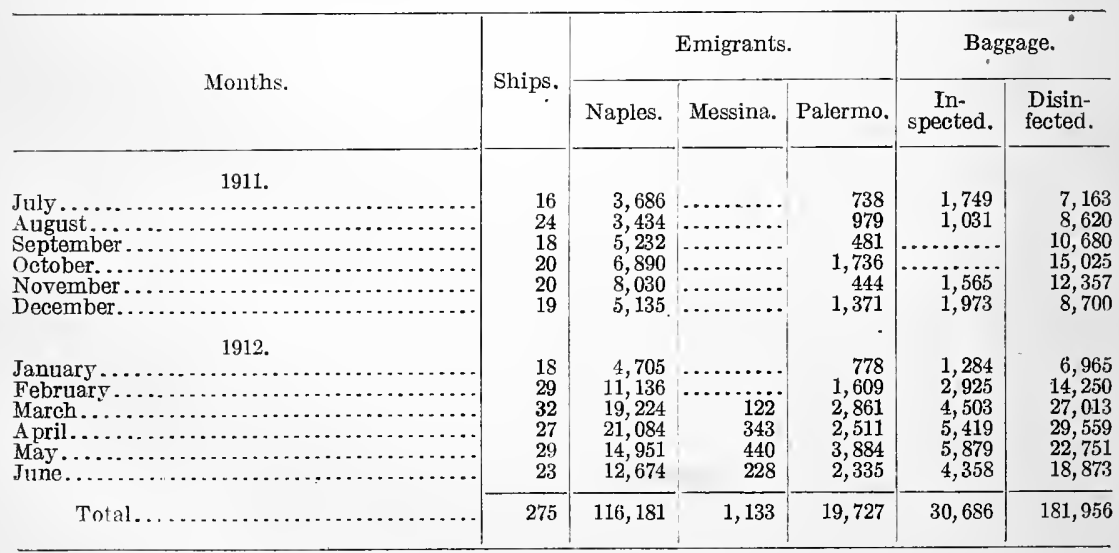


Statistics of the service at Naples, Messina, and I'alermo, Italy-Continued.

REMETIONS RECOMMENUEI.

Months.

1911.

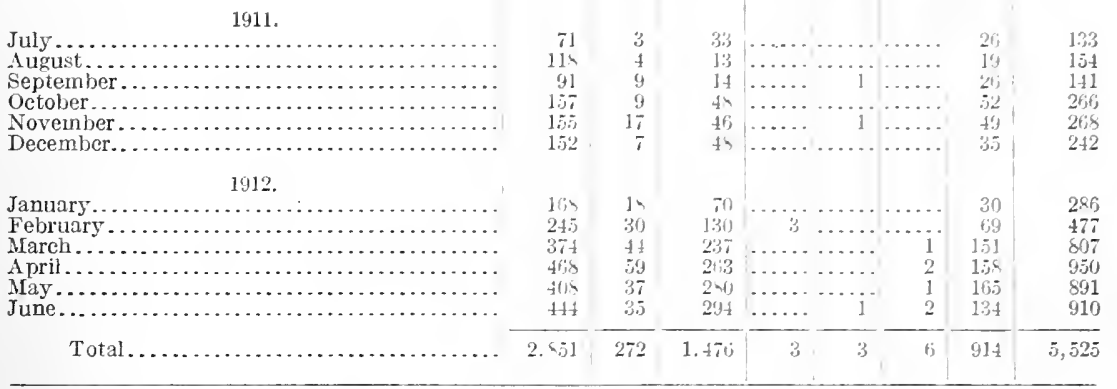

COMPARISON WITH LAST TWO YEARS.

\begin{tabular}{|c|c|c|c|c|c|}
\hline \multirow{2}{*}{ Years. } & \multirow{2}{*}{$\begin{array}{l}\text { Number of } \\
\text { emigrants } \\
\text { inspected. }\end{array}$} & \multirow{2}{*}{$\begin{array}{l}\text { Number of } \\
\text { emigrants } \\
\text { embarked. }\end{array}$} & \multicolumn{2}{|c|}{ Baggage. } & \multirow{2}{*}{$\begin{array}{l}\text { Rejections } \\
\text { recom- } \\
\text { mended. }\end{array}$} \\
\hline & & & Disinfected. & Passed. & \\
\hline $\begin{array}{l}1909-10 \ldots \ldots \ldots \ldots \ldots \\
1910-11 \ldots \ldots \ldots \ldots \\
1911-12 \ldots \ldots \ldots\end{array}$ & $\begin{array}{l}214,332 \\
162,485 \\
142,366\end{array}$ & $\begin{array}{l}202,831 \\
153,782 \\
13 i, 041\end{array}$ & $\begin{array}{l}237,650 \\
165,982 \\
151,956\end{array}$ & $\begin{array}{l}59,521 \\
52,050 \\
30,686\end{array}$ & $\begin{array}{r}11,501 \\
8,703 \\
5,525\end{array}$ \\
\hline
\end{tabular}

The figures given thus show a marked decline for Italian emigration for the port of Naples as compared with the figures for the year 1910-11, and a very notable decline from those for the year 1909-10, which latter was, however, rather a record year at this port. For the very obvious decline in numbers a variety of reasons might be assigned, among which may be mentioned the enforcement of quarantine regulations during the summer of 1910, and for the six months from July to the end of December during the vear 1911, on account of cholera. Naturally the steamship companies were unwilling to enter into transportation agreements on account of the trouble and the additional expense incident to handling emigrants in the face of the very disseminated prevalence of cholera infection in Italy, and in addition the existence of a state of war between Italy and Turkey, and the extensive military operations carried on by Italy in northern Africa, had an undoubted effect in diminishing the embarkation of able-bodied men of military age. Numerous reserves were summoned into active service, and many others were summoned to hold themselves in readiness for duty with the colors, and these purely military reasons naturally produced an unsettled feeling and an indisposition to leave the country until a more settled condition of affairs should prevail. These reasons are simply offered in possible explanation, though it is quite possible that there were also at the time cogent reasons of an economic character which exercised an equal if not greater influence.

$69450-$ H. Doc. $971,62-3-9$ 
Return of aliens from the United States.-But there is another feature of alien emigration at this port which is not easy of explanation, and this is the unusually heary return of Italian citizens who were more or less domiciled in their adopted country. The return of large numbers of Italians from the United States is not a new feature, and is always quite numerous, but for the calendar year 1911 there were returned to Naples from various ports in the United States 125,502 individuals, as compared with 78,781 for the calendar yea $r$ 1910. Moreover, a comparison of the figures of departures and returns for the calendar year 1911 shows that the returns exceeded the departure by more than 7,000. Of course a small part of this return may be accounted for by the summoning to military duty of Italians domiciled abroad, and those so summoned would naturally bring their families, but it is very improbable that this cause alone would account for this singular condition, which, according to Italian emigration officials, has been noted in Naples for the first time.

The explanation must be sought in some disturbed industrial and economic condition in the United States, the reason for which is as yet unknown, and will possibly be only slowly revealed. To hazard an explanation would therefore be futile and unprofitable. 


\section{MEDICAL INSPECTION OF IMMIGRANTS.}

In accordance with the immigration act of February 20,1907, the medical inspection of all aliens arriving at the various ports in the United States, its possessions and dependencies, is conducted by officers detailed for that purpose.

During the fiscal year 26 commissioned officers and 55 acting assistant surgeons were assigned to this work exclusively. In addition a large number of officers, primarily detailed to other service duty, have examined aliens whenever presented to them.

Those officers of the service stationed at consulates for quarantine duty in Italy have also made inspections of departing aliens at the request of the Department of Commerce and Labor. This work has exceeded in volume and difficulty the quarantine function.

Medical inspection of alien immigrants is now being conducted at 83 stations.

During the fiscal year ended June 30, 1912, 1,143,234 immigrants were examined by medical officers of the service to determine their physical and mental fitness for entrance at ports in the United States and its dependencies, Porto Rico and Hawaii. During the fiscal year 27,021 aliens were certified for physical reasons.

The following table furnishes a summary of the transactions at the several ports in the United States and its dependencies and in Canada. 


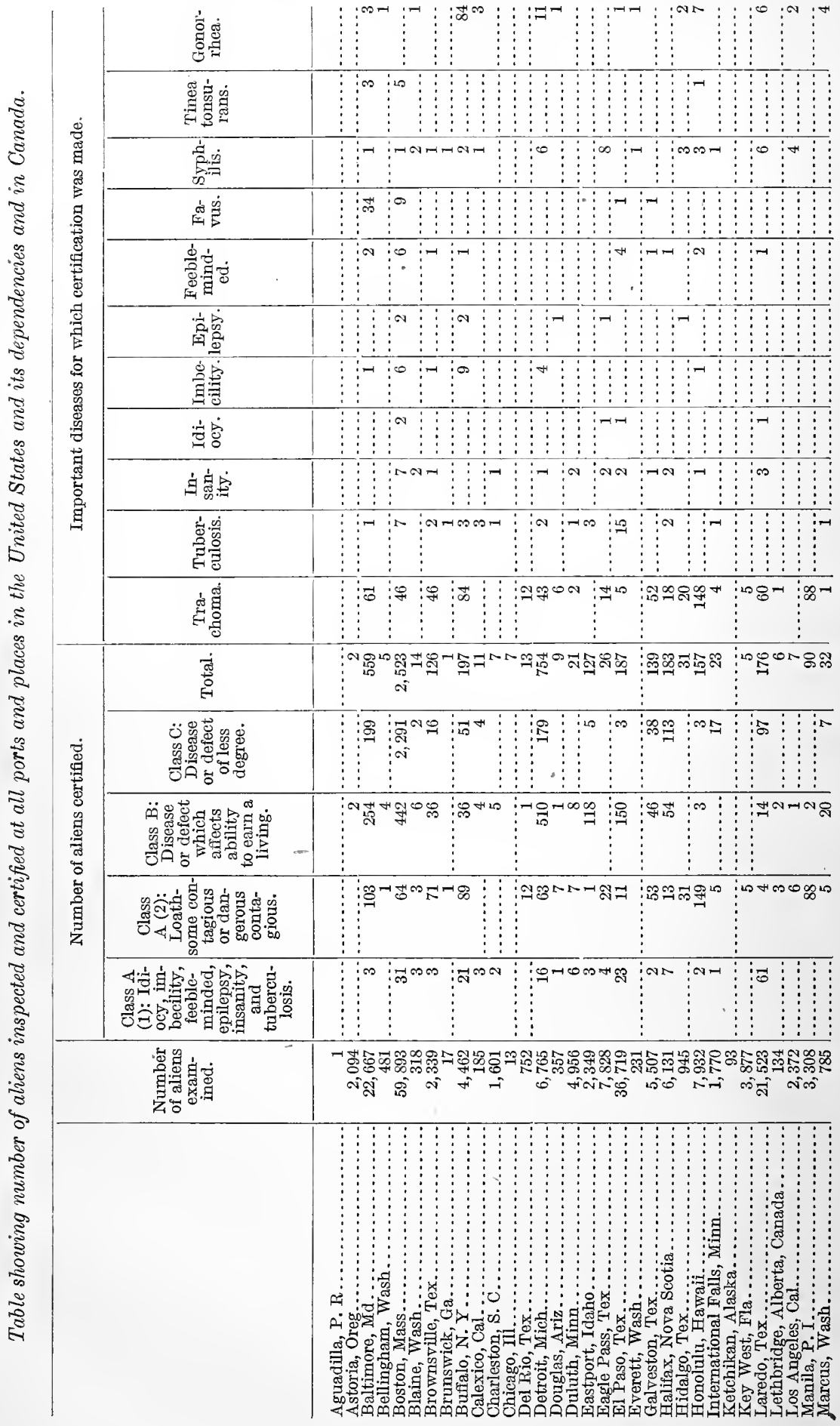




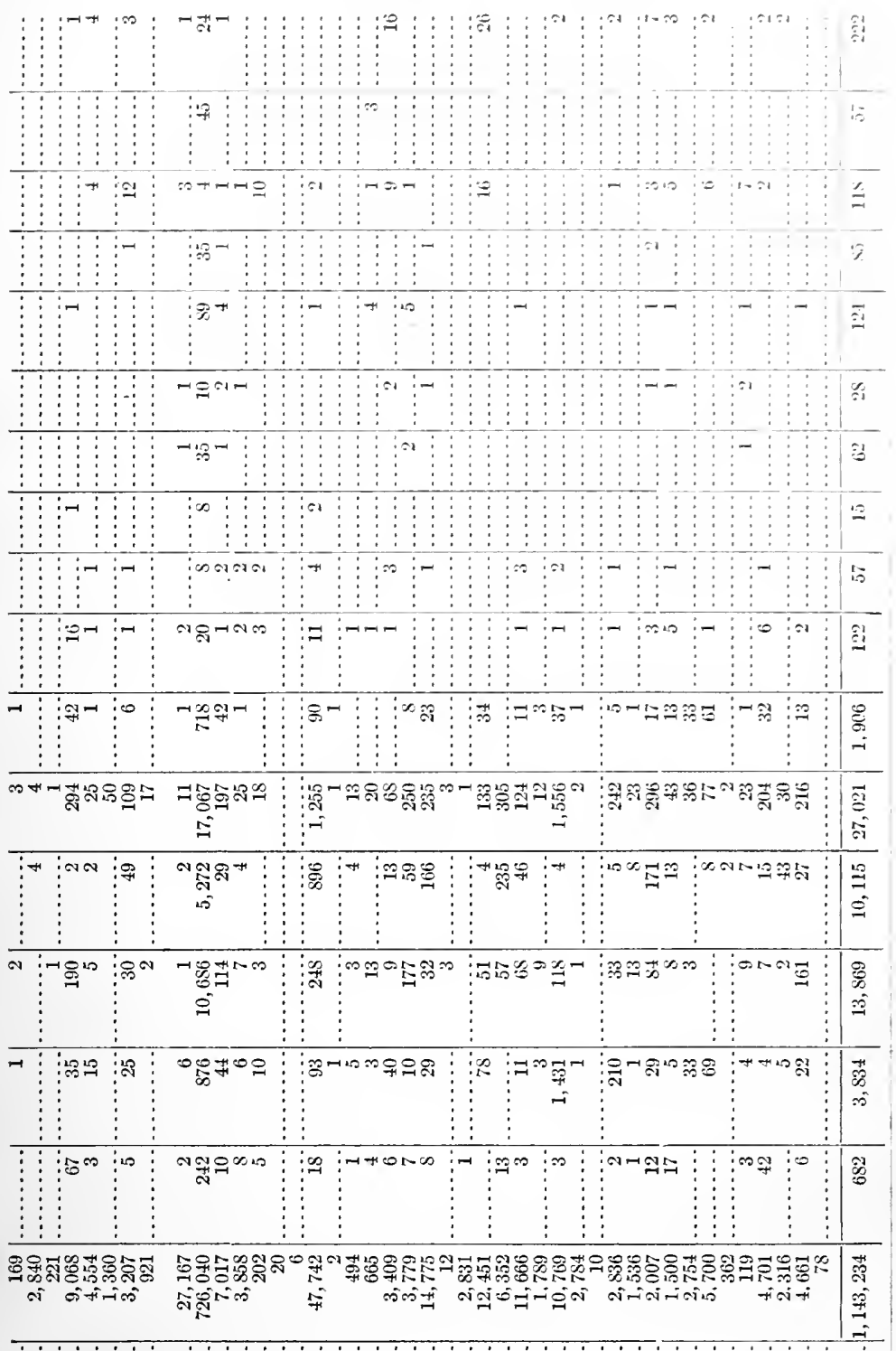

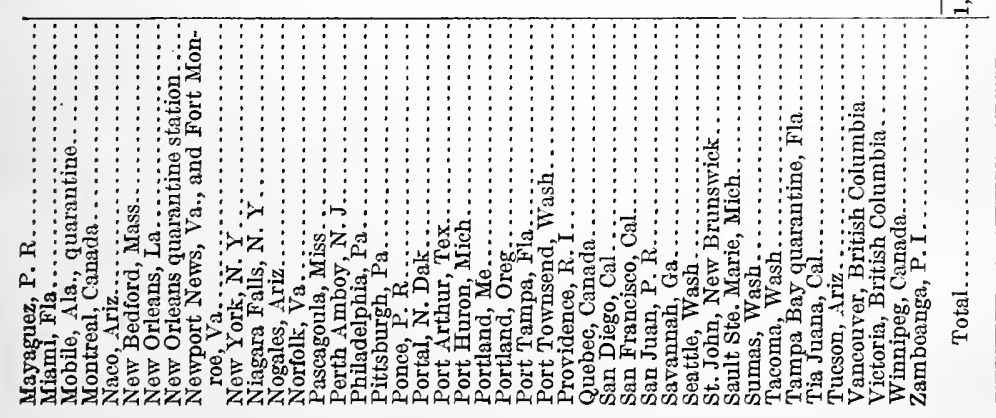




\title{
Excerpts from Reports Made by Service Officers Detailed FOR THE MEDICAL INSPECTION OF ImMigRants.
}

\author{
BUFFALO, N. Y.
}

The work at this port is increasing greatly with each succeeding year. At present there are 26 passenger trains arriving daily from Canada, besides 24 dummies across the international bridge, ferry, and excursion boats to and from across the lake and river.

The work of the medical officer consists in the physical examination of all aliens crossing the border from Canada that are held for the board of special inquiry. He is required to report at the immigration office at 10 a. m., earlier if called, where he remains till 1.30 , more often 2.30, when he goes home to lunch. He returns for the 4.15 train and remains till about 6 . He then goes home for his dinner and generally returns to the office at about 7.30 , where he remains till 10.30 , more frequently much later. Often it is 12 to 12.30 before he leaves the office for the night. Outside of these hours he is obliged to hold himself in readiness to be called at any other time during the day and night. These conditions, coupled with the fact that he is called upon for the examination of aliens who become public charges in the local hospitals and for the care and examination of those aliens detained in the county jail by the immigration service, gives him little or no time to himself.

BOSTON, MASS.

During the year 379 passenger ships, bringing 66,245 passengers, were examined by the officers of the service stationed at Boston, and of this number 23 ships, bringing 6,352 passengers, arrived at the subport of Providence, R. I. ${ }^{1}$

With respect to classification on shipboard, the Providence ships brought 198 first cabin, 215 second cabin, and 5,526 steerage passengers; 413 were United States citizens and 5,939 were aliens, of whom 13 received class $A, 57$ class $B$, and 235 class $C$ medical certificates. ${ }^{2}$

The total number of arriving passengers claiming the attention of the medical officers within the district were divided with respect to citizenship and classification on shipboard as follows:

BOSTON.

\begin{tabular}{|c|c|c|c|c|}
\hline Class. & $\begin{array}{l}\text { Number } \\
\text { of citi- } \\
\text { zens. }\end{array}$ & $\begin{array}{l}\text { Number } \\
\text { of aliens. }\end{array}$ & $\begin{array}{l}\text { Total } \\
\text { passen- } \\
\text { gers. }\end{array}$ & $\begin{array}{l}\text { Proportion } \\
\text { of United } \\
\text { States citi- } \\
\text { zens. }\end{array}$ \\
\hline 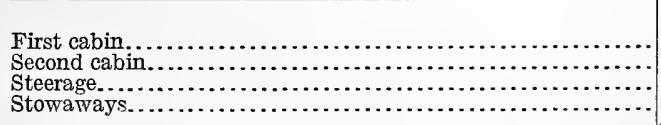 & $\begin{array}{r}3,561 \\
4,447 \\
2,503 \\
6\end{array}$ & $\begin{array}{r}1,153 \\
12,742 \\
35,320 \\
49\end{array}$ & $\begin{array}{r}4,714 \\
17,189 \\
37,823 \\
55\end{array}$ & $\begin{array}{r}\text { Per cent. } \\
75 \frac{1}{2} \\
25^{\frac{7}{8}} \\
7 \\
10 \frac{10}{11}\end{array}$ \\
\hline Total... & 10,517 & 49,264 & 59,781 & $17 \frac{1}{2}$ \\
\hline
\end{tabular}

PROVIDENCE.

\begin{tabular}{|c|c|c|c|c|}
\hline 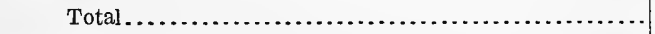 & 413 & 5,939 & 6,352 & $6 \frac{1}{2}$ \\
\hline
\end{tabular}

1 Aliens arriving at Boston on ships from British-American ports are examined at the foreign ports of departure and are consequently not subject to examination on arrival at Boston and have not been included

in this report. Passed Asst. Surg. Creel had been placed in charge of the medical examination of aliens there. 
The proper medical examination of the large and increasing proportion of aliens to be found among the cabin passengers at Boston constitutes one of the most troublesome practical problems with which the medical officers of this port are called on to deal.

The importance of the medical cxamination of alien cabin passengers is shown by the following:

Distribution of certificates.

BOSTON.

\begin{tabular}{|c|c|c|c|c|c|}
\hline Classification on shipboard. & $\begin{array}{l}\text { Number } \\
\text { of alien } \\
\text { arrivals. }\end{array}$ & $\begin{array}{l}\text { Class } \\
\text { A and B } \\
\text { certifi- } \\
\text { cates. }\end{array}$ & $\begin{array}{l}\text { Class } \\
\text { C } \\
\text { certif. } \\
\text { cates. }\end{array}$ & $\begin{array}{l}\text { Total } \\
\text { certifi- } \\
\text { cates. }\end{array}$ & $\begin{array}{c}\text { Ratio } \\
\text { certified. }\end{array}$ \\
\hline 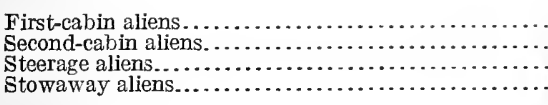 & $\begin{array}{r}1,153 \\
12,742 \\
35,320 \\
49\end{array}$ & $\begin{array}{r}3 \\
170 \\
276 \\
18\end{array}$ & $\begin{array}{r}767 \\
1,288\end{array}$ & $\begin{array}{r}4 \\
937 \\
1,564 \\
18\end{array}$ & $\begin{array}{l}1: 288 \\
1: 14 \\
1: 23 \\
1: 3\end{array}$ \\
\hline Total............... & 49,264 & 467 & 2,056 & 2,523 & 1: 19 \\
\hline
\end{tabular}

PROVIDENCE.

\begin{tabular}{|c|c|c|c|c|c|}
\hline 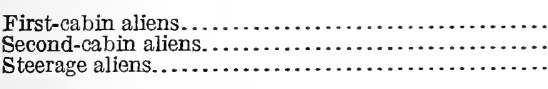 & $\begin{array}{r}198 \\
215 \\
5,526\end{array}$ & $\begin{array}{r}10 \\
4 \\
56\end{array}$ & $\begin{array}{r}23 \\
19 \\
193\end{array}$ & $\begin{array}{r}33 \\
23 \\
249\end{array}$ & $\begin{array}{lr}1: & 6 \\
1: & 9 \\
1: & 22\end{array}$ \\
\hline Total. & 5,939 & 70 & 235 & 305 & 1: 19 \\
\hline
\end{tabular}

From the above it will be seen that while at Boston but 1 alien steerage passenger out of 23 was certified as diseased or defective, 1 alien second cabin passenger out of 14 , or nearly twice as many proportionately, were so certified.

In connection with the various diseases and defective conditions certified during the year and the disposition eventually made of the individuals concerned the following may be observed. An appreciable proportion of the aliens found to have diseases or defects calling for class A certificates were eventually admitted to the country. Out of 448 aliens receiving class B certificates, whose issuance was intended to be limited to cases involving the probability of temporary or permanent incapacity for self-maintenance, 397, or 89 per cent, were allowed to land. In this connection it may be stated that according to the practice at this port it is not intended that class $\mathrm{C}$ shall include defects except those which are deemed to be an actual handicap to self-maintenance. Notations of defects regarded as of no practical importance and so declared to be were issued to the number of about 1,000 during the year, but are not included in this report.

The number of diseases classifiable as "loathsome" or "dangerous contagious" was comparatively small in proportion to the total immigration of the port, as has been the case for several years past. To a considerable extent aliens afflicted with such diseases have been permitted to land for treatment. Forms of tuberculosis other than pulmonary were also usually admitted to the country.

HOSPITAL CASES.

During the year 196 arriving aliens were sent to hospital, seven institutions in this vicinity being regularly utilized for this purpose. 
In addition many cases of minor ailments were held and cared for in the hospital quarters at the immigration station itself. By means of a contract with the Massachusetts State board of insanity a very satisfactory provision has been made for the temporary care at the Boston Insane Hospital of aliens arriving insane.

The number of cases of diseases of an acute nature requiring hospital treatment at this port has shown for the past three years such an abrupt decrease in comparison with previous years that the conclusion seems unavoidable that the cause may be the amendment to the navigation laws which went into effect January 1, 1909, and reduced materially the legal steerage passenger capacity of ships entering this port.

The passenger travel to this port during the past fiscal year was adversely affected by the cholera in Italy, an unusual number of accidents to passenger ships and the Italian-Turkish War, all of which led to the withdrawal of ships from the Boston service. Larger and faster ships are, however, being put in the Boston trade, and there are various other reasons also for believing that passenger travel via this port will tend to increase in the immediate future regardless of whether immigration as a whole increases or not. The completion of the new immigration station, the construction of which is about to be begun, will undoubtedly favorably influence new immigrant trade through this port.

Passenger ships arrived:

Summary of transactions.

Boston ............................................. 356

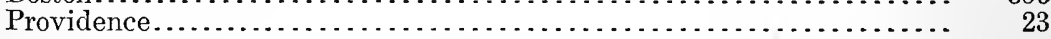

Total.............................................. 379

Alien passengers inspected:

Boston............................................ 49, 264

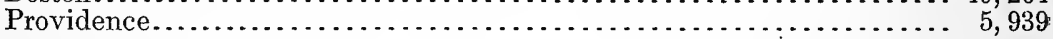

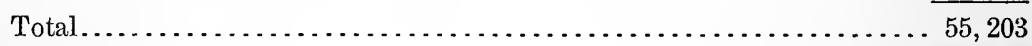

Number of passengers:

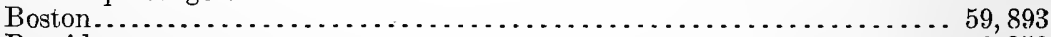

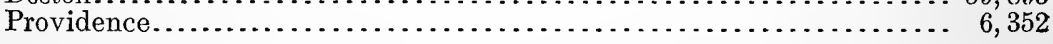

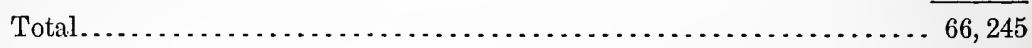

Alien passengers passed:

Boston......................................... 46,555

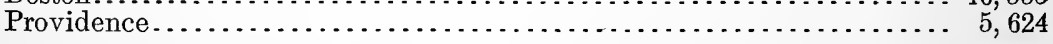

Total....................................... 52,179

Certified on account of disease, etc:
Boston $\ldots \ldots \ldots \ldots \ldots \ldots \ldots \ldots \ldots \ldots \ldots \ldots \ldots \ldots \ldots \ldots \ldots \ldots \ldots \ldots \ldots \ldots \ldots \ldots \ldots \ldots \ldots \ldots \ldots$

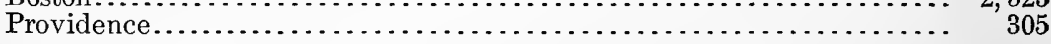

Total.................................... 2,828

Sent to hospital:

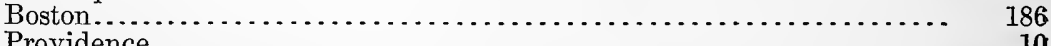

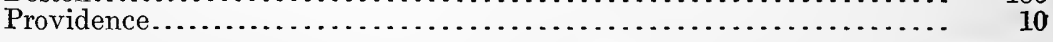

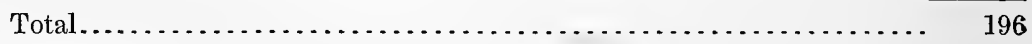


Cases pending beginning of year................................. 1

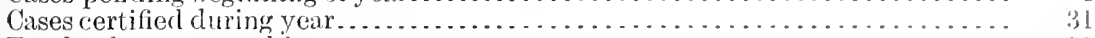

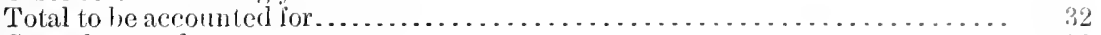

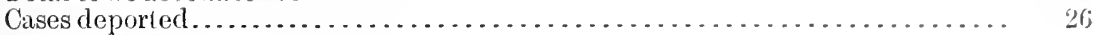

Cases landed............................................. 4

Cases pending at close of year................................... 2

Class $A(1 \mathrm{I})$.

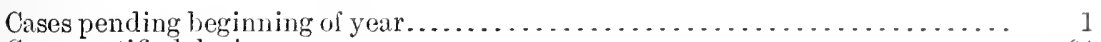

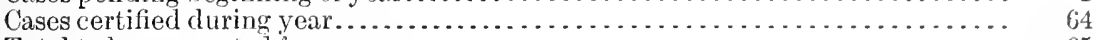

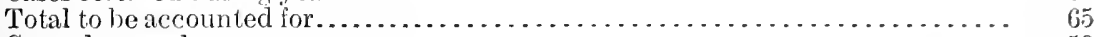

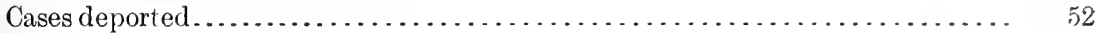

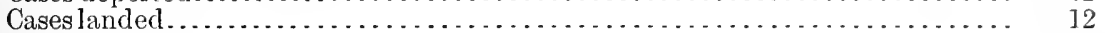

Cases pending at close of year................................. 1

Class B.

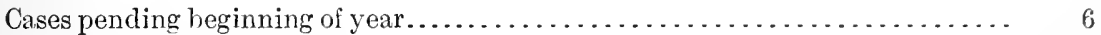

Cases certified during year....................................... 442

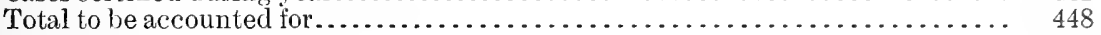

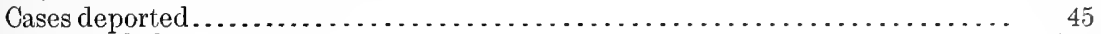

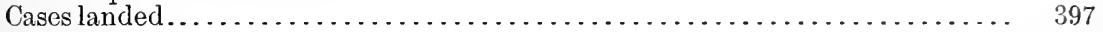

Cases pending at close of year.................................... ${ }_{6}$

Class C.

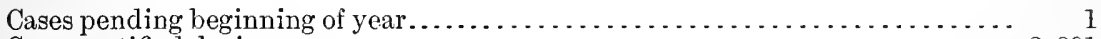

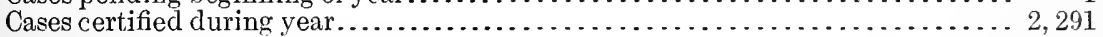

Total to be accounted for........................................ 2, 292

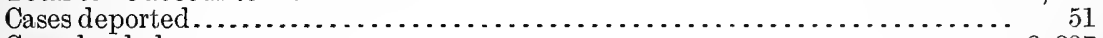

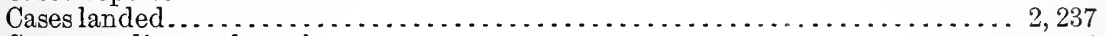

Cases pending at close of year.................................. 4

\section{HONOLULU, HAWAII.}

Seven thousand nine hundred and thirty-two aliens arrived during the year, and of this number 157 were certified for diseases or disabilities in accordance with the immigration laws and regulations.

The medical examination of arriving aliens is conducted at the immigration station immediately after disembarkation. At the present time all immigrants leaving Japan for Hawaii are examined by physicians of the Japanese Government, prior to embarkation, and those found to be suffering from trachoma, etc., are rejected. Recently, owing to the number of cases of trachoma among arriving aliens, the practice was begun of questioning each person who was detained as to the number of times they had been rejected before being finally passed and allowed to embark. It was learned that a large number was rejected for from 5 to 10 times before finally passing, and that treatment in many cases had been from 30 days to 4 or 5 months, and in one case a year. During the year several aliens were allowed hospital treatment for trachoma.

Two hundred Chinese residents of the Hawaiian Islands were examined at the request of the immigration inspector in charge at this port, prior to their departure for China, to determine whether they were free from any dangerous contagious or loathsome diseases. 
MANILA, P. I.

The immigration into the Philippines is of an entirely different character from that encountered at any other place under the jurisdiction of the United States. There the immigrants belong to the skilled classes, whereas in the United States the bulk of the immigration belongs to the unskilled or laboring classes. In this connection it is of interest to note that the causes of the rejections also differ greatly, as may be seen by the statistical table.

There were examined at the several ports of entry of the Philippine Islands 3,132 immigrants, of whom 90 were rejected, and of these 84 were actually deported. This makes the percentage of rejections 0.029 . It is believed that the number deported, compared with the number of rejections, is much greater than obtains at any other place where immigrants are examined under the United States Immigration Laws and Regulations. Of the total number of immigrants, 2,653 came through the port of Manila, 12 at Cebu, 115 at Iloilo, 79 at Zamboanga, and 73 at Jolo.

Immigrants who arrived and were medically examined by service officers were classed as follows:
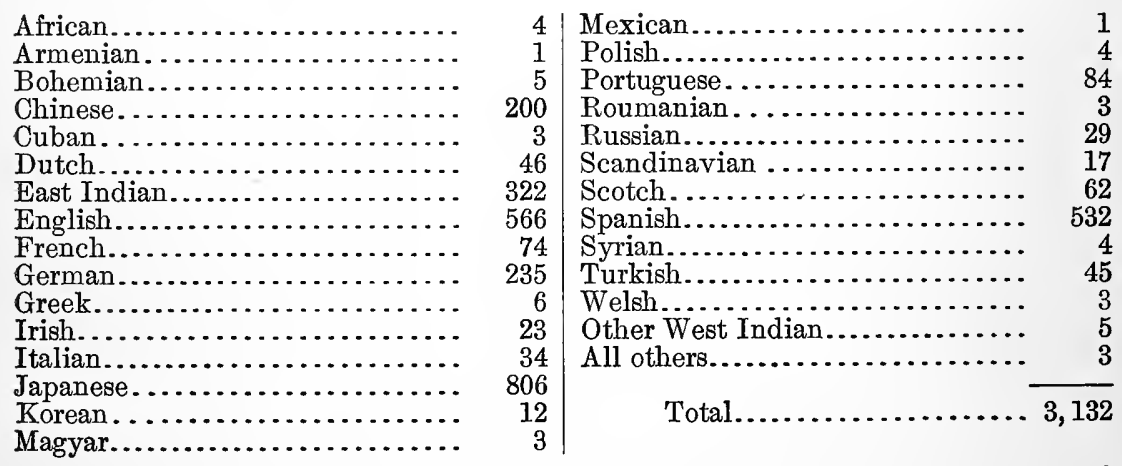

The rejections were from among the following nationalities: Japanese, 52; East Indians, 25; Chinese, 5; Turks, 4; Mexicans, 1; Russians, 1 ; Spaniards, 2.

It will be noted from the foregoing that the percentage of rejections among Indians is very much higher than among any of the other nationalities that make up the bulk of the total number.

At Manila the facilities for detaining immigrants have been greatly improved by the building which has been set aside for this purpose near the mouth of the Pasig River. At the remaining ports of entry in the Philippines there are no facilities for detaining aliens on shore.

During the year foreign vessels with immigrants called more frequently at more than one port. For convenience of administration it has been customary to examine all the aliens at the first port at which a vessel calls, and in the event of certificates being necessary the papers are sent, and notations made upon the original manifest, to the port at which the alien is to disembark. 
Surg. George W. Stoner, chicl medical oflicer, reports as follows:

Seven hundred and twenty-six thousand and forty alions were examined upon arrival, including 181,919 (ab)in and 544,121 steerage passengers. Besides these there were 179,306 passengers (147,723 cabin and 31,583 steerage) who, upon further examination by the immigrant inspectors, proved to be citizens of thr United States, and therefore were not subject to medical examination for purposes of the Immigration Service.

Seventeen thousand and sixty-seven aling were certified for physical or mental discases or defects, including 222 mentally diseased or defective, viz, iäiot, 8 ; imbecile, 35 ; feeble ninded, 89; epilepsy, 10; insane, 80. Twenty were certified for tuberculosis.

Under the classification of loathsome contagious or dangrous contagious there were certified 867, including trachoma, 718; tinea tonsurans, 45; favus, 35; gonorrhea, 24; sycosis barbæ, 21; renereal ulcer, 12 ; tinea unguium, 5; syphilis, 4; uncinariasis, 3.

Ten thousand six hundred and eighty-six were certified for disease or defect which affects ability to earn a living, including senility, 5,312; hernia, 944; poor muscular development, 442; curvature of spine, 242; varix, 235; defective vision, 210 ; flat feet, 207 ; dislocation of hip, 206; weak abdominal walls, 163; valvular disease of heart, 132; inflammation lymph glands of neck, 125; atrophy of leg, 98 ; stiff kneejoint, 94 ; stiff hip joint, 65 ; club feet, 42 ; loss of leg, 38 ; goiter, 37 ; stammering, 36; malnutrition, 36; deformity of hand, 36; deformity of legs, 34; loss of fingers, 28; spastic paraplegia, 28; arteriosclerosis, 27; deafness, 27; deaf-mutism, 23; deformity of chest, 21 ; psoriasis, 21 ; abdominal tumor, 19; hemiplegia, 18; undersized; 17; organic disease nervous system, 17 ; exophthalmic goiter, 16 ; chronic alcoholism, 16 ; atrophy of arm, 15; cataracts, 14 ; knockknees, 14; loss of arm, 14; arrested sexual development, 13 ; blind, 12; lupus, 11; hypertrophy of spleen, 9 ; inflammation of middle ear, 8 ; dwarf, 8; and for disease or defect of less degree there were certified 5,272. (See also report (Form 8948) herewith.)

\section{Disposition of immigrants certified.}

Class A (I).--Idiocy, imbecility, feebleminded, epilepsy, insanity, and tuberculosis:

Cases pending beginning of year......... Cases certified during year.............. Total to be accounted for.................. Cases deported.

Cases landed.......................... Cases pending close of year

Class B.-Disease or defect which affects ability to earn a living:

Cases pending beginning of year....... 66

Cases certified during year............... 10,686

Total to be accounted for . . . . . . . . . . . . 10,752

Cases deported ..................... 2,368

Cases landed......................... 8,217

Cases pending close of year........... 167
Class A (II.)-Loathsome contagious or dan- 준 gerous contagious:

Cases pending beginning of year........ 35

Cases certified during year............. 867

Total to be accounted for ............... 902

Cases deported......................... 798

Cases landed....................... $\quad 73$

Cases pending close of year................ 31

Class $\mathrm{C}$. Disease or defect of less degreo:

Cases pending beginning of year........ 5

Cases certified during year.............. 5,272

Total to be accounted for.............. 5,277

Cases deported....................... 208

Cases landed.......................... 5,059

Cases pending close of year............. ${ }_{10}$

Seven thousand two hundred and forty-six aliens were admitted to immigrant hospitals, Ellis Island, during the fiscal year, including men, 3,640; women, 1,860; male children under 12 years of age, 901 ; female children under 12 years of age, 845; and there were 110 
patients in hospitals at the beginning of the fiscal year, making a total of 7,356 furnished hospital care and treatment. Of these, 361, including 149 landed aliens (public charges), were mentally diseased.

Seventeen men, 5 women, and 32 male and 19 female children (total 73) died in immigrant hospitals during the year. Fourteen (6 male, 8 female) were born.

Of the 73 deaths during the year, 38 occurred in the Immigrant General Hospital and were due to: Enteric fever, 1; erysipelas, 1; pneumouia, 5; tuberculosis, 1; hemophilia, 1; debility, 3; senility, 1; poliomyelitis, anterior, 1; inflammation of brain, tubercular, 1; insane, 1 ; inflammation middle ear, suppurative, 1 ; valvular disease of heart, 1 ; thrombosis, 1 ; broncho-pneumonia, 12 ; tonsilitis, suppurative, 1; hernia, strangulated, 1 ; peritonitis, tubercular, 1 ; nephritis, acute, 1 ; nephritis, chronic, 2 ; premature birth, 1.

Seven hundred and fifty-two, including observation cases and accompanying persons, were admitted to Immigrant ContagiousDisease Hospital, including: Measles, 500; scarlet fever, 41; cerebrospinal meningitis, 14; diphtheria, 5; German measles, 5; chicken pox, 26 ; whooping cough, 8 .

Three cases of cerebrospinal fever and three of whooping cough were treated in Immigrant General Hospital during the year.

The mortality during the year among the patients afflicted with acute contagious disease was: In measles, 5 per cent; scarlet fever, 12 per cent; diphtheria, 20 per cent; cerebrospinal meningitis, 28 per cent; chicken pox, German measles, and whooping cough, no deaths.

This mortality record shows a remarkable improvement, being only about one-half as high as the mortality rate recorded for previous years, cluring which time it was necessary to transfer this class of patients to local contract hospitals in the city or to hospital at the State quarantine.

Besides the number of aliens admitted to Immigrant Hospital, 50 (emergency cases) requiring immediate attention on arrival at the docks were, in accordance with special arrangement, cared for by the different steamship companies during the year in hospitals of their own selection in the city. Of these 5 died.

One hundred and twenty-four alien immigrants who had become public charges or inmates of State or local hospitals or institutions in New York, New Jersey, and Connecticut were visited and examined during the year by medical officers attached to this station to determine the nature of the disease, mental or physical, from which the aliens were suffering and whether or not due to causes existing prior to landing in the United States; and a medical certificate in each case was rendered for the information of the commissioner of immigration.

\section{QUEBEC, CANADA.}

During the fiscal year (July 1 to Nov. 30, 1911, and May 1 to June $30,1912), 231$ ships, an increase of 8 ships as compared with the preceding year, arrived at the port of Quebec, bringing 16,967 passengers destined to the United States. This number represents a decrease of over 8,000 as compared with last year and is due probably to the increased Canadian immigration and the general decrease of immigration at all United States ports. 
The 16,967 passengers arriving subject to inspection by the officer of the service were divided as to citizcmilap and classification on shipboard as follows:

\begin{tabular}{|c|c|c|}
\hline & N liens. & $\begin{array}{l}\text { 'nited } \\
\text { States } \\
\text { citizens. }\end{array}$ \\
\hline $\begin{array}{l}\text { First cabin.... } \\
\text { Second cabin.. } \\
\text { Steerage....... }\end{array}$ & $\begin{array}{l}\frac{441}{2,71} \\
x, 4 ; 8\end{array}$ & $\begin{array}{l}1,450 \\
3,0152 \\
789\end{array}$ \\
\hline Total... & $11,6 i 6 f_{j}$ & ;,301 \\
\hline
\end{tabular}

In addition to the above, there were eximined 1,697 passengers in transit through the United States to C'anada, via the Grand Trunk Railroad. Of this class of aliens examiner, those not passed by the medical officer are reticketed to their destination in ('anadia via the Canadian Pacific Railroad Co.

Of the 11,666 aliens examined, there were 55 records of minor defects recorded, and 124 aliens were certified (15 second, 109 steerage) for physical or mental defects and diseases. Of the 124 certified, 24 were deported, 9 were admitted on bond, 7 were admitted by the secretary (1 acute miliary tuberculosis), $\tilde{5}$ were admitted by the board of special inquiry, and 39 were admitted as recorered.

The ratio of medical certifications to total aliens examined is practically the same this year as it has been at this port for several years past, but less than 2 per cent were actually deported, and of the 24 so deported, 13 were deported for diseases which under the law render their exclusion mandatory.

There has been a marked reduction in the certification for trachoma, there having been but 11 so certified this year, due to better system of examination at ports of foreign embarkation and the fact that the Canadian immigration authorities have instigated ciril suits and recovered damages for the landing of diseased aliens.

The medical examining rooms and accommodations for the medical officer have been enlarged and improved during the year. The Canadian immigration department is erecting a modern reenforced two-story concrete building, 800 feet long by 80 feet wide. There has been set aside in this building a space 140 feet by 80 feet for the United States Immigration Service, and the medical officer will have better facilities for the conduct of medical inspection of immigrants. It is contemplated that part of this building will be ready for occupancy by the spring of 1913 .

The port of Quebec, Province of Quebec, was closed the latter part of November, and the medical officer was transferred to St. John, New Brunswick, for the winter season.

At St. John during the fiscal year (Dec. 1, 1911, to May 1, 1912), 44 ships landed 1,649 passengers destined to the United States, as follows:

\begin{tabular}{|c|c|c|}
\hline - & Aliens. & $\begin{array}{c}\text { United } \\
\text { States } \\
\text { citizens. }\end{array}$ \\
\hline $\begin{array}{l}\text { First cabin...... } \\
\text { Sccond cabin..... } \\
\text { Steerage.............. }\end{array}$ & $\begin{array}{r}23 \\
108 \\
1,405\end{array}$ & $\begin{array}{l}22 \\
33 \\
58\end{array}$ \\
\hline Total..... & 1,536 & 113 \\
\hline
\end{tabular}


Of the 1,536 alien passengers examined, there were recorded 6 records of minor defects and 23 aliens were certified (steerage) for physical or mental defects or diseases. Of the 23 certified, 8 were deported, 1 was admitted by the secretary, 10 were admitted by the board of special inquiry, and 6 were admitted as recovered.

\section{SAN FRANCISCO, CAL.}

From the report of Passed Asst. Surg. W. C. Billings the rollowing is taken:

During the fiscal year ended June 30,1912, the total number of immigrants examined by the medical officers of this station was 10,769 , and the total number certified as presenting any of the various conditions of which notice must be taken under the medical portions of the immigration law was 1,556.

Of this number, 1,386 were cases of uncinariasis, or more than double the number of cases of that disease occurring last year. This increase in the number of detected cases may be chiefly ascribed to a difference in the method of handling the examination. Now all aliens which are brought to Angel Island and held for 24 hours in order to determine their immigration status are examined for hookworm, advantage being taken of this time to make a microscopical examination whether they show the usual clinical symptoms of anemia, emaciation, lassitude, etc., or not. The results amply justify this method of procedure, and in the opinion of the medical officer in charge demonstrate conclusively that, at least when dealing with oriental races, it is quite impossible to detect on primary examination anywhere near all the cases of hookworm, and a microscopical examination is therefore indicated.

A record is now being kept, in which is noted the age, weight, and height of all aliens examined for hookworm, and a note as to whether or not they present any of the "primary examination" signs of anemia, lassitude, or emaciation. It is thought that this report will show an extremely interesting percentage of positive infection with negative clinical signs.

The percentage of trachoma cases compared to the number certified last year is less than 50 per cent. No attempt is made to explain the continually decreasing number of cases of this disease in the last few years unless it be the moral effect of the continued stringent examination at the port of arrival.

A slightly larger percentage of certificates for all causes were issued this year, but the difference is so small as to be negligible.

Great effort has been made during the year to stretch the capacity of the hospital to accommodate the number of certified aliens granted permission for hospital treatment, but notwithstanding the best endeavor there were, on June 30,75 certified cases awaiting admission to hospital. Unless there is a diminution in the number of aliens infected with hookworm arriving at this port, it is hard to see how to avoid the necessity of enlarging the hospital, both as to actual room and number of attendants.

The relative proportion, according to races, of aliens admitted to the hospital has changed to some extent during the fiscal year. The 
Japanese have increased their percentage and the Hindus have fallen off to a total of only 27.

Hospital report for fiscal year ending June \$0, 1912, United Slates Immigration Hospital, Angel Island, C'al.

\begin{tabular}{|c|c|c|c|c|c|c|c|c|}
\hline Disease. & $\begin{array}{l}\text { In hos- } \\
\text { pital } \\
\text { July 1, } \\
1911 .\end{array}$ & $\begin{array}{l}\text { Admit- } \\
\text { terl dur- } \\
\text { ing } \\
\text { year. }\end{array}$ & $\begin{array}{l}\text { Total in } \\
\text { hospital } \\
\text { during } \\
\text { year. }\end{array}$ & $\begin{array}{l}\text { Recot- } \\
\text { ered. }\end{array}$ & $\begin{array}{l}\text { Im- } \\
\text { prover. }\end{array}$ & $\begin{array}{l}\text { Notim- } \\
\text { proved. }\end{array}$ & Died. & $\begin{array}{c}\text { In hos- } \\
\text { pital } \\
\text { June } 30, \\
1912 .\end{array}$ \\
\hline Anemia.. & & 6 & 6 & & 1 & 5 & & \\
\hline 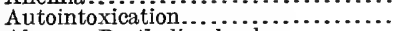 & & 4 & 4 & & & & & \\
\hline A bscess, Bartholin gland............ & ... & 1 & 1 & 1 & & & & \\
\hline 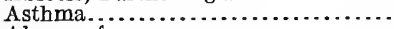 & $\ldots$ & 1 & 1 & & 1 & & ... & \\
\hline 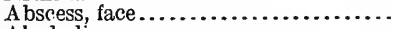 & $\ldots \ldots$. & 1 & 1 & 1 & & & $\ldots$ & \\
\hline$\ldots \ldots \ldots \ldots \ldots \ldots$ & $\ldots \ldots$ & 1 & 1 & 1 & & & $\ldots$ & \\
\hline$\ldots \ldots \ldots \ldots \ldots \ldots$ & $\ldots \ldots$ & 6 & 6 & 6 & & & $\ldots$ & \\
\hline$\ldots \ldots \ldots \ldots \ldots \ldots$ & $\ldots \ldots$. & 9 & 9 & $\ldots \ldots$. & 5 & 4 & 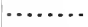 & \\
\hline$\ldots \ldots \ldots \ldots \ldots \ldots$ & $\ldots \ldots$ & 3 & 3 & $\ldots \ldots$ & 3 & & $\cdots$ & \\
\hline$\ldots \ldots \ldots . . . . . . .$. & $\ldots \ldots$ & 1 & 1 & & & 1 & $\cdots$ & \\
\hline$\ldots \ldots \ldots \ldots$ & $\mid \ldots \ldots \ldots$ & 1 & 1 & & 1 & & $\cdots$ & \\
\hline 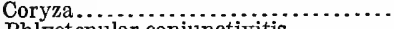 & $a \ldots \ldots$ & 1 & 1 & 1 & & & $\cdots$ & \\
\hline itis. ......... & $\mid \ldots \ldots$ & 1 & 1 & $\cdots$ & & & $\cdots$ & \\
\hline Conjunctivitis, follicular............ & $\ldots \ldots$ & 28 & 28 & 28 & $\cdots$ & & $1 \ldots$. & ....... \\
\hline $\begin{array}{l}\text { is: } \\
\text { urulent } \ldots \ldots \ldots \ldots \ldots \ldots \ldots \text {. }\end{array}$ & ... & 4 & 4 & 4 & & & & \\
\hline .............. & $\cdots$ & 14 & 14 & 14 & & & & \\
\hline$\ldots \ldots \ldots \ldots \ldots \ldots$ & $\cdots$ & 13 & 13 & & 3 & 10 & & $\cdots$ \\
\hline Chalazi & $\cdots \cdots \cdot$ & 1 & 1 & & 1 & & & 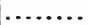 \\
\hline$\ldots \ldots \ldots \ldots \ldots$ & -....... & 2 & 2 & 1 & $\vec{I}$ & & $\cdots$ & $\cdots \cdots$ \\
\hline$\ldots \ldots \ldots \ldots$ & $\ldots \ldots$ & 1 & 1 & 1 & ... & & $\ldots$ & $\ldots . .$. \\
\hline t, post op & $\ldots . .$. & 1 & 1 & 1 & + & & $\ldots$. & $\cdots \ldots$ \\
\hline denitis... & $\cdots$ & 1 & 1 & 1 & & & & \\
\hline ver....... & $\ldots \ldots$ & 1 & 1 & $\ldots$. & .. & 1 & $\ldots .$. & $\ldots . .$. \\
\hline re, spine, lateral............ & $\ldots \ldots$ & 1 & 1 & $\ldots \ldots \ldots$ & $\ldots$ & 1 & $\ldots \ldots$ & ...... \\
\hline ion $\ldots . . . \ldots \ldots \ldots \ldots \ldots \ldots$ & $\ldots \ldots$ & 4 & 4 & 4 & $\ldots$ & & $\ldots \ldots$ & $\cdots$ \\
\hline soft. ..................... & $\ldots \ldots \ldots$ & 1 & 1 & $\ldots \ldots \ldots$ & $\ldots \ldots$ & 1 & $\ldots \ldots$ & $\ldots \ldots$ \\
\hline 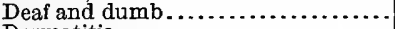 & $\ldots \ldots$. & 1 & 1 & 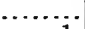 & $\ldots$ & 1 & ....... & $\ldots \ldots$ \\
\hline 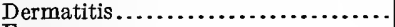 & $\ldots \ldots$ & 1 & 1 & & & & $1=-x$ & $\ldots \ldots$ \\
\hline$\ldots \ldots \ldots \ldots \ldots \ldots \ldots \ldots \ldots \ldots \ldots$ & $\cdots$ & 1 & 1 & $\ldots \ldots$. & & & & $\cdots \cdots \cdots$ \\
\hline 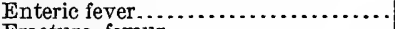 & $\cdots$ & 1 & 1 & $\ldots \ldots$ & & & & $\ldots . .$. \\
\hline 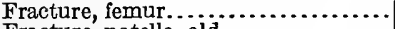 & $\ldots . .$. & 1 & 1 & $\ldots \ldots$. & & & $\ldots .$. & \\
\hline ure, patella, old............... & $\cdots$ & 1 & 1 & & & 1 & $\ldots .$. & *.... \\
\hline 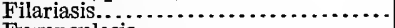 & $\ldots .$. & 4 & 4 & & & 4 & $\ldots \ldots$ & $\cdots \cdots$ \\
\hline$\ldots \ldots \ldots \ldots \ldots \ldots \ldots \ldots \ldots \ldots \ldots$ & $\ldots . .$. & 1 & 1 & 1 & & & & (2) \\
\hline ................ & $\cdots$ & 3 & 3 & $\ldots \ldots$. & & 1 & $\ldots$ & $\ldots .$. \\
\hline$\ldots \ldots \ldots \ldots \ldots$ & ... & 1 & 1 & ...... & & $\tilde{\mathbf{1}}$ & .... & $\ldots \ldots$ \\
\hline$\ldots \ldots \ldots \ldots \ldots \ldots \ldots \ldots \ldots$ & $\ldots$ & 2 & 2 & ... & & & $\cdots \ldots$ & ...... \\
\hline oids, internal . . . . . . . . . . & $\ldots$ & 1 & 1 & ... & & & $\ldots . .$. & ...... \\
\hline esis . . . . . . . . . . . . . . . . . & $\cdots$ & 1 & 1 & & 1 & & $\ldots$ & …. \\
\hline$\because \ldots \ldots \ldots \ldots \ldots \ldots \ldots \ldots$ & ... & 2 & 2 & & & 2 & $\ldots$ & 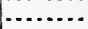 \\
\hline 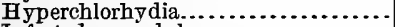 & $\cdots$ & 1 & 1 & 1 & & & $\ldots$ & $\cdots$ \\
\hline ted wound, knee............... & ....... & $\tilde{1}$ & 1 & ...... & & & $\ldots$ & $\ldots \ldots$ \\
\hline Infected wound, finger.............. & $\ldots . .$. & 1 & 1 & & 1 & & $\ldots$ & $\cdots$ \\
\hline 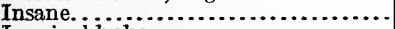 & - & 1 & 1 & & $\ldots$. & 1 & $\ldots$ & $\cdots \cdots$ \\
\hline 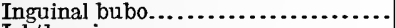 & ... & 1 & 1 & 1 & . & & .... & $\cdots \ldots$ \\
\hline 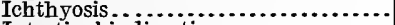 & $\ldots$ & 1 & 1 & $\ldots .$. & & 1 & $\ldots . .$. & $\ldots$. \\
\hline Intestinal indigestion . . . . . . . . . . & $\ldots .$. & 2 & 2 & & $\ldots$. & $\cdots \cdots$ & $\ldots .$. & $\ldots \ldots$ \\
\hline 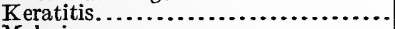 & $\ldots . .$. & 1 & 1 & 1 & ..... & $\ldots$. & $\ldots$. & $\ldots$ \\
\hline$\ldots \ldots \ldots \ldots \ldots$ & $\ldots$ & 2 & 2 & $\ldots \ldots$ & & $\cdot$ & $\cdot$ & \\
\hline dte...................... & $\ldots$ & 1 & 1 & & $\cdots$. & & $\ldots .$. & \\
\hline nia $\ldots \ldots \ldots \ldots \ldots \ldots$ & $\ldots$. & 1 & 1 & ........ & …. & & & $\ldots . .$. \\
\hline or ataxia .................. & & 1 & 1 & & & & $\cdots$ & 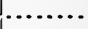 \\
\hline 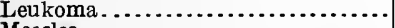 & $\cdots$ & 1 & 1 & $\ldots \ldots$ & & $\cdots$ & $\cdots . .$. & $\cdots$ \\
\hline$\ldots \ldots \ldots \ldots \ldots \ldots$ & $\ldots \ldots$ & 1 & 1 & & & & & \\
\hline ( $\ldots \ldots \ldots \ldots \ldots \ldots$ & $\ldots \ldots$ & 2 & 2 & $\ldots \ldots \ldots$ & & $\cdots$ & $\cdots$ & \\
\hline a & $\cdots$ & 227 & 227 & $\ldots \ldots$ & & 227 & $\cdots$ & \\
\hline ation, mental $\ldots \ldots \ldots \ldots \ldots \ldots$ & $\ldots$ & 4 & 4 & & & & $-\cdots$ & \\
\hline y tuberculosis............... & $\cdots$ & 2 & 2 & $\ldots \ldots$ & $\cdots$ & & & \\
\hline 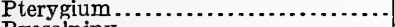 & $\ldots$ & 1 & 1 & $\ldots \ldots \ldots$ & $\cdots$ & 1 & & \\
\hline $\mathrm{nx}$. & $\ldots$ & 1 & 1 & $\cdots \cdots$ & & 1 & $\ldots \ldots \ldots$ & \\
\hline & & 27 & 27 & 26 & & & & \\
\hline & .......... & 4 & 4 & $\cdots \ldots$ & & 4 & $\ldots \ldots$ & \\
\hline crusis. . . . . . . . . . & & 3 & 3 & & $\cdots$ & 1 & $\ldots \ldots \ldots$ & $\cdots \ldots$ \\
\hline itis $\ldots \ldots \ldots \ldots \ldots$ & $\cdots \cdots$ & 1 & & & $\cdots$ & & $\cdots \cdots \cdots$ & \\
\hline ma & 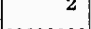 & $\begin{array}{l}32 \\
14\end{array}$ & & & & 21 & $\ldots \ldots \ldots$ & \\
\hline 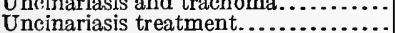 & $\cdots \cdots$ & 993 & $\begin{array}{r}14 \\
1,009\end{array}$ & $\begin{array}{r}1 \\
958\end{array}$ & & 13 & & 5 \\
\hline 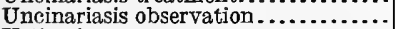 & 7 & 342 & 349 & & & 349 & & \\
\hline Urticaria. . . . . . . . . . . . . . . . . & ........ & 1 & 1 & & & & $\ldots \ldots$ & \\
\hline Vaginitis......... & & 2 & & & & & & \\
\hline
\end{tabular}


Hospital report for fiscal year ending June 30, 1912, United States Immigration Hospital, Angel Island, Cal.-Continued.

\begin{tabular}{|c|c|c|c|c|c|c|c|c|}
\hline Disease. & $\begin{array}{l}\text { In hos- } \\
\text { pital } \\
\text { July 1, } \\
1911 .\end{array}$ & $\begin{array}{l}\text { Admit- } \\
\text { ted dur- } \\
\text { ing } \\
\text { year. }\end{array}$ & 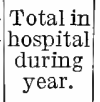 & $\begin{array}{l}\text { Recov- } \\
\text { ered. }\end{array}$ & $\begin{array}{c}\text { Im- } \\
\text { proved. }\end{array}$ & $\begin{array}{l}\text { Notim- } \\
\text { proved. }\end{array}$ & Died. & $\begin{array}{l}\text { In hos- } \\
\text { pital } \\
\text { June } 30, \\
1912 .\end{array}$ \\
\hline 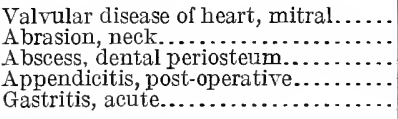 & & $\begin{array}{l}2 \\
1 \\
1 \\
1 \\
1\end{array}$ & $\begin{array}{l}2 \\
1 \\
1 \\
1 \\
1\end{array}$ & $\begin{array}{l}1 \\
1 \\
1\end{array}$ & $\begin{array}{ll}\cdots \\
\cdots \\
\cdots\end{array}$ & $\mid \begin{array}{l} \\
\cdots \\
\cdots \\
\cdots\end{array}$ & & 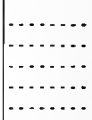 \\
\hline Total....... & 26 & 1,806 & 1,832 & 1,074 & 38 & 658 & 2 & 60 \\
\hline
\end{tabular}

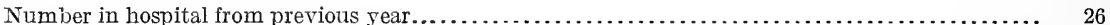

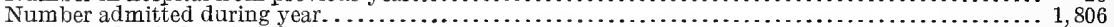

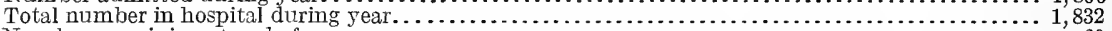

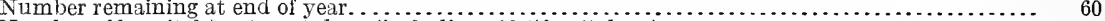

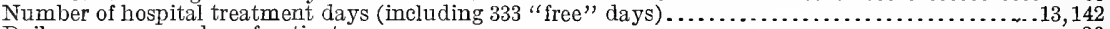

Daily average number of patients. . . . . . . . . . . . . . .

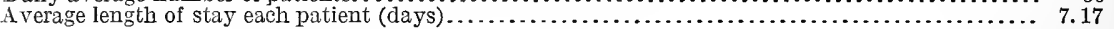

MONTHLY TOTALS AND DAILY AVERAGE.

\begin{tabular}{|c|c|c|}
\hline Month. & $\begin{array}{l}\text { Monthly } \\
\text { total. }\end{array}$ & $\begin{array}{c}\text { Daily } \\
\text { average. }\end{array}$ \\
\hline 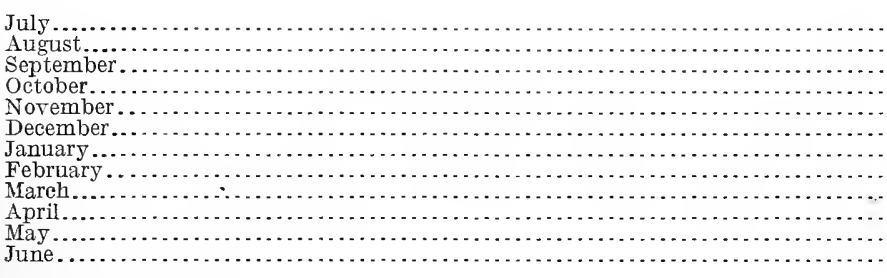 & $\begin{array}{r}681 \\
834 \\
614 \\
833 \\
\mathbf{1}, 105 \\
\mathbf{1}, 245 \\
1,050 \\
1,015 \\
1,196 \\
1,111 \\
1,673 \\
1,785\end{array}$ & $\begin{array}{l}22.00 \\
26.90 \\
20.60 \\
29.90 \\
36.90 \\
40.20 \\
33.84 \\
35.00 \\
38.58 \\
37.00 \\
54.00 \\
59.50\end{array}$ \\
\hline Yearly total..................... & 13,142 & 36.00 \\
\hline
\end{tabular}




\title{
DOMESTIC (INTERSTATE) QUARANTINE.
}

\author{
Plague-Suppressive Measures.
}

Plague-suppressive measures in California and near-by States were carried out during the fiscal year in accordance with the plan which was outlined in the amnual report for the fiscal year ended June 30, 1910.

The present outbreak of bubonic plague in California was discovered in 1907, and during the following year the infection was also found among ground squirrels in rural districts in Contra Costa County. As a result of the cooperation between the Public Health Service and State and municipal health authorities, the disease has been eradicated from the California cities. The infection still prevails, however, among ground squirrels in rural districts. The officers in command of these operations during the fiscal year were as follows:

Surg. (now Surg. Gen.) Rupert Blue, July 1, 1911, to October 24, 1911.

Passed Asst. Surg. (now Asst. Surg. Gen.) IT. C. Rucker, October 24, 1911, to March 3, 1912.

Passed Asst. Surg. D. H. Currie, March 3, 1912, to April 6, 1912.

Passed Asst. Surg. J. D. Long, April 6, 1912, to July 1, 1912.

Passed Asst. Surg. G. W. McCoy was in charge of the laboratory until October 24, 1911, since which time Passed Asst. Surg. D. H. Currie has commanded the plague laboratory.

\section{PLAGUE PREVENTION IN SAN FRANCISCO AND NEAR-BY CITIES.}

During the fiscal year ended June 30, 1912, the following measures for the examination and eradication of rats in San Francisco have been consistently applied:

First. Measures for the immediate recognition of rat plague, should such occur.

Second. Measures for the destruction of rats.

Third. Measures for the destruction of rat food.

Fourth. Measures for the destruction of rat harbors and for the permanent ratproofing of buildings.

Measures for the immediate recognition of rat plague, should such occur.-A city's first line of defense lies in the thorough and continuous examination of the rodent population. Should an infected rat be found, measures for the destruction of all rats in the vicinity of the infected animal may be at once instituted, the small focus destroyed, and the further spread of the disease prevented.

As a post-epidemic measure this policy has been continuously. followed in San Francisco since the eradication of plague in 1908, when for the purpose of systematizing this work the city was divided into a number of districts, each district being in turn divided into a number of smaller units or sections.

During the fiscal year 8,000 traps, spread over the entire city, have been in continuous operation. These traps were placed, baited, and inspected daily by a force of Federal employees, consisting of 26 
expert rat catchers (each in charge of one or more units or sections) acting under the direction of three foremen (one assigned to each district). All rats trapped were carefully tagged, giving the exact location where caught and the date, then segregated according to species, and these facts recorded in a journal. They were then forwarded to the Federal laboratory, where a careful post-mortem examination was made of each rat.

The following tabulated statement indicates the character and number of premises trapped, number and kind of traps used, and the resultant catch.

\begin{tabular}{|c|c|c|c|c|}
\hline Character of premises. & $\begin{array}{c}\text { No. of } \\
\text { premises. }\end{array}$ & $\begin{array}{l}\text { No. of } \\
\text { cage } \\
\text { traps. }\end{array}$ & $\begin{array}{l}\text { No. of } \\
\text { snap } \\
\text { traps. }\end{array}$ & $\begin{array}{c}\text { No. of } \\
\text { rats } \\
\text { trapped. }\end{array}$ \\
\hline 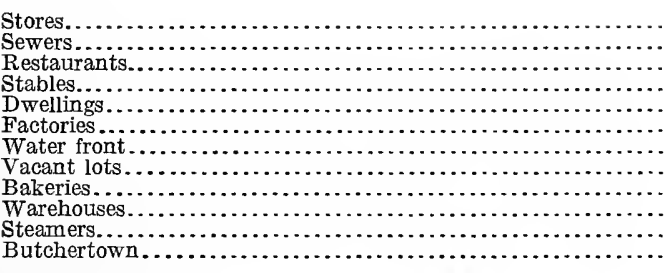 & $\begin{array}{r}758 \\
289 \\
257 \\
167 \\
611 \\
65 \\
61 \\
46 \\
12 \\
116 \\
93 \\
31\end{array}$ & $\begin{array}{r}97 \\
254 \\
42 \\
46 \\
52 \\
19 \\
33 \\
4 \\
3 \\
23 \\
22 \\
20\end{array}$ & $\begin{array}{r}2,915 \\
45 \\
1,069 \\
554 \\
1,501 \\
311 \\
175 \\
134 \\
42 \\
605 \\
334 \\
190\end{array}$ & $\begin{array}{r}21,233 \\
8,962 \\
9,766 \\
5,710 \\
9,368 \\
2,250 \\
1,295 \\
841 \\
337 \\
4,994 \\
2,508 \\
858\end{array}$ \\
\hline 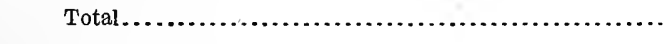 & 1,906 & 615 & 7,875 & 68,122 \\
\hline
\end{tabular}

During the fiscal year 67,289 rats trapped, 8,382 mice trapped, and 833 rats found dead were forwarded to the Federal laboratory for examination.

Only once during the year was a suspicious rat reported by the laboratory. Pending the time required for the complete investigation of this case the trapping squad was doubled in the section from which the suspicious rat came, and every preparation was made for the vigorous application of all measures necessary for the destruction of this focus. Fortunately the laboratory's findings proved negative.

Measures for the destruction of rats. - In addition to the destruction of rats by trapping incidental to their examination, only one other method has been applied directly for the destruction of rats, namely, the placing of rat poison. Neither trapping nor poisons nor the combination of the two will rid a city of rats, but used in conjunction with rat-proofing methods they form an important adjunct. Poisoning is of especial value in ridding large rat-proofed buildings of contained rats, which finding harbor and sustenance therein might otherwise perpetuate themselves. Poison is also of value in destroying rats in locations presenting difficult and expensive rat-proofing problems, which in San Francisco have been found in freight depots and freight yards, the water front, the garbage dump, and Butchertown.

The following is a summary of trapping and poisoning operations for the fiscal year:

Number of rats trapped.

67,289

Number of rats found dead.

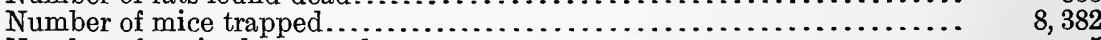

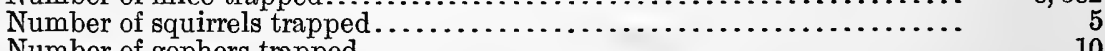

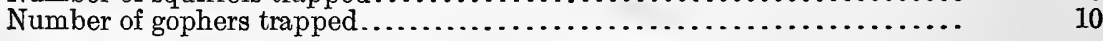

Remarks: The number of mice is an unavoidable incident in the trapping of rats. 
Bait used:

Number of pounds of bucon......................... 4, 3996

Number of pounds of cheese.......................... 930

Number of loaves of bread........................... 6. 117

Number of poisons placed.............................. 1. 405,400

While the number of rats destroyed by poison can not be accurately stated, from the evidence of rat carcasses found and the absence of rats in premises poisoned it can be assumed that results were very satisfactory.

Measures for the destruction of rat food.-By rat food is meant waste food, or food refuse, such as is thrown carelessly on vacant lots or around garbage cans or into imperfect garbage cans, or surplus food thrown to chickens or dropped in transportation or handling.

Complaints covering nuisances of a minor character made by citizens generally, whether involving the question of rat food or not, have all been referred to this office for investigation and adjustment, since the majority relate in some way to rat-proofing requirements or exposed rat food; 2,581 such complaints were investigated during the year.

The imperfect garbage can represents the most important source of rat food and provides amply for rat sustenance, but the continuous inspection of all garbage cans in San Francisco would require the examination of all premises contained within about 2,500 city blocks, and such work is not feasible with the small force available. However, as an index to the condition of garbage cans, a sufficient number of blocks have been inspected to justify the statement that from 20 per cent to 25 per cent of all cans at present in use are defective and should be renewed. As a result of this partial inspection 2,556 new garbage cans have been installed during the year. Plans are now receiving consideration which it is hoped will permit the complete reinspection of all garbage cans in the city.

Chicken yards offer a convenient source of rat food and must be rat proofed or abandoned. During the fiscal year 344 such yards have been inspected, with the result that 69 have been made rat proof, while 274, containing 3,212 chickens, have been abandoned. With the continued growth of the city the keeping of chickens will probably become a sufficient nuisance to justify prohibition. Vacant tots, buildings, basements, passageways, and yards containing perishable food, 1,488 premises in all, have been thoroughly cleaned.

The following tabulation covers such work for the fiscal year:

For the destruction of rat food.

Number of complaints inspected............................... 2, 581

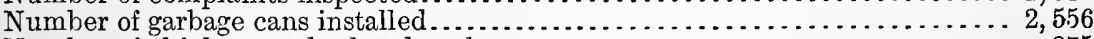

Number of chicken yards abandoned..................................... 275

Number of chicken yards concreted....................................... $\quad 69$

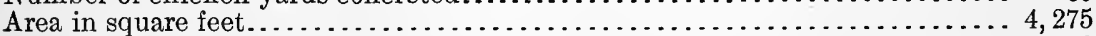

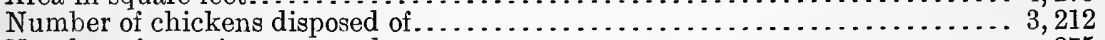

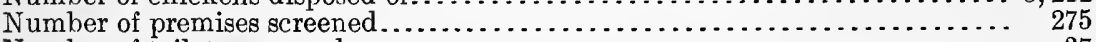

Number of toilets screened..................................... $\quad 37$

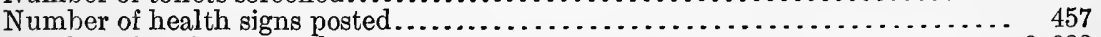

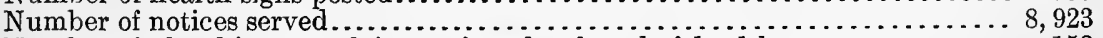

Number of plumbing complaints referred to board of health.............. ${ }^{158}$

Number of vacant lots cleaned.................................... 263

Number of buildings cleaned.......................................... $\quad 361$

Number of basements cleaned...................................... 269 
Number of passageways cleaned ............................. 134

Number of yards cleaned. . . . . . . . . . . . . . . . . . . . . . . . . . . . . . . 461

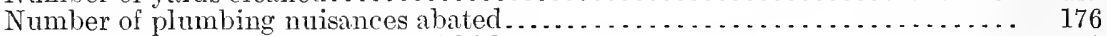

Number of premises cleaned of rubbish . . . . . . . . . . . . . . . . . . . . . . 1, 209

Number of lots from which stagnant water has been pumped........... 26

Measures for the destruction of rat harbors and for the permanent rat proofing of buildings. - The complete destruction of all rats can be accomplished only by the separation of this rodent from his food supply. This is to be approached by the removal of all rat harbors and reached by the rat proofing of all buildings and the screening of all rat food. The rat must be "built out of existence" by the application of the following measures:

(a) The erection and maintenance of rat-proof buildings only

(b) The closure of all accidental openings in existing buildings of rat-proof construction.

(c) The remodeling of all nonrat-proof buildings using rat-proof material, or the destruction of such buildings.

(d) The removal of all material covering yards, sidewalks, and passageways which will permit rat refuge.

Measures in accord with the above classification have been in operation in the city of San Francisco throughout the fiscal year. Two Federal inspectors and six city employees, acting under the direction of the service and designated special sanitary inspectors, have been engaged. in carrying out this work.

The erection and maintenance of rat-proof buildings only.--The inspection of new buildings in the course of erection has required the constant attention of two special sanitary inspectors. The board of public works provides a list of permits for the erection of new buildings, and with this list as a general guide all buildings in the course of erection have been carefully inspected, and construction in accordance with rat-proofing requirements rigidly enforced.

During the fiscal year 1,666 new buildings were inspected. In 25 per cent of these cases the presence of the inspector alone prevented the omission of important rat-proofing construction, and when it is remembered that the erection of rat-proof buildings limits the task of rat proofing the city to existing buildings, the value of this work can be estimated.

Number of buildings rat proofed......................... 1,666

Basements concreted, 2,603; area. square feet....................... 3, 040, 951

Floors concreted, 45 ; area, square feet....................... 194, 432

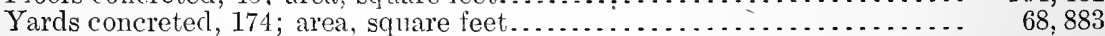

Passageways concreted, 558; area, squme feet......................... 142,868

Sidewalks concreted, 1,$370 ;$ area. square feet........................ 616,500

Total number of square feet laid in new premises............ 4, 063, 634

The closure of all accidental openings in existing buildings of ratproof construction. - The majority of the buildings included in this classification are located in what is commonly known as the down town business and wholesale produce sections of San Francisco, all within the fireproof limits of the city. Located here and there throughout this district remain about 600 temporary frame structures, which though ordered demolished and without legal status, for reasons of equity, have been allowed to remain. Because of the substantial construction of the majority of buildings located herein, measures for the eradication of rats were very successful. The common rat of San Francisco, the brown or Norvegicus, usually inhabiting ground floors and 
basements, was quickly eliminated from this section and is now rancly found. But, following his extermination, the few black and roof rats inhabiting the upper floors and roots of these buildings brean to increase, and this section now furnishes the bulk of the catch of these forms. It was found that these rats found passige loom one buildiner to another through various accidental and overlooked openings, and the work of locating and closing such openings has received especial attention.

During the fiscal year 82 such structures have been inspected and the following detailed work carried out:

Ventilators on roofs screened ............................ 431

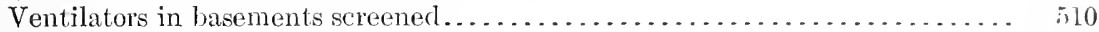

Openings around pipes closed with cement....................... 1,900

Openings in walls, ceilings, and floors closed by wire lath and cement. . . . . . 2, 334

Unused chimney flues screened . . . . . . . . . . . . . . . . . . . .

While mention has been made in previous reports noting the increase in the number of rats in buildings of the abore character, this increase has now assumed such proportions as to render it a problem requiring special attention for its solution. Under the title "The increase in Mus Rattus and Alexandrinus" it will be discussed in detail later.

The remodeling of all existing nonrat-proof buildings using rat-proof materials, or the destruction of such buitdings. - Under this division is included all frame structures, with or without basements, and generally lacking foundation walls and floors impervious to rats. The majority of buildings within the city fall within this class, and since they permit the easy access of rats, afford refuge and supply food, and exist in large numbers, they represent the principal obstacle to be overcome in the rat proofing of San Francisco. This is especially true where such buildings are occupied by stores or markets which prepare food, or keep food for sale, such as restaurants, bakeries, fish and meat markets, fruit and vegetable stores, delicatessens, candy factories, etc. Under the city ordinance all such structures in the city wherever found must be remodeled and constructed with brick or concrete foundation walls extending 18 inches below the surface of the soil and upward to the floor level above. All basement floors must be constructed of concrete, and all floors above such basements, where the building contains food products, must be constructed with double floors, between which is placed $\frac{1}{2}$-inch No. 20 gauge wire cloth. When the building does not extend beyond 55 feet in height this double floor and wire mesh may be omitted provided the basement ceiling is left open and unfinished.

The only exception to the above general requirements refers to frame buildings occupying not more than 800 square feet of ground area and lying without prescribed limits (remote portions of the city). Such buildings may be temporarily rat proofed by elevation to a height of not less than 18 inches, with open underpinning.

All buildings falling within this general classification found rat infested and in a generally insanitary condition are inspected, and the owners invited to comply with all city health regulations relating to rat proofing or other requirements necessary to put them in a sanitary condition. Wherever such owners, after notification, fail, neglect, or refuse to comply, the case is transmitted to the board of health with the recommendation that the premises be repaired as required by law or condemned, vacated, and demolished. 
During the fiscal year the following detailed work has been accomplished:

Number of buildings rat proofed by concreting......................

Number of square feet of wire cloth laid ............................

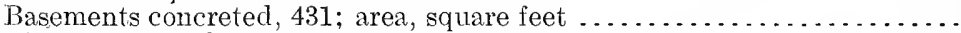

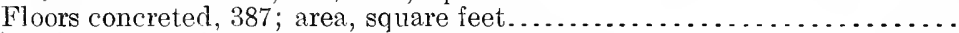

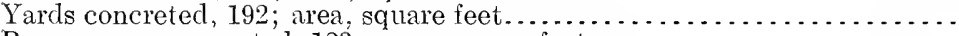

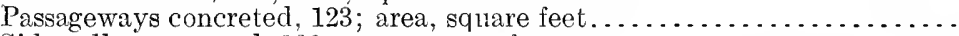

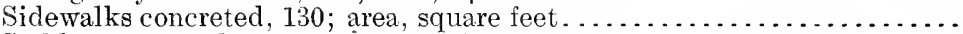

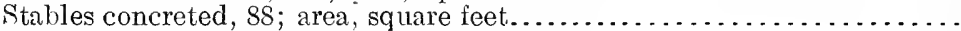

Chicken yards concreted, 69 ; area, square feet.

Total number square feet laid in old premises................ 1, 170,060

As rapidly as careful inspection with the force detailed for this purpose will permit, all rat-infested structures of this character in the city will be taken up for remodeling.

The removal of all material from yards, sidewalks, and passageways which will permit rat refuge. - Wooden floors, whether covering yards, basements, or passageways, when lying in close proximity to the ground offer easy access to rats, and wherever such have been found harboring these rodents they have been ordered removed and the ground area left bare or covered with gravel, cinders, or cement. During the fiscal year wooden coverings have been removed from 310 yards, 450 basements, 196 passageways, 390 floors, and 150 sidewalks.

The increase in black and roof rats.-As the result of rat eradicative measures during and prior to the year 1908, the rat catch per quarter was reduced in 1908 from 72,250 to 22,359 , a reduction of practically 50,000 rats in the quarterly catch.

Since 1908, however, with a greater number of traps in the field, but slight further reduction has been effected, the number averaging 19,000 per quarter and fluctuating between fifteen and twenty-three thousand. This is indicated clearly on chart A.

An examination of the following statement indicating the rat catch for 1909, 1910,1911, and 1912, according to species, at once locates the cause for the slight decrease in the catch, and directs attention to an important problem.

\begin{tabular}{|c|c|c|c|c|}
\hline Species. & 1909 & 1910 . & 1911 & 1912 \\
\hline $\begin{array}{l}\text { Norvegicus } \\
\text { Rattus and Alexandrinus... }\end{array}$ & $\begin{array}{r}78,630 \\
4,162\end{array}$ & $\begin{array}{l}72,613 \\
10,509\end{array}$ & $\begin{array}{l}58,856 \\
13,429\end{array}$ & $\begin{array}{l}46,597 \\
21,525\end{array}$ \\
\hline Total catch... & 82,792 & 83,122 & 72,285 & 68,112 \\
\hline
\end{tabular}

Note.-Since Mus rattus and Alexandrinus are practically always trapped in the same localities, and in equal numbers, the catch is consolidated.

Whereas the brown or Norway rat (Mus norvegicus), as the result of rat-proofing operations, is steadily decreasing, black and roof rats (M. rattus and Alexandrinus) show a marked yearly increase. This is shown graphically in profile on chart B. Black and roof rats are replacing the Norway rat in certain sections of the city, and the reason for this substitution is to be explained as follows:

The brown rat, Mus norvegicus, is larger than either the black or roof rat and more ferocious. He is a more prolific breeder. He is a burrower, and in San Francisco by choice usually makes his home in or in close proximity to the ground, being most commonly found 
inhabiting only the ground area of buildings. He is rarely trapped in upper stories. Under natural conditions, when unchecked, he drives out both the Mus rattus and Alexandrinus because of his larger size and greater strength. Only mice (Mus musculus) persist and occupy the same premises, their smaller size permitting escape into crevices and small holes.

CHART "A," SHOWING QUARTERLY RAT-CATCH IN SAN FRANCISCO.

Average number of traps in the fieli ......................... 8,000

Average quarterly catch prior to rat eradicative measures ........... 75, 000

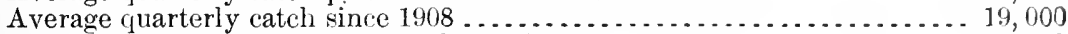

Reduction effected in the quarterly catch ...................... 50,000

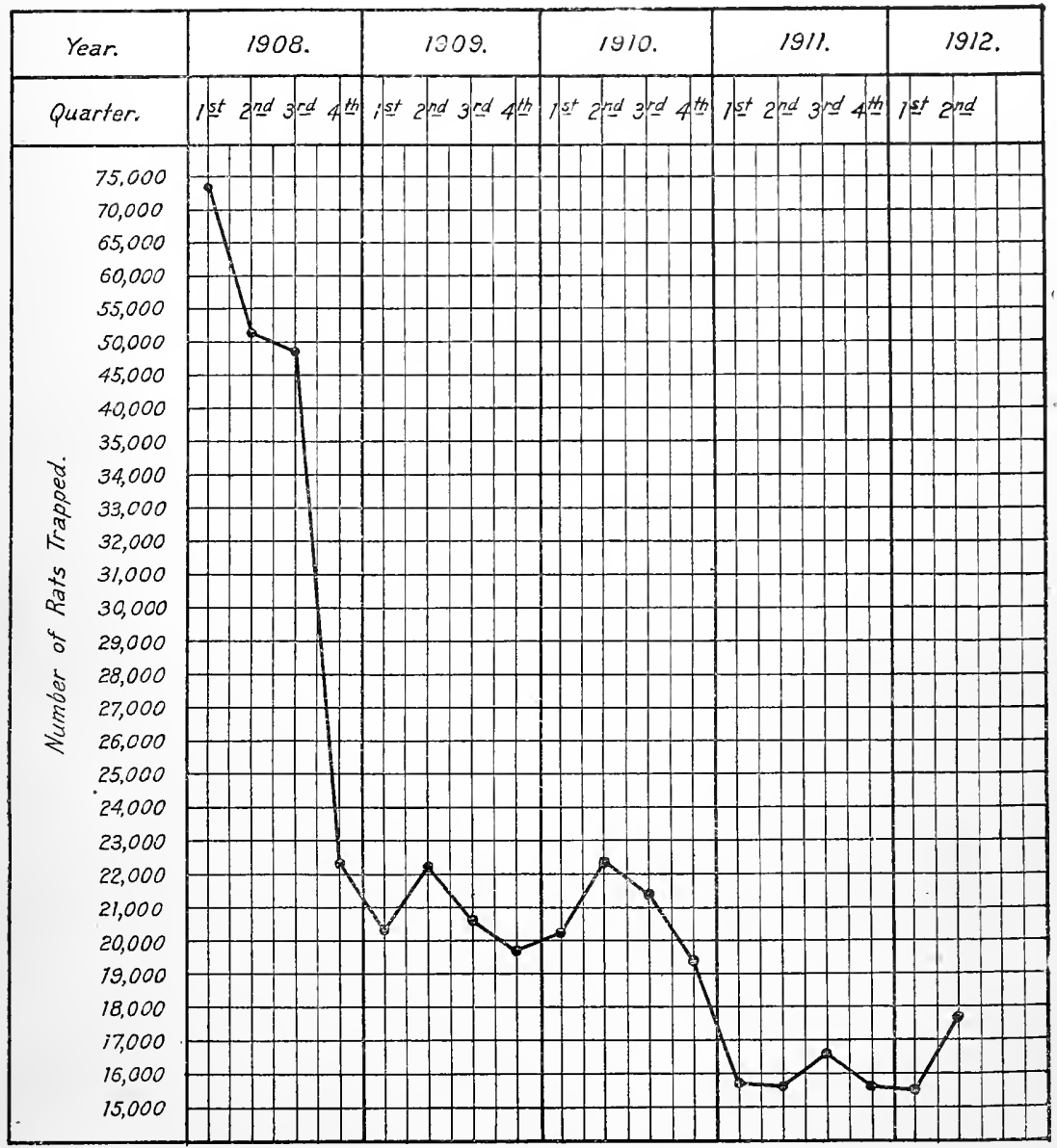

This condition obtained at the beginning of operations for the rat proofing of the city. The brown rat, present in large numbers, effectually prevented the entrance and increase of the smaller variety (Rattus and Alexandrinus), and for a time the latter forms were not trapped in large numbers. However, with the adoption and application of permanent rat-proofing methods the larger Norway rat is 
being effectually built out of existence and is slowly but surely decreasing in numbers, as indicated by chart B and tabulated statement. Many portions of the city, especially in the downtown section, where practically all buildings are constructed with ground areas of concrete which prevent burrowing, the Norway rat is now

CHART "B."-SHOWING INCREASE IN BLACK AND ROOF RATS (MUS RATTUS AND ALEXANDRINUS) COINCIDENT WITH THE DECREASE IN BROWN OR NORIVAY RATS (MUS NORVEGICUS).

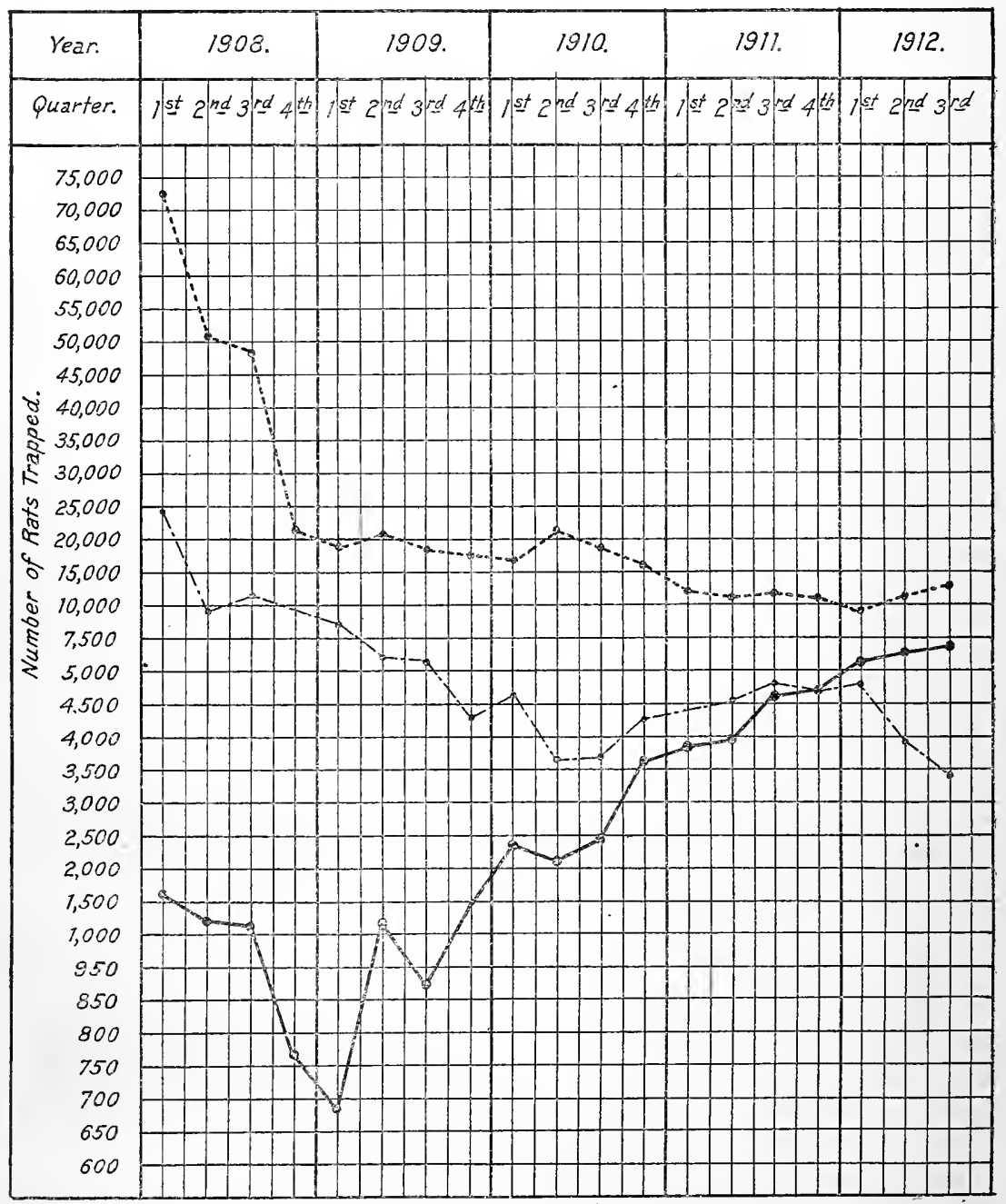

Musculus. -...-Rattus and Alexandrinus. - Norvegicus........

rarely trapped. However, within this area and in others of a similar character, where the Norway rat has been practically eliminated, Rattus and Alexandrinus, their old enemy having been destroyed, are beginning to increase. Their preference for upper floors and their ability to live in any portion of a building (above ceilings, in 
walls, and on roofs, and their agility as climber's permitting 1 hem to pass from roof to roof by telephone and clorific wires, and other means, and their greater trap shyness and rmuning, all render them more difficult of control than their larger relative.

From the foregoing explanation it maty be assumed that the removal of the Norway rat has permitted the incrase of Rattus and Alexandrinus, but it is improbable that this increase is dur wholly to natural development, since opportunity is now present lor the arlelition of this variety from foreign sources. It is gencrally concerled that Rat tus and Alexandrinus are the most common ship-borne rats. Certainly these are the most common forms arriving at San Francisco, and this fact increases materially the importance of the problem. An examination of the records covering trapping operations on steanners arriving at this port since January, 1910, will bear out this statement. From January, 1910, to October, 1912, 7,08 4 rats have been recovered from vessels arriving at this port. Segregation according to species indicates that 2,868 Mus rattus and 4,125 Mus alexandrinus, a total of 6,993 , have been found, while only 91 Mus norregicus were identified. Examining the history of the ressels fumishing this latter form, it has been found that only 50 such rats were recovered from trans-Pacific or other ships engaged in foreign trade. Prior to ratproofing operations Mus rattus and Alexandrinus escaping from ships arriving at the wharves of this city at once net in large numbers their common enemy, the Norvegicus, and were probably not permitted to gain a foothold. But Norvegicus is now rarely caught along the water front and no longer acts as a barrier, and the close proximity of the wholesale fruit and vegetable district, containing many temporary nonrat-proof frame structures, which every legal effort has failed to remove, affords ready refuge and sustenance. However, pursuing this examination further, it has been found that temporary frame structures provide not more than 10 per cent of the catch of such rats. Practically 90 per cent of all black and roof rats trapped are obtained from theoretically rat-proof buildings falling within the $\mathrm{A}, \mathrm{B}$, or $\mathrm{C}$ classification of the building laws. All such buildings are covered with fireproof roofs, and are constructed with side walls and foundations of material impervious to rats. A careful inspection of such buildings shows that they have become nonrat-proof, partially through the omission of screens to basement windows and to ventilators, light wells, and other roof openings, but principally through the neglect of plumbers, electricians, and others to properly close openings around pipes, introduced for the conveyance of water, gas, steam heat, electric wires, etc.

To summarize: (1) The brown rat is slowly decreasing generally and has disappeared from rat-proofed ground areas which prevent refuge by burrowing. (2) The black and roof rat is rapidly increasing and is reinfesting premises previously occupied by the brown rat. (3) This substitution occurs principally in theoretically rat-proof buildings through neglect of unnecessary or accidental openings. (4) Because of the elimination of the Norway rat from the water front the shipborne Rattus and Alexandrinus now find entry and lodgment at this port less difficult. (5) Rattus and Alexandrinus, because of ability to live above ceilings, between walls, and on roofs, and because of great cunning and trap shyness are more difficult to reach with poison and traps, and because of great agility as climbers 
are more difficult to confine and control. It will be seen, therefore, that the disturbance of the natural balance between the species is resulting in the substitution of rodents more difficult of elimination, and in order to prevent their further increase the application of the following measures is necessary and will be actively employed during the coming fiscal year:

First. Greater vigilance for the prevention of the escape of rats from ships.

Second. Thorough rat proofing of water-front property under the jurisdiction of the State.

Third. The removal of all temporary frame structures (about 600) within the fire limits.

Fourth. Increased force for the inspection of A, B, and C structures containing accidental openings and more vigorous prosecution of delinquents.

Fifth. Increase in trapping operations within and on the roofs of such buildings and thorough poisoning of their interiors wherever possible.

RATS TRAPPED IN OTHER CITIES.

During the fiscal year rats have been trapped in the following bay cities: Oakland, Berkeley, and Alameda; and in the following interior towns: Fresno, Modesto; and Stockton.

Operations in Fresno, Modesto, and Stockton were of a temporary character, made in order to anticipate the possible transmission of plague from infected ground squirrels to the rats of these small cities. All rats obtained were forwarded to the laboratory in San Francisco for examination. No infection was found.

The result of the examination of the rats trapped in Fresno is of interest. During the period November 16 to December 17, 1911, 544 rats and 34 mice were trapped. Vith the exception of 13 rats, all rats trapped were either Alexandrinus or a cross with Rattus, the so-called Rattus-Alexandrinus. In no instance was a specimen of Norvegicus obtained. Since the Norway rat, "because of its size and strength, would likely survive all other prevailing forms, it seems reasonable to assume that this species of rat had never been present there.

The above 13 rats excepted were "pied forms," all trapped in a restaurant in Chinatown. The species was not determined.

OPERATIONS IN BERKELEY, OAKLAND, AND ALAMEDA.

Arrangements for the permanent rat proofing of these cities have never been perfected, and the work has been confined to the trapping of rodents for laboratory examination. The following rodents have been collected and identified:

\begin{tabular}{|c|c|c|}
\hline Species of rat trapped. & $\begin{array}{l}\text { Oakland } \\
\text { and } \\
\text { Alameda. }\end{array}$ & Berkeley. \\
\hline $\begin{array}{l}\text { Mus porvegicus } \ldots \ldots \ldots \\
\text { Mus alexandrinus } \\
\text { Mus rattus } \ldots \ldots\end{array}$ & $\begin{array}{r}19,387 \\
38 \\
75\end{array}$ & $\begin{array}{r}5,291 \\
1 \\
5\end{array}$ \\
\hline Mus musculus. & $\begin{array}{r}19,500 \\
5,426\end{array}$ & $\begin{array}{l}5,297 \\
2,472\end{array}$ \\
\hline
\end{tabular}


A force of 12 Federal employees is detailed as follows:

Trappers.

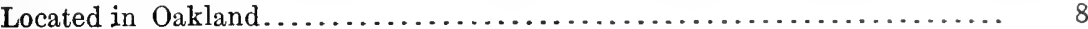

Located in Berkley...................................... 3

All under the direction of one foreman. Average number of traps in field, 1,600 .

The cities of Oakland and Berkeley provide a nominal sum for the purchase of traps, twine, and bait, but trapping in Alameda has been carried on without expense to that eity until recently, when a necessary reduction in the force required the withdrawal of the trapper located there.

In Berkeley particular attention has been paid to the trapping of rats in suburban districts adjoining territory infested with plagueinfected squirrels.

The segregated rat catch of the above cities shows a very small number of black and roof rats trapped; total catch, 119, as compared with 24,797 Norway rats caught during the same period of time. This again draws attention to the fact that wherever Norway rats exist unchecked by permanent rat-proofing operations they predominate to the practical exclusion of the smaller forms.

\section{WORK OF PLAGUE LABORATORY, SAN FRANCISCO, CAL.}

The chief work of this laboratory during the past fiscal year, as at previous times, has been a routine and systematic examination of rodents and other animals for plague infection. These animals have been obtained in San Francisco.

Among the squirrels, the only animals found infected during the year, the rate of infection differs widely from time to time, depending chiefly upon the district from which these rodents are secured and to a less extent on the time of year in which the collections are made. During the spring and early summer months, when there are a large number of young squirrels in the burrows, the infection runs high, and many of the cases are found among these immature rodents. This period also corresponds to the months of little or no rainfall, when fleas are most abundant and meet with the least danger from the ill effects of moisture when going from one animal to the other, owing to the dry nature of the soil. It has been suggested that, aside from the greater abundance of fleas at this time, it is probable that the old squirrels have had plague and those that have not been destroyed by it have become partially immune, so as to suffer from the disease in the chronic form without serious detriment to their general health. When the young squirrels are born they are, of course, exposed to these chronic cases of the disease among their elders and contract it in an acute and more fatal form.

Besides this routine work, for which purpose the laboratory was established, numerous other lines of work have been carried on, the most important of which was the investigation of a means by which the bacilli of rat leprosy could be cultivated on artificial media. It was considered highly important that a cheap and effective means be secured for the destruction of ground squirrels in their burrows. In cooperation with Passed Asst. Surg. Long, in charge of field operations, Passed Asst. Surg. Currie carried out a number of experiments with this in view. After numerous tests the conclusion was reached 
that of the chemicals that were employed for this purpose carbonbisulphide was the most efficient and convenient. It has been determined that this chemical was more effective when used in an unexploded vapor than after the combustion had taken place.

A long series of experiments was conducted to ascertain what apparatus would be the most practical and efficient in the employment of this chemical for the destruction of rodents in their burrows, and after a number of trials two machines were constructed, one volatizing the carbon bisulphide from the metal chamber by means of air pumped to it through a bellows. The other machine differed from this one in having a metal air chamber with plunger instead of the accordion-shaped bellows. Both machines had a device for holding the carbon bisulphide and a measuring device attached thereto. Both of these machines have been found sufficiently effective for practical purposes.

The plague laboratory undertook the examination of various specimens from the United States Marine Hospital. Numerous stools were examined for typhoid bacilli. The officer in charge of the laboratory states that he has also made Widal tests of typhoid blood, sectioned and examined tumors, examined gastric contents, etc. In addition to the above, much minor research and clinical work has been performed.

Private property owners have been very active in the extermination of ground squirrels, but difficulties have arisen in connection with infested Federal lands. Private owners find that it is both a waste of time and money to attempt to exterminate squirrels on lands adjoining lands of national parks and forest reserves when these are infested with ground squirrels. These possessions of the National Government are frequently alive with rodents, and during certain seasons ground squirrels migrate in large numbers from them to the ranches and farms in the lower valleys. In view of this fact, the farmers in certain localities have refused to undertake to attempt to eradicate rodents on their premises until some eradicative work has also been undertaken on unoccupied portions of the public domain in their vicinity.

In April, 1911, inspectors appointed by the supervisors of Tulare County reported that the larger portion of the public land in that county was infested with ground squirrels and stated that the farmers and ranchers could not comply with the act of March 13, 1909, "An act for the extermination of rodents," on account of the fact that the Government lands adjoining private lands served for breeding places for ground squirrels, and that squirrels migrated from public lands to the private lands adjoining. This was followed by resolutions passed by county boards of supervisors, reiterating the above statement and requesting the cooperation of the Departments of the Interior and Agriculture in the extermination of rodents on lands under their respective jurisdictions. Upon the receipt of the information above outlined from the officer of the Public Health Service in charge of antiplague measures in California, the Secretary of the Treasury addressed letters to the Secretaries of Agriculture and Interior outlining the situation and requesting their cooperation to the extent of causing the destruction of squirrels on land under their control. Letters were received from the Secretaries of both departments which stated in effect that instructions would be sent to the 
oflicers in charge of forest reserves and national parkis to cooperate in this work so far as authority in law and appropriations would permit.

This conperation was oflered, and on several leservat inns the rangers poisoned squirels with matrials furnished l,y the service. I)ifliculties of transportation, lowerer, male the work rely liard to perform, and the other duties of the langer's weresuch that it was latrdly fair to expect them to carry on this work.

\section{OPERATIONS FOR THE ERADICATION OF PLAGUE FROM AMONG GROUND SQUIRRELS, CALIFORNIA.}

With the close of the fiscal year encling June 30, 1911, the following plan was outlined for the control and erarlication of plague in California, to be applied during the fiscal year which has just ended:

First. The maintenance of squirrel-free zones around the cities bordering upon San Francisco Bay.

Second. The maintenance of squirrel-free zones around the foci situated at Ripon and Modesto in the counties of San Joaquin and Stanislaus, to prevent the spread of infection among rodents to the eastward.

Third. The destruction of all foci east of the San Joaquin River.

Fourth. Joint Federal and county inspection and squirrel extermination in all counties in which infection has been demonstrated and in counties contiguous thereto.

Fifth. Reconnoissance work and the collection of squirrels in such parts of the States of California, Oregon, Nevada, and Arizona as may be deemed necessary to determine whether infection has spread beyond the area to which it is now believed to be confined.

In general accord with the above plan the following measures have been carried out during the fiscal year ending June 30, 1912:

I. Work in the squirrel-free zone surrounding the bay cities of Berkeley, Alameda, and Oakland has continued without interruption, and no changes in the limits of this zone have been made during the fiscal year. A strip of territory about 16 miles long and from 1 to 2 miles broad has been maintained practically free through the operations of movable camps situated within this area.

During the fiscal year ended June 30, 1912, 135,714 acres have been poisoned, 24,684 pounds of poisoned grain and 710 gallons of bisulphide $\left(\mathrm{CS}_{2}\right)$ having been applied for this purpose.

II. In order to stamp out the foci of plague found in the vicinity of Ripon and Modesto and to prevent the advance of this disease eastward toward the Sierras, in August, 1911, movable camps were established in San Joaquin and Stanislaus Counties, and during the period August 1911, to April, 1912, practically 250 sections or 160,000 acres of land were thoroughly poisoned for the eradication of squirrels. In this work the service was assisted by local landowners and by the county board of supervisors in each county. It is estimated that an average of 80 per cent of the squirrels infesting this territory were destroyed. Thus a squirrel-free zone was practically established.

III. Wherever in the above counties, locations were reached from which plagueinfected squirrels had been received, the forces employed gave particular attention to the destruction of all squirrels infesting such areas. Hunters recently returned to these localities have found few squirrels, not one of which has proven plague infected. This shooting will be continued until a thorough examination of the entire territory has been made.

Altamont Pass, in Alameda County, is the natural gateway for travel by railroad and by county road between this county and the counties of San Joaquin and Stanislaus. It is very probable that the infection found in these latter counties entered through this pass from Alameda County. In April, 1912, the camp force previously operating in San Joaquin and Stanislaus Counties was transferred to Altamont Pass, squirrels being numerous and the degree of infection very high. The extent of this infection is accurately indicated as follows: 5,539 squirrels from the vicinity of Altamont Pass were received and examined at the laboratory and 128 of this number were found plague infected. In this connection it is interesting to note that many of the squirrels found infected were young squirrels born since January, 1912 . 
The area from which the above squirrels were received is contained within T. 2 S. R., $3 \mathrm{E}$., which includes the pass, and this territory was selected for the operations of the camp. 23,040 acres have been thoroughly poisoned with grain, the entire acreage, as was found necessary, being repoisoned three times, and many portions four times. As the result of the work this extensive focus of epizootic plague has been destroyed and Altamont Pass may be considered, for practical purposes, squirrel free.

IV. Squirrel eradicative work in the San Joaquin Valley previously begun in May, 1911, and undertaken in cooperation with the boards of supervisors and in the manner authorized by the squirrel eradicative act of 1909, continued without interruption until December 31, 1911. The following valley counties were included: San Joaquin, Calaveras, Stanislaus, Merced, Madera, Mariposa, Fresno, Kings, Tulare, and Kern. From the inception of the work in May, 1911, until its cessation in December, 1911, 22,456 separate inspections of property were made, representing an area of $6,956,160$ acres. Carefully compiled reports of the results obtained indicated at that time that landowners representing 4,670,741 acres were complying with the law in an endeavor to eradicate squirrels, while the owners of 363,702 had completely abated the nuisance. Over an area of 496.855 acres, squirrels were found absent.

From these figures it can be estimated with reasonable accuracy that the owners or lessees controlling about 60 per cent of 7,000,000 acres of land lying in the San Joaquin Valley, as a result of this campaign, made an earnest endeavor to eradicate squirrels, reducing their number from 50 to 80 per cent, while the owners representing about 7 per cent, or nearly 500,000 acres, succeeded in completely eradicating these pests.

A campaign similar in character in every way was carried out simultaneously in the following coast counties, namely: Alameda, Contra Costa, Monterey, San Benito, Santa Clara, Santa Cruz, and San Luis Obispo. With the exception of Contra Costa, Alameda, Santa Clara, and San Joaquin Counties, this work was discontinued with the close of the year 1911, results equal in every way to those secured in the San Joaquin Valley having been obtained. This discontinuance of general cooperative county work followed the reduction of the appropriation available for the control of plague in this State and made necessary the confinement of such measures to those counties in which epizootic plague was most extensive, namely: Contra Costa, Alameda, Santa Clara, and San Joaquin. Tulare, San Luis Obispo, and Santa Cruz, realizing the value of eradicative work from an economic viewpoint, continued the work independently with county employees, the counties of San Luis Obispo and Santa Cruz, upon request, having each been aided by the detail of a Federal inspector to act in a supervisory capacity.

Following the restriction of cooperative county work to Contra Costa, Alameda, Santa Clara, and San Joaquin Counties, all available employees were, on January 1, detailed to these counties, where an intensive campaign along the same original lines has been continued. This detail of additional inspectors to these counties permitted the reduction in size of districts assigned to each and has enabled them to cover the territory more frequently and has afforded time for the instruction of the land owners and lessees in the proper methods for the mixing and application of poisoned grain.

In practically all of the above counties various closely associated communities of landowners have been persuaded to elect and set aside certain days as "poison days," at which time all in the neighborhood go over their land thoroughly with poisoned grain, service field inspectors superintending and directing the work. Much good has been accomplished by this cooperative plan. In addition to the above, supervising inspectors in charge of these counties have appeared before local agricultural and horticultural improvement associations and have obtained official expressions of approval of eradicative measures. The various members of these associations, by resolution having pledged themselves, have given aid and full support to the work.

As the result of the measures here outlined a general and marked reduction in the number of squirrels in each county has been accomplished and over many large areas squirrels have been completely eradicated.

V. During the first half of the fiscal year, from July to December, hunting operations for the examination of rodents was carried out in the following States: California, Nevada, and Oregon.

In the State of California squirrels were secured and examined from the following counties: Alameda, Amador, Butte, Calaveras, Colusa, Contra Costa, Eldorado, Fresno, Imperial, Kern, Kings, Glenn, Lake, Los Angeles, Madera, Mariposa, Mendocino, Merced, Monterey, Plumas, Riverside, San Joaquin, San Benito, San Luis Obispo, Shasta, Siskiyou, Sonoma, Stanislaus, Sutter, Tehama, Tuolumne, and Yolo.

Total squirrels received ...........................6. 63,006

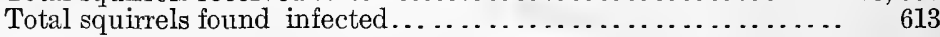

The infected squirrels were received from the following counties: Alameda, 123; Contra Costa, 485; Fresno, 1; Merced, 1; San Joaquin, 3. 
The following is a statement showing the amount and character of work performed:

Character of work performed.

\begin{tabular}{|c|c|c|}
\hline $\begin{array}{l}\text { Total for } \\
\text { fiscal } \\
\text { year. }\end{array}$ & $\begin{array}{l}\text { Prerious- } \\
\text { ly re- } \\
\text { ported. }\end{array}$ & $\begin{array}{c}\text { Total to } \\
\text { date. }\end{array}$ \\
\hline 6,805 & 23,880 & 30,685 \\
\hline ii & $\begin{array}{l}9.33 \\
100\end{array}$ & $\begin{array}{l}933 \\
111\end{array}$ \\
\hline 6,819 & 3,908 & 10,727 \\
\hline & 16 & 22 \\
\hline 57,553 & 277,831 & 335,384 \\
\hline 56,703 & 271,647 & 328,350 \\
\hline 1,448 & 2,778 & 4,220 \\
\hline & $\begin{array}{r}438 \\
1\end{array}$ & \\
\hline 579,888 & 52,109 & 631,997 \\
\hline
\end{tabular}

\section{HUMAN CASES.}

Oakland.-Fifteenth case. Name, Joseph Kelley; age, 16; male' American; recovered. Address, Nineteenth Street and Telegraph Avenue. Date of seizure, August 9, 1911; type of disease, bubonic; date of diagnosis, August 19, 1911; probable source of infection, ground squirrels.

Contra Costa County.-Third case. Name, Horace Flood; age, 7 years; male; American; died. Address, 1 mile northwest of Lafayette. Date of seizure, July 21, 1911. Date of death, July 26, 1911. Type of disease, bubonic; date of diagnosis, July 31, 1911. Probable source of infection, ground squirrels.

San Joaquin County.-First case. Name, Angelo Bianchi; age, 28; male; Swiss; recovered. Address, Ripon. Date of seizure, September 18, 1911; type of disease, bubonic; date of diagnosis, September 23, 1911. Probable source of infection, ground squirrels.

Record of plague infection.

\begin{tabular}{|c|c|c|c|c|}
\hline Places. & $\begin{array}{l}\text { Date of last case } \\
\text { of human plague. }\end{array}$ & $\begin{array}{l}\text { Date of last case } \\
\text { of rat plague. }\end{array}$ & $\begin{array}{c}\text { Date of last case } \\
\text { of squirrel } \\
\text { plague. }\end{array}$ & $\begin{array}{l}\text { Total number of } \\
\text { rodents found } \\
\text { infected since. } \\
\text { May, 1907. }\end{array}$ \\
\hline 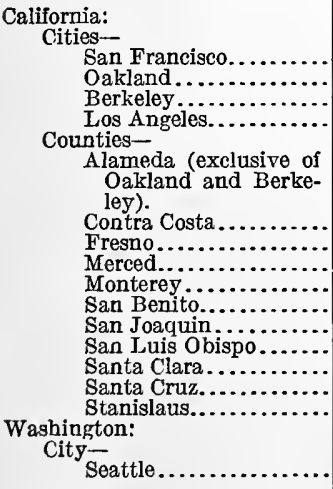 & 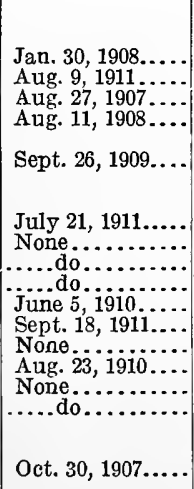 & 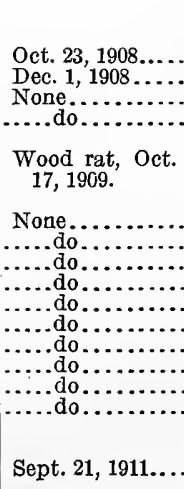 & 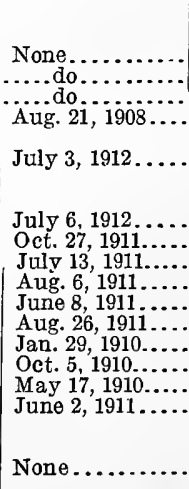 & $\begin{array}{l}398 \text { rats. } \\
126 \text { rats. } \\
\text { None. } \\
1 \text { squirrel. } \\
237 \text { squirrels and } \\
1 \text { wood rat. } \\
869 \text { squirrels. } \\
1 \text { squirrel. } \\
5 \text { squirrels. } \\
6 \text { squirrels. } \\
22 \text { squirrels. } \\
18 \text { squirrels. } \\
1 \text { squirrel. } \\
23 \text { squirrels. } \\
3 \text { squirrels. } \\
13 \text { squirrels. } \\
25 \text { rats. }\end{array}$ \\
\hline
\end{tabular}


The expenditure for plague eradication in California has been gradually reduced until at the present time it is costing $\$ 11,250$ per month. Of this sum, $\$ 10,000$ is being expended in the field work for the eradication of bubonic plague among the ground squirrels in the counties of Contra Costa, Alameda, San Joaquin, Santa Clara, San Benito, Santa Cruz, and Stanislaus, and in the prevention of the reintroduction of plague into the city of San Francisco; $\$ 1,250$ per month is being expended for the plague laboratory in San Francisco, in which rodents are examined to determine the presence or absence of plague in the various localities in order to keep accurate check on the work. In view of the important relation which the eradication of plague from California bears to the health and commercial prosperity of that State, it is necessary that this work be continued. It is quite important that this disease be eradicated in California, and the danger of its spread in interstate traffic be prevented. The sum which is being expended at present is the minimum amount with which this work can be continued. Therefore the sum of $\$ 135,000$ is necessary for the purpose of continuing the work during the next fiscal year.

Expenditures, Public Healih Service, San Francisco, Cal.

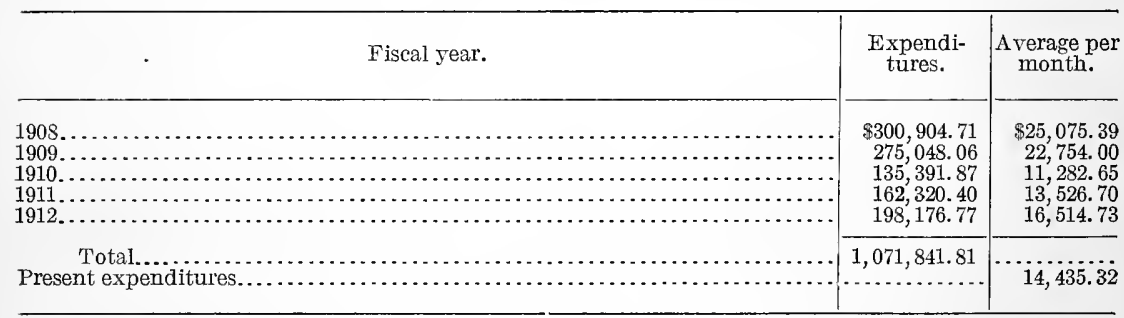

Past expenditures:

State and local authorities.

From August 12, 1907, to date, State, municipal, and county authorities

have expended a sum estimated to be between $\$ 500,000$ and $\$ 600,000$. Present expenditures:

Per month.

State of Califormia... . . . . . . . . . . . . . . . . . . . . . . . . . . $\$ 700$

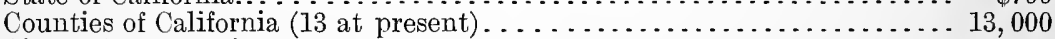

City of San Francisco................................... 1,350

Total.................................... 15,050

The Departments of Interior and Agriculture and the cities of Oakland and-Berkeley are doing work the value of which can not be estimated in money, as it is done in addition to or in connection with other work.

Particular attention is invited to chart B, in the report of the San Francisco division, which shows the increase in black and roof rats. Inasmuch as these rats are the principal cause of the continuation and spread of plague in the Orient, the necessity of protecting this country against the entrance of rats from plague-infected countries may readily be seen, and at first sight it might appear that the spread of plague within the city might probably be more rapid than has formerly occurred, due to the fact that the natural enmity of the Norway rat can not be counted upon in the future to prevent the access of the black rat from the Orient to the rats of the city.

The efficiency of the squirrel-free zone has apparently been demonstrated inasmuch as prolonged and careful trapping of rats in suburban 
districts of the city of Berkeley, adjoining teritory infisted with plague-infected squirrels, has failed to reveal that any infertion has extended from tlus squirrels to the rats of the city. 'The report of the field operations also indicates that the reduction of squireds thoughout the rural districts has been extensire, and inspretion shws that in the localities whre squirrols were formenty numerous, theil numbers have been greatly diminished, due to the iperations that have been carried on.

\section{SUMAIAY}

The achievements of the service in plague suppresive measures in California during the past year have been at follows:

1. Through the opsrations that have been conducted in the cities around San Francisco Bay, sanitaly conclitions in the citiss have been materially and constantly improved.

2. Through the maintenance of squirrel-free zoncs, the reinfection of the cities above mentioned has been prevented.

3. Through the operations of the service in those areas east of the San Joaquin River in which plague had appeared, the squirrels have been almost eradicated, and extensive and intensive hunting over the infected section and the territory contiguous thereto has failed to reveal the presence of plague among squirrels in that vicinity. It is therefore felt that a reasonable hope nay be entertained that one possible avenue for the extension of infection to the eastward has beén closed.

4. A renewed and more active interest in squirrel eradication has been manifested by boards of supervisors, landowners, and others, and during the coming year it is hoped that the results to be obtained will be satisfactory.

\section{PLAN OF OPERATIONS FOR THE COMING FISCAL YEAR.}

Unless some unforeseen emergency arises, the plan of operations for the coming fiscal year will be substantially as follows:

1. The continuation of the measures now in force in the cities around San Francisco Bay.

2. The maintenance of squirrel-free zones around the cities above mentioned.

3 . The maintenance of such operations and surveillance as may be necessary to to prevent the increase of squirrels in the vicinity of the foci of plague which had been found near Ripon and Modesto, in the counties of San Joaquin and Stanislaus.

4. Joint Federal and county inspection, and squirrel extermination in all counties in which infection has been demonstrated and in counties contiguous thereto. Especial attention will be paid to those sections of infected counties in which infection has been actually demonstrated, for the purpose of destroying known foci of infection as rapidly as possible. In the meantime hunters will be detailed for the purpose of determining whether the infection has spread to points beyond the localities in which plague now exists or has heretofore existed.

It is expected that during the coming year numbers of plagueinfected squirrels will be found on account of the fact that particular attention will be directed to the elimination of known foci of infection and the destruction of new foci that may be discovered.

From the State of Nevada squirrels were received from the following counties: Ormsby, Douglas, and Washoe.

Total squirrels received.

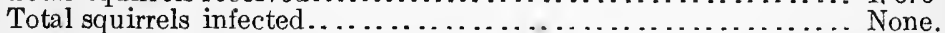

From Jackson County, in Oregon, 382 squirrels were obtained. Infected, none.

$69450-$ H. Doc. $971,62-3-11$ 
ANTIPLAGUE OPERATIONS IN SEATTLE, WASH.

Antiplague operations in Seattle have been continued as in the past. 'Trapping, poisoning, and other measures have been carried out by the municipal department of health and sanitation. All rats collected were delivered to the service representative stationed at Seattle, who made the bacteriological examinations.

During the fiscal year a total of 45,131 rats were examined and 25 infected rats found.

No human plague has been reported from Seattle since October 30 , 1907. The last infected rat was found September 21, 1911.

ANTIPLAGUE OPERATIONS ELSEWHERE.

Oregon.

Number of squirrels collected. 382

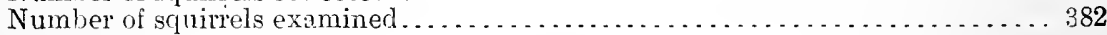

Nevadu.

Number of squirrels collected . . . . . . . . . . . . . . . . . . . . . . . . 1, 670

Number of squirrels examined . . . . . . . . . . . . . . . . . . . . . . .

Plague has not been found in the States of Oregon and Nevada.

PLAGUE IN PORTO RICO.

On June 17, 1912, the bureau was in receipt of advices from Porto Rico that considerable alarm was felt on account of rumors of plague. Shortly afterwards the acting governor of the island requested through Passed Asst. Surg. S. B. Grubbs that the Surgeon General send immediately by next steamer an expert for the purpose of taking charge of the situation. On June 20 Passed Asst. Surg. R. H. Creel and Asst. Surg. C. L. Williams were ordered to proceed immediately to New York in time to take steamer sailing Saturday for Porto Rico. Dr. Creel was ordered to assume command of plague suppressive measures in the island, with Dr. Williams as his assistant. Dr. Creel was directed to visit the governor or acting governor of Porto Rico and offer to cooperate in locating the various foci both of human and of rat infection and to submit a plan of campaign for the eradication of the disease.

The first case of human plague was recognized on June 14, 1912, in the person of a Porto Rican who had taken sick June 12. This case terminated fatally June 17.

From June 14 to June 30,1912 , there were 26 cases of plague, with 17 deaths.

Up to June 30 there had been examined in the laboratory 321 rats, 24 of which were found infected.

The officer in charge of plague suppressive measures in Porto Rico reports that the plague suppressive measures consist in the eradication of plague infection from San Juan and the prevention of its spread to other points, and that similar work was being conducted in Carolina. Active measures are being taken to prevent the spread of the disease. As a rigid maritime quarantine has been maintained at San Juan against all vessels arriving from ports known to be plague infected, it is possible that the infection was introduced from some foreign port in which plague exists but has not been recognized, or, if recognized, has not been reported. 
NECESSITY FOR PLAGUE PREVENTIVE MEASURES IN ATIAANTIC ANI GULF COAST CITIES.

There can be no doubt that one of the most important public-health measures to-day is the systematic examination of rodents in all of our ports, and from an economic standpoint there can be no better investment made for protection not only of commerce but of the public; health than by such a survey. The health authorities of the various ports on the Atlantic and Gulf seacoasts have been urged to commence immediately the collection, examination, and extermination of rodents, and in several of the ports they have already responded to this suggestion. Should human cases appear in any of the American ports, the effect would be to cripple commerce seriously, and thereby cause great financial losses, not only to the locality attacked, but also to the country as a whole. Carefully conducted rat surveys are indicated to-day as probably never before. IIuman cases almost invariably follow infection in rats.

As an example of this may be mentioned conditions in Porto Rico, where plague established itself in five foci and attacked 57 persons, of whom 23 have already died. There is also a very high percentage of infection among the rodents in the Porto Rican foci. The conditions in Habana may be taken as another example, where three persons were attacked and two died. It is therefore apparent that plague not only threatens from near by places which we know to be infected, but it is probable that the United States is threatened from other ports which have not as yet been reported as infected.

This bureau, in so far as its limited resources would allow, has endeavored to meet the various requirements of this situation.

\section{LEPROSY.}

During the fiscal year cases of leprosy have been reported in the following States: Missouri, Michigan, Colorado, Massachusetts, Connecticut, Indiana, and Utah.

There was reported as being present, January 1, 1912, in continental United States, 146 cases. Two States, namely, Louisiana and Massachusetts, and one city, San Francisco, have leprosaria, where lepers are isolated and cared for. In the other States cases of leprosy are provided for in various ways and with varying degrees of isolation. In Porto Rico there were 28 known lepers on January 1, 1912. In Hawaii and the Philippines the disease is present to such an extent that its control constitutes one of the important functions of the health authorities.

\section{TRANSPORTATION OF LEPERS IN INTERSTATE TRAFFIC.}

REVISION OF THE INTERSTATE QUARANTINE REGULATIONS.

Before promulgation it was deemed necessary to refer the proposed amendments to the department for the opinion of the Solicitor of the Treasury. In a letter to the Secretary under date of May 15, 1912, the Solicitor states as follows:

The Secretary of the Treasury has power under the act of February 15, 1893 (27 Stats., 449), to make quarantine regulations *** necessary to prevent the introduction of contagious or infectious diseases into the United States from foreign countries or into one State or Territory or the District of Columbia from another State or Territory or the District of Columbia. 
I have received from the Surgeon General of the Marine Hospital Service a draft of a proposed regulation governing the movement of persons suffering from leprosy. I have carefully examined this draft, and, with the slight change that I have made in paragraph 11, am of the opinion that it is in proper form; and that the regulation is such as you have power to make.

AMENDMENT TO INTERSTATE QUARANTINE REGULATIONS.

Treasury Departhent, OfFICE OF THE SECRETARY, Washington, May 15, 1912.

To medical officers of the Public Health and Marine-Hospital Service, State and local health authorities, and others concerned:

The following amendment is hereby made to the Interstate Quarantine Regulations promulgated by this department September 27, 1894, and amended August 17, 1905, and June 24, 1909, said amendment and regulations being in accordance with section 3, act of Congress approved February 15, 1893.

Article 3, General Regulations, is hereby amended by the addition of the following paragraphs:

"Paragraph 9. Common carriers shall not, under authority of paragraph 8, accept for transportation nor transport in interstate traffic any person suffering from or afflicted with leprosy unless there has been obtained from the Surgeon General of the Public Health and Marine-Hospital Service or his accredited representative a permit stating that said person may be received under such restrictions as will prevent the spread of the disease, and said restrictions shall be specified in each instance: Provided, That in addition to the above, permits shall also be obtained from the health authorities of the States, Territories, or districts to and from which the patient intends to travel.

"Paragraph 10. No person knowing or having reason to believe that he is a leper shall accept transportation nor engage in travel in interstate traffic unless permits have been obtained, as set forth in the preceding section, and unless said person shall have agreed in writing to comply with the restrictions as specified in the permits mentioned above.

"Paragraph 11. Any person who presents symptoms of leprosy and who is traveling or who has left the State where he resides, in violation of the above regulations, shall be detained, and if proven to be a leper shall be returned to such State or removed to such Federal quarantine station as the Secretary of the Treasury may designate and the proper health authorities notified.

"Paragraph 12. Compartments or places in cars, vessels, or conveyances operated in interstate traffic and that have been occupied by persons afflicted with leprosy shall be immediately closed after being vacated by the patient and so kept until after proper disinfection."

James F. Curtis, Acting Secretary.

\section{Cholera.}

During the fiscal year cases of cholera and suspected cholera have been reported in the United States at the following places: New York, N. Y., Boston, Mass., and Providence, R. I.

\section{Rocky Mountain Spotted Fever.}

Passed Asst. Surg. T. B. McClintic, the officer who had charge of the investigation of Rocky Mountain spotted fever in the Bitter Root Valley of Montana, submitted the following report:

A REPORT OF WORK DONE ON SPOTTED FEVER IN COOPERATION WITH THE STATE BOARD OF HEALTH OF MONTANA.

Rocky Mountain spotted fever has prevailed in Montana and Idaho for at least several decades. The earliest available record of the disease having been reported was in the year 1873. Cases of the disease have from time to time occurred in other States, until now Rocky Mountain spotted fever has been reported from practically all of the Rocky Mountain States, including Arizona, California, Colorado, Idaho, Montana, Nevada, Oregon, Utah, Washington, and Wyoming. 
Although the disease is far more prevalent in Montand and Idaho than in any of the other States. its spread has assumed such proportions in the last decade as to call for the gravest consideration on the part of both the State and national health authorities. In fact, the disease has so spread from State to State that it has undoubterly become a very serious interstate problem demanding the institution of measures for its control and suppression. There is, however, a marker variation in the severity of the disease in rlifferent localities, notably in Montana. as compared with Idaho. Particularly in the Bitter Root Valley in Montana the unortality rate is very high, while in Idaho it is comparatively low.

The reason for this variation in severity still remains an unsolved problem. On account of its persistent selsonal prevalence and severity the disease has become a very serious public health and econosnic problem in the Bitter Poot Valley, where, in addition to the lives that are annually sacrificed, very valuable agricultural lands have depreciated in value and in certain localities have been almost abandoned on account of the fear and dread that the inhabitants have of Rocky Mountain spotted fever.

For several years the State Brodid of Health of Montana has been carrying on a campaign of investigation with the purpose in view of eradicating, if possible, the disease from that State. It has had the services of such workers as II ilson and Chowning of the University of Ninnesota; Ashburn, Craig, and Keifer of the Army; Cobb, Anderson, Stiles, Francis, and King of the Public Health and Marine-Hospital Service; and, finally, Ricketts and his associates.

The State Legislature of Montana early in 1911 made an appropiation for continuing the work for a period of two years, and at the request of the Statc boarl of health, through its secretary, Dr, T. D. Tuttle, the work was again taken up by the Public Health and Marine-Hospital Service in May, 1911. It at once became evident that the rational lines along which the work should be carried were in accordance with those laid down by Dr. H. T. Ricketts. While the appropriation available was not large enough to allow the taking up of the work on an extensive scale, nevertheless it was apparently sufficient, exclusive of the officers' salaries which were paid by the Treasury Department, for determining or making a demonstration as to the feasibility of eradicating the tick, Dermacentor andersoni Stiles, the real causative agent concerned in the transmission of Rocky Mountain spotted fever. It was therefore decided to select a limited area in one of the worst-infected territories and to put into operation the best-known measures for the eradication of the tick. It was also considered advisable to continue Rickett's work of testing the susceptibility of the wild mammals to experimental inoculation with spotted fever and to search for the infection of that disease among the wild mammals in nature.

Accompanied by Dr. Tuttle, I arrived in the Bitter Root Valley the latter part of May, and after looking over the situation in the valley it was decided to carry on the work in the vicinity of Victor, Mont. An infected territory of about 8 square miles was selected about 3 miles from Victor. It is situated in the foothills of the mountains on the west side of the valley and has its boundaries rather well defined on the north and south by Sweathouse Creek and Bear Creek, respectively. In this territory the ticks are found in large numbers during the tick season, and many cases of spotted fever have been reported from there during past years; in fact, this territory has been almost depopulated because of the presence of spotted fever. From this district Ricketts, during the season of 1908, collected ticks with which he was able to infect guinea pige.

As most of the cases of spotted fever occur in the Bitter Root Valley during the months of April and May, it will be seen that the latter part of May was very late in the season to begin work. It was decided, however, that a start should be made and that the work could again be taken up at the beginning of the tick season of the next year. The ticks begin to decrease in number during the month of June, and by the Ist of July they have largely disappeared. Throughout most of the year it is, however, possible to find, from time to time, a few ticks in certain localities.

The work was carried on at Victor until August 7, when it was transferred to the Hygienic Laboratory at Washington, where the laboratory side of the work was continued.

About the middle of June Passed Asst. Surg. W. C. Rucker was detailed to assist in the work.

As the State of Montana made the appropriation for conducting this investigation, the work is being done in conjunction with the State board of health. Dr. T. D. Tuttle, secretary of the board, has heartily cooperated in every way possible and in an advisory capacity has rendered valuable service in outlining the work and in furthering its success. 
The studies of Dr. Ricketts on spotted fever have been of the greatest value, and it has been endeavored to take up the work where he left off and to continue it by putting into effect his plans and recommendations.

The work as contemplated and as carried on may be embraced under two general headings as follows:

1. The eradication of the tick.

2. Laboratory investigations.

*

$*$

ㅊ.

米

SUMMARY AND REMARKS.

In the work on Rocky Mountain spotted fever, which was begun on May 26, 1911, an infected district of about $S$ square miles was selected, on which a concrete dipping vat was constructed, the dipping of domestic stock was begun, and considerable headway was made in destroying the wild mammals in the infected district that was selected for demonstrative purposes. The number of small wild mammals killed, by shooting and trapping, and collected was 3,465 , of which 3,233 were ground squirrels. This does not include the number killed with poison or carbon bisulphide.

A search was made for the infection of spotted fever among the ground squirrels in nature, the results of which were negative.

The susceptibilty to experimental infection with spotted fever was studied in the cases of 25 ground squirrels caught at random in the infected district. They were inoculated with the virus of spotted fever and subsequent inoculations of their blood made into guinea pigs. As shown by the results in the guinea pigs, 23 of the ground squirrels were positively infected with spotted fever, one of them was probably infected, while the result with 1 squirrel, the blood of which was injected into a guinea pig on the second day following its inoculation, was negative. In all probability this negative result was due to the early date in the period of incubation at which the blood was transferred from the ground squirrel to the guinea pig.

There is, therefore, no positive evidence that any of the 25 ground squirrels were immune to spotted fever. As these ground squirrels all came from an infected territory and assuming that one attack of spotted fever in the ground squirrel renders that animal immune to further infection with that disease these results tend to minimize the probability of the ground squirrel actually playing a part in the spread of spotted fever. Further work with ground squirrels from other infected territories will be done in order to determine whether or not immune ground squirrels can be found existing in nature.

Out of a total of 4 badgers that were experimented with only one of them was found susceptible to infection with spotted fever, and of 5 guinea pigs that were inoculated with blood taken from this badger at three different times only one of them developed spotted fever. Provided that none of these badgers had an acquiled immunity at the time they were experimented with, and it does not seem likely that they did, the badger is evidently only very slightly suceptible to experimental infection with spotted fever and very probably plays no part in the spread of the disease.

The results with experiments of infecting 5 coyotes and 4 domestic cats were negative. It is not thought that either one of these animals has anything to do with the spread of spotted fever except that the cat may possibly carry infected ticks into dwelling houses.

Only two weasels were experimented with, one of which was experimentally infected with spotted fever, while the results obtained in the case of the other were negative but not conclusive. Although the weasel was found to be susceptible to infection, further work along this line will be done this year.

Rhesus monkeys and guinea pigs were infected with spotted fever and treated with different drug preparations, namely, salvarsan, sodium cacodylate, and urotropin. The results obtained, however, do not indicate that any of these drugs possess any value whatever either as a prophylactic or in the treatment of spotted fever, but on the contrary their administration seems on the whole rather to intensify the severity of the disease in the animals as compared with the course of the disease in the controls.

The work on spotted fever will be again taken up early in the season of 1912 when the tick and the ground squirrel first make their appearance, it having been begun too late in 1911 to accomplish a great deal. The work will be continued on the same lines along which it was carried on in 1911. The dipping of domestic stock and the destruction of wild mammals in the selected district will be thoroughly carried out in order to determine the results that these measures may have in eradicating the tick from the district. There is no doubt that the domestic animals are a source of food for a great many adult ticks. However, the hope of completely eradicating them by dipping the domestic stock is rather discouraged by information obtained from 
reliable inhabitants to the effect that although the number of domestir animals hus been greatly reduced in certain localities during the past yrars the 11 muber of ticks has by no means been proportionately reduced.

Furthermore, the tick is found rather abundantly in places in the nountains at high altitudes and in localities that are practically never frequenterl by domestic stock. That the tick can be practirally eradicated from the infected districts or even from the whole valley there is no cloubt, but it will contail considerable cost and labor" to do so. In this connection it may be remarkerl that the statement by II unter and Bishopp, to the effect that the practical eradication of the spotterl-fevere tick from the Bitter Root Valley can be accomplished in three seasons for the approximate sum of $\$ 23,692$, and that after that time the prevention of reinfestation of the valley can be easily accomplished by employing an inspector for six months' service each year, is somewhat more optimistic than the facts would seem to warrant.

The dipping of domestic stock, the destruction of wild mammals, and the clearing and burning over of land are all excellent methods for eradicating the tick. The exact extent to which the dipping of domestic stock alone will eradicate the tick is as yet more or less problematical, but as soon as the efficiency of the different methods, either singly or together, can be demonstrated to the ranch owners and inhabitants they will no doubt give their hearty cooperation and utmost assistance in carrying on the work and furthering its success.

There is urgent necessity for a State law under which the dipping of stock in infected districts can be enforced. It should require the dipping of all stock in territories declared by the State board of health or its secretary to be infected. Experience has shown that most of the stock owners want their stock dipped, but some of them insist on waiting until it suits their own convenience to have it done, while a small percentage of them object, for one reason or another, to having anything done. They thus handicap the work and this should not be permitted in a condition as serious as spotted fever, and where most of the stock owners are anxious to cooperate in stamping out the disease.

A State law should also be passed requiring property owners to make a reasonable effort to exterminate the rodents on their property.

\section{Alaska.}

An officer of the Public Health Service was detailed to the Department of the Interior for duty, for the purpose of supervising all measuies relative to the medical and surgical relief of the natives of southern Alaska and the sanitary improvement of their surroundings and for the purpose of making studies of the prevalence of disease and of the conditions which favor its spread, with a view to inaugurating adequate measures of prevention.

The following is taken from his report:

In attempting to propose measures to furnish medical care and relief to the natives of Alaska, one is immediately impressed with the inherent difficulties of the problem.

Alaska has an area approximately equal to one-fifth of the rest of the United States, and many thousands of miles of coast line. Scattered through this vast country is a population of about 25,000 natives, living in villages and communities ranging from 30 or 40 up to 300 or 400 persons. Transportation is chiefly by boats, and during the long and severe winters many places are accessible by dog teams only. To attempt under such conditions to provide skilled care for all of the villages or even all of the larger ones would involve an expense which is prohibitive. To cover such a vast field thoroughly is manifestly impossible. To endeavor to do a little something for all the natives with a limited appropriation will surely end in failure to accomplish satisfactory results anywhere. The problem must be attacked on certain lines and the work concentrated at given points.

Under present conditions the Indian can not be effectively treated in his own home except for a few minor complaints. Every physician of experience in Alaska states that they will not carry out instructions or take medicine as directed. If the drug is palatable or they can feel its effects, they are very likely to take it all at one dose. If it is distasteful or if no immediate results follow, they take it a few times and then stop. I know of a case where a physician was called in to see a native ill with pneumonia. He left some strychnine tablets with explicit directions that one was to be taken every two hours. The brother of the sick man, despite these directions, reasoning that if one was good, more were better, gave the entire supply at one time, and 
the man died in a few hours. While it is not known that the strychnine was the cause of his death, it is very evident from such an occurrence that they can not be trusted with potent drugs. When a native is really ill, he requires hospital care, and more good can be accomplished by taking three or four into a hospital than by attempting to treat a large number in their villages.

For these reasons I would emphatically recommend the discontinuance of traveling physicians. A doctor visiting a town for a few days or hours is afraid to leave more than one or two doses of any powerful remedy. As most of their ailments are of a chronic nature and require prolonged treatment, he is unable to treat such cases at all, and his efforts are chiefly confined to administering a few headache tablets, giving compound cathartic pills, or dressing an emergency case if one should happen to be at hand at the time of his arrival. There are no facilities for proper examinations or operations, nor could he operate on a major case and leave it in the village. Neither is it practicable to leave directions with the teachers, for the condition of all sick persons changes from day to day, and no doctor can foresee it for more than a few days at. most. The attempt to practice medicine under such restrictions can afford but slight benefit to the patient. This is the consensus of opinion of every physician whom I met in Alaska who had had experience in the field. I had ample opportunity in visiting 27 villages and attempting to treat the natives when necessary to satisfy myself of its correctness. The traveling physicians shuuld be replaced by trained nurses. Such a nurse going into a town and remaining for three months would find a wide and fruitful field of action. She could dress the chronic ulcers, irrigate infected eyes and running ears daily, and thus bring many of these cases to a permanent cure. A course of antisyphilitic treatment continued for this period would produce some lasting results. Such cases as she found to resist her treatment or were beyond her skill could be sent to the nearest hospital. A capable nurse could successfully handle many of the minor ills and accidents coming up during her stay. Two nurses in a year would cover eight villages in this manner at the same expense as one traveling physician and accomplish much more.

Quite a number of the settlements are adjacent to towns where there is a regular physician practicing. I would advise in all instances the employment of these doctors at a salary proportionate to the amount of work involved to give relief to such natives living in their vicinity as apply for treatment; the making of contracts with local hospitals whenever available at a fixed rate per diem for the natives who require hospital treatment (there are a number of such hospitals who would build a small ward for this purpose if they were assured of a certain number of patients, but will not generally take natives into their white wards, for obvious reasons); the employment of trained nurses who will spend three months at a time in the larger towns where no local physician can be secured; and the enlargement of the present native hospital at Juneau for the Indians of Treadwell, Douglas, and Juneau. This hospital should also be used as a central hospital for the villages where no local hospital is available and also for any case where treatment is likely to be prolonged.

This, in brief, I believe will be the most satisfactory way to endeavor to furnish medical relief to those people as well as the most economical.

There are certain measures badly needed which can not be taken up without an act of Congress. These are:

First. By far the most important and urgent need is the immediate establishment of a sanitarium for active cases of pulmonary tuberculosis requiring hospital treatment. A very conservative estimate would place the total number of such cases now in the District as about 6,000. Only a part of these would be detected or consent to go to a hospital, so the capacity of that institution should be 200 beds at the start. The cost of the erection and equipment of the necessary buildings would be about $\$ 180,000$ and its annual maintenance would require an expenditure of $\$ 75,000$. In selecting a site for such a sanitarium, climatic conditions, ease of access with present means of transportation, and the means of obtaining suitable supplies, especially fresh fish and meat, must all be considered. The vicinity of Haines, Alaska, appears to satisfy these requirements more completely than any location yet proposed.

Second. The establishment of a home for destitute blind and crippled Indians. There are about 300 blind and crippled natives, and many in need of assistance. The home should have a capacity of at least 100 , could be erected at a cost of $\$ 60,000$, and would require about $\$ 25,000$ annually for maintenance.

Third. The passing of an act of Congress authorizing the Surgeon General of the United States Public Health and Marine-Hospital Service to appoint one of the officers of that service to act as commissioner of public health for Alaska. Th s commissioner to be empowered to enforce the United States quarantine regulations at the ports of entry of the District; to make such regulations as, in his judgment, may be necessary to prevent the spread of transmissible diseases from one part of the District 
to another or from one person to another; to approint suitable persons to act as hralth officers in any unineorporated town or native village; and to have general charge of all measures instituted by the Government for the inedical and simrgical relief of thrs natives. Such officer to receive 50 prer cent increase on his regular pay and allowances while on this duty.

A yearly appropriation of $\$ 50,000$ will lor required for this purpose.

I would further respectfully recominend concerning the schorls as follows:

That all schools where a rloctor is not accessible be furnishorl with a well-erguipgred medicine chest and a simple book of directions for using tho samp.

That special instructions be issued for the care and trratment of inflamed ryes. Such daily treatment to be a part of the routine work just before closing.

That all schools be furnished with an ample supply of soap and baths whenerer possible.

That in villages where a doctor is uot available, to fit up a room to be used as a dispensary; also a living room for a trained nurse in each school building. To do effective and satisfactory work, the nurse must have her dressings, irrigators, medi. cines, etc., at hand and properly arranged, especially in handling casts of this kind where there is so much infection. The greatest difficulty in treating the natives, in my experience, has been the absolute lack of facilities of this kind.

That assistance be given to the natives whenever possible toward securing a good and plentiful water supply.

\section{Sanitary Inspection of Government Bulldings.}

\section{EXECUTIVE ORDER.}

(No. 1498.)

The Surgeon General of the Bureau of Public Health and Marine-Hospital Service is hereby directed to inspect, or cause to be inspected, all buildings and offices used by the Government of the United States in the District of Columbia for the purposes of any of the executive departments, at least once in each month, and to report to the head of the department by which such building is occupied the sanitary or hygienic condition of such buildings and offices, making to the head of such department such recommendations and suggestions as may be deemed necessary to promote the sanitary or hygienic condition of such department or office.

Copies of such reports shall also be filed with the Secretary to the President.

MARCH 15, 1912.

WM. H. TAFT.

In accordance with this Executive order, on May 12, 1912, the Surgeon General detailed for this duty Passed Asst. Surg. B. S. Warren.

A preliminary visit was made to each department and a blank form was prepared in order that a permanent record might be made of existing sanitary conditions in each room in each department.

Beginning with the Treasury Department, detailed inspections have been made of buildings in all the departments and reports made of conditions found. 


\section{SANITARY REPORTS AND STATISTICS.}

\section{Public Health Reports.}

In the administration of the laws and regulations for the prevention of the introduction of disease into the United States, it is necessary to have reliable information regarding sanitary conditions and the occurrence of epidemics in foreign countries. Current knowledge of the prevalence of disease abroad has been obtained through the regular reports of the service officers and American consuls.

A knowledge of the occurrence and geographic distribution in the United States of the diseases dangerous to the public health is a requisite in the prevention of their spread from one State to another. This information has been obtained in so far as possible through the reports of State and municipal health authorities.

The knowledge thus obtained of the occurrence and prevalence of dangerous diseases in the United States and in foreign countries has been made available to quarantine officers, collectors of customs, health officers, and other sanitarians through the medium of the Public Health Reports, which have been issued weekly in editions of 4,500. These reports have shown each week the world prevalence of such diseases as plague, cholera, yellow fever, and smallpox. In the United States they have shown the occurrence of plague, smallpox, leprosy, and poliomyelitis (infantile paralysis), and, in addition, the occurrence in cities of cerebrospinal meningitis, erysipelas, pneumonia, rabies, tetanus, diphtheria, measles, scarlet fever, tuberculosis, and typhoid fever.

The information that it is possible to obtain regarding the prevalence of most diseases in the United States is at best incomplete. Public health work, be it city, State, or national, must be based upon a knowledge of the occurrence and prevalence of disease. It is apparent that to eradicate a disease or to prevent its spread there must first be information as to where the disease is present. In view, therefore, of the functions for the control of disease and the prevention of its spread imposed upon the Public Health Service it is of the utmost importance that adequate provision be made whereby the service can keep currently informed regarding the prevalence of disease throughout the country.

\section{Sanitation of Cities.}

According to the 1910 census, 46.3 per cent of the population of the United States was urban; that is, lived in cities having populations of over 2,500. With so large a proportion of the population living in cities, municipal sanitation occupies an important position in the conservation of the public health. When people live in close proximity to each other, as they do in cities, with the consequent constant intermingling, sanitary supervision and regulation are especially necessary for the control of the preventable diseases. The health officers of cities, and more especially the smaller cities, are usually appointed from among the practicing physicians of the community. It frequently happens, therefore, that the health officer is a man without experience in, or anything but the most superficial knowledge of, 
public health work. If under these conditions the appointee takes his office seriously, his first concern is to secure a knowledge of public health work in general and municipal health work in particular. This is most readily obtained by studying the sanitary practice operative in those cities supplied with efficient and experienced health officors.

To show the trend of municipal sanitation and to make readily available information regarding current practice in the hygienic administration of cities and the control and prevention of disease in urban communities, municipal ordinances and regulations pertaining to public hygiene have been published rogularly in the Public Health Reports, which goes each week to all city health officers. This shows the authorities of each city how other cities are handling general or special problems.

The publication of these ordinances and regulations in this war serves not only a useful educational purpose, but will have a potent influence in producing a uniformity in municipal measures for the protection of health, and will have a tendency to standardize municipal practices.

\section{Cerebrospinal Meningitis in the United States.}

Early in January, 1912, it became apparent that cerebrospinal meningitis was epidemic in certain localities in Texas.

Cases were reported in Dallas as follows:

\begin{tabular}{|c|c|c|}
\hline & Cases. & Deaths. \\
\hline 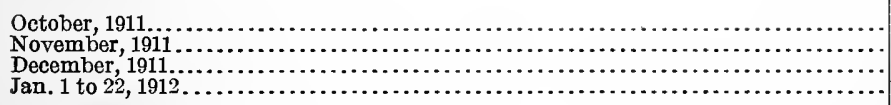 & $\begin{array}{r}1 \\
9 \\
73 \\
156\end{array}$ & $\begin{array}{r}1 \\
4 \\
45\end{array}$ \\
\hline Total............ & 239 & 107 \\
\hline
\end{tabular}

All ages were affected. The cases were widely scattered and occurred in all parts of the city. The examination of contacts showed that over 50 per cent were healthy carriers of the disease.

In Fort Worth cases were reported as follows:

\begin{tabular}{|c|c|c|}
\hline & Cases. & Deaths. \\
\hline 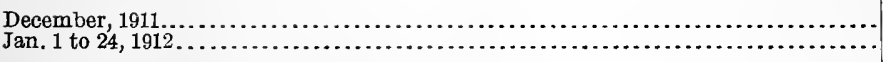 & $\begin{array}{r}4 \\
57\end{array}$ & $\underset{\mathbf{2 3}}{2}$ \\
\hline 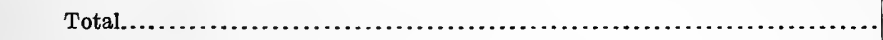 & 61 & 25 \\
\hline
\end{tabular}

In Waco cases were reported as follows:

\begin{tabular}{|c|c|c|}
\hline & Cases. & Deaths. \\
\hline 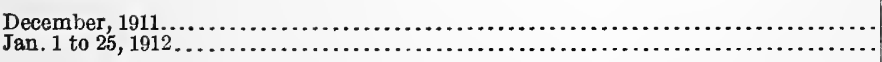 & $\begin{array}{l}51 \\
68\end{array}$ & $\frac{20}{24}$ \\
\hline 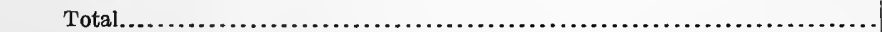 & 119 & 44 \\
\hline
\end{tabular}

At Houston 26 cases with 9 deaths were reported between January 1 and $29,1912$.

The Texas State board of health up to January 24 received reports of 550 cases, with 210 deaths. These reports came from 49 localities. 
There were undoubtedly many unreported cases. It is evident that the disease was widely prevalent in Texas. The cases reported to January 24 were as follows:

Texas, cerebrospinal meningitis, cases and deaths reported to Jan. 24, 1912. .

\begin{tabular}{|c|c|c|c|c|c|}
\hline Towns. & Cases. & Deaths. & Towns. & Cases. & Deaths. \\
\hline 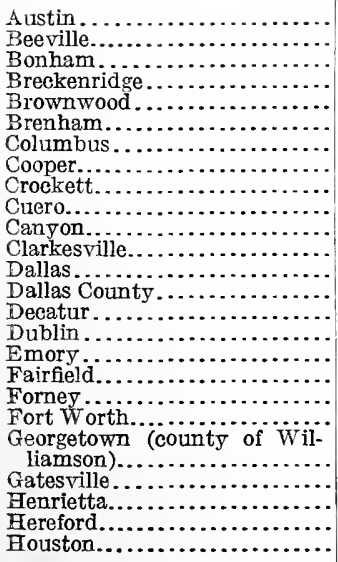 & $\begin{array}{r}5 \\
1 \\
1 \\
1 \\
4 \\
2 \\
1 \\
1 \\
1 \\
1 \\
1 \\
12 \\
249 \\
6 \\
1 \\
1 \\
11 \\
4 \\
1 \\
61\end{array}$ & 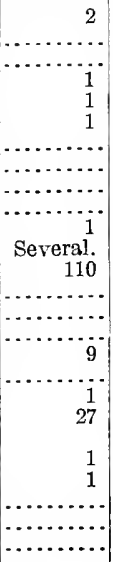 & 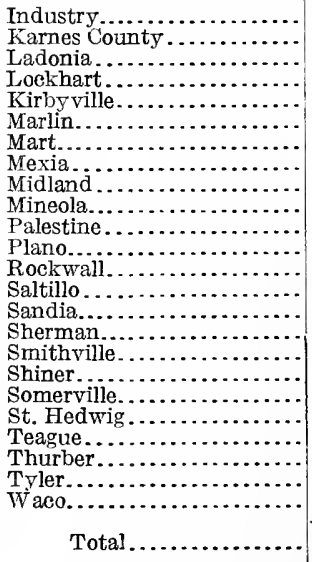 & $\begin{array}{r}1 \\
\text { Present. } \\
2 \\
1 \\
1 \\
1 \\
2 \\
3 \\
2 \\
1 \\
1 \\
10 \\
\text { Epidernic. } \\
1 \\
3 \\
3 \\
1 \\
3 \\
1 \\
1 \\
2 \\
4 \\
118 \\
550\end{array}$ & 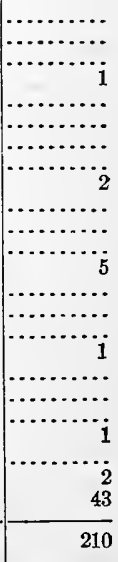 \\
\hline
\end{tabular}

After its appearance in Texas cases of the disease were noted in Oklahoma and Kansas. Presumably cases also occurred in other neighboring States, but their presence remained unknown to the health authorities, because of the absence of laws requiring the notification of cases or the lack of official machinery for enforcing the laws or recording the cases reported.

In Oklahoma 415 cases with 159 deaths were reported from December 1, 1911, to March 27, 1912, as follows:

Oklahoma, cerebrospinal meningitis, cases and deaths reported from Dec. 1, 1911, to Mar. 27, 1912.

\begin{tabular}{|c|c|c|c|c|c|}
\hline Counties. & Cases. & Deaths. & Counties. & Cases. & Deaths. \\
\hline Mayes... & 1 & & Garfield. . & 4 & 3 \\
\hline Washita. & $\tilde{1}$ & & Beaver... & 1 & \\
\hline Custer... & $\overline{3}$ & 2 & Haskell......... & 4 & ..... \\
\hline Kiowa... & 2 & & Le Flore........... & 4 & \\
\hline Garvin... & 9 & 3 & Washington ....... & 1 & 1 \\
\hline Bryan...... & 54 & 24 & Pottawatomie.......... & 11 & 2 \\
\hline Carter.... & 17 & 6 & Creek............... & 6 & ..... \\
\hline Love....... & 20 & 7 & Woods......... & 1 & ...... \\
\hline Marshall... & 24 & 7 & Tulsa.......... & 3 & -10 \\
\hline MeClain... & 11 & 4 & Grant.............. & 2 & 1 \\
\hline Comanche.. & 13 & 3 & Wagoner..................... & 5 & 3 \\
\hline Johnson... & 24 & 9 & Coal $\ldots \ldots \ldots \ldots \ldots \ldots \ldots \ldots \ldots$ & & \\
\hline MeCurtain. & 18 & 10 & Okmulgee...... & 4 & \\
\hline Murray.... & 4 & 2 & MeIntosh....... & 7 & 5 \\
\hline Osage......... & 11 & 5 & Tillman...$\ldots \ldots \ldots \ldots \ldots \ldots$ & 1 & \\
\hline Choetaw..... & 9 & 4 & Lincoln........................ & 1 & \\
\hline Pontotoc... & 49 & 16 & Pittsburg........ & & \\
\hline Pawnee...... & 3 & 1 & Oklahoma.... & 9 & 3 \\
\hline Harmon... & 3 & 2 & Sequoyah...... & & \\
\hline Muskogee... & 6 & 3 & Latimer $\ldots \ldots \ldots \ldots \ldots \ldots \ldots$ & 3 & \\
\hline Pushmataha... & 4 & 1 & 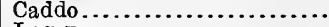 & & 1 \\
\hline Atoka............................ & $\begin{array}{l}4 \\
1\end{array}$ & 1 & Logan...$\ldots \ldots \ldots \ldots \ldots \ldots \ldots$ & 1 & $\cdots \cdots \cdots \cdot$ \\
\hline 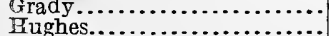 & $\begin{array}{r}1 \\
15\end{array}$ & $\cdots$ & $\begin{array}{l}\text { Rogers } \\
\text { Canadian } \\
n_{1}, \ldots\end{array}$ & $\begin{array}{l}1 \\
3\end{array}$ & \\
\hline Jackson.... & 2 & 1 & & & \\
\hline Stephens.. & 5 & ..... & Total................... & 415 & 159 \\
\hline Seminole.. & 5 & 3 & & & \\
\hline
\end{tabular}




\section{Malta or Mediterranean Fever in the United States.}

Cases of Malta or Mediterranean fever have been reported in various localities in Texas, New Mexico, and Arizona. The disease is known to be endemic among goats in these States. It has undoubtedly spread also to other States, but being unlooked for has not been recognized. The disease should be made notifiable and the attention of practicing physicians east of the Mississippi River should be called to the fact that the disease is present in certain sections. Physicians should also familiarize themselves with the symptoms of Malta fever and the methods of diagnosis. It is only by this means that an accurate idea of the prevalence of the disease can be obtained.

\section{Pellagra in the United States.}

Pellagra continues present in certain sections of the country. Its greatest prevalence is in the States south of the Ohio River and east of the Mississippi. Cases, however, have been reported in practically every State. Whether the disease is increasing or not can not be told in the absence of a record of the occurrence of cases. Undoubtedly the disease is being recognized more frequently than in former years, due to the greater familiarity of physicians with the symptoms. The disease should be made notifiable in all States, so that its relative prevalence might be known. Information of its relative frequency of occurrence in different localities and under varying conditions would undoubtedly aid materially in determining the cause of the disease.

Pellagra seems to be largely limited to the tropical and warmer portions of the Temperate Zones. Furthermore, it appears to occur commonly in certain localities which are often limited in extent, and in some instances have rather sharply defined boundaries. In other words, the disease occurs frequently in what must be considered well-defined endemic areas. Whether these areas are determined by the topography, the flora, the fauna, climatic conditions or the special manner of life, or customs of the inhabitants remains to be determined, and when this has been done the discovery of the cause of the disease will without doubt be near at hand.

The disease occurs at times in what appear to be distinct outbreaks. It does not, however, appear to be contagious; that is, spread by contact with the sick. The theory is held by some that it is spread by a biting fly or other insect. This, however, has not been satisfactorily shown to be so.

In Italy the importance of pellagra economically and as a sanitary problem has been officially recognized. In certain sections of the United States of considerable size the disease is perhaps as serious a problem as in Italy and as worthy of the most careful study.

\section{Poliomyelitis (Infantile Paralysis) in the United States.}

Cases of poliomyelitis (infantile paralysis) are required by State law or regulation to be reported to the health authorities in the following States and Territories: California, District of Columbia, Hawaii, Idaho, Iowa, Maine, Massachusetts, Minnesota, New Jersey, New York, Ohio, Oregon, Pennsylvania, Rhode Island, South Carolina, South Dakota, Tennessee, Utah, Virginia, Washington, and Wisconsin. 
Of the above States and Territories in which the disease is notifiable, no case was reported to the Public Health Service during the year 1911 from Hawaii, Maine, New Jersey, South Carolina, or Tennessee.

The table on pages 176 and 177 shows the recorded prevalence of the disease during the calendar years 1910 and 1911, as given by State and other reports.

The States that made reports for each of the 12 months of the year 1911, and for which, therefore, the data should include all cases reported to the health department, are as follows: District of Columbia, Indiana, Iowa, New York, Pennsylvania, Rhode Island, South Dakota, Virginia, Wisconsin, Oregon, Idaho, and Washington.

The table which, in addition to giving the cases and deaths reported for 1911, shows the totals for 1910 indicates that the disease has been present during the last two years in all sections of the country. Asst. Surg. Hasseltine, while cruising in Alaskan waters on the revenue cutter Rush during the summer of 1910 , reported that poliomyelitis had been recognized in Alaska at Douglas, Chicagoff, and Yakutat. It has also occurred in Alaska during the present year. It is probable that no State or Territory in the continental United States has been entirely free from the disease, and that the absence of reported cases simply indicates a lack of official means on the part of the State health authorities for being informed of their occurrence, or a failure on the part of physicians to recognize or report sporadic cases and limited mild outbreaks.

From the reports of cases and deaths it appears that during 1910 the greatest prevalence of the disease was in Iowa, Massachusetts, Minnesota, New York, and Pennsylvania, and that a considerable, although lesser, number of cases occurred in Connecticut, District of Columbia, Illinois, Indiana, Kansas, Michigan, New Jersey, Ohio, Rhode Island, Washingtom, and Wisconsin. The seeming greater prevalence in these States may, however, have been due, to some extent at least, to an active interest on the part of the health authorities and the more general recognition of cases on the part of practicing physicians. In those States in which the disease is not notifiable its prevalence must remain unknown.

During 1911 the greatest numbers of cases appear to have occurred in Illinois, Indiana, Iowa, Massachusetts, Minnesota, New York, Pennsylvania, and Wisconsin. There seems, however, to have been a marked decrease in the prevalence of the disease from that of 1910 .

For the purpose of arriving at the case-fatality rate only those States can be considered in which especial effort was made to trace all cases of the disease. In Massachusetts, of 601 cases occurring during 1910, studied by Lovett and Sheppard, 54 ended fatally. This gives a case-fatality rate of 9 for each 100 cases. In Vermont, among 72 cases studied by Caverly there were 10 deaths, giving a case-fatality rate of 13.9 per 100 cases. Of 506 cases in 1910 in the District of Columbia studied by a special committee of the medical association there were apparently only 16 deaths, giving a casefatality rate of 3.1 per 100 cases.

BUFFALO, N. Y., AND VICINITY.

In June, 1912, poliomyelitis appeared in Buffalo, N. Y. It suon became apparent from the number of cases reported that the disease was in epidemic form. Every effort was made by the city health 
department, assisted by the State department of health and the United States Public Health Service, to control the disease. Careful epidemiological studies were made of all reported cases. The disease later appeared in other cities and counties in western New York, and in some of these localities there were at least as many cuses in proportion to the population as occurred in Buffalo. From June 1 to October 5 there were reported in Buffalo 280 cases, with approximately 40 deaths. October 5 the outbreak had not yet subsided. Cases also appeared in Erie, Niagara, Chautauqua, Genesee, and other counties in the vicinity. The disease seems to have been unusually prevalent throughout the western part of New York State during the summer of 1912.

\section{LOS ANGELES, CAL., AND VICINITY.}

During the week ended Saturday, June 15, 1912, one case of poliomyelitis was reported to the health office of Los Angeles. In the next 7 days 7 additional cases were reported. Eleven cases were reported in the 7 days following. The next 2 weeks totaled 34 and 25 new cases, respectively. Practically all of these cases were reported from the southeastern section of the city, and were grouped, roughly, along both sides of the river bed.

Soon after its appearance in Los Angeles, cases of the disease were noted at the beach resorts in the vicinity. Later cases were reported in neighboring counties and also in those more remote. Among these were Riverside, Ventura, Merced, Sacramento, San Joaquin, and San Francisco Counties.

In Los Angeles there were 254 cases reported between June 8 and September 28. The outbreak was at its highest during July. During September it subsided rapidly, and was practically at an end by the middle of the month.

\section{GENERAL.}

During the summer of 1912 poliomyelitis was unusually prevalent in many localities in Ohio.

In Chicago, 66 cases were reported during the first 8 months of the calendar year 1912. During the first 8 months of 1911 only 2 cases were reported.

In New York City, 184 cases of poliomyelitis were reported from June 1 to September 28, 1912. Twenty-six of the cases had terminated fatally at the latter date. The largest number of cases reported during any one week was 34 for the week ended September 14.

In Alaska, 5 cases with 1 death were reported at St. Michael, and 10 cases with 2 deaths at Unalakleet, during the summer of 1912. Cases had been known to have occurred previously in Alaska as follows: In 1908, at Sitka, 5 cases with 2 deaths; in 1910, at Douglas 7 cases; at Chicagoff, 1 case, and at Yakutat, 1 case. 


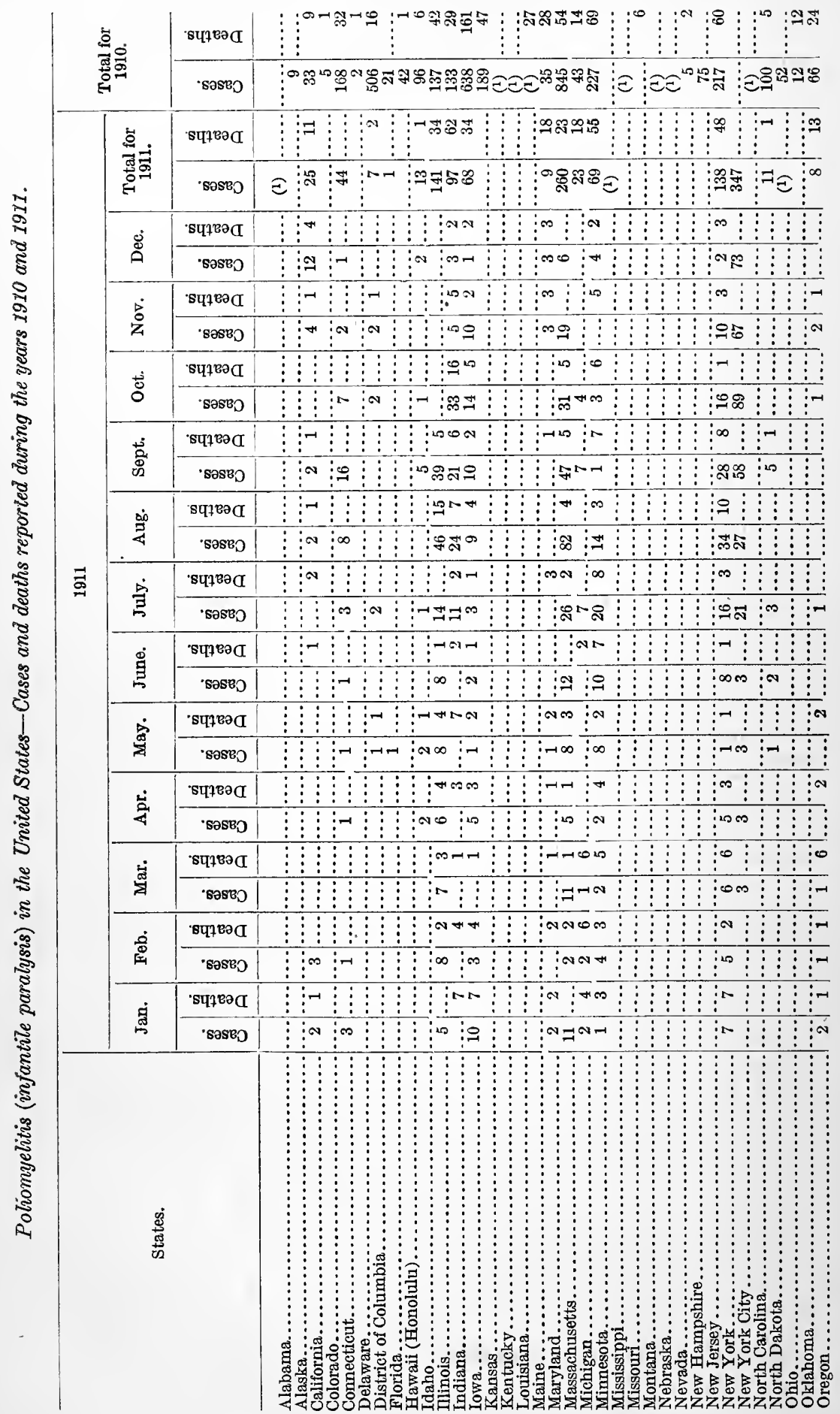




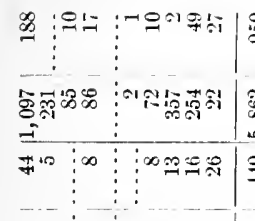

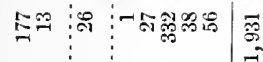

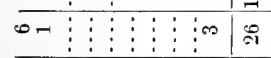

出-

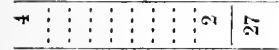

ㅇ: $: \vdots:$ N

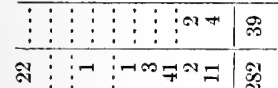

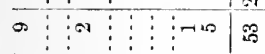

कि:

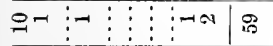

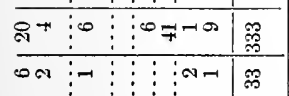

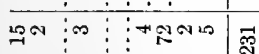

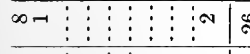

๑ー

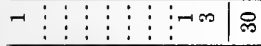

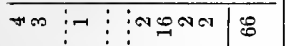

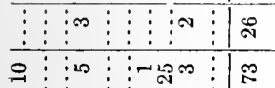

\begin{tabular}{l:l:l|l} 
& & $\infty$ \\
\hline$\vdots$ & $\vdots$ & $\vdots$ & $\vdots$ \\
\hline
\end{tabular}

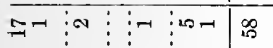

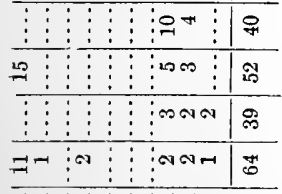

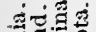

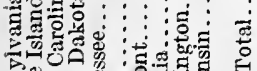

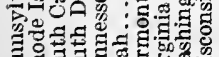

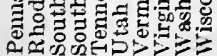

䓠

69450-H. Doc. 971, 62-3--12 
Poliomyelitis (infantile paralysis) reported to the United States Public Health Service from Jan. 1 to June 30, 1912.

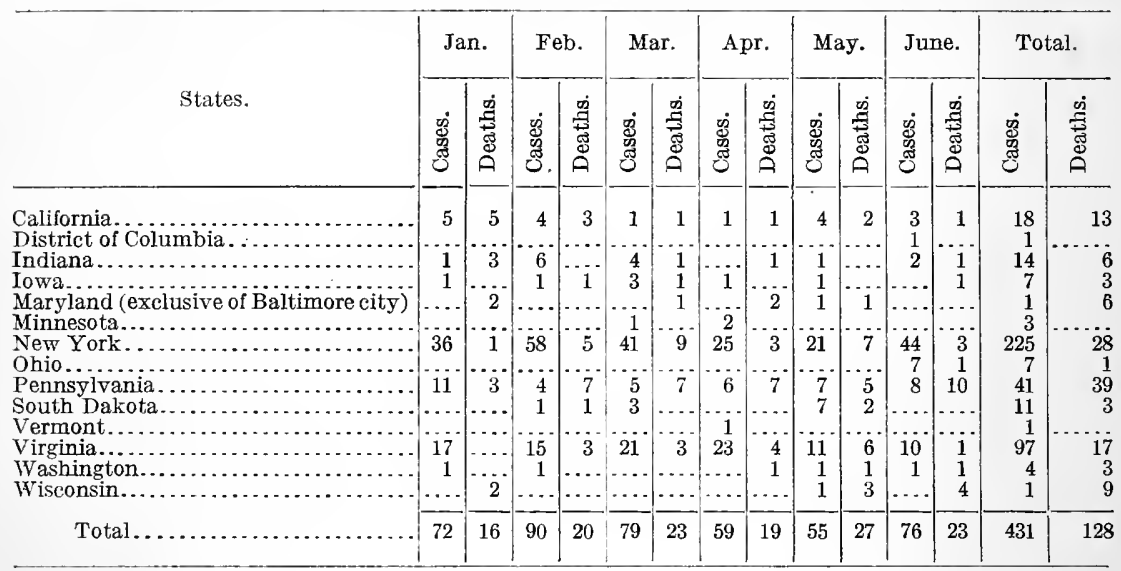

Leprosy in the United States.

There was reported as being present January 1, 1912, a total of 146 cases of leprosy in the continental United States. Of these, 40 were new cases coming first under official recognition during the year 1911. This number, however, necessarily represents only a part of those present, as in many States the disease is not notifiable and in others the requirement of notification is for various reasons difficult of enforcement.

Leprosy has been specifically made a notifiable disease in the following 18 States and the District of Columbia: Alabama, California, Connecticut, District of Columbia, Florida, Idaho, Illinois, Indiana, Iowa, Massachusetts, Nebraska, New Jersey, New York, Oregon, Pennsylvania, South Carolina, Utah, Washington, Wisconsin. It is also notifiable in Hawaii, Porto Rico, and the Philippine Islands.

In Michigan a regulation of the State board of health specifies that cases of leprosy shall be reported for statistical purposes. In certain other States the law requires that cases of all infectious or contagious diseases shall be reported, and among these leprosy would naturally in most cases be included. However, in the absence of a statement of the diseases that shall be construed to be infectious or contagious, it would appear to be left to the personal opinion of each practicing physician as to which diseases came properly under such a classification, and were, therefore, notifiable. Under these conditions the reports are likely to be incomplete.

In 1901 a commission composed of officers of the Marine-Hospital Service made a careful study of the prevalence of leprosy in the United States. They attempted to locate all cases possible, and to do this carried on an extensive correspondence with State and local health authorities and practicing physicians, and in addition a member of the commission visited certain localities to verify the accuracy of reports. A total of 278 cases was found at that time, although the commission believed that the number present was 
greater and that there were undoubtedly cases which they had been unable to locate.

Of the 278 cases reported by the commission, 145 were born in the United States, 120 in foreign countries, and the place of birth of 13 was unknown. Of the total number, 186 were reported as having probably contracted the disease in the United States. Of the 278 cases, only 72 were isolated and provided for by the States or cities in which they wore domiciled.

Although the number of cases of leprosy reported by the State authorities as present January 1, 1912, was only 146, whereas the commission above referred to found 278 in 1901, it can not properly be inferred that there is a lessened prevalence of the disease.

The 146 cases reported as present the first of this year are, with one or two exceptions, isolated and under the control of State or local authorities. These 146 cases are therefore probably comparable with the 72 reported in 1901 as isolated and provided for by States or cities.

During the year 1911 cases of leprosy were diagnosed in 18 States, and January 1, 1912, cases were officially known to be present in 17 States. Three States, namely, California, Louisiana, and Massachusetts, have lepresaria where lepers are isolated and cared for. In the other States cases of leprosy are provided for in various ways and with varying degrees of isolation.

In Porto Rico there were 28 known lepers January 1, 1912. In Hawaii and the Philippines the disease is present to such an extent that its control constitutes one of the important functions of the health authorities.

Leprosy cases reported during the calendar year 1911 and cases present Jan. 1, 1912.

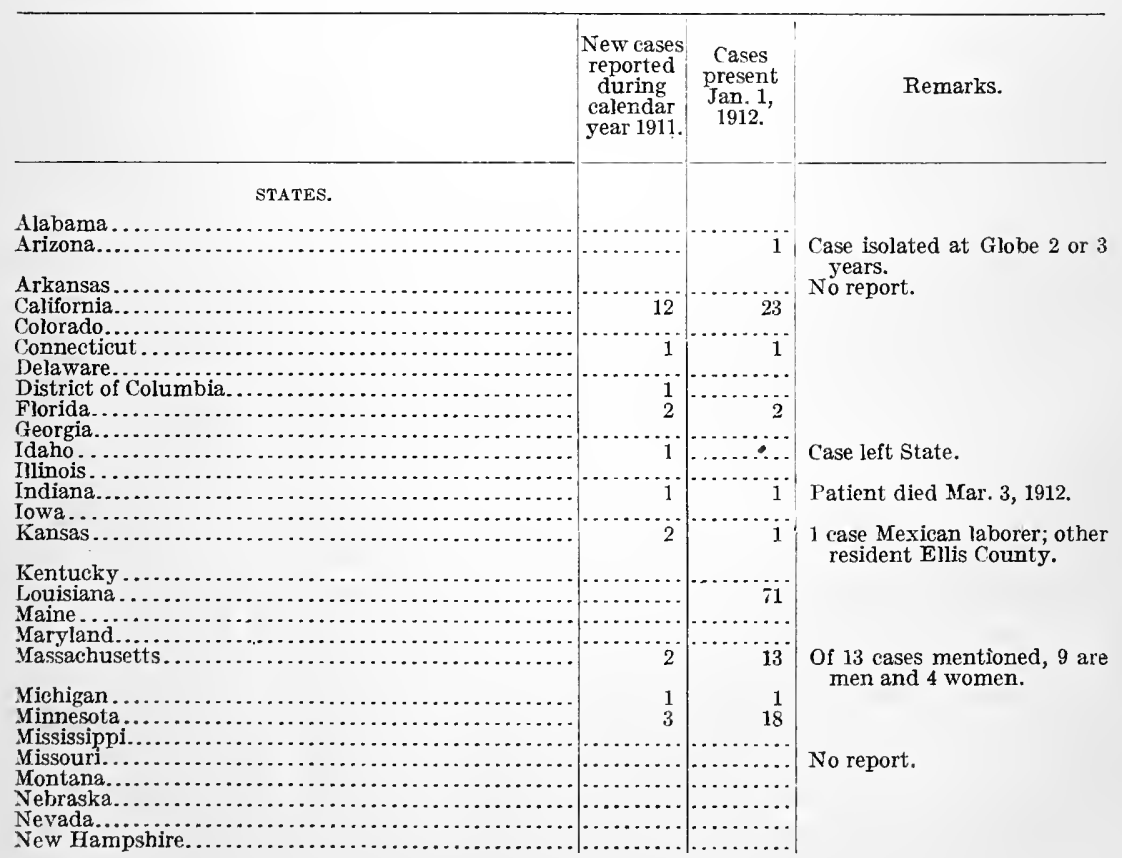


Leprosy cases reported during the calendar year 1911 and cases present Jan. 1, 1912-Con.

\begin{tabular}{|c|c|c|c|}
\hline & $\begin{array}{c}\text { New cases } \\
\text { reported } \\
\text { during } \\
\text { calendar } \\
\text { year } 1911 .\end{array}$ & $\begin{array}{c}\text { Cases } \\
\text { present } \\
\text { Jan. 1, } \\
1912 .\end{array}$ & Remarks. \\
\hline \multicolumn{4}{|l|}{ STATES-continued. } \\
\hline 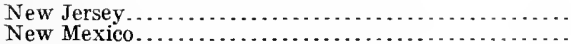 & & & \\
\hline New York....................... & 5 & 5 & $\begin{array}{l}\text { These cases were reported in } \\
\text { New York City. }\end{array}$ \\
\hline North Carolina ................ & & & \\
\hline 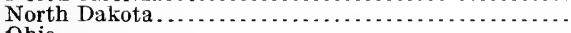 & 1 & 1 & \\
\hline $\begin{array}{l}\text { Ohio } \\
\text { Oklahoma...1. }\end{array}$ & $\cdots$ & $\cdots \cdots$ & \\
\hline $\begin{array}{l}\text { Oklahoma } \\
\text { Oregon }{ }_{1}, \ldots \ldots\end{array}$ & & & \\
\hline Pennsylvania.......... & 3 & 3 & \\
\hline 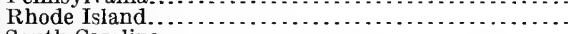 & 2 & 1 & \\
\hline S suth Carolina..................... & $\cdots \cdots$ & ........... & \\
\hline 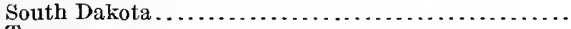 & ..... & & \\
\hline 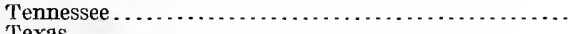 & $\ldots \ldots . . .$. & & \\
\hline 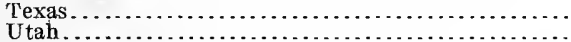 & $\cdots \cdots$ & $\cdots \cdot$ & \\
\hline Vermont. & & & \\
\hline Virginia & & & \\
\hline 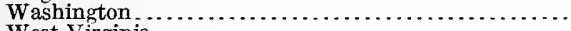 & 1 & 2 & \\
\hline $\begin{array}{l}\text { West Virginia } \\
\text { Wisconsin }\end{array}$ & $\cdots \cdots$ & $\cdots$ & \\
\hline $\begin{array}{l}\text { Wisconsin } \\
\text { Wyoming } \\
\text { y }\end{array}$ & .......... & & \\
\hline Total. . & 40 & 146 & \\
\hline HAWAI AND THE INSULAR POSSESSIONS. & & & \\
\hline Hawaii...................... & 65 & 696 & \\
\hline Philippine Islands. & 1,142 & 2,754 & \\
\hline Porto Rico & 10 & & \\
\hline Total.. & 1,217 & 3,478 & \\
\hline
\end{tabular}

\section{CONNECTICUT.}

Dr. Joseph H. Townsend, secretary of the State board of health, reported February 13, 1912, as follows, regarding the case occurring in Connecticut: The one case reported during the calendar year 1911 is, so far as I know, the only case that has ever been reported in the State. This case is in a man, a Lithuanian Jew, who has been in this country about 20 years. Fifteen years ago he had frostbites on both feet which did not heal readily, and for the past 10 years he has been an invalid confined to his home, his case having previously been diagnosed as syphilis.

\section{DISTRICT OF COLUMBIA.}

Dr. William C. Woodward, health officer of the District of Columbia, reported February 13, 1912, regarding the case occurring in the District as follows: The case reported January 24, 1911, was in a Filipino, age 20 years, who had been brought to the United States by a naval officer as a domestic. He was returned by the health department September 9, 1911, to the Philippine Islands, on board a transport.

\section{INDIANA.}

Dr. J. N. Hurty, State health commissioner, reported February 12, 1912, regarding the case of leprosy in Indiana as follows:

One case of leprosy was reported in Indianapolis December 27, 1911. The patient, female, colored, was born in Hawkins County, 
Tenn. After her thirteenth year she lived in Knoxville until 1908, when she removed to Indianapolis. She never had been farther south than Knoxville. She is the mother of six children; two are living, both grown to adult life. Previous to being attacked she had always been well. In November, 1910, she noticed some blotehes on face, arms, and legs, and in March, 1911, consulted a physician, who diagnosed her trouble as lichen planus. Nodules first appeared on face, arms, and ears in October, 1911. (The patient died in March, 1912.) One other case of leprosy was reported in this State about eight years ago. The case we now have we presume would be called sporadic, for we can not in the least degree trace the time and place of infection.

\section{MICIIIGAN.}

The history of the case in Michigan is as follows:

The case was located at Calumet, Mich. Name, M. J.; born in Alten, Norway, 38 years ago; father, two sisters, and two brothers all living and apparently in good health; one brother was recently killed in a railroad accident; his mother died of leprosy in Norway on May 13 of this year after an illness of approximately four years. M. J. came to this country from Norway on July 20, 1900, and settled in Calumet. Since his arrival in this country he has not returned to Norway, nor has he seen his mother. He worked in the copper mines in Calumet, and while so engaged during the spring of 1904 the first symptoms of the disease made their appearance.

It first appeared in his nose, for the relief of which he had an operation performed. His nasal passages had become occluded and the operation temporarily relieved this. During the summer of the same year (1904) he went to Alaska under contract with the United States Government to herd reindeer, and while there, during the following fall, the trouble with his nose returned and the disease began to manifest itself on his face and hands.

He stated that his face and hands felt as though they had been slightly sunburned.

At the expiration of his one year's contract with the Government in Alaska he returned to Calumet and engaged in mining and carpentering. Since his return he has had exacerbations and remissions of the disease until now he presents a typical picture of a welladvanced case of tubercular leprosy. His hands, face, and feet are simply one mass of tubercles. Scrapings from these tubercles and from the nasal mucous membrane obtained showed microscopically enormous numbers of lepræ bacilli.

MINNESOTA.

Dr. H. M. Bracken, secretary State board of health, reported February 14, 1912, as follows:

Two of the three cases reported to us last year were in persons American born. One, a woman, had a father and a brother die of leprosy in this country; the brother also American born. The other, a boy, had a leprous mother who died in this country.

Of the 18 cases of leprosy in this State now, 6 are in persons American born. Of these 6,1 is a Canadian, the other 5 were born in Minnesota. 
The source of origin in the Canadian case is not known, but the origin of all of the other 17 cases was in the immediate family of the leper.

We have no record of leprosy occurring outside of the family of a leper in Minnesota, and we know of many cases where with a leper in the family no other cases of leprosy appear. These have been cases where the lepers have been carefully isolated in their own homes.

PHILIPPINE ISLANDS.

Victor G. Heiser, passed assistant surgeon Public Health and MarineHospital Service, and director of health of the Philippine Islands, reported March 23, 1912, as follows:

The number of cases of leprosy reported in the Philippines during the calendar year 1911 was 3,339 . This includes 2,172 remaining at the Culion leper colony January 1, 1911, and 25 in the Moro Province, not taken to Culion.

The number of cases of leprosy present in the Philippines January 1,1912 , was 2,754 .

The number of cases of leprosy reported from January 1 to March 23,1912 , was 135 .

In round numbers there have been collected in the Philippine Islands and transferred to the Culion leper colony 6,000 lepers. Of this number, in round numbers, 3,000 came from the island of Cebu. This island has a population of approximately 700,000 , and as the total population of the Philippine Islands is approximately $7,000,000$, it will be noted that although it has only one-tenth of the population of the entire islands, it has furnished approximately 50 per cent of the lepers up to date. On this island many instances have come to light which indicate that leprosy is a so-called "house disease." The bureau of health is now collecting statistics, and already has a number of instances on hand in which cases of leprosy have developed year after year after the first leper was taken from a house.

\section{UTAH.}

Dr. T. B. Beatty, secretary of the State board of health, reported March 11,1912, regarding the case of leprosy occurring in Utah as follows: The State board of health received a report of one case of leprosy during the year 1911. The case in question was reported from Uintah County, where the patient still resides. He is described as a man aged 25 years and a native of the Samoan Islands; has resided in Utah five years, and is a homesteader on land which was formerly a part of the Uintah Reservation. The local health officer is under instructions to enforce strict isolation, not permitting him to leave his farm.

The only additional case of leprosy that has been discovered in Utah in recent years was in the person of a native of Greece, who had the macular form of the disease, and was reported in 1910. This patient escaped from the authorities and returned to Greece after having been under observation for a short period. 


\section{RABIES IN THE UNITED STATES.}

The following table compiled by Passed Asst. Surg. $\Lambda$. M. Stimson shows the prevalence of rabies in man and animals and the number. of infected localities in the United States in 1911 and 1908 in so far as it has been possible to collect the information:

Rabies in the United States, 1908 and 1911.

\begin{tabular}{|c|c|c|c|c|c|c|}
\hline \multirow{2}{*}{ States. } & \multicolumn{2}{|c|}{ Deaths in man. } & \multicolumn{2}{|c|}{ Infected localities. } & \multirow{2}{*}{$\begin{array}{l}\text { l'ersorns } \\
\text { treated, } \\
\text { l911. }\end{array}$} & \multirow{2}{*}{$\begin{array}{l}\text { Rabid } \\
\text { animals, } \\
\text { 1911. }\end{array}$} \\
\hline & 1911 & 1908 & 1911 & 1908 & & \\
\hline Alabama.... & 4 & 1 & 147 & 13 & 281 & $1 ; 04$ \\
\hline Arizona.... & & 1 & 1 & 1 & 1 & \\
\hline Arkansas... & & 1 & 18 & $\hat{5}$ & 29 & 9 \\
\hline California.. & & & 49 & & 124 & 310 \\
\hline Colorado..... & & & 10 & 1 & 10 & 16 \\
\hline Connecticut. & & $i$ & 11 & $i$ & 8 & 19 \\
\hline Delaware........... & & & 15 & 5 & 22 & 17 \\
\hline District of Columbia. & 1 & & 1 & 1 & 41 & 72 \\
\hline Florida.............. & 4 & & 36 & 11 & 128 & 100 \\
\hline Georgia...... & 2 & 3 & 24 & 17 & 4.57 & \\
\hline Idaho $\ldots \ldots \ldots$ & & & & & & \\
\hline 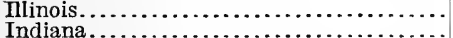 & $\begin{array}{l}8 \\
4\end{array}$ & $\frac{2}{5}$ & $\begin{array}{l}35 \\
62\end{array}$ & $\begin{array}{l}18 \\
57\end{array}$ & $\begin{array}{l}292 \\
104\end{array}$ & $\begin{array}{l}265 \\
119\end{array}$ \\
\hline $\begin{array}{l}\text { Indiana } \\
\text { Iowa. } \\
\text { Iow }\end{array}$ & 1 & 1 & 29 & 5 & 92 & $\begin{array}{r}19 \\
35\end{array}$ \\
\hline Kansas............ & & 2 & 86 & 4 & 175 & 80 \\
\hline Kentucky...... & 2 & 1 & 14 & 7 & 24 & $2 \pi$ \\
\hline 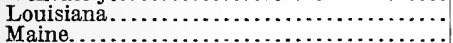 & 3 & 4 & 61 & 3 & 233 & 19 \\
\hline Maryland............. & 3 & $\dddot{6}$ & 59 & 12 & 122 & 52 \\
\hline Massachusetts....... & 1 & 5 & 45 & 9 & 27 & 139 \\
\hline Michigan......... & $\overline{3}$ & 3 & 46 & 11 & 58 & 70 \\
\hline Minnesota... & & 2 & 31 & 18 & 117 & 60 \\
\hline Mississippi...... & & 1 & 34 & 10 & 51 & 11 \\
\hline Missouri........... & 6 & 8 & 52 & 9 & 187 & 102 \\
\hline Montana.................................. & & & $\cdots \cdot$ & & $\cdots \cdots$ & $\cdots \cdot$ \\
\hline $\begin{array}{l}\text { Nebraska............ } \\
\text { Nevada.......... }\end{array}$ & & 1 & $\cdots \cdot \cdot$ & 5 & $\cdots \cdots$ & $\cdots$ \\
\hline New Hampshire.... & i & 2 & $\cdots$ & 7 & 2 & \\
\hline New Jersey.......... & 13 & 11 & 68 & 41 & 189 & 77 \\
\hline $\begin{array}{l}\text { New Mexico.......... } \\
\text { New York......... }\end{array}$ & 13 & $\dddot{19}$ & 238 & 52 & 899 & \\
\hline North Carolina....... & 1 & & 96 & 19 & 166 & $\begin{array}{l}488 \\
101\end{array}$ \\
\hline North Dakota........ & & & 12 & 2 & 15 & 22 \\
\hline Ohio .............. & 8 & 4 & 91 & 32 & 275 & 295 \\
\hline Oklahoma... & 1 & 3 & 51 & 6 & 106 & 58 \\
\hline Oregon............ & & & & & & 11 \\
\hline Pennsylvania... & 10 & 14 & 152 & 25 & 246 & $3 \pm 7$ \\
\hline Rhode Island.... & & 1 & 4 & 10 & 5 & 5 \\
\hline South Carolina................ & 1 & 1 & 132 & 5 & 114 & 63 \\
\hline South Dakota..................... & 1 & & 7 & 2 & 14 & 11 \\
\hline Tennessee............ & & 1 & 16 & 7 & 13 & \\
\hline Texas.............. & 2 & 3 & $(2)$ & 15 & $(2)$ & $\left({ }^{2}\right)$ \\
\hline 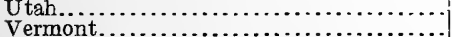 & & & $\cdots \cdots$ & & & …... \\
\hline $\begin{array}{l}\text { Vermont.... } \\
\text { Virginia..... }\end{array}$ & $\cdots$ & $\ddot{1}$ & 38 & 37 & $\ddot{54}$ & $5 \overline{5}$ \\
\hline ( & & & 7 & & 2 & 22 \\
\hline 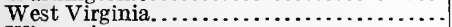 & & & 21 & 2 & 30 & 7 \\
\hline 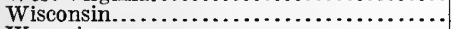 & 2 & 3 & 83 & 42 & 112 & 114 \\
\hline Wyoming............................ & & $\cdots$ & 3 & (.......... & 4 & 7 \\
\hline Total.. & 98 & 111 & 1,381 & 534 & 4,625 & 3,393 \\
\hline
\end{tabular}

1 Counties.

2 Incomplete.

The most striking feature of the figures shown in this table is the spread of rabies to the Pacific Coast States, which were apparently entirely free from the disease in 1908. Another feature of interest is the greatly increased number of localities from which the disease, in man or animals, was reported. The most obvious explanation of these figures is that there has actually been a generalized spread of the disease to territory previously uninfected. While this is undoubt- 
edly true, and is in fact the conclusion reached by those who have been observing the disease for some years, we can not assume that this spread has been proportional to the figures shown. Increased activities of health authorities and greatly extended facilities for the administration of protective treatment have undoubtedly brought to light many cases of animal infection which formerly would have escaped record. In contrast with the increased distribution in the lower animals, there has been a diminution in the number of human deaths, amounting to nearly 12 per cent. While this decrease may possibly be attributed to chance, there is another element which must be given due consideration - the much more widespread resort to antirabic inoculations of exposed persons.

\section{Smallpox in the United States.}

Smallpox was still prevalent throughout the United States during the year 1911. The general type of the disease was the same as that which has been common for the last 14 or 15 years. Most of the cases were mild, so mild in fact that frequently it was difficult to make a diagnosis. Many cases were undoubtedly pronounced chicken pox. Some of those attacked suffered so little inconvenience that a physician was not called in attendance, and in some cases the patients had not discontinued their regular occupations.

This mild type of the disease is not one peculiar to this country. During recent years there has been a similarly benign form in certain sections of Brazil, and for many years a disease, undoubtedly a mild form of smallpox, has occurred in certain localities in Africa, where it has been known by various names, among which are "Amaas," "Kaffir smallpox," and "Kaffir pox." A type apparently identical with that common in this country is also prevalent in Canada, and outbreaks of the same nature have at times been reported in the West Indies. It has been stated that similarly mild, benign outbreaks were noted previous to the nineteenth century. The reason why the disease assumes this mild form at times and continues so for a considerable period, often involving extensive territory, is not understood.

In the United States there have been during the year only a few outbreaks of the severe type of the disease. These were limited to Texas, California, and Kansas. The occurrence of malignant smallpox always arouses an acute interest on the part of both the public and the local officials, with the result usually that strenuous efforts are made to control the disease, and this end is invariably accomplished by means of general vaccination.

During the calendar year 1911 reports were received from the health authorities of 29 States and the District of Columbia, giving the occurrence of smallpox as notified in their respective jurisdictions. In these States there was a total of 21,768 cases and 134 deaths reported. During the year 1910 there were notified in these same States 25,598 cases with 403 deaths, and in 1909, 20,679 cases with 132 deaths.

From such information as was obtainable the disease during 1911 appears to have been equally prevalent, if not more so, in the States from which no reports were received. The fact that certain States did not report on the prevalence of the disease was not due to an 
absence of cases of smallpox within their territory, but to an absence of laws requiring the notification of 'ases, or in the presence of such laws, to a failure to enforce them.

It must not, therefore, be understood that the States enunorated in the tables which follow later had more smallpox than the States that do not appear. In fact, many of the States that are not mentioned because of a lack of the necessary reports are known to have been heavily infected with the disease. The States included in the tables are those having health departments that keep informed with a certain degree of accuracy regarding the prevalence of discase within their respective jurisdictions.

PPEVALENCE.

Cases of smallpox occurred at some time luring the year in all of the States reporting. The greatest numbers of cases were notified in North Carolina, Florida, Kansas, Utah, and Colorado, with 2,484, $2,195,2,043,1,660$, and 1,381 cases, respectively, in the order named.

Although the number of cases reported in North Carolina was greater than that in any other State, there was a marked decrease from the preceding year, when 4,281 cases were reporterl. In Florida only 3 cases were reported in 1909 . In 1910 the number was 1,286, and in 1911, 2,195 cases. In Kansas the annual number of cases was practically the same during the three years 1909,1910 , and 1911. The 1,660 cases reported in Utah was an increase over the 966 cases reported in 1910, and a decrease from the 1,854 cases for 1909 .

A decrease in the prevalence of the disease is noted in Michigan, there having been in 1911 only 691 reported cases, whereas in 1910 there were 2,585 . Oklahoma also showed a decrease, there being only 1,080 cases in 1911, against 2,342 during the preceding year. In Texas the number decreased from 2,925 reported cases in 1910 to 687 in 1911.

The States with the smallest number of cases were Connecticut, Massachusetts, District of Columbia, Maryland (exclusive of Baltimore), New Jersey, and Maine, with 2, 11, 28, 31, 40, and 68 cases, respectively.

\section{CASE RATE.}

The case rate, based upon the population, gives a much better idea of the relative prevalence of the disease. Using the estimated midyear populations, the highest case rates were in Utah, Florida, Colorado, Kansas, and North Carolina, these States in the order named having the following case rates per thousand inhabitants: $4.31,2.81,1.66,1.19$, and 1.10 . The lowest case rates per thousand population were those of Connecticut, Massachusetts, New Jersey, Pennsylvania, and New York, with rates of $0.002,0.003,0.015$, 0.02 , and 0.036 , respectively. Utah also had the highest case rates in 1909 and 1910, with rates of 5.07 in the former year and 2.57 in the latter.

\section{CASE FATALITY.}

On the whole, the case fatality rate was very low. Among the 21,767 cases only 134 deaths were reported. This makes the exceedingly low aggregate fatality rate of 0.61 for each 100 cases. 
The greatest number of deaths occurred in Texas, Kansas, California, Utah, and Florida, with $51,26,10,8$, and 6 deaths, respectively, in the order named. No deaths were reported in Connecticut, District of Columbia, Maine, Maryland (exclusive of Baltimore), North Carolina, North Dakota, Vermont, Virginia, and Wisconsin. The 11 cases with 2 deaths in Massachusetts gave a fatality rate per hundred cases of 18.18. This was higher than that of any other State. Texas with 687 cases and 51 deaths had a fatality rate of 7.42 per hundred cases; California had a rate of 5.4; New Jersey of 2.5; Kansas and Pennsylvania each a rate of 1.27 .

VIRULENT OUTBREAKS.

During the year the disease appeared in virulent form in El Paso and Guadalupe Counties, Tex. In El Paso County there were 25 deaths among 97 cases. Many of the cases were confluent and some hemorrhagic. In Guadalupe County there were 2 deaths in 5 cases.

In Kansas a severe outbreak occurred in Topeka. This outbreak began in May and continued into October. There were in all 143 cases, with 23 deaths. Many of the cases were hemorrhagic.

In Osage County, Kans., 3 deaths from smallpox also occurred.

The malignant type of the disease appeared in Los Angeles, Cal., in November, 1911. The first case was in a district occupied by Mexicans. The mild form of the disease had been present in the city from March to the end of October. The cases were few, however, and during these months there were in all only 26 reported. These were all of the benign type of the disease so prevalent throughout the United States, and among them there was no fatality. During the last two months of the year, however, the disease appeared in virulent form, and out of 25 cases reported during these months 6 ended fatally.

The virulent outbreaks during the year 1911 were less numerous than those of the preceding year. The only two outbreaks of any extent were those in Topeka, Kans., and El Paso, Tex. These are comparable with the outbreaks which occurred during the preceding year in Bay City, Saginaw, and Lapeer, Mich. The fact that there were 2 deaths among the 11 cases in Massachusetts would indicate that at least some of the cases occurring in that State were of the virulent type. The infection, however, appears to have been kept under control and not to have spread. 


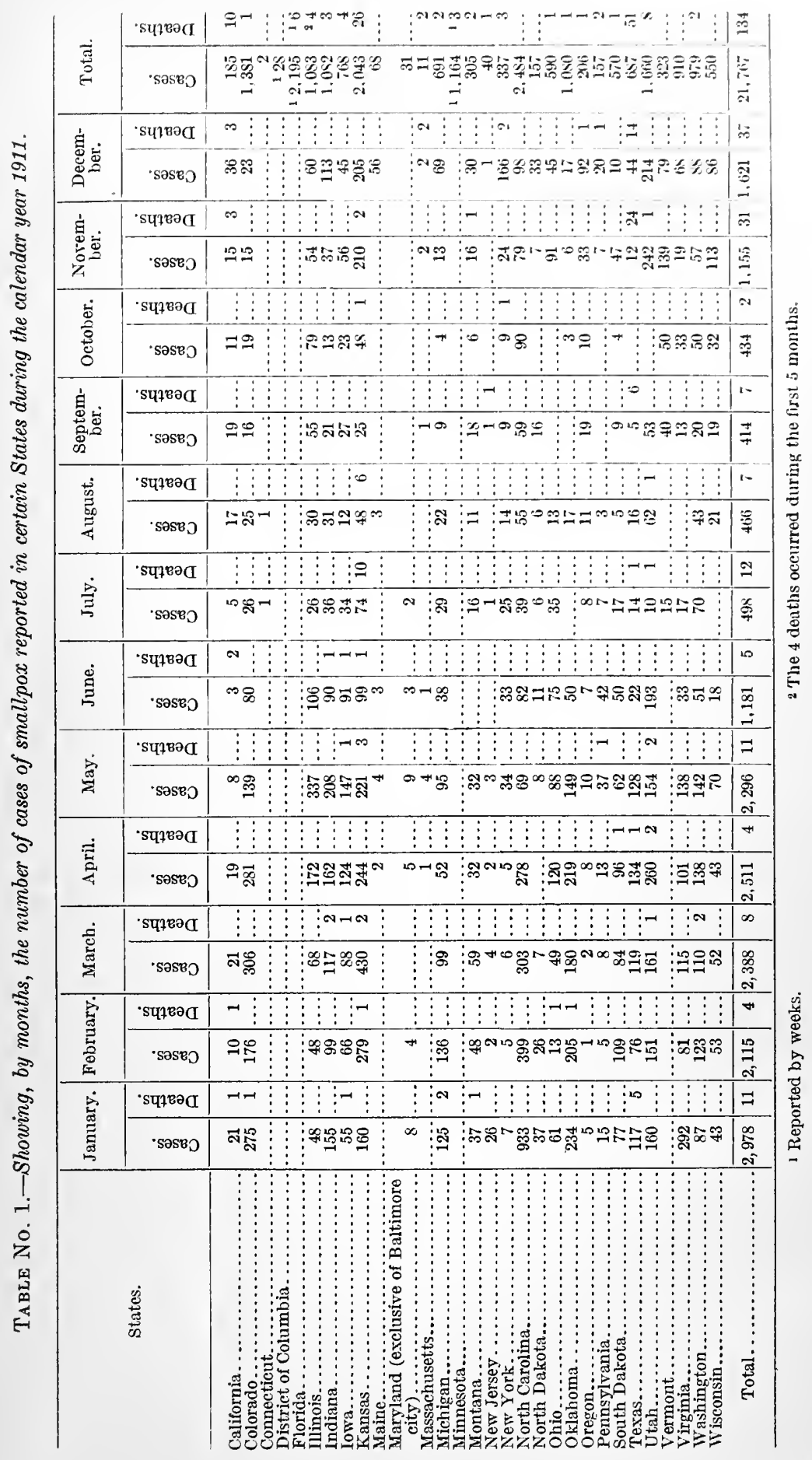


TABLE No. 2.-Showing the number of cases of and deaths due to smallpox reported in certain States during the calendar years 1909, 1910, and 1911.

\begin{tabular}{|c|c|c|c|c|c|c|}
\hline \multirow{2}{*}{ States. } & \multicolumn{2}{|c|}{1909} & \multicolumn{2}{|c|}{1910} & \multicolumn{2}{|c|}{1911} \\
\hline & Cases. & Deaths. & Cases. & Deaths. & Cases. & Deathš. \\
\hline California $\ldots \ldots \ldots \ldots \ldots \ldots \ldots \ldots \ldots$ & 180 & 6 & 177 & 1 & 185 & \\
\hline 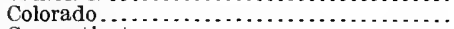 & 345 & $\ldots$ & 1,096 & 7 & 1,381 & \\
\hline Connecticut $\ldots \ldots \ldots \ldots \ldots \ldots \ldots \ldots \ldots \ldots \ldots \ldots$ & 3 & & $\cdots \cdots$ & & 2 & \\
\hline District of Columbia................. & 24 & & 96 & & 28 & \\
\hline 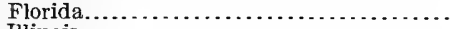 & 3 & 1 & 1,286 & 12 & 2,195 & \\
\hline Illinois $\ldots \ldots \ldots \ldots \ldots \ldots \ldots \ldots \ldots \ldots \ldots$ & 2,135 & 8 & 730 & $(?)$ & 1,083 & \\
\hline 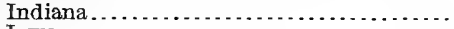 & 1,363 & 5 & 764 & 1 & 1,082 & \\
\hline Iowa $\ldots \ldots \ldots \ldots \ldots \ldots \ldots \ldots \ldots \ldots \ldots \ldots$ & 825 & 4 & 850 & 1 & 768 & \\
\hline 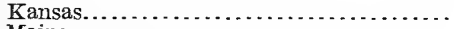 & 2,197 & 4 & 2,202 & 12 & 2,043 & 26 \\
\hline 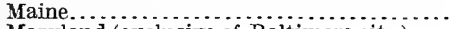 & 36 & $\ldots$ & 8 & .. & 68 & \\
\hline Maryland (exclusive of Baltimore city).... & 26 & & 6 & ..... & 31 & \\
\hline 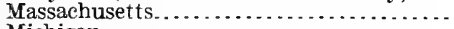 & 14 & & 144 & - & 11 & \\
\hline 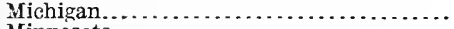 & 1,175 & 4 & 2,585 & 121 & 691 & \\
\hline 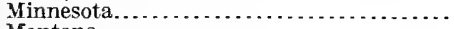 & 1,430 & 14 & 1,002 & 10 & 1,164 & \\
\hline 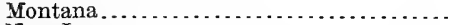 & 685 & 3 & $63 \dot{4}$ & 2 & 305 & \\
\hline 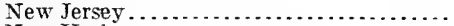 & 88 & 2 & 22 & & 40 & \\
\hline New York $\ldots \ldots \ldots \ldots \ldots \ldots$ & 762 & 4 & 353 & 8 & 337 & \\
\hline North Carolina. . & 1,733 & 2 & 4,281 & 8 & 2,484 & \\
\hline 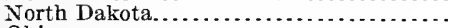 & 204 & & 306 & 2 & 157 & \\
\hline 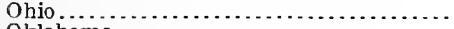 & 1,328 & 4 & 750 & 13 & 590 & \\
\hline 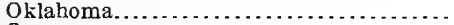 & 1,434 & 6 & 2,342 & 99 & 1,080 & \\
\hline 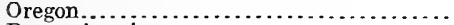 & 252 & ... & 164 & 5 & 206 & \\
\hline 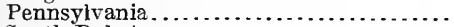 & 25 & $\ldots \ldots$ & 168 & 8 & 157 & \\
\hline 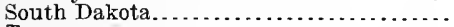 & 13 & 2 & 365 & 1 & 570 & \\
\hline 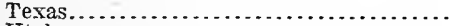 & 752 & 14 & 2,925 & 67 & 687 & 51 \\
\hline 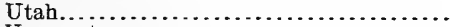 & 1,854 & 5 & 966 & 2 & 1,660 & \\
\hline 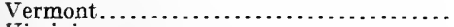 & 73 & & & & 323 & \\
\hline 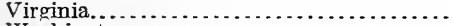 & 202 & 18 & 350 & 6 & 910 & \\
\hline 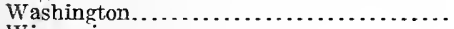 & 310 & 9 & 583 & 14 & 979 & \\
\hline 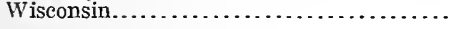 & 1,208 & 16 & 443 & .3 & 550 & \\
\hline 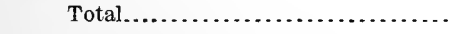 & 20,679 & 132 & 25,598 & 403 & 21,767 & 134 \\
\hline
\end{tabular}

TABLE No. 3.-Showing the smallpox case rate per 1,000 inhabitants and fatality rate per 100 cases in certain States during the calendar years 1909, 1910, and 1911.

\begin{tabular}{|c|c|c|c|c|c|c|}
\hline \multirow[b]{2}{*}{ States. } & \multicolumn{2}{|c|}{1909} & \multicolumn{2}{|c|}{1910} & \multicolumn{2}{|c|}{1911} \\
\hline & $\begin{array}{c}\text { Case rate } \\
\text { per } 1,000 \\
\text { inhabit- } \\
\text { ants. }\end{array}$ & $\begin{array}{l}\text { Case } \\
\text { fatality } \\
\text { rate } \\
\text { per } 100 .\end{array}$ & $\begin{array}{c}\text { Case rate } \\
\text { per } 1,000 \\
\text { inbabit- } \\
\text { ants. }\end{array}$ & $\begin{array}{c}\text { Case } \\
\text { fatality } \\
\text { rate } \\
\text { per } 100 .\end{array}$ & $\begin{array}{c}\text { Case rate } \\
\text { per } 1,000 \\
\text { inbabit- } \\
\text { ants. }\end{array}$ & $\begin{array}{c}\text { Case } \\
\text { fatality } \\
\text { rate } \\
\text { per } 100 .\end{array}$ \\
\hline California ......... & & & & & 0.074 & 5.40 \\
\hline 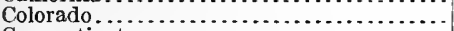 & 0.443 & & 1.362 & 0.64 & 1.662 & .07 \\
\hline 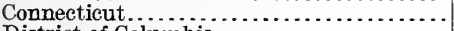 & .003 & .......... & $\ldots . . .$. & .......... & .002 & ..... \\
\hline 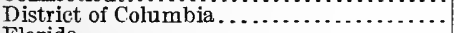 & .073 & $\ldots \ldots \ldots$ & .289 & & .083 & $\ldots$. \\
\hline & .004 & 33.33 & 1. 696 & .93 & 2.814 & .27 \\
\hline & .383 & .37 & .129 & & .189 & .37 \\
\hline 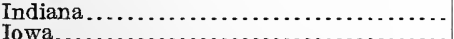 & .507 & .37 & .282 & .13 & .397 & \\
\hline & $\begin{array}{r}.371 \\
1.317\end{array}$ & .48 & .382 & .12 & .345 & .52 \\
\hline & $\begin{array}{r}1.317 \\
.049\end{array}$ & .18 & 1. 298 & .54 & 1.190 & 1.27 \\
\hline Maryland (exclusive of Baltimore city) ... & $\begin{array}{l}.049 \\
.036\end{array}$ & - $\ldots \ldots \ldots$ & $\begin{array}{l}.011 \\
.008\end{array}$ & $\because$ & .091 & .... \\
\hline 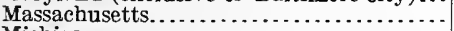 & .004 & 7. 14 & .043 & & .041 & 18.18 \\
\hline 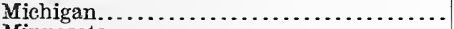 & .424 & .34 & .917 & 4. 68 & .242 & .28 \\
\hline 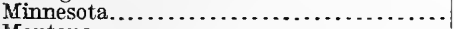 & .694 & .98 & .482 & .99 & .550 & .25 \\
\hline 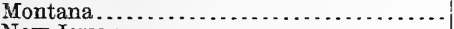 & 1. 875 & .44 & 1. 673 & .31 & .778 & .65 \\
\hline 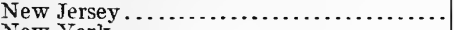 & .036 & 2.27 & .009 & $\ldots \ldots \ldots$ & .015 & 2.50 \\
\hline 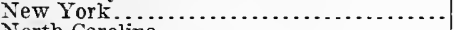 & .085 & .52 & .039 & 2.26 & .036 & .89 \\
\hline 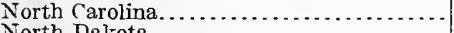 & .795 & .12 & 1. 934 & .18 & 1. 109 & $\ldots . . . . .$. \\
\hline 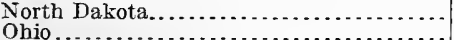 & .367 & $\cdots 3$ & .525 & .65 & .258 & ........ \\
\hline 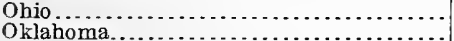 & .281 & .30 & .159 & 1. 73 & .122 & .17 \\
\hline $\begin{array}{l}\text { Oklahoma } \\
\text { Oregon } \ldots \ldots \ldots \ldots \ldots \ldots\end{array}$ & .904 & .42 & 1. 398 & 4. 22 & .613 & .09 \\
\hline $\begin{array}{l}\text { Oregon } \\
\text { Pennsylvania } \ldots \ldots \ldots \ldots \ldots \ldots \ldots \ldots \\
\end{array}$ & .387 & ........... & .242 & 3.05 & .293 & .48 \\
\hline 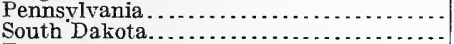 & .003 & & .022 & 4. 76 & $\begin{array}{r}.020 \\
.941\end{array}$ & $\begin{array}{r}1.27 \\
.19\end{array}$ \\
\hline Texas........ & & & .747 & 2.29 & .172 & 7.42 \\
\hline Utah......... & 5.071 & .27 & 2.573 & .21 & 4.312 & .48 \\
\hline Vermont........ & .206 & & $\ldots \ldots$ & & .905 & ... \\
\hline Virginia......... & 48 & 000 & & 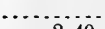 & .436 & \\
\hline Washington....... & .284 & 2.90 & .505 & 2.40 & .803 & .20 \\
\hline 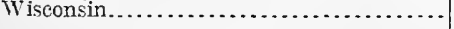 & .521 & 1.32 & .189 & .67 & .232 & \\
\hline
\end{tabular}


Typhus Fever in tine United States.

The so-called Brill's disease, of which many eases hare occurred in New York during the last 15 years, has been shown to be the same disease as the typhus fever of Mexico. The typhus ferer of Mexico is very probably the same as the typhus fever of Europe and Asia. and presumably the infection known to exist in New lork and understood to have occurred in other American cities was imported by European or Asiatic immigrants. This gives the American physician a new disease with the symptoms of which he should familiarize himself and the possible appearance of which among patients he should kecp constantly in mind. To the health authorities of the United States it presents a new infectious disease for consideration and control.

From 1896 to the end of 1910 Dr. Nathan E. Brill noted among the medical patients in one hospital in New York City 25.5 cases of a disease which in general symptoms resembled typhoid fever to some extent and which very probally has usually been so diagnosed. Dr. Brill, however, clearly diflerentiated the two diseases, and in various reports drew attention to the similarity of his cases to typhus fever. That the disease could be typhus fever, however, he could hardly believe, because of its mildness. Among the 2.5.5 cases which he had observed there was but one death.

In addition to the cases reported by Brill, Dr. Leon Jauria reported 18 cases observed during the summer and autumn of 1910 in one hospital in Brooklyn.

The fact that cases of typhus fever have been confused with typhoid fever in New York City, and that they are without doubt being so confused in other large cities, is of interest in view of the fact that originally these two diseases were both included under typhus fever, and no differentiation was made between them. Gerhard and Pennock, of Philadelphia, are commonly given credit for having in 1837 first definitely established that typhoid ferer and typhus were distinctly separate entities.

\section{Cholera.}

So far as known, cholera is always present in certain localities in Asia. From these endemic areas the disease periodically spreads through commercial channels to other continents. In certain of these secondary infected localities the disease persists for several years, subsiding during part of each year, usually the colder months, and becoming epidemic during the other months. After a few years the disease subsides and then disappears from the locality. In Russia, cholera was epidemic from 1907 to 1911 ; in Italy during 1910 and 1911. During 1911 the United States was seriously threatened by the extensive prevalence of the disease in Italy, and during the summer months cases of cholera and cholera carriers repeatedly arrived at New York from Italian ports. This year, however (1912), the disease seems to have disappeared from both Russia and Italy, and the pandemic that was extending in successive annual waves seems to be now receding. Europe has been practically free from cholera since December, 1911, more nearly 
free than has been the case for several years. Fortunately cholera has not spread to South America.

During the summer of 1912, outside of southern Asia and the East Indies, the most noteworthy outbreaks of cholera have been in Japan and Zanzibar. In Japan the disease appeared in a number of localities between June and October. No very great number of cases, however, seems to have occurred. In Zanzibar 65 cases were reported between August 5 and September 7, 1912.

\section{ITALY.}

Italy was invaded by cholera in August, 1910, The disease was epidemic from August 17, 1910, to January 30, 1911, during which period there were 1,840 cases with 804 deaths. The disease again broke out in June, 1911, and from June 8 to December 31, 1911, there were 15,985 reported cases with 6,022 deaths. During the present year cholera was not reported in Italy until August 14, when cases appeared in Cagliari, in Sardinia. In Cagliari there were 30 cases with 8 deaths reported between August 14 and September 10, 1912. No cases have so far been reported elsewhere in Italy this year.

\section{RUSSIA.}

Very few cases of cholera have been reported in Russia this year as compared with the preceding four years. In 1908 there were reported in Russia approximately 17,000 deaths from cholera; in 1909 approximately 28,000. From May 8, 1910, to February 4, 1911 , there were recorded 216,796 cases with 100,982 deaths, and all parts of Russia except the most northern provinces were invaded. From April 21 to November 12, 1911, there were 3,313 cases with 1,596 deaths. During the present year the only cases reported were 6 that occurred in Astrakhan between June 11 and July 27.

Cases of cholera reported on vessels from July 1, 1911, to Oct. 1, 1912.1

\begin{tabular}{|c|c|c|c|c|c|c|}
\hline \multirow{2}{*}{ Port of arrival. } & \multicolumn{2}{|c|}{ Number of- } & \multirow{2}{*}{ Date. } & \multirow{2}{*}{ Name of vessel. } & \multirow{2}{*}{$\begin{array}{l}\text { Itinerary of } \\
\text { vessel. }\end{array}$} & \multirow{2}{*}{ Remarks. } \\
\hline & Cases. & Deaths. & & & & \\
\hline Trieste, Austria. . & 1 & & July $\quad 3,1911$ & Oceania..... & $\begin{array}{l}\text { From New York } \\
\text { via Naples. }\end{array}$ & $\begin{array}{c}\text { A fatal case on } \\
\text { the Oceania } \\
\text { June } 26 .\end{array}$ \\
\hline Laurium, Greece... & 1 & 1 & July $\quad 5,1911$ & ("A German & Via Naples...... & \\
\hline Nagasaki, Japan.... & 1 & & Sept. 11,1911 & Kasuga Maru... & $\begin{array}{l}\text { Plies between } \\
\text { Yokohama and } \\
\text { Shanghai. }\end{array}$ & \\
\hline Varna, Bulgaria.... & 2 & 1 & $\begin{array}{l}\text { Oct. } 18-31, \\
1911 .\end{array}$ & Boris............... & From Asia Minor & \\
\hline Trieste, Austria .... & $\frac{1}{2}$ & $\therefore$. & July 21,1911 & Bandiero Moro.. & From A sia Minor & \\
\hline Alexandria, Egypt. & 2 & & 1911. & $\begin{array}{l}\text { ing vessel). } \\
\text { Siadieh.......... }\end{array}$ & From Constan- & \\
\hline Piraeus Quaran- & 1 & & July 30,1911 & Margarita....... & tinople. & \\
\hline $\begin{array}{l}\text { tine, Greece. } \\
\text { Osaka, Japan...... }\end{array}$ & 6 & & Sept. 1-16, & Kasuga Maru... & Plies between & \\
\hline Nikoliaev, Russia.. & 8 & …..... & Aug. 9,1911 & $\begin{array}{l}\text { ("A German } \\
\text { steamer.") }\end{array}$ & $\begin{array}{l}\text { via Constanti- } \\
\text { nople. }\end{array}$ & \\
\hline
\end{tabular}

This table does not include the vessels arriving at New York from Italian ports during the summer of 1911 . These will be found in the service annual report for 1911 on $\mathrm{pp} .246$ to 255. 
Cases of cholera reported on vessels from July 1, 1911, to Oct. 1, 1912-Continued.

\begin{tabular}{|c|c|c|c|c|c|c|}
\hline \multirow{2}{*}{ Port of arrival. } & \multicolumn{2}{|c|}{ Number of - } & \multirow{2}{*}{ Date. } & \multirow{2}{*}{ Name of vessel. } & \multirow{2}{*}{$\begin{array}{l}\text { Itinerary of } \\
\text { vessels. }\end{array}$} & \multirow{2}{*}{ lemarks. } \\
\hline & Cases. & Deaths. & & & & \\
\hline $\begin{array}{l}\text { Mohammera, Per- } \\
\text { sia. }\end{array}$ & 1 & & July $28,191 !$ & (A cruiser)... & & \\
\hline $\begin{array}{l}\text { sia. } \\
\text { Novoryssisk, Rus- } \\
\text { sia. }\end{array}$ & 6 & & July $2 x-\Lambda$ ug. & Wakeficld....... & & \\
\hline $\begin{array}{l}\text { Rostov on Don, } \\
\text { Russia. }\end{array}$ & 1 & & Aug. & $\begin{array}{l}\text { ("A Turkish } \\
\text { ship.") }\end{array}$ & From 'f'rebizond & \\
\hline Basra, Turkey..... & 1 & & Aug. 9,1911 & Budrie . ............ & & \\
\hline At sea.............. & 2 & & July 25,1913 & Czar Nicolai il. & $\begin{array}{l}\text { Frorn Batoum } \\
\text { to Hamburg } \\
\text { via Algiers. }\end{array}$ & \\
\hline Nagasaki, Japan... & 2 & & Aug. $10-13$ & (Nol stater)... & …............... & $\begin{array}{l}\text { Vessel of Rus- } \\
\text { sian volun. } \\
\text { teer fleet. }\end{array}$ \\
\hline Dalney, China..... & 3 & & Aug. $23-29$, & Nitsusho Магı.. & From Shanghai. & \\
\hline Do.............. & 1 & & ....do......... & Kobe Maru..... & .....do.. & \\
\hline Kuchinotsu, Japan. & 1 & & Aug. $21--29$, & Otaru Maru..... & .....do... & \\
\hline $\begin{array}{r}\text { Moji, Japan } . . . \ldots \ldots \\
\text { Do............ }\end{array}$ & $\begin{array}{l}2 \\
4\end{array}$ & & ..... do......... & $\begin{array}{l}\text { Yokohama Maru } \\
\text { Mexico Maru }\end{array}$ & .....do...... & \\
\hline Nagasaki, Japan... & $\begin{array}{l}4 \\
1\end{array}$ & $\begin{array}{l}\cdots \\
\cdots\end{array}$ & ....dodo............ & Penza........... & ...do do......... & \\
\hline Do................. & 4 & & .....do.......... & Seiun Maru..... & ...do...... & \\
\hline 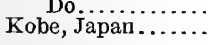 & 3 & & Aug. 28,1912 & Nitsusho Maru. & ................ & \\
\hline
\end{tabular}

Plague.

The pandemic of plague which began in 1894 in southeastern Asia and which since then has invaded all parts of both the Eastern and Western Hemispheres has continued to spread. Escaping from south central China, where it has probably been endemic for centuries, it first invaded the Chinese ports of Canton, Hongkong, Amoy, and Macao. It then extended to India, Japan, and Asiatic Turkey; then to Russia, Austria, and Portugal in Europe, and to a number of localities in Africa; then in 1899 to Hawaii, New Caledonia, and to various countries in South America; in 1900 to Australia, New Zealand, and the Philippines, Germany, Great Britain, and California. By 1901 plague was known to have invaded practically every country. having any considerable maritime commerce. Since then the disease has continued to spread, involving new localities one after another. In the Western Hemisphere by 1907 plague had been reported in Argentina, Brazil, Chile, Mexico, Panama, Paraguay, Peru, Trinidad, and Uruguay, and in the United States in the States of California and Washington. The disease during the present year appeared in Porto Rico and Cuba for the first time during the present pandemic. The occurrence of plague in these islands does not, however, materially alter the plague situation, so far as the continental United States is concerned, excepting that it shows the disease has come one step nearer the Atlantic and Gulf coasts.

In some of the localities invaded by plague during the last 18 years the disease has persisted to the present time; in others it seems to have disappeared, or at least not to have recently affected man; in others outbreaks have recurred at intervals. Because of the number of species of rodents susceptible to plague, and the persistence of the infection among them when a focus has once been established, it may properly be suspected that many of the 
invaded localities in which human cases have not been recognized for some time still harbor the infection among rodents. Plague is primarily a disease of rodents and may exist among them for long periods without affecting man. This is well illustrated by the conditions in California, where the disease has been present among the ground squirrels in the rural districts, and yet in the last four years only 11 known cases have occurred in man.

\section{PLAGUE IN THE UNITED STATES AND INSULAR POSSESSIONS.}

California.-During the fiscal year 1912 three cases of plague in man occurred in California. There was a fourth case that was probably plague. One case occurred July 21, 1911, in Contra Costa County, in an American boy 7 years old, who was probably infected from ground squirrels. One case occurred in the city of Oakland August 9, 1911, in a 16-year old boy who probably received his infection from ground squirrels in Contra Costa County. One case occurred September 18, 1911, in a man 28 years old at Ripon, in San Joaquin County. The source of the infection in this case was also probably squirrels. A fourth case that was probably one of plague occurred July 26, 1911, in a man at Modesto in Stanislaus County.

Plague still persists among the ground squirrels to some extent, and during the year infected squirrels have been found in Alameda, Contra Costa, Fresno, Merced, Monterey, and San Joaquin Counties.

Seattle, Wash.-Between August 26 and September 21, 1911, three plague-infected rats were found in Seattle. None has been found since.

Porto Rico.-Between June 14 and September 11, 1912, 56 cases of plague were reported in Porto Rico as follows: At Arroyo, 1 case on schooner from San Juan; at Carolina, 2 cases; at Dorado, 1 case; at Loiza, 1 case; at San Juan, 38 cases; at Santurce, 13 cases.

Philippine Islands.-At Manila there was a case of plague April 6, 1912 , ir a member of the crew of the steamship Zafiro, which had arrived two days before from Hongkong; between June 14 and August 24, 1912, there were 7 cases in Manila. At Iloilo between July 5 and August 30,1912, there were 5 cases. One case of plague arrived at the Mariveles quarantine station April 30 on the steamship Taisan from Amoy.

Hawaii.-At Kapulena there was a case of plague October 28, 1911. At Honakaa there were four cases between February 9 and March 18, 1912. At Pepeekeo there was a case September 13, 1912.

\section{PLAGUE-FOREIGN.}

Plague was present at some time during the year in most of the countries in Asia. It also occurred in many localities in Africa, in Russia, and in South America. In the West Indies cases were reported in Trinidad and Grenada. A case was reported in Suffolk, England, in October, 1911, and a case at Liverpool July 26, 1912. In Cuba three cases were reported in Habana between July 4 and 27, 1912. 
Cases of plague reported on vessels from July 1, 1911, to Oct. 1, 1912.

\begin{tabular}{|c|c|c|c|c|c|}
\hline \multirow{2}{*}{ Port of arrival. } & \multicolumn{2}{|c|}{ Number of - } & \multirow{2}{*}{ Date. } & \multirow{2}{*}{ Name of vessel. } & \multirow{2}{*}{ Itinerary of vessel. } \\
\hline & Cases. & Deaths. & & & \\
\hline Panama, Canal Zone........ & 1 & 1 & Oct. $11-17,1911 \ldots$. & Not stated.... & From Guayaquil, \\
\hline $\begin{array}{l}\text { Cebu Quarantine Station, } \\
\text { P.I. }\end{array}$ & 1 & & Dec. $4,1911 \ldots .$. & Montrose....... & From Shanghai. \\
\hline At sea......................... & 1 & 1 & Mar. $1-11,1912$. & Macedonia... & $\begin{array}{l}\text { From Bombay to } \\
\text { Aden. }\end{array}$ \\
\hline 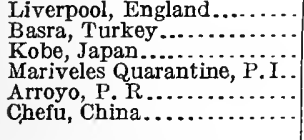 & $\begin{array}{l}1 \\
3 \\
1 \\
1 \\
1\end{array}$ & $\begin{array}{l}1 \\
\cdots \\
1 \\
2\end{array}$ & $\begin{array}{l}\text { Apr. } 27-30,1912 \ldots \ldots \\
\text { Apr. } 10-12,1912 \ldots \ldots \\
\text { May } 8,1912 \ldots \ldots \ldots \\
\text { Apr. } 30-\text { May } 7,1912 . \\
\text { July } 2,1912 \ldots \ldots \ldots \\
\text { June } 2-8,1912 \ldots \ldots\end{array}$ & $\begin{array}{l}\text { Italian Prince. } \\
\text { Adalia....... } \\
\text { Panama Maru. } \\
\text { Taisang....... } \\
\text { A sehooner... } \\
\text { Cheongshing.. }\end{array}$ & $\begin{array}{l}\text { From Newcastle. } \\
\text { From Hongkong. } \\
\text { From Amoy. } \\
\text { From San Juan. } \\
\text { Between 'Tientsin }\end{array}$ \\
\hline $\begin{array}{l}\text { Tientsin, China } \\
\text { Hongkong, China.............. } \\
\text { Aden, Arabia ............... }\end{array}$ & $\begin{array}{r}1 \\
\cdots \cdots \cdots\end{array}$ & $\begin{array}{l}1 \\
2 \\
1\end{array}$ & June $19,1912 \ldots \ldots$ & Persia............... & From Hongkong. \\
\hline At sea.......... & 3 & & July $15-20,1912 \ldots .$. & Ezan Maru.... & $\begin{array}{l}\text { From Bombay, June } \\
22 . \\
\text { From Muke to Hong. }\end{array}$ \\
\hline Hamburg, Germany.... & 2 & & $\begin{array}{l}\text { July } 14-25,1912 \ldots . \\
\text { Sept. } 2-5,1912 \ldots \ldots\end{array}$ & $\begin{array}{l}\text { Amphitrite.... } \\
\text { Bellailsa...... }\end{array}$ & $\begin{array}{l}\text { From Mersina via } \\
\text { Port Said and } \\
\text { Alexandria. } \\
\text { From Rosario via } \\
\text { Cape Verde Islands. }\end{array}$ \\
\hline
\end{tabular}

\section{Yellow Fever.}

\section{CALENDAR YEAR 1911.}

During the calendar year 1911 yellow fever was reported in the Eastern Hemisphere on the west coast of Africa, and in the Western Hemisphere in tropical South America, in Mexico, and the West Indies. There occurred in Hawaii two cases of which the source of infection was known to have been imported.

In Africa cases were reported in the British Gold Coast, Portuguese Guinea, Gambia, Senegal, and the Bissagos Islands. These are all on the west coast of Africa where the disease is endemic and undoubtedly has been for years and possibly centuries.

In South America yellow fever was reported in Brazil, Colombia, Ecuador, and Venezuela. The disease was probably present in some other localities but was not recognized, or if recognized was not reported. Yellow fever is endemic in certain places in northern South America. Just how extensive these endemic areas are is not known.

In Mexico cases were reported at Frontera, a seaport in the State of Tobasco on the Gulf of Campeche; in Merida in the State of Yucatan; and in Salina Cruz, a seaport in the State of Oaxaca on the Gulf of Tehuantepec.

In the West Indies two cases were reported in Barbados. 69450 - H. Doc. $971,62-3-13$ 
A table of the cases reported during the calendar year 1911 follows: Yellow fever cases and deaths reported during 1911.

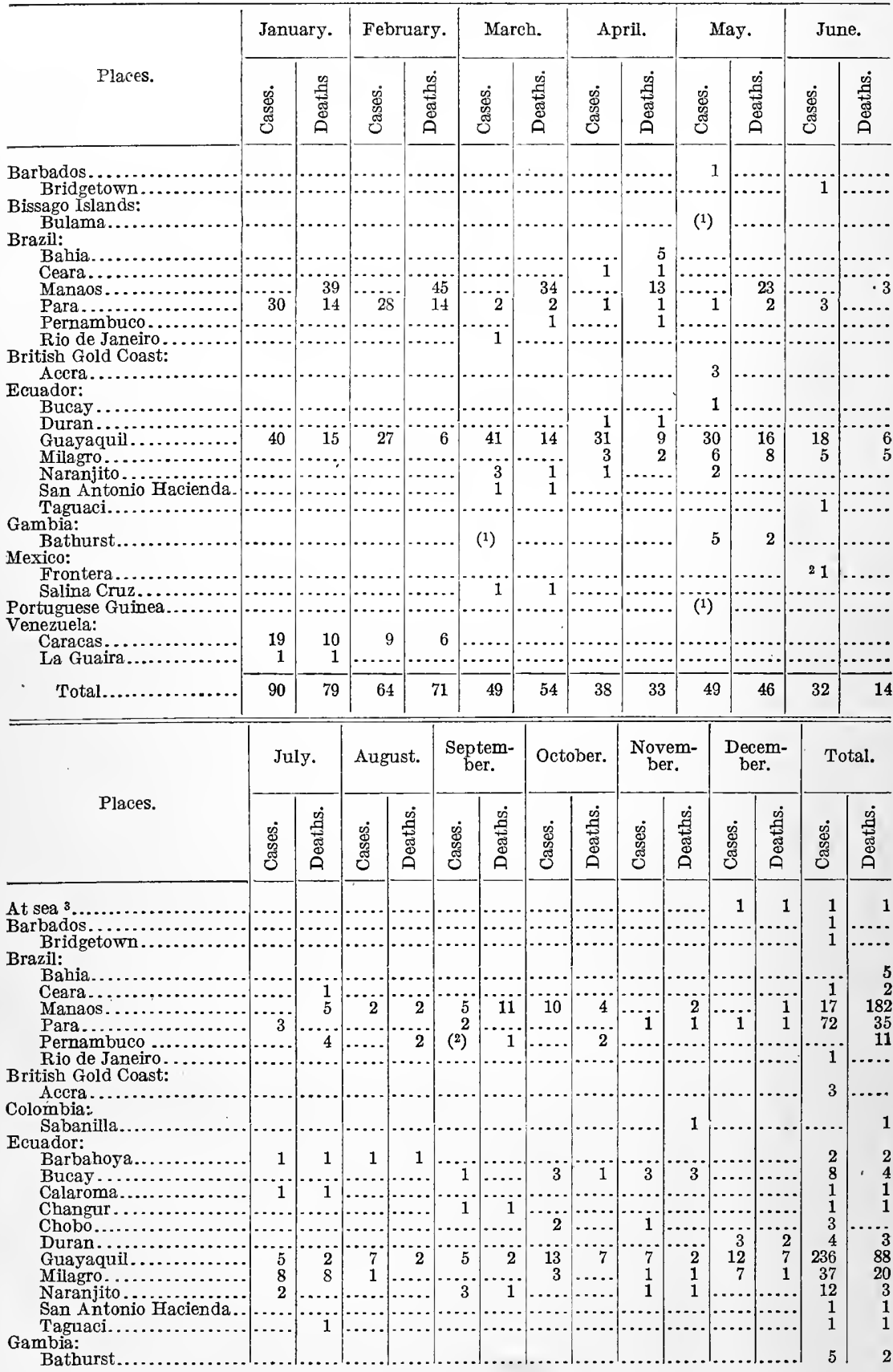


Yellow fever cases and deaths reported during 1911-Continued.

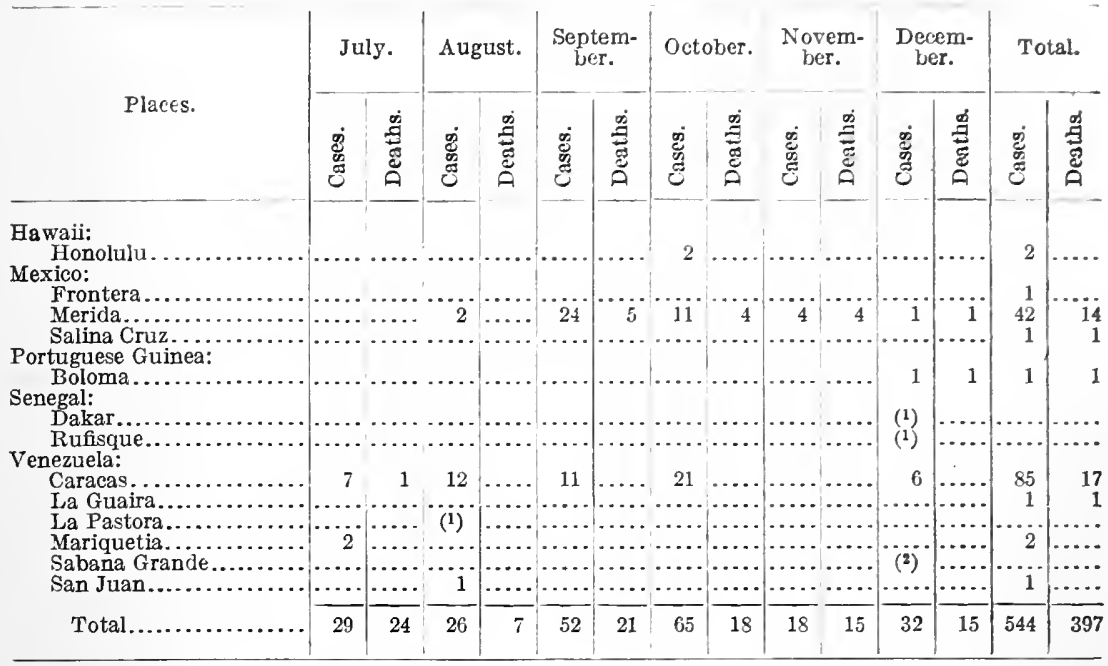

1 Present.

2 Epidemic.

CALENDAR YEAR 1912.

Since January 1, 1912, yellow fever has been reported in South America in Brazil at Bahia, Ceara, Manaos, Para, Pernambuco, and Rio de Janeiro; in Chile at Tocopilla and in Toco district; in Colombia at Barranquilla; in Ecuador at Bucay, Chobo, Duran, Guayaquil, Huigra, Milagro, Naranjal, Naranjito, and Yaguachi; in Peru at Iquitos; and in Venezuela at Caracas, Cua, El Valle, Guarenas, La Guaira, La Victoria, Macuto, Maiquetia, and Sabana Grande.

Three cases have arrived at the Canal Zone on vessels from Guayaquil, Ecuador.

In Mexico yellow fever has been reported at Carmen, Comalcalco, Espita, Frontera, Kambul, Maxcanu, Merida, Puerto Mexico, Salina Cruz, San Juan Bautista, and Temax.

The only cases reported in the West Indies were one arriving at Bridgetown, Barbados, on the steamship Francis from Para, Brazil, and one at St. Vincent.

A case of yellow fever arrived at Liverpool, England, on a vessel from Cabedelo, Brazil.

The most extensive outbreak reported during the present year was one at Tocopilla, a small maritime town in the Province of Antofagasta, Chile. The first case was January 28, 1912, in a passenger on the steamship Condor from Guayaquil, Ecuador. The patient was supposed to have typhus fever and was taken to the detention hospital, where, on February 12, yellow fever broke out among the other patients in the hospital. The disease spread throughout the city and by June 17 there had been 1,072 reported cases with 374 deaths. The disease also spread to localities in the surrounding territory.

A tabular statement of the cases of yellow fever reported from January 1 to June 30,1912 , follows. 


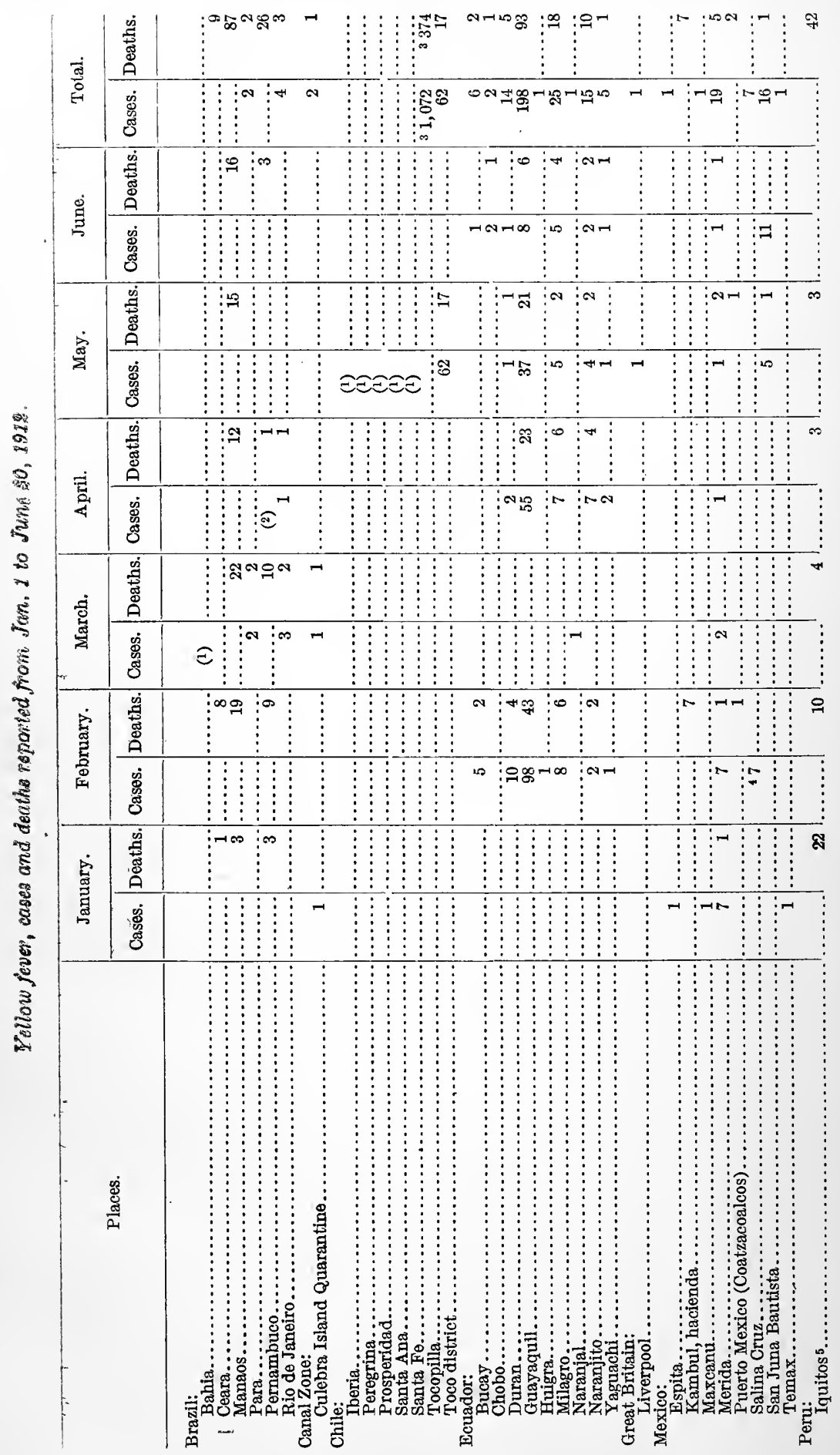




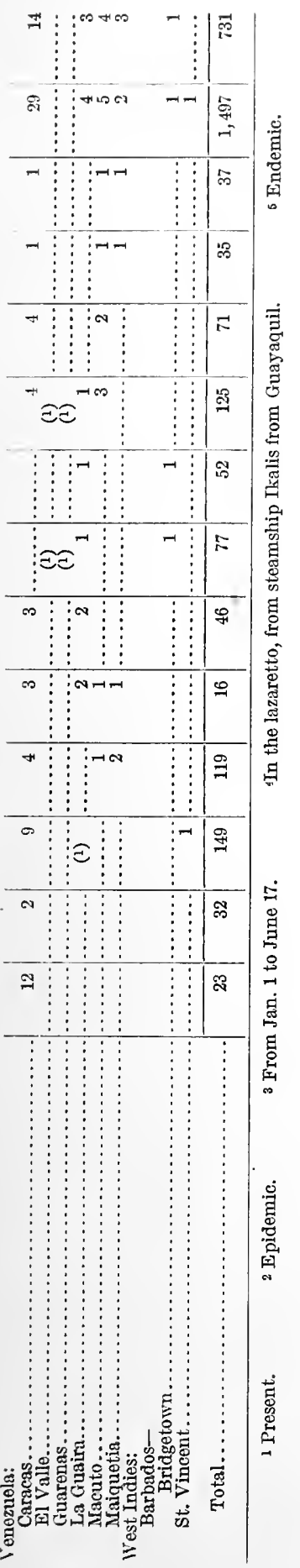




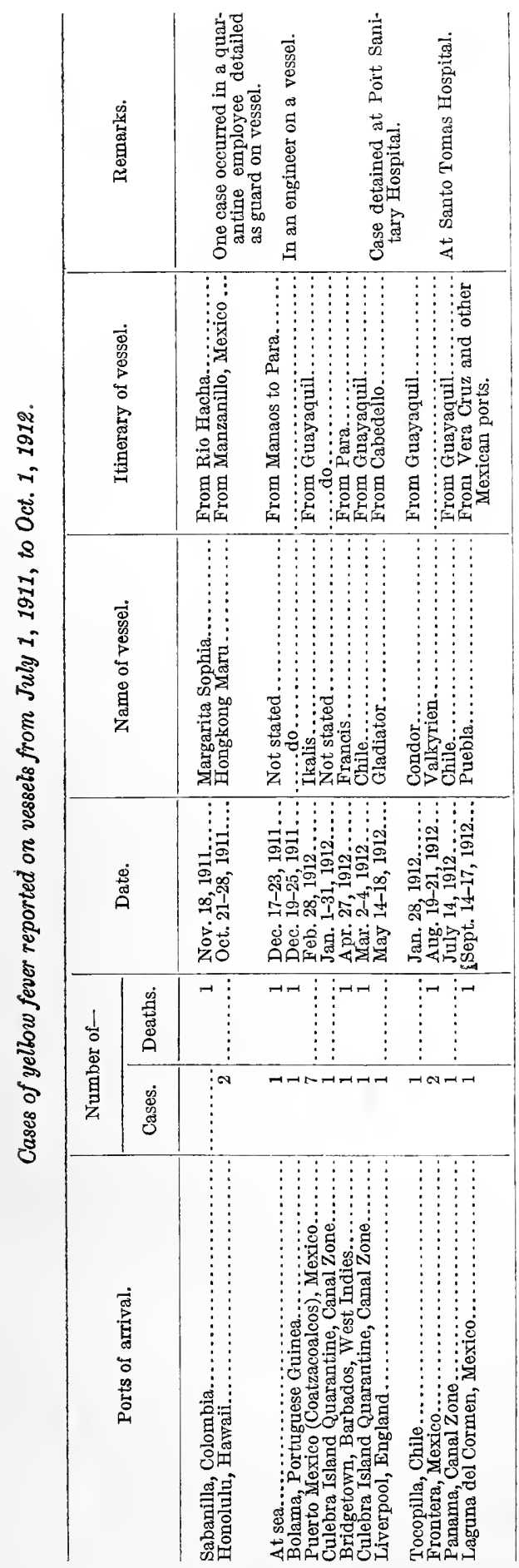




\section{MARINE HOSPITALS AND RELIEF.}

\section{Relief Stations.}

During the year the service operated 23 marine hospitals, all of which are owned by the Government, and maintained 125 other relief stations where hospital and dispensary relief were furnished. The service made arrangements to reimburse the War Department for the care of sick and disabled seamen at the Ancon and Colon hospitals, located at Ancon and Cristobal, Panama Canal Zone. Owing to the small amount of relief furnished, the third-class relief station at Dubuque, Iowa, was closed during the year.

\section{Relief to Seamen.}

$\mathrm{D}$ ing the fiscal year 51,078 seamen were treated in the various mar e hospitals and relief stations of the service. Of this number 14,717 were treated in hospitals a total of 440,050 days, and 36,361 were treated at the dispensaries a total of 62,711 times.

During the year 479 seamen engaged on foreign vessels received hospital care and treatment a total of 6,141 days.

The medical officers of the service made 10,264 physical examinations during the year. These examinations include those made of applicants for original or renewal of license as master, mate, or pilot; applicants desiring to enter into, and those already engaged in, the various branches of the Government service; examinations made of American seamen, foreign seamen, and persons contemplating service in the Philippine Islands.

\section{Relief to Natives of Alaska.}

The medical officers of the service detailed for duty on board the the different vessels of the United States Revenue-Cutter Service cruising in northern waters furnished a great amount of medical and surgical relief to the natives inhabiting both the mainland and the neighboring islands of Alaska. The general health of these people is very poor, due, to a great extent, to the insanitary conditions under which they live. Tuberculosis is the cause of the greater number of deaths, the disease being almost a scourge to the natives of these northern regions.

\section{Am to Different Branches' of the Government Service.}

Revenue-Cutter Service.-Twelve hundred and thirty-two men were examined physically, of whom 182 were rejected.

Steamboat-Inspection Service.-Five thousand four hundred and eighty-nine pilots were examined as to visual capacity, of which number 224 were rejected.

Life-Saving Service.-Two thousand keepers and surfmen were physically examined, of which number 73 were rejected. 
Four hundred and thirty-five disability certificates referred to this bureau by the General Superintendent of the Life-Saving Service were passed upon. These call for the expression of opinion on the medical evidence of disability submitted in claims for benefits under the act of Congress approved March 4, 1882; upon the physical fitness of keepers and surfmen for enlistment, reenlistment, promotion, and retention, and upon evidences of death submitted by widows or orphans in their claims for benefits.

The services of 17 acting assistant surgeons were continued during the year for the physical examinations of keepers and surfmen at points not easily accessible to regular officers at stations of the service. In addition, three medical officers were detailed during July, 1912 , at the request of the general superintendent, to various points along the Atlantic coast to examine candidates for reenlistment.

Coast and Geodetic Survey.-One hundred and twelve employees and applicants for appointment were examined, of which number 11 were rejected.

Lighthouse Service.-Eighty-four applicants for enlistment were examined, of which number seven were rejected.

Immigration Service.-Three hundred and thirty-five persons connected with the Immigration Service were physically examined; of this number, seven were rejected.

Civil Service Commission.-One hundred and sixty-eight applicants for appointment were physically examined; of this number, two were rejected.

Isthmian Canal Commission.-Two employees and applicants for appointment were physically examined. None were rejected.

\section{Physical Examination of Merchant Seamen.}

Physical examinations were made of 782 American merchant seamen, of whom 43 were rejected, and 15 foreign seamen, of whom 7 were rejected.

\section{Physical Examinations, Philippine Islands.}

Physical examinations were made of 45 applicants in the United States to serve in the islands, of which number two were rejected.

\section{Purvering Depot.}

The following statistics show the transactions of the purveying depot during the fiscal year:

SUPPLIES PURCHASED.

Drugs and chemicals. $\$ 15,020.71$

Surgical instruments and appliances................................... $11,057.96$

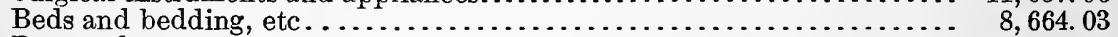

Dry goods............................................ $5,860.64$

Pharmacal implements, etc........................................ $4,103.53$

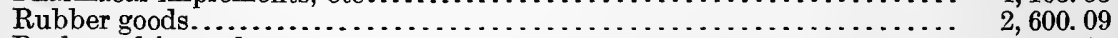

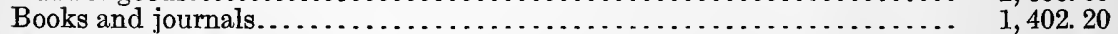

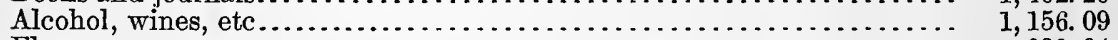

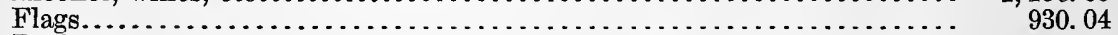

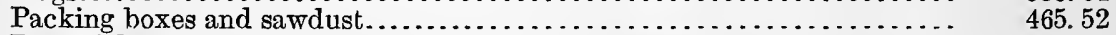

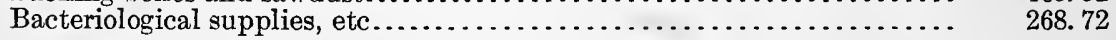

Total 
By bills paid direct from funds:

Quarantine service......................\$1, 272. 77

Maintenance.............................. 4... 430. 96

Care of seamen............................... 424.49

Bureau.................................... 408.30

Epidemic fund............................. 93.92

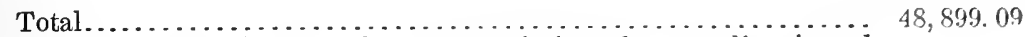

By amounts reimbursed from other sppropriations for supplies issued from stock:

Quarantine service...................... \$3, 826.77

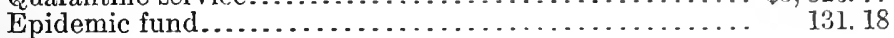

Net expenditures chargeable to appropriations for purveying depot (in amount $\$ 45,000) \ldots \ldots \ldots \ldots \ldots \ldots \ldots \ldots . . . \ldots \ldots$

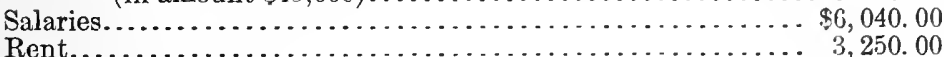

$44,941.14$

Operating expenses.

292. 69

Total net expenditures

Number of requisitions filled.

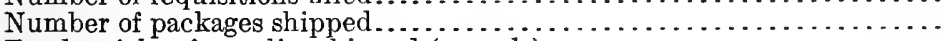

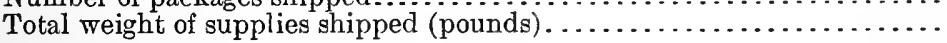

\section{Tuberculosis Sanatorium at Fort Stanton, N. Mex.}

Passed Asst. Surg. F. C. Smith, in charge, reports as follows regarding the transactions of the sanatorium for the fiscal year ended June 30, 1912:

\section{General information.}

Number of patients on hand July $1,1911 \ldots \ldots \ldots \ldots \ldots \ldots \ldots \ldots \ldots \ldots \ldots$

Number of patients admitted during the year $\ldots \ldots \ldots \ldots \ldots \ldots \ldots \ldots \ldots \ldots \ldots \ldots \ldots . \ldots \ldots$

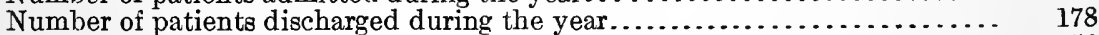

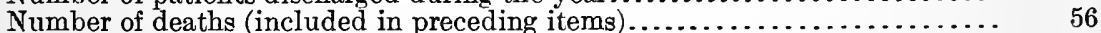

Number of patients on hand June $30,1912 \ldots \ldots \ldots \ldots \ldots \ldots \ldots \ldots \ldots \ldots \ldots \ldots \ldots \ldots$

Maximum number of patients during year . . . . . . . . . . . . . . . . . . . . . 220

Minimum number of patients during year. . . . . . . . . . . . . . . . . . . . .

Total number of patients treated during the year......................... 354

Total number of days treatment furnished patients. . . . . . . . . . . . . . 71,905

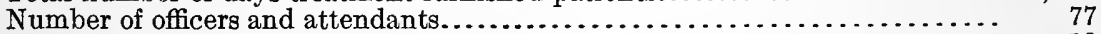

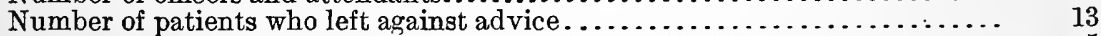

Number of patients discharged for causes affecting discipline..............

Number of patients transferred to other stations:

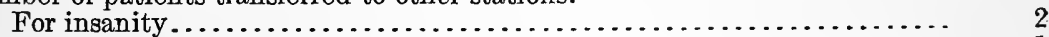

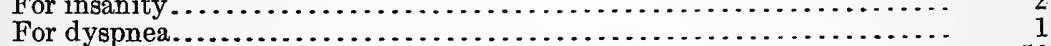

Number of bodies interred in sanatorium cemetery $\ldots \ldots \ldots \ldots \ldots \ldots \ldots \ldots \ldots \ldots$

Ages of patients treated during the year:

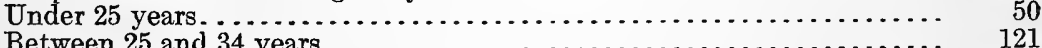

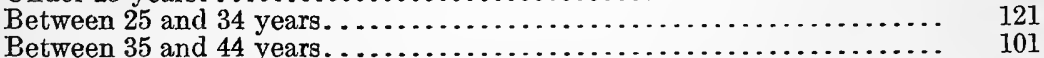

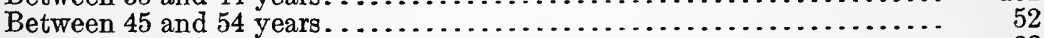

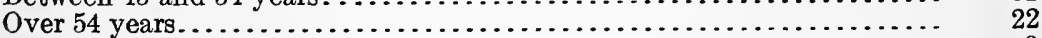

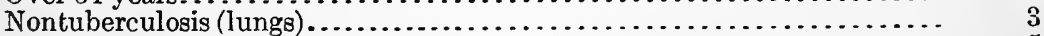

Cases admitted, discharged, and readmitted .................... 5

Total........................................... 354 
Heredity in patients treated during the year:

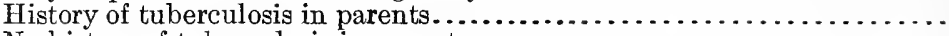

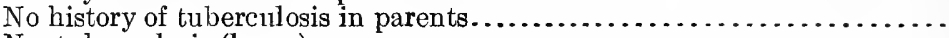

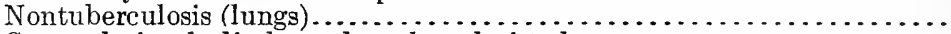

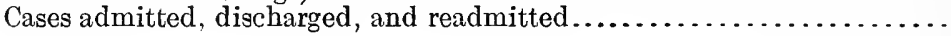

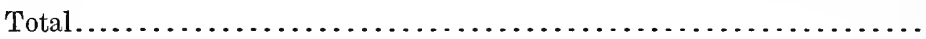

Tubercle bacilli in sputum:

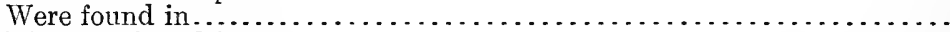

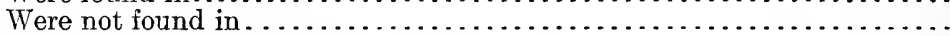

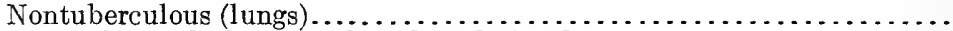

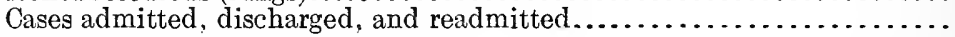

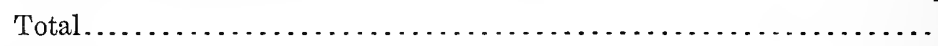

Prognosis on arrival:

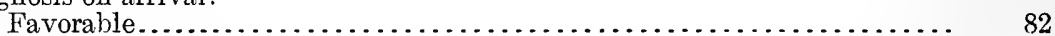

Favorable for arrest....................................... 21

Favorable for prolongation of life by living under favorable conditions... 20

Unfavorable......................................... 40

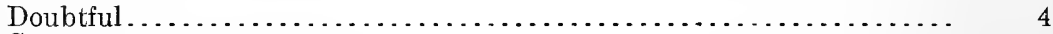

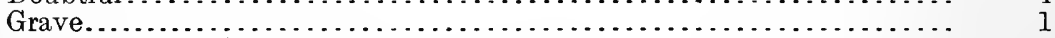

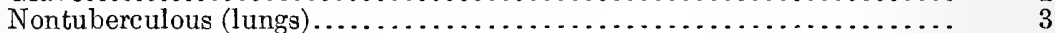

Cases admitted, discharged, and readmitted........................ 5

Total.......................................... 176

Record of pulmonary hemorrhage of patients admitted:

Before arrival only $. . \ldots \ldots \ldots \ldots \ldots \ldots \ldots \ldots \ldots \ldots \ldots \ldots \ldots \ldots \ldots \ldots, 42$

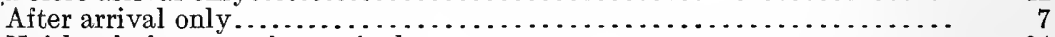

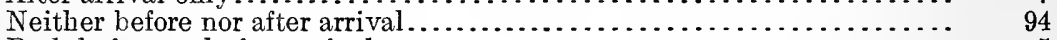

Both before and after arrival.................................... 5

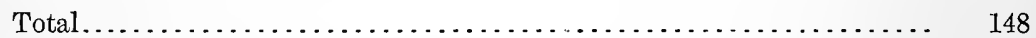

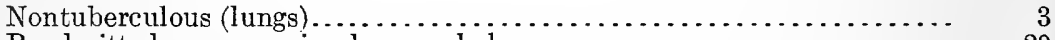

Readmitted cases previously recorded $\ldots \ldots \ldots \ldots \ldots \ldots \ldots \ldots \ldots \ldots \ldots, 20$

Cases admitted, discharged, and readmitted ( 1 hemorrhage before original admission, 4 hemorrhages neither before nor after)................

Total ........................................... 176

Patients discharged during the year, with stage of disease and result of treatment.

\begin{tabular}{|c|c|c|c|c|c|c|}
\hline & $\begin{array}{l}\text { Ap- } \\
\text { peared } \\
\text { cured. }\end{array}$ & $\begin{array}{l}\text { Ar- } \\
\text { rested. }\end{array}$ & Im- & $\begin{array}{l}\text { Unim- } \\
\text { proved. }\end{array}$ & Died. & Total. \\
\hline 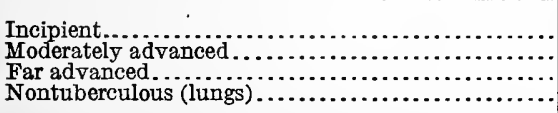 & $\begin{array}{r}10 \\
7 \\
3\end{array}$ & $\begin{array}{r}99 \\
114 \\
34\end{array}$ & $\begin{array}{r}12 \\
10 \\
113\end{array}$ & $\begin{array}{r}12 \\
2 \\
11\end{array}$ & $\begin{array}{r}8 \\
247 \\
\cdots\end{array}$ & $\begin{array}{r}23 \\
41 \\
108 \\
2\end{array}$ \\
\hline \multicolumn{6}{|c|}{ 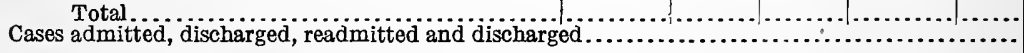 } & $\begin{array}{r}174 \\
4\end{array}$ \\
\hline Grand total............. & & & & & & 178 \\
\hline
\end{tabular}

11 under treatment less than 30 days.

2 under treatment less than 30 days. 
Patients discharged during the year, with stage of disease and result of treatment-Contd. DURATION OF STAY AND CHARACTER OF CASES DISCHARGED.

\begin{tabular}{|c|c|c|c|c|c|c|c|c|c|c|}
\hline \multirow[b]{2}{*}{ Character of cases. } & \multicolumn{3}{|c|}{ Longest stay. } & \multicolumn{3}{|c|}{ Shortest stay. } & \multicolumn{3}{|c|}{ Average stay. } & \multirow[b]{2}{*}{ Totai. } \\
\hline & $\stackrel{\dot{m}}{\tilde{\Xi}}$ & 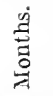 & $\stackrel{\dot{\theta}}{\vec{\omega}}$ & 总 & 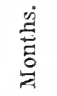 & $\begin{array}{c}\dot{n} \\
\stackrel{5}{5} \\
\stackrel{5}{0}\end{array}$ & 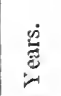 & 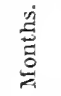 & $\stackrel{\dot{n}}{\vec{n}}$ & \\
\hline 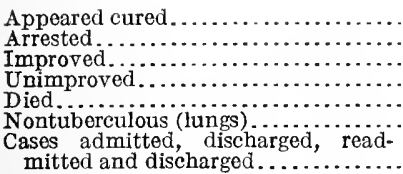 & $\begin{array}{l}1 \\
3 \\
2 \\
2 \\
7\end{array}$ & $\begin{array}{r}10 \\
2 \\
9 \\
8 \\
11\end{array}$ & $\begin{array}{r}3 \\
14 \\
18 \\
6 \\
1\end{array}$ & … & $\begin{array}{r}4 \\
2 \\
2 \\
\cdots \cdots \\
\cdots \\
\ldots\end{array}$ & $\begin{array}{r}8 \\
17 \\
26 \\
11 \\
1\end{array}$ & {$\left[\begin{array}{c}\cdots \\
1 \\
\cdots \cdots \\
\cdots \\
\cdots \\
\end{array}\right.$} & $\begin{array}{r}11 \\
9 \\
10 \\
7\end{array}$ & $\begin{array}{r}7 \\
20 \\
4 \\
2 \\
29\end{array}$ & $\begin{array}{r}20 \\
57 \\
25 \\
15 \\
5.5 \\
2 \\
4\end{array}$ \\
\hline Total.. & & & & & & & & & & 178 \\
\hline
\end{tabular}

Length of time under treatment at sanatorium of 178 discharged cases:

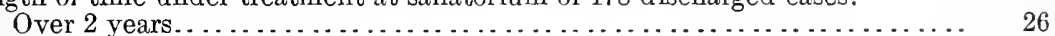

Between 1 and 2 years........................................... 42

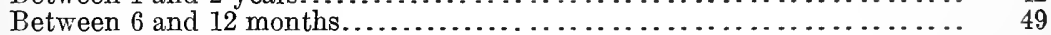

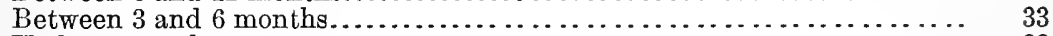

Under 3 months................................................ 22

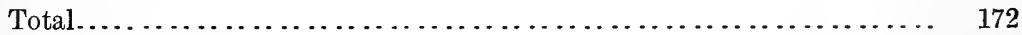

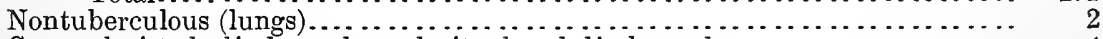

Cases admitted, discharged, readmitted and discharged .................. 4

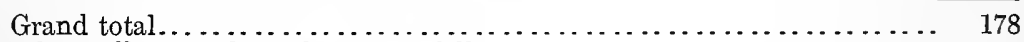

Tuberculous officers and employees, as follows:
Under treatment July $1,1911 \ldots \ldots \ldots \ldots \ldots \ldots \ldots \ldots \ldots \ldots \ldots \ldots \ldots \ldots \ldots \ldots \ldots \ldots \ldots \ldots \ldots \ldots \ldots \ldots$

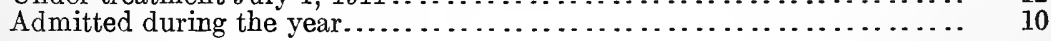

Total.............................................. 22

Remaining under treatment June $30,1912 \ldots \ldots \ldots \ldots \ldots \ldots \ldots \ldots \ldots . . \ldots 13$

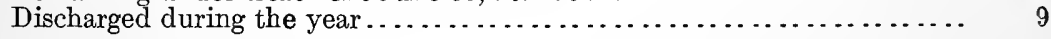

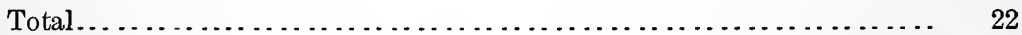

Condition of tuberculous officers and employees at time of discharge:

Apparently cured........................................... 2

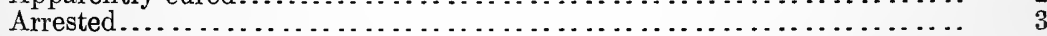

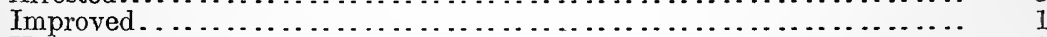

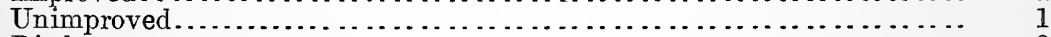

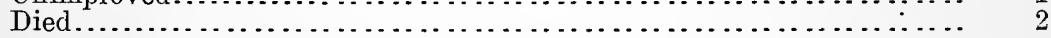

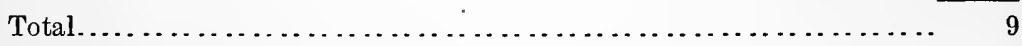

Number of physical examinations made during the year. .............

Number of autopsies performed. .............................. ${ }_{24}$

The routine work in the laboratory during the fiscal year included the following:

Examination of sputum for tubercle bacilli.

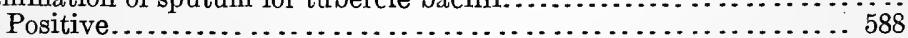

Negative................................................. 740

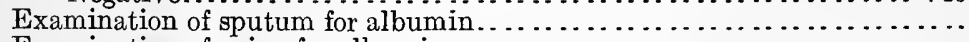

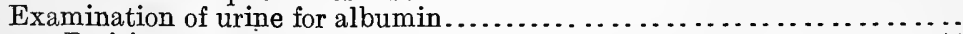

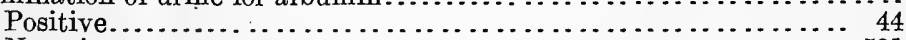

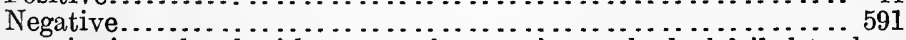

Guinea pigs inoculated with sputum from patients who had failed to show

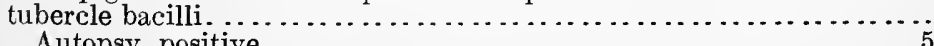

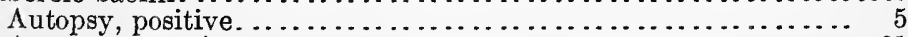

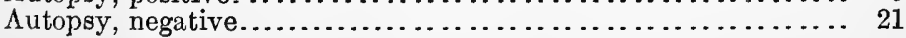


An expert farmer, a dietitian, and two trained female nurses have been added to the station force during the year. The farmer was placed in charge of the farm, rlairy, and mechanics' forces and has relieved the medical officer in command of many petty details of administration. The dietitian was placed in charge of the dining rooms and kitchens, and by her assistance the pharmacist in charge of this department was able to make more careful supervision of the cuisine in all the minute details essential to its complete success. A more varied diet was possible, waste of material prevented, and some studies of food in reference to the total consumption by different classes of patients and its prognostic importance were made.

The two trained female nurses, authorized by the bureau during the year, have rastly increased the efficiency of the clinical work at the infirmary. They are on duty from $6 \mathrm{a}$. m. to $6 \mathrm{p}$. m., with two hours recreation at different times in the afternoon. Male nurses are still retained for duty in the tent village and for night duty in the infirmary.

The dentist, authorized by the bureau in September, remained until June and has rendered valuable assistance in the treatment of patients. Eight hundred and fifty-two operations, including 272 fillings, were performed by him without expense to patients or this service. It is believed that if some compensation could be allowed this official it might be possible to keep the position permanently filled.

In accordance with prevailing medical ideas regarding the treatment of the tuberculous, increased attention has been given to graduated exercise in convalescent cases, especially in those approaching fitness for discharge. One hundred and eighteen patients have been furnished with an average employment of 71 days on the station force with remuneration. All these had qualified for their position by work in exercise squads under medical advice.

\section{CHARACTER OF CASES RECEIVED.}

The cases received during the year contained a larger percentage of favorable ones than ever before. Out of the 176 admitted, favorable prognoses on first examination were made in 123. Only two deaths occurred within 30 days after arrival, and each patient had apparently been earnestly instructed as to the chronic nature of his trouble and the long duration of sanatorium residence probably required for the arrest of his disease. Of the incipient cases admitted, the focus of disease could not be located by the examining physician at this point in 10 instances, and 6 of these were classified here as nonclinical cases of tuberculosis.

\section{ULTIMATE RESULTS.}

During the year effort was made to trace discharged cases without great success, owing to the difficulty in locating them. Only 326 were traced, of which 91 were living and in good health, 63 of these having been absent more than two years; 215 were dead, a large number of these having died soon after leaving the institution.

\section{WATER SUPPLY.}

The diversion of the water from the Rio Bonito above us by the El Paso \& Southwestern Railroad Co. has been continued at the rate of from 7.264 to 8.39 cubic feet per second during the entire year, or whenever that amount of water was available for their purpose. Although the season was an unusually wet one, the river was dry at this station from August 7, 1911, to March 21, 1912, except occasionally after local showers, and very little water was available for irrigation purposes. It has been necessary to recommend extensive expenditures on pumps and wells to provided an adequate supply of water for domestic purposes.

FARM.

At the present writing the range herd contains approximately 2,131 head, including 503 calves branded this spring. The dairy herd contains 148 head, making a total of 2,279 horned cattle. The number of horses is 84, including colts of all ages. Seventeen blooded bulls have been added to the range herd at a cost of $\$ 2,200$, and 3 miles of fencelwere built to divide the range so that these animals can be used for six years instead of three as heretofore. 
Products of farm, dairy and garden:

Beef

Veal

81,217 pounds.

Pork......................................... 626 pounds.

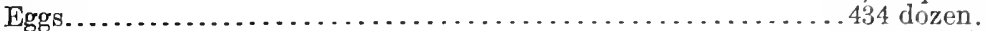

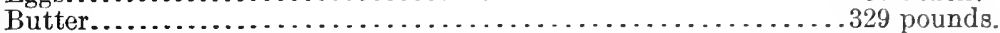

Milk......................................... 40,307 gallons.

Garden produce .....................................

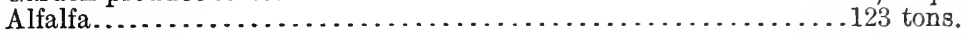

Corn ensilage............................................

Hides sold......................................... $\$ 951.77$.

Excess Jersey calves sold............................\$51 .25..

Amount of labor loaned sanatorium, 1,571 man days.

Expenditures.

\begin{tabular}{|c|c|c|}
\hline . & $\begin{array}{c}\text { Per } \\
\text { annum. }\end{array}$ & $\begin{array}{l}\text { Per day } \\
\text { per } \\
\text { patient. }\end{array}$ \\
\hline \multirow{2}{*}{\multicolumn{3}{|c|}{$\begin{array}{l}\text { Salaries: } \\
\text { Medical care and executive, inciuding all medical officers and pharmacists.... }\end{array}$}} \\
\hline & $\S 8,149.99$ & 80.1133 \\
\hline 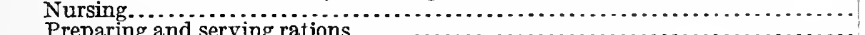 & $2,728.99$ & .0379 \\
\hline 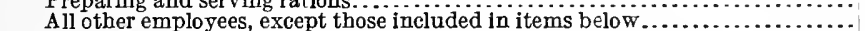 & $14,964.30$ & .2081 \\
\hline Milk, cost of production, including pay of four dairy men, etc................... & $7,351.18$ & .1022 \\
\hline Beef, cost of production, including pay of stock men, fencing, feed, etc...... & $3,775.15$ & .0525 \\
\hline Pork, eggs, poultry, and garden produce, including pay, seeds, ete ........... & $1,589.75$ & .0221 \\
\hline Subsistence supplies purchased for 71,905 rations furnished patients........ & $26,137.47$ & .3635 \\
\hline Subsistence supplies furnished for 19,416 rations furnished employees...................... & $7,057.72$ & .0981 \\
\hline Fuel, light, and power, including refrigeration, etc., and pay $\ldots \ldots \ldots \ldots \ldots \ldots \ldots \ldots$ & $16,138.06$ & .2244 \\
\hline 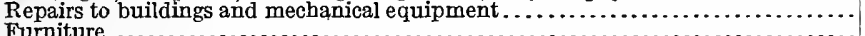 & $7,629.49$ & .1062 \\
\hline 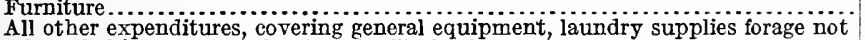 & & \\
\hline 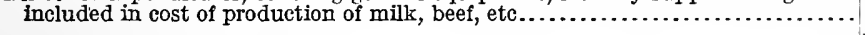 & $12,735.60$ & .1770 \\
\hline \multirow{3}{*}{ 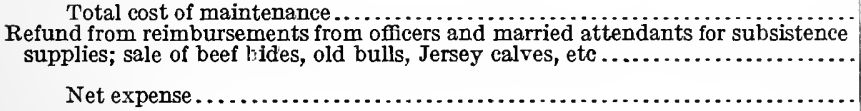 } & $115,900.29$ & 1. 6114 \\
\hline & $4,028.48$ & .0560 \\
\hline & $111,871.81$ & 1.5554 \\
\hline
\end{tabular}

The cost of maintenance as given in the above table is not greater than that in similar institutions in this part of the country, and only five of the United States marine hospitals have a lower average cost of maintenance than Fort Stanton for the eight years ending June 30, 1912. 


\section{PERSONNEL.}

\section{COMMISSIONED AND OTHER OfFICERs.}

The commissioned medical officers at the beginning of the fiscal year, July 1, 1911, numbered 135, as follows: The Surgeon General, 6 assistant surgeons general, 36 surgeons, 67 passed assistant surgeons, and 25 assistant surgeons.

At the close of the fiscal year, June 30,1912, the total number was 138 , consisting of the Surgeon General, 6 assistant surgeons general, 36 surgeons, 71 passed assistant surgeons, and 24 assistant surgeons.

The changes during the year were as follows: 'Two passed assistant surgeons were promoted to the grade of surgeon, 6 assistant surgeons were promoted to the grade of passed assistant surgeon, and 6 candidates who passed the examination required by the regulations were commissioned as assistant surgeons. On account of physical disability 2 surgeons and 1 passed assistant surgeon continued on "waiting orders." Surg. Gen. Walter Wyman died at Washington, D. C., November 21, 1911; Surg. Eugene Wasdin died at Philadelphia, Pa., November 17, 1911; and Passed Asst. Surg. Thomas D. Berry died at Austin, Tex., December 18, 1911.

Assignments.-Among other assignments of commissioned medical officers during the fiscal year were the following: Twenty-six were assigned to exclusive immigration duty, their services being supplemented by employment of acting assistant surgeons; 6 to the quarantine service of the Philippine Islands; 13 to vessels of the RevenueCutter Service; 19 to the quarantine stations in the continental United States, Porto Rico, and the Hawaiian Islands; 6 to duty in foreign countries to prevent the introduction of epidemic diseases into the United States.

Special details.-Two commissioned medical officers continued on detail duty with the Isthmian Canal Commission. Passed Asst. Surg. V. G. Heiser, in addition to his duties as chief quarantine officer, has been continued as director of health of the Philippine Islands, and Passed Asst. Surg. Carroll Fox has been continued as assistant director of health. Passed Asst. Surg. D. E. Robinson has been assigned for duty at Naples, Italy, under the act of Congress approved February 15, 1893. Upon the request of the Commissioner of Education, Department of the Interior, Passed Asst. Surg. Emil Krulish has been detailed for duty in Alaska for the promotion of the sanitary welfare of the natives.

Personnel, Hygienic Laboratory.--At the close of the fiscal year there were on duty in the Hygienic Laboratory, in addition to the director and assistant director, 3 chiefs of divisions, 8 passed assistant surgeons, 3 assistant surgeons, 2 pharmacists, 1 artist, 8 technical assistants, and 29 attendants.

Quarantine inspector.-One quarantine inspector served throughout the entire year. 
Acting assistant surgeons. - The serviees of 42 acting assistant surgeons have been discontinued during the fiseal year, 2 have died, and 23 have been appointed, leaving on duty at the end of the fiscal year 227 such officers.

Medical inspectors. - Two female inspectors served during the entire year for the inspeetion of women passengers-1 at Honolulu, Liawaii, and 1 at San Francisco quarantine station.

Internes.-At the beginning of the fiscal year there were 12 internes on duty at the various marine-hospital stations; 25 were appointed and 21 were separated from the service by reason of resignation, leaving 16 on duty at the elose of the fiscal year.

Pharmacists. - At the beginning of the fiseal year there were on duty 47 pharmacists, divided as follows: Pharmacists of the first class, 16 ; second class, 23 ; third elass, 8 . One pharmacist of the first class, 2 of the second class, and 1 of the third class resigned; 2 pharmacists of the third class were appointed, 1 pharmacist of the third class was reinstated, and 1 pharmacist of the second class was promoted, leaving at the close of the fiseal year 46 pharmacists on duty, as follows: Pharmacists of the first elass, 16; seeond elass, 21; third class, 9 .

Pilots and marine engineers.-At the beginning of the fiscal year there were on duty 15 pilots and 20 engineers; 2 pilots resigned and 3 were appointed; 4 marine engineers resigned and 5 were appointed. The number on duty at the close of the fiscal year were as follows: Pilots, 16; marine engineers, 21.

\section{Hospital and Quarantine Attendants.}

At the beginning of the fiscal year 1,009 attendants were employed at the various marine hospitals, quarantine stations, and on epidemie duty, including 72 such employees on duty in the Philippine Islands, and at the close of the fiscal year there were so employed as follows:

\begin{tabular}{|c|c|c|c|c|}
\hline Branch of service in which employed. & $\begin{array}{l}\text { In service } \\
\text { July } 1 \text {, } \\
\text { 1911. }\end{array}$ & $\begin{array}{l}\text { Appointed } \\
\text { during } \\
\text { year. }\end{array}$ & $\begin{array}{l}\text { Separated } \\
\text { from serv- } \\
\text { ice. }\end{array}$ & $\begin{array}{l}\text { In service } \\
\text { June } 30 \\
\text { 1912. }\end{array}$ \\
\hline 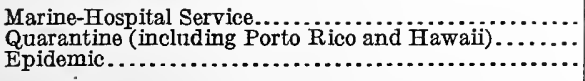 & $\begin{array}{l}494 \\
315 \\
200\end{array}$ & $\begin{array}{l}684 \\
256 \\
172\end{array}$ & $\begin{array}{l}657 \\
249 \\
247\end{array}$ & $\begin{array}{l}521 \\
322 \\
125\end{array}$ \\
\hline 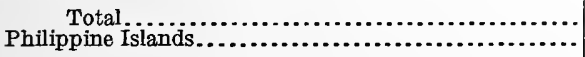 & $\begin{array}{r}1,009 \\
72\end{array}$ & $\begin{array}{r}1,112 \\
30\end{array}$ & $\begin{array}{r}1,153 \\
30\end{array}$ & $\begin{array}{r}968 \\
72\end{array}$ \\
\hline
\end{tabular}

RECAPITULATION.

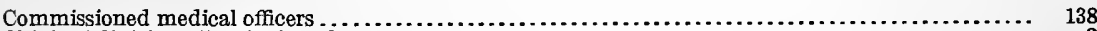

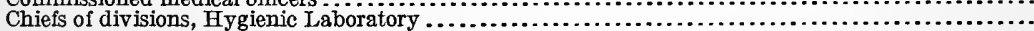

Artist.

Technical assistants

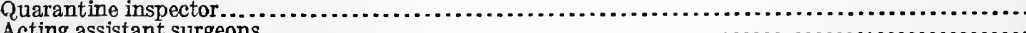

Acting assistant surgeons.

Medical inspectors. . . . . . .

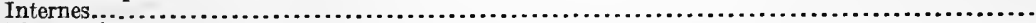

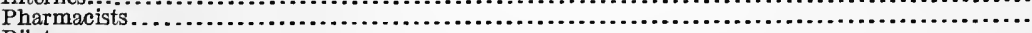

Pilots..

Marine Eugineers

Expert farmer

Trained nurses.

Attendants

Laborers. 


\section{Bonrds Convened.}

Twenty-two boards were convened at different times and at various stations throughout the United States for the physical examination of officers of the Revenue-Cutter Service and applicants for entrance therein; three for the examination of passed assistant and assistant surgeons to determine their fitness for promotion to the next higher grades of the service; five for the physical examination of detained aliens; two for the examination of pharmacists, to determine their fitness for promotion to a higher grade; one for examination of applicants for entrance as assistant surgeons, and two for the physical examination of commissioned officers of the service.

The bureau sanitary board has been convened in 11 sessions to pass upon reports of inspections of establishments engaged in the manufacture of vaccines, serums, toxins, etc., prior to recommending a license, and to pass upon advertised remedies and appliances to determine if said advertisements should be excluded from the mails. 


\section{PUBLICATIONS.}

As in previous years, the bureau has been unable to meet the request made on it for its publications. There is an increasing demand for literature dealing with public health and matters of sanitary importance, and the general public, as well as physicians, are showing a greater interest along these lines.

Three hundred and eighty-one thousand seven hundred and seventy-two copies of the various reports and bulletins were distributed during the year. While this shows an increase of about 65,000 copies over last year, there is still a great need of more ample provisions for printing larger editions. It is estimated that not over onehalf of the requests could be complied with on account of the small size of the editions.

Several important bulletins have been printed as public documents in comparatively large editions to meet certain demands in special sections of the country. This measure was necessary because of the limited funds available for printing for this bureau.

\section{Special Articles.}

Many articles by service officers have appeared during the year in the various medical and scientific journals. Others bearing also on public health and sanitary matters have been published in the weekly Public Health Reports, and the following is a list of these articles:

Cholera in the United States. July 7, 14, 1911.

Additional Measures against Importation of Cholera. July 14, 1911.

Establishments Licensed for the Propagation and Sale of Viruses, Serums, Toxins, and Analogous Products. July 21, 1911.

Cholera-Infected Vessels Arriving at New York. July 21, 1911.

Importance of Cholera-Bacillus Carrlers. July 21, 1911.

Typhus Fever in El Paso, Tex. July 21, 1911.

Rat Plague in London. July 21, 1911.

The Cholera Situation. New York. July 28, 1911.

Antirabic Treatments. Inoculations at the Hygienic Laboratory. July 28, 1911.

Leprosy in New Jersey. July 28, 1911.

Circular to Quarantine Officers, the Commissioner of Customs, Shipowners, Agents, and Others Concerned. August 4, 1911.

Leprosy in Massachusetts. August 4, 1911.

Examination of Cholera-Bacillus Carriers. Boston, Mass. August 11, 1911.

The Cholera Situation. New York. August 18, 1911.

The Cholera Situation. New York. August 25, 1911.

The Presence of Entamoeba Histolytica and E. Coli in North Carolina. Ch. Wardell Stiles. August 25, 1911.

A Health Movement Inaugurated Among the Negro Population of Wilmington, N. C. August 25, 1911 .

The Cholera Situation. New York. September 1, 1911.

The Cholera Situation. New York. September 8, 1911.

The Presence of Lamblia Duodenalis in Man in North Carolina and the Recognition of Amebae in Feces Several Days Old. Ch. Wardell Stiles. September 8, 1911. The Cholera Situation. Boston. September 15, 1911.

Pellagra: An Investigation of a Local Outbreak in Kentucky. R. M. Grimm. September 22, 1911.

The Cholera Situation. September 29, 1911.

The Cholera Situation. October 6, 1911.

The Cholera Situation. October 13, 1911. 
Observations on the Viability of the Eggs of Hookworms (Necator americanus) and of Eelworms (ascaris lumbricoides) In Feces Allowed to Decompose in Water. Ch. Wardell Stiles. October 13, 1911.

Vessels Arriving at Quarantine. New York. October 20, 1911.

Notification of Poliomyelitis. October 20, 1911.

The Cholera Situation. New York. Vessels arriving at Quarantine. October 27, 1911.

The Cholera Situation. November 3, 1911.

The Cholera Situation. November 10, 1911.

Case of Leprosy at St. Louis, Mo.

The Cholera Situation. November 17, 1911.

An Investigation of the Prevalence of Typhoid Ferer at Charlestown, W. Va. J.

R. Ridlon. November 17, 1911.

The Cholera Situation. November 24, 1911.

Pellagra. November 24, 1911.

Second Annual Conference of California State, County, and City Health Officials.

November 24, 1911.

The Cholera Situation. December 1, 1911.

Administration of Thymol in Hookworm Disease. Ch. Wardell Stiles. December

8, 1911.

The Cholera Situation.

Pellagra as Observed in Barbados. P. G. Smith. December 15, 1911.

\section{Reprints from the Public Health Reports.}

Twenty-two special articles which were printed in the Public Health Reports have been reprinted. In order to make available to health authorities throughout the United States ordinances relating to public health, city and municipal, have been printed in full or abstract in the Public Health Reports. These have been compiled and classified and printed as Reprint No. 70. This reprint will be of particular value to health officials in formulating new laws and ordinances, by showing how similar conditions have been met elsewhere. Many letters of appreciation have been received and further bulletins will be printed with a view to completing the more important ordinances bearing upon the public health.

The following is a list of the Reprints that were published during the year:

62. Experimental Measles in the Monkey: A Supplemental Note. By John F. Anderson and Joseph Goldberger.

63. Smallpox in the United States-Prevalence and Geographic Distribution during the Calendar Year 1910. By John W. Trask.

64. Data Regarding Operations of Infants' Milk Depots in the United States in 1910. By J. W. Kerr.

65. The Salient Epidemiological Features of Pellagra. By C. H. Lavinder.

66. Antityphoid Vaccination. Extracts from the Report of the Commission Appointed by the Academy of Medicine of Paris. Translation by Joseph W. Schereschewsky.

67. Origin and Prevalence of Typhoid Fever in Fort Smith, Ark., and Measures Necessary for its Control. By W. H. Frost.

68. The Tarbagan (Arctomys bobac) and Plague. By Paul Preble.

69. Epidemic Cerebrospinal Meningitis. A Review of its Etiology, Transmission, and Specific Therapy, with Reference to Public Measures for its Control. , By W. H. Frost.

70. Municipal Ordinances, Rules, and Regulations pertaining to Public Hygiene. Adopted from January 1, 1910. to June 30, 1911, by Cities of the United States Having a Population of over 25,000 in 1910. Prepared by direction of the Surgeon General.

71. The Relation of So-called Brill's Disease to Typhus Fever. An Experimental Demonstration of their Identity. By John F. Anderson and Joseph Goldberger.

72. Vegetables as a Possible Factor in the Dissemination of Typhoid Fever. By R. H. Creel.

73. Typhus Fever in the United States. Differential Diagnosis from Typhoid Fever. 
74. The Transmission of Typhus Fever. with Esperia] Reference to Transuission l,g the Head Touse (Pediculosis capitis), by Joseph fividherger and J. F. Anderson.

75. The Pacteriological Diagnosis of Cholera. 1 Report Presented to the Permanens Committee of the International Office of Public Hygiene in the Name of a Commission Composed of Messrs. Ruffer. President; Calmette, Gaffky, Gerldings, Murillo, Praum, and Pottevin, reporter. Translated from the French by Surg. H. D. Geddings, American Delegate on the Permanert Committee.

76. The Necessity for Safe Water Supplies in the Control of Typhoid Fever. Iy $\Lambda . J$. Mclaughlin.

77. Sewage-Polluted Water Supplies in Relation to Infaut Mortality. By Allan J. Mclaughlin.

78. Report of the Commission on Milk Stanrlards $\Lambda$ ppointed by the New York Mill Committee.

79. Investigation of and Tick Eradication in Porky Mountain Spotted Fever. By Thomas B. McClintic.

80. Examination of Excreta for Typhoid Barilli. By I. L. Lumsden and $\boldsymbol{A}$. M. Stimson.

81. Sanitary Advice for Summer Tourists. Sanitary Advice for the Keepers of Summer Resorts. By W. C. Rucker.

82. Studies on the Virus of Typhus. By John F. Anderson and Joseph Goldberger.

83. Resolutions Adopted by the Tenth Annual Conference of State and Territorial Health Authorities with the Public Health and Marine-Hospital Service, Washington. June 1, 1912. A List of the State and Insular Health Authorities of the United States.

\section{Public Health Bulletins.}

No. 46. Transactions of the Ninth Annual Conference of State and Territorial Health Officers with the Public Health and Marine-Hospital Service, San Francisco, Cal., June 24, 1911.

This publication is an exact transcript of the proceedings of the annual conference held, according to law, by State health authorities with the service. The following subjects were discussed at the conference: Transportation of the dead; collection of morbidity reports; control of poliomyelitis; railway sanitation; and antiplague measures on the Pacific coast.

No. 47. Studies upon Leprosy. XIV. The Artificial Cultivation of the Bacillus of Leprosy. XV. Attempts at Specific Therapy in Leprosy. By D. H. Currie, M. $\mathbf{T}$. Clegg, and H. T. Hollmann.

The results of new investigations made at the leprosy investigation station are presented in these two papers.

The fourteenth paper reviews previous attempts by other investigators to grow the B. lepræx, and describes the success of the authors in finally cultivating and isolating an acid-fast bacillus morphologically similar to the leprosy bacillus in tissue from the tissues and organs of lepers.

The fifteenth paper reviews the existing literature relative to the therapy of leprosy, and presents the results obtained by the authors through the therapeutic use of various substances prepared directly or indirectly from the cultures of $B$. lepræ obtained by them.

No. 48. Pellagra. A precis. By C. H. Lavinder.

This bulletin is a revised edition of a previous publication of the service, Public Health Bulletin No. 23, the supply of which had been exhausted. The new publication contains much new material, and summarizes the knowledge acquired in the last few years relative to pellagra.

This bulletin has been in great demand and a second edition has been printed. It has also been published as House Document No. 583 in an edition of 16,000 copies. 
No. 49. Ophthalmia neonatorum. An Analysis of the Laws and Regulations relating thereto in Force in the United States. By J. W. Kerr.

The legal provisions existing in the United States for the prevention of ophthalmia neonatorum (infant blindness) are analyzed in this bulletin, and references made to action taken in foreign countries for the same purpose. The text of the laws themselves follows the analysis and historical introduction.

No. 50. Studies upon Leprosy. XVI. Immunity. By D. H. Currie and M. T. Clegg. XVII. Further Observations in Rat Leprosy. By D. H. Currie and H. T. Hollmann. XVIII. A Statistical Study of the Nasal Lesions in Leprosy. By H. T Hollmann.

The sixteenth paper contains a review of previous literature relative to complement deflection test and agglutination experiments with lepers' serum, and presents the conclusions reached by them after a series of experiments.

The seventeenth paper amplifies some observations made by the authors in Public Health Bulletin No. 41, relative to the pathology of rat leprosy, and reports their failure to cultivate the bacillus of rat leprosy.

The eighteenth paper is, as the title expresses, a statistical study of nasal lesions based on the examination of 500 persons suffering from leprosy.

No. 51. The Causation and Prevention of Typhoid Fever, with Special Reference to Conditions Observed in Yakima County, Wash. By L. L. Lumsden.

This bulletin presents in a striking form the success that can be obtained by a community in the prevention of typhoid fever through the thorough application of prophylactic measures and an efficient health organization. While the conclusions were directly derived from the author's experiences in Yakima, they are of general application and will be found valuable by any community desiring the elimination of typhoid fever and the improvement of sanitary conditions in general.

A second edition of this bulletin has been printed and it has been printed as a House and Senate document.

No. 52. Vaccination. An Analysis of the Laws and Regulations relating thereto in Force in the United States. By J. W. Kerr.

The legislation in force in the United States in regard to vaccination has been compiled in this bulletin, with the decisions rendered by the courts on existing laws, and the provisions existing in various foreign countries, the contents being preceded by a historical introduction and thorough analysis of the legislation under consideration.

No. 53. Studies of Plague and Tuberculosis among Rodents in California. By G. W. McCoy and C. W. Chapin.

Six papers containing the result of original laboratory studies have been included by the authors in this bulletin: I. A Study of Virulence of Cultures of Bacillus Pestis of Various Sources and Ages; II. The Virulence of Bacillus Pestis of ground Squirrel Origin; III. Immunity of Wild Rats (Mus Norvegicus) to Plague Infection; IV. Susceptibility of a Ground Squirrel (Ammospermophitus Leucurus, Merriam) to Plague; V. Bacterium Tularense the Cause of a Plague-like Disease of Rodents; VI. A Note on the Susceptibility of Ground Squirrels (Citellus Beechyi, Richardson) to Tuberculosis. 


\section{Bulletins of the Hygienic Laboratory.}

The work of the laboratory the last fiscal year is well shown by the bulletins published during the year or which are now in press. These bulletins are as follows:

No. 79. Digest of comments on the pharmacopceia of the United States of America (eighth decennial revision) and the national formulary (third edition) for the calendar year ending December 31, 1909. By Murray Galt Motter and Martin I. Wilbert.

This bulletin is the fifth of the series on digest of comments on the pharmacopœia and the national formulary, now in the course of preparation. The available literature for the year 1909 was reviewed and practical suggestions and references are cited. Considerable space is devoted to a consideration of possible development of international standards for potent medicaments. The pharmacopœias published in 1909 and 1910 are reviewed and a summary of the compliances with the Protocol of the Brussels conference is presented in the form of a table.

No. 80. Physiological studies in anaphylaxis. Reaction of smooth muscle from various organs of different animals to proteins. (Including reaction of muscle from nonsensitized, sensitized, tolerant, and immunized guinea pigs.) By W. H. Schultz.

This bulletin is a continuation of the studies upon anaphylaxis and the reaction of the animal organism to foreign proteins, and forms the basis of an explanation as to why the injection of large doses of serum and various forms of proteins may cause grave symptoms and even death. It is shown that smooth muscle may be rendered highly sensitive to proteins and that by proper treatment this highly sensitized condition may be brought back to normal. It is a contribution to our knowledge of just what changes in the tissues themselves result from the injection of a foreign protein into an animal.

No. 81. Tissue proliferation in plasma medium. By John Sundwall.

Recent investigations by various workers have opened up an extensive field in biological research by showing that with the use of certain media and special technic it is possible to grow normal tissues and even new growths outside the animal body. On account of the use of this knowledge in the study of tumors, such as cancer, the results contained in this bulletin are considered of great importance. It was found that mammalian tissue would proliferate in plasma medium when incubated, but the degree of proliferation would depend upon the age of the animals from which the cultures were taken. Tissues from young embryos were most proliferative, the degree of proliferation increasing with the age of the animal. Generally speaking, it was found that the degree of proliferation of the various tissues in plasma bear a close relation to ther egenerative capacities of the same tissues in the animal. That is, those tissues which regenerate the greatest in the body show the greatest proliferation in plasma.

No. 82. Method of standardizing disinfectants with and without organic matter. By John F. Anderson and Thomas B. McClintic. The determination of the phenol coefficient of some commercial disinfectants. By Thomas B. McClintic.

The first article in this bulletin describes a standard method of determining the phenol coefficient of disinfectants. Two procedures are proposed: One without organic matter and the other with organic matter. The name suggested for this method is "the Hygienic Laboratory phenol coefficient." The method is now in general use. in the United States among those working with disinfectants and 
has been adopted by some of the large firms and State boards of 通ealth. The General Supply Committee requires a coefficient of not less than 2, according to the Hygienic Laboratory method, on disinfectants on which bids are invited for the present fiscal year.

The second paper gives the results of a study of 54 commercial disinfectants according to the Hygienic Laboratory phenol coefficient, both with and without organic matter, where the coefficient was determinable. It is shown that the manufacturers' claims can not always be taken as a true index of the value of a preparation as a disinfectant. A formula is given for the preparation of a comparatively cheap and efficient disinfectant for the use of those who do not care to use commercial preparations.

No. 83. Sewage pollution of interstate and international waters with special refarence to the spread of typhoid fever. II. Lake Superior and St. Mary's River. UII. Lake Michigan and the Straits of Mackinac. IV. Lake Huron, St. Clair River, Lake St. Clair, and the Detroit River. V. Lake Ontario and St. Lawrence River. Sy Arran J. McLaughlin.

This is a completion of work on the drainage basin of the Great Lakes and shows that the undue prevalence of typhoid fever in many sommunities in the basin of the Great Lakes is a serious interstate menace. The fact is brought out that the undue prevalence is attributable to drinking sewage-polluted water from the interstate and international waterways. In many places in this section conditions are acute, and the bulletin aims to be of use in pointing out remedies for reducing the prevalence of typhoid.

No. 84. Digest of comments on the pharmacopœia of the United States of America (eighth decennial revision) and on the national formulary (third edition) for the calendir year ending December 31, 1910. By Murray Galt Motter and Martin I. Wilbert.

The present bulletin is the sixth of the series on this subject. The iiterature for 1910 , as well as routine matter of interest to the revisers of the pharmacopœia and national formulary, are reviewed and an effort made to reflect these comments with an outline of the proceedings of the United. States pharmacopœial convention held in Washington in May, 1910.

No. 85. Index-catalogue of medical and veterinary zoology. Subjects: Cestoda and cestodaria. By Ch. Wardell Stiles and Albert Hassall.

The second number of the Subject-Catalogue, arranged with the Department of Agriculture under bureau authority, is represented by this bulletin, namely, Cestoda and Cestodaria. The bulletins of this series are of great value to zoologists, and the parts issued have already become the standard work of reference on the subject which they cover.

\section{LIBRARY.}

Thirty-six medical and scientific journals were subscribed to during Sfle fiscal year. In addition to these, a large number are received regularly either gratuitously or as exchanges. In most instances these are bound and become a part of the bureau library. Many books, especially ones dealing with sanitation, public health, sewage treatment and water purification, etc., have been purchased for the library, which now numbers about 4,000 volumes.

There is an urgent need for new covered bookcases in order to properly protect these books, many of which can not be replaced. As complete a set as possible of city and state boards of health reports have been procured and added to the library. 


\section{NEEDS OF THE SERVICE.}

In order to meet the demands made upon the service for aid in State and municipal sanitation, as well as to enforce the Federal quarantine laws, an increase in the number of field officers is imperative. Important statistical inquiries, and the collection and issuance of information relating to the public health, which have been authorized by Congress, will require the services of additional clerical help in the bureau.

In order to carry into effect the provisions of the act of August 14, 1912 , and to investigate scientifically. and practically all problems bearing on the pollution of navigable streams and the safe disposal of sewage, ample appropriations should be provided.

One of the most important subjects requiring legislation is that of establishing a division of sanitary engineering in the Public Health Bureau for the adequate and early investigation of public water supplies. Stream pollution is a problem of increasing gravity, and one that must sooner or later be taken up by the State and municipal authorities.

Provision should also be made for the study and investigation of pellagra, Rocky Mountain spotted (tick) fever, and malaria. Systematic studies on pellagra have been made in certain limited areas, but the work should be extended and epidemiological surveys made of the entire country with a view to determining the extent and prevalence of the disease.

I would again invite attention to the necessity of adding to the facilities of the Hygienic Laboratory. A new building should be erected on the present site in which the scientific investigations of the service having to do with the cause and mode of transmission of the diseases of man can be safely conducted.

Respectfully submitted.

Hon. Frankin MacVeagh,

RUPERT BLUE, Surgeon General. Secretary of the Treasury. 



\section{APPENDIX.}

\section{FINANCIAL STATEMENT.}

\section{Receipts and Expenditures, Public Health Service, for the Fiscal Year ended June 30, 1912.}

Public Health and Marine-Hospital Service, 1912.

\begin{tabular}{|c|c|c|c|c|}
\hline Subheads of appropriations. & $\begin{array}{l}\text { Appropria- } \\
\text { tion and } \\
\text { repayments. }\end{array}$ & $\begin{array}{l}\text { Expendi- } \\
\text { tures. }\end{array}$ & $\begin{array}{c}\text { Balances } \\
\text { June } 30,1912 .\end{array}$ & $\begin{array}{c}\text { Less esti- } \\
\text { mated en- } \\
\text { cumbrances. }\end{array}$ \\
\hline 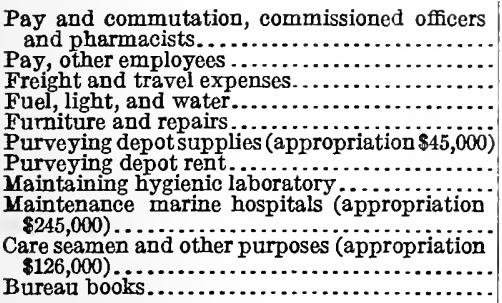 & $\begin{array}{r}\$ 316,000.00 \\
394,000.00 \\
30,450.00 \\
72,000.00 \\
8,000.00 \\
48,957.95 \\
3,250.00 \\
14,900.00 \\
\\
253,909.27 \\
126,955.00 \\
500.00\end{array}$ & $\begin{array}{r}\$ 308,099.25 \\
379,227.72 \\
29,752.78 \\
70,459.42 \\
6,601.18 \\
48,801.01 \\
3,250.00 \\
14,463.30 \\
245,133.41\end{array}$ & $\begin{array}{r}\$ 7,900.75 \\
14,772.28 \\
697.22 \\
1,540.58 \\
1,398.82 \\
156.94 \\
\ldots \ldots \ldots . . \\
436.70\end{array}$ & 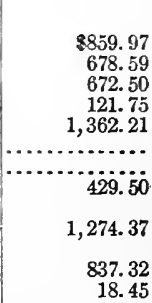 \\
\hline Total (appropriation $\$ 1,255,100) . \ldots \ldots \ldots$ & $1,268,922.22$ & $1,226,811.88$ & $42,110.34$ & $6,254.66$ \\
\hline
\end{tabular}

For expenditures by stations, see statistical Table II.

\section{Quarantine service, 1912 .}

Amount of appropriation

Total.

Balance June 30, 1912.

\section{EXPENDITURES BY STATIONS}

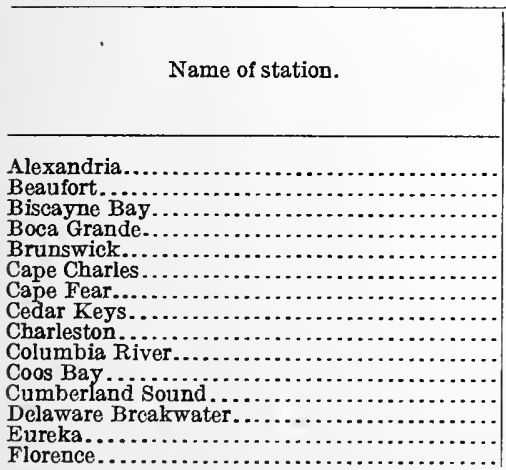

\begin{tabular}{|c|c|c|}
\hline $\begin{array}{l}\text { Pay and } \\
\text { allowances, } \\
\text { officers and } \\
\text { employees. }\end{array}$ & $\begin{array}{l}\text { Subsistence } \\
\text { and miscel- } \\
\text { laneous. }\end{array}$ & $\begin{array}{l}\text { Medical } \\
\text { and hospital } \\
\text { supplies. }\end{array}$ \\
\hline $\begin{array}{r}\$ 30.00 \\
1,500.00\end{array}$ & $\begin{array}{r}\$ 0.25 \\
160.08\end{array}$ & \\
\hline $\begin{array}{r}1,573.50 \\
2,858.34 \\
2,923.34 \\
10,311.83 \\
6,247.00\end{array}$ & $\begin{array}{r}590.27 \\
2,031.36 \\
10,652.96 \\
2,238.40\end{array}$ & $\begin{array}{l}\$ 10.92 \\
129.77 \\
189.86 \\
222.24\end{array}$ \\
\hline $\begin{array}{r}321.17 \\
6,391.67 \\
10,308.33\end{array}$ & $\begin{array}{l}1,738.50 \\
5,375.76\end{array}$ & $\begin{array}{l}114.17 \\
336.91\end{array}$ \\
\hline $\begin{array}{r}3,226.60 \\
4,000.00 \\
900.00\end{array}$ & $\begin{array}{r}123.75 \\
1,627.68 \\
1,005.41\end{array}$ & $\begin{array}{r}8.48 \\
384.64 \\
4.62\end{array}$ \\
\hline & & \\
\hline
\end{tabular}

Total.

Florence. 
EXPENDITURES BY STATIONS-continued.

\begin{tabular}{|c|c|c|c|c|}
\hline Name of station. & $\begin{array}{l}\text { Pay and } \\
\text { allowances, } \\
\text { officers and } \\
\text { employees. }\end{array}$ & $\begin{array}{l}\text { Subsistence } \\
\text { and miscel- } \\
\text { laneous. }\end{array}$ & $\begin{array}{c}\text { Medical } \\
\text { and hospital } \\
\text { supplies. }\end{array}$ & Total. \\
\hline 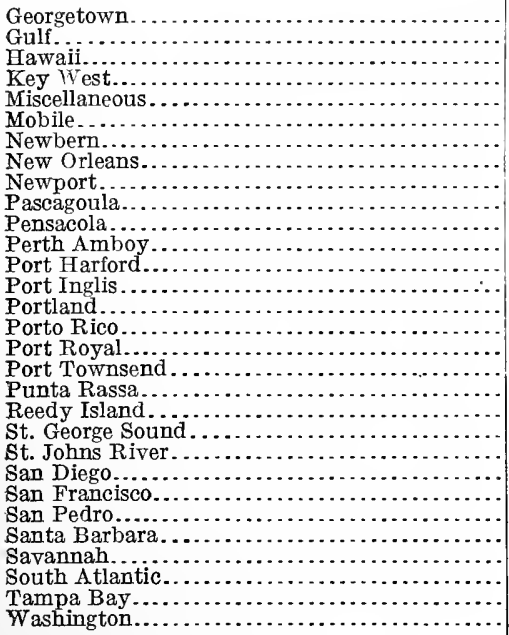 & $\begin{array}{r}\$ 240.00 \\
8,759.34 \\
32,444.79 \\
4,280.00 \\
10,709.66 \\
200.00 \\
23,611.99 \\
16.66 \\
1,590.00 \\
8,800.23 \\
1,554.00 \\
380.00 \\
270.00 \\
6,718.34 \\
22,871.34 \\
1,500.00 \\
10,570.50 \\
325.00 \\
16,076.00 \\
3,160.00 \\
1,980.00 \\
6,690.00 \\
27,152.00 \\
50.00 \\
50.00 \\
7,694.35 \\
1,140.00 \\
6,549.24 \\
600.00\end{array}$ & $\begin{array}{r}\$ 46.09 \\
3,518.56 \\
15,654.66 \\
1,668.07 \\
1,602.20 \\
10,501.70 \\
12,171.07 \\
\ldots \ldots \\
3,037.20 \\
1,042.15 \\
\ldots \ldots 8 \\
2,035.87 \\
8,663.21 \\
133.27 \\
2,216.82 \\
\ldots \ldots 31 \\
13,480.04 \\
284.00 \\
545.58 \\
2,563.40 \\
18,840.79 \\
195.91 \\
\ldots \ldots\end{array}$ & 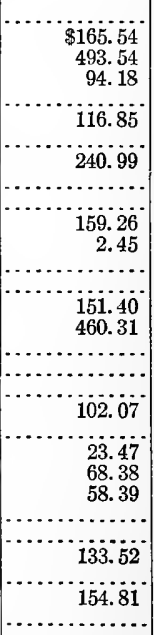 & $\begin{array}{r}\$ 286.09 \\
12,443.44 \\
48,592.99 \\
6,042.25 \\
1,602.20 \\
21,328.21 \\
200.00 \\
36,024.05 \\
16.66 \\
1,938.00 \\
12,996.69 \\
2,598.60 \\
380.00 \\
478.31 \\
8,905.61 \\
31,994.86 \\
1,633.27 \\
12,787.32 \\
325.00 \\
29,658.11 \\
3,444.00 \\
2,549.05 \\
9,321.78 \\
46,051.18 \\
245.91 \\
50.00 \\
10,856.80 \\
1,595.87 \\
10,471.69 \\
600.00\end{array}$ \\
\hline
\end{tabular}

Preventing the spread of epidemic diseases.

Balance July 1, 1911

$\$ 415,689.11$

\section{EXPENDITURES.}

Foreign medical service, salaries and miscellaneous:

China, Japan, Italy, Central and South America, and

West Indies.

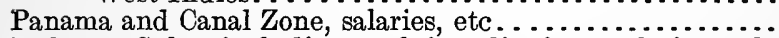

Habana, Cuba, including outlying districts, salaries, subsistence, supplies, and miscellaneous. . . . . . . . . . . . . .

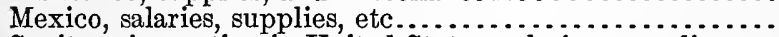

Sanitary inspection in United States, salaries, traveling expenses, and miscellaneous........................

Plague, suppressive measures, Pacific coast...............

Yellow fever, maintenance of detention camps, precautions against outbreak, salaries, medical and hospital supplies, disinfectants, etc.............................

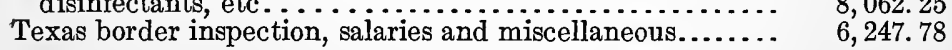

$10,256.66$

$3,684.31$

$29,362.85$

$202,535.31$

$8,062.25$

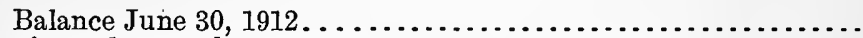

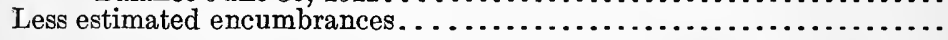

$326,067.38$

$89,621.73$

$32,927.50$

National quarantine and sanitation.

Balance July 1, 1911

$78,493.17$

Expenditures for improvements and miscellaneous:

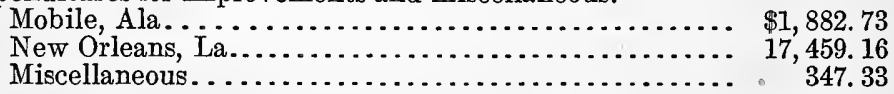

Balance June $30,1912 \ldots \ldots \ldots \ldots \ldots \ldots \ldots \ldots \ldots \ldots \ldots \ldots \ldots \ldots .58,803.95$

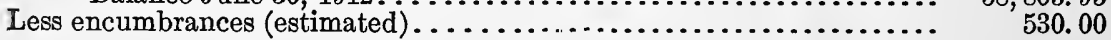


Salaries, Odfice of Surgeon General, 1912.

Amount of appropriation.

$\$ 40,980.00$

Expenditures. $38,981.92$

Balance June 30, 1912 . $1,998.08$

Maintenance of leprosy hospital, Hawaii, 1912.

Amount of appropriation. $33,000.00$

Expenditures

Balance June 30, 1912 $27,468.71$

Less encumbrances (estimated)

$5,531.29$ $2,596.40$

Leprosy hospital, Hawaii.

BUILDING AND EQUTPMENT.

Balance June 30, 1912 (act Mar. 3, 1905)

$16,956.35$

Hygienic Laboratory.

Balance June 30, 1912 (act June 25, 1910). $15,000.00$

Cleveland, Ohio:

Appropriations, marine hospitals.

Balance June 30, 1912 (act Mar. 4, 1909).......................

Balance June 30, 1912 (act Mar. 4, 1907)....................

Chicago. Ill.:

Balance June 30, 1912 (act June 25, 1910)

Reedy Island:

Appropriations, quarantine stations.

Balance June 30, 1912 (act Mar. 4, 1909)

66.71

Charleston:

Balance July 1, 1911 (act Mar. 4, 1909).

Expended July 1, 1911, to June 30, 1912............ $\$ 15,122.95$

Encumbrances.......................... $2,595.50$

$20,026.59$

$17,718.45$

Balance June 30, 1912.

$2,308.14$

Savannah:

Balance July 1, 1911 (act Mar. 4, 1909).

$1,510.95$

Expended July 1, 1911, to June 30, 1912

$1,100.10$

Balance June 30, 1912

410.85

San Francisco, Cal.:

Balance June 30, 1912 (act June 30, 1906)

Honolulu.

Balarce June 30, 1912 (act May 27, 1908)

$3,201.35$

180.75

Balan June 30, 1912 (act Mar. 4, 1907) ................. 390.52

Balan June 30, 1912 (act Mar. 4, 1907)................ 390.52

Gulf:

Balance Juise 30, 1912 (act Mar. 4, 1907)................. 353.35

Pensacola:

Balance July 1, 1911 ' 'ct Mar. 4, 1907). .

Expended July 1, 1911, to June 30, 1912

424.52

Encumbrances. 
Delaware Breakwater:

Balance June 30, 1912 (act Mar. 4, 1907)

$\$ 857.00$

Brunswick:

Balance July 1, 1911 (act June 25, 1910). .

Expended July 1, 1911, to June 30, $1912 \ldots \ldots \ldots \ldots \ldots \ldots \ldots 4,697.18$

Encumbrances............................. 2,248.00

Balance June 30, 1912 .

$1,718.82$

Columbia River:

Balance July 1, 1911 (act June 25, 1910) . . . . . . . . . . . . . . 897.69

Expanded July 1, 1911, to June $30,1912 \ldots \ldots \ldots \ldots \ldots \ldots \ldots \ldots$

Balance June 30, 1912.

745.47

\section{Balances carried to surplus fund.}

\section{MARINE HOSPITALB.}

Wilmington, N. C., act Mar. 4, 1909. . . . . . . . . . . . . . . . .

Chicago, Ill., act Mar. 3, 1905. . . . . . . . . . . . . . . . . . . . .

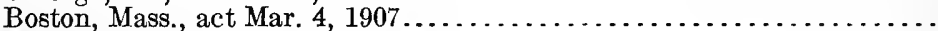

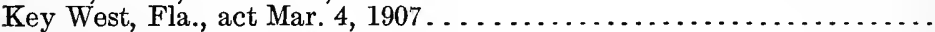

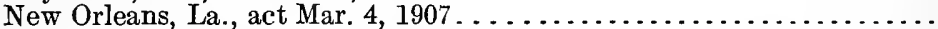

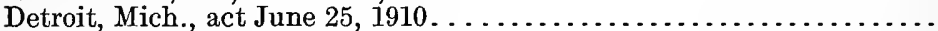

Mobile, Ala., act June 25, 1910.

QUARANTINE STATIONS.

San Francisco, act Mar. 4, 1909.

Carried by Supervising Architect.

Marine Hospital, Key West (act Mar. 4, 1911).

\section{STATISTICAL TABLES.}

TABLE I.-Comparative table of number of patients annually treated, 1868 to 1912.

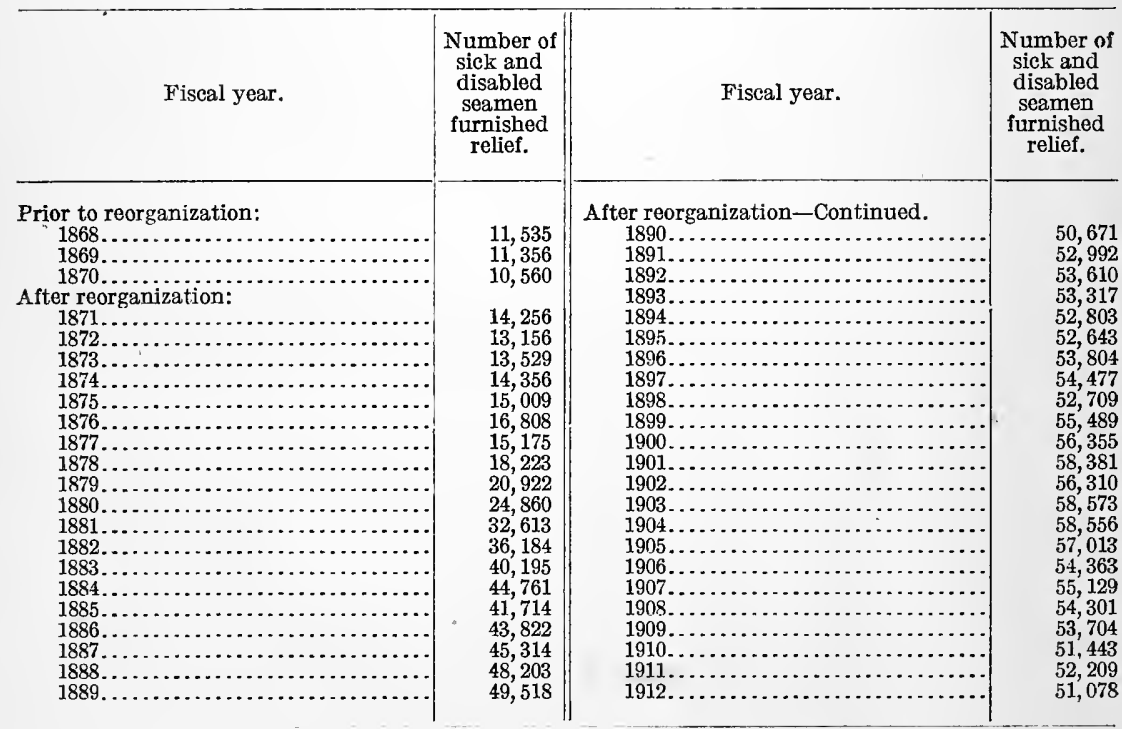


PUBLIC HEALTH SERVICE.

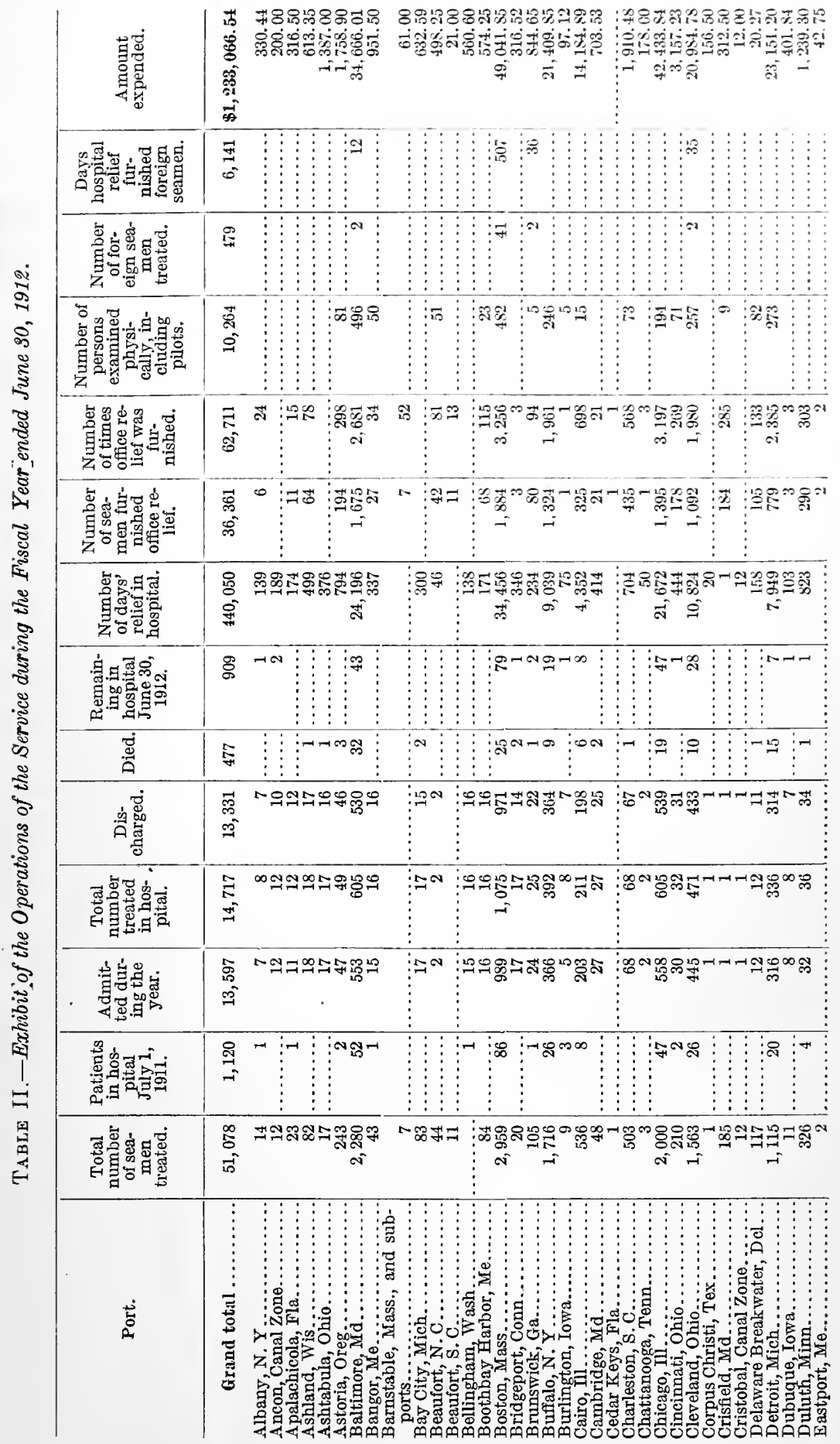




\begin{tabular}{|c|c|c|c|}
\hline 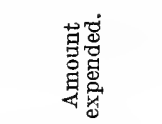 & 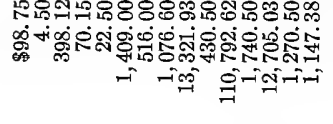 & 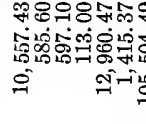 & 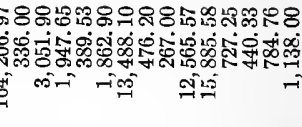 \\
\hline 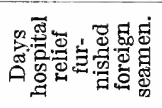 & & & 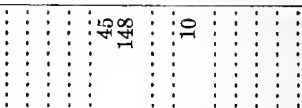 \\
\hline 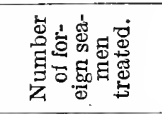 & & & \begin{tabular}{l:l}
$\infty$ & $\vdots$ \\
\hdashline & $\vdots$
\end{tabular} \\
\hline 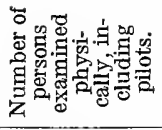 & 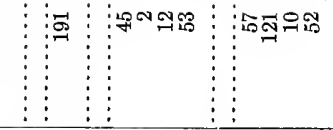 & 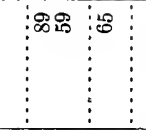 & 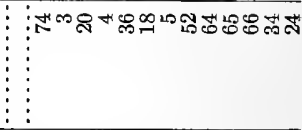 \\
\hline 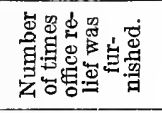 & 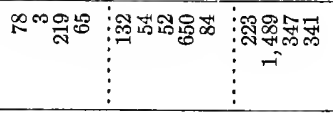 & $\begin{array}{cc}\mathfrak{w}_{\infty}^{\infty} \\
\vdots \\
\vdots \\
\vdots \\
\vdots\end{array}$ & : \\
\hline 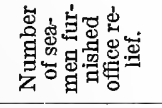 & 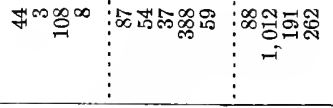 & \begin{tabular}{c|c}
$\vdots$ \\
$\vdots$ \\
$\vdots$ \\
$\vdots$ \\
\hdashline
\end{tabular} & 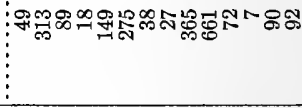 \\
\hline 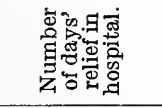 & 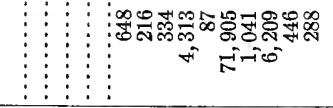 & 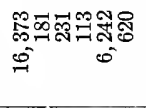 & 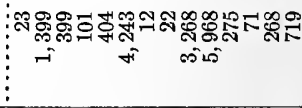 \\
\hline 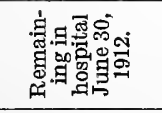 & : & $\$ \vdots$ & 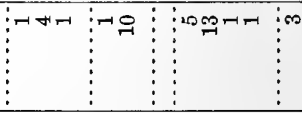 \\
\hline تृّं & 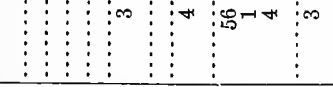 & \begin{tabular}{c|c}
$\infty$ & $\vdots$ \\
$\vdots$ & $\vdots-1$ \\
$\vdots$ & $\vdots$ \\
\end{tabular} & 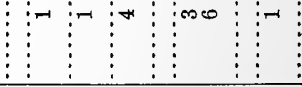 \\
\hline 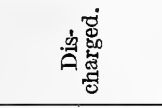 & : & m & 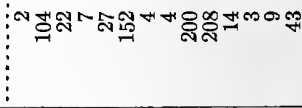 \\
\hline 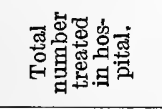 & 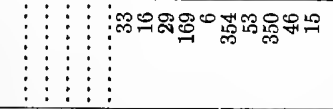 & 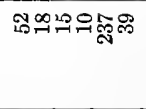 & 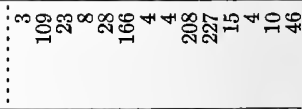 \\
\hline 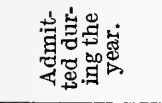 & 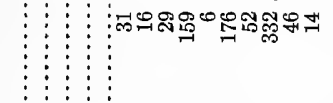 & 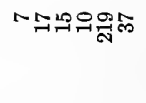 & 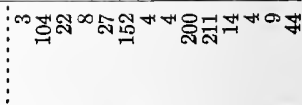 \\
\hline 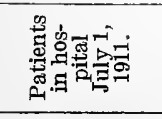 & 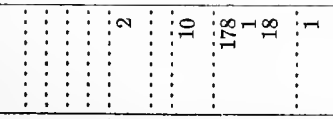 & $\begin{array}{c:c}\text { Fa }^{-1} \\
\vdots \\
\vdots\end{array}$ & 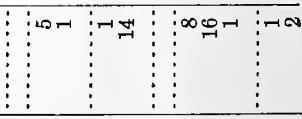 \\
\hline 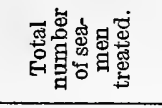 & \multicolumn{3}{|c|}{ 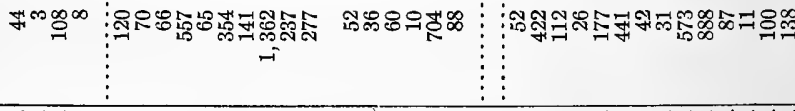 } \\
\hline$\underset{\dot{0}}{\stackrel{5}{\circ}}$ & 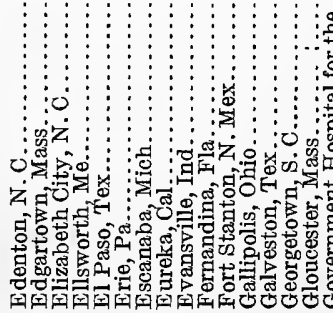 & 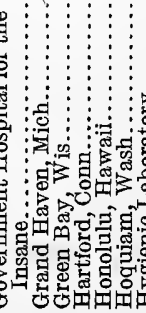 & 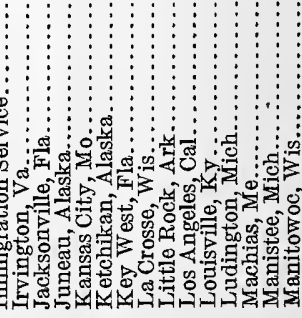 \\
\hline
\end{tabular}




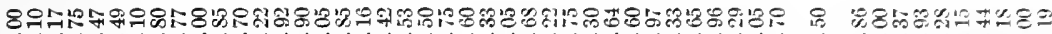

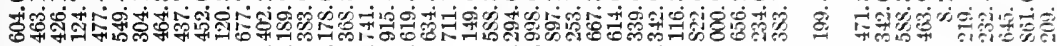

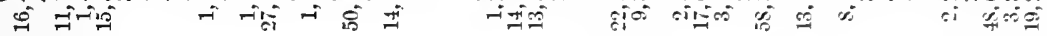

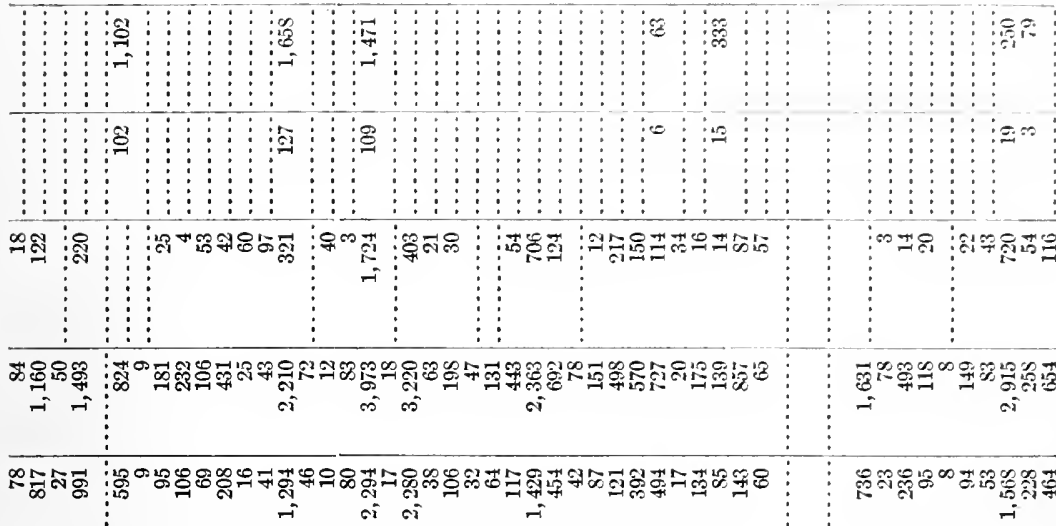

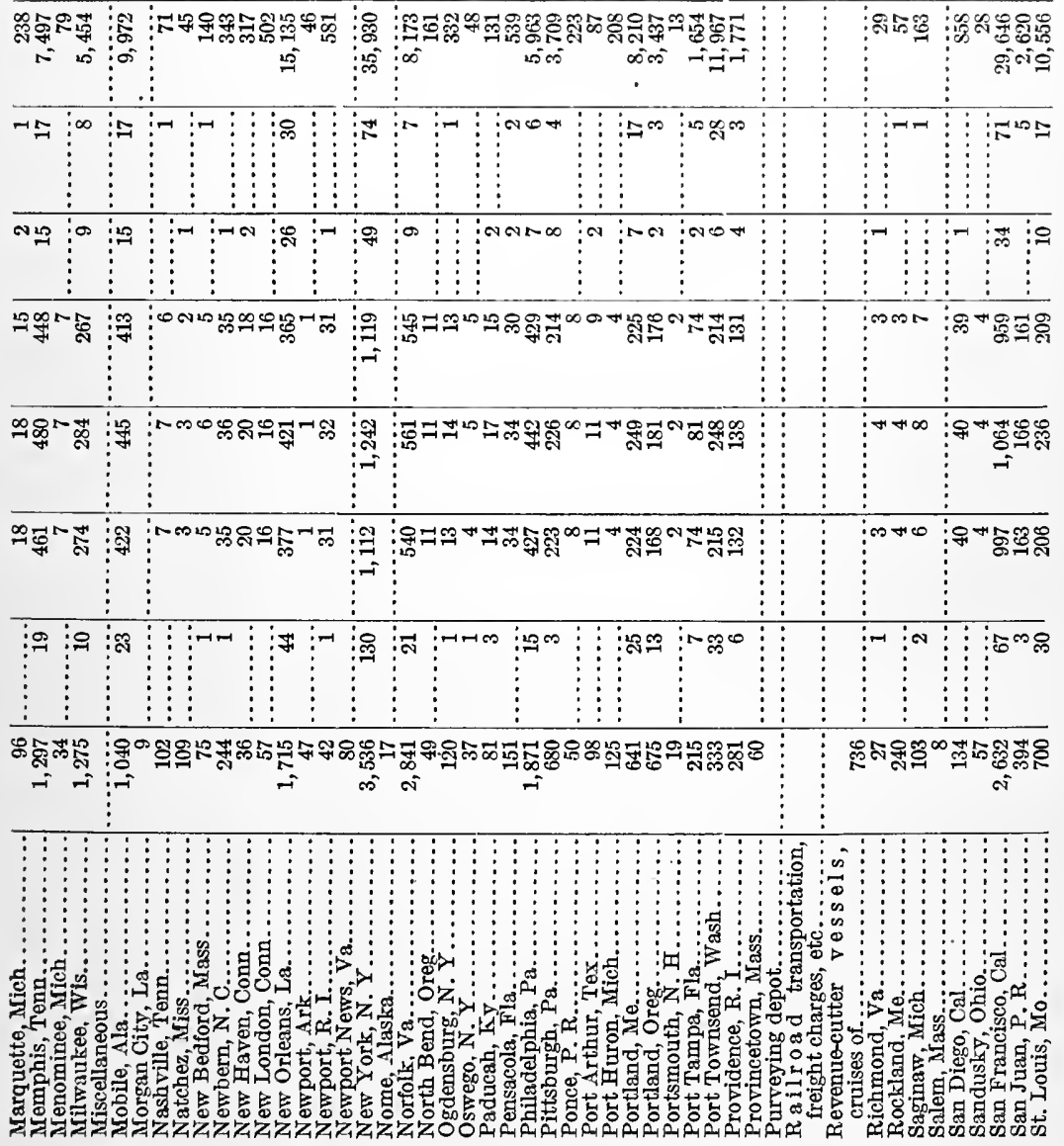




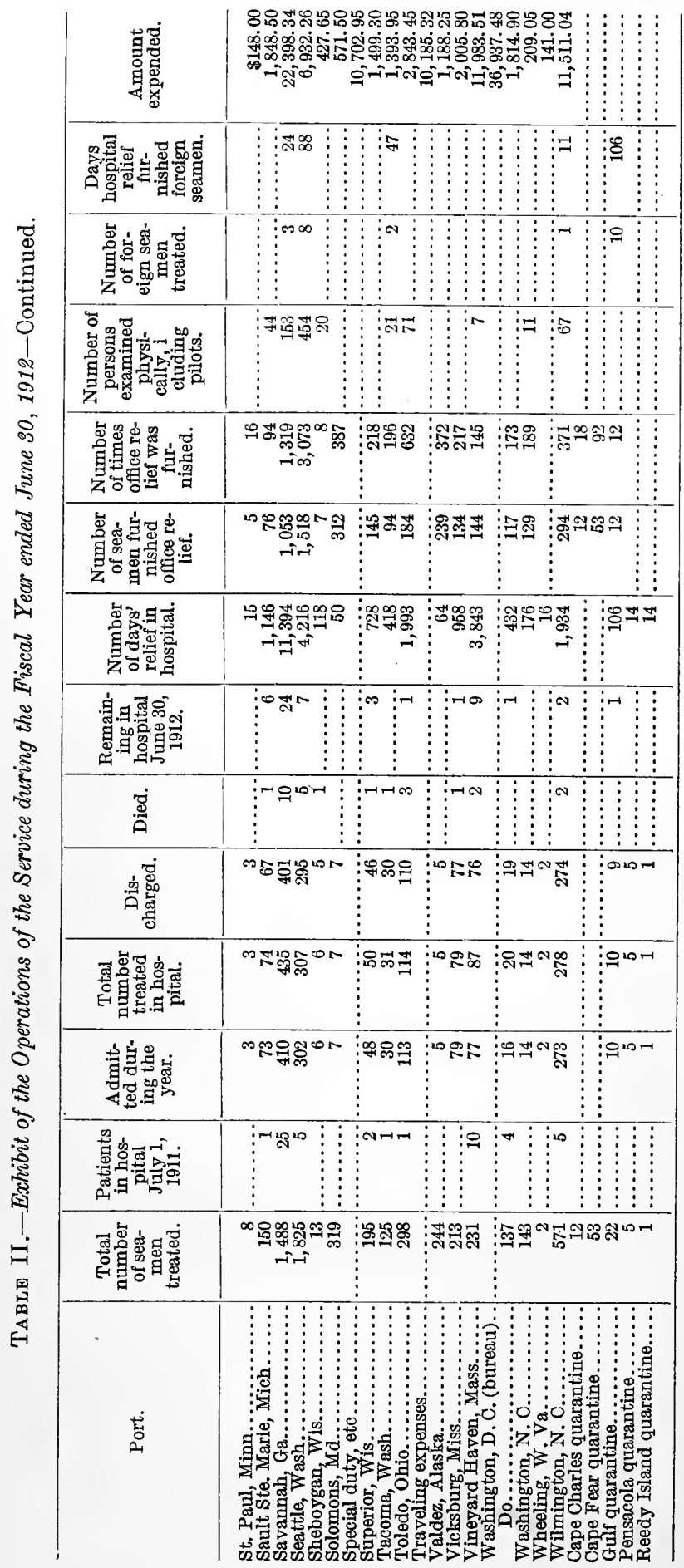




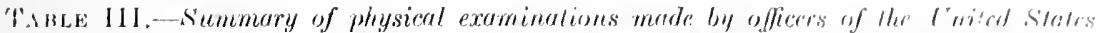

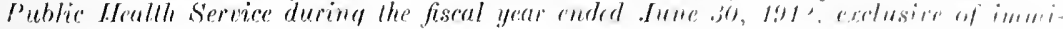
gratuls.

Sinmmary of examinations and rejections.

Total number examined.

Number passed.

Number rejected

Causes of rejection, discases, disability, etc.

Abscess of connective tissue......

$\Lambda$ denoids.

Albuminuria.

$\Lambda$ trophy of muscle

Blind in one eye.

Bright's disease.

Bronchitis:

Acute.

Chronic.

Cataract, lenticular.

Color blindness.

Conjunetivitis, chronic

Contusion of testicle with hematocele.

Contusion of back

('ontusion of finger

Cinrvature of spine, anterior

Cyst, sebaceous

Defective vision.

Debility

Deformity of chest

Defective hearing .

Defective teeth.

Disease dependent on vegetable parasite.

Disease dependent on animal parasites:

Pediculus capitis.

Sarcoptes scabiei.

Eczema.

nlarged testicle.................

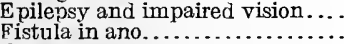

Flat foot...

Gonorrhea.

Hernia.

Hydrocele tunica vaginalis

Hy pertrophy of tonsils

1ch thyosis

Imflammation of tonsils, follicular, acute.

Inflammation of larynx, acute...

Inflammation of lymph glands,

Inflammation of knee joint

Irregular action of heart-abnor-

mal rapidity

Infected wound of leg...............

Loss of one eye.

loss of one hand

Malarial fever, intermittent.

Malformation of hand.

Norvous weakness.

Phthirius inguinalis.

Physical degeneration, general

Poor physique.

Piles, external

P'soriasis

Rheumatism.

Syphilis, secondary

Sore throat, chronic

Squint ...........................

Tubercle of liung.

Timmor of testicle.

indercender lesticle.

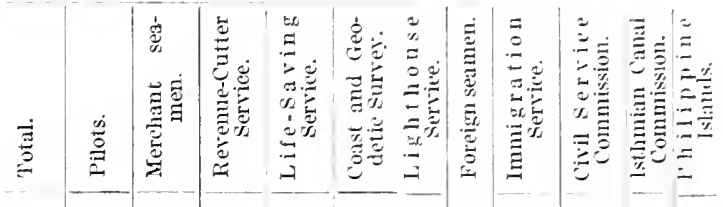

\begin{tabular}{|l|l|l|lll|ll|l|l|lll}
10,264 & 5,489 & 782 & 1,232 & 2,000 & 112 & 84 & 15 & 335 & 168 & 2 & 1.5
\end{tabular}

\begin{tabular}{rr|r|rr|rrr|r|rr|r}
9,706 & 5,265 & 739 & 1,050 & 1,927 & 101 & 77 & 8 & 328 & 16,6 & 2 & 4.3 \\
558 & 224 & 43 & 182 & 73 & 11 & 7 & 7 & 7 & 2 & & \\
\hline
\end{tabular}


TABLE III.-Suminary of physical examinations made by officers of the United States Public Health Service during the fiscal year ended June 30, 1912, exclusive of immigrants-Continued.

Summary of examinations and rejections.

\section{Causes of rejection, diseases, disa-} bility, etc.-Continued.

Ulcer of stin.

Ulcer of penis.

Under weight.

Under height.

Urethritis, chronic

Varicose veins of leg.

Varicocele.

Valvular disease of heart: Mitral.

Aortic

Varix.

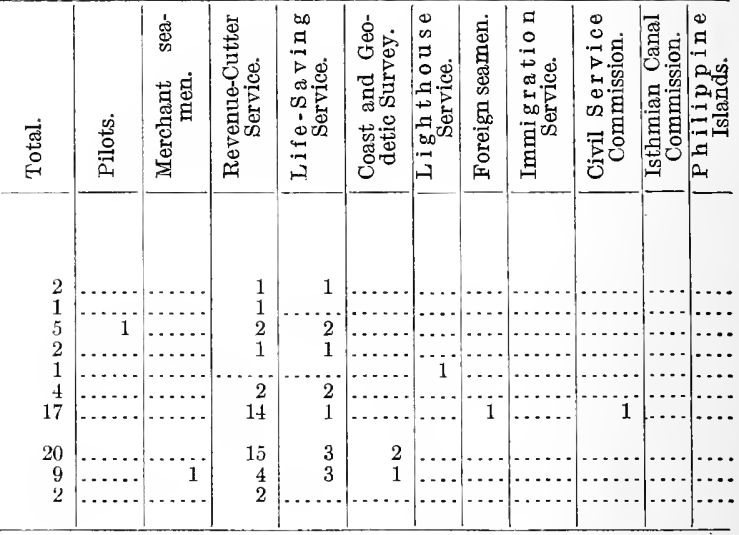

TABLE IV.-Tabular statement of diseases and injuries treated during the year ended June 30, 1912.

\begin{tabular}{|c|c|c|c|c|c|c|c|c|c|}
\hline \multirow[b]{2}{*}{ Diseases. } & \multicolumn{9}{|c|}{ Number of cases. } \\
\hline & 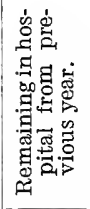 & 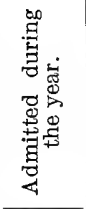 & 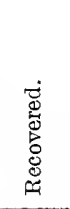 & 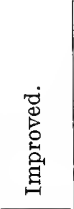 & 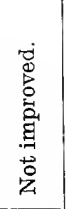 & 㞧 & 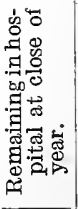 & 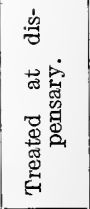 & 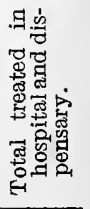 \\
\hline Total cases & 1,114 & 13,603 & 7,794 & 5,254 & 427 & 435 & 807 & 36,361 & 51,078 \\
\hline General diseases.. & 513 & $\check{5}, 470$ & 2,694 & 2,498 & 192 & 221 & 378 & 11,812 & 17,795 \\
\hline Smallpox.. & 1 & 13 & 10 & 2 & 1 & & 1 & 4 & 18 \\
\hline Cowpox..... & & 3 & & 3 & & & & 38 & 41 \\
\hline Chicken pox. & & 4 & 4 & & $\cdots$ & & & 3 & 7 \\
\hline Measles........ & & 29 & 28 & 1 & & & 1 & 8 & 38 \\
\hline Rubeola.......... & $\cdots$ & 3 & 3 & & & & $\cdots$ & 1 & 4 \\
\hline Scarlet fever..... & & $\begin{array}{l}3 \\
1\end{array}$ & 1 & 1 & & & & 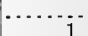 & $\stackrel{3}{2}$ \\
\hline $\begin{array}{l}\text { Dengue } \\
\text { Influenza............ }\end{array}$ & 2 & 251 & $\begin{aligned} 1 \\
218\end{aligned}$ & 31 & $\ddot{1}$ & $i$ & $\ddot{2}$ & 573 & $\begin{array}{r}2 \\
826\end{array}$ \\
\hline Whooping cough. & & & & & & & & & 1 \\
\hline Mumps.......... & 2 & 32 & 26 & 8 & & & $\ldots$ & 38 & 72 \\
\hline Diphtheria............. & 2 & 27 & 25 & 2 & & & & 1 & 30 \\
\hline Cerebrospinal fever....... & $\cdots \cdots \cdots$ & 4 & 1 & & & 3 & & & 4 \\
\hline Simple continued fever... & & 15 & 11 & 1 & 1 & & 2 & 7 & 22 \\
\hline Enteric fever.................. & 31 & 396 & 348 & 13 & $\cdots \cdots$ & 40 & 26 & 47 & 474 \\
\hline Choleraic diarrhea.............. & & $\begin{array}{r}1 \\
57\end{array}$ & 1 & 13 & -..... & & & $\begin{array}{r}4 \\
03\end{array}$ & 5 \\
\hline $\begin{array}{l}\text { Dysentery .......... } \\
\text { Malarial fever: }\end{array}$ & & & 38 & 13 & & & & & 150 \\
\hline Intermittent. . & 18 & 644 & 528 & 119 & 4 & 3 & 8 & 989 & 1,651 \\
\hline Remittent................. & 9 & 169 & 115 & 54 & & 4 & 5 & 45 & 223 \\
\hline Phagedena, hospital gangrene.......... & & 1 & & & & 1 & & & 1 \\
\hline Erysipelas................... & 1 & 30 & 26 & 1 & & 2 & 2 & 28 & $5 \hat{9}$ \\
\hline Pyemia.......... & & 2 & 1 & & & 1 & & 1 & 3 \\
\hline Septicemia..................... & & 6 & 2 & 2 & & 1 & 1 & 43 & 49 \\
\hline 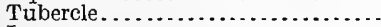 & 236 & 708 & 32 & 460 & 117 & 120 & 215 & 232 & 1,176 \\
\hline $\begin{array}{l}\text { Leprosy } \\
\text { Syphilis: }\end{array}$ & 1 & & & & & & 1 & & \\
\hline Primary...... & 1 & 50 & 3 & 40 & 7 & & 1 & 109 & 160 \\
\hline Secondary........ & 58 & 847 & 22 & 831 & 16 & 5 & 31 & 2,036 & 2,941 \\
\hline Tertiary............ & 1 & 17 & & 15 & 1 & 1 & 1 & 27 & 45 \\
\hline Gonorrhea................................ & 51 & 615 & 332 & 300 & 10 & 1 & 23 & 3,829 & 4,495 \\
\hline Diseases dependent on animal para- & & & & & & & & & \\
\hline sites......................................... & 5 & 250 & 52 & 200 & 1 & & 2 & 251 & 506 \\
\hline 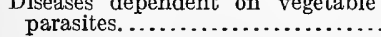 & 1 & 4 & 4 & & & & & 50 & 55 \\
\hline
\end{tabular}


TABLE IV.-Tabular statemont of diseases and injuries treated during the year orded Jure si), 191\%-Continued.

\begin{tabular}{|c|c|c|c|c|c|c|c|c|c|}
\hline \multirow[b]{2}{*}{ Diseases. } & \multicolumn{3}{|c|}{. } & \multicolumn{6}{|c|}{ Number of cases. } \\
\hline & 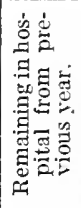 & 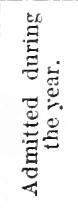 & 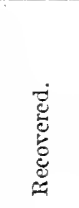 & 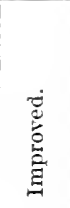 & 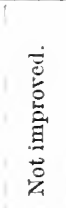 & $\stackrel{\mathscr{E}}{\overparen{G}}$ & 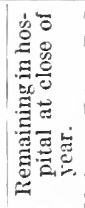 & 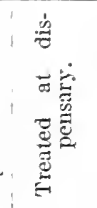 & 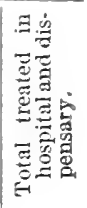 \\
\hline Effects of animal poisons. & & $\mathrm{s}$ & & & & & & 4 & 12 \\
\hline Effects of vegetable poisons & & 7 & 4 & 3 & & & & 5 & 12 \\
\hline Opium ............... & & 3 & 3 & & & & & 1 & 4 \\
\hline Tobacco............... & & 1 & $\because$ & & & & & 4 & 4 \\
\hline $\begin{array}{l}\text { Rhus toxicodendron...... } \\
\text { Turpentine.............. }\end{array}$ & & 1 & 1 & & & & & $\begin{array}{l}9 \\
2\end{array}$ & 10 \\
\hline Effects of inorganic puisolis. & & 3 & 2 & 1 & & & & 2 & 5 \\
\hline Lead....................... & & 1 & $\cdots$ & 1 & & & & 4 & 5 \\
\hline Mercury........................... & & & & & & & & 3 & 3 \\
\hline Potassium iodide ...................... & & & & & & & & 2 & 2 \\
\hline 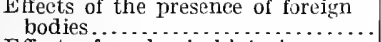 & & 8 & 5 & 2 & 1 & & & $3 x$ & 46 \\
\hline Effects of mechanical injuries...... & & 4 & 1 & 3 & & & & 49 & 53 \\
\hline Effects of heat ................... & & $1 \mathrm{~s}$ & 17 & 1 & & & & 10 & 34 \\
\hline Effects of electricity $\ldots \ldots \ldots \ldots \ldots \ldots$ & $\cdots$ & 1 & 1 & & & & & 1 & 2 \\
\hline Effects of chemical agents........... & & 1 & 1 & & & & & (i & 7 \\
\hline $\begin{array}{l}\text { Effects of excessive exertions and } \\
\text { strain } \ldots \ldots \ldots \ldots \ldots \ldots \ldots \ldots \ldots \ldots \ldots\end{array}$ & & 17 & 16 & 1 & & & & 2 & 19 \\
\hline 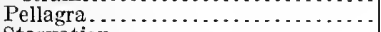 & & 18 & 1 & 10 & & 4 & 3 & 1 & 19 \\
\hline Starvation $\ldots \ldots \ldots \ldots \ldots$ & & 1 & $\ddot{2}$ & $\cdots$ & & 1 & & $\cdots \cdot$ & 1 \\
\hline 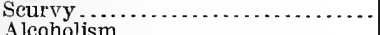 & o & 3 & 2 & & & $\frac{1}{2}$ & & & 3 \\
\hline 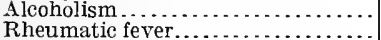 & 13 & $\begin{array}{l}246 \\
124\end{array}$ & $\begin{array}{r}197 \\
91\end{array}$ & 44 & $\begin{array}{l}5 \\
2\end{array}$ & 2 & 4 & 180 & 432 \\
\hline $\begin{array}{l}\text { Rheumatic fever } \ldots \ldots \\
\text { Rheumatism } . . . . .\end{array}$ & 45 & $\begin{array}{l}124 \\
640\end{array}$ & $\begin{array}{r}91 \\
419\end{array}$ & $\begin{array}{r}38 \\
237\end{array}$ & 8 & $\ddot{2}$ & $\begin{array}{r}6 \\
19\end{array}$ & $\begin{array}{r}53 \\
2,227\end{array}$ & $\begin{array}{r}190 \\
2,912\end{array}$ \\
\hline Gout............................... & & & & & & & & & 2,012 \\
\hline Osteoarthritis $\ldots \ldots \ldots \ldots \ldots \ldots \ldots \ldots$ & 2 & 10 & 2 & 7 & ... & 2 & 1 & 3 & 15 \\
\hline $\begin{array}{l}\text { Cyst: } \\
\text { Mucous...................... }\end{array}$ & & 1 & 1 & & & & & 5 & \\
\hline Sebaceous............... & & 13 & 9 & 2 & 1 & & 1 & 22 & $\begin{array}{r}6 \\
35\end{array}$ \\
\hline New growth, nonmalignant.... & 4 & 57 & 45 & 14 & 1 & $i$ & & 184 & 245 \\
\hline New growth, malignant............. & 6 & 35 & 7 & 6 & 8 & 15 & 5 & 32 & 73 \\
\hline 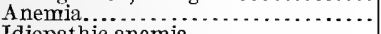 & & 8 & 3 & 3 & & 2 & $\cdots$ & 37 & 43 \\
\hline Idiopathic anemia................... & 1 & 3 & $i$ & 3 & & 1 & & 2 & 6 \\
\hline Puerpura.......................... & 1 & 1 & 1 & 1 & & & & 6 & 8 \\
\hline $\begin{array}{l}\text { Diabetes mellitus } \ldots \ldots \ldots \ldots \ldots \ldots \ldots \\
\text { Diabetes insipidus }\end{array}$ & 4 & 14 & 2 & 6 & 1 & 4 & 5 & 42 & 60 \\
\hline Leukocythemia........................... & 1 & 1 & & 2 & & & & $\begin{array}{r}20 \\
2\end{array}$ & 40 \\
\hline Congenital malformations............ & 3 & 5 & 6 & 1 & & & 1 & 4 & 12 \\
\hline Debility & 5 & 35 & 17 & 13 & 3 & 1 & 6 & 380 & 420 \\
\hline 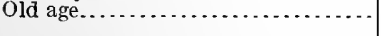 & & & & 1 & & & 1 & & 3 \\
\hline Local diseases. & & & & & & & & & \\
\hline DISEASES OF THE NERVOUS SYSTEM. & 142 & 272 & 75 & 141 & 56 & 37 & 105 & 713 & 1,127 \\
\hline $\begin{array}{l}\text { Of the nerves: } \\
\text { Inflammation-- }\end{array}$ & & & & & & & & & \\
\hline - Neuritis........................ & 3 & 27 & 9 & 17 & 1 & 1 & 2 & 49 & 79 \\
\hline of the spinal cord and mem- & 6 & 4 & & 7 & 2 & 1 & & 2 & 12 \\
\hline $\begin{array}{l}\text { branes-Membranes: } \\
\text { Inflammation of pia mater }\end{array}$ & & & & & & & & & \\
\hline of the spinal cord and mem. & & 3 & & & 1 & 2 & & & 3 \\
\hline $\begin{array}{l}\text { Of the spinal cord and mem- } \\
\text { branes-Cord: } \\
\text { Inflammation, diffuse...... }\end{array}$ & & & & & & & & & \\
\hline $\begin{array}{l}\text { Inflammation, diffuse....... } \\
\text { Degeneration-- }\end{array}$ & 1 & & & & & 1 & & & 1 \\
\hline Of lateral columns....... & 2 & 1 & & 2 & 1 & & & & 3 \\
\hline $\begin{array}{l}\text { Of posterior columns.... } \\
\text { Of lateral and posterior }\end{array}$ & 24 & 28 & ....... & 18 & 8 & 5 & 21 & 11 & 63 \\
\hline of the brain and its mem- & 3 & $\cdots$ & & & & & 3 & & 3 \\
\hline 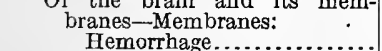 & & & & & & & & & \\
\hline of the brain and its mem- & & 2 & & 2 & & & & 2 & 4 \\
\hline $\begin{array}{l}\text { branes_Brain: } \\
\text { Inflammation............... }\end{array}$ & & 2 & & & & 2 & & & \\
\hline Softening................... & 1 & 1 & & & 1 & 1 & & & , \\
\hline Hemorrhage. & 3 & 13 & $\cdots \cdots$ & 10 & 1 & 2 & & 3 & 19 \\
\hline Anemia...... & & & & & & & & 1 & 2 \\
\hline
\end{tabular}


TABLE IV.-Tabular statement of diseases and injuries treatcd during the year ended June 30, 1912-Continued.

\begin{tabular}{|c|c|c|c|c|c|c|c|c|c|}
\hline \multirow[b]{2}{*}{ Diseases. } & \multicolumn{9}{|c|}{$\mathrm{um}$} \\
\hline & 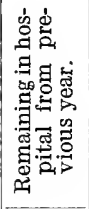 & 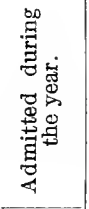 & 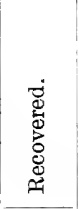 & 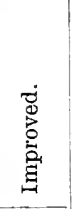 & 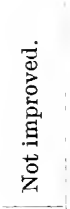 & 兽 & 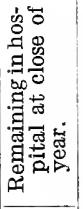 & 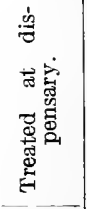 & 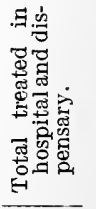 \\
\hline \multicolumn{10}{|l|}{ Local diseases-Continued. } \\
\hline $\begin{array}{l}\text { DiSEASES OF THE NERVOUS SYS- } \\
\text { TEM-Continued. } \\
\text { Functional nervous disorders } \\
\text { with other diseases of undeter- } \\
\text { mined nature: }\end{array}$ & & & & & & & & & \\
\hline $\begin{array}{l}\text { Apoplexy } \\
\text { Paralysis }-\end{array}$ & & 11 & 1 & 4 & & 6 & & 1 & 12 \\
\hline Paraplegia.... & 2 & & & & & 1 & 1 & & 2 \\
\hline $\begin{array}{l}\text { Hemiplegia....... } \\
\text { Monoplegia...... }\end{array}$ & 28 & 26 & 2 & 24 & 16 & 6 & 6 & $\begin{array}{r}13 \\
1\end{array}$ & $\begin{array}{r}67 \\
1\end{array}$ \\
\hline Local paralysis.... & & 16 & 3 & $\dddot{7}$ & & & 6 & 16 & 32 \\
\hline Incomplete paralysis ....... & 1 & 4 & & & & & 2 & 3 & 8 \\
\hline $\begin{array}{l}\text { Paralysis from acute disease. } \\
\text { Chorea................... }\end{array}$ & & & & & & & & $\begin{array}{l}1 \\
2\end{array}$ & $\begin{array}{l}1 \\
3\end{array}$ \\
\hline $\begin{array}{l}\text { Chorea } . . . \ldots \ldots \ldots \\
\text { Spasm } \ldots \ldots \ldots \ldots\end{array}$ & & & & & & & & 4 & 4 \\
\hline Torticollis.......... & & 2 & 1 & & & & 1 & 5 & 7 \\
\hline $\begin{array}{l}\text { Facial spasm........ } \\
\text { Eclampsia, uremic. }\end{array}$ & $\cdots$ & & & . & & & & 2 & 2 \\
\hline $\begin{array}{l}\text { Eclampsia, uremic. } \\
\text { Epilepsy. . . . . . . . }\end{array}$ & $\ddot{2}$ & $\begin{array}{r}1 \\
18\end{array}$ & & & & 1 & & & $\begin{array}{r}1 \\
43\end{array}$ \\
\hline $\begin{array}{l}\text { Epilepsy ... } \\
\text { Vertigo .... }\end{array}$ & 1 & $\begin{array}{r}18 \\
9\end{array}$ & $\begin{array}{l}2 \\
5\end{array}$ & $\begin{array}{r}10 \\
4\end{array}$ & $\begin{array}{l}3 \\
1\end{array}$ & 3 & 2 & $\begin{array}{l}20 \\
36\end{array}$ & $\begin{array}{l}43 \\
46\end{array}$ \\
\hline Headache ......... & 1 & 8 & 7 & & & & i & 110 & 119 \\
\hline Hyperesthesia.......... & & $\cdots$ & & & & & & 3 & 3 \\
\hline Anesthesia............ & $\dddot{4}$ & $\overline{3} \overline{7}$ & & & & & & $\begin{array}{r}1 \\
214\end{array}$ & $\begin{array}{r}1 \\
255\end{array}$ \\
\hline Neuralgia.......... & $\begin{array}{l}4 \\
1\end{array}$ & $\begin{array}{r}37 \\
3\end{array}$ & 30 & 9 & 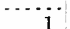 & 1 & 1 & $\begin{array}{r}214 \\
6\end{array}$ & $\begin{array}{r}255 \\
10\end{array}$ \\
\hline $\begin{array}{l}\text { Hysteria............ } \\
\text { Nervous weakness... }\end{array}$ & $\begin{array}{l}1 \\
4\end{array}$ & $\begin{array}{r}3 \\
30\end{array}$ & $\begin{array}{l}1 \\
9\end{array}$ & 15 & 10 & & & 187 & 221 \\
\hline \multicolumn{10}{|l|}{ Hiccough. .......... } \\
\hline \multicolumn{10}{|l|}{ Mental diseases: } \\
\hline Mania.............. & 12 & 2 & 1 & 1 & & & 12 & 2 & 16 \\
\hline Melancholia........ & 2 & 7 & 2 & 3 & 2 & & 2 & 9 & 18 \\
\hline Dementia.................. & 27 & 6 & & 2 & 2 & 1 & 28 & 2 & 35 \\
\hline \multicolumn{10}{|l|}{ 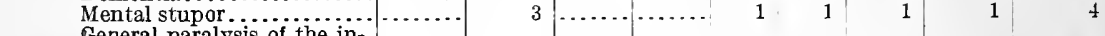 } \\
\hline \multicolumn{4}{|l|}{ General paralysis of the in- } & 1 & & 1 & 9 & & \\
\hline 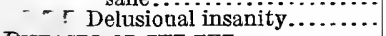 & 4 & 3 & 2 & & & 1 & 4 & 1 & 8 \\
\hline \multirow{2}{*}{\multicolumn{10}{|c|}{$\begin{array}{l}\text { DISEASES OF THE EYY } \ldots \ldots \ldots \ldots \ldots \\
\text { Conjunctivitis: }\end{array}$}} \\
\hline & & & & & & & & & \\
\hline \multicolumn{10}{|l|}{$\begin{array}{c}\text { Catarrbal- } \\
\text { Acute... }\end{array}$} \\
\hline $\begin{array}{r}\text { Chronic............... } \\
\text { Purulent......... }\end{array}$ & & 3 & 3 & & & & & 13 & 16 \\
\hline \multirow{2}{*}{\multicolumn{9}{|c|}{ Chronic hyperemia of conjunctiva }} & \\
\hline & & & & & & & & & \\
\hline \multicolumn{10}{|l|}{$\begin{array}{l}\text { Keratitis } \\
\text { Ulceration of cornea. }\end{array}$} \\
\hline \multirow{2}{*}{\multicolumn{10}{|c|}{$\begin{array}{l}\text { Opacity of cornea } \\
\text { Congestion of eyeball } . . . \ldots \ldots \ldots\end{array}$}} \\
\hline & & & & & & & & & \\
\hline \multicolumn{10}{|l|}{ 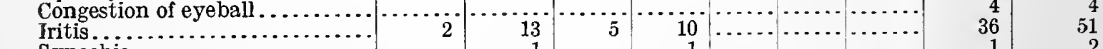 } \\
\hline 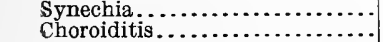 & $\cdots$ & $\begin{array}{l}1 \\
1\end{array}$ & & $\begin{array}{l}1 \\
1\end{array}$ & & $\ldots$ & & & 1 \\
\hline Glaucoma. $=\ldots \ldots \ldots \ldots \ldots \ldots \ldots$ & 1 & 3 & & 2 & 1 & $\cdots$ & 1 & 1 & 5 \\
\hline Optic neuritis .......................... & & 1 & $\cdots \cdots \cdot$ & 1 & & & & & 1 \\
\hline $\begin{array}{l}\text { A trophy and degeneration of } \\
\text { optic nerve or papilla............ }\end{array}$ & 1 & & & & & & 1 & 3 & 4 \\
\hline Retinitis . . . . . & & 1 & 1 & & & & & & 1 \\
\hline Lenticular cataract............. & 1 & 16 & 2 & 3 & 1 & & 11 & 19 & 36 \\
\hline $\begin{array}{l}\text { Detachment of retina } . . \ldots \ldots \ldots \ldots \\
\text { Neuralgia of eyeball. } . . . \ldots \ldots\end{array}$ & & & $\cdots$ & & & & & $\dddot{i}$ & $\begin{array}{l}1 \\
1\end{array}$ \\
\hline $\begin{array}{l}\text { Neuralgia of eyeball } \\
\text { Amblyopia-Functional night }\end{array}$ & & & & & & & & & \\
\hline blindness.................... & & 2 & & 2 & & & & 1 & 3 \\
\hline Ametropia..... & & $\cdots$ & - $\cdots \cdot \cdot$ & & $\ldots \therefore$ & & $\cdots$ & 9 & 9 \\
\hline Color blindness .................. & & & & & & & & 1 & 1 \\
\hline 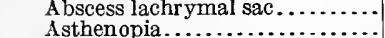 & & & & & & 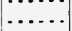 & & 4 & 4 \\
\hline 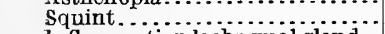 & & 4 & 2 & 1 & 1 & & & 1 & 5 \\
\hline Inflammation lachrymal gland.. & & & & & & & & 1 & $\frac{1}{2}$ \\
\hline $\begin{array}{l}\text { Obstruction of nasal duct...... } \\
\text { Epiphora. } \ldots \ldots \ldots \ldots \ldots \ldots\end{array}$ & & 1 & 1 & & & & & 1 & $\begin{array}{l}2 \\
1\end{array}$ \\
\hline 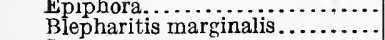 & & & & & & & & 9 & 9 \\
\hline Sty $\ldots \ldots \ldots \ldots \ldots \ldots$ & & 3 & 2 & 1 & & & & $\begin{array}{r}31 \\
3\end{array}$ & $\begin{array}{r}3+ \\
3\end{array}$ \\
\hline & & & & & & & & & 3 \\
\hline
\end{tabular}




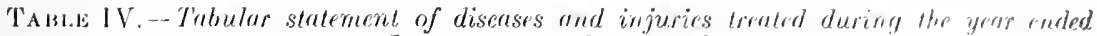
June ?n, 191:-Contimuerl.

\begin{tabular}{|c|c|c|c|c|c|c|c|c|}
\hline \multicolumn{9}{|c|}{ Number of cases. } \\
\hline 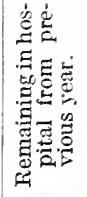 & 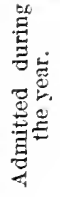 & 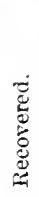 & 7 & 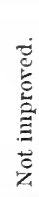 & 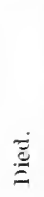 & 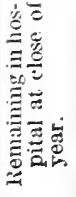 & 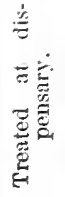 & 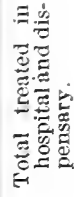 \\
\hline
\end{tabular}

Local diseases-Continued.

Diseases OF THE EYE-Contd.

Erchymosis of eyelid....

Trichiasis.

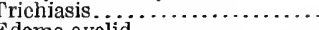

Entropin.

Ptosis.

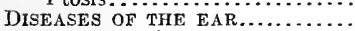

Inflammation of the external meatus-

Acute....

Chrovic.

Abscess.

Hematoma of the auricle

Accumulation in external me-

atus of wax or epidermis

Inflammation of the middle

ear-

Suppurative..................

Perforation of membrana tym-

pani.

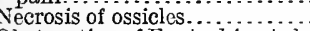

Obstruction of Eustachian tube.

Tinnitus

Deafness.

Diseases OF THE NOSE..........

Inflammation of soft parts...

Inflammation of framework, Necrosis.

Diseases of septum-

Abscess...

Deviations

Epistaxis.

Inflainmation of the accessory sinuses .....................

Inflammation of the nasopharynx...................

DISEASES OF THE CIRCULATORY SYSTEM.

Pericarditis

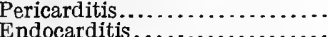

Valvular disease-

Aortic.

Mitral.

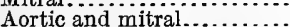

Degeneration of heart, fatty

Myocarditis......................

Hypertrophy of heart

Dilatation of heart

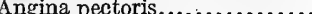

Disordered action of the heartAbnormal slowness

Abnormal rapidity.

gularity...

Arteritis

Degeneration of arteries-Arterio-capillary fibrosis.

Aneurism of arteries .............

Obstruction of arteries-Throm-

phlebitis.

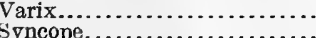

Disease of coronary arteries ...

DISEASES OF THE RESPIRATORY SYSTEM.

II ay fever

......

Tracheitis, catarrhai

Inflammation of mucous membrane of larynx-Catarrhal,

acute.

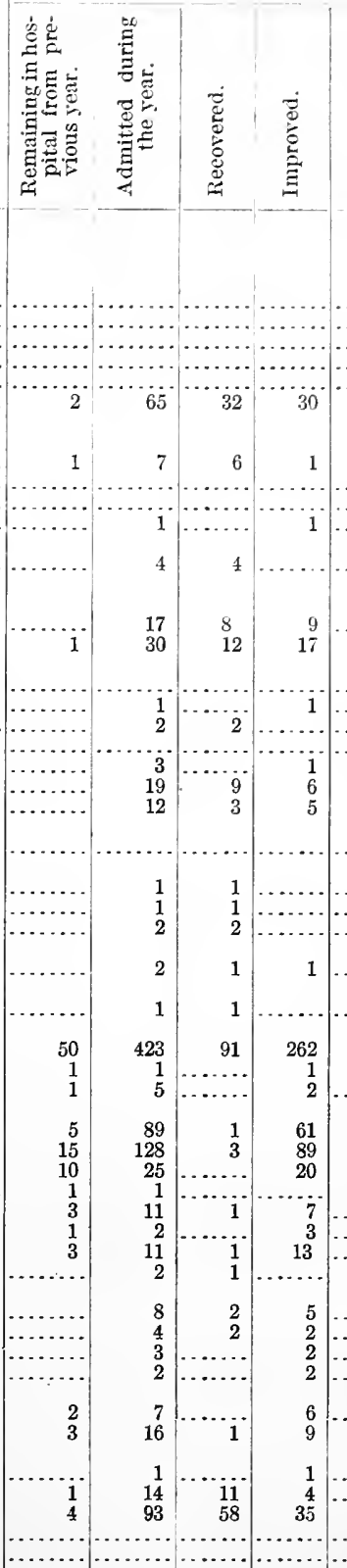

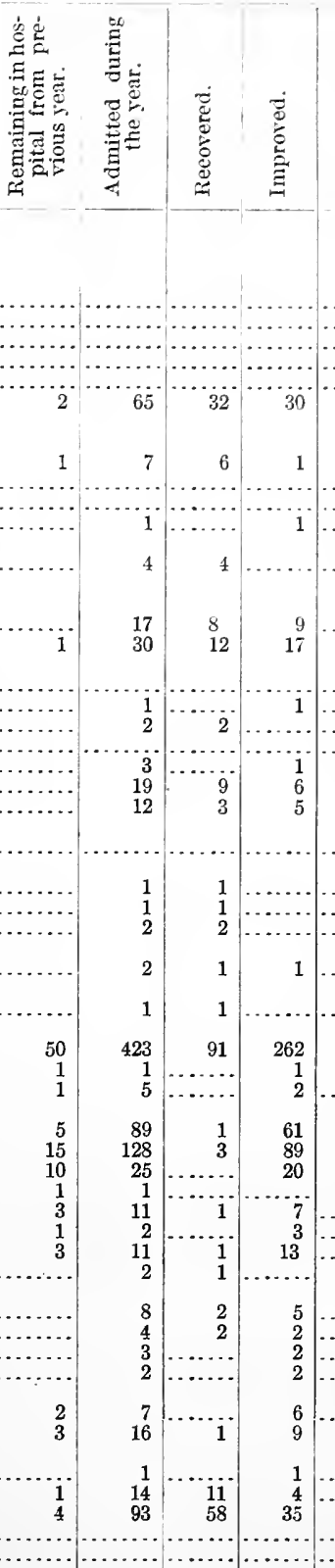

,

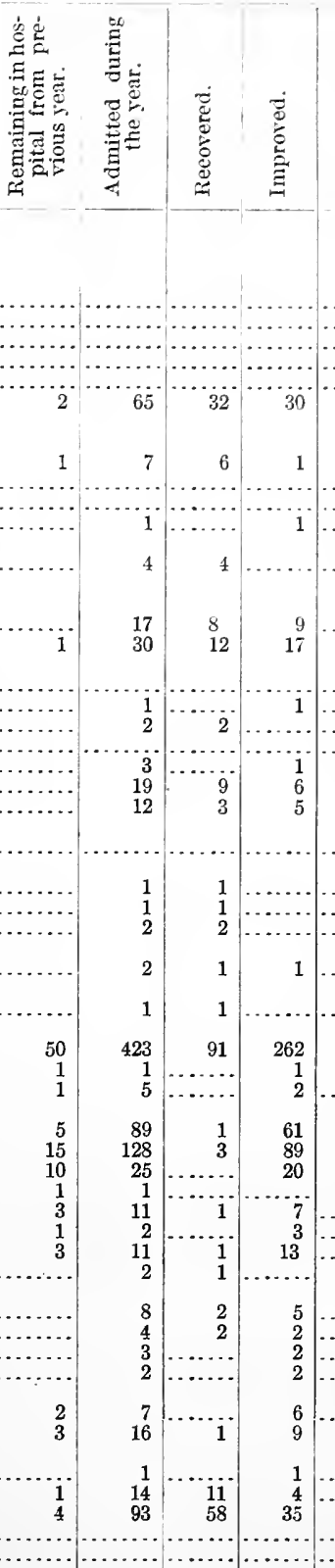

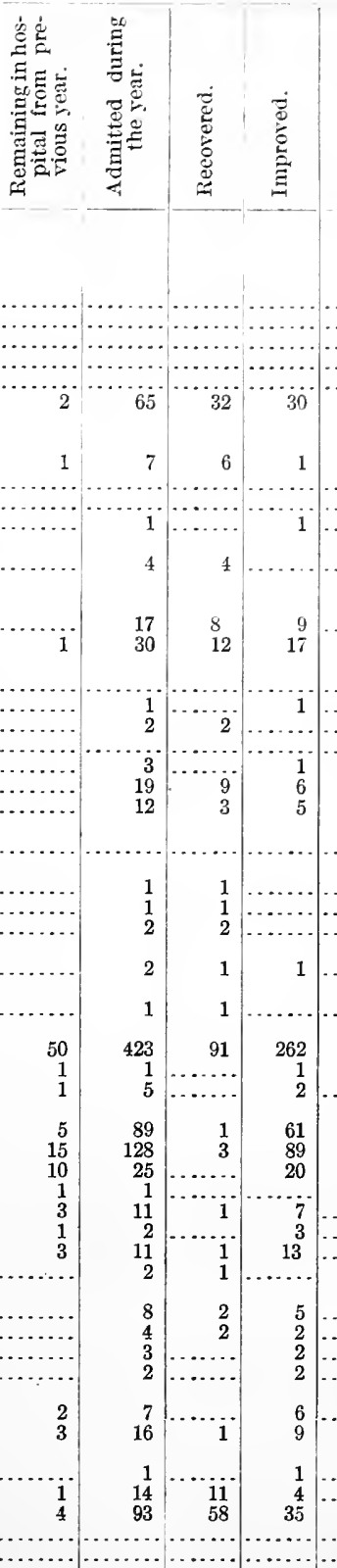

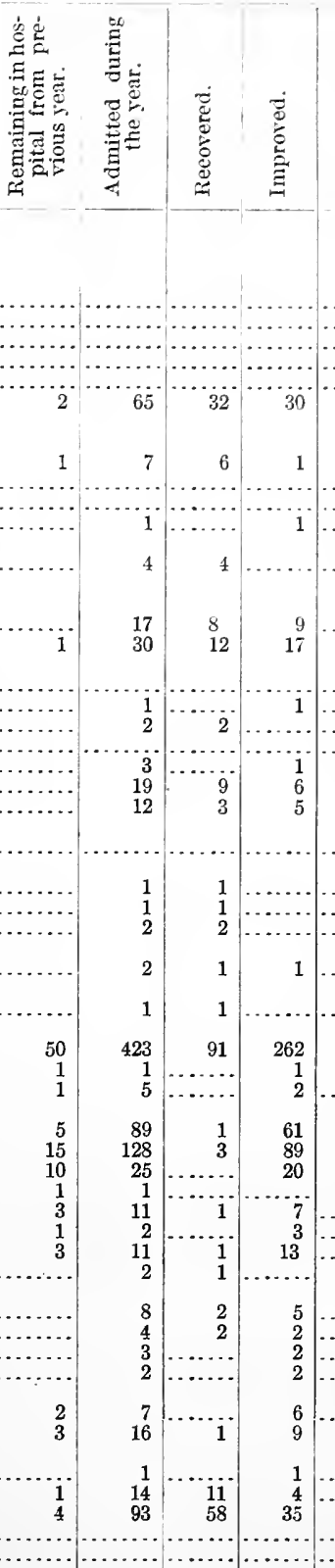

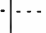

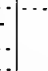

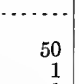

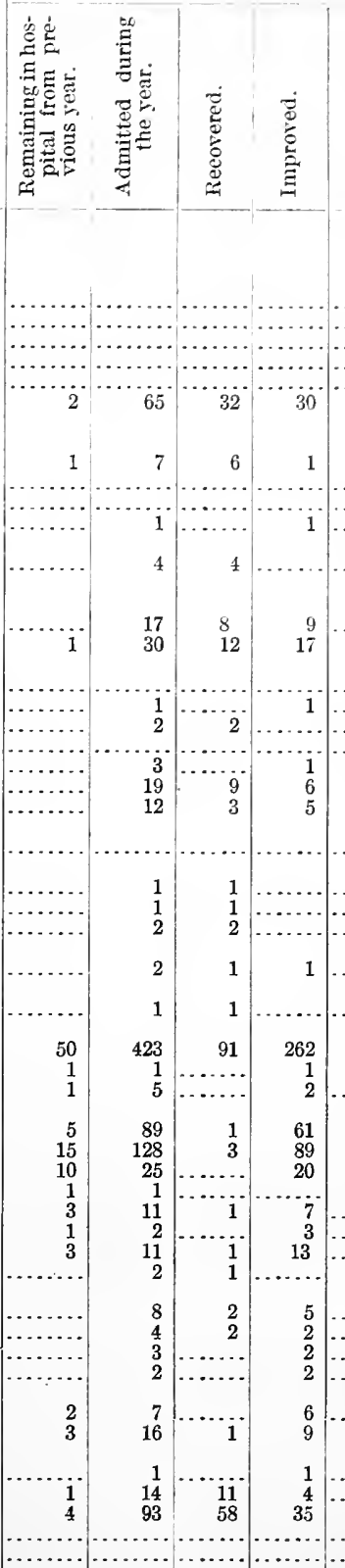

.

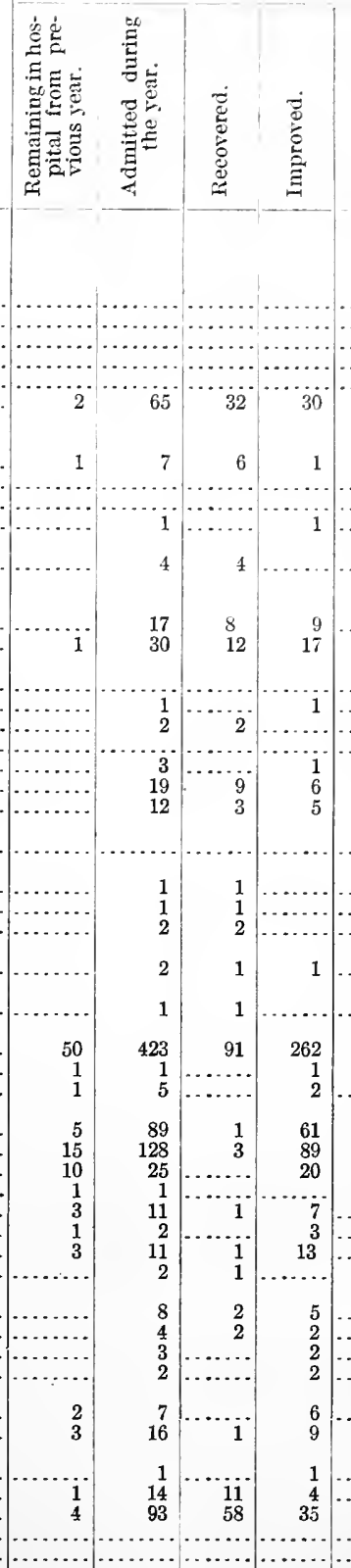

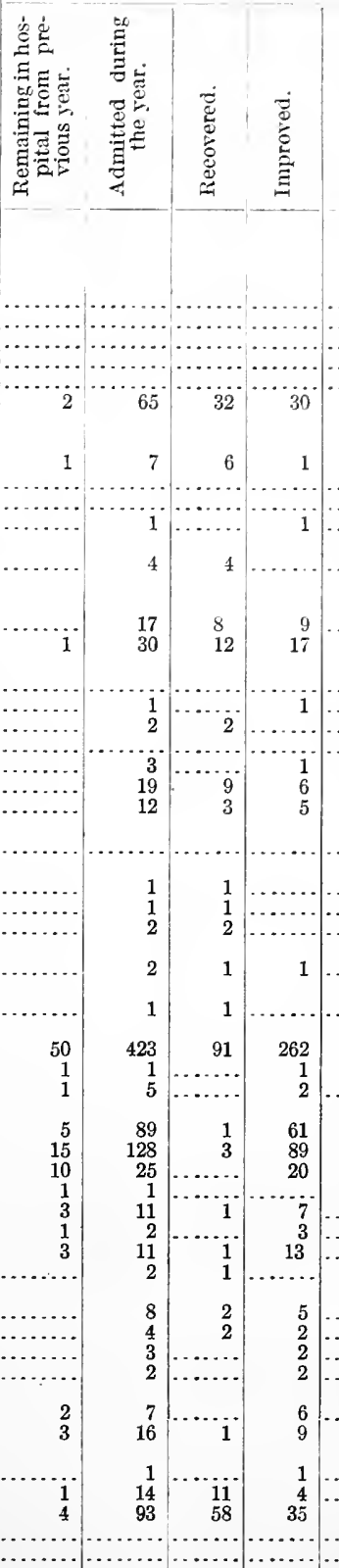

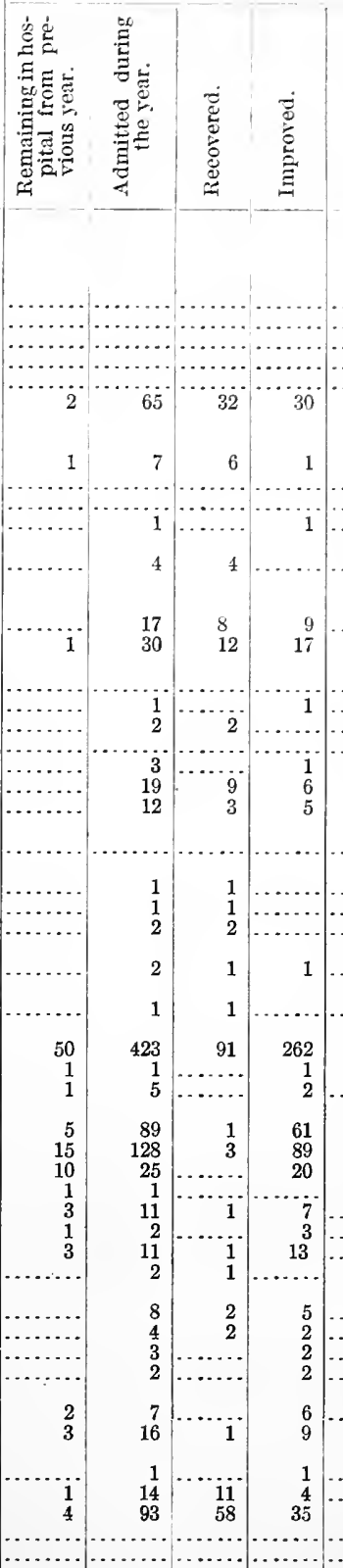

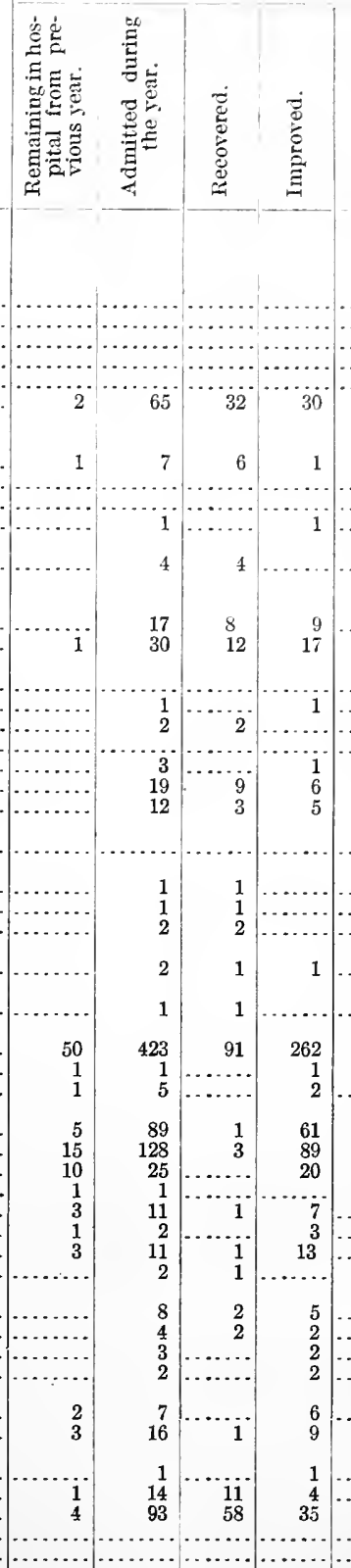

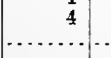

31

$\ldots . .$.

31

755

240

$\ldots \ldots \ldots$

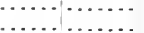

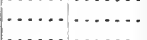


TABLE IV.-Tabular statement of diseases and injuries treated during the year ended June 30, 1912-Continued.

\begin{tabular}{|c|c|c|c|c|c|c|c|c|c|}
\hline \multirow{2}{*}{ Diseases. } & \multicolumn{9}{|c|}{ Number of cases. } \\
\hline & 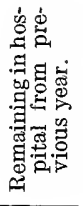 & 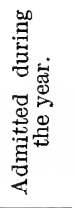 & 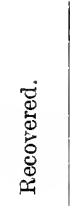 & 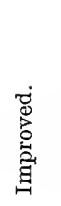 & 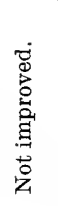 & 总 & 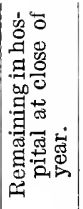 & 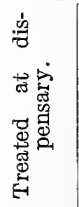 & 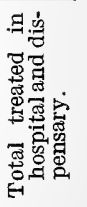 \\
\hline \multicolumn{10}{|l|}{ Local diseases-Continued. } \\
\hline \multicolumn{10}{|l|}{$\begin{array}{l}\text { DISEASES OF THE RESPIRATORY SYS- } \\
\text { TEM-Continued. }\end{array}$} \\
\hline Catarrhal, acute.... & 3 & 271 & 206 & 58 & 6 & & 4 & 1,931 & 2,205 \\
\hline Catarrhal, chronic. & 6 & 130 & 33 & 92 & 4 & 1 & 6 & 231 & 367 \\
\hline Spasmodic asthma.... & 4 & 39 & 9 & 29 & 1 & 1 & 3 & 115 & 158 \\
\hline \multirow{2}{*}{\multicolumn{10}{|c|}{ 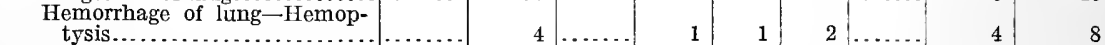 }} \\
\hline & & & & & & & & & \\
\hline 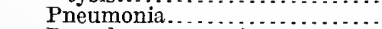 & $\ddot{7}$ & 130 & 95 & 9 & 1 & 28 & 5 & $\begin{array}{l}4 \\
8\end{array}$ & $\begin{array}{r}8 \\
145\end{array}$ \\
\hline Broncho-pneumonia. & 2 & 16 & 14 & 1 & & 3 & & & 18 \\
\hline Abscess of lung..... & & 3 & 2 & & & & 1 & & 3 \\
\hline \multirow{2}{*}{\multicolumn{10}{|c|}{$\begin{array}{l}\text { Phthisis- } \\
\text { Acute........ }\end{array}$}} \\
\hline & 1 & & & & & & 1 & 3 & 4 \\
\hline Chronic.......... & 3 & 3 & $\ldots$ & 2 & 1 & & 3 & 8 & 14 \\
\hline Tubereular....... & & 2 & & & 1 & 1 & & 2 & 4 \\
\hline \multicolumn{10}{|l|}{ Pleurisy- } \\
\hline 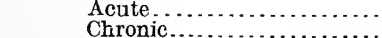 & & 108 & 77 & 23 & 1 & 5 & 2 & 214 & 322 \\
\hline $\begin{array}{r}\text { Chronic.......... } \\
\text { Empyema......... }\end{array}$ & $\ddot{3}$ & 16 & 6 & 8 & & 1 & 1 & 16 & 32 \\
\hline $\begin{array}{l}\text { Empyema............ } \\
\text { Hydrothorax....... }\end{array}$ & $\begin{array}{l}3 \\
1\end{array}$ & $\begin{array}{l}5 \\
1\end{array}$ & 3 & 2 & & 2 & 1 & 5 & 13 \\
\hline $\begin{array}{l}\text { Hydrothorax ........... } \\
\text { Adhesions of pleura.... }\end{array}$ & & & & 1 & & & & 1 & $\because$ \\
\hline Emphysema, vesicular............. & 1 & 6 & 1 & 5 & & 1 & & & $\frac{1}{7}$ \\
\hline \multicolumn{10}{|l|}{ DISEASES OF THE DIGESTIVE SYS- } \\
\hline 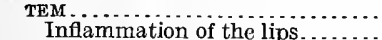 & 61 & 1,765 & 1,331 & 383 & 51 & 28 & 33 & 5,866 & 7,692 \\
\hline Ulceration of the lips........... & & 1 & $\cdots$ & 1 & & & & $\begin{array}{l}6 \\
3\end{array}$ & $\begin{array}{l}6 \\
4\end{array}$ \\
\hline Fissure of the lips........ & & & & & & & & 1 & 1 \\
\hline Inflammation of the mouth..... & 1 & 4 & 3 & 1 & 1 & 1 & & 97 & 102 \\
\hline Ulceration of the mouth......... & & 1 & 1 & & & & & 14 & 15 \\
\hline Inflammation of the dental pulp. & & & & & & & & 1 & 1 \\
\hline Suppuration of the dental pulp. & & & & & & & & 5 & 5 \\
\hline Caries of dentine and cementum. & & & & & & & & 87 & 87 \\
\hline Necrosis of cementum & & & & & & & & 4 & 4 \\
\hline $\begin{array}{l}\text { Inflammation of dental perios- } \\
\text { teum } . \ldots \ldots \ldots \ldots \ldots\end{array}$ & & 3 & 1 & 2 & & & & 7 & 10 \\
\hline Abscess of dental periostem..... & 1 & 6 & 3 & 4 & & & & 74 & 81 \\
\hline \multicolumn{10}{|l|}{$\begin{array}{l}\text { Inflammation of gums and al- } \\
\text { veoli..... }\end{array}$} \\
\hline 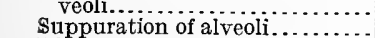 & & $\begin{array}{l}3 \\
7\end{array}$ & 1 & 2 & & & & 16 & 19 \\
\hline Ulceration of gums an & & 1 & 1 & 5 & & & & $\begin{array}{r}10 \\
3\end{array}$ & $\begin{array}{r}17 \\
4\end{array}$ \\
\hline Caries of the alveoli... & & 2 & 2 & & & & & 1 & 3 \\
\hline Toothache.......... & & & & & & & & 120 & 120 \\
\hline Necrosis of alveoli. & & 1 & 1 & & & & & & 1 \\
\hline Ulceration of tonsils............. & & 5 & 2 & 3 & & & & & 5 \\
\hline Inflammation of the tongue..... & & 2 & 1 & 1 & & & & 7 & 9 \\
\hline Ulceration of the tongue........ & 1 & 2 & 1 & 2 & & & & 5 & 8 \\
\hline \multicolumn{10}{|l|}{ Inflammation of tonsils - } \\
\hline Follicular....................... & & 177 & 160 & 15 & 2 & & & 482 & 659 \\
\hline Suppuration... & & 65 & 36 & 29 & & & & 31 & 96 \\
\hline Hypertrophy of tonsils. & & 7 & 4 & 3 & & & & 5 & 12 \\
\hline 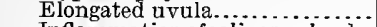 & & & & & & & & 2 & 2 \\
\hline Inflammation of salivary glands. & & 2 & 2 & & & $\cdots$ & & 1 & 3 \\
\hline 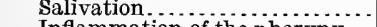 & & & & & & & & 3 & 3 \\
\hline \multicolumn{10}{|l|}{ Inflammation of the pharynx- } \\
\hline Catarrhal...................... & & 18 & 15 & 3 & & & & 260 & 278 \\
\hline Granula & & 1 & & 1 & & & & 4 & $\begin{array}{r}5 \\
10\end{array}$ \\
\hline Follicular ........... & & $\begin{array}{l}6 \\
1\end{array}$ & 3 & 2 & $\cdots \cdots$ & 1 & & 4 & 10 \\
\hline Post-pharyngeal abscess.. & & 1 & 1 & & & & & 1 & 2 \\
\hline \multirow{2}{*}{\multicolumn{10}{|c|}{ Dysphagia........................... }} \\
\hline & & & & & & & & & \\
\hline \multicolumn{10}{|l|}{$\begin{array}{l}\text { Stricture of esophagus........... } \\
\text { Inflammation of the stomach- }\end{array}$} \\
\hline $\begin{array}{l}\text { Inflarnmation of the stomach- } \\
\text { Catarrhal .................... }\end{array}$ & 5 & 192 & 113 & 73 & 5 & 2 & 4 & 321 & 518 \\
\hline Ulceration of the stomach- & & & & & & & & & 010 \\
\hline Superficial....................... & 2 & 11 & 4 & 7 & 2 & & & 10 & 23 \\
\hline $\begin{array}{l}\text { Perforating } \\
\text { Hemorrhage of the }\end{array}$ & & $\mathbf{3}$ & 1 & 1 & & 1 & & & $\begin{array}{l}3 \\
3\end{array}$ \\
\hline Hemorrhage of the s & & 3 & 21 & & & 1 & & & 3 \\
\hline
\end{tabular}


Table IV.--Tabular statement of diseases and injuries treated during the your conded June 89, 1912-Continued.

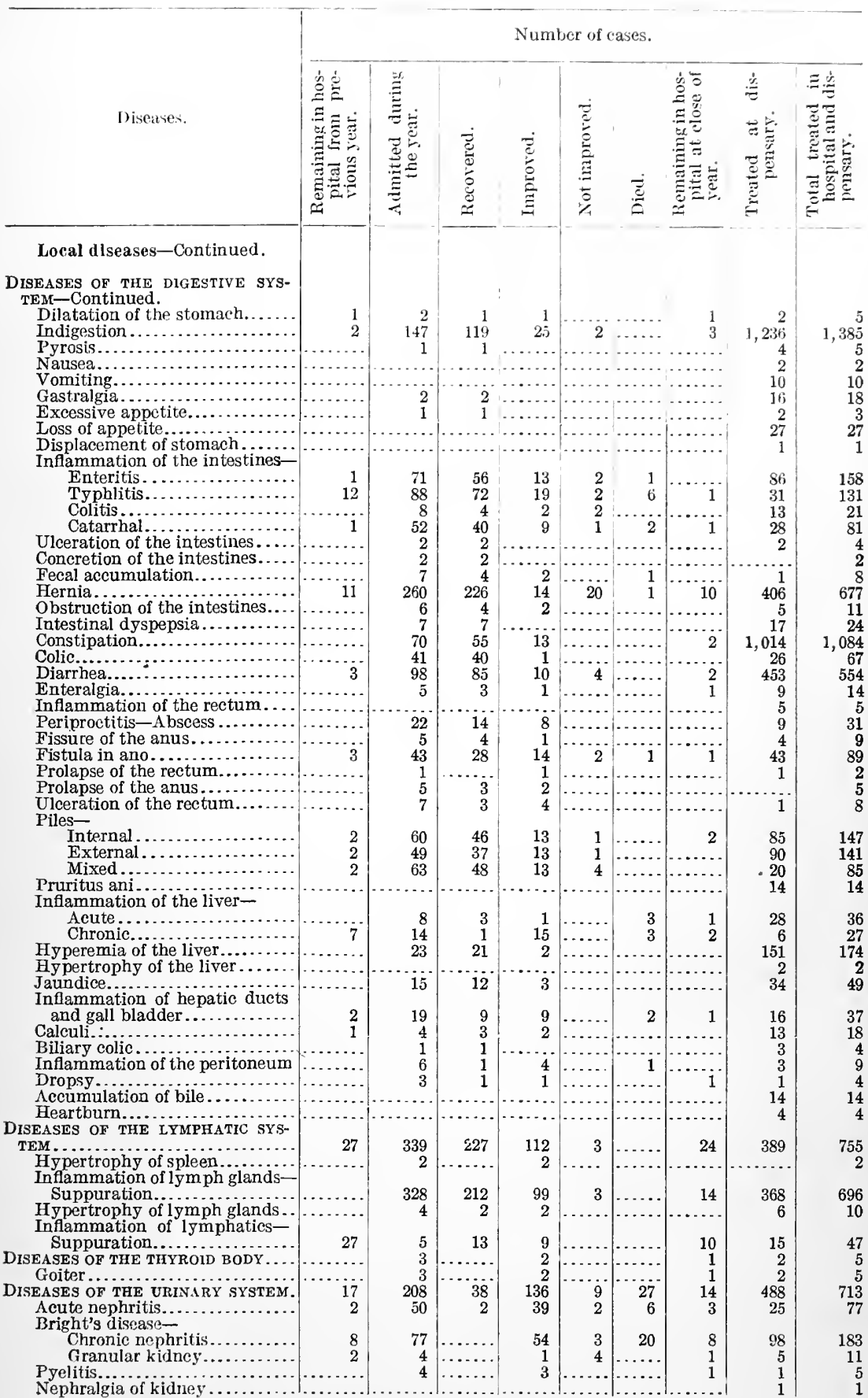


TABLE IV.- Trinlar stutement of diseases and injuries treated during the year ended June 30, 191?-Continued.

\begin{tabular}{|c|c|c|c|c|c|c|c|c|c|}
\hline \multirow[b]{2}{*}{ Diseases. } & \multicolumn{9}{|c|}{ Number of cases. } \\
\hline & 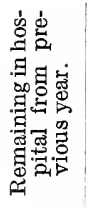 & 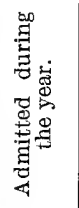 & 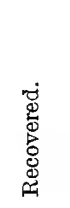 & 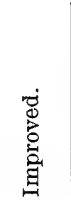 & 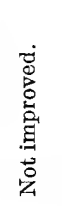 & $\stackrel{\ddot{g}}{\ddot{A}}$ & 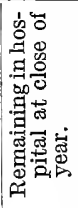 & 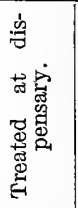 & 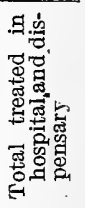 \\
\hline Local diseases-Continued. & & & & & & & & & \\
\hline $\begin{array}{l}\text { DISEASES OF THE URINARY SYS- } \\
\text { TEM-Continued. } \\
\text { AbScess- }\end{array}$ & & & & & & & & & \\
\hline 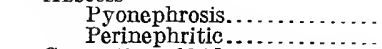 & 1 & $\begin{array}{l}1 \\
3\end{array}$ & 2 & 1 & & 1 & 1 & & $\stackrel{2}{3}$ \\
\hline Congestion of kidney....... & & 1 & 1 & & & & & 1 & $\begin{array}{l}3 \\
2\end{array}$ \\
\hline Movable kidney ...... & & & & & & & & 1 & 1 \\
\hline Calculus in kidney........ & & 11 & 3 & 8 & & & & 10 & 21 \\
\hline Calculus in ureter................. & & 4 & 2 & 2 & & & & 4 & 8 \\
\hline $\begin{array}{l}\text { Suppression of urine } \ldots \ldots \\
\text { Hematuria } \ldots \ldots \ldots\end{array}$ & & $\begin{array}{r}2 \\
12\end{array}$ & $\dddot{7}$ & $\frac{2}{5}$ & & & & $\dddot{9}$ & 2 \\
\hline Albuminuria............... & & 12 & ... & $\therefore$ & & & & $\begin{array}{l}9 \\
1\end{array}$ & $\begin{array}{r}21 \\
1\end{array}$ \\
\hline Lithuria...................... & & & ..... & & & & & 5 & $\frac{1}{5}$ \\
\hline Phosphaturia................. & & & $\cdots \cdots$ & & & & & 8 & 8 \\
\hline $\begin{array}{l}\text { Ulceration of bladder } . . . . . . . . \\
\text { Inflammation of bladder- }\end{array}$ & & 1 & & 1 & & & & & 1 \\
\hline Acute....................... & 2 & 23 & 14 & 11 & & & & 145 & 170 \\
\hline Suhacute........... & & 2 & & 2 & & & & 59 & 61 \\
\hline 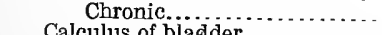 & 2 & 6 & 2 & 6 & & & & 21 & 29 \\
\hline $\begin{array}{l}\text { Calculus of bladder.................. } \\
\text { Oxaluria. }\end{array}$ & & 1 & & & & & & 3 & 4 \\
\hline 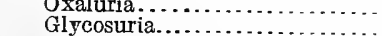 & & & & & & & & 1 & 1 \\
\hline Irritability of bladder..... & & $\ddot{i}$ & $\ddot{1}$ & & & & & 6.5 & $\underset{6 i 6}{1}$ \\
\hline Retention of urine.......... & & 3 & 2 & & & & & 12 & 1.5 \\
\hline Incontinence of urine......... & & 2 & 1 & 1 & & & & 12 & 14 \\
\hline DISEASES OF THE GENERATIVE & & & & & & & & & \\
\hline $\begin{array}{l}\text { SYSTEM } \\
\text { Urethritis. } . . \cdots \cdots\end{array}$ & 64 & $\begin{array}{r}908 \\
2\end{array}$ & 572 & $\begin{array}{r}349 \\
2\end{array}$ & 14 & 6 & 31 & 2,145 & 3,117 \\
\hline Gleet........................... & & & & & & & & & 22 \\
\hline Abscess of the urethra... & & 3 & 2 & 1 & & & & 2 & 5 \\
\hline Ulcer of the urethra ........... & . & 1 & 1 & & & & & & \\
\hline $\begin{array}{l}\text { Stricture of urethra } \\
\text { Organic................. }\end{array}$ & 12 & 110 & 34 & 79 & 4 & 2 & 3 & 336 & 458 \\
\hline Traumatic................... & & & & 18 & $\boldsymbol{4}$ & & & $\begin{array}{r}500 \\
5\end{array}$ & $\begin{array}{r}408 \\
5\end{array}$ \\
\hline Urethral fistula. . . . & & $\ddot{2}$ & 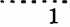 & 1 & & & & & 2 \\
\hline Inflammation of the prostate- & & & & & & & & & \\
\hline Acute $\ldots \ldots \ldots \ldots \ldots \ldots$ & & 3 & 1 & 2 & & & & 15 & 18 \\
\hline Chronic.... & & 5 & 3 & 2 & & & & 7 & 12 \\
\hline 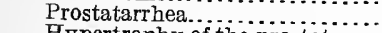 & & 1 & 1 & & & & & 4 & \\
\hline Hypertrophy of the prostate... & $i$ & 10 & & 5 & & $\ddot{3}$ & 3 & 16 & 27 \\
\hline 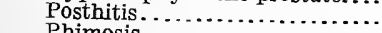 & & 4 & 3 & 1 & & & & 7 & 11 \\
\hline Phimos & $i$ & 86 & 69 & 14 & 3 & & 1 & 39 & 126 \\
\hline Paraphimosis................. & & 13 & 10 & 3 & & & & 9 & 22 \\
\hline Inflammation of the penis-of & & & & & & & & & \\
\hline 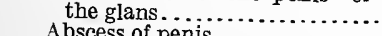 & & 6 & 4 & & & & 2 & 24 & 30 \\
\hline $\begin{array}{l}\text { Abscess of penis ................. } \\
\text { Ulcer of penis }\end{array}$ & $\ddot{8}$ & $\begin{array}{r}2 \\
103\end{array}$ & 2 & & & & & 1 & 3 \\
\hline 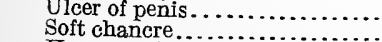 & 30 & $\begin{array}{l}103 \\
333\end{array}$ & $\begin{array}{r}47 \\
220\end{array}$ & $\begin{array}{r}58 \\
128\end{array}$ & $\begin{array}{l}3 \\
2\end{array}$ & & $\begin{array}{r}3 \\
13\end{array}$ & .312 & 423 \\
\hline 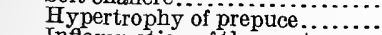 & & 2 & $\begin{array}{r}220 \\
2\end{array}$ & & & & & $\begin{array}{r}808 \\
2\end{array}$ & $\begin{array}{r}1,201 \\
4\end{array}$ \\
\hline Inflammation of the scrotum... & & & & & & & & 4 & \\
\hline Edema of the scrotum.......... & & 1 & 1 & & & & & & \\
\hline Abscess of the scrotum............ & & 5 & 2 & 1 & 1 & ....... & 1 & 4 & 9 \\
\hline $\begin{array}{l}\text { Inflammation of the spermatic } \\
\text { cord } . . . . . . . . . . . . . .\end{array}$ & & 1 & 1 & & & & & 6 & \\
\hline Hydrocele of the spermatic cord. & & 14 & 10 & 2 & & 1 & 1 & 20 & 34 \\
\hline 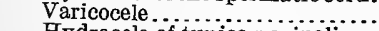 & 2 & 40 & 34 & 7 & & & 1 & 101 & 143 \\
\hline Hydrocele of tunica vaginalis... & & 30 & 19 & 8 & 1 & & 2 & 39 & 69 \\
\hline Inflammation of the testicle- & & & & & & & & & \\
\hline Acute orchitis... & 5 & 93 & 74 & 23 & & & 1 & 217 & 315 \\
\hline Epididymitis............... & 5 & 28 & 24 & 9 & & & & 13 & 46 \\
\hline Abscess of testicle.............. & & 1 & & & & & & & \\
\hline Spermatorrhea....... & & $\hat{1}$ & $i$ & & & & & 6 & 7 \\
\hline 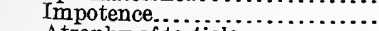 & & & & & & .. & & 17 & 17 \\
\hline Atrophy of testicle....... & & 1 & & 1 & & & & 1 & \\
\hline Inflammation of the ovary ....... & & & & & & & & 1 & 1 \\
\hline Inflammation of the fallopian & & & & & & & & & \\
\hline Infiammation of the uterus. & & $\begin{array}{l}5 \\
1\end{array}$ & $\stackrel{5}{1}$ & & & & & 2 & i \\
\hline
\end{tabular}


ТАвнE IV.-T'Jubular statement of diseases and injuries treated during the year evded June 30, 1912-Continued.

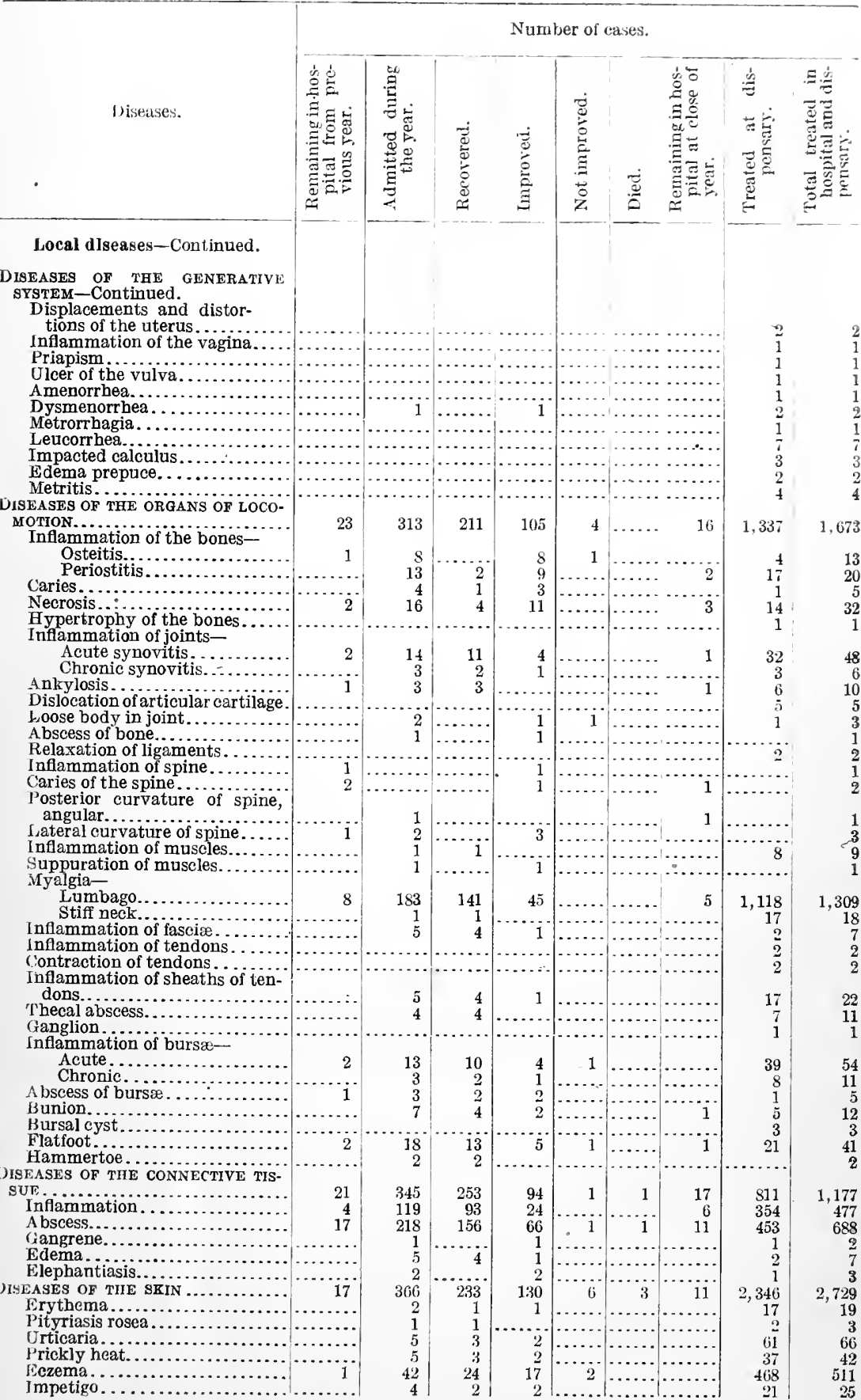


TABLE IV.-Tabular statement of diseases and injuries treated during the year ended June 30, 1912-Continued.

viseases.

Local diseases-Continued.

DISEASES OF THE SKIN-Continued.

Pityriasis rubra.....................

Prurigro.

Lichen...................................

Psoriasis.

Herpes

Zona

Pemphigus

Dermatitis herpetiform is...............

Acne ....................... 1

Gutta rosea.

Sycosis....

Iohthy

Sudamina.

Cholọasma.

Alopecia

Chilblain

Ulcer....

Cicatrices.

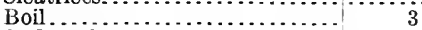

Carbuncle.

Whitlow.

Onychia.

Corn

Cheloid.

Wen.

Hyperidrosis

Pruritis

Lupus.

Keratosis pilaris

Bromidrosis .

Anidrosis.

Tylosis

General InJURTES

Effects of heat-

Burns and scalds.....

Heat stroke.

Effects of cold

Effects of chemical irritants and

corrosives.

Multiple injury.

Exhaustion

Shock.

LOCAL INJURIES

ture of rein......

wound of blood vessel, punc

tured........................

Contusion of veins.

Wound of kidney...

Contusion of muscles. . . . . .

Strain of muscles.

Wound of muscle.

Strain of tendons ....

Rupture of tendons.

Wound of tendons.

Contusion of skin

Abrasion of skin

Wound of skin.

Burn or scald of skin. . ...........

Frostbite ..............................

corrosives .

Contusion of mucous membrane

Abrasion of mucous membrane.

Wound of mucous membrane..

Burn or scald of mucous mem-

Number of cases.

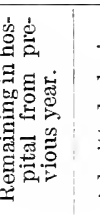

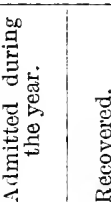

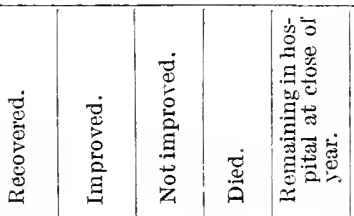

点

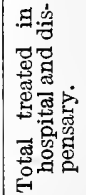
brane. 
TABLE IV.- Tabular statement of diseases and injuries treatad during the yror tmol June 30, 1912-Continued.

Number of cases.

\begin{tabular}{|c|c|c|c|c|c|c|c|c|}
\hline 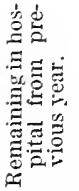 & 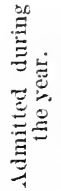 & 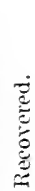 & 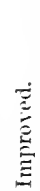 & $\begin{array}{l} \\
\\
0 \\
0 \\
0\end{array}$ & $\stackrel{\vec{Z}}{=}$ & 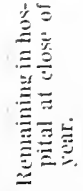 & 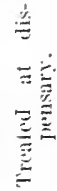 & 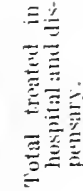 \\
\hline
\end{tabular}

Local dlseases-Continued.

LOCAL INJURIES-Continued.

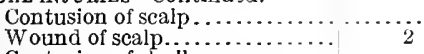

\begin{tabular}{ll|lllll}
20 & 11 & 8 & 1 & $\ldots$ & $\ldots$ & 24
\end{tabular}$\quad 44$

Contusion of skull.....................

Fracture of the vault of skull. ..........

Fracture of the bas e of skull.

Wound of skull.

Concussion of brain.

Contusion of face ..........

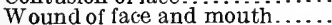

Fracture of facial bones

Dislocation of nasal cartilages.

Injury to alveloi

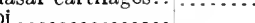

Contusion of cyelid.

Wound of eyelid

Subconjunctival hemorrhage.

Injuries to lachrymal gland.

d...............

Contusion of eyeball

Chemical injury to eye.........

Foreign bodies in the conjune-

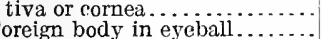

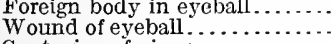

Contusion of pinna.

Wound of pinna ...................

Foreign body in external meatus

Fracture thyroid cartilage.....

Contusion of neck.

Wound of neck.

Foreign body in the food pas

sages...

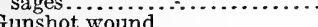

Contusion of chest ....................

Dislocation of costal cartilages..
Fracture of ribs..................

Fracture of sternum

Wound of parietes of chest...

Penetrating wound of pleura or linng.

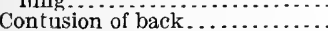

Sprain of back.

Sprain of back. .................

Wound of back

Fracture of spine.

Contusion of abdomen

Wound of parietes of abdomen

Contusion of the pelvis ........

Contusion of the perineum, scrotum, or penis.

Wound of the male urethra perineum, scrotum, testis, or penis.

wound of rectum

Rupture of urethra............

Fracture or dislocation of pelvic bones.

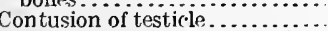
Contusion of upper extremities.

Sprain of shoulder ...............

Srain of elb

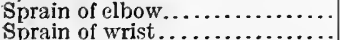

Sprain of hand.

Sprain of thumb...........................

Sprain of upper extremities....

Sprain of upper extremities...

wound of joint, upper extremi-

ties.

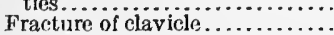

Fracture of seapula.

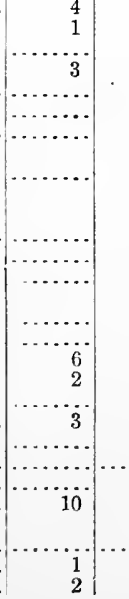

....................... 
TABIE IT.- Tabular statement of diseases and injuries treated during the year ended June 30, 1912-Continued.

Number of cases.

Diseases.

\begin{tabular}{|c|c|c|c|c|c|c|c|c|}
\hline 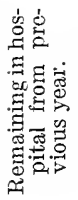 & 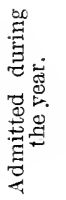 & 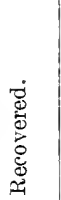 & 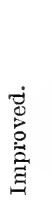 & 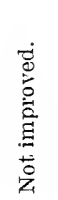 & 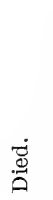 & 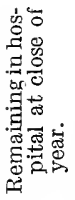 & 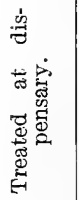 & 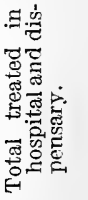 \\
\hline 2 & 25 & 14 & 8 & 3 & 1 & 1 & 4 & 31 \\
\hline 3 & 15 & 9 & 7 & & & 2 & 20 & 38 \\
\hline 1 & 8 & 5 & 3 & & & 1 & 6 & 15 \\
\hline 3 & 33 & 22 & 12 & 2 & & & 18 & 54 \\
\hline & 18 & 8 & 8 & 1 & & 1 & 158 & 176 \\
\hline$\frac{2}{1}$ & 36 & 24 & 14 & . & ... & …..... & 15 & 53 \\
\hline & 5 & 3 & 1 & & & 1 & 5 & 10 \\
\hline & & & & & & & 2 & 2 \\
\hline & 1 & 1 & & & & & $\ddot{2}$ & $\begin{array}{l}1 \\
2\end{array}$ \\
\hline & 25 & 22 & 2 & & & 1 & $7 \overline{3}$ & 98 \\
\hline 9 & 240 & 161 & 80 & 2 & & 6 & 569 & 818 \\
\hline 1 & 13 & 8 & 5 & & & 1 & 18 & 32 \\
\hline $2 \frac{2}{1}$ & 35 & 23 & 14 & & & & 26 & 63 \\
\hline 11 & 83 & 70 & 22 & $\cdots \cdots$ & ...... & 2 & 63 & 157 \\
\hline & 2 & $\begin{array}{l}6 \\
1\end{array}$ & 1 & & & & & 21 \\
\hline 9 & 205 & 148 & 58 & & & 8 & 533 & 747 \\
\hline & 5 & 3 & 2 & & & & 1 & 6 \\
\hline 3 & 26 & 13 & 9 & & 1. & 6 & 2 & 31 \\
\hline & 8 & $\begin{array}{r}4 \\
25\end{array}$ & 2 & 1 & ....... & 1 & & 8 \\
\hline $\begin{array}{r}17 \\
2\end{array}$ & 24 & 13 & 11 & & & $\begin{array}{l}3 \\
2\end{array}$ & 7 & 33 \\
\hline 8 & 56 & 41 & 16 & ...... & 2 & 5 & 3 & 67 \\
\hline 1 & 20 & 16 & 5 & $\ldots$ & & & 3 & 24 \\
\hline 1 & 8 & 2 & 6 & . & $\ldots$ & 1 & 4 & 13 \\
\hline & 5 & 2 & 2 & & & 1 & 4 & 9 \\
\hline & 1 & 1 & . & .... & $\cdots$ & & & 1 \\
\hline & 3 & 2 & 1 & & & & $\because$ & 3 \\
\hline & & & & & & & & \\
\hline & 1 & 1 & & & & & 1 & 2 \\
\hline
\end{tabular}

TABLE V.-Comparative exhibit--Ratio of deaths from specific causes, 1903-1912.

\begin{tabular}{|c|c|c|c|c|c|c|c|c|c|c|c|}
\hline Deaths from- & $\begin{array}{l}\text { Gen- } \\
\text { eral } \\
\text { aver- } \\
\text { age. }\end{array}$ & 1903 & 1904 & 1905 & 1906 & 1907 & 1908 & 1909 & 1910 & 1911 & 1912 \\
\hline $\begin{array}{l}\text { General diseases.... } \\
\text { Diseases of the- }\end{array}$ & 49.14 & 48.06 & 49.49 & 53.46 & 51.52 & 52.17 & 44.92 & 50.00 & 49.03 & 41.90 & 50.80 \\
\hline Diservous system.... & 5.75 & 5.36 & 5.30 & 6.32 & 4.87 & 6.72 & 5.06 & 6.51 & 3.67 & 5.18 & 8.50 \\
\hline Circulatory system. & 11.33 & 10.72 & 8.76 & 11.88 & 11.16 & 10.47 & 12.06 & 8.74 & 13.39 & 15.12 & 11.04 \\
\hline Respiratory system. & 11.74 & 11.64 & 14.66 & 8.81 & 9.13 & 11.06 & 13.42 & 9.87 & 13.60 & 14.90 & 10.35 \\
\hline $\begin{array}{l}\text { Digestive system... } \\
\text { Genito-urinary sys- }\end{array}$ & 6.49 & 7.39 & 7.33 & 4.79 & 5.88 & 5.34 & 4.67 & 10.08 & 7.13 & $5: 83$ & 6.44 \\
\hline 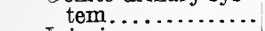 & 7.01 & 6. 65 & 6.72 & 5.74 & 6.09 & 5.54 & 10.13 & 7.85 & 4. 97 & 8.86 & 7.59 \\
\hline Injuries............. & 6.57 & 6.47 & 5.09 & 7.09 & 9.13 & 7.12 & 7.20 & 5.61 & 7.34 & 6.26 & 4. 37 \\
\hline com an otner causes.. & & & & & & & & & & & \\
\hline
\end{tabular}


TABLE VI.-Nativities of patients treated in hospitals during the fiscal yemt cudd fone 30, 1912.

Countries.

Total.

Arabia

Austria .

Australia.

Bahama Islands

Belgium .

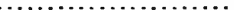

British Guiana.......................

British West Indies

Brazil.

Cape Breton.

Cape Verde Islands......................

Chile.

China

Colombia.

Costa Rica. ........................

Cuba.

Curacso......

Denmark.

Dutch Guiana.....................

Dutch West Indies

East Indies.

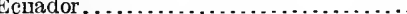

Egypt..

England

Finland.

France.

Germany .....

Grand Cayman

Greece.

Hawailan Islands

Holland
Number.

14,717

187

10

1

8
6

26

6

33

2

12

79

15

8

1

8

20

1

4

8

3

2

345 .

346.

755

8

58

32
Countries.

Nimiler.

Honduras.

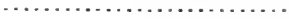

Ireland.

Italy

Jamaica ..........

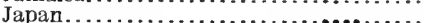

Jore.

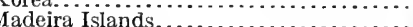

Malta

(n)

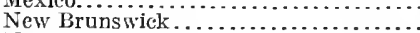

New foundland.

Norway .......

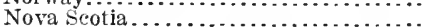

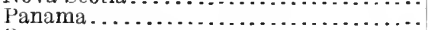

P'eru.......

Philippine Islands

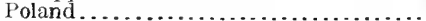

Portugal ................................

Porto Rico.

Prince Edward Island

Roumania.............................

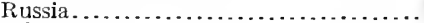

Saba Island

Servia...

Scotland .................

Spain...

Sweden.

Switzerland

Turkey.

Uruguay

United States.

Wales.

West Indies........................

\section{-}

599

20

Table VII.-Surgical operations, fiscal year 1912.

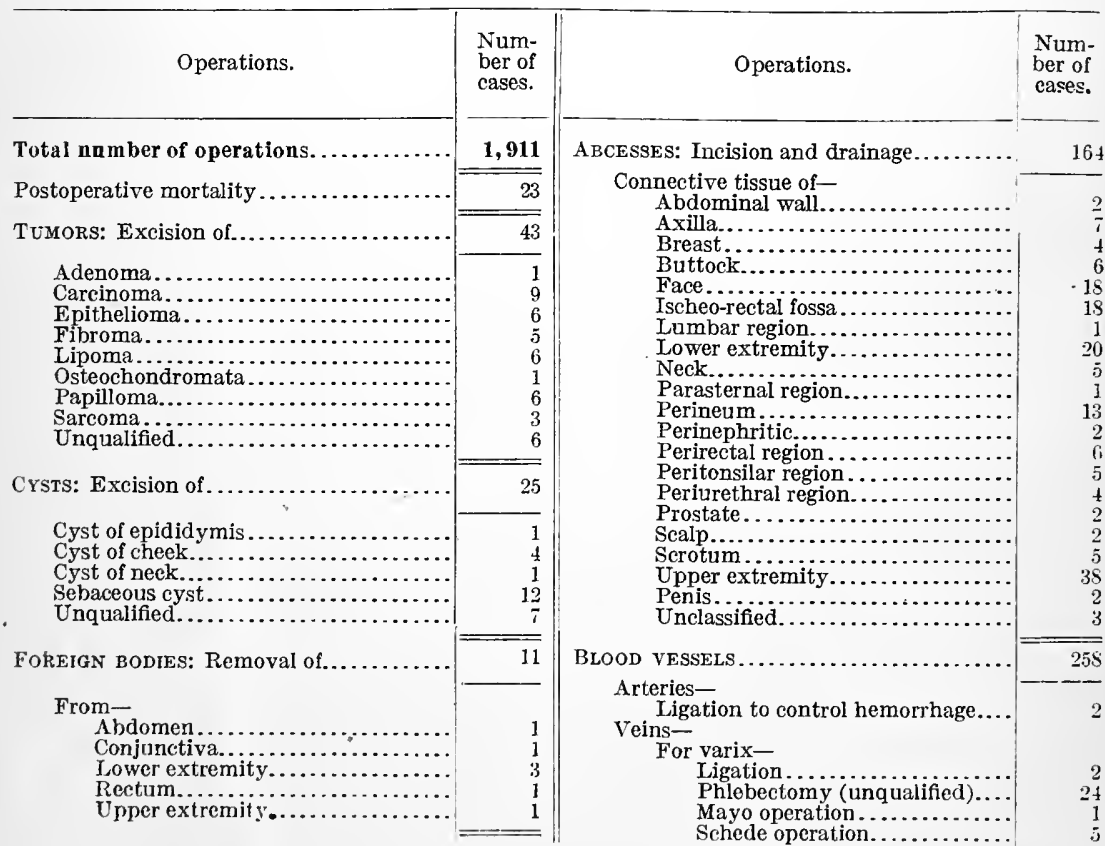


TABLE VII.-Surgical operations, fiscal year 1912-Continued.

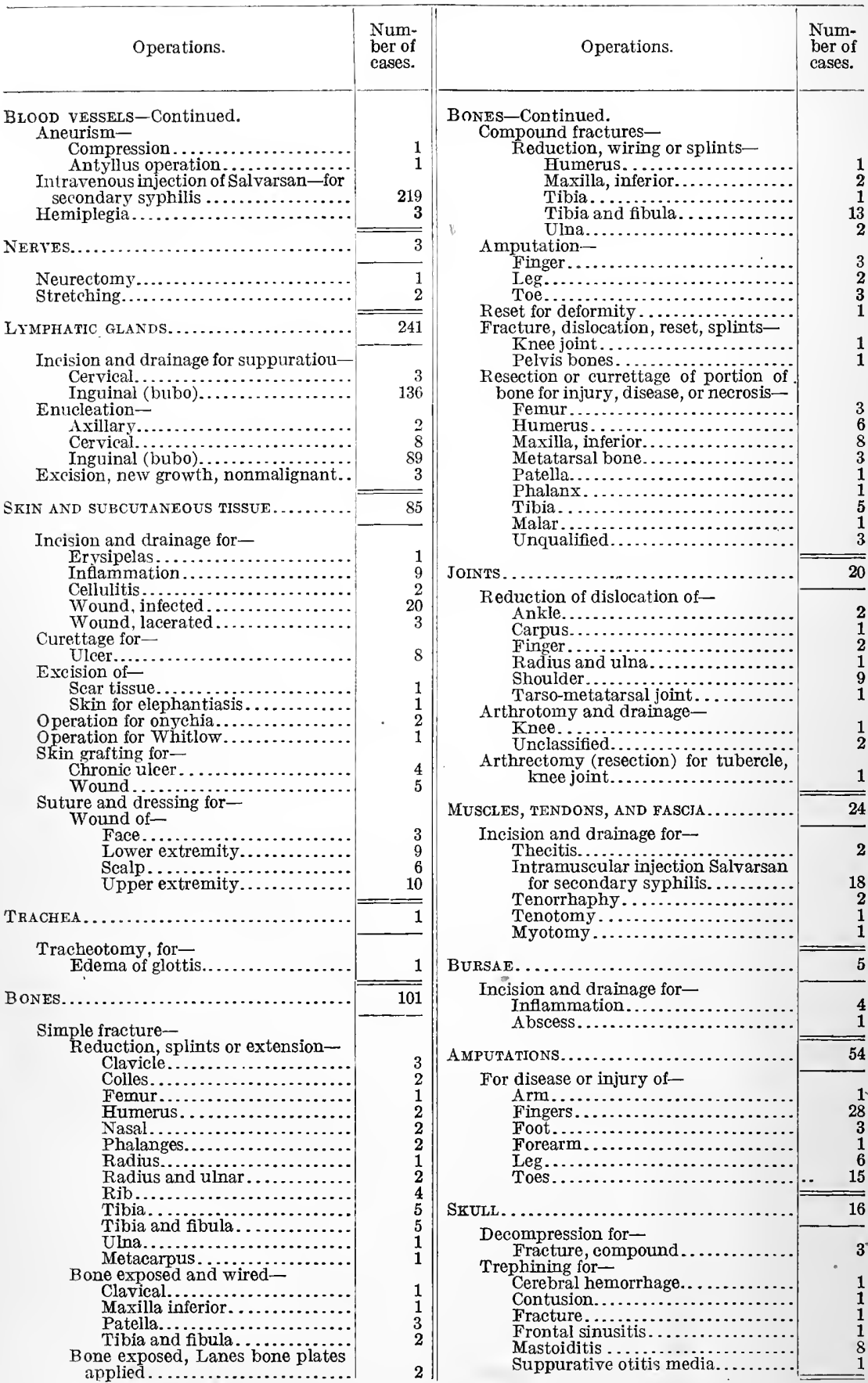


TABLE VII.-S Surgical operations, fiscal year 191:-Continued

\begin{tabular}{l|l} 
& Num- \\
Operations. & Der of
\end{tabular}

cases.

SPINE AND SPINAL CORD

Incision and drainage, for--

Tubercular abscess...

Spinal puncture.

Lamenectomy, for-

Fracture of veriebre.

Face, nasal cayities, and mouth .....

\section{Excision of -}

Nasal septum

Nasal polypus.

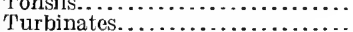

Incision and drainage, for-

Suppurative tonsillitis............

Tomsillot

EYE

Enucleation of eyeball, forInjury .............

Cataract.

Iredectomy, for Glaucoma.

External canthoplasty, for Eetropion.

probing and slitting, forStricture of puncta Iterygium...

Tenotomy, for-

Sirabismus.

THORAX

Thoracentesis, for

Empyemá.

Pleurisy, chronic.

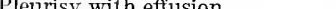

Resection of rib, for Empyema.

Esophagus-

Dilatation for stricture.

ABDOMEN

Abdominal section, forA ppendectomy Closure...

Drainage .

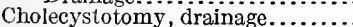

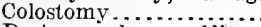
Drainage, abscess of liver.

Entero-enterostomy, forT'ubercle of colon...

Enterorrhaphy, forGunshot wound..

Typhoid perforation.

Exploration, for -

Hypertrophy of liver.

Gastroenterostomy, forCarcinoma of stomach.

Peptic ulcer..... .

Gastroorrhaphy, for-
Perforating gastric ulce

Gastrostomy

Obstruction of bowels.

Omental adhesions........

Hernioplasty, for-

Femoral hernia.

Inguinal hernia-

Jassini opcration.

Ferguson operation

Unclassified.

al hernia......

. Mayo)..........

Ventral hernia (Mayo)............

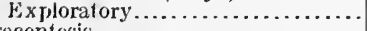

paracentesis.

4

i.

RECTUM ANU ANCS.

Excision of

Uleer (tubercle) of anus......

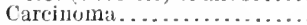

Fistula in ano-

Jncision. .

$\ldots \ldots \ldots \ldots \ldots \ldots$

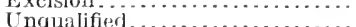

Hemorrhoids-

External-

Clamp and cautiry.......... 10

lixcision.

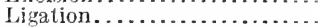

Whitehear operation..........

Internal

Clamp and cautery..........

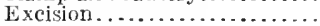

lnjection. . . . . . . . . . . . .

Mixed-

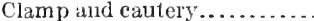

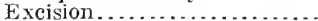

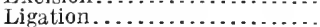

Prolapsus ani-

Clamp and cautery.

Nuin.

ber of

cases.

KIDNEY

Incision and drainage, for-

A bseess of kidney..............

SPLEEN

Splenectomy

URINARY BLADDER

Suprapubic cystotomy, for-

Lithopaxy .................. 1

Perineal fistula and urethal stric-

ture $-\cdots$

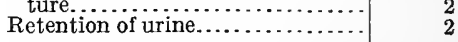

URETHRA......................

Organic stricture-

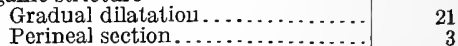

Urethrotomy-

External.

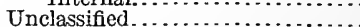

Fistula-

Dissection.

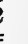

Male organs of Gener 4 TION ..........

Penis-

Amputation, for-

Circumcision, for

Paraphimosis

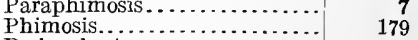

Redundant prepuce........... $\quad \begin{array}{r}179 \\ \text { Ulcer. }\end{array}$

Dorsal incision, for--

Paraphimosis.............. 3

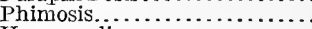

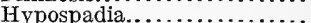

Excision of venereal warts ........

Operations for hydrocele-

Bottle operation..

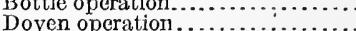

Fxcision of sac .

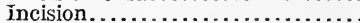

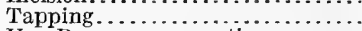

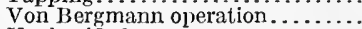

Unelassified...................

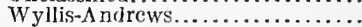

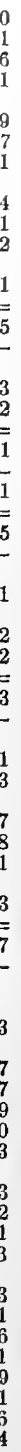


T:ABLE VII.--Surgical operations, fiscal year 1912--Continued.

\begin{tabular}{|c|c|c|c|}
\hline Operations. & $\begin{array}{l}\text { Num- } \\
\text { ber of } \\
\text { cases. }\end{array}$ & Operations. & $\begin{array}{l}\text { Num- } \\
\text { ber of } \\
\text { cases. }\end{array}$ \\
\hline 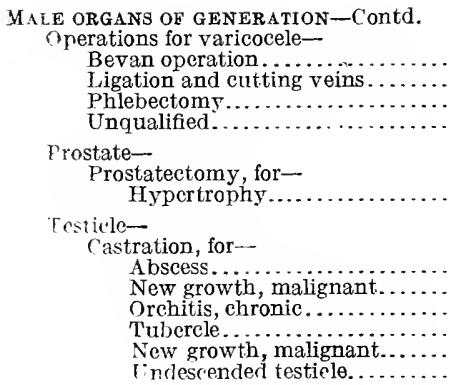 & $\begin{array}{r}3 \\
14 \\
17 \\
9\end{array}$ & 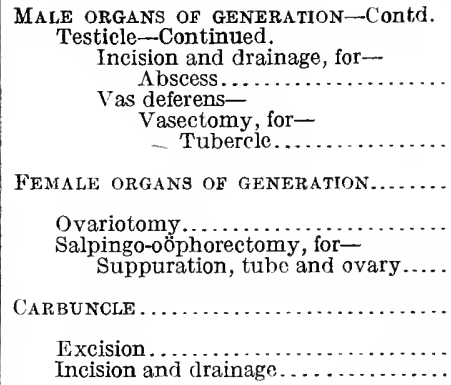 & $\begin{array}{r}=-\frac{2}{3} \\
1 \\
=-=\frac{2}{10}\end{array}$ \\
\hline
\end{tabular}




\section{N D EX.}

A.

Page.

Aricl-last bacillus grown from cases of rat leprosy . . . . . . . . . . . . . . . . . Health Service, increase the pay of officers, and for other purposes.........

$\Lambda$ ct of the General Assembly of Rlode Island concerning the establishment of national quarantine at Providence, R. I.....................

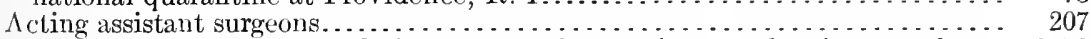

$\Lambda$ ddition to quarantine regulations, precautions against rats leaving vessels... $69-70$

$\Lambda$ griculture, Bureau of, aid to, by service in Philippines. . . . . . . . . . . . 96

$\Lambda$ id rendered to other branches of the Federal Government. . . . . . . . 94-96, 199-200

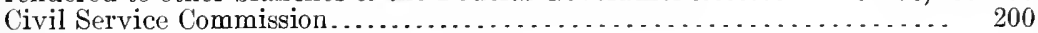

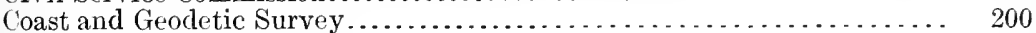

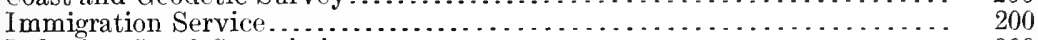

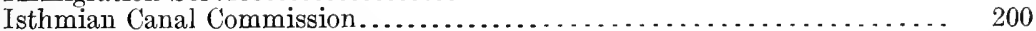

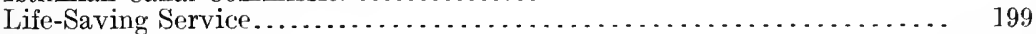

Lighthouse Service. . . . . . . . . . . . . . . . . . . . . . . . . . . . 200

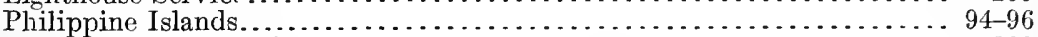

Revenue-Cutter Service. . . . . . . . . . . . . . . . . . . . . . . . . . . . . 199

Steamboat-Inspection Service.............................. 199

Ajd to Texas authorities in the installation of a laboratory ............. 40

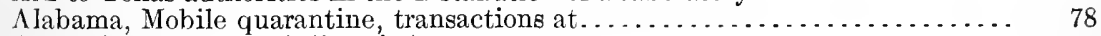

Alameda, Cal. (See California.)

$\Lambda$ laska:

Relief to natives of...................................... 199

Report of service officer relative to furnishing medical care to natives of. 167-169

Studies of the prevalence of disease among natives of . . . . . . . . . 167-169

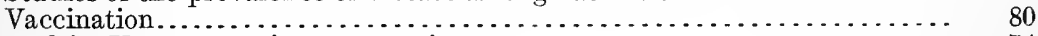

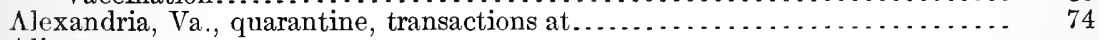

$\Lambda$ liens:

Inspected and certified, table of ........................ 132-133

Return of, from United States to Italy.............................. 130

$\Lambda$ mendment to United States Interstate Quarantine Regulations, relative to

transportation of lepers in interstate traffic.................. 163-164

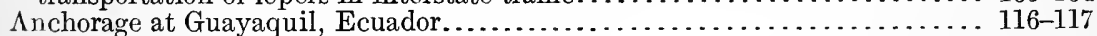

Anderson, Passed Asst. Surg. J. F.:

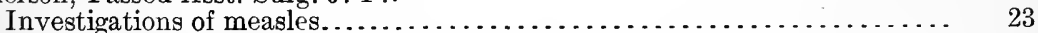

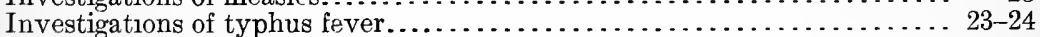

Angel Island, Cal., immigration hospital, report of ...... . . . . . . . . . . . 143-144

Auimal Industry, Bureau of, aid to by the Hygienic Laboratory ............... 47

Antiplague operations in Seattle, Wash............................ 162

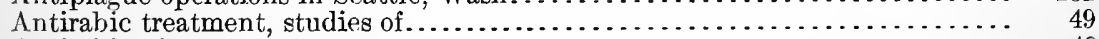

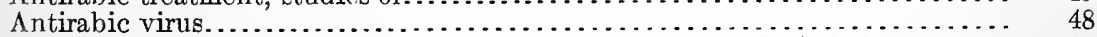

Antityphoid vaccination of Government employees at Hygienic Laboratory ... 47

Appendix:

Financial statement. ................................. 217-220

Statistrcal tables, relating to relief of seamen and medical examinations. 220-240

$\Lambda$ ppropriation for quarantine service, Philippine Islands................ 99

Army, United States, aid to, by service in Philippines..................... 96

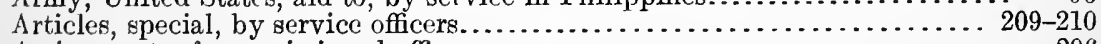

A ssignments of commissioned officers. . . . . . . . . . . . . . . . . . . . . . . .

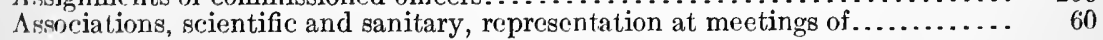

69450-H. Doc. 971, 62-3-16 
B.

Page.

Bacillus, acid-fast, grown from cases of rat leprosy.................. 41

Bacteriology, Pathology and, Division of, Hygienic Laboratory . . . . . . . . . . . 48-50

Baltimore, Md. (See Maryland.)

Beaufort, S. C. (See South Carolina.)

Berkeley, Cal. (See California.)

Bills of health, Philippine Islands.

Biscayne Bay quarantine, transactions at. . . . . . . . . . . . . . . . . . . . 77

Bitter Root Valley, Mont., Rocky Mountain spotted fever, investigations of . . . 28-30

Blue, Surg. R.:

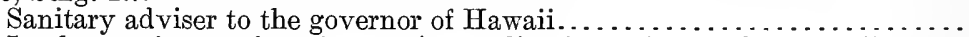
Boards:

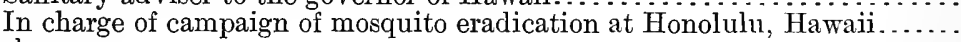

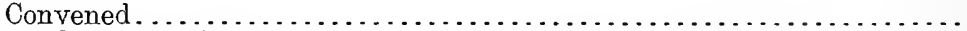

Food and drug inspection, aid to, by the service in the Philippine Islands.

Health Hawaii. 95

Marine examinations, aid to by the service in the Philippine Islands.... $94-95$

Boca Grande quarantine, transactions at. . . . . . . . . . . . . . . . . . . . . . . 77

Boggess, Passed Asst. Surg. J. S., detailed to assist in the work and collection of data bearing on sanitary survey of the Missouri watershed..............

Boston, Mass. (See Massachusetts.)

Bratton, steamer, fitted with a rat-destroying device $\ldots \ldots \ldots \ldots \ldots \ldots \ldots \ldots \ldots . . \ldots 72$

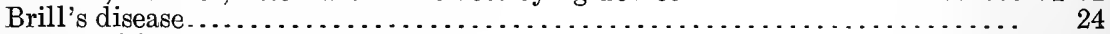

Brownsville, Tex. (See Texas.)

Brunswick, Ga., quarantine. (See Georgia.)

Buffalo, N. Y. (See New York.)

Buildings:

Government, sanitary inspection of, Executive order.............. 169

Ground and, Hygienic Laboratory .............................. 46

Nonrat-proof, remodeling of, or destruction of, in San Francisco....... 149-150

Rat-proof construction, San Francisco, Cal., closure of all acciclental open-

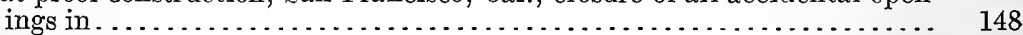

Bureau:

Rat-proof, erection and maintenance of, in San Francisco, Cal.......... 148

Agriculture, aid to, by service in the Philippine Islands . . . . . . . . . . 96

Animal Industry, aid to, by the Hygienic Laboratory . . . . . . . . . . . . . 47

Customs, aid to, by service in the Philippine Islands . . . . . . . . . . . . 95 96

Health, Philippine Islands, aid to, by service.................. 95

Library of . . . . . . . . . . . . . . . . . . . . . . . . . . . . . . . . . 214

Mines, aid to, by the Hygienic Laboratory ....................... 47

Navigation, aid to, by service in the Philippine Islands............... 95

Posts, Philippine Islands, aid to ............................ 96

Bubonic plague in Porto Rico and Habana, Cuba...................... $62-69$

Bulletins:

Hygienic Laboratory . . . . . . . . . . . . . . . . . . . . . . . . . . . . . . . 213-214

Public Health............ . . . . . . . . . . . . . . . . . . . . . . . . 211-212

California:

C.

Alameda, trapping operations in . . . . . . . . . . . . . . . . . . . . . 154-155

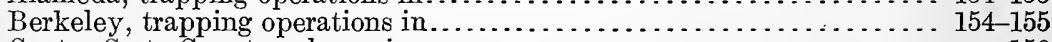

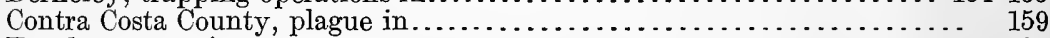

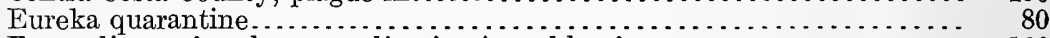

Expenditures for plague eradication in, table of ................. 160

Expenditures, State and local authorities, for plague eradication.......... 160

Los Angeles and vicinity:

Poliomyelitis in ..................................... 175

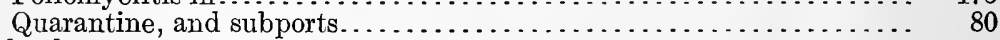

Oakland:

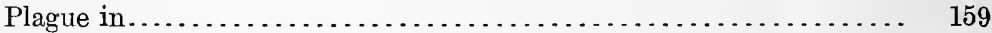

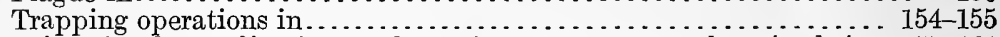

Operations for the eradication of plague from among ground squirrels in. 157-161

Plague......................................... 192

Plague among ground squirrels, eradication of, table showing character of

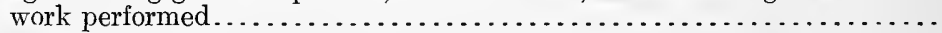


California-Continued. Page.

Plague infection in, table of . . . . . . . . . . . . . . . . . . . 159

Record of plague infection in . . . . . . . . . . . . . . . . . . . . 159

san Francisco-

Buildings, rat-proof construrtion, resure of all arecirlental ofendinge in 148

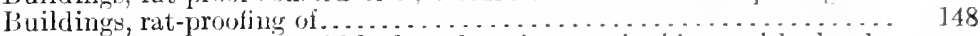

Chart showing increase of black and roof rats ceinrident with tlas docrease in brown or Norway species. . . . . . . . . . . . . . . . . 152

('hart showing quarterly catch of rats in ................... 151

Erection and maintenance of rat-proof buillings in . . . . . . . . . . 148

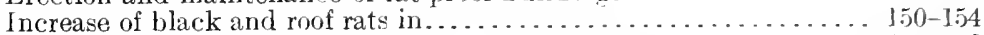

Measures for the destruction of food of rats in ............... 147-148

Measures for the destruction of harbors of rat: in . . . . . . . . . . . 148

Measures for the destruction of rats in . . . . . . . . . . . . . . . 146-147

Medical inspection of immigrants at . . . . . . . . . . . . . . . . 142-144

Plague laboratory, work of............. . . . . . . . . . . 15.5-157

Plague prevention in, and near-by cities............... . . . . . . . 161

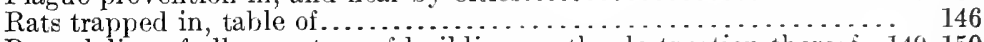

Remodeling of all nonrat-proof buildings or the destruction thereof. 149-150

Removal of all material permitting lefige of rats in . . . . . . . . . 150

Summary of operations in trapping and poisoning rats in . . . . . . . 146-147

Tabulation covering destruction of rat food in ................ 147-148

Tabulation showing closure of all accidental openings in existing buildings of rat-proof construction ........................ 149

Tabulation showing work of rat-proofing existing buildings in . . . . 150

Tabulation showing work of rat-proofing new buildings in ........ 148

San Joaquin County, plague in ... . . . . . . . . . . . . . . . . . . . . . . . . . 159

Summary of achievements in plague-suppressive medsures in . . . . . . . . 161

Campaign of mosquito eradication at Honolulu, Hawaii................ 42

Canada:

Quebec, citizenship classification on shipboard of passengers arriving at,

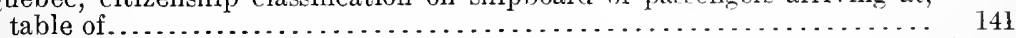

Quebec, medical inspection of immigrants at . . . . . . . . . . . . . . . . . . 140-141

St. John, New Brunswick, citizenship classification on shipboard of passengers arriving at, table of .............................. 141

St. John, New Brunswick, medical inspection of immiorants at . . . . . 141-142

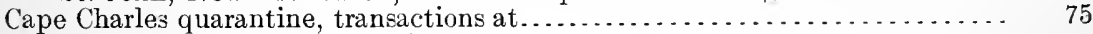

Cape Charles, Va. (See Virginia.)

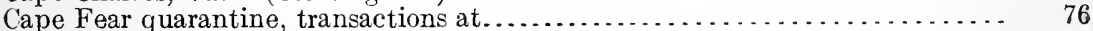

Carbon monoxide, improvements in air tester for . . . . . . . . . . . . . . . . 54

Cavite and Olongapo, P. I., inspection stations at . . . . . . . . . . . . . . . . . . 97

Catalogue, Index, of Medical and Veterinary Zoology . . . . . . . . . . . . . 50

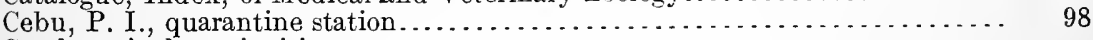

Cerebrospinal meningitis:

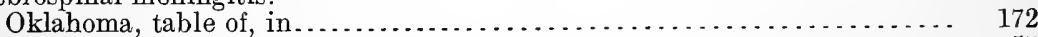

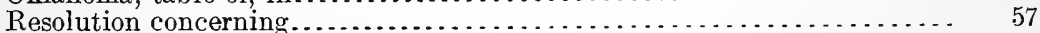

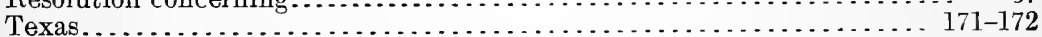

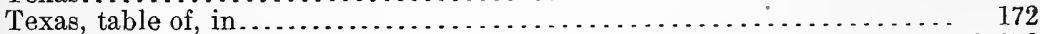

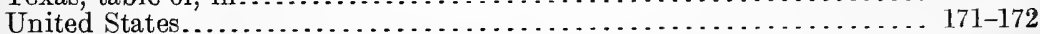

Certificates:

Cargo, at Guayaquil, Ecuador............................. 117

Nedical inspection of aliens at Boston, Mass., and Providence, R. I., table

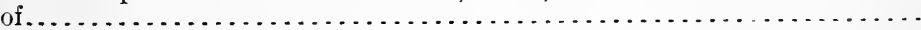

Charitable institutions, Philippine Islands, aid to

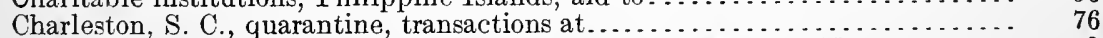

Chase, old revenue bark, fitted out for service at Fort Monroe, Ya. . . . . . . . 73

Chemistry, Division of, Hygienic Laboratory . . . . . . . . . . . . . . . . . 53-54

China:

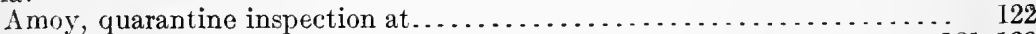

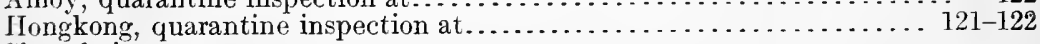

Shanghai-

Quarantinable diseases at.......................... 123

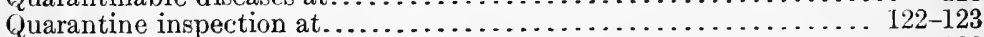

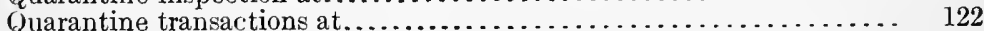

Cholera:

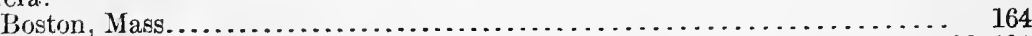

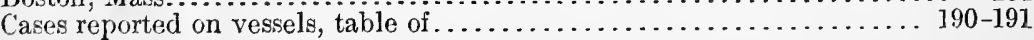


Cholera-Continued

Circular relative to................................... 62

General . . . . . . . . . . . . . . . . . . . . . . . . . . . . . . .

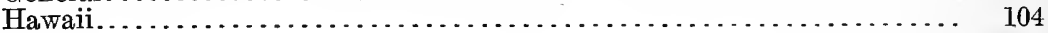

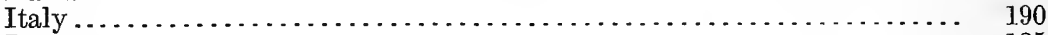

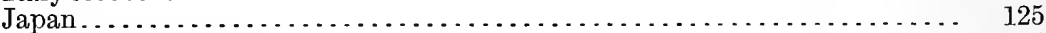

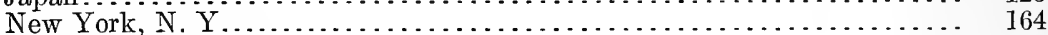

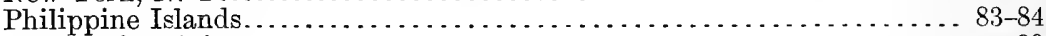

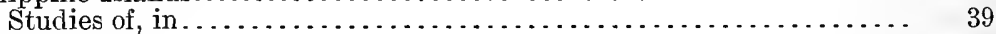

Providence, R. I...................................... 164

Russia.................................................... 190-191

Studies of, in cooperation with the International Office of Public Hygiene.. 38-39 Cincinnati, Ohio. (See Ohio.)

Circulars:

Cholera, relative to ............................................. 62

Quarantine of vessels and cargo at Hahana, Cuba................. $66-69$

Rats leaving vessels, relative to . . . . . . . . . . . . . . . . . . . . . . $69-70$

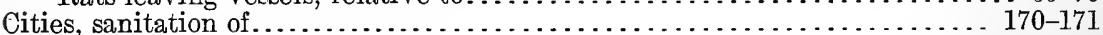

Civil Service Commission, aid to ........................... 46-47, 200

Clark, Surg. Taliaferro, investigation of trachoma in Minnesota............. 24-27

Closure of all accidental openings in existing buildings of rat-proof construc-

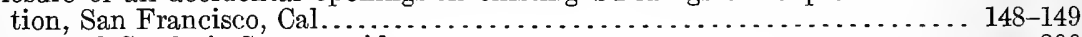

Coast and Geodetic Survey, aid to.................................... 200

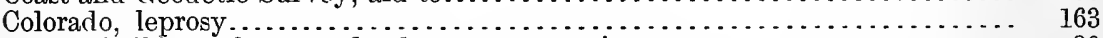

Columbia River, Oreg., and subports, transactions at................ 80

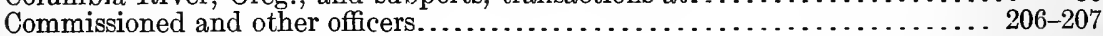

Compilation of health laws........................................ $\quad 39$

Conferences:

Sixth International Sanitary, of the American Republics............ 57

Tenth Annual, of State and Insular Health Authorities................. 56

Congresses, scientific and sanitary, representation at meetings of.............. 60

Consular quarantine work, Philippine Islands..................... 94

Consular services, foreign, aid to, by service in Philippine Islands.......... 96

Contents, table of............................................ $3-6$

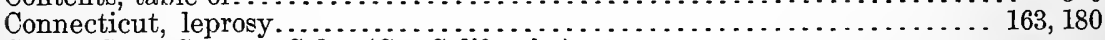

Contra Costa County, Cal. (See California.)

Cooperation with Territorial authorities....................... 41-43

Coos Bay, Wash., subport North Bend, transactions at................... 80

County health officers, full-time, needed ........................... 35

Creel, Passed Asst. Surg. R H.:

Assumed command of plague-suppressive measures in Porto Ricn....... 162

Detailed to assume duties of quarantine officer at the port of Providence, Cuba:

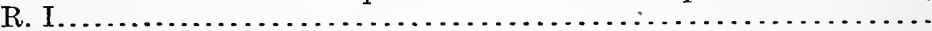

General health condition in ............................... 111

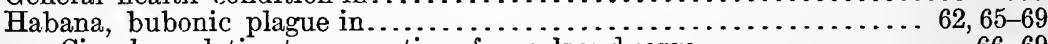

Circulars relative to quarantine of vessels and cargo.............. $66-69$

Fumigation of vessels at................................ 69

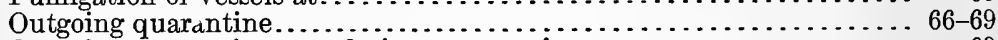

Outgoing quarantine, regulations concerning passengers........... 69

Outgoing quarantine, special regulations concerning vessels......... 68

Quarantine, inspection at.................................... 110

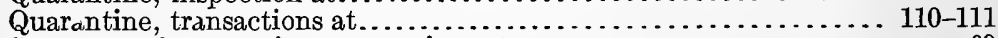

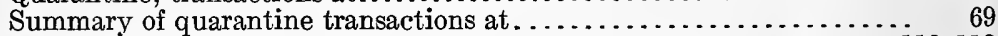

Cuban quarantine transactions.......................................... 112-113

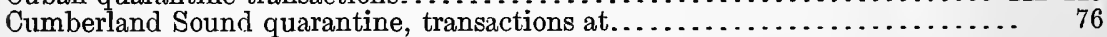

Currie, Passed Asst. Surg. D. H.:

Carried out experiments on destruction of ground squirrels.......... . 155-156

In charge of campaign of mosquito eradication at Honolulu, Hawdii..... 42

Relieved from leprosy-investigation station, Hawaii, and transferred to

San Francisco, Cal...................................... 40

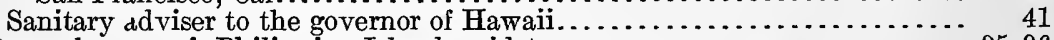

Customs, burean of, Philippine Islands, aid to......................... 95-96

D.

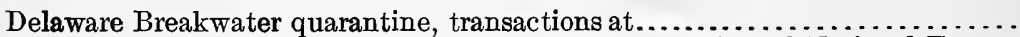

Digest of comments on the United States Pharmacopœia and National Formu-

lary. 
Diphtheria, Japan....................... 125

Director, leprosy, investigation station, server as member of Sanitary Commission of Honolulu. . . . . . . . . . . . . . . . . . . . . . . . . . . . . . . 43

Diseases:

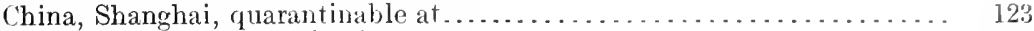

Cuba, transmissible, table of ............................... 111

Japan-

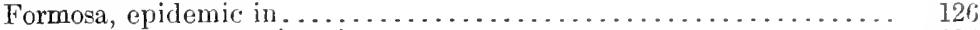

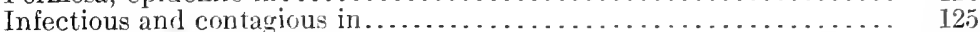

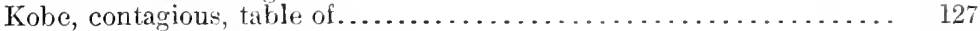

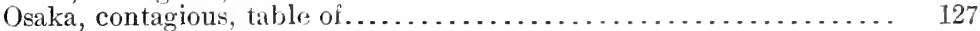

Yokohama, contarious at, tables of ....................... 124

Quarantinable, Hawaii, occurrence of ................... 103-107

Treated during 1912, table of . . . . . . . . . . . . . . . . . . . 226-236

Disinfectants........................................ 48

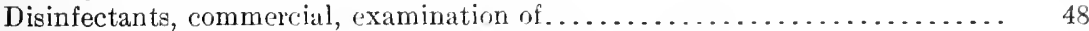

Disinfectants, phenol coefficient of, resolution concerning........... 57

District of Columbia:

Health officer of, aid to, by Hygienic Laboratory................. 46

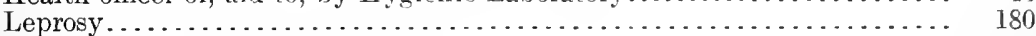

Divisions of the Hygienic Labolatory . . . . . . . . . . . . . . . . . . . . . . 48-54

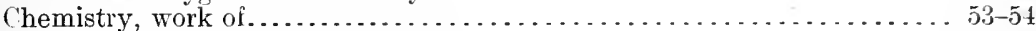

Pathology and Bacteriology, work of ...................... $48-50$

Pharmacology, work of ............................ 51-53

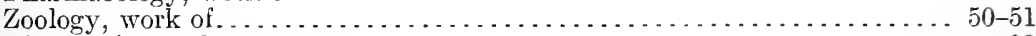

Dock inspection and reports . . . . . . . . . . . . . . . . . . . . . . . . . . . . . . 93

Domestic (interstate) quarantine. . . . . . . . . . . . . . . . . . . . . . . 145-169

Drugs, examination of, miscellaneous analyses, by Division of Pharmacology, Hygienic Laboratory.

Drugs, standardization of, by Division of Pharmacology, Hygienic Laboratory.

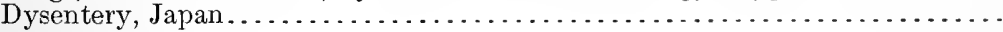

E.

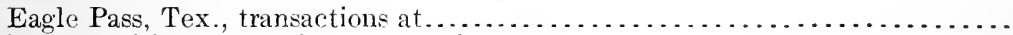

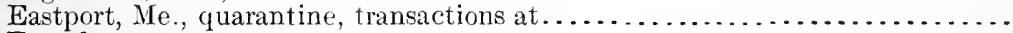

Ecuador:

Guayaquil-

Anchorage at.

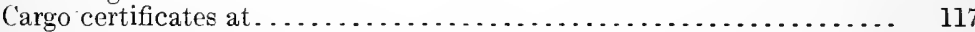

Fumigation of vessels at. . . . . . . . . . . . . . . . . . 117

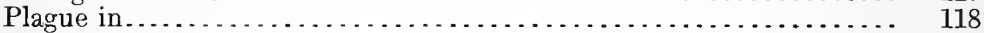

Plague on board vessels at. . . . . . . . . . . . . . 117

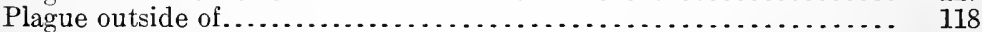

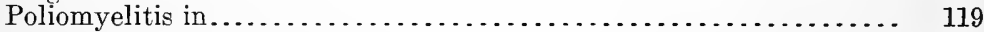

Quarantine inspection at.......................... 116-120

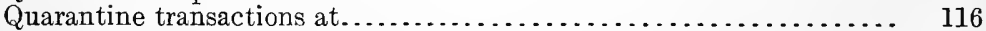

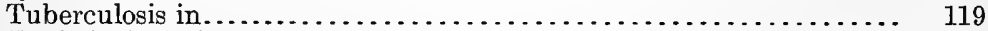

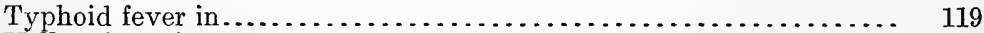

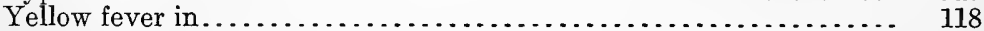

Yellow fever on board vessels at............................. 117

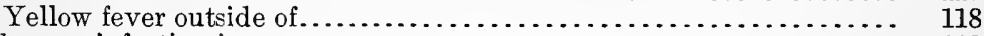

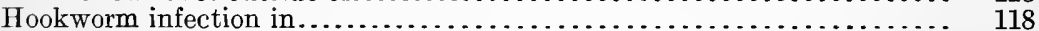

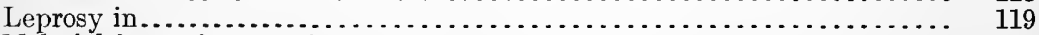

Malarial fevers in ...................................... 118

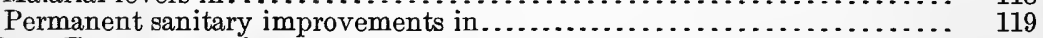

El Paso, Tex., transactions at.................................. 81

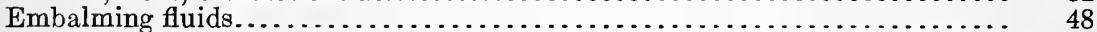

Epidemiological study of a milk-borne outbreak of septic sore throat in Baltimore, Md....................................... $36-37$

Establishment, lighthouse, aid to, by service in the Philippine Islands........ 95

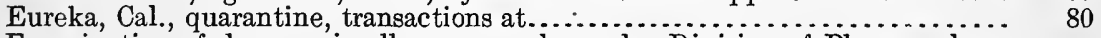

Examination of drugs, miscellaneous analyses, by Division of Pharmacology, Hygienic Laboratory . . . . . . . . . . . . . . . . . . . . . . . .

Examination of Government employees for tuberculosis at Hygienic Laboratory 
Excerpts from reports made by service officers detailed for the medical inspec-

tion of immigrants. . . . . . . . . . . . . . . . . . . . . . . . . . . . . . . . 134-144

Boston, Mass......................................... 134-137

Buffalo, N. Y . . . . . . . . . . . . . . . . . . . . . . . . . . . 134

Honolulu, Hawaii. . . . . . . . . . . . . . . . . . . . . . . . . . . . 137

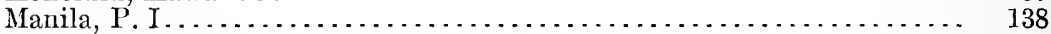

New York, N. Y. . . . . . . . . . . . . . . . . . . . . . . . . 139-140

Providence, R. I. . . . . . . . . . . . . . . . . . . . . . . . . . . . . . 134-137

Quebec, Canada.................................... 140 . . 141

San Francisco, Cal. . . . . . . . . . . . . . . . . . . . . . . . . . . . . . . . . . 142-144

St. John, N. B., Canada... . . . . . . . . . . . . . . . . . . . . . . . . . . . . 141-142

Executive order, sanitary inspection of Government buildings . . . . . . . . . $\quad 169$

Exhibits, Public Health. . . . . . . . . . . . . . . . . . . . . . . . . 55

Expenditures:

California, State and local authorities for plague eradication . . . . . . 160

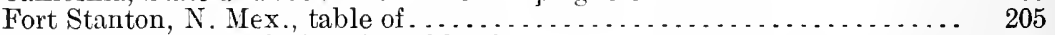

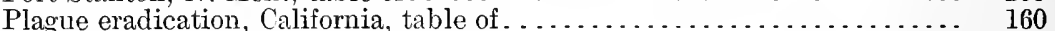

Service... . . . . . . . . . . . . . . . . . . . . . . . . . . . . 217-220

E.

Field, laboratory and, investigations, authority for . . . . . . . . . . . . . . . 10

Financial statement. . . . . . . . . . . . . . . . . . . . . . . . . . . . 217-220

Foreign consular services, aid to by service in the Philippine Islands . . . . . . 96

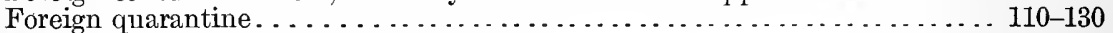

Fort Stanton, N. Mex. (See New Mexico.)

Florida, Key West, hospital ship Wistaria transferred to . . . . . . . . . . . . .

Francis, Passed Asst. Surg., Edward:

Assigned to conduct investigation to determine the presence of tetanus spores in vaccine virus at the Hygienic Laboratory . . . . . . . . . . . .

Investigations of poliomyelitis in Cincinnati, Ohio . . . . . . . . . . . .

Studies upon embalming fluids continued. . . . . . . . . . . . . . .

Frost, Passed Asst. Surg., W. H. :

Epidemiological study of a milk-borne outbreak of septic sore throat, in

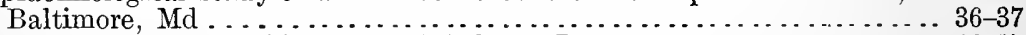

Investigation of typhoid fever at Oskaloosa, Iowa . . . . . . . . . . . . . . . 16-17

Investigation of typhoid fever at Little Rock, Ark., and Fort Smith, Ark.. 11

Full-time county health officers needed. . . . . . . . . . . . . . . . . . ... 35

Fumigation of vessels:

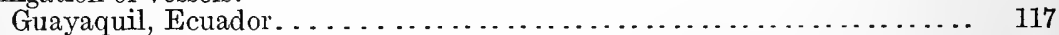

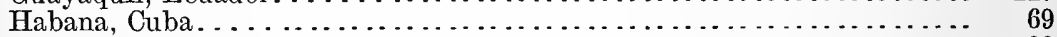

Philippine Islands................................... 88

G.

Geddings, Surg., H. D.:

Delegate at the meeting of the permanent committee of the International Office of Public Hygiene at Paris. . . . . . . . . . . . . . . . . . . . . .

Member of international commission for making studies of cholera in cooperation with the International Office of Public Hygiene . . . . . . . . . 38-39

General health conditions in Cuba.................................... 111

Georgetown, S. C., quarantine, transactions at. . . . . . . . . . . . . . . . .

Georgia, Brunswick, quarantine, transactions at. . . . . . . . . . . . . 76

Goldberger, Passed Asst. Surg., J.:

Investigations of measles. . . . . . . . . . . . . . . . . . . . . . . . . . 23

Investigations of typhus fever. . . . . . . . . . . . . . . . . . . . . . 23-24

Government employees:

Antityphoid vaccination of, at the Hygienic Laboratory . . . . . . . . . . . . 47

Examination of, for tuberculosis at Hygienic Laboratory . . . . . . . . . . . . . 47

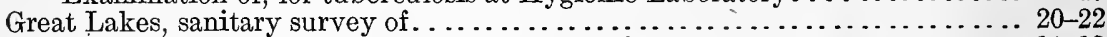

Grimm, Asst. Surg., R. M., investigations of pellagra . . . . . . . . . . . . . . . . 31-32

Grounds, buildings, and hygienic laboratory ....................... 46

Guiteras, Surg. G. M., delegate to Sixth International Sanitary Conference of

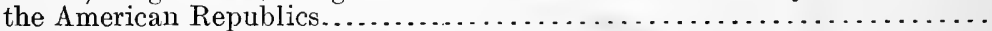

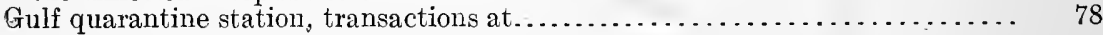


H.

I'awaii:

Page.

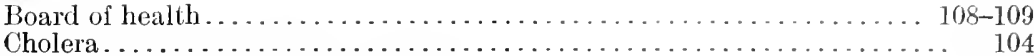

Diseases, quarantinable, occurrence of ......................... 103-107

Honolulu-

Medical inspection of inmigrants at.................... 137

Mosquito eradication campaign at. . . . . . . . . . . . . . . . . . 42

Plague laboratory ................................ $109-110$

Plague laboratory, statistical data on rat work at ............ 109-110

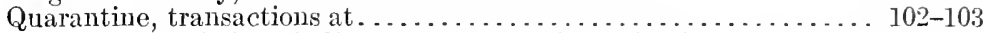

Sanitary commission of, director of leprosy investigation station served

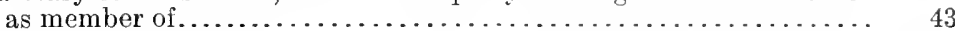

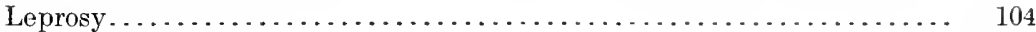

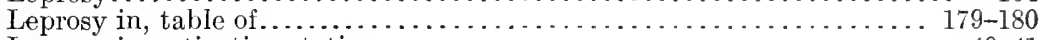

Leprosy investigation station.......................... 40-41

Personnel of service on duty in ....................... 108-109

Plague................................................ 103, 192

Rat quarantine ....................................... 107-108

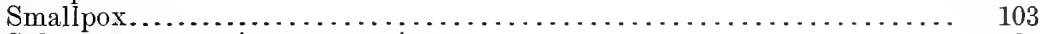

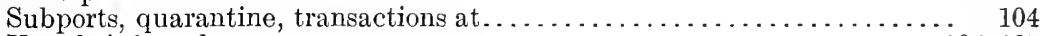

Vessels infected ...................................... 104-107

Vessels inspected......................................... 104

Yellow fever................................................... 103-104

Health conditions, Habana, Cuba................................. 111-112

Health laws, compilation of ................................ ${ }_{39}$

Health officer, District of Columbia, aid to, by the hygienic laboratory...... 46

Heiser, Passed Asst. Surg. V. G., studies of cholera similar to those outlined

by the committee of the International Office of Public Hygiene under way

in the Philippine Islands.

Honolulu, Hawaii. (See Hawaii.)

Hotchkiss, Asst. Surg. H. C., engaged in investigations of health conditions

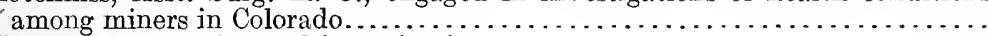

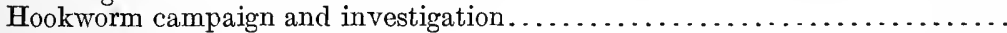

Hookworm disease:

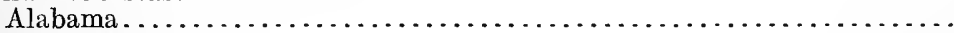

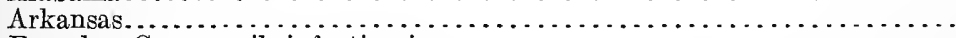

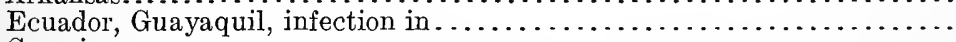

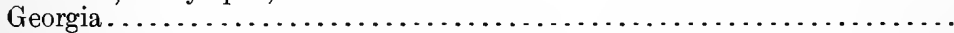

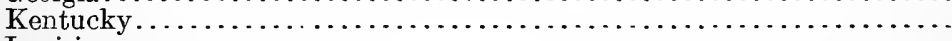

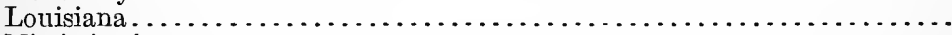

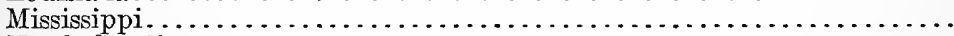

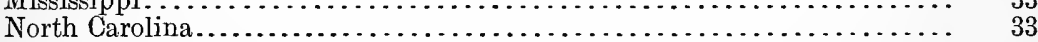

Wilmington, study of, in marine hospital at..................... $34-35$

South Carolina........................................... 33

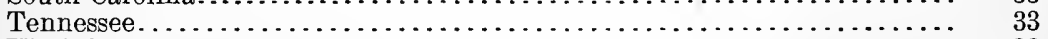

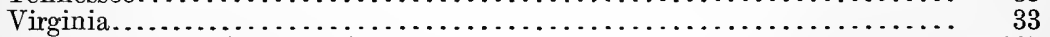

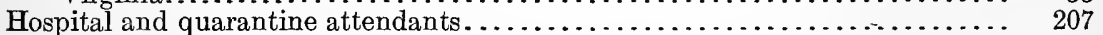

Hospital cases among arriving aliens at Boston, Mass.......................... 135-136

Hospital report for United States immigration hospital, Angel Island, Cal... 143-144

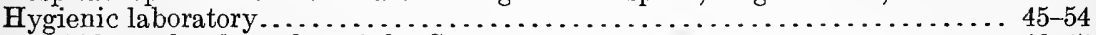

Aid to other branches of the Government.................. 46-47

Antityphoid vaccination of Government employees................. 47

Bureau of Animal Industry ................................ 47

Bureau of Mines. ..................................... 47

Civil Service Commission............................... 46-47

Examination of Government employees for tuberculosis............ 47

Health officer, District of Columbia........................ 46

Isthmian Canal Commission............................... 46

Lectures at Naval Medical School.......................... 47

Aid to the revision committee of the Pharmacopœia.................. 48

Aid to State and municipal authorities............................. 47

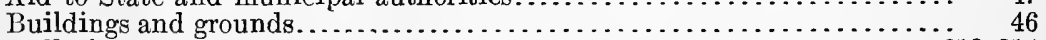

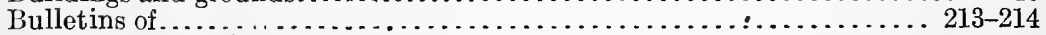

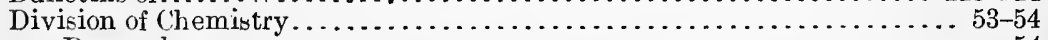

Research...................................... 54 
Hygenic laboratory-Continued.

Division of Pathology and Bacteriology ...................... 48-50

Antirabic virus............................................... 48

Branch laboratory at New York, N. Y ........................ 49

Disinfectants.............................................. 48

Embalming fluids...................................... 48

Examination of commercial disinfectants.................. 48

Division of Pharmacology............................... 51-53

Cooperation with the United States Pharmacopœia, other depart-

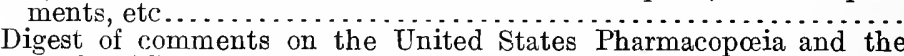

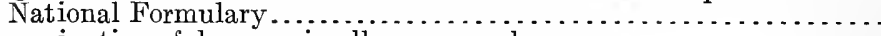

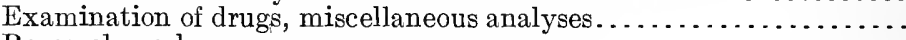

Research work ...................................... $52-53$

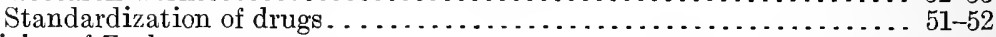

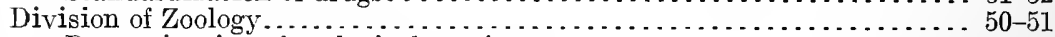

Determination of zoological specimens..................... 51

Hookworm campaign and investigation............................ 51

Index Catalogue of Medical and Veterinary Zoology ................ 50

International Commission of Zoological Nomenclature........... 50

Navy Medical School....................................... 51

Publications.................................................. 51

Public health lectures................................. 51

Work in marine hospital, Wilmington, N. C...................... 35

Personnel....................................................... 45

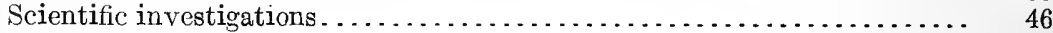

I.

Iloilo, P. I., quarantine station................................. 97

Immigrants:

Arriving at Manila, P. I., classification of .................... 138

Disposition of, at Boston, Mass., and Providence, R. I., table of......... 137

Disposition of, at New York, N. Y., table of..................... 139

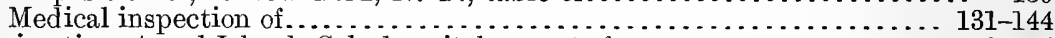

Immigration, Angel Island, Cal., hospital, report of .................. 143-144

Immigration Service, aid to .................................... 96, 200

Improvements, sanitary, permanent, in Ecuador ..................... 119

Index Catalogue of Medical and Veterinary Zoology................... 50

Indiana, leprosy .............................................. 180 181

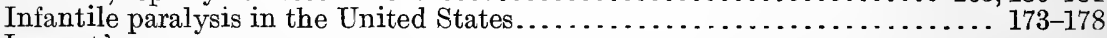
Inspections:

Arriving vessels, Philippine Islands. . . . . . . . . . . . . . . . . . . 87-88

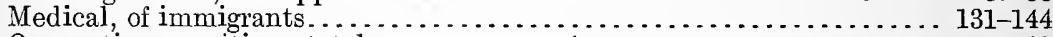

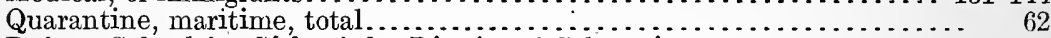

Reform School for Girls of the District of Columbia................. 32

Texas-Mexican border...................................... 81

Vessels in Philippine ports......................................... 91

Instructions relative to fumigation of vessels for the destruction of rats....... 70

Insular quarantine ............................................... $83-110$

Interisland quarantine, Philippine Islands............................ $90-91$

International Commission of Zoological Nomenclature................ 50

International Office of Public Hygiene, studies of cholera in cooperation with. $38-39$

Internes.......................................................... 207

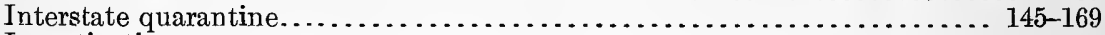

Investigations:

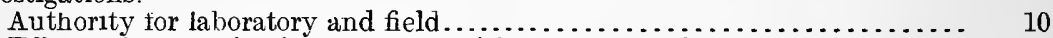

Effects of pasteurization on the nutritive value of milk. . . . . . . . . . $37-38$

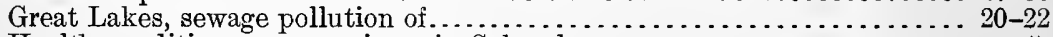

Health conditions among miners in Colorado....................... 47

Hookworm campaign.................................. 51

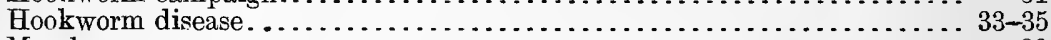

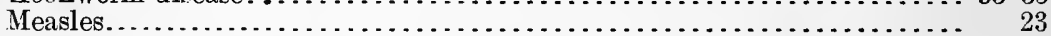

Milk-borne outbreak of septic sore throat in Baltimore, $\mathrm{M}$ d.............. $36-37$

Pellagra.................................................. $31-33$

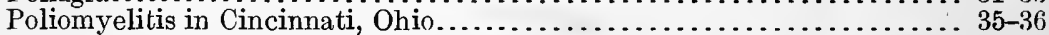

Rocky Mountain spotted fever............................ 28-30 
In vestigatione--Continued.

Scientific, at Hygienic Laboratory......................... ft

Sielma, Ala., sanitary conditions in, relation to the prevention of typhoid

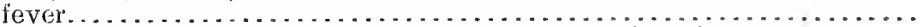

To deternine the presence of tetanus sposes in vaccine virıs..........

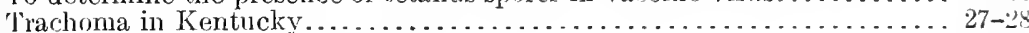

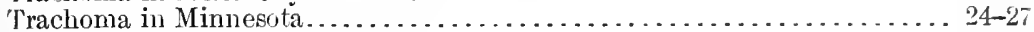

Tvphoid fever at Lincoln, Nebr............................ . 12-14

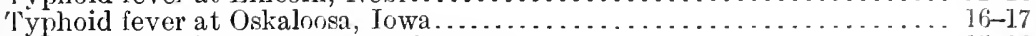

Typhoid fever in Texarkana, Ark.-Tex. . . . . . . . . . . . . . . . . 15-16

Typhoid fever in two schools in Washingtom, D. ( ................. 14-15

Typhus fever. . . . . . . . . . . . . . . . . . . . . . . . . . . . . 24

Virginia, rual districts ol, typhoid fever in . . . . . . . . . . . . . . 18-]9

Isthmian Canal Commission, aid to . . . . . . . . . . . . . . . . . . . . . 46.200 Italy:

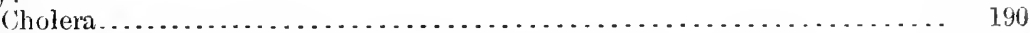

Naples, Messina, and Palermo, statistics of the service, table of . . . . . . 128-129

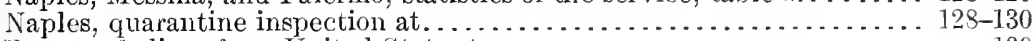

Return of aliens from United States to ............................ 130

J.

Jajar.

Cholera in

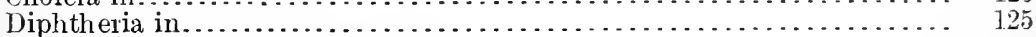

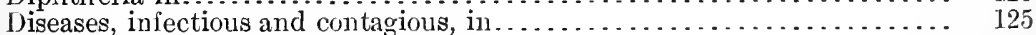

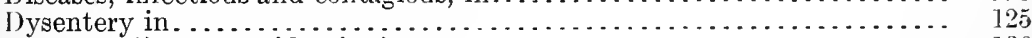

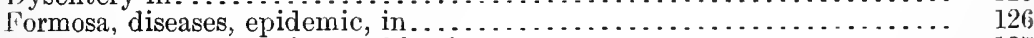

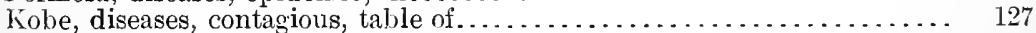

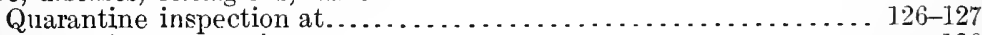

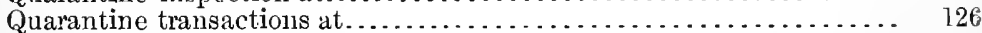

Leprosy in . . . . . . . . . . . . . . . . . . . . . . . . . . . . . . 125

Usaka, diseases, contagious, table of . . . . . . . . . . . . . . . . . . . . . 127

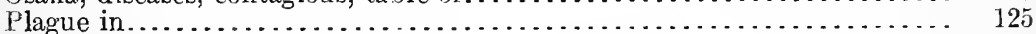

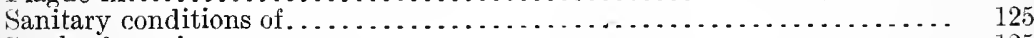

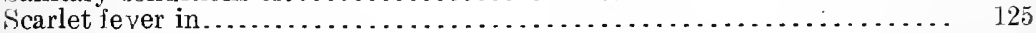

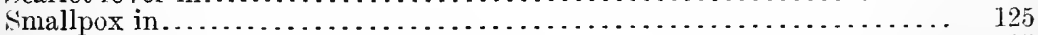

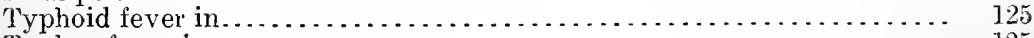

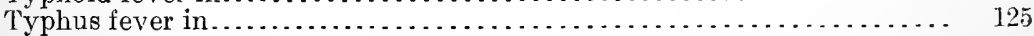

Yokohama-

Contagious diseases at, tables of......................... 124

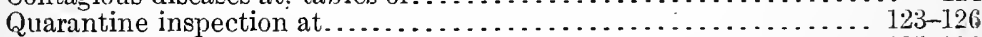

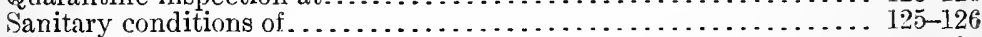

Sumnmary of quarantine transactions at. . . . . . . . . . . . . . . . .

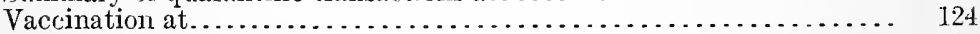

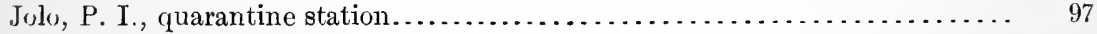

K.

Kentucky, trachoma, investigations of........................ $27-28$

Kerr, Asst. Surg. Gen. J. W., represented service at meetings of various conlmittees of the Fifteenth International Congress of Hygiene and Demography, Washington, D. C.

Ketchikan, Alaska, transactions at. . . . . . . . . . . . . . . . . . . . . . .

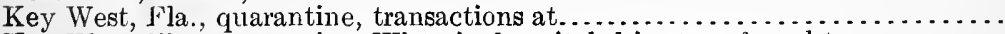

Key West, Fla., quarantine, Wistaria, hospital ship, transferred to..........

Iaboratory:

L.

$A$ id to Texas authorities in the installation of a.................. to

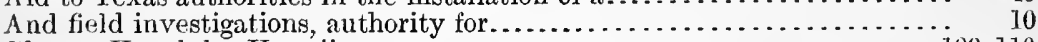

Plague, Honolulu, Hawaii............................... 109-110

Plague, Honolulu, Hawaii, statistical data on rat work at............ 109-110

Laredo, 'Tex. (See Texas.)

lavinder, Passed Asst. Surg. (.. H., investigations of pellagra........... 31-32

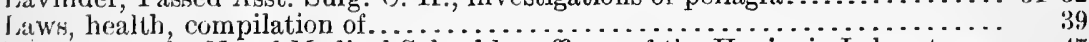

lectures at the Naval Medical School by officers of the Hygienic Iaboratory.. 47

fectures on public health by officers of division of zoology, Hygienic Labora-

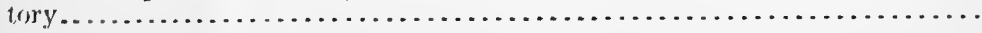




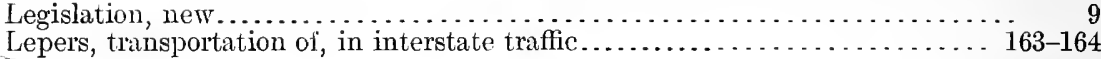

Leprosy:

Colorado............................................. 163

Connecticut....................................... 163, 180

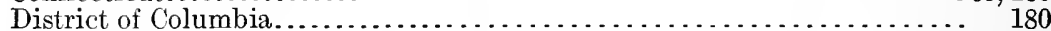

Ecuador, in .......................................... 119

Hawaii................................................ 104

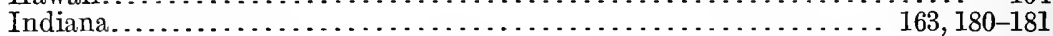

Investigation station................................. 40-41

Investigation station, director of, served as member of sanitary commission of Honolulu............................................. 43

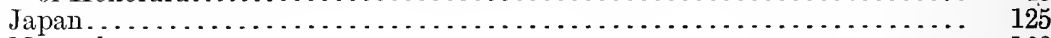

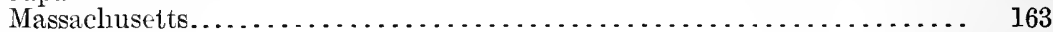

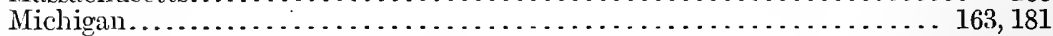

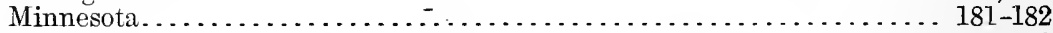

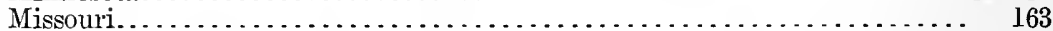

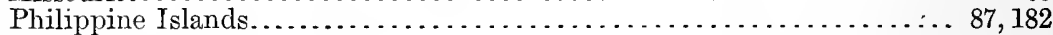

Russia......................................... 128

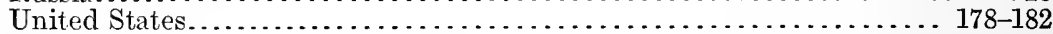

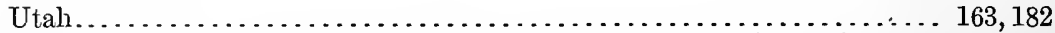

Letter of instructions to medical officers in command, and acting assistant surgeons in charge national quarantine stations, relative to fumigation of vessels

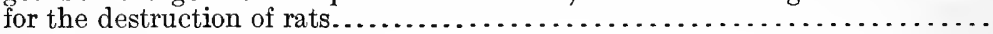

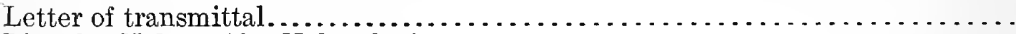

Lincoln, Nebr. (See Nebraska.)

Library of the bureau.......................................... 214

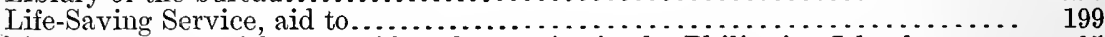

Lighthouse Establishment, aid to, by service in the Philippine Islands....... 95

lighthouse Service, aid to.................................. 200

List of ports from which vessels must be fumigated for destruction of rats upon arrival in United States

Los Angeles, Cal. (See California.)

Long, Passed Asst. Surg. J. D., carried out experiments on destruction of

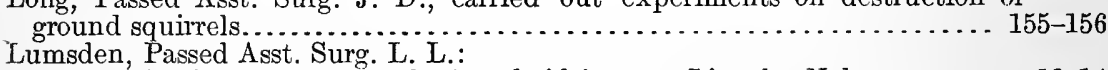

Investigation of an outbreak of typhoid fever at Lincoln, Nebr......... 12-14

Investigation of an outbreak of typhoid fever in two schools in Washing-

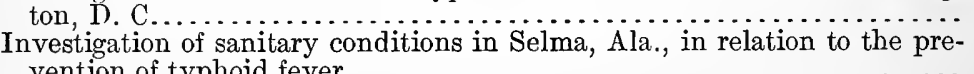
vention of typhoid fever.......................................... 17-18

Investigation of typhold fever in the rural districts of Virginia......... 18-19

Studies of typhoid fever in Yakima County, Wash................. 11

M.

McClintic, Passed Asst. Șurg. T. B.:

Investigations of Rocky Mountain spotted fever................. 28-30

Rocky Mountain spotted fever in Montana, investigation of, report on. . 164-167

Work on standard methods for examination of disinfectants, continued.... 48

McCoy, Passed Asst. Surg. G. W.:

Detailed to take command leprosy investigation station............. 40

In charge of campaign of mosquito eradication at Honolulu, Hawaii ...... . 42

Sanitary adviser to the governor of Hawaii..................... 41

McLaughlin, Passed Asst. Surg. A. J.:

Sanitary survey of the Great Lakes......................... 20-22

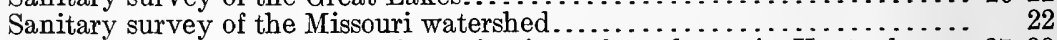

McMullen, Passed Asst. Surg. J., investigations of trachoma in Kentucky.... 27-28

MacVeagh, Secretary of the Treasury, Franklin.................... 57

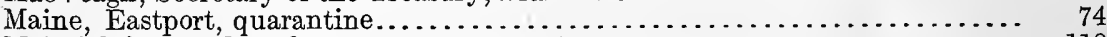

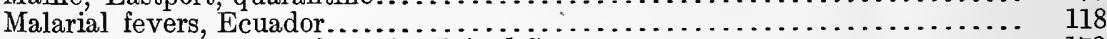

Malta or Mediterranean fever in United States.......................... 173

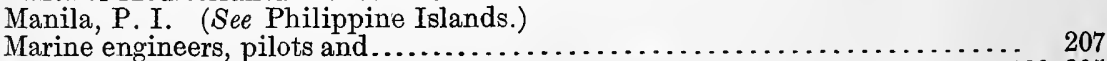

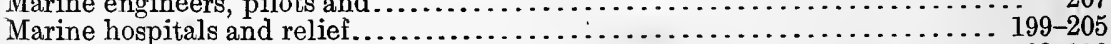

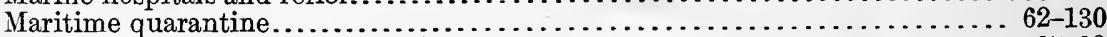

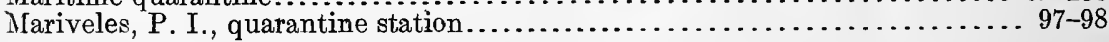




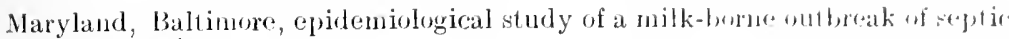

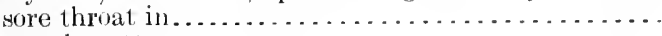

Massachusetts:

Boston-

Certificates of medical inspection of aliens, tablo ol ........... J.3.

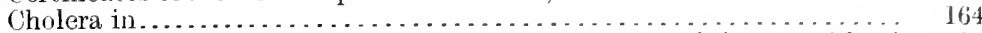

Citizenship classification on shiploard of passengers andingat, table of 134

Hospital cases among arriving aliens at . . . . . . . . . . . . . . 135-136

Medical inspection of immigrants at . . . . . . . . . . . . . . . . 1:34-13i

Summary of transactions of mediral inspection of inmigrants at . . . 1:36-137

Table showing disposition of immigrants at ................. . . . . . . . . . . . . .

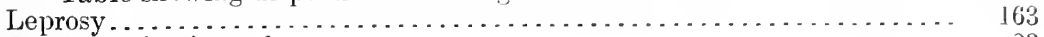

Measles, investigations of . . . . . . . . . . . . . . . . . . . . . . . 23

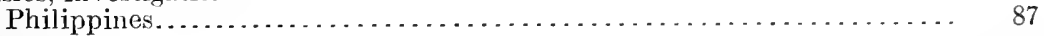

Measures:

For the destruction of rats, San Francisco, Cal................. . . 146-147

For the destruction of rat food, San Francisco, Cal .......... . . . . . 147-148

For the destruction of rat harbors and for the permanent ratproofing of

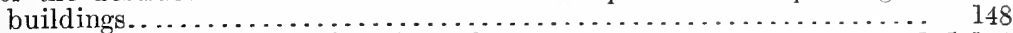

For the immediate recognition of rat plague. . . . . . . . . . . . . . . . 145-146

Plague suppressive... . . . . . . . . . . . . . . . . . . . . . . . . . . . . 145-163

Medical and Veterinary Zoology, Index Catalogue of.................. . 50

Medical inspection of immigrants............................... . 131-144

Philippine Islands...................................... 89

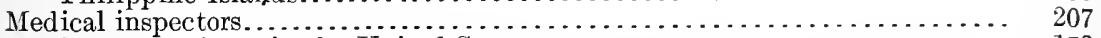

Mediterranean fever in the United States ... . . . . . . . . . . . . . . . . . . . . 173

Meetings of scientific and sanitary associations and congresses, representation at . 60

Mexican typhus....................................... 23-24

Mexico:

Puerto Mexico (Coatzacoalcos), quarantine inspection at ........... 113

Salina Cruz, quarantine inspection at....................... 113

Vera Cruz, quarantine inspection at.......................... 113

Michigan, leprosy............................................ . . 163,181

Milk, investigation of effects of pasteurization on the nutritive value of ... . . . 37-38

Mines, Bureau of, aid to, by the Hygienic Laboratory . . . . . . . . . . . . . . . $\quad 47$

Minnesota:

Leprosy. . . . . . . . . . . . . . . . . . . . . . . . . . . . . 181-182

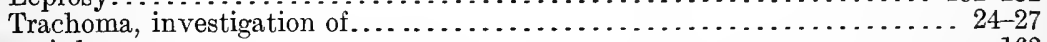

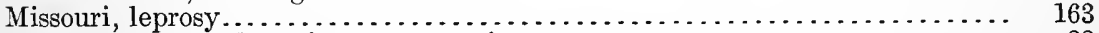

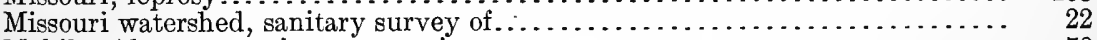

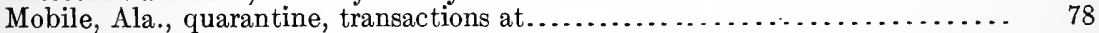

Montana:

Bitter Root Valley, Rocky Mountain spotted fever, investigations of. _. . . 28-30

Rocky Mountain spotted fever, in ........................ 164-167

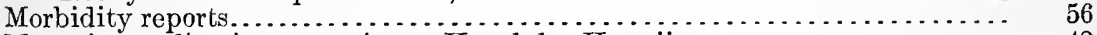

Mosquito-eradication campaign at Honolulu, Hawaii................... . . 42

Municipal and State authorities, aid to, by Hygienic Laboratory . . . . . . . . . . $\quad 47$

N.

Navigation, Bureau of, aid to by service in the Philippine Islands. . . . . . . . 95

Navy Medical School, lectures at, by officers of the Hygienic Laboratory...... 47

Nebraska, Lincoln, outbreak of typhoid fever, investigation of . . . . . . . . . 12-14

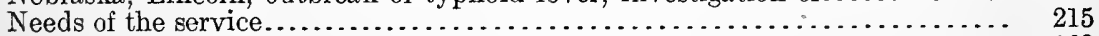

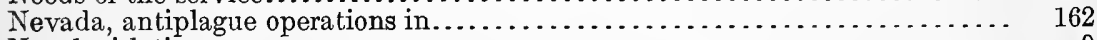

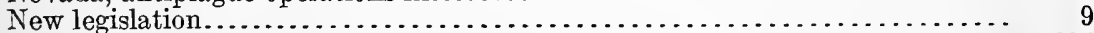

New Mexico, Fort Stanton, tuberculosis sanatorium at. . . . . . . . . . . . 201-205

New Orleans, quarantine, transactions at....................... 78

New York:

Buffalo and vicinity, poliomyelitis in................... 174-175

Medical inspection of immigrants at. . . . . . . . . . . . . . . . . . 134

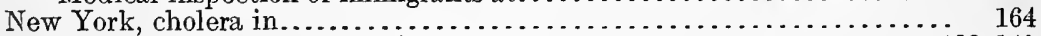

Medical inspection of immigrants at. . . . . . . . . . . . . . . . 139-140

Table showing disposition of immigrants at. . . . . . . . . . . . . 139 
O.

Oakland, Cal. (See California.)

Page.

Ohio. Cincinnati, poliomyelitis, investigations of, at. . . . . . . . . . $35-36$

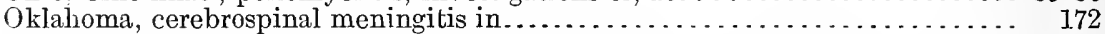

Olongapo and Cavite, P. I., inspection stations at.................. 97

Operations for the eradication of plague from among ground squirrels, Cali-

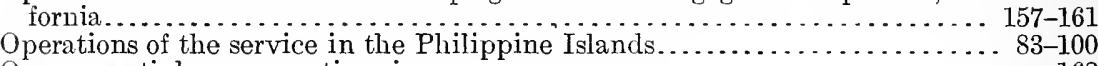

Oregon, antiplague operations in.............................. 162

Oskaloosa, Iowa, typhoid fever, investigation of . . . . . . . . . . . . 16-17

Outgoing quarantine, Habana, Cuba.......................... 66-69

\section{P.}

Panama Canal Zone, baggage destined thereto, disinfected, by service in the

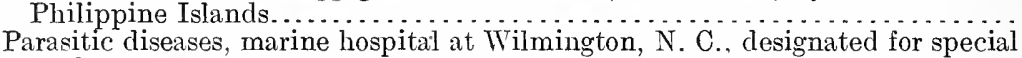
study of.

Pascagoula, Miss., quarantine, transactions at........................

Pasteurization, effects of, on the nutritive value of milk, investigation of ....

Pathology and Bacteriology, Division of, Hygienic Laboratory............

Patients treated in quarantine station hospitals, Philippine Islands........

Pellagra:

Analysis of an alleged remedy for

District of Columbia, Reform School for Girls in . . . . . . . . . . . . . . . .

Further comprehensive studies of, necessary .....................

Investigations of.

Study of, in marine hospital at Savannah, Ga.......................

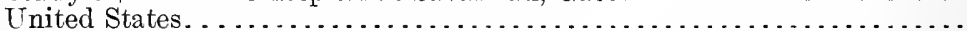

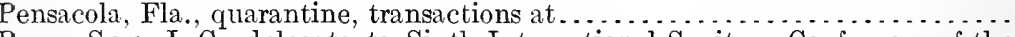

Perry, Surg. J. C., delegate to Sixth International Sanitary Conference of the

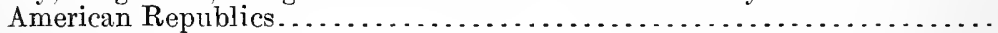

Personnel:

Hawaii, service in . . . . . . . . . . . . . . . . . . . . . . . . . 108-109

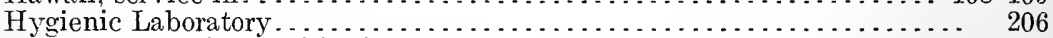

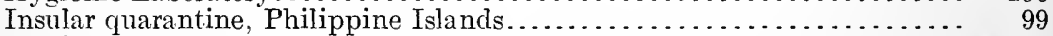

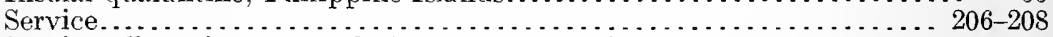

Service officers in command of plague-suppressive measures........... 145

Perth Amboy, N. J., quarantine, transactions at...................... $\quad 74$

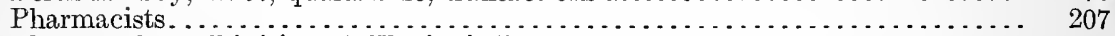

Pharmacology, Division of, Hygienic Laboratory..................... 51-53

Pharmacopoia:

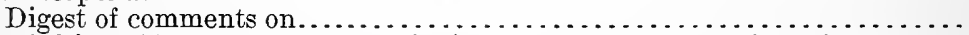

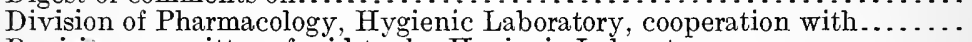

Revision committee of, aid to, by Hygienic Laboratory .................

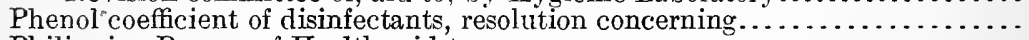

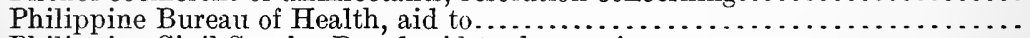

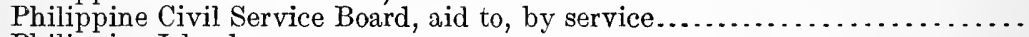

Philippine Islands:

Aid to other branches of the Government. . . . . . . . . . . . . . . . . . 94-96

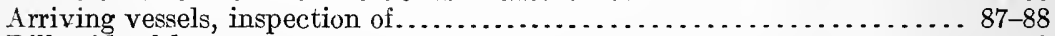

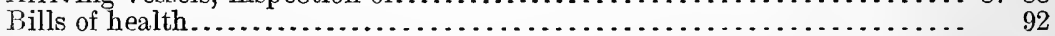

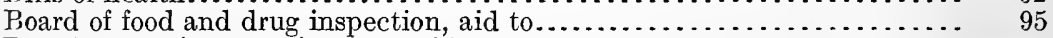

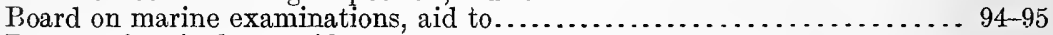

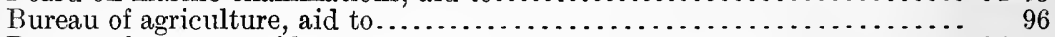

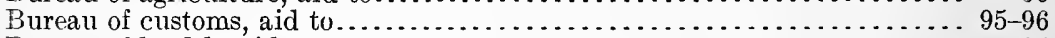

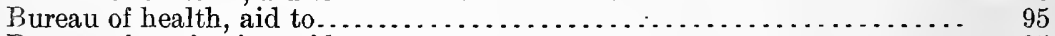

Bureau of navigation, aid to........................................... 95

Cavite and Olongapo quarantine inspection stations................ 97

Cebu quarantine............................................. 98

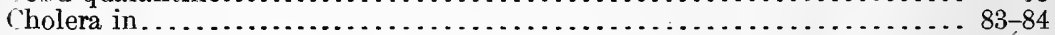

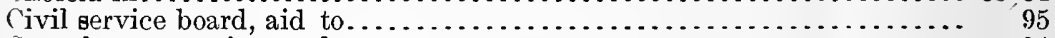

Consular quarantine work......................................... 94

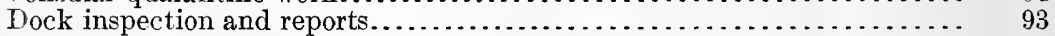

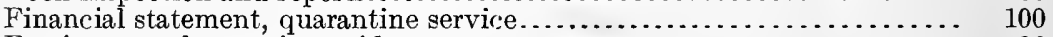

Foreign consular services, aid to.............................. 96

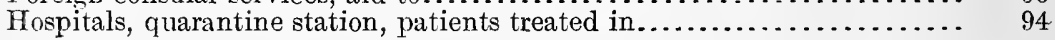


Philippine Islands Continued

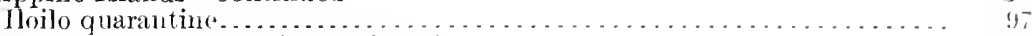

Immigrants, medical inspection of . . . . . . . . . . . . . . . . . . . .

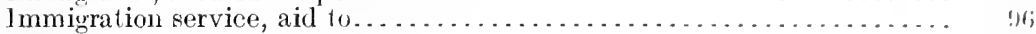

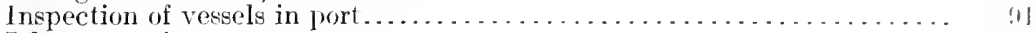

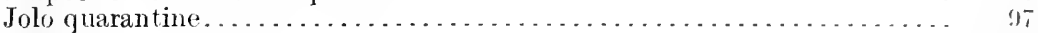

Leprosy . . . . . . . . . . . . . . . . . . . . . .

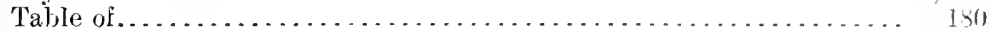

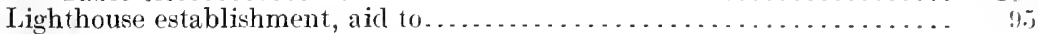

Manila-

('lassification of arriving immigrants at.................. 1:34

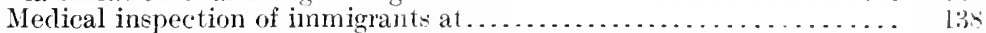

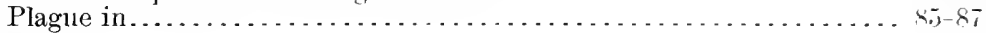

Mariveles-

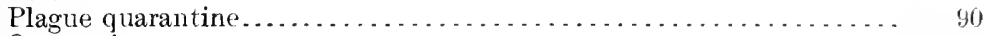

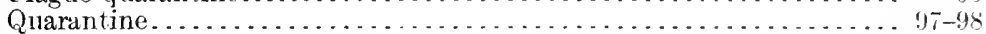

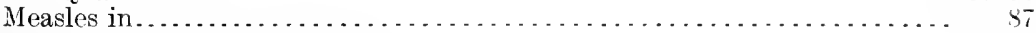

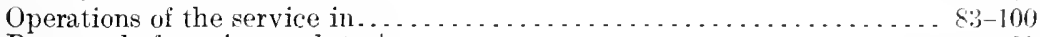

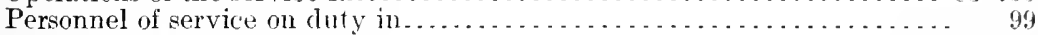

Physical examinations.............................. . . . . . . . . 200

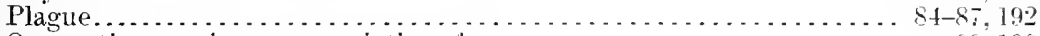

Quarantine service, appropriations for ... . . . . . . . . . . . . . . 99-100

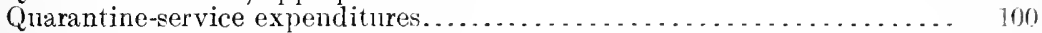

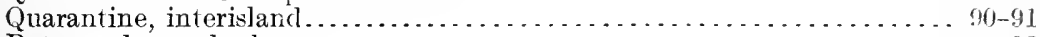

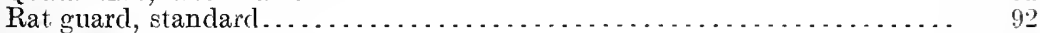

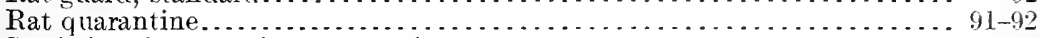

Statistics of quarantine transactions. . . . . . . . . . . . . . . . . . . . . . $98-99$

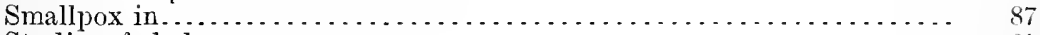

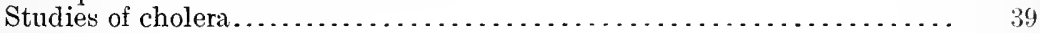

United States Army, aid to . . . . . . . . . . . . . . . . . . . . 96

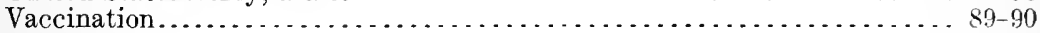

Vessels-

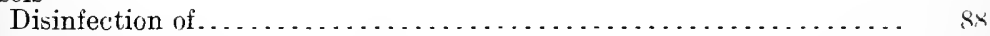

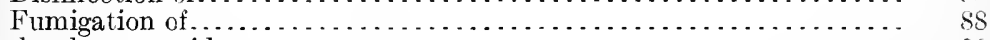

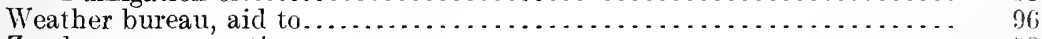

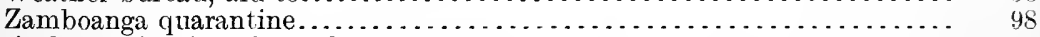

Physical examination of merchant seamen. . . . . . . . . . . . . . . . . . . . 200

Physical examinations, Philippine Islands. . . . . . . . . . . . . . . . . . . 92-93, 200

Pilots and marine engineers.................................. 207

Plague:

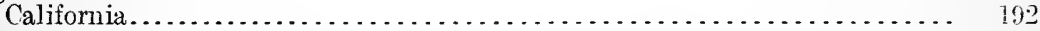

Eradication of, among ground squirrels, table showing character of work performed.

Ecuador, Guayaquil-.

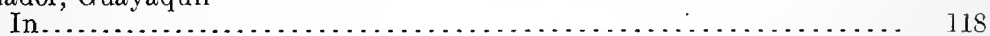

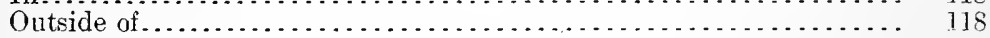

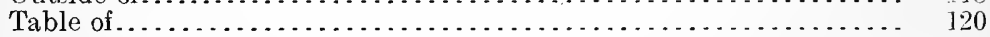

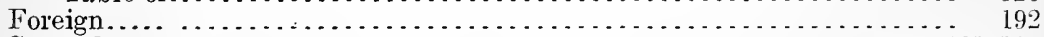

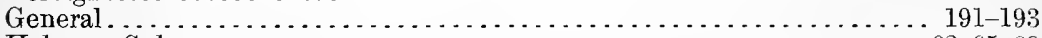

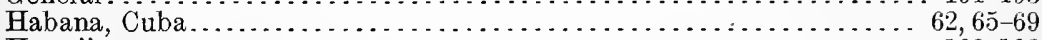

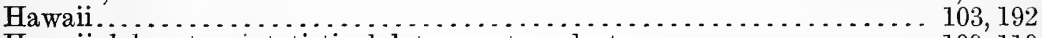

Hawaii, laboratory, statistical data on rat work at.............. . . . 109-110

Japan. . . . . . . . . . . . . . . . . . . . . . . . . . . . . .

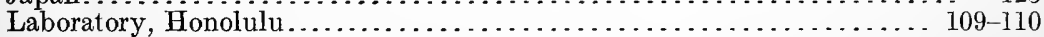

Manila, P. I. ...............

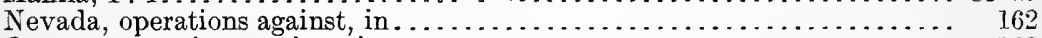

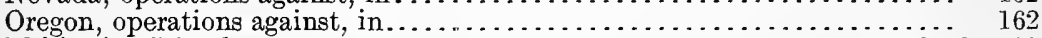

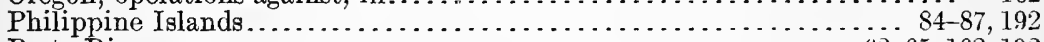

Porto Rico. . . . . . . . . . . . . . . . . . . . . . . . . . 6 62 $65,162,192$

Prevention in San Francisco and near-by cities... . . . . . . . . . . . . . 145-161

Preventive measures in Atlantic and Gulf coast cities, necessity for . . . . . 163

Quarantine at Mariveles, P. I. . . . . . . . . . . . . . . . . . . . . . . . 90

Rat, measures for the immediate recognition of . . . . . . . . . . . . . . 145-146

Reported on vessels, table of . . . . . . . . . . . . . . . . . . . . . . . 193

Seattle, Wash. . . . . . . . . . . . . . . . . . . . . . . . . . . . . . . . 192

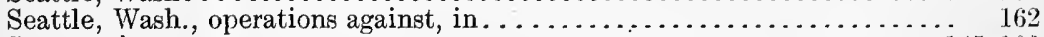

Suppressive measures................................. $145-163$ 
Plague-Continued.

Suppressive measures, plan for the coming fiscal year . . . . . . . . . . . . . 161

Suppressive measures, summary of achievements in.............. 161

United States and insular possessions. . . . . . . . . . . . . . . . . . . 192

Venezuela, Caracas, 1910, 1911, and 1912, table of ................ 115

Plan of operations for the coming fiscal year in plague suppressive measures... 161

Poliomyelitis:

Buffalo, N. Y., and vicinity.

174-175

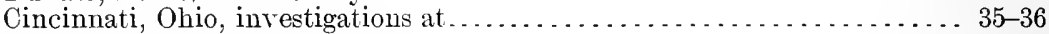

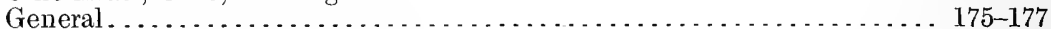

Los Angeles, Cal., and vicinity . . . . . . . . . . . . . . . . . . . . 175

United States. . . . . . . . . . . . . . . . . . . . . . . . . . . . . 173-178

United States, table of . . . . . . . . . . . . . . . . . . . . . . . . 176-177

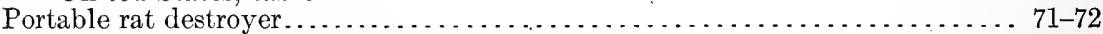

Port Angeles, Wash., and subport. . . . . . . . . . . . . . . . . . . . . . . . 80

Port Hartford, Cal., quarantine, trausactions at................... 78

Port Inglis, Fla., quarantine, transactions at. . . . . . . . . . . . . . 77

Portland, Me., quarantine, transactions at. . . . . . . . . . . . . . . . . 74

Port Royal, S. C., quarantine, transactions at . . . . . . . . . . . . . . . . . . . 76

Port Townsend, Wash., quarantine station and subports, transactions at..... 80

Porto Rico:

Bubonic plague in . . . . . . . . . . . . . . . . . . . . . . . . . . . . . . 62-65

Leprosy in, table of . . . . . . . . . . . . . . . . . . . . . . . . . . . 180

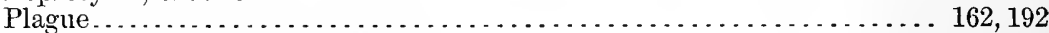

Providence, R. I. (See Rhode Island.)

Publications . . . . . . . . . . . . . . . . . . . . . . . . . . . . . 209-214

Public Health bulletins... . . . . . . . . . . . . . . . . . . . . . . . . . . . . . 211-212

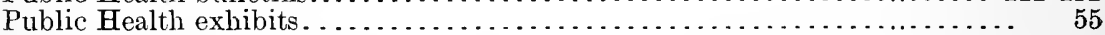

Public Health reports. . . . . . . . . . . . . . . . . . . . . . . . . . . . . . . 170

Public Health reports, reprints from . . . . . . . . . . . . . . . . . . . . . . . 210-211

Purveying depot............. . . . . . . . . . . . . . . . . . . . . . 200-201

Quarantine:

Q.

Against cholera from Russia and Italy ....................... 62

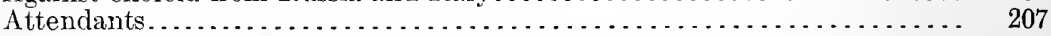

Galveston, Tex., new station at........................... 74

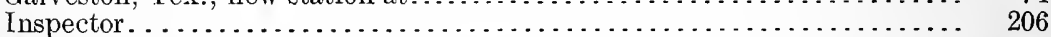

Maritime........................................... $62-130$

National stations, reports from . . . . . . . . . . . . . . . . . . 74-110

Providence, R. I., transfer to national control.................... $72-73$

Rat, destruction of rats on vessels ........................ $69-70$

Regulations, addition to. . . . . . . . . . . . . . . . . . . . . . . 69-70

Quarantine, domestic (interstate) . . . . . . . . . . . . . . . . . . 145-169

Regulations, amendment to, relative to transportation of lepers in inter-

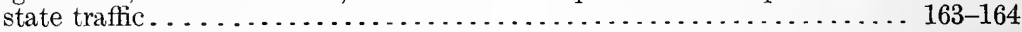

Quarantine, foreign:

China-

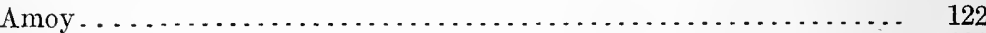

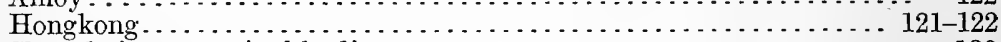

Shanghai, quarantinable diseases at. . . . . . . . . . . . . . . 123

Transactions at . . . . . . . . . . . . . . . . . . . . . . . . . 122

Cuba; Habana . . . . . . . . . . . . . . . . . . . . . . . . . . . . . . . . . 110.113

transactions at ......................................... 110

Ecuador; Guayaquil. . . . . . . . . . . . . . . . . .

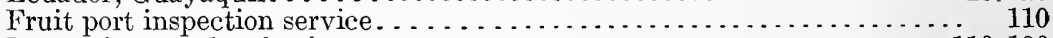

Inspection at other foreign ports . . . . . . . . . . . . . . . . . . . 110 130

Italy $;$ Naples. . . . . . . . . . . . . . . . . . . . . . . . . . . . . . . 128 130

Japan-

Kobe...................................... 126-127

Transactions at. . . . . . . . . . .

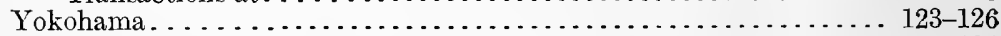

Contagious diseases, table of . . . . . . . . . . . . . . . . . 124

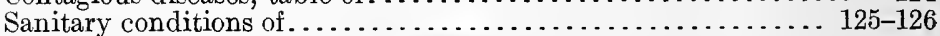

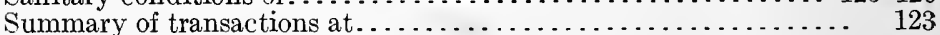

Vaccination at. . . . . . . . . . . . . . . . . . . 
Quarantine, foreign-Continued.

Mexico-

Page.

Puerto Mexico (Coatzacoalcos) . . . . . . . . . . . . . . . . . . . . . . 113

Salina Cruz. . . . . . . . . . . . . . . . . . . . . . . . . . . 113

Vera Cruz...................................... 113

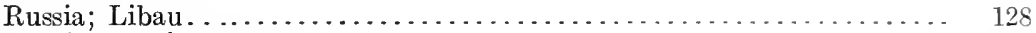

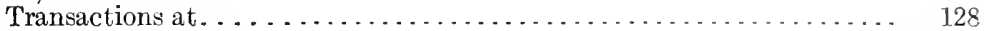

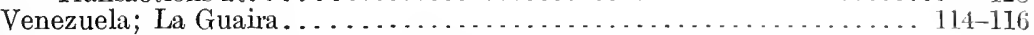

Quarantine, insular. . . . . . . . . . . . . . . . . . . . . . . . 83-110

Cavite and Olongapo, P. I., inspection stations at ............ 97

Cebu, P. I . . . . . . . . . . . . . . . . . . . . . . . . 98

Cuba; Habana, transactions at. . . . . . . . . . . . . . . . .

Transactions at, summary. of . . . . . . . . . . . . . . . . . . . 69

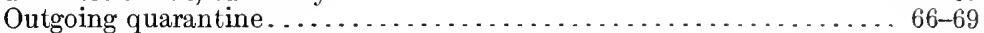

Cuban transactions. . . . . . . . . . . . . . . . . . . . . . 112-113

Hawaii-

Diseases, occurrence of, in . . . . . . . . . . . . . . . . . . . . . . 103-107

Honolulu, transactions at . . . . . . . . . . . . . . . . . . . . 102-103

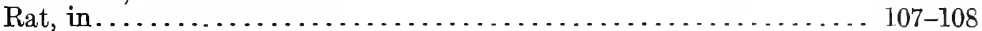

Subports, transactions at. . . . . . . . . . . . . . . . . . . . . 103

Operations in . . . . . . . . . . . . . . . . . . . . . . . $102-110$

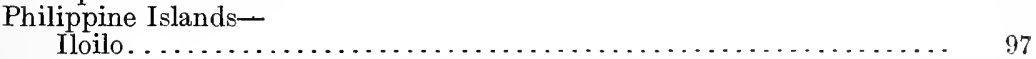

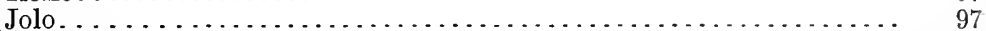

Mariveles. . . . . . . . . . . . .

Operations in the ............................... $83-100$

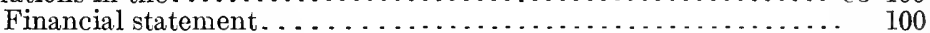

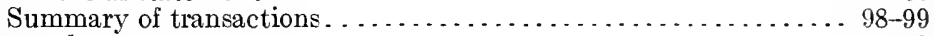

Personnel. . . . . . . . . . . . . . . . . . . . . . . . . . . . . . . . 99

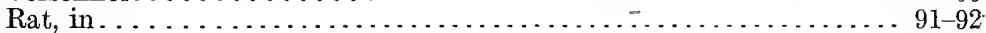

Zamboanga. . . . . . . . . . 98

Porto Rico-

Operations in . . . . . . . . . . . . . . . . . . . . . . . . 101-102

Quebec, Canada:

Summary of transactions............................... 101-102

Citizenship classification on shipboard of passengers arriving at, table of.. 141

Medical inspection of immigrants at....................... 140-141

R.

Rabies, United States.................................... 183-184

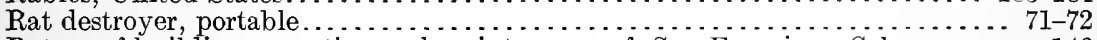

Rat-proof buildings, erection and maintenance of, San Fraucisco, Cal....... 148

Rat quarantine:

Destruction of rats on vessels. . . . . . . . . . . . . . . . . . . $69-70$

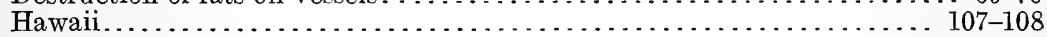

Philippine Islands........................................ 91-92

Rats, California:

San Francisco-

Black and roof, chart showing increase in, coincident with the decrease in brown or Norway species. . . . . . . . . . . . . . . . . . . 152

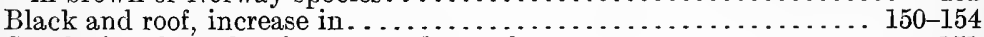

Caught in, chart showing quarterly catch......................... 151

Food of, measures for the destruction of ...................... 147-148

Harbors of, measures for the destruction of . . . . . . . $\ldots \ldots \ldots \ldots \ldots \ldots \ldots$

Measures for the destruction of, in . . . . . . . . . . . . . . . 146-147

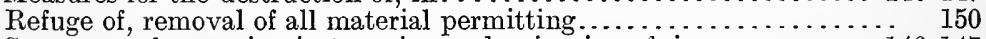

Summary of operation in trapping and poisoning of, in ........... 146-147

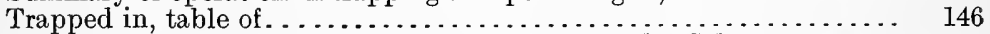

Species of, trapped in Berkeley, Oakland, and Alameda, Cal.......... 154

Trapped in cities nearby to San Francisco, Cal . . . . . . . . . . . . 154

Trapping operations in Berkeley, Oakland, and Alameda, Cal . . . . . 154-155

Reedy Island, quarantine, transactions at.............................. 75

Reform School for Girls of the District of Columbia, inspection of . . . . . . . 32

Regulations:

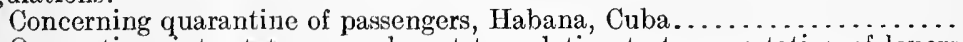

Quarantine, interstate, amendment to, relative to transportation of lepers

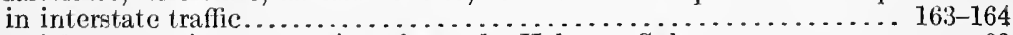

Special, concerning quarantine of vessels, IJabana, Cuba................ 68 
Reliei:

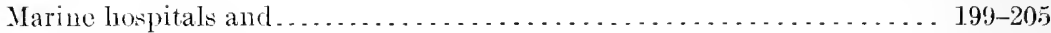

Stations. . . . . . . . . . . . . . . . . . . . . . . . . . . . . . . . . . . . 199

To natives of Alaska . . . . . . . . . . . . . . . . . . . . . . . . . . . 199

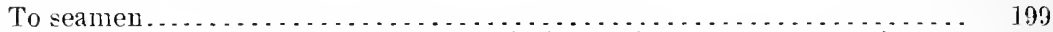

Remodeling of all existing nonrat-proof buildings using rat-proof materials, or the destruction of such buildings, San Francisco, Cal ...................

Report of work done on spotted fever in cooperation with the State Board of Health of Montana. . . . . . . . . . . . . . . . . . . . . . . . . . . $161-167$ Reports:

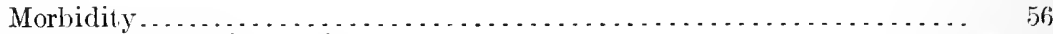

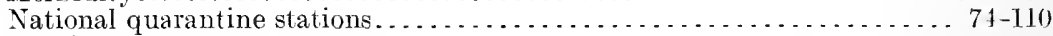

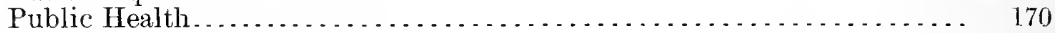

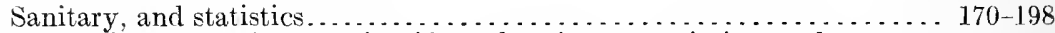

Representation at meetings of scientific and sanitary associations and congresses. 60-61

Reprints from the Public Health Reports. . . . . . . . . . . . . . . . . . . 210-211

Research work in Division of Chemistry, Hygienic Laboratory.......... 54

Research work in Division of Pharmacology, Hygienic Laboratory .......... 52-53

Resolution of the city council of Providence, R. I., requesting Secretary of the

Treasury to establish national quarantine at.................... $72-73$

Revenue-Cutter Service, aid to . . . . . . . . . . . . . . . . . . . . . . . 199

Revision Committee of the Pharmacopœia, aid to, by Hygienic Laboratory... 48

Revision to the United States Interstate Quarantine Regulations, relative to

transportation of lepers in interstate traffic . . . . . . . . . . . . . . .

Rhode Island. Providence:

Act of the general assembly of, concerning the establishment of national

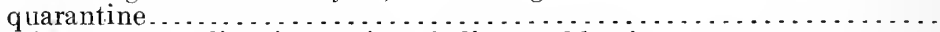

Certificates of medical inspection of aliens, table of . . . . . . . . . . .

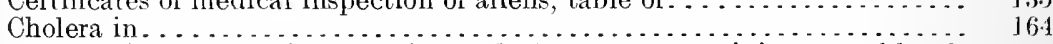

Citizenship classification on shipboard of passengers arriving at, table of. 1:34

Medical inspection of immigrants at...................... 134-137

Resolution of the city council of, requesting Secretary of the Treasury to

establish national quarantine at........................... $72-73$

Summary of transactions of medical inspection of immigrants at. . . . . . 136-137

Table showing disposition of immigrants at...................... 137

Transfer to national control of quarantine functions at . . . . . . . . . $72-73$

Ridlon, Asst. Surg. J. R.:

Investigation of typhoid fever in Texarkana, Ark.-Tex ............. 15-16

Studies of typhoid fever at Charlestown, W. Va................ 11

Roberts. Passed Asst. Surg. Norman:

Detailed to conduct experiments with funnel gas................. 71-72

Improvements in a sanitary air tester for carbon monoxide............. 54

Rocky IIountain spotted fever............................. 23, 28-30 Russia:

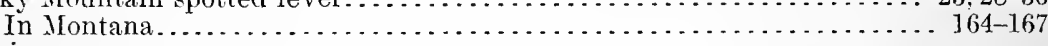

Cholera................................................ 190

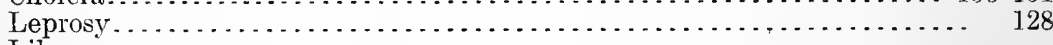

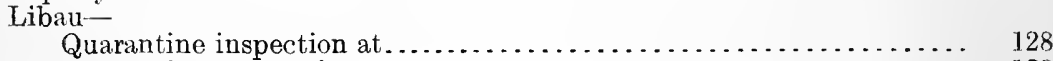

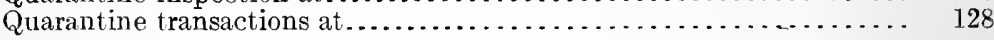

S.

Sanatorium, tuberculosis, at Fort Stanton, N. Mex................ 201-205

San Diego, Cal., quarantine transactions at............................ 78

San Francisco, Cal. (See Califormia.)
Sanitary Commission of Honolulu, director of leprosy investigation station

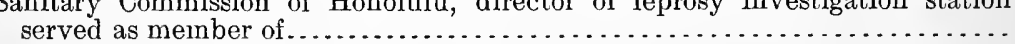

Sanitary conditions:

Alabama, Selma, investigation of, in relation to the prevention of typhoid

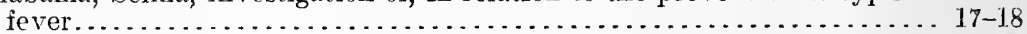

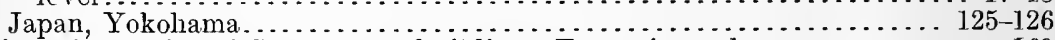

Sanitary inspection of Government buildings, Executive order............ 169

Sanitary reports and statistics................................. 170 198

Sanitary survey:

Of the Great Lakes..................................... 20-22

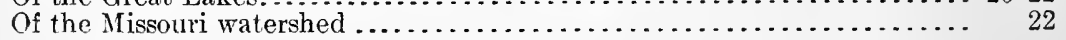


San Joaquin County, Cal. (See (alitornia.)

Savannah, Ga.:

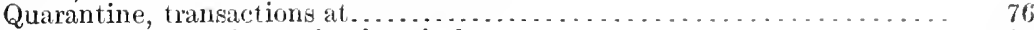

Study of pellagra in marine hospital at .....................

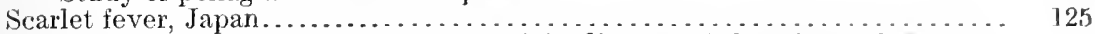

Schereschewsky, Passed Asst. Surg. J. W., director of the Fiftenth Intrunational Congress of Hygienr and Deinography at Washington, D. C. .

Scientific research and sanitation.

Seamen:

Merchant, physical examination of.

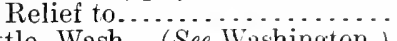

Seattle, Wash. (See Washington.)

Secretary of the Treasury, Franklin Mac Veagh.

Selma, Ala., investigation of sanitary conditions in relation to the prevention

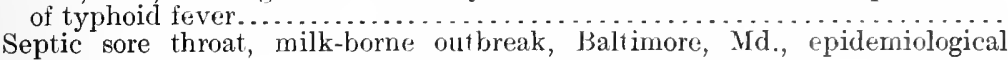

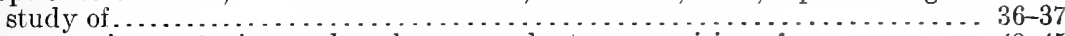

Serums, viruses, toxins, and analogous products, supervision of ............ $43-45$

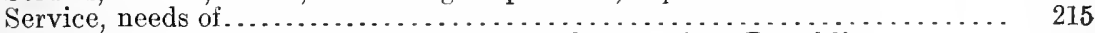

Sixth International Sanitary Conference of the American Republice....... . 57

Smallpox:

Hawaii. . . . . . . . . . . . . . . . . . . . . . . . . . . . . . 104

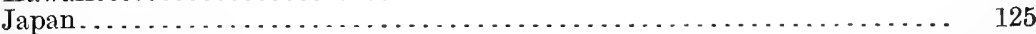

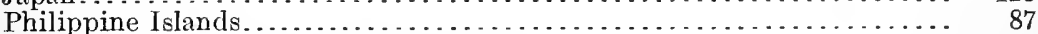

United States............ . . . . . . . . . . . . . . . . . . . . . . . . 184-188

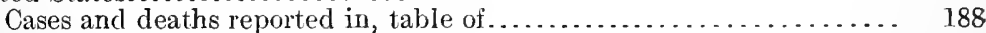

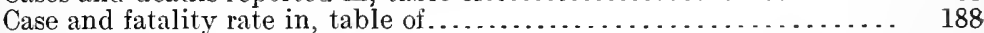

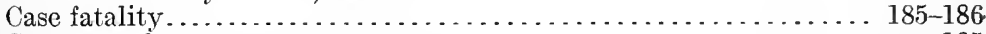

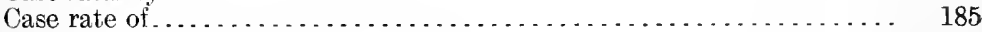

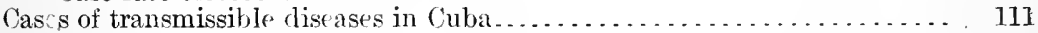

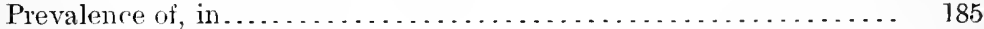

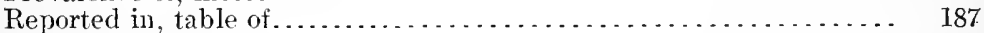

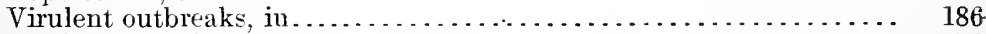

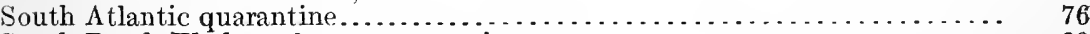

South Bend, Wash., subport, transactions at...................... 80

South Carolina:

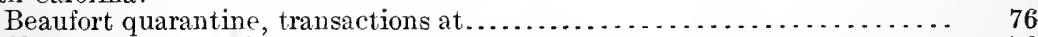

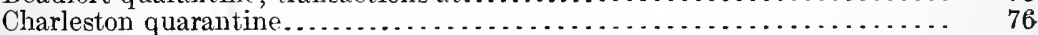

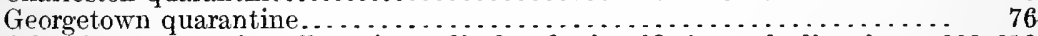

Special articles by service officers in medical and scientific journals, list of . . . 209-210

Special details of commissioned officers. . . . . . . . . . . . . . . . . . . 206

Specimens, zoological, determination of....................... 51

Spotted fever, Rocky Mountain................................. 23, 28-30

In Montana........................................... 164-167

St. George Sound quarantine, transactions at......................... 77

St. John, New Brunswick, Canada:

Citizenship classification on shipboard of passengers arriving at, table of. . 141!

Medical inspection of immigrants at ....................... 141

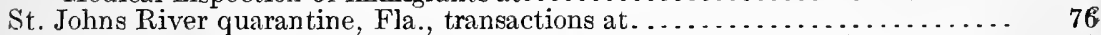

Standardization of drugs by Division of Pharmacology, Hygienic Laboratory.. 51

Standard rat guard, Philippine Islands. . . . . . . . . . . . . . . . . . . 92

State and municipal authorities, aid to, by Hygienic Laboratory ............ . 47

Statistical data on rat work at plague laboratory, Honolulu . . . . . . . . . . . . . 109-110:

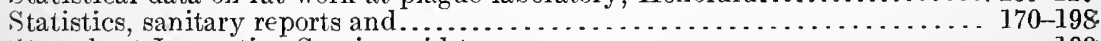

steamboat-Inspection Service, aid to................................. 199

Steamer Bratton fitted with a rat-destroying device................. $71-72$

Stimson, Passed Asst. Surg. A. M.:

Ordered to proceed to Texas to aid the authorities in the installation of a

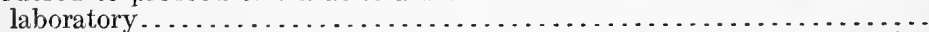

Placed in charge of investigation of effects of pasteurization on the nutritive

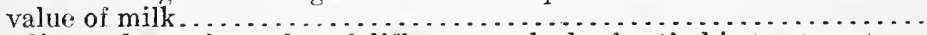
Situdies:

Studies to determine value of different methods of an tirabic treatment...

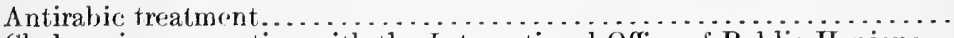

Cholera, in croperation with the International Office of Public Hygiene. .

69450-U. 1)०c. 971, 62-3-17 17 
Studies-Continued.

Embalming fluids...

Milk-borne outbreak of septic sore throat in Baltimore, Md............ 36-37 Summaries:

Achievements in plague-suppressive measures in California............ 161

Operations in trapping and poisoning rats in San Francisco, Cal...... 146-147

Quarantine transactions at Habana, Cuba, from July 6, 1912, to September 1, 1912 .

Transactions of medical inspection of immigrants at Boston, Mass., and

Providence, R. I................................... 136-137

Transactions at La Guaira, Venezuela.................................. 116

Supervision of viruses, serums, toxins, and analogous products............. 43-45 Survey, sanitary:

Of the Great Lakes...

Of the Missouri watershed.

T.

Tabardillo.

Tables:

Aliens inspected and certified........................ 132-133

Branch of service where attendants were employed............... 207

Cases and deaths, yellow fever-.

1911.

Cases of cholera reported on vessels......................... . 190-191

Cases of smallpox, and deaths from, in United States................. 188

Cases of transmissible diseases in Cuba . . . . . . . . . . . . . . . . . 111

Cases of yellow fever on vessels................................ 198

Cerebrospinal meningitis-

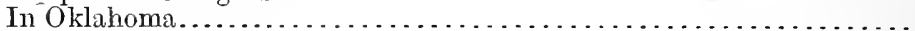

In Texas. . . . . . . . . . . . . . . . . . . . . . . . . . . . . . . . . 172

Character and number of premises where rats were trapped, kind of traps used, and resultant catch, San Francisco, Cal ...................

Character of work performed in operations for the eradication of plague from among ground squirrels in California.

Citizenship classification on shipboard of passengers arriving at Boston, Mass., and Providence, R. I.

Citizenship classification on shipboard of passengers arriving at Quebec, Canada, and St. John, N. B., Canada....................

Contagious diseases-

In Kobe, Japan................................. 127

In Osaka, Japan . . . . . . . . . . . . . . . . . . . . . . . . . . . . . . . . . . . .

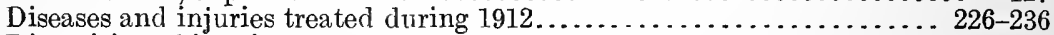

Disposition of immigrants-

At Boston, Mass., and Providence, R. I.................... 137

At New York, N. Y.................................. 139

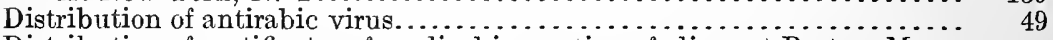

Distribution of certificates of medical inspection of aliens at Boston, Mass.,

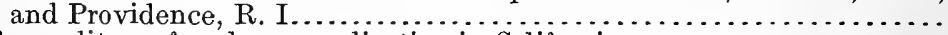

Expenditures for plague eradication in California $\ldots \ldots \ldots \ldots \ldots \ldots \ldots \ldots \ldots$

Foreign, oriental and insular stations and transactions........................... $82-83$

Inspections of mosquito-breeding places in mosquito eradication campaign

at Honolulu . . . . . . . . . . . . . . . . . . . . . . . . . . . . . . . 43

Leprosy in the United States, Hawaii, and insular possessions......... 179-180

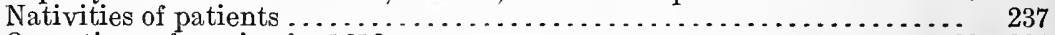

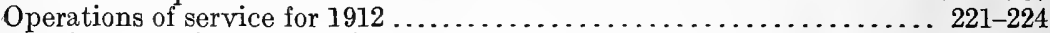

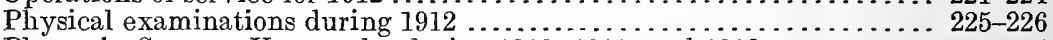

Plague in Caracas, Venezuela, during 1910,1911 , and $1912 \ldots \ldots \ldots \ldots \ldots \ldots . . . . .115$

Plague infection in California................................ 159

Plague in Guayaquil, Ecuador, during $1912 \ldots \ldots \ldots \ldots \ldots \ldots \ldots \ldots \ldots \ldots \ldots . . \ldots \ldots$

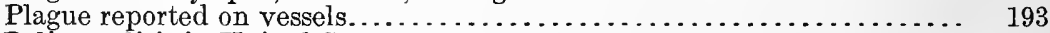

Poliomyelitis in United States... . . . . . . . . . . . . . . . . . . . . 176-177

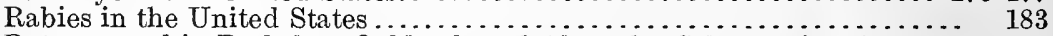

Rats trapped in Berkeley, Oakland, and Alameda, Cal., species of....... 154

Smallpox case and fatality rate in United States................ 188

Smallpox reported in the United States........................ 187

Special articles by service officers.... . . . . . . . . . . . . . . . . . . . . 209-210

Statistics of the service at Naples, Messina, and Palermo, Italy....... 128-129 
Tables-Continued.

Statistical, relating to relief of soanen and molical wximinations..... 220-240)

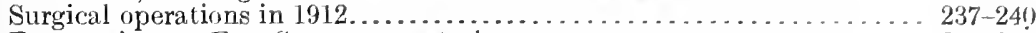

Transactions at Fort Stanton sauatorium . . . . . . . . . . . . . 20 20 -20ij

Transactions at national quarantine stations ................. 82

Yellow fever-

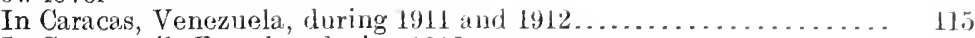

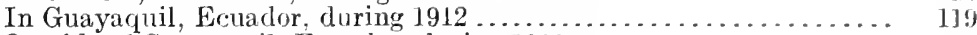

Outside of Guayaquil, Ecıarlor, dıring $1912 \ldots \ldots \ldots \ldots \ldots \ldots \ldots \ldots$. . . . . . . .

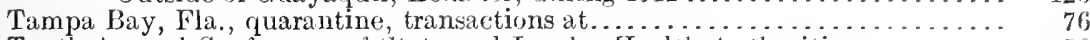

Tenth Annual Conference of State and Insular Heal th Authorities.......... 5f;

Territorial authorities, cooperation with..................... $41-4: 3$

Tetanus, spores, investigation to determine the presence of, in vaccine virus.. 44

Texarkana, Ark.-Tex., typhoid fever, investigation of . . . . . . . . . . . . . 15-16

Texas:

Aid to authorities in the installation of a laboratory ............... $40^{\circ}$

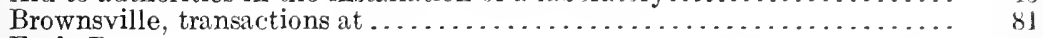

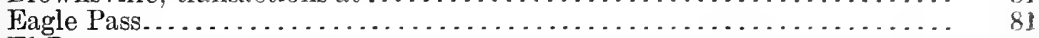

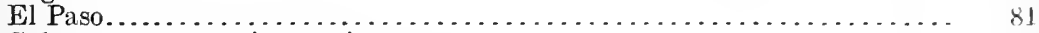

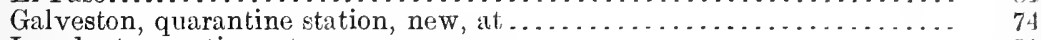

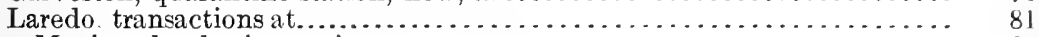

Texas-Mexican border inspection............................. 81

Toxins, viruses, serums, and analogous products, supervision of . . . . . . . . $43-45$

Transfer of the hospital ship Wistaria to Key West, Fla . . . . . . . . . . . . . . 73

Transfer to national control of quarantine functions at Providence, $\mathrm{R}$. I. . . . . . 72-73

Transportation of lepers in interstate traffic................... 163-164

Tuberculosis:

Ecuador, Guayaquil, in................................ 119

Examination of Government employees for, at Hygienic Iaboratory . . . . . 47

Sanatorium at Fort Stanton, N. Mex .................... 201-205

Typhoid fever:

Control of, resolution concerning . . . . . . . . . . . . . . . . . . . 57

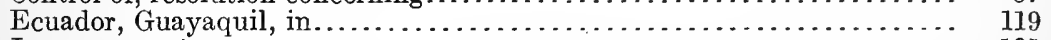

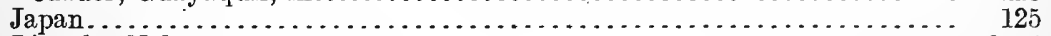

Lincoln, Nebr. . . . . . . . . . . . . . . . . . . . . . . . . . . . . . . . 12-14

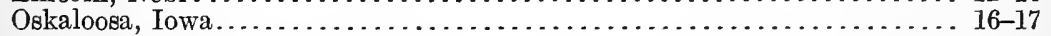

Selma, Ala........................................... 17-18

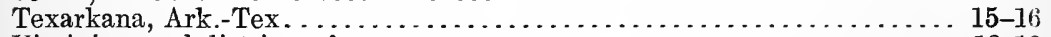

Virginia, rural districts of . . . . . . . . . . . . . . . . . . . .

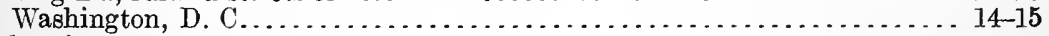

Typhus fever:

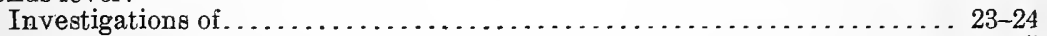

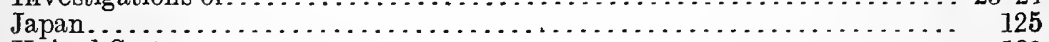

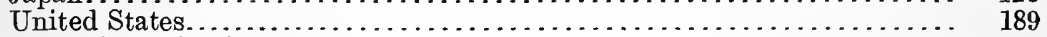

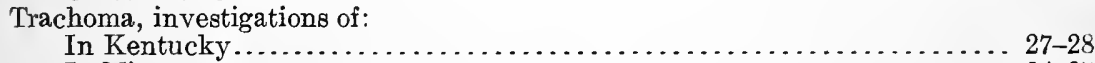

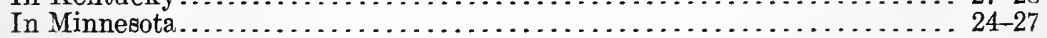

United States: U.

Cerebrospinal meningitis in......................... 171-172

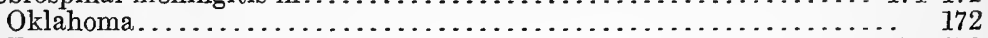

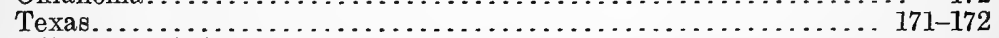

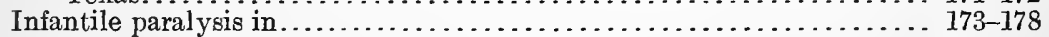

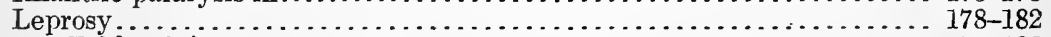

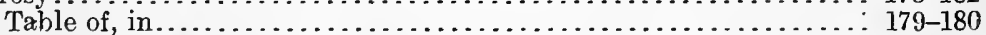

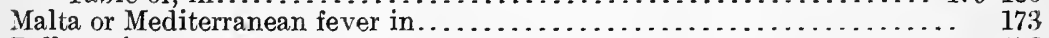

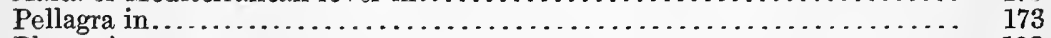

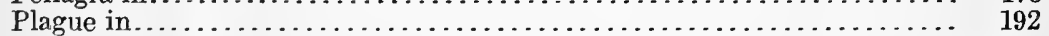

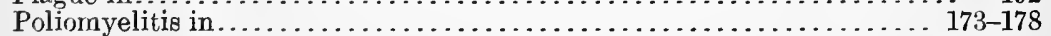

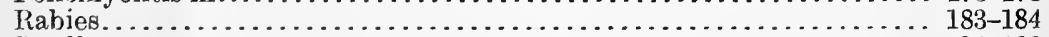

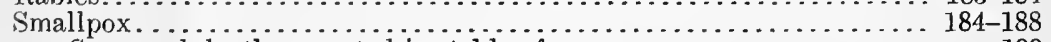

Cases and deaths reported in, table of . . . . . . . . . . . . . 188

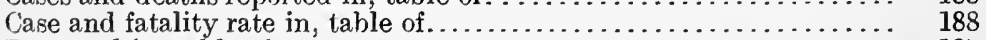

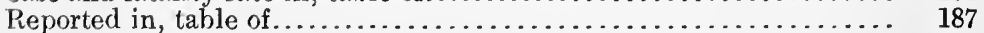

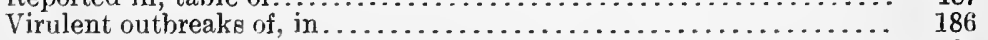

Typhus fever...................................... 189 
United States Army, aid to, by service, in the Philippine Islands.

Vaccination

Alaskan $\quad 80$

Antityphoid, of Government employees at Hygienic Laboratory . . . . . . . 47

Japan, Yokohama..................................... 124

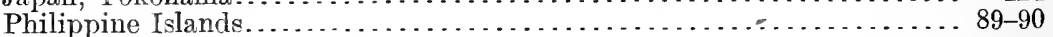

Venezuela:

Caracas, talble showing plague in, during 1910, 1911, and 1912 ....... 115

Caracas, table showing yellow fever in, during $1911,1912 \ldots \ldots \ldots \ldots \ldots . . \ldots 115$

La Guaira-

Quarantine inspection at............................ 114-116

Yessels:

Summarv of transactions at. . . . . . . . . . . . . . . . . . . 116

Cholera reported on, table of........................... 190-191

Ecuador, Guayaquil-

Anchorage of, at ................................ 116-117

Cargo certificates at. . . . . . . . . . . . . . . . . . . . . . . . . 117

Fumigation of at. . . . . . . . . . . .

Plague on board of, at................................ 117

Yellow fever on board of, at............................ 117

Hawaii-

Infected ............................................. 104-107

Inspected at.......................................... 104

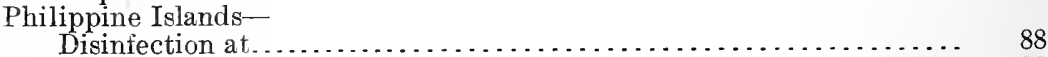

Fumigation at $\ldots \ldots \ldots \ldots \ldots \ldots \ldots \ldots \ldots \ldots \ldots \ldots \ldots \ldots \ldots \ldots, 8{ }_{8}$

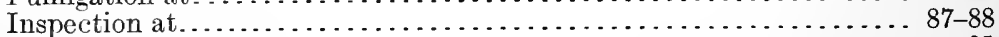

Inspection of, in port............................. 91

Plague reported on, table of................................ 193

Yellow fever, cases on, table of ............................... 198

Veterinary and Medical Zoology, Index Catalogue of.................. $\quad 50$

Virginia:

Fort Monroe, old revenue bark Chase fitted out for service at......... 73

Rural districts of, investigation of typhoid fever in................ 18-19

Virus, antirabic.......................................... 48

Table showing distribution of . . . . . . . . . . . . . . . . . . . . 49

Viruses, serums, toxins, and analogous products, supervision of.......... $43-45$

W.

Warren, Passed Asst. Surg. B. S.:

Detailed for making sanitary inspections of Government buildings........

Inspection of Reform School for Girls of the District of Columbia, to determine the influence of existing conditions on the possible causation of a

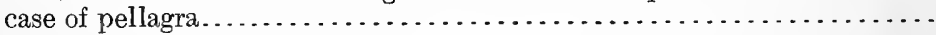

Washington:

Plague .............................................. 192

Seattle, antiplague operations in . . . . . . . . . . . . . . . . . . 162

Washington, D. C., outbreak of typhoid fever in two schools, investigation of.. 14-15

Washington, N. C., quarantine, transactions at. ................... 75

Watershed, Missouri, sanitary survey of........................... 22

Weather bureau, aid to, by service in the Philippine Islands............ 96

vilmington, N. (..:

Marine hospital at, designated for special study of parasitic diseases..... 34-35

Study of hookworm disease in marine hospital at. . . . . . . . . . . . . $34-35$

Wistaria, hospital ship, transfer to Key West, Fla.................... 73

Yellow fever:

Y.

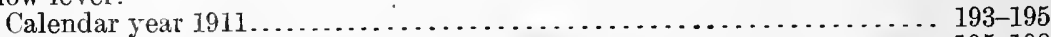

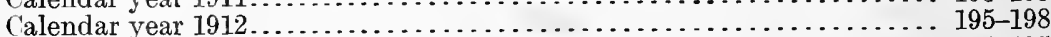

Calendar year 1911, cases and deaths reported, table of.............. 194-195

Calendar year 1912, cases and deaths reporterl, table of.............. 196-197 
Yellow fever-Continued.

Page.

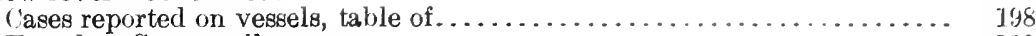

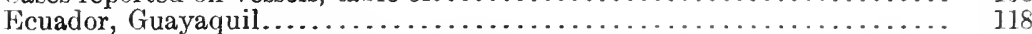

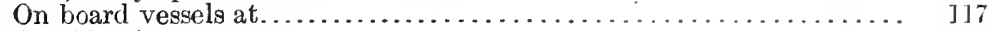

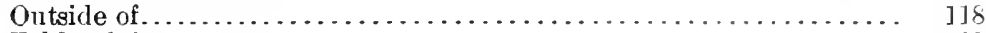

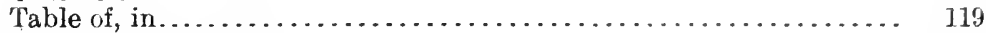

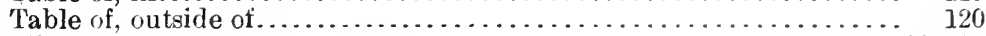

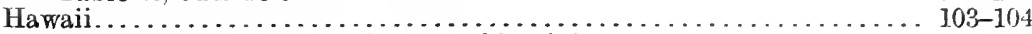

Venezuela, (aracas, 1911 and 1912 , table of, in .................... 115

Z.

Zamboanga, P. I., quarantine station......................... 48

Zoological Nomenclature, International Commission of ......................... 50

Zoology, Division of, Hygienic Laboratory ........................ $50-51$

Zoology, Medical and Veterinary, Index Catalogue of................. 50

Zoological specimens, determination of . . . . . . . . . . . . . . 51

\section{O}









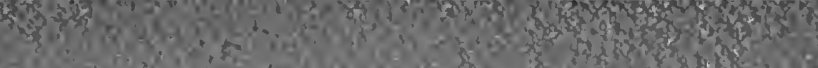

